Florida International University FIU Digital Commons

\title{
Neogene Changes in Caribbean Paleoproductivity and the Diversity and Paleobiogeography of Deep- sea Benthic Foraminifera
}

Crystal Pletka

cpletka@gmail.com

DOI: 10.25148 /etd.FIDC000256

Follow this and additional works at: https:// digitalcommons.fiu.edu/etd

Part of the Geology Commons, Paleobiology Commons, Paleontology Commons, and the Sedimentology Commons

\section{Recommended Citation}

Pletka, Crystal, "Neogene Changes in Caribbean Paleoproductivity and the Diversity and Paleobiogeography of Deep-sea Benthic Foraminifera" (2016). FIU Electronic Theses and Dissertations. 2468.

https://digitalcommons.fiu.edu/etd/2468 


\section{FLORIDA INTERNATIONAL UNIVERSITY}

Miami, Florida

NEOGENE CHANGES IN CARIBBEAN

\section{PALEOPRODUCTIVITY AND THE DIVERSITY}

AND PALEOBIOGEOGRAPHY OF DEEP-SEA

\section{BENTHIC FORAMINIFERA}

A dissertation submitted in partial fulfillment of

the requirements for the degree of

DOCTOR OF PHILOSOPHY

in

GEOSCIENCES

by

Crystal Renae Pletka 
To: Dean Michael R. Heithaus

College of Arts, Sciences and Education

This dissertation, written by Crystal Renae Pletka, and entitled Neogene Changes in

Caribbean Paleoproductivity and the Diversity and Paleobiogeography of Deep-Sea Benthic Foraminifera, having been approved in respect to style and intellectual content, is referred to you for judgment.

We have read this dissertation and recommend that it be approved.

$\begin{array}{r}\hline \text { James Fourqurean } \\ \hline \text { Rosemary Hickey-Vargas } \\ \hline \text { Florentin Maurrasse } \\ \hline \text { Laurel Collins, Major Professor }\end{array}$

Date of Defense: March 28, 2016

The dissertation of Crystal Renae Pletka is approved.

Dean Michael R. Heithaus

College of Arts, Sciences and Education

Andres G. Gil

Vice President for Research and Economic Development

And Dean of the University Graduate School

Florida International University, 2016 


\section{ACKNOWLEDGMENTS}

First and foremost, I would like to thank my advisor, Laurel Collins, for the amazing opportunity so many years ago to learn from and work with her. Her advice, support and dedication to science and her students has helped me immeasurably. I am greatly indebted to the faculty and staff of the Department of Earth and Environment, Florida International University. My committee's help was invaluable and the assistance of everyone in the department over the years was extremely helpful. I am also thankful to the continuous funding by the department during my time there. Thanks are also due to the group at the Smithsonian Institution, Washington, D.C., Martin Buzas, Jennifer Jett, and Loren Petruny, for their assistance with studying the type collections there. I was honored to have received the Garry Jones Award for NAMS student research to fund my trip to the collections.

I could never have finished this dissertation without a great deal of support from my dear family and friends. I thank both my wonderful friends within the department who helped me by talking about my work and what steps to take, as well as distracting me when I needed it, to my other friends and family, including my father, Tom Pletka, who always listened and supported my goals and dreams, and provided endless amounts of encouragement. I would also like to thank my husband, Zach Mester, who has stood by me and served as a sounding board throughout my Ph.D. career, as well as a good portion of my life. His encouragement to finish, and willingness to deal with so many things allowed me the strength to complete this dissertation. Many thanks are also due to the staff at Ellington \& Associates who have helped me finish my degree by being my cheerleaders and giving me the time off necessary to achieve this goal. 


\author{
ABSTRACT OF THE DISSERTATION \\ NEOGENE CHANGES IN CARIBBEAN \\ PALEOPRODUCTIVITY AND THE DIVERSITY AND \\ PALEOBIOGEOGRAPHY OF DEEP-SEA BENTHIC \\ FORAMINIFERA \\ by
}

Crystal Renae Pletka

Florida International University, 2016

Miami, Florida

Professor Laurel Collins, Major Professor

The Neogene history of Caribbean deep-sea benthic foraminifera was investigated by calculating changes in paleoproductivity, diversity and paleobiogeography 26 to $2 \mathrm{Ma}$, which includes the progressive closure of the Central American Seaway. Three hypotheses were tested: (1) Paleoproductivity values prior to closure of the Central American Seaway are similar in both the Caribbean and equatorial Pacific and then diverge by the time of early shoaling events; (2) Diversity values of benthic foraminifera prior to the closure of the Central American Seaway were similar in the Caribbean and EEP, and had changed by the time of early shoaling; and (3) during the Miocene and into the Pleistocene, the progressive constriction of the CAS affected deep-sea benthic foraminiferal assemblages by increasing their dissimilarity between the Caribbean and equatorial Eastern Pacific. These hypotheses were tested with 104 samples from five Caribbean and EEP deep-sea cores by 
calculating paleoproductivity with multiple proxies, determining diversity indices and calculating biogeographic similarity coefficients.

The data supported the first two hypotheses: The greatest change in paleoproductivity occurred at $~ 8$ Ma during seaway constriction, when values diverged between the Caribbean and EEP. After complete seaway closure at $~ 4 \mathrm{Ma}$, the Caribbean became oligotrophic, noted by a decrease in high-organic flux species, and an increase in Nuttalides umbonifera, an indicator species. The largest changes in species-level diversity occurred with the barrier to deep-water flow at $12 \mathrm{Ma}$, and Caribbean diversity increased at $~ 8$ Ma with seaway constriction. However, the third hypothesis was rejected: Increases in assemblage similarity actually occurred during most major paleoceanographic events, with the only decrease in Caribbean-EEP similarity occurring at $12 \mathrm{Ma}$, coincident with a drop in diversity and emplacement of the Panama isthmian sill.

Thus, the barrier to deep-water flow at 12 Ma affected the composition of tropical American benthic foraminifera more than the largest change in paleoproductivity at $\sim 8 \mathrm{Ma}$, or closure of the Central American Seaway at $\sim 4 \mathrm{Ma}$. 


\section{TABLE OF CONTENTS}

CHAPTER

PAGE

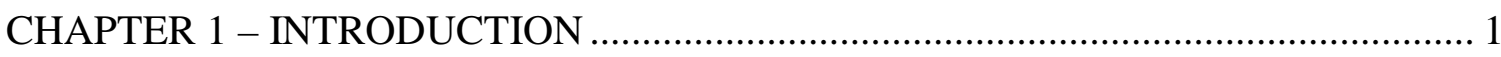

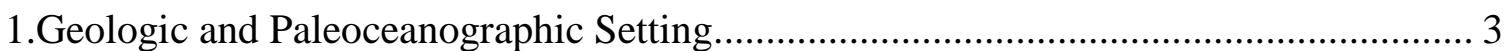

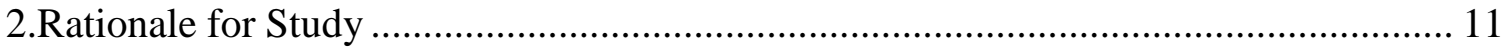

CHAPTER 2 - NEOGENE PALEOPRODUCTIVITY OF THE CARIBBEAN AND EQUATORIAL EASTERN PACIFIC FROM 26-2 MA ……………………….............. 21

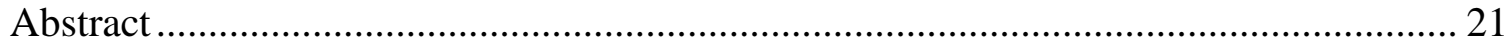

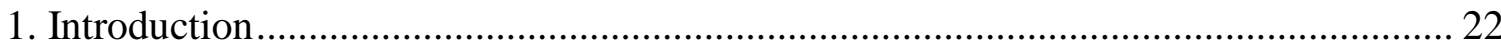

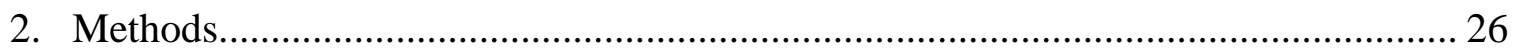

2.1 Site Locations ............................................................................................ 26

2.2 Sample Preparation and Foraminiferal Taxonomy............................................... 27

2.3 Age Determinations ................................................................................... 28

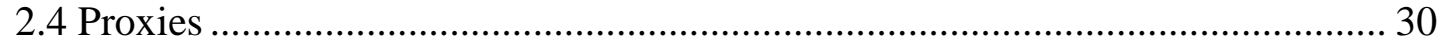

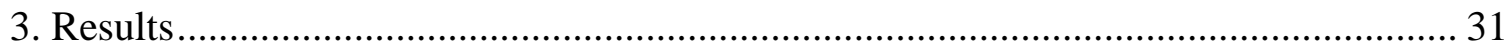

3.1 Nuttalides umbonifera, Proxy for High Oligotrophy......................................... 32

3.2 Proxies for Organic Carbon Flux............................................................................ 33

3.3 Infaunal/Epifaunal Ratio (I/E Ratio) - Proxy for High/Low Flux ........................ 34

3.4 Benthic Foraminiferal Accumulation Rate (BFAR)............................................ 34

3.5 Current Velocity Proxy.................................................................................... 35

4. Discussion ....................................................................................................... 35

4.1 Differentiation of Bottom-Water Source 16 Ma ............................................... 36

4.2 Barrier to Deep Circulation 12 Ma ................................................................ 37

4.3 Seaway Constriction 8 Ma.......................................................................... 38

4.5 Closure of the Central American Seaway 4 Ma .................................................. 39

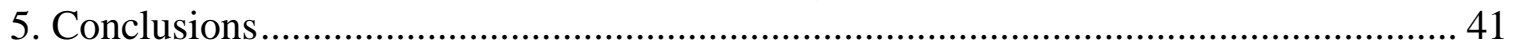

CHAPTER 3 - NEOGENE DIVERSITY OF CARIBBEAN BENTHIC FORAMINIFERA RELATED TO THE CLOSURE OF THE CENTRAL

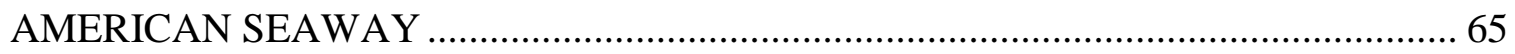

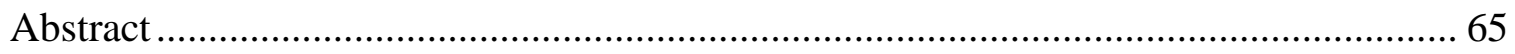

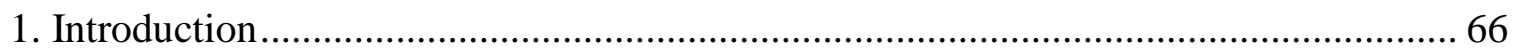

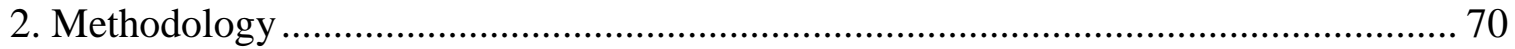

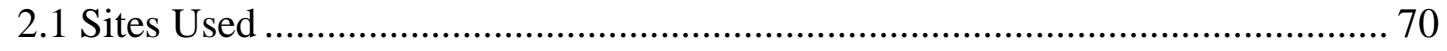

2.2 Sample Preparation and Foraminiferal Taxonomy............................................ 71

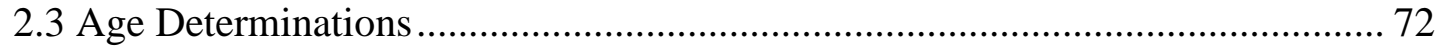

2.4 Diversity Indices ....................................................................................... 74

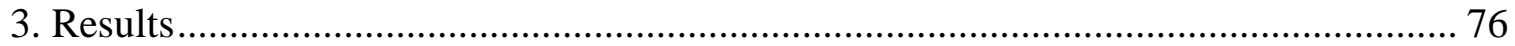

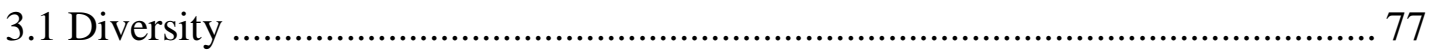

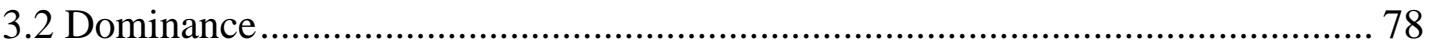

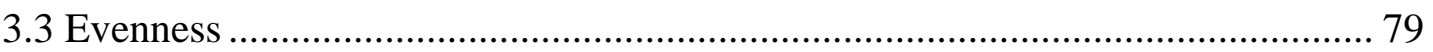




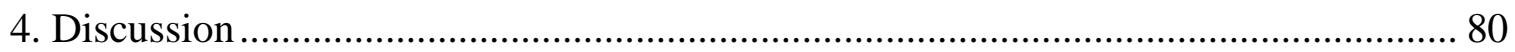

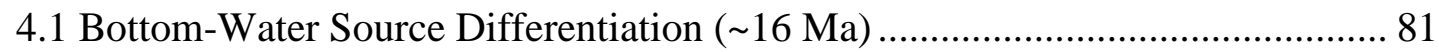

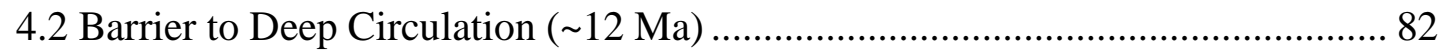

4.3 Seaway Constriction $(\sim 8 \mathrm{Ma})$......................................................................... 84

4.4 Complete Closure of the Central American Seaway ( $4 \mathrm{Ma})$............................. 86

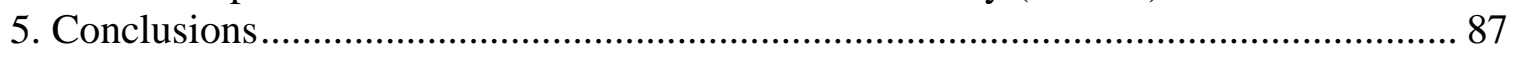

\section{CHAPTER 4 - NEOGENE PALEOBIOGEOGRAPHY OF CARIBBEAN}

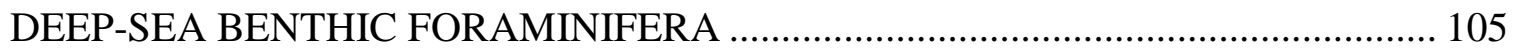

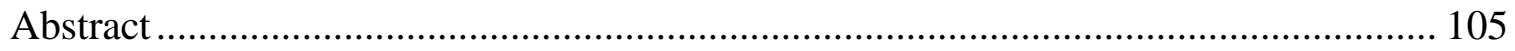

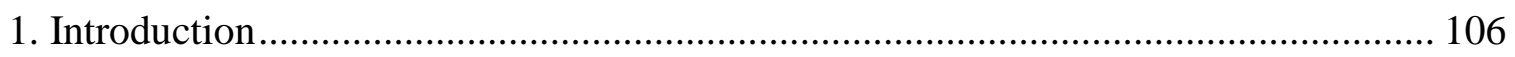

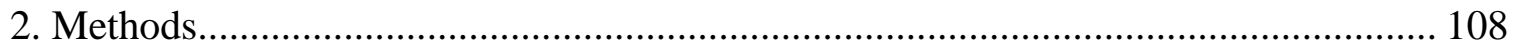

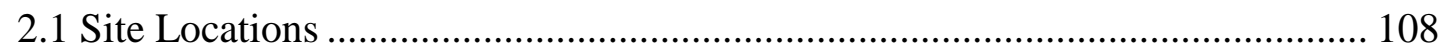

2.2 Sample Preparation and Taxonomy.............................................................. 109

2.3 Age Determinations ........................................................................................... 111

2.4 Data Analysis and Interpretation ................................................................. 113

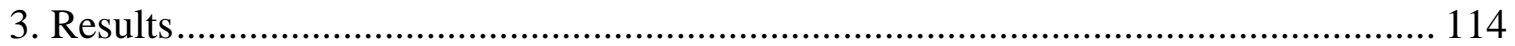

$3.1 \sim 26$ - 16 Ma and older (Differentiation of Bottom-water Source Between

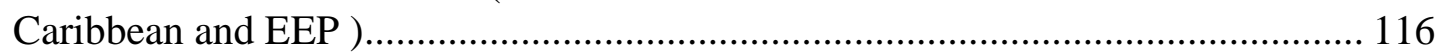

$3.2 \sim 16-12 \mathrm{Ma}$ (Deep circulation barrier between Caribbean and EEP) ........... 117

$3.3 \sim 12-8$ Ma (Constriction of Seaway Between Caribbean and EEP) ............. 117

$3.4 \sim 8-4 \mathrm{Ma}$ (Constriction to Complete Closure of the CAS) ……………….... 118

$3.5 \sim 4-2$ Ma (Post-CAS Closure) .................................................................... 118

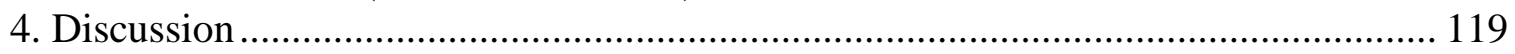

4.1 26 - 16 Ma (Differentiation of Bottom-water Source Between Caribbean

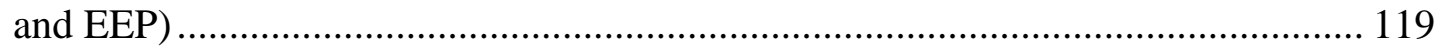

$4.2 \sim 16-12$ Ma (Deep Circulation barrier Between Caribbean and EEP).......... 120

$4.3 \sim 12-8$ Ma (Constriction of Seaway Between Caribbean and EEP) .............. 122

$4.4 \sim 8-4$ Ma (Complete Closure of the CAS) ……………………………......... 123

$4.5 \sim 4-2$ Ma (Post-CAS Closure)..................................................................... 124

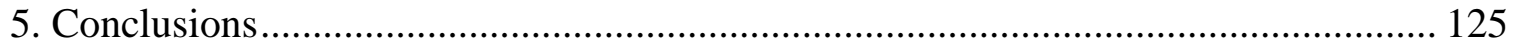

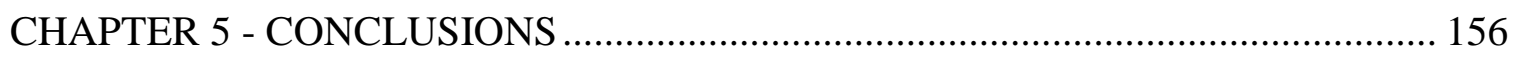

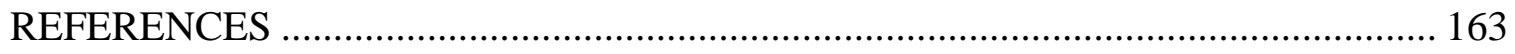

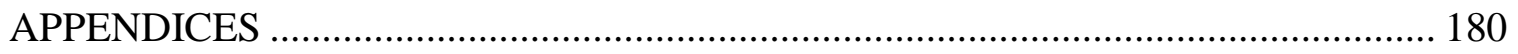

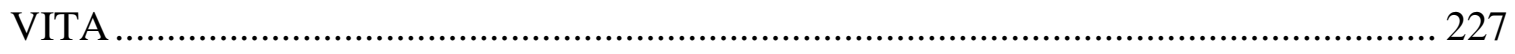




\section{LIST OF TABLES}

CHAPTER

PAGE

\section{CHAPTER 1}

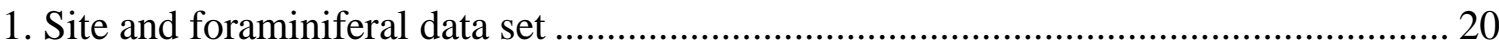

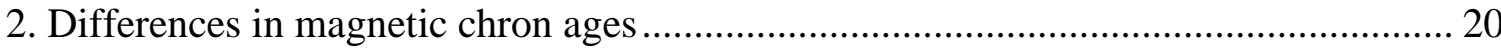

\section{CHAPTER 2}

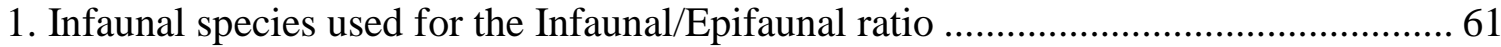

2. Epifaunal species used for the Infaunal/Epifaunal ratio ........................................ 62

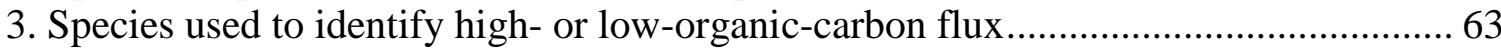

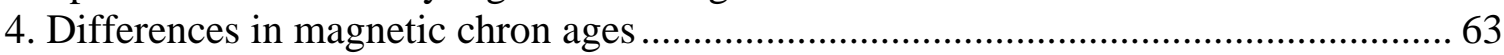

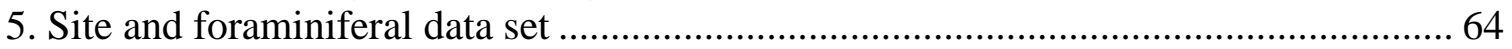

\section{CHAPTER 3}

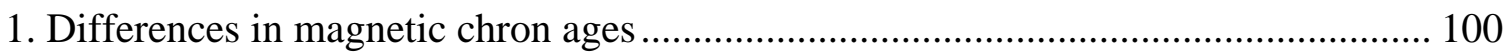

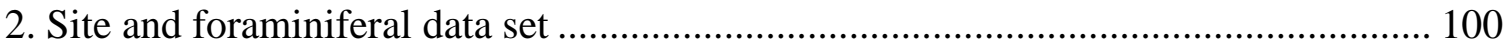

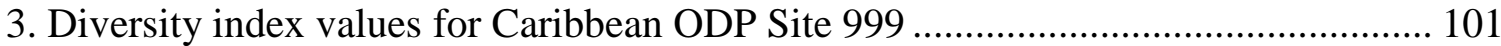

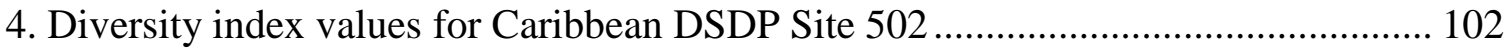

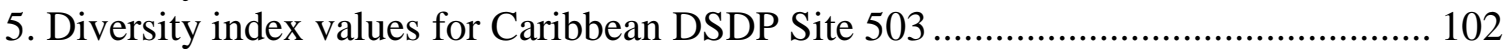

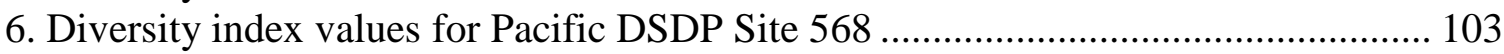

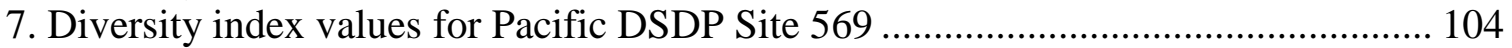

\section{CHAPTER 4}

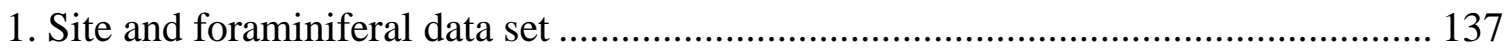

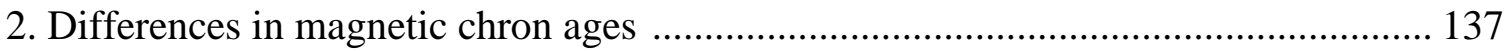

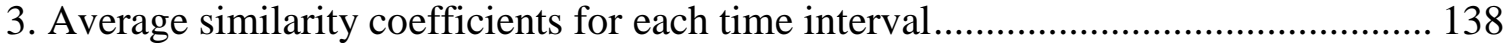

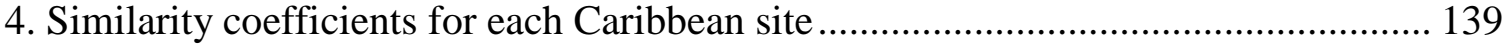

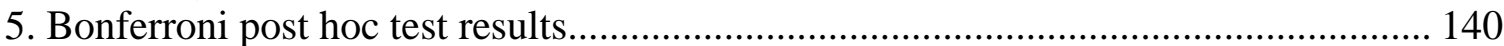

6. Abundances of species $(>1 \%)$ in percentages for older than $~ 16 \mathrm{Ma}$........................ 141

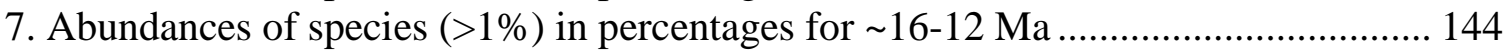

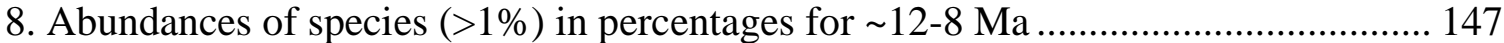

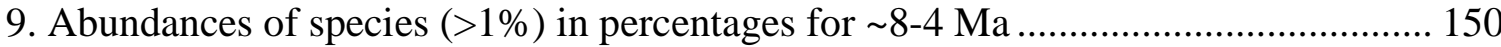

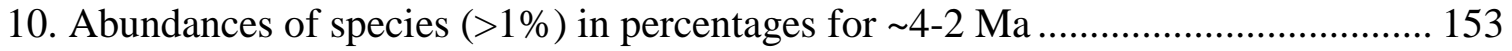




\section{LIST OF FIGURES}

CHAPTER

PAGE

\section{CHAPTER 1}

1. Reconstruction of geologic setting at (A) $20 \mathrm{Ma}$, (B) $12 \mathrm{Ma}$, and (C) $6 \mathrm{Ma}$................. 15

2. Site locations used for this study: Caribbean ODP Site 999, DSDP Site 502, and Equatorial Eastern Pacific DSDP sites 503, 568 and 569 ................................. 16

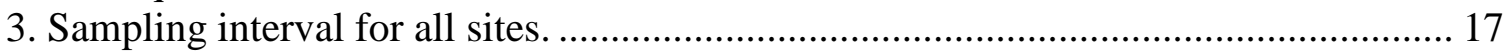

4. Thirty-seven samples prepared for benthic foraminiferal assemblages, ODP Site 999. 18

5. Time scale of Cande and Kent (1995) used for age calibration of datasets (after Sigurdsonn, et al., 1997). 19

\section{CHAPTER 2}

1. Geologic setting at (A) $20 \mathrm{Ma},(\mathrm{B}) 12 \mathrm{Ma}$, and (C) 6 Ma. 43

2. Site locations used for this study: Caribbean ODP Site 999, DSDP Site 502, and Equatorial Eastern Pacific DSDP sites 503, 568 and 569

3. Sampling interval for all sites.

4. Samples prepared for benthic foraminiferal assemblages, ODP Site 999

5a. Relative abundance curves of Nuttalides umbonifera (oligotrophy indicator) for all five sites: Caribbean ODP Site 999 and DSDP Site 502, and Pacific DSDP sites 503, 568 and 569 (younger interval).

5b. Relative abundance curves of Nuttalides umbonifera (oligotrophy indicator) for all five sites: Caribbean ODP Site 999 and DSDP Site 502, and Pacific DSDP sites 503, 568 and 569 (older interval).

6a. Relative abundance curves of Epistominella exigua (mesotrophy indicator) for all five sites: Caribbean ODP Site 999 and DSDP Site 502, and Pacific DSDP sites 503, 568 and 569 (younger interval)

6b. Relative abundance curves of Epistominella exigua (mesotrophy indicator) for all five sites: Caribbean ODP Site 999 and DSDP Site 502, and Pacific DSDP sites 503, 568 and 569 (older interval).

7a. Relative abundance curves of eutrophic species (high-organic-carbon flux) for all five sites: Caribbean ODP Site 999 and DSDP Site 502, and Pacific DSDP sites 503, 568 and 569 (younger interval).

7b. Relative abundance curves of eutrophic species (high-organic-carbon flux) for all five sites: Caribbean ODP Site 999 and DSDP Site 502, and Pacific DSDP sites 503, 568 and 569 (older interval).

8a. Relative abundance curves of oligotrophic species (low-organic-carbon flux) for all five sites: Caribbean ODP Site 999 and DSDP Site 502, and Pacific DSDP sites 503, 568 and 569 (younger interval).

8b. Relative abundance curves of oligotrophic species (low-organic-carbon flux) for all five sites: Caribbean ODP Site 999 and DSDP Site 502, and Pacific DSDP sites 503, 568 and 569 (older interval). 
9a. Infaunal/Epifaunal Ratios (High-organic-carbon/low-organic-carbon) for all five sites: Caribbean ODP Site 999 and DSDP Site 502, and Pacific DSDP sites 503, 568 and 569 (younger interval)

9b. Infaunal/Epifaunal Ratios (High-organic-carbon/low-organic-carbon) for all five sites: Caribbean ODP Site 999 and DSDP Site 502, and Pacific DSDP sites 503, 568 and 569 (older interval). 56

10a. BFAR for three sites where data were available. BFAR values for Caribbean ODP Site 999 were calculated in this study and those for Caribbean DSDP Site 502, and Pacific DSDP Site 503 were acquired from Bornmalm (1997) (younger interval).

10b. BFAR for three sites where data were available. BFAR values for Caribbean ODP Site 999 were calculated in this study and those for Caribbean DSDP Site 502, and Pacific DSDP Site 503 were acquired from Bornmalm (1997) (older interval)

11a. Relative abundance curves of Globocassidulina subglobosa plus Cibicidoides wuellerstorfi (proxy for current velocity) for all sites: Caribbean ODP Site 999 and DSDP Site 502, and Pacific DSDP sites 503, 568 and 569 (younger interval) 59

11b. Relative abundance curves of Globocassidulina subglobosa plus Cibicidoides wuellerstorfi (proxy for current velocity) for all sites: Caribbean ODP Site 999 and DSDP Site 502, and Pacific DSDP sites 503, 568 and 569 (older interval).

\section{CHAPTER 3}

1. Site locations used for this study: Caribbean ODP Site 999, DSDP Site 502, and Equatorial Eastern Pacific DSDP sites 503, 568 and 569.

2. Sampling interval for all sites.

3. Samples prepared for benthic foraminiferal assemblages, ODP Site 999.

4a. Fisher's $\alpha$ for all five sites: Caribbean ODP Site 999 and DSDP Site 502, and Pacific DSDP sites 503, 568 and 569 (older interval). 92

4b. Fisher's $\alpha$ for all five sites: Caribbean ODP Site 999 and DSDP Site 502, and Pacific DSDP sites 503, 568 and 569 (younger interval).

5a. Shannon H (diversity measure) for all five sites: Caribbean ODP Site 999 and DSDP Site 502, and Pacific DSDP sites 503, 568 and 569 (older interval).

5b. Shannon H (diversity measure) for all five sites: Caribbean ODP Site 999 and DSDP Site 502, and Pacific DSDP sites 503, 568 and 569 (younger interval) .......... 95

6a. Dominance for all five sites: Caribbean ODP Site 999 and DSDP Site 502, and Pacific DSDP sites 503, 568 and 569 (older interval).

6b. Dominance for all five sites: Caribbean ODP Site 999 and DSDP Site 502, and Pacific DSDP sites 503, 568 and 569 (younger interval).

7a. Evenness (diversity measure) for all five sites: Caribbean ODP Site 999 and DSDP Site 502, and Pacific DSDP sites 503, 568 and 569 (older interval).

7b. Evenness (diversity measure) for all five sites: Caribbean ODP Site 999 and DSDP Site 502, and Pacific DSDP sites 503, 568 and 569 (younger interval). 


\section{CHAPTER 4}

1. Site locations used for this study: Caribbean ODP Site 999, DSDP Site 502,

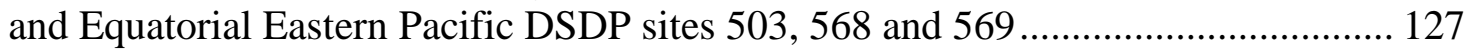

2. Sampling interval for all sites. .................................................................... 128

3. Samples prepared for benthic foraminiferal assemblages, ODP Site 999 ................. 129

4. Average of Dice, Jaccard, and Simpson similarity coefficients for Caribbean and

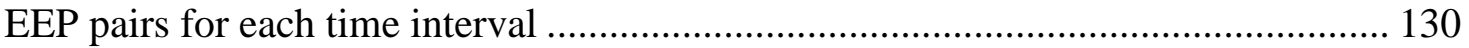

5. Similarity Coefficients: average of all EEP sites (within interval) similarities is shown for each Caribbean Site.

6. Non-metric MDS (Simpson coefficient of similarity) 16 Ma and older; blue $=$ Equatorial Eastern Pacific, orange $=$ Caribbean

7.Non-metric MDS (Simpson coefficient of similarity) 16 - $12 \mathrm{Ma}$; blue=Equatorial Eastern Pacific, orange $=$ Caribbean

8. Non-metric MDS (Simpson coefficient of similarity) 12 - $8 \mathrm{Ma}$; blue=Equatorial Eastern Pacific, orange=Caribbean

9. Non-metric MDS (Simpson coefficient of similarity) 8 - $4 \mathrm{Ma}$; blue=Equatorial Eastern Pacific, orange $=$ Caribbean

10. Non-metric MDS (Simpson coefficient of similarity) 2 - $4 \mathrm{Ma}$; blue $=$ Equatorial Eastern Pacific, orange $=$ Caribbean

\section{CHAPTER 5}

1. Summary chart of major results, entire study interval. 161

2. Summary chart of similarity coefficients, younger interval with regression lines 


\section{CHAPTER 1 - INTRODUCTION}

The closure of the Central American Seaway had a great impact on marine habitats and the evolution and distribution of organisms in both the Caribbean Sea and the tropical eastern Pacific Ocean. With the gradual emergence of the Isthmus of Panama (Duque-Caro, 1990; Coates and Obando, 1996; Collins et al., 1996a; Coates, et al., 2003; Coates, et al., 2004), a barrier between the Caribbean and equatorial Eastern Pacific was erected, preventing flow between the two regions. This study tests the hypotheses that with similar water chemistry, food availability, and temperature, the pre-isthmus Caribbean and tropical Eastern Pacific sites had (1) similar paleoproductivity, (2) diversity, and (3) faunal composition, until a barrier existed that was sufficient to impede significant exchange.

Due to their long geologic record of 500 million years (Douglas, 1979; Douglas and Woodruff, 1981), cosmopolitan distribution, and large abundance in all oceans, benthic foraminifera are useful for showing changes in paleoproductivity, diversity, and biogeography related to changing physical factors. Deep-sea species often have wider geographic ranges than coastal taxa because of the greater homogeneity of bathyal to abyssal environments (Gooday and Jorissen, 2012). In the deep-sea, oxygen concentration and organic matter flux to the seafloor have the most impact on assemblages (Gooday and Rathburn, 1999). Woodruff's and Savin’s (1985) study of Miocene Pacific benthic foraminifera examined $\delta^{13} \mathrm{C}$ values and found greater organic matter availability during sea level transgressions. Another Miocene study examined changes in benthic faunal assemblages and found that noted changes were likely due to 
surface productivity (Thomas and Vincent, 1987). Additional studies have examined the utility of benthic foraminifera in determining surface water productivity (Herguera, 1992; Licari, et al., 2003; Jain and Collins, 2007), diversity (Buzas and Culver, 1991; Grassle, 1991; Jain et al., 2007), oxygen tolerance and other microhabitat preferences, such as substrate, water depth and temperature (Murray, 1973; Moodley and Hess, 1992; Schmiedl, et al., 1997). Often, paleoenvironmental information is obtained from comparing fossil to modern assemblages with known ecological and environmental preferences (Douglas, 1979).

Benthic foraminifera have been extensively studied with regard to their distribution. Thomas (1985) found that common, equatorial Pacific, deep-sea benthic foraminifera had long age ranges, some of which encompassed the entire study interval of Late Eocene to Recent, and a high diversity of 50-70 species per 200 specimens. Gooday and Jorissen (2012) found that deeper-water benthic foraminifer have broad geographic ranges that are controlled more by the amount of organic matter they receive. Studies have examined the effects of a widespread, mid-Pleistocene extinction of benthic foraminifera in the Caribbean at mid-bathyal depths (Hayward, et al., 2002, 2006).

Benthic foraminifera can be opportunistic and resilient to change, so they can maintain a presence with low abundance during conditions that are not ideal, and then show a resurgence when there are more favorable changes to their environment (Murray, 2000). For example, Kuhnt et al. (2005) showed that after the eruption of Mt. Pinatubo, opportunistic benthic foraminifers with high dispersal rates had an "almost instantaneous” recolonization. Recent studies using propagule banks of foraminifera (Goldstein and Alve, 2011; Alve and Goldstein, 2014) have examined the ability of 
propagules to stay dormant for long periods of time and then respond to varying environmental conditions such as temperature and salinity. These studies found that differing assemblages could develop under these changing conditions, leading to an increased presence of certain species. The cosmopolitan distribution, resilience and the utility of benthic foraminifera in terms of determining paleoproductivity, paleoenvironments, bathymetry, and temperature provide a unique, comprehensive methodology to examine large-scale geologic change.

\section{Geologic and Paleoceanographic Setting}

The southern Central American isthmus is a narrow strip of land that serves as a barrier between the tropical Atlantic and Pacific oceans, and as such, is an area of intense study. Paleoceanographic studies have examined stable isotopes (Keigwin, 1982a, b), water mass formation (Burton et al., 1997; Lear, et al., 2003), circulation (Haug and Tiedemann, 1998; Nisancioglu, et al., 2003; Nof and Van Gorder, 2003; Steph et al., 2006a, b) and salinity and sea-surface temperatures (Haug et al., 2001; Gussone et al., 2004; Prange and Schulz, 2004). Additional studies of the isthmus have examined the geology of the region (Duque-Caro, 1990; Coates et al., 1992; Coates and Obando, 1996; Collins et al., 1996a, b; Ibaraki, 1997; Coates et al., 2004; Kirby et al., 2008), the biology/paleontology (Saito, 1976; Iturralde-Vincent, 2006; Lessios, 2008) and climatology (Bartoli, et al., 2005; Lunt, et al., 2008).

The tectonic history of the Caribbean region has been studied in great detail by multiple scientists. Beginning in the late Cretaceous and continuing through the Cenozoic, the subduction of the Pacific Farrallon, Cocos and Nazca plates beneath the 
Caribbean Plate initiated the development of a volcanic arc (Pindell and Barrett, 1990; Coates and Obando, 1996). During the same time period, the western margin of the Caribbean plate was the southern Central American arc. The Caribbean Plate collided with South America in the Neogene after moving eastward through the Cenozoic. The initial collision with South America is seen as a regional unconformity above the middle Miocene Clarita Formation in the Darien Province (eastern Panama), where the lithology changes from an open-ocean sedimentary facies to shallowing-upwards facies (Coates et al., 2004). Further affecting the western Panama/eastern Costa Rica region was the subduction of the Cocos Ridge which caused rapid Pleistocene uplift (Collins et al., 1995; Leon-Rodriguez, 2007).

The Isthmus of Panama began shoaling and affecting deep circulation in the Early Neogene as seen in decreased radiolarian productivity and shell thickness (Maurrasse, 1979) and, according to paleobathymetry determined from benthic foraminifera, shallowing water depth (Duque-Caro, 1990; Coates et al., 2003, 2004). Lunt et al. (2008) stated that seaway closure lasted from $13 \mathrm{Ma}$ to $2.6 \mathrm{Ma}$, but based on $\delta^{18} \mathrm{O}$ values, complete closure actually happened at 4 Ma (Keigwin, 1978; Haug and Tiedemann, 1998). Saito (1976) attributed the change in coiling direction patterns between IndoPacific and Atlantic Pulleniatina at 3.5 Ma to the isolation of the genus on either side of the Isthmus of Panama.

The Neogene history of the seaway included periods of shallowing and deepening (Fig. 1). The growth of a volcanic arc and volcanic deposits are seen during the middle to late Miocene from 17-8 Ma (Coates et al., 1992; Coates and Obando, 1996; Coates et al., 2003). The initial uplift of the isthmus resulted in changes in open-ocean sedimentation, 
producing a hiatus in both the Caribbean and the Pacific which is attributed to bottomwater source differentiation around 16-15 Ma (Keller and Barron, 1983; Duque-Caro, 1990). The change in bottom-water is attributed to the foundering of the Northern Nicaragua Rise which led to the development of the North Component Deep Water in the Caribbean (Droxler et al., 1998). Presently, North Atlantic Deep water has been found to enter the Colombian Basin between Jamaica and Hispaniola (Morrison and Nowlin, 1982; Haddad and Droxler, 1996). Duque-Caro (1990) examined Neogene paleobiogeography and paleoceanography in regards to the evolution of the Central American Seaway (CAS) in the area of northwest South America and found that beginning at $16 \mathrm{Ma}$, changes occurred in bottom water circulation, associated with the gradual closure of the CAS. Coates et al. (2003) in a study of Bocas del Toro, western Panama, suggested a pre-isthmian sill between 18-15 Ma, followed by a rapid shallowing, with a volcanic backarc established at 12 Ma. Duque-Caro (1990) suggested a deep circulation barrier between the tropical Pacific and Atlantic between 12.9 and 11.8 Ma with a partial emergence of the isthmus and a closing of the intermediate water connection. He also suggested that during this interval the California current was established and there was a drop in sea level (Duque-Caro, 1990). This is based on the presence of distinctly deep-sea benthic foraminiferal assemblages that shallowed to middle bathyal depths from lower bathyal depths. An additional study by Coates et al. (2004) of eastern Panama was similarly able to identify the steps in the gradual closure of the CAS, with an unconformity at 14.8-12.8 Ma marking initial uplift of the isthmus. A distinct shallowing of the assemblages was recorded at $8 \mathrm{Ma}$ (Coates et al., 2003). Studies by Collins et al. (1996a, 1996b) utilized benthic foraminifera and 
geological data from the Gatun and Chagres formations, sediments of Miocene age located in the Panama Canal Basin. At approximately 8 Ma, they suggested an effective barrier between the surface waters of the equatorial Eastern Pacific and the Caribbean based on the Caribbean affinity of the shallow-water assemblages of the Gatun Formation (Collins, et al., 1996a). Coates et al. (2004), identified the collision of the volcanic arc by 7.1 Ma and noted that complete emergence of the isthmus at $\sim 4.8 \mathrm{Ma}$ is supported by a lack of younger marine sediments (Coates et al., 2004). Studies using deep-water Nd and $\mathrm{Pb}$ isotopes of hydrogenous ferromanganese crusts of the equatorial Eastern Pacific and the Atlantic were conducted to determine timings of variations (Frank et al., 1999). They found a shift in isotopes beginning at 8 Ma which supported the "restriction of watermass exchange” between the Pacific and Atlantic (Frank et al., 1999; Reynolds et al., 1999). The event at $\sim 8 \mathrm{Ma}$ is also partially noted by changes in $\delta{ }^{13} \mathrm{C}$ and $\delta^{18} \mathrm{O}$ over a broader interval (12.5-4.5 Ma), which shows a general cooling of the Bahamas at this time (Spezzaferri et al., 2002). In a study of multiple Pacific and Atlantic sites, Billups (2002) found a gradient in $\delta{ }^{13} \mathrm{C}$ that supported the modern gradient between the Pacific Ocean and North Atlantic that was established between 8-7 Ma.

The arc subsided, causing a marine transgression, from 8-5 Ma (Coates et al., 2003). This time interval also had low epibenthic $\delta^{13} \mathrm{C}$ values at Caribbean ODP Site 999 which indicated a corrosive, nutrient-rich water mass that was poorly ventilated (Bickert et al., 2004). Deepening of the Panama isthmian strait to $\geq 200 \mathrm{~m}$ in the Panama Canal area at approximately 6 Ma allowed limited interchange between the surface waters of the tropical Eastern Pacific and the Caribbean, which is evidenced by a return to Pacific affinity of the benthic foraminifera within the overlying Chagres Formation (Collins et 
al., 1996a). In another study by Collins et al. (1996b), a large increase in originations of Caribbean benthic foraminifera between 6 and 3.5 Ma was related to an increase in basinwide carbonate deposition. This increase could be due to the absence of Pacific water interchange caused by the restriction of the seaway (Collins et al., 1996b), which reduced productivity and nutrients through a lessening of coastal upwelling. These studies show some of the evolutionary effects of the shoaling of the Central American isthmus on populations of benthic foraminifera. Timing of the rise of the isthmus is also documented in the Bocas del Toro basin of Panama by changes in water depths interpreted from benthic foraminifera (Coates et al., 2003, 2004, 2005). The shallow-water connection closed with the complete emergence of the Central American isthmus during the early Pliocene ( $\sim \mathrm{Ma}$ ), as identified by salinity gradients determined from $\delta^{18} \mathrm{O}$ values from planktic foraminifera (Keigwin 1978, 1982a, b; Haug and Tiedemann, 1998; Haug et al., 2001, 2004).

When the surface currents flowed between the tropical Atlantic to the Pacific, significant mixing occurred, causing both the tropical Atlantic and Pacific surface waters to have similar salinity values as interpreted from stable isotopes of foraminifera. Although flow between the two regions has commonly been described as "Atlantic to Pacific,” driven by the trade winds, studies by Steph et al., (2006a, b; 2009) found an absence of significant gradients in planktonic foraminiferal $\delta^{18} \mathrm{O}$ values between the two regions, as measured through planktic foraminifera, suggested a lack of flow from the Caribbean to the Pacific. Nof and Van Gorder's (2003) examination of bottom-water masses and flow direction found that the lower salinity values in the Atlantic would have prevented North Atlantic Deep Water (NADW) formation prior to the closure of the 
CAS. Prior to the closure, the lower salinity Pacific waters invaded Atlantic, therefore lowering the overall salinity of the region. Once closure occurred, which prevented the influx of lower salinity waters, a salinity gradient was established that allowed for formation of NADW (Nof and Van Gorder, 2003).

Haug and Tiedemann (1998), using $\delta^{13} \mathrm{C}$ values of the benthic foraminifer Cibicides wuellerstorfi as a proxy to determine deep-water circulation, showed that before 4.6 Ma, the dominant water mass of the Caribbean was Antarctic Intermediate Water. After this time, less corrosive bottom water from the north was indicated by increases in carbonate preservation and deep-water ventilation. A maximum Caribbean ventilation was noted at 3.6 Ma when $\delta^{13} \mathrm{C}$ values were similar to those of North Atlantic waters. A study of planktic foraminifera by Haug et al. (2001) used high-resolution $\delta^{18} \mathrm{O}$ data to further constrain the timing of surface-water changes. They found that prior to 4.7 Ma, salinity values of the Caribbean were lower than, or similar to those of, the tropical Eastern Pacific. The study determined that around 4.7 Ma, a sill of $<100 \mathrm{~m}$ depth had shoaled to restrict water exchange between the tropical Eastern Pacific and Caribbean based on the subsequent increase in Caribbean $\delta^{18} \mathrm{O}$ values. Another increase in Caribbean salinity values at 4.2 Ma showed the stepwise constriction of flow.

When flow restriction between the tropical Eastern Pacific and Atlantic surface waters occurred, the tropical western Atlantic and Caribbean became approximately 1 per mil more saline than the tropical eastern Pacific due to atmospheric transport of vapor to the Pacific across the isthmus (Haug et al., 2001). Steph et al. (2006a) found the same increase in salinity in the Caribbean (ODP Site 999) as noted by Haug et al. (2001) and attributed the change to the increased transport of heat and water vapor away from the 
Caribbean region as a result of the impact of the closure of the Central American Seaway on the linked ocean, atmospheric, and climate system. Additional causes of salinity maxima in the Caribbean were found to be the result of the North Atlantic subtropical gyre and the Florida Current (Steph et al., 2006b).

Studies by Keigwin (1982a, b) and Haug et al. (2001) both show the increase in salinity in Caribbean surface water compared to the equatorial Eastern Pacific in the interval between 4.7 Ma and 4.2 Ma. According to Haug et al. (2001), without the restriction of surface-waters by the closure of the CAS, the changes recorded in Atlantic and Pacific deep-ocean and surface circulation would not have happened. General Circulation Model simulations (Maier-Reimer et al., 1990; Nisancioglu et al., 2003; Lunt et al., 2008) examining the effects of the closure of the Central American Seaway on oceanic circulation show that with a shoaling of the isthmus and the prevention of the flow of North Atlantic Deep Water to the Pacific, modern global circulation was achieved. General Circulation Model simulations also show that an open Central American Seaway would reduce the present salinity contrast due to mixing of the tropical Pacific and Atlantic surface waters, which is supportive of the stable isotopic findings (Keigwin, 1982a, b; Haug et al., 2001). Neritic benthic foraminiferal taxa showed that changes in assemblages increased 3-5 million years prior to the final closure of the CAS (Collins et al., 1996a).

Additionally, global paleoceanographic and geologic events have occurred that impacted the region under study. Woodruff (1985) and Woodruff and Savin (1985) attributed changes in benthic foraminiferal distribution patterns and a strong $\delta^{13} \mathrm{C}$ maxima at $\sim 16-15$ Ma to global oceanographic and climatic changes that occurred as a 
result of Antarctic glacial growth and deep Pacific Ocean cooling. They also noted a benthic foraminiferal faunal turnover at $\sim 14 \mathrm{Ma}$ and suggested that the source of the turnover was in deep and bottom water masses (Woodruff, 1985; Woodruff and Savin, 1985). At $7.5-6.5 \mathrm{Ma}$, a carbon isotope shift has been noted both globally and regionally and is inferred to be either the result of a an expansion of C4 plants and grasslands which was accompanied by a global biomass decrease or an increase in the erosion of organic carbon from terrigenous and shelf sediments due to Antarctic glaciation (Shackleton and Kennett, 1975; Bickert et al., 2004).

Recent studies (Montes, et al., 2012, 2015) have argued that the closure of the Central American Seaway occurred much earlier than the previously established closure date of 4 Ma (Keigwin, 1978; Haug and Tiedemann, 1998). Montes et al. (2012, 2015) applied Uranium-Lead geochronology to several granitic plutons of the Panama magmatic arc and Andean terranes. According to these studies, based on characteristics of the detrital populations, the fluvial connection was established between origination points in the Panama arc and northern South America in the middle Miocene (13-15 Ma), which implies the lack of a connecting seaway. However, Coates and Stallard (2013) discussed a "Standard model" with closure at 3-4 Ma and a "New model" with closure at $15 \mathrm{Ma}$, and were able to suggest a manner in which they both could be applied. They found that the "New Model" could be used to describe the Isthmus of Panama's "geological collision of the elements" at depth, and the "Standard Model" could be applied to oceanographic and land changes that occurred gradually (Coates and Stallard, 2013). 


\section{Rationale for Study}

This research tests the hypotheses that (1) paleoproductivity proxies and (2) diversity indices showed the effects of the closure of the Central American Seaway during intervals of known geologic and paleoceanographic change, and that (3) equatorial Eastern Pacific and Caribbean benthic foraminiferal assemblages showed a greater degree of similarity prior to closure of the Central American Seaway, with dissimilarity growing as closure progressed. These hypotheses are tested by examining the entire benthic foraminiferal assemblages of Caribbean ODP Site 999 and comparing the data to those of another Caribbean site and equatorial Eastern Pacific sites 26 - 2.5 Ma (Fig. 2). Paleoproductivity is calculated from the paleoproductivity proxies benthic foraminiferal accumulation rate (BFAR), infaunal/epifaunal ratio (I/E ratio), and organic-flux-indicator species using the methodology of Jain and Collins (2007). Diversity is measured with the indices Shannon H, Evenness, and Dominance using PAST paleontological statistical package (Hammer et al., 2001). Divergence between the benthic foraminiferal communities is accomplished through examination of relative abundance of dominant species and the use of non-metric multidimensional scaling to determine similarity. All methodologies are described in detail in each chapter.

Each chapter examines the data and results over multiple intervals determined by times of known geologic or paleoceanographic changes that affected the region. Divergences, increases or decreases, and changes in species composition are discussed in terms of the effect each event had on the data. The first, and oldest, is the differentiation of bottom water source, between the Caribbean and equatorial Eastern Pacific noted at 16 Ma, with the Caribbean changing to North Atlantic Deep Water (Morrison and 
Nowlin, 1982; Keller and Barron, 1983; Duque-Caro, 1990; and Haddad and Droxler, 1996). The second noted event is the deep circulation barrier between the two regions at $\sim 12$ Ma (Duque-Caro, 1990), followed by the third event at $~ 8 \mathrm{Ma}$, which was a constriction of seaway (Wright et al., 1991, Billups, 2002). The final event used in this study is the complete closure of the Central American Seaway at 4 Ma (Keigwin, 1978; Haug and Tiedemann, 1998).

Although previous studies have utilized the same cores from the Caribbean, they examined stable isotopic differences (Bickert, et al., 2004), diversity (Jain, 2006; Jain et al., 2007), planktic foraminiferal biostratigraphy (Chaisson and D’Hondt, 2000) and paleoproductivity (Jain, 2006; Jain and Collins, 2007), primarily over the last 8 Ma. Specifically, a paleobiogeographical reconstruction of Caribbean benthic foraminifera for any time interval has not been done, nor has paleoproductivity or diversity using benthic foraminifers been determined prior to $8 \mathrm{Ma}$. Examining the interval prior to previously documented changes provides a broader basis for their interpretation. An additional issue with studies of the older intervals is that the poor preservational quality of the benthic foraminifera does not allow for stable isotope studies. The ultimate goal of this work is to show the effects of a major geologic and oceanic change on benthic foraminiferal assemblages, as well as to provide additional constraints in the timing of closure, including pre-closure events that have been more poorly constrained.

Five cores (Fig. 2) yielded the samples and data (Figs. 3, 4), either from new analysis of previously prepared or new samples (37 samples) from Caribbean ODP Site 999 or data from previously studied sites in the Caribbean (DSDP Site 502 - 12 samples) 
or equatorial Eastern Pacific DSDP Sites 503 (11 samples), 568 (24 samples), and 569 (20 samples). Data from 104 samples were used in this study (Table 1, Appendices 1-5). A potential problem with age determination arose when comparing datasets from different sites and studies. Ages for Caribbean Site 999 (this study) were taken from published tables (Sigurdsson, et al., 1997), that used calcareous nannofossil and planktic foraminiferal biostratigraphy (Berggren et al., 1995; Curry, Shackleton, Richter, et al., 1995) to achieve preliminary age designations which were then calibrated to Cande and Kent’s (1995) magnetic polarity time scale (Fig. 5). The EEP Sites 568 and 569 did not have any published absolute age data, but utilized planktic foraminiferal zonation (Berggren et al., 1995) and calcareous nannofossil zonation (Bukry, 1973, 1975; Okada and Bukry, 1980) to identify biozones. Since the ages provided for Site 999 were determined from a calibrated time scale that utilized these biozonations, absolute age datums were established for this study by identifying the limits of each identified zonation and interpolating ages between points, so that data from previously studied sites could be directly compared to those of ODP Site 999.

Caribbean site 502 and EEP site 503 had published absolute age data (McDougall, 1996). These ages were calculated from planktic foraminiferal zonations and magnetostratigraphy using the time scales of Zenker (1986), Zenker et al. (1987), Keller et al. (1989) and Kent and Spariosu (1982a, b). Since these data were not established using the same schemes, limits on identified magnetochrons were compared to those used in the current study (Berggren et al., 1995) to identify differences (Table 2). The ages calculated for Site 999 used several magnetic polarity time scales, including that of Berggren et al. (1995) but there is no difference in age determination that affects the 
definition of the four time intervals used in this study, approximately 25-16 Ma, 16 - 8 Ma, and 8-4 Ma. For example, this comparison found that there is up to only a 32-34 kyr discrepancy, the largest identified (Table 2) surrounding the complete closure of the CAS at 4 Ma. The data points from Caribbean Site 502 and EEP Site 503 are younger than the other noted geologic events at 16,12, and $8 \mathrm{Ma}$, and therefore, the possible discrepancy only applies to the data younger than 8 Ma. Since Caribbean Site 999 uses a different time scale than that of Caribbean Site 502 and EEP 503, data points at exactly the same age datums cannot be directly compared.

The chapters are as follows:

Chapter 1 - Introduction

Chapter 2 - Neogene Paleoproductivity of the Caribbean and Equatorial Eastern Pacific from 26-2 Ma

Chapter 3 - Neogene Diversity of Caribbean Benthic Foraminifera Related to the Closure of the Central American Seaway

Chapter 4 - Neogene Paleobiogeography of Caribbean Deep-Sea Benthic

Foraminifera

Chapter 5 - Conclusions 


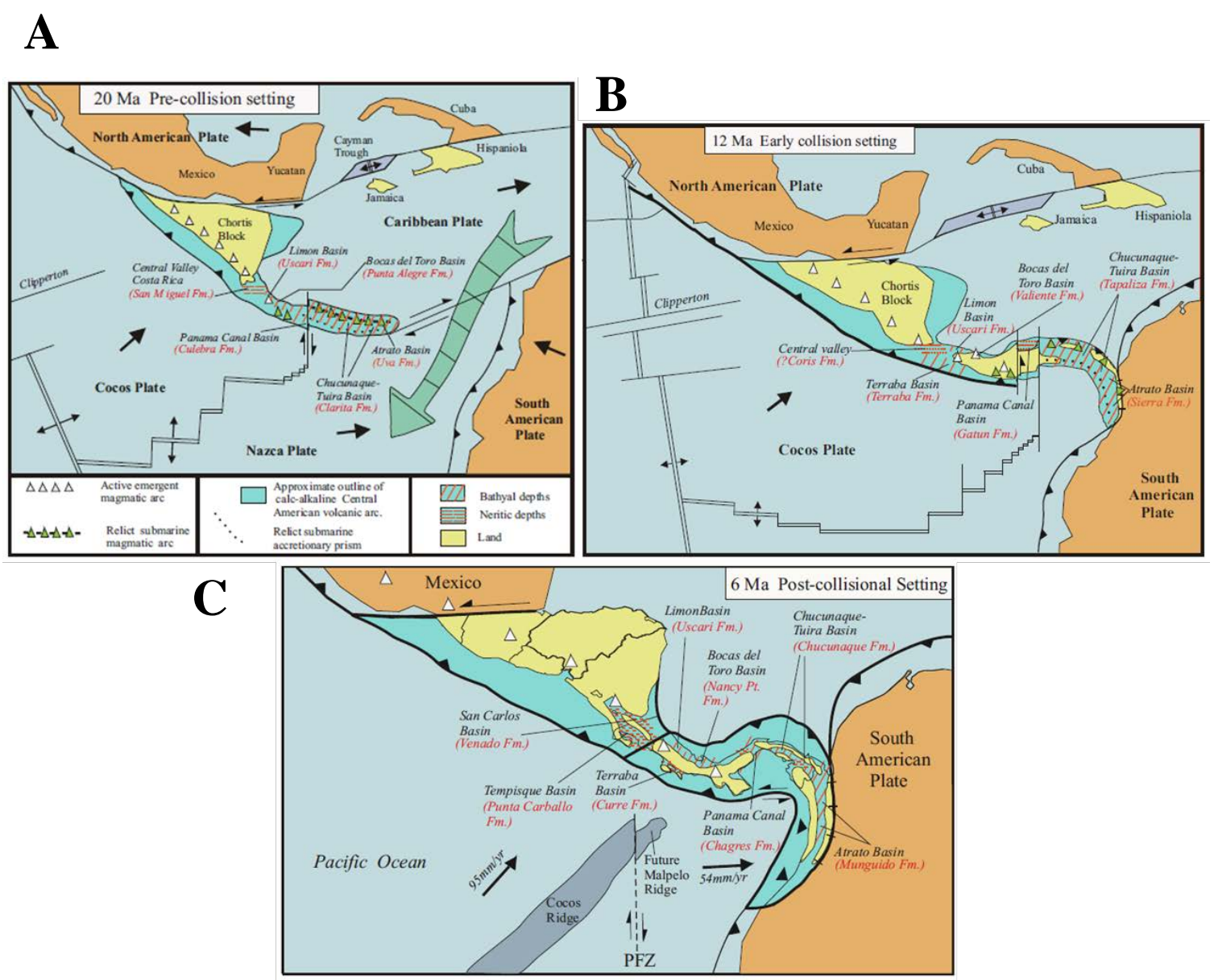

Figure 1. Reconstruction of geologic setting at (A) $20 \mathrm{Ma}$, (B) $12 \mathrm{Ma}$, and (C) $6 \mathrm{Ma}$. Black arrows indicate plate motion; large green arrow (Map A) shows complete tropical Atlantic - Pacific water interchange (Coates, et al., 2004). 


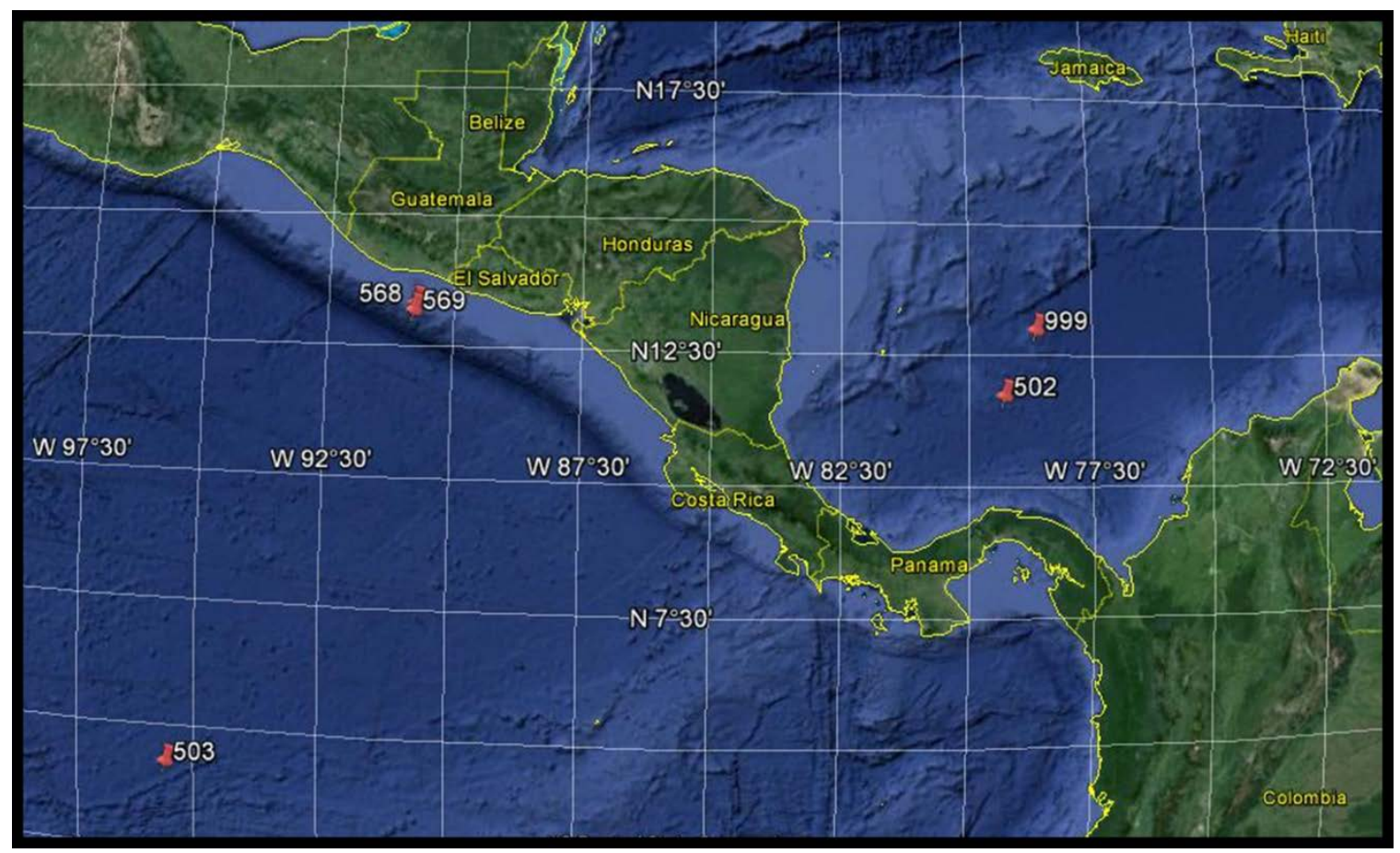

Figure 2. Site locations used for this study: Caribbean ODP Site 999, DSDP Site 502, and Equatorial Eastern Pacific DSDP sites 503, 568 and 569. 


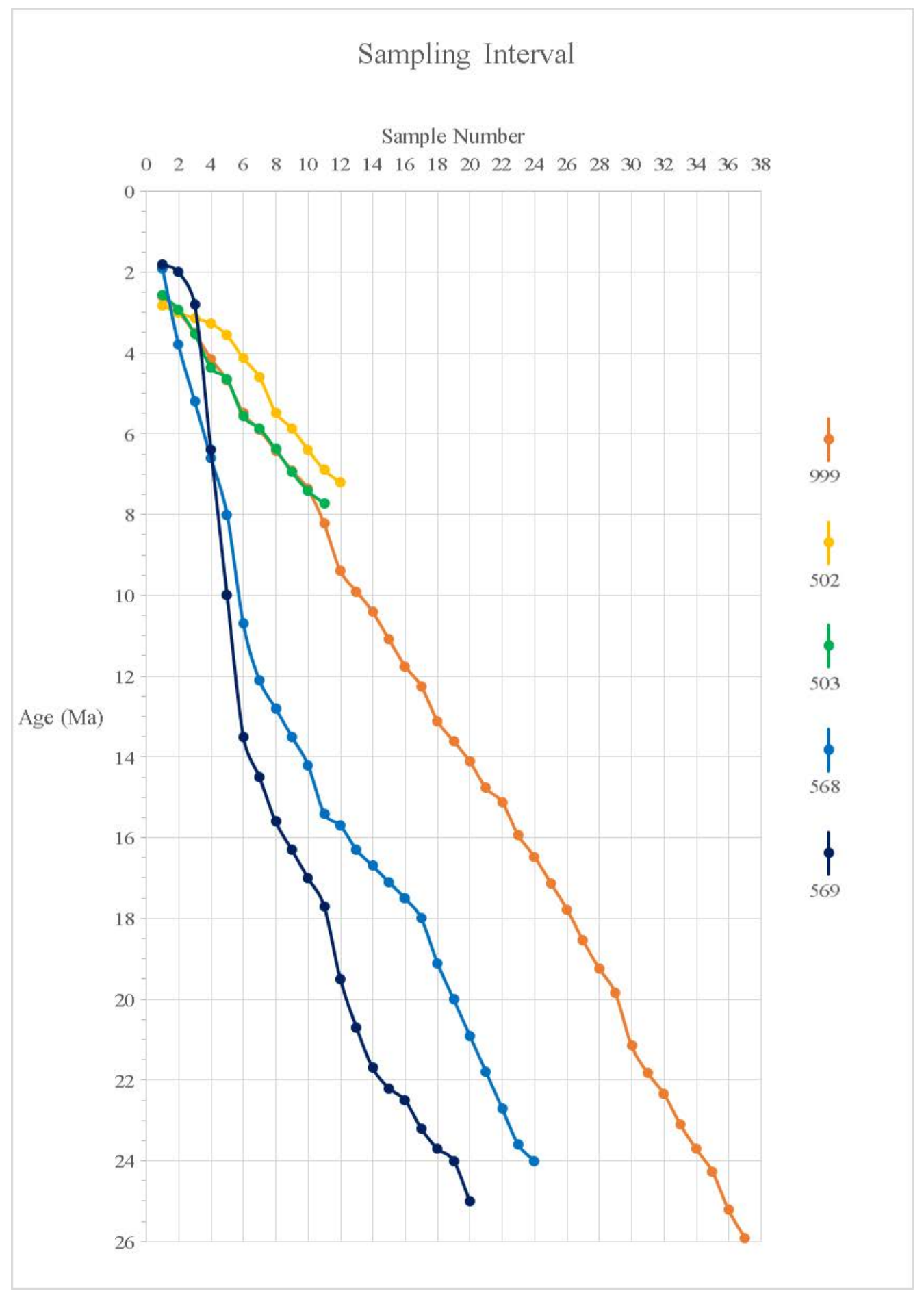

Figure 3. Sampling interval for all sites. 


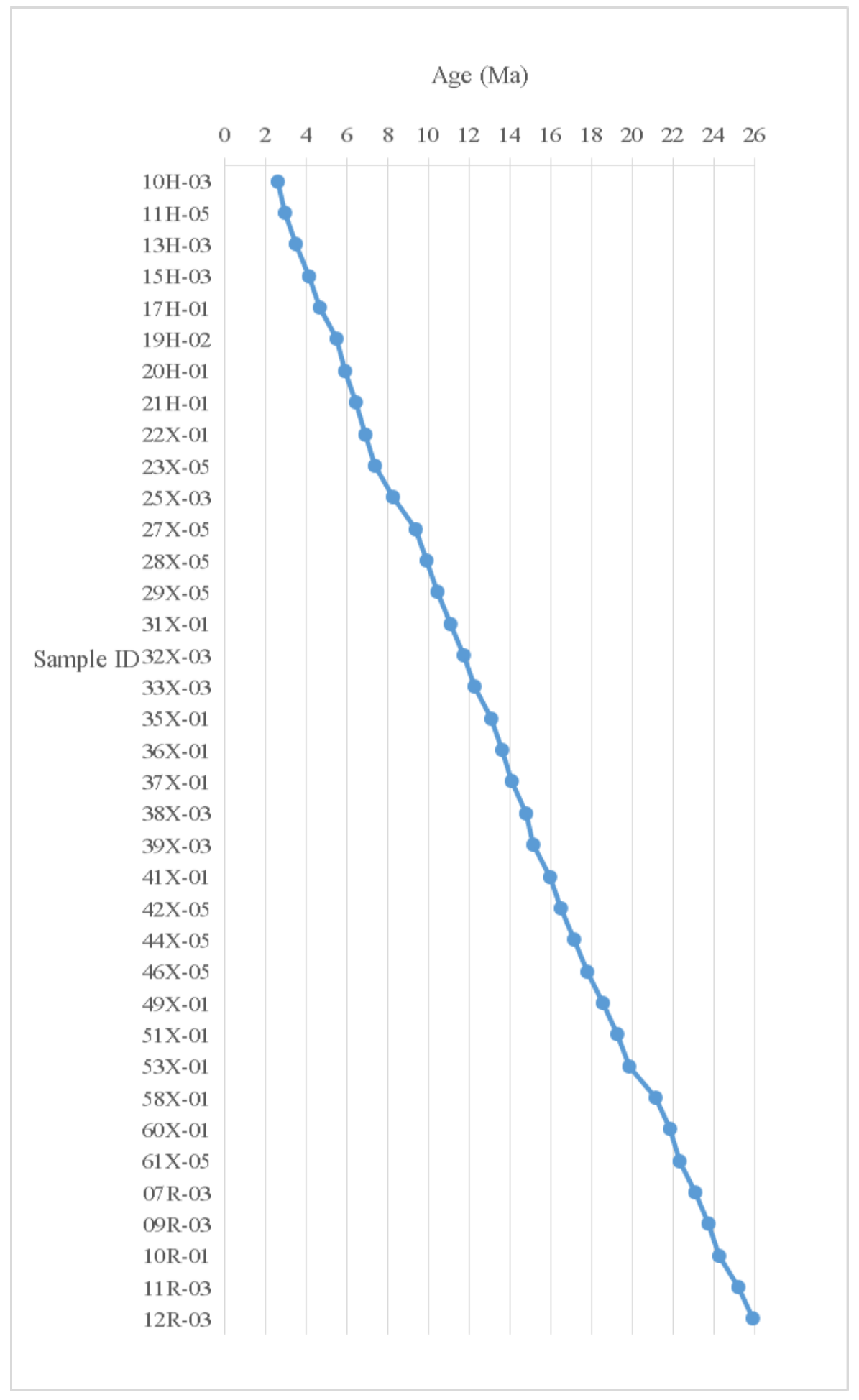

Figure 4. Thirty-seven samples prepared for benthic foraminiferal assemblages, ODP Site 999. Where sample conditions allowed, samples were selected at a 0.5 million year interval. All ages acquired from ODP Site 999 publications (Sigurdsson, et al., 1997). 

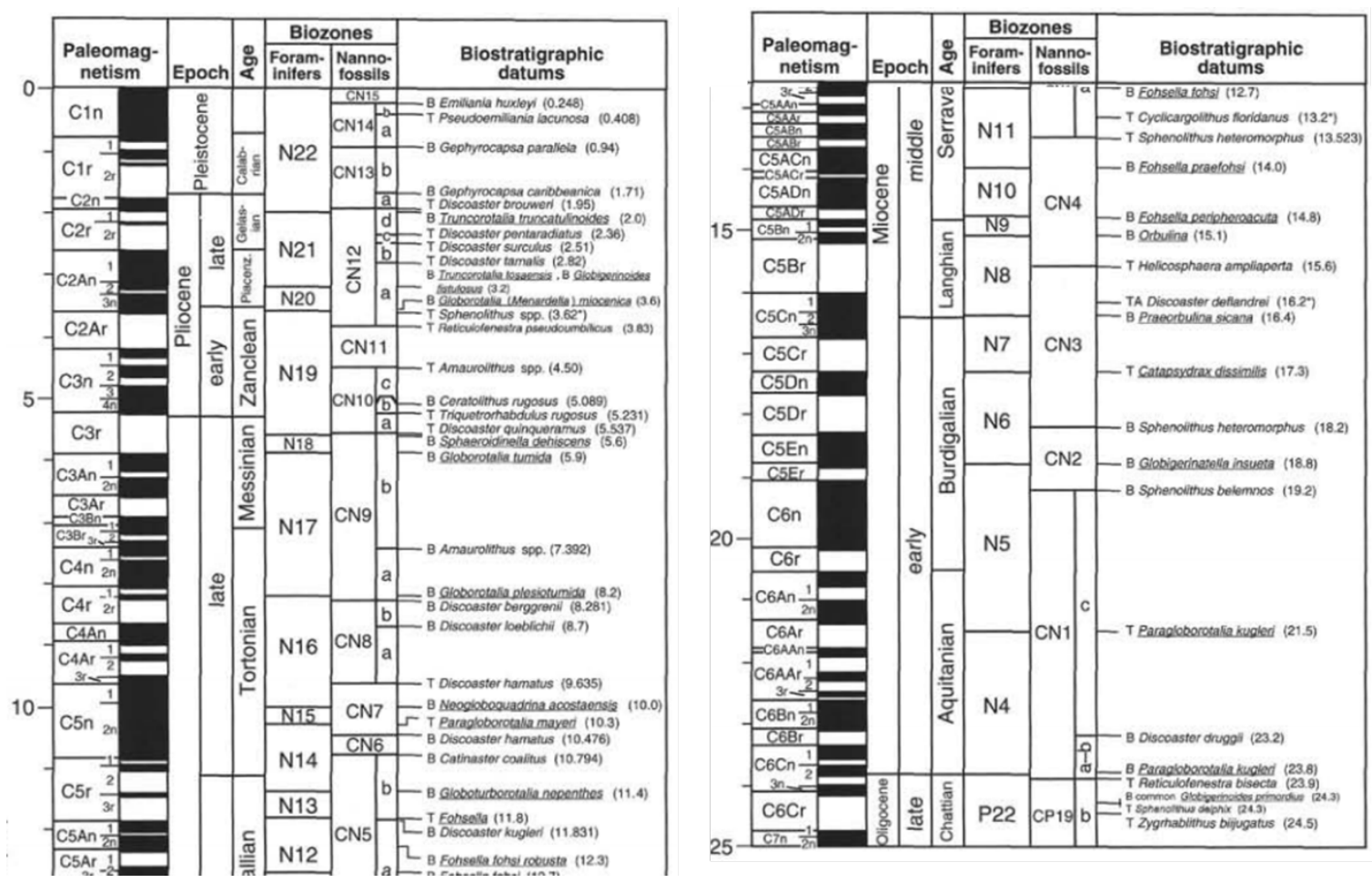

Figure 5. Time scale of Cande and Kent (1995) used for age calibration of datasets (after Sigurdsonn, et al., 1997). 
Table 1. Site and foraminiferal data set. Data for Site 999 (Jain, 2006; Jain and Collins, 2007; Jain et al., 2007; this study); sites 502, 503, 568, 569 (McDougall, 1985, 1996, written comm., 2015).

\begin{tabular}{|c|c|c|c|c|c|c|c|c|c|}
\hline Region & $\begin{array}{c}\text { ODP/DSD } \\
\text { P Site }\end{array}$ & $\begin{array}{c}\text { Water } \\
\text { Depth } \\
\text { Drilled }(\mathrm{m})\end{array}$ & $\begin{array}{l}\text { Number of } \\
\text { Samples } \\
\text { (utilized in } \\
\text { this study) }\end{array}$ & $\begin{array}{l}\text { Minimum } \\
\text { Specimen } \\
\text { Number per } \\
\text { Sample }\end{array}$ & $\begin{array}{l}\text { Maximum } \\
\text { Specimen } \\
\text { Number per } \\
\text { Sample }\end{array}$ & $\begin{array}{c}\text { Average } \\
\text { Specimen } \\
\text { Number per } \\
\text { Sample }\end{array}$ & $\begin{array}{l}\text { Minimum } \\
\text { Number of } \\
\text { Species per } \\
\text { Sample }\end{array}$ & $\begin{array}{l}\text { Maximum } \\
\text { Number of } \\
\text { Species per } \\
\text { Sample }\end{array}$ & $\begin{array}{l}\text { Average } \\
\text { Number of } \\
\text { Species per } \\
\text { Sample }\end{array}$ \\
\hline \multirow{2}{*}{ Caribbean } & 999 & 2828 & 37 & 126 & 995 & 350 & 28 & 70 & 44 \\
\hline & 502 & 3051 & 12 & 15 & 659 & 326 & 8 & 62 & 43 \\
\hline \multirow{3}{*}{$\begin{array}{c}\text { Eastern } \\
\text { Equatorial } \\
\text { Pacific }\end{array}$} & 503 & 3672 & 11 & 49 & 335 & 154 & 24 & 63 & 39 \\
\hline & 568 & 2010 & 24 & 1 & 382 & 103 & 1 & 61 & 21 \\
\hline & 569 & 2744 & 20 & 1 & 424 & 125 & 1 & 67 & 28 \\
\hline
\end{tabular}

Table 2. Differences in magnetic chron ages (Kent and Sapriosu, 1982 a, b; Berggren et al., 1995)

\begin{tabular}{|c|c|c|c|c|c|c|}
\hline Chron & $\begin{array}{c}\text { Upper Age Limit } \\
\text { (Ma) from Berggren } \\
\text { et al., (1995) }\end{array}$ & $\begin{array}{c}\text { Upper Age Limit } \\
\text { (Ma) from Kent and } \\
\text { Sapriosu (1982a,b) }\end{array}$ & $\begin{array}{c}\text { Difference in } \\
\text { Upper Age } \\
\text { Limit (Ma) }\end{array}$ & $\begin{array}{c}\text { Lower Age Limit } \\
\text { (Ma) from } \\
\text { Berggren et al., } \\
\text { (1995) }\end{array}$ & $\begin{array}{c}\text { Lower Age Limit } \\
\text { (Ma) from Kent } \\
\text { and Sapriosu (1982 } \\
\text { a,b) }\end{array}$ & $\begin{array}{c}\text { Difference in } \\
\text { Lower Age } \\
\text { Limit (Ma) }\end{array}$ \\
\hline Matuyama & 0.78 & 0.73 & 0.05 & 2.58 & 2.48 & 0.1 \\
\hline Olduvai & 1.77 & 1.66 & 0.11 & 1.95 & 1.88 & 0.07 \\
\hline Gauss & 2.58 & 2.48 & 0.1 & 3.58 & 3.4 & 0.18 \\
\hline Mammoth & 3.22 & 3.18 & 0.04 & 3.33 & 3.4 & -0.07 \\
\hline Cochiti & 4.18 & 3.86 & 0.32 & 4.29 & 3.95 & 0.34 \\
\hline
\end{tabular}




\title{
CHAPTER 2 - NEOGENE PALEOPRODUCTIVITY OF THE CARIBBEAN AND EQUATORIAL EASTERN PACIFIC FROM 26-2 MA
}

\begin{abstract}
This study examines paleoproductivity values determined from benthic foraminifera from the Late Oligocene ( 26 Ma) until the Late Pliocene/Early Pleistocene ( 2.5 Ma), and tests the hypothesis that paleoproductivity values prior to closure of the Central American Seaway are similar in both the Caribbean and equatorial Pacific and then diverge by the time of early shoaling events. Published data from the equatorial Eastern Pacific (DSDP Sites 503, 568, and 569), are examined in conjunction with new data from ODP Site 999 and previously published Caribbean data (DSDP Site 502). Identifications of deep-sea benthic foraminifera in previous studies of the Caribbean and equatorial Eastern Pacific were taxonomically standardized and examined for trends in paleoproductivity.
\end{abstract}

Prior to the differentiation in bottom water source for the Caribbean and equatorial Eastern Pacific $16 \mathrm{Ma}$, there were similar trends in proxies for organic carbon flux. The curves for these proxies showed similar increases and decreases in both the Caribbean and equatorial Eastern Pacific. The initial differentiation in bottom water at $\sim 16 \mathrm{Ma}$ is noted in the Caribbean with a sharp decrease in Benthic Foraminiferal Accumulation Rate, followed by a large increase to $\sim 450$ foraminifers per $\mathrm{cm}^{2}$ per kyr. Larger-scale changes were not seen until 8 Ma when a deep-circulation barrier was formed. At this point, the Caribbean values of paleoproductivity diverged from those of the equatorial Eastern Pacific with a marked Caribbean decrease in paleoproductivity, as recorded by increase in low-carbon-flux indicator species. With final closure of the 
Central American Seaway at $4 \mathrm{Ma}$, the Caribbean sites underwent a decrease in productivity, leading to the conclusion that without surface exchange with the nutrientrich equatorial Eastern Pacific, or a large scale decrease of upwelling, the Caribbean became oligotrophic with a decrease in BFAR values.

\section{Introduction}

The closure of the Central American Seaway had a major impact on marine habitats and organisms in both the Caribbean Sea and the tropical eastern Pacific Ocean. The Isthmus of Panama may have begun affecting deep circulation in the Early Neogene as seen in decreased radiolarian productivity and shell thickness (Maurrasse, 1979) and, according to paleobathymetry determined from benthic foraminifera, shallowing water depths in sediments that would later be uplifted as the Isthmus in the Middle Miocene (Duque-Caro, 1990; Coates et al., 2003, 2004). Lunt et al. (2008), utilizing a oceanatmosphere general circulation model, stated that seaway closure lasted from 13 Ma to 2.6 Ma, but based on $\delta^{18} \mathrm{O}$ values, complete closure actually happened at $\sim 4 \mathrm{Ma}$ (Keigwin, 1978; Haug and Tiedemann, 1998). Saito (1976) attributed the change in coiling direction patterns between Indo-Pacific and Atlantic Pulleniatina at 3.5 Ma to the isolation of the genus on either side of the Isthmus of Panama. The closure of the seaway occurred in multiple steps with differentiation of bottom water source between the Caribbean and equatorial Eastern Pacific, barriers to deep-water circulation, seaway constriction, and finally complete closure of the seaway (Fig. 1).

When Central America was emplaced between North and South America in the Neogene, it provided a major barrier to dispersal amongst tropical marine populations 
that, prior to the rise of the isthmus, had no major restrictions in range. With similar water chemistry, food availability and temperature, the pre-isthmus tropical Eastern Pacific is predicted to have had similar paleoproductivity values to those in the Caribbean until a barrier sufficient to impede flow existed. This study tests the hypothesis that paleoproductivity proxies showed the effects of the closure of the Central American Seaway during intervals of previously identified geologic and paleoceanographic changes.

The data and results are examined over multiple intervals determined by times of known geologic or paleoceanographic changes that affected the region. Atlantic-Pacific divergence, increases or decreases are discussed in terms of the effect each event had. The first, and oldest event is the differentiation of bottom water source between the Caribbean and equatorial Eastern Pacific (EEP), with North Atlantic Deep Water occupying the Caribbean noted at $16 \mathrm{Ma}$ (Morrison and Nowlin, 1982; Keller and Barron, 1983; Duque-Caro, 1990; and Haddad and Droxler, 1996). The second noted event is the deep circulation barrier between the two regions at 12 Ma (Duque-Caro, 1990), followed by the third event, seaway constriction, at 8 Ma (Wright et al., 1991, Billups, 2002). The final event used in this study is the complete closure of the Central American Seaway at 4 Ma (Keigwin, 1978; Haug and Tiedemann, 1998).

Paleoproductivity has previously been studied relative to the closure of the Central American Seaway. In Jamaica, suggestion of a strong subsurface flow, indicative of NADW influence, was evidenced by the presence of sponge spicules in the middle upper middle Miocene Montpelier Formation, with productivity fluctuations shown by varying numbers of radiolarians indicating upwelling and/or higher productivity 
(Maurrasse, 1993). Bornmalm (1997) calculated Benthic Foraminiferal Accumulation Rate (BFAR) for Caribbean site 502 and EEP site 503 and found that overall, the flux of organic matter to the seafloor was higher at the Caribbean site after 4 Ma. However, the EEP site had a consistently lower BFAR rates ranging from 22 - 169 tests $\mathrm{cm}-2 \mathrm{ky}-1$ while the Caribbean was 34 - 379 tests cm-2 ky-1. Jain and Collins (2007) examined paleoproductivity in both the equatorial Eastern Pacific and the Caribbean adjacent to the shoaling Central American Isthmus. They found that during early shoaling (8.3-7.9 Ma), paleoproductivity between the Caribbean and EEP showed similar values, and the highest $\delta^{13} \mathrm{C}$ values for the equatorial Pacific also occurred during this period (Jain and Collins, 2007). Paleoproductivity values then diverged between the two sites during the preclosure interval (7.9-4.2 Ma), with productivity values from BFAR and Infaunal/Epifaunal (I/E) ratios showing a decrease in the Caribbean. After the Central American Seaway closed at $\sim 4$ Ma, BFAR, I/E ratios and organic flux values for the Caribbean showed a decrease, which supports the prediction of an increase in nutrientpoor waters (Jain and Collins, 2007). A recent study of benthic foraminifera of the equatorial Eastern Pacific from International Ocean Drilling Project Site U1338 was conducted by Tsujimoto et al. (2013). They saw an increase in paleoproductivity from 6.4-5.4 Ma because of a biogenic bloom in the late Miocene/early Pliocene and a marked increase of phytodetrital input at final closure from 4.5-3 Ma due to the constriction of the seaway.

The paleoproductivity proxies used by Jain (2006) and Jain and Collins (2007), and followed for the present study that extends their results on the same core further back in time, are as follows: benthic foraminifer accumulation rate (BFAR), ratio of 
infaunal/epifaunal species (I/E), and relative abundances of mesotrophic, eutrophic and oligotrophic species. The BFAR is calculated as the number of foraminifers per $\mathrm{cm}^{2}$ per kyr and indicates productivity as seen in the resultant seafloor organic carbon flux, since it has shown to be correlated with surface water productivity (Gooday, 1988; Herguera and Berger, 1991; and Herguera 1992). The I/E ratio is based on the microhabitat preferences (Tables 1,2) of benthic foraminifera. A higher percentage of infaunal species generally indicates an increase in organic flux to the seafloor because of the greater amount of organic material preserved below the sediment surface (Jorissen et al., 1993).

The proxy used for mesotrophy is Epistominella exigua (Brady), an indicator for pulsed phytodetrital input (Sun et al., 2006). It can tolerate a wide range of organic flux rates and is predominantly abyssal and epifaunal (Gooday and Jorissen, 2012). As a “phytodetritus-exploiting species" (Gooday and Jorissen, 2012), it can be linked to relatively high primary productivity and serves as a good proxy for input of organic matter (Smart et al., 1994; Thomas, et al., 1992).

The relative abundance of Nuttalides umbonifera (Cushman) is used to indicate levels of oligotrophy (Loubere, 1991; Mackenson et al., 1995). Nuttalides umbonifera indicates low organic flux and is found in areas with low seasonality and a decreased food supply (Gooday, 1993; Nomura, 1995; Schmiedl, et al., 1997; Singh, et al., 2004). Oligotrophic conditions allow the opportunistic $N$. umbonifera to grow in abundance where a very low food supply or high carbonate corrositivity does not allow the survival of other species (Loubere, 1991; Gooday, 1993; Nomura, 1995, Schmiedl, et al., 1997, Singh, et al, 2004). This species is also indicative of Antarctic Bottom Water in the Indian and Pacific oceans (Corliss, 1979). 
Based on their modern associations, multiple other species (Table 3) were used in calculations to determine eutrophic (high-organic-flux) and oligotrophic (low-organicflux) conditions. The proxy used for current velocity was the relative combined abundance of Cibicidoides wuellerstorfi and Globocassidulina subglobosa since both of these species have been shown to be associated with faster moving water (Lutz and Thiel, 1989; Murray, 1991; Mackensen et al., 1995; Schmiedl and Mackensen, 1997; Hayward et al., 2002, 2004). Higher values of these two species indicated higher current velocity due to their established association with faster moving waters.

\section{Methods}

\subsection{Site Locations}

This study utilizes data from sites (Fig. 2) drilled by the Ocean Drilling Project (ODP) and Deep Sea Drilling Project (DSDP). The current study incorporates new benthic foraminiferal data from Caribbean ODP Site 999, with previously studied data from Caribbean DSDP Site 502 and equatorial Eastern Pacific (EEP) sites 503, 568 and 569. Sites 568 and 569 were ultimately chosen from DSDP Leg 85 for their more extensive age range, with fewer hiatuses, thereby providing more data points to correspond to the current study. All of these comparison sites were also selected for their availability of complete benthic foraminiferal datasets (McDougall, written comm., 2015), and publication of foraminiferal images (McDougall, 1985; Thomas, 1985; Woodruff, 1985; McDougall, 1996), improving taxonomic standardization. Sampling interval (Fig. 3) and sample size varied at the EEP sites, so to avoid biased interpretations 
when sample sizes had large discrepancies, percentages and general trends were used, as opposed to absolute abundances.

\subsection{Sample Preparation and Foraminiferal Taxonomy}

Thirty-seven samples were chosen for preparation from Caribbean ODP Site 999 (Fig. 4) at an approximate 0.5-million-year interval. Because of differences in preservation and benthic foraminiferal abundance, this interval was adjusted at times to provide a more robust data set. Eleven of these samples were included from a previous study (Jain, 2006). For purposes of taxonomic standardization with older samples and previously studied datasets, the author re-identified all species on faunal slides provided by Jain. Jain's samples (10H-03 thru $25 \mathrm{X}-03)$, which were $10 \mathrm{~cm}^{3}$ samples, were treated with $1 \%$ hydrogen peroxide, soaked, and washed through a $63 \mu \mathrm{m}$ sieve, then dried in an oven. All benthic foraminifera from the residues were then picked and mounted on faunal slides. New sediment samples were soaked in deionized water for several days to disaggregate clays, and were also washed over a $63 \mu \mathrm{m}$ sieve. However, differing from Jain’s original study, samples were split using a standard sample splitter to achieve $\geq 200$ specimens, a statistically robust number. In sampling, it is statistically important to achieve a biologically representative sample set. At a sample size range of 200-400, a confidence level of $+/-93-95 \%$ is achieved, which means that there is $93-95 \%$ confidence that there will be less than +/-0.07 error per sample (Hayek and Buzas, 1997). In cases where the assemblage did not support a > 200-specimen recovery, the entire sample was counted. 
Individual benthic foraminifera were then sorted into species and identified using literature and comparative collections at the U.S. National Museum and in the collections of L. Collins (FIU). Correctly identifying benthic foraminifera is difficult due to morphologic variation in populations, synonyms and rare species, so species were identified using only comparative collections, and literature with excellent plates and figures. All specimens were identified to the species level where possible. When species level could not be achieved, because of preservation or quality of identifying features, specimens were assigned to the generic level and listed as spp. (Appendix 1). To standardize comparisons throughout the current study, once a specimen was identified, that specimen's sample, slide location, and reference citation were listed, in the author's collection. Subsequent specimens were then compared to those initially identified to maintain consistency. After data of McDougall for DSDP sites 502, 503, 568, and 569 were incorporated into the study set, all species names were checked for synonymies and updated generic assignation. Several species in the additional data sets were found to be in synonymy, and in those instances, all species were researched to determine current names.

\subsection{Age Determinations}

A potential problem with age determination arose when comparing datasets from different sites. Ages for Caribbean Site 999 (this study) were taken from published tables from Proceedings of the Ocean Drilling Program, Volume 165 (Sigurdsson, et al., 1997), based on calcareous nannofossil and planktic foraminiferal biostratigraphy (Berggren et 
al., 1995; Curry et al., 1995) to achieve preliminary age designations, which were then calibrated to Cande and Kent’s (1995) magnetic polarity time scale.

The EEP sites 568 and 569 had no published absolute ages, but utilized planktic (Berggren et al., 1995) and calcareous nannofossil zonations (Bukry, 1973, 1975; Okada and Bukry, 1980) to identify biozones. Since the ages provided for Site 999 were determined from a calibrated time scale that utilized these biozonations, absolute age datum levels were established for these two EEP sites by identifying the limits of each identified zonation and interpolating ages between points, so that data could be directly compared to that of the present study. This technique assumed a steady rate of sedimentation within a biozone.

DSDP Caribbean Site 502 and EEP Site 503 had published absolute age data (McDougall, 1996) that were calculated from planktic foraminiferal zonations and magnetostratigraphy using the time scales of Kent and Spariosu (1982a, b), Zenker (1986), Zenker et al., (1987), and Keller et al., (1989). Since these datums were not established using the same time scales described above, limits on identified magnetochrons were compared to those used in the current study (Berggren et al., 1995) to identify differences (Table 3). The ages calculated for Site 999 used several magnetic polarity time scales, including that of Berggren et al. (1995) but there is no significant difference between time scales that affects that affects definition of the four time intervals used in this study, approximately 25-16 Ma, 16-8 Ma, and 8-4 Ma. For example there is up to only a 32-34-kyr discrepancy, the largest identified (Table 3) surrounding the complete closure of the CAS at $\sim 4$ Ma. The data points from Caribbean Site 502 and 
EEP Site 503 are younger than the other noted geologic events at $\sim 16, \sim 12$, and $~ 8 \mathrm{Ma}$, and therefore, the possible discrepancy only applies to the data younger than $~ 8 \mathrm{Ma}$. Since Caribbean Site 999 uses a different time scale (Berggren et al., 1995) than that of Caribbean Site 502 and EEP 503 (Kent and Spariosu, 1982a, b; Zenker, 1986; Zenker et al., 1987; and Keller et al., 1989), data points at exactly the same age datums cannot be directly compared.

\subsection{Proxies}

All analysis and interpretation of paleoproductivity follow the methodology of Jain (2006) and Jain and Collins (2007) so those data can be compared with results from this study. Individual species counts from all sites were used in calculating relative abundances of $N$. umbonifera, E. exigua, the I/E ratio, and all "flux" proxies. However, because of lack of data on previously studied sites, and lack of compatibility of sampling/counting methods, the Benthic Foraminifera Accumulation Rate (BFAR) was only calculated for ODP Site 999. The BFAR is calculated as the number of foraminifers per $\mathrm{cm}^{2}$ per kyr. The values for the sedimentation rate and dry bulk density of ODP Sites 999A and 999B were acquired from data on shipboard physical properties (Sigurdsson, et al., 1997). For comparison purposes, published BFAR values calculated by Bornmalm (1997) for Site 502/503 were utilized. However, Bornmalm’s study (1997) calculated BFAR using counts from the $125 \mu$ sieve, and therefore, missed the smaller species and juveniles found in the $>63 \mu$ size fraction of this study; thus, trends but not values can be compared between studies. 
All species counts were input into Excel spreadsheets, and calculations for proxies were plotted graphically. Both original values and 3-point-moving-averages were calculated. Since the 3-point-moving-averages are calculated using the two prior data points, the two youngest points could not be calculated using moving averages so the actual data points for those two samples are used for ease of graphical display. The 3point-moving-average allows for "smoothing" of the data so that the noise within each proxy or graph is subdued enough to see general trends.

\section{Results}

This study of ODP Site 999 produced 12,522 identified foraminiferal specimens, including 237 species in 71 genera. These counts, coupled with previously published counts for EEP DSDP Sites 503, 568 and 569, and Caribbean DSDP Site 502 (McDougall, 1985, 1986; McDougall written comm., 2015) were used in all calculations of paleoproductivity (Figs. 5-13). It is important to note the usability of some of the EEP datasets that were acquired. Whereas EEP sites 568 and 569 provide substantial data for comparison, especially for the older studied interval ( 26 - $8 \mathrm{Ma})$ that is not present at sites 502 and 503, paleoproductivity proxies cannot be directly compared with either Caribbean site or EEP Site 503 because multiple samples contain very low abundances that directly affect the proxies calculated from the species composition of the samples. In my study of ODP Site 999, samples were selected to provide a robust species count where possible, so Site 999 possesses the higher number of average specimens, as well as a much higher minimum specimen number (153), compared to a minimum of 1 or 15 at all other sites (Table 4). These low numbers in terms of both taxa and counts of 
individuals have therefore distorted the calculations of proxies so many fluctuations or peaks visible in the curves are not discussed here. Appendices $1-5$ list all counts of each site. Noted times of paleoceanographic change, as previously documented, are as follows, in chronologic order:

16 Ma - differentiation of bottom water source between Caribbean and EEP

12 Ma - deep circulation barrier between Caribbean and EEP

$\sim 8 M a-$ Constriction of seaway

$\sim 4 M a$ - complete closure of the CAS

\subsection{Nuttalides umbonifera, Proxy for High Oligotrophy}

At all sites, from 26 Ma to $10 \mathrm{Ma}$, the relative abundance of Nuttalides

umbonifera ranges from relatively low to none (Fig. 5 a,b). (Note that McDougall (1996)

refers to Nuttalides umbonifera as Epistominella umbonifera). There are two small

increases, one at $20 \mathrm{Ma}$ (Site 569; Pacific) and one each at 15 Ma and $\sim 12 \mathrm{Ma}$ (both at Caribbean Site 999). At $\sim 9 \mathrm{Ma}$, there is an increase in N. umbonifera at both Caribbean Site 999 and EEP Site 569. DSDP sites 502 and 503 were not sampled older than 8 Ma and the other EEP site (568) was only sampled once 12-6 Ma. The interval between 8-6 Ma contains the oldest data points for the samples of DSDP sites 502 and 503. Site 502 has a high abundance in this interval but sharply drops at $\sim 6 \mathrm{Ma}$, as does Caribbean ODP Site 999. EEP Site 503 has one peak at 6 Ma and moderately increases, which is the same pattern as at the two Caribbean sites, but then sharply drops. From 4-2 Ma, EEP DSDP Site 503 has fairly consistent abundances ranging from 10\%-15\%. Around $4 \mathrm{Ma}$, there is a very sharp increase in abundance (30\%-50\%) at both Caribbean sites. 


\subsection{Proxies for Organic Carbon Flux}

Epistominella exigua, an indicator of mesotrophy and/or variable organic carbon flux, is much less abundant in the EEP than in the Caribbean throughout the 24 million

years (Fig. 6 a,b). Prior to 11 Ma, all sites had less than $11 \%$ E. exigua. However, at $\sim 11$ Ma, there is a rapid increase at Caribbean Site 999 to 55\% and a corresponding peak at EEP Site 569 of 33\%. From 7.5 Ma to 6 Ma, there are also corresponding increases at Caribbean Site 999 and EEP Site 503, but not at Caribbean Site 502 or EEP sites 568 and 569. From 6-4 Ma there is a higher consistent presence at EEP site 503 and both Caribbean sites. From 4-2 Ma, E. exigua at all sites decreases, with the exception of Caribbean Site 502, which initially shows a slight increase. Although this increase at Site 502 occurs during the discrepancy noted in the different time scales around $4 \mathrm{Ma}$, the trend extends past that interval of time, indicating that the actual increase did occur after the closure of the CAS.

Before $12 \mathrm{Ma}$, the percentages of high-carbon-flux species (eutrophic indicators) show a fairly consistent trend of little change (Fig. 7) with values ranging between $10 \%$ and $40 \%$ for the majority of the samples, although the EEP sites are more variable. Immediately after $\sim 12$ Ma, percentages at EEP Site 568 drop to near zero for the remainder of the younger samples. Both Caribbean sites maintain fairly consistent percentages between $10 \%$ and $40 \%$. After 6 Ma, Caribbean values are mostly lower than EEP values at sites 503 and 569 .

The oligotrophic indicator species, those that are indicative of a low-organiccarbon flux (Fig. 8 a,b), show more variation than the high-organic-carbon flux indicators (described above) with the EEP sites being especially variable. Around 10.5 Ma, there is 
a general decrease in percentages in both the Caribbean and EEP. In the interval from 8-2 Ma, and especially after $4 \mathrm{Ma}$, both Caribbean sites show higher levels, on average, than the EEP sites.

\subsection{Infaunal/Epifaunal Ratio (I/E Ratio) - Proxy for High/Low-Flux}

The Infaunal/Epifaunal ratio (Fig. 9) is generally low (0-4) at all three sites in the interval from 26-8 Ma, and generally declines from 16-8 Ma. From 6 Ma to the youngest samples at 2 Ma, EEP sites were generally higher than in the Caribbean, with sharp increases after $4 \mathrm{Ma}$ at the EEP Sites.

\subsection{Benthic Foraminiferal Accumulation Rate (BFAR)}

The BFAR values are only available for Caribbean ODP Site 999 (Fig. 10 a,b). As a result of the absence of necessary parameters, BFAR was not calculated for all sites. Values calculated for DSDP Sites 502 (Caribbean) and 503 (EEP) by Bornmalm (1997) are shown only for general comparison. The values for BFAR show a great deal of fairly intense fluctuation throughout the studied interval, but values are much higher before 8 Ma than afterwards. After the events noted at $16 \mathrm{Ma}, 12 \mathrm{Ma}$, and $8 \mathrm{Ma}$, BFAR shows marked decreases. The lowest values for BFAR are in the interval between 8 and $4 \mathrm{Ma}$, and then increase around the time of seaway closure. After $6 \mathrm{Ma}$, BFAR in the Caribbean shows a slow, slight increase, also seen at $~ 4.5 \mathrm{Ma}$ in the Pacific, after which all sites converge on similar values 2.5 Ma. BFAR stays much lower after the constriction of the seaway at $\sim 8 \mathrm{Ma}$. When the previously calculated BFAR values for sites 502 and 503 (Bornmalm, 1997) are compared, Caribbean Site 502 shows a very 
similar trend to Caribbean Site 999 values calculated in this study. EEP Site 503 shows a lower value for BFAR than does the Caribbean.

\subsection{Current Velocity Proxy}

The proxy for current velocity (Fig. 11 a,b) resulted in very low numbers for EEP sites 568 and 569 when compared to the Caribbean and EEP Site 503 data. Between 8-7 Ma, Caribbean values peaked and declined thereafter. The proxy at Caribbean Site 502 also declined after 7 Ma, except for one major peak at 4 Ma. EEP Site 503 shows a trend similar to that of the Caribbean with the decrease before $4 \mathrm{Ma}$, but increases to a higher value than in the Caribbean by 2.5 Ma. The values for the Caribbean tend to fluctuate more than for the EEP.

\section{Discussion}

The proxy results can be discussed in terms of major geologic events that occurred in the region: $16 \mathrm{Ma}$ - differentiation of bottom-water source for the Caribbean and equatorial Eastern Pacific (Keller and Barron, 1983; Duque-Caro, 1990); 12 Madeep circulation barrier between the Caribbean and the Pacific (Duque-Caro, 1990); 8 Ma - effective barrier to surface water exchange (Collins, 1996a; Frank et al., 1999) and constriction of the seaway (Wright et al., 1991, Billups, 2002); 4 Ma - complete closure of the CAS (Keigwin, 1978; Haug and Tiedemann, 1998). These events are compared to trends in the nutrient- and productivity-related proxies. Each subsection below covers the interval from the named event until the next. 


\subsection{Differentiation of Bottom-Water Source 16 Ma}

Prior to $16 \mathrm{Ma}$, there was open communication between the waters of the Caribbean and equatorial Eastern Pacific (Duque-Caro, 1990; Keller and Barron, 1983). The differentiation of bottom-water source at middle Miocene Hiatus NH2 is seen as a change in circulation and sedimentation (Keller and Baron, 1983; Duque-Caro, 1990), and did not appear to have much effect on the paleoproductivity proxies, with two exceptions. At the time of the event there was a high peak that was then followed by a low peak of Nuttalides umbonifera at ODP Site 999 (Fig. 6 a,b) which, according to Corliss (1979), is an indicator of Antarctic Bottom Water. This species is also noted for showing increased abundances when there is high carbonate corrositivity or low food supply (Loubere, 1991; Gooday, 1993; Nomura, 1995; Schmiedl, et al., 1997; Singh, et al, 2004). The change in bottom-water source coincides with the global event noted by Woodruff (1985) and Woodruff and Savin (1985) which was attributed to deep Pacific Ocean cooling and Antarctic glacial growth, which did not have a great deal of impact on the paleoproductivity proxies.

The other change seen in paleoproductivity values is in the BFAR (Fig. 9) calculated for Caribbean Site 999. The interval before the event at 16 Ma contains fluctuating values of BFAR, but are on average higher compared to intervals younger than $\sim 12 \mathrm{Ma}$. There is a peak of BFAR (433.5 tests $\mathrm{cm}-2 \mathrm{ky}-1)$ preceding the time of differentiated bottom-water source at $\sim 16 \mathrm{Ma}$, and it drops to 156.8 tests $\mathrm{cm}-2 \mathrm{ky}-1$ at 15 Ma but values rebounded again, the highest levels of the entire studied interval. The changes seen in BFAR are likely the result of the effect of a change in the source of bottom water affecting food availability, as well as possibly increasing corrosivity, 
allowing for more dissolution resistant species such as N. umbonifera to flourish. According to Herguera and Berger (1991), changes in BFAR can be attributed to an increase in surface-water productivity. The decrease in BFAR and current velocity that coincided with the increase in $N$. umbonifera could have been due to the decrease in food supply that occurred with the change in bottom-water source.

\subsection{Barrier to Deep Circulation 12 Ma}

The barrier that prevented deep circulation at $~ 12 \mathrm{Ma}$ (Duque-Caro, 1990) is also visible in several of the proxies used in this study. This barrier to flow was identified by a change in paleobathymetry (determined by foraminifera) from lower bathyal depths to middle bathyal depths (Duque-Caro, 1990). The increase in the abundance of $N$. umbonifera (Fig. 5 a,b) at ODP Site $999 \sim 16$ Ma was followed by a drop to very low values. Although abundances of E. exigua (Fig. 6 a,b) dropped 12 Ma, at 10.5 Ma the values at Caribbean Site 999 show a very large increase to over 55\%. As E. exigua is an indicator of mesotrophy because of its ability to "exploit phytodetritus" and tolerate wide ranges of organic flux rates (Thomas, et al., 1992; Smart et al., 1994; Sun et al., 2006; Gooday and Jorissen, 2012), this barrier to deep circulation may have resulted in a pulse of phytodetritus and an increase in primary productivity.

Following emplacement of the deep-circulation barrier, EEP Site 568 also shows a peak of high-organic-carbon-flux-indicator species (Fig. 7 b), which supports the effect of a deep-circulation on paleoproductivity. However, BFAR for Site 999 shows a drop after $\sim 12 \mathrm{Ma}$ and does not rebound until $10.5 \mathrm{Ma}$, when pulses of phytodetrital material are inferred from the high abundance of E. exigua. The data in this study show that the 
deep-circulation barrier at 12 Ma most likely had an impact on both EEP and Caribbean sites. In the EEP, a response was seen in terms of an increase in paleoproductivity (eutrophic and mesotrophic indicator species, Figs. 6 a,b and 7 a,b), while the Caribbean underwent a delayed reaction with a decrease in paleoproductivity, followed by a resurgence at $\sim 10.5$ Ma to very high levels. There is also a response in the Caribbean in terms of current velocity (Fig. 8 b), which increased rapidly from just prior to and after the event and following. This increase in current velocity could have occurred due a change in current temperature and density, driven by the rise of a barrier and the hypothesized beginning of the cooler California current (Duque-Caro, 1990).

\subsection{Seaway Constriction $~ 8 M a$}

The constriction of the seaway at 8 Ma (Wright et al., 1991; Billups, 2002), identified by deep-water $\mathrm{Nd}$ and $\mathrm{Pb}$ isotopes and changes in $\delta{ }^{13} \mathrm{C}$ and $\delta^{18} \mathrm{O}$ values, had a major impact on the paleoproductivity of the region. At this event, both Caribbean sites diverged from similar values in the abundance of oligotrophic species from the EEP sites (Fig. 8 a). This divergence is seen with a sharp decrease in low-flux-indicator species at EEP Site 569 and a fairly steady increase at Caribbean Site 999 (Fig. 8 a). The Caribbean sites therefore become oligotrophic, a trend documented by Jain and Collins (2007). This interval also includes the oldest samples of sites 502 and 503, and they show the similar trends, with the EEP site being much lower in oligotrophy (higher in nutrients), than the Caribbean.

Seaway constriction, which effectively divided the Caribbean and the EEP biogeographically, also prevented high levels of nutrients from reaching the sea floor in 
the Caribbean, thereby resulting in a higher percentage of low-organic-carbon-flux species (Fig. 8 a). Collins et al., (1996) found that at $\sim 8 \mathrm{Ma}$, there was an effective barrier preventing water interchange. This difference in nutrient levels is shown in the EEP with a decrease in oligotrophic indicators and a slightly corresponding increase in eutrophic indicators. From 8-4 Ma there is also a very noticeable decrease in BFAR (Fig. 10 a) for Caribbean Site 999 (Fig. 7 a), to the lowest values of the entire studied sample interval, as well as low values for the I/E ratio (Fig. 9 a) and $N$. umbonifera (Fig. 5 a) abundance. The proxy for current velocity (Fig. 11 a) indicates a marked increase following the event at 8 Ma, followed by a noticeable decrease at Caribbean site 999 and 503, which is in agreement with decreased paleoproductivity and less food availability for benthic communities. This time interval also included a "carbon isotope shift” that reflects a global decrease in $\delta^{13} \mathrm{C}(\sim 7.5-6.5 \mathrm{Ma})$ and is attributed to terrigenous erosion due to Antarctic glaciation and/or a decrease in biomass (Shackleton and Kennett, 1975; Bickert et al., 2004). This change in carbon isotopes is seen in the present study with the local decrease in paleoproductivity and food availability.

\subsection{Closure of the Central American Seaway 4 Ma}

The complete closure of the Central American Seaway, shown well and fairly precisely by changes in stable isotopes from surface waters, occurred at 4 Ma (Keigwin, 1978; Haug and Tiedemann, 1998). The closure is identified by the establishment of the modern salinity contrast between the Atlantic and Pacific. A study by Haug et al. (2001) found that present-day conditions in the surface waters and deep-ocean of the Pacific and Atlantic would not have occurred without the shoaling of the CAS because the 
established salinity gradient and differences in ocean chemistries could only occur with the closure of the CAS. Complete closure, preventing tropical Atlantic - Pacific mixing, had a great impact on multiple proxies in the study area. After the closure, the Caribbean sites showed a lower current velocity (Fig. 11 a), consistent with less Pacific inflow through narrow straits. After 4 Ma, BFAR actually showed a sharp increase (Fig. 10 a) in the Caribbean with continuing lower values at EEP Site 503. EEP sites 568 and 569 had very large increases in the I/E ratio (Fig. 9 a), corresponding to an increase in organic flux (Jorrissen et al., 1995) although EEP Site 503 continued at low values in agreement with low BFAR (Fig. 10a). The Caribbean increased in percentages of low-flux species (Fig. 8 a), with a corresponding drop in high-flux species (Fig. 7 a) at $~ 3-3.5$ Ma, while EEP sites 568 and 569 continued at low levels of low-flux species, and EEP Site 503 dropped in low-flux species and peaked in high-flux species. Curiously, EEP Site 569 also experienced a large increase in high-flux species consistent with EEP Site 503, but nearby (to Site 569), Site 568 continued at low level of high-flux species, possibly because the average number of species, and thus amount of data, was lower (Table 4). Both Caribbean sites also showed a large increase in Nuttalides umbonifera (Fig. 5 a), indicating a sharp decrease of food supply (Loubere, 1991; Gooday, 1993; Nomura, 1995; Schmiedl, et al., 1997; Singh, et al, 2004) while Pacific sites remained the same.

The complete closure of the seaway prevented the input of high-organic-carbon fluxes, as evidenced by changes in eutrophic and oligotrophic indicator species. The sharp increase in BFAR (Fig. 10 a) at Caribbean Site 999 at 3.5 Ma is the result of a large influx of $N$. umbonifera, which confirms the increased input of some type of food source. These calculations support the findings by Jain and Collins (2007), who 
concluded that the closure of the CAS at 4.2 Ma resulted in nutrient depleted and oxygen rich waters in the Caribbean. They suggested that with this increased oxidation of available food, there is a reduced amount of paleoproductivity. The current study found that similarly, there was a depletion of nutrient-rich waters. The increase in BFAR, however, is likely due to the overwhelming presence of $N$. umbonifera, a low-organiccarbon-flux species.

\section{Conclusions}

Examining the full Neogene history of paleoproductivity in the Caribbean versus the equatorial Eastern Pacific provides a baseline in values for the full effects of the constriction and gradual closure of the Central American Seaway that previous studies of the pre-8-Ma interval (Bornmalm, 1997; Jain and Collins, 2007; Jain et al., 2007) did not cover. The geologic events affecting seaway closure that were noted in previous studies (Keigwin, 1978; Keller and Barron, 1983; Duque-Caro, 1990; Haug and Tiedemann, 1998) can be seen in the paleoproductivity indicators examined here.

Prior to the bottom-water source differentiation at $\sim 16 \mathrm{Ma}$, there were similar trends in oligotrophy and eutrophy (high-carbon-flux, low-carbon-flux, and abundance of Nuttalides umbonifera) for the Caribbean and EEP. (While there are noted differences, they cannot be construed as truly comparable proxy data because of the previously mentioned differences in sampling strategy and sample size.) Once there was an interoceanic differentiation in bottom-water source, some interoceanic trends were noted in the proxy data. The change in bottom-water is attributed to the foundering of the Northern Nicaragua Rise which led to the development of the North Component Deep 
Water in the Caribbean (Droxler et al., 1998). Presently, North Atlantic Deep water has been found to enter the Colombian Basin between Jamaica and Hispaniola (Morrison and Nowlin, 1982; Haddad and Droxler, 1996). Prior to the differentiation of bottom-water source, Caribbean Site 999 had the highest values of the study interval. While BFAR fluctuated through the rest of the study interval with multiple increases and decreases, overall averages of BFAR decreased in each interval. Some changes were noted around the event at $12 \mathrm{Ma}$. In the time interval after the deep-circulation barrier at $\sim 12 \mathrm{Ma}$, the Caribbean showed pulses of phytodetrital material with high abundances of Epistominella exigua, while the equatorial eastern Pacific had an increase in paleoproductivity evidenced by increases in eutrophic and mesotrophic species. When there was a constriction of the seaway at $\sim 8 \mathrm{Ma}$, Caribbean and EEP sites diverged in organic carbon flux values, with the Caribbean undergoing major decreases in high-organic flux and decreases in paleoproductivity in general. The complete closure of the CAS at $4 \mathrm{Ma}$ is seen in the Caribbean with marked decreases in multiple paleoproductivity proxies and sharp decreases in diversity (Chapter 3 of this study), leading to the conclusion that without the nutrient-rich EEP waters, the Caribbean attained the level of oligotrophy that has continued until present. 


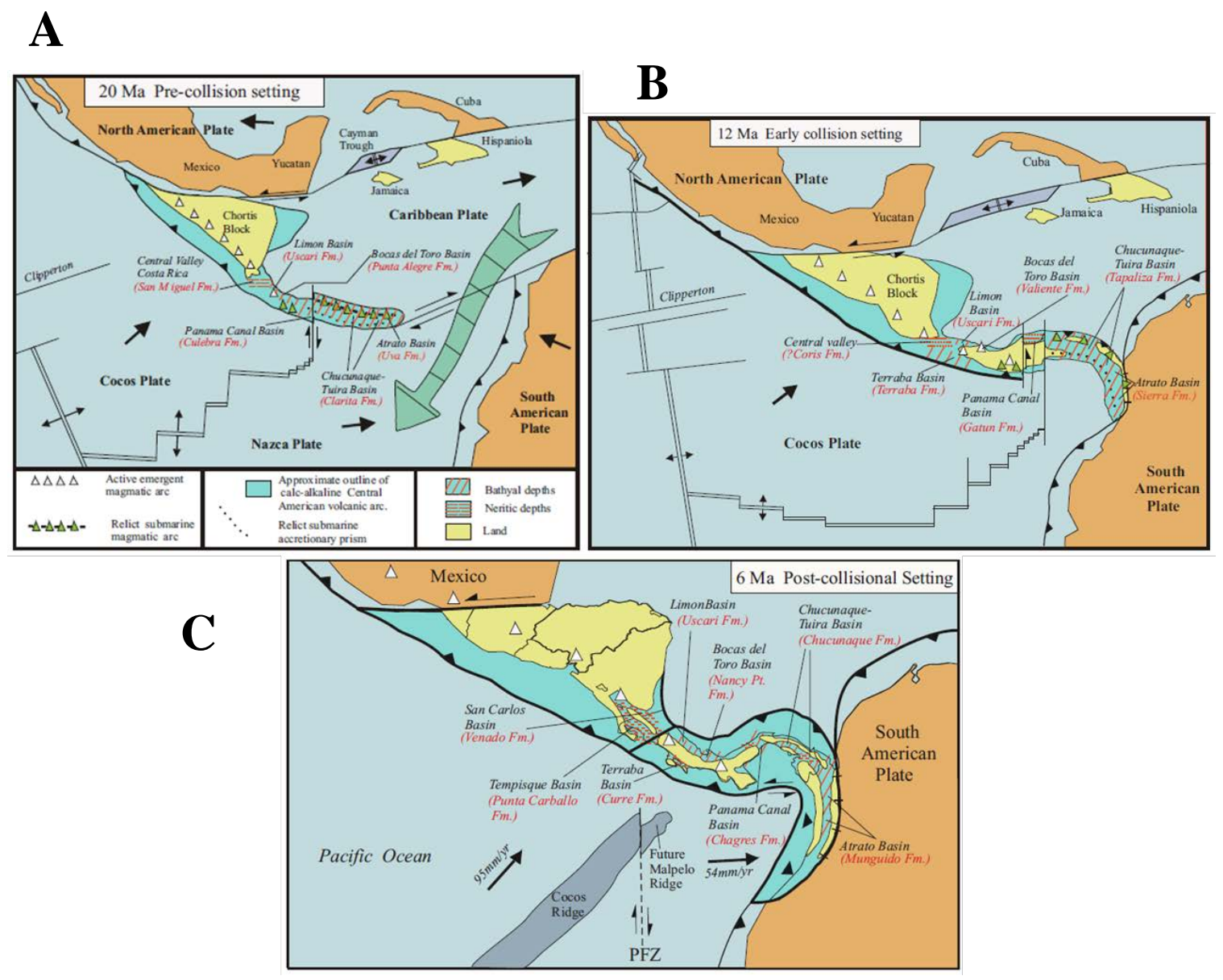

Figure 1. Geologic setting at (A) $20 \mathrm{Ma}$, (B) $12 \mathrm{Ma}$, and (C) $6 \mathrm{Ma}$. Black arrows indicate plate motion; large green arrow (Map A) shows hypothetical tropical Atlantic - Pacific surface flow (Coates, et al., 2004). 


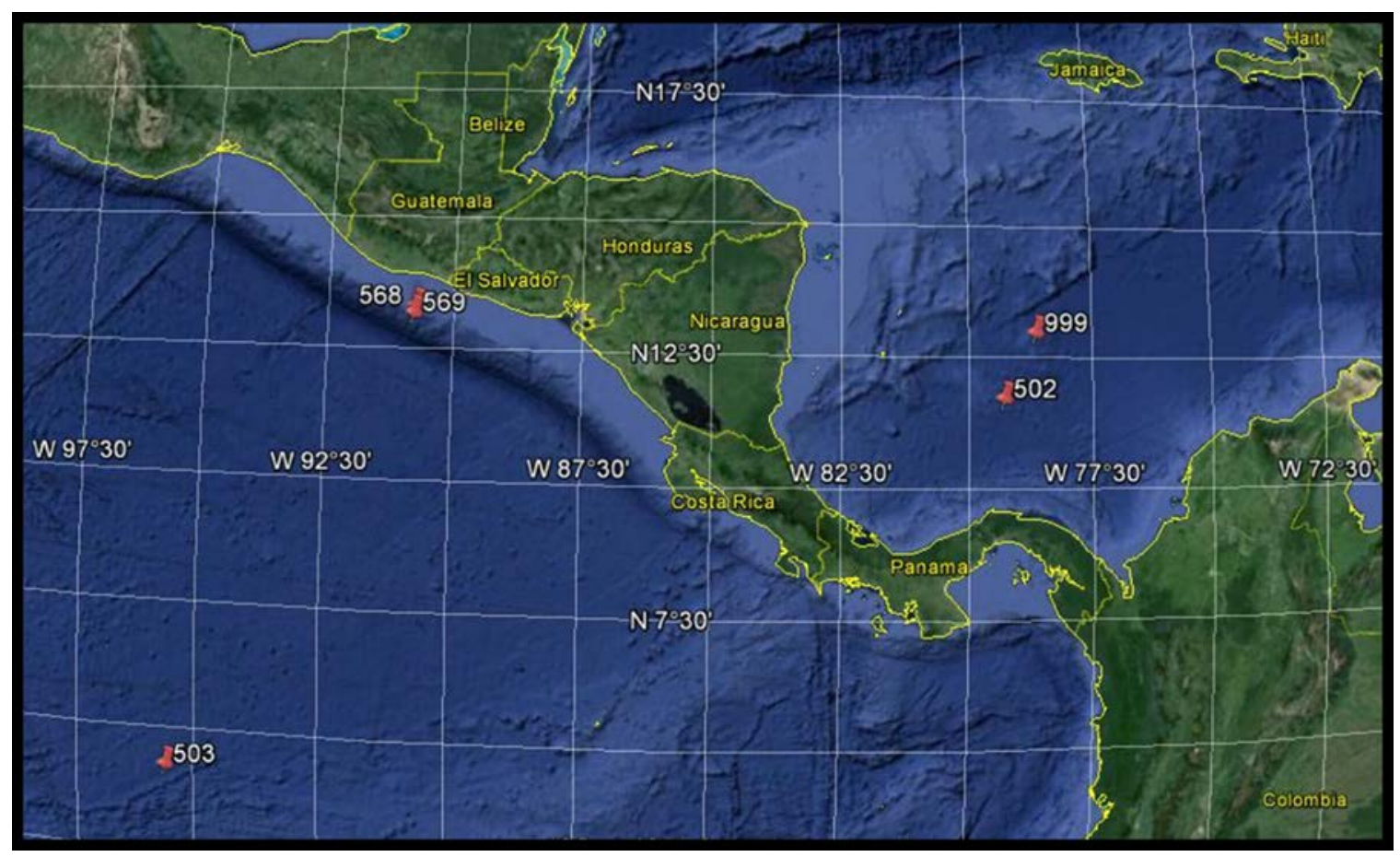

Figure 2. Site locations used for this study: Caribbean ODP Site 999, DSDP Site 502, and Equatorial Eastern Pacific DSDP sites 503, 568 and 569. 


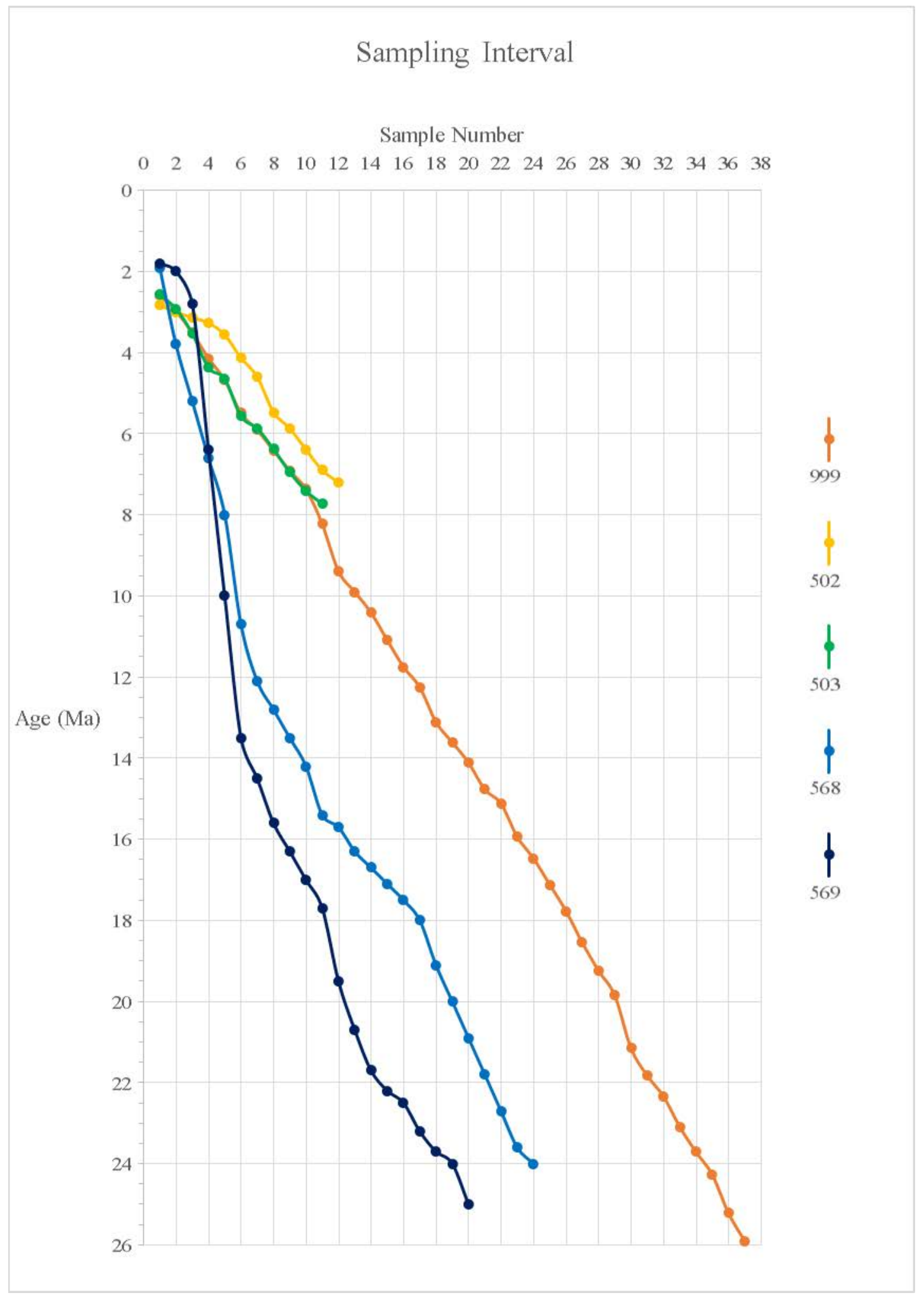

Figure 3. Sampling interval for all sites. 


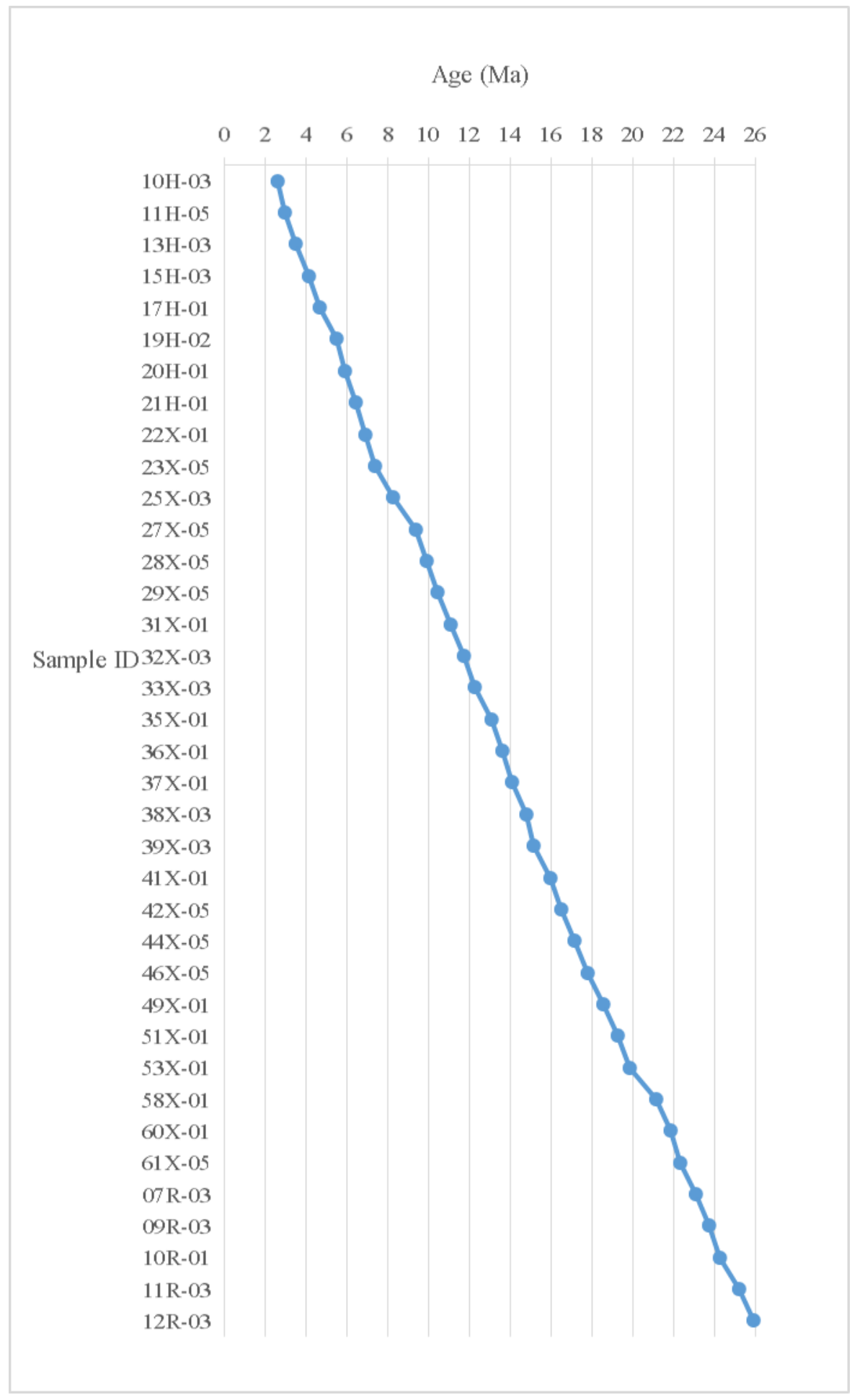

Figure 4. Samples prepared for benthic foraminiferal assemblages, ODP Site 999. Where possible, samples were selected at a 0.5-million-year interval. All ages acquired from ODP Site 999 publications (Sigurdsson, et al., 1997). 


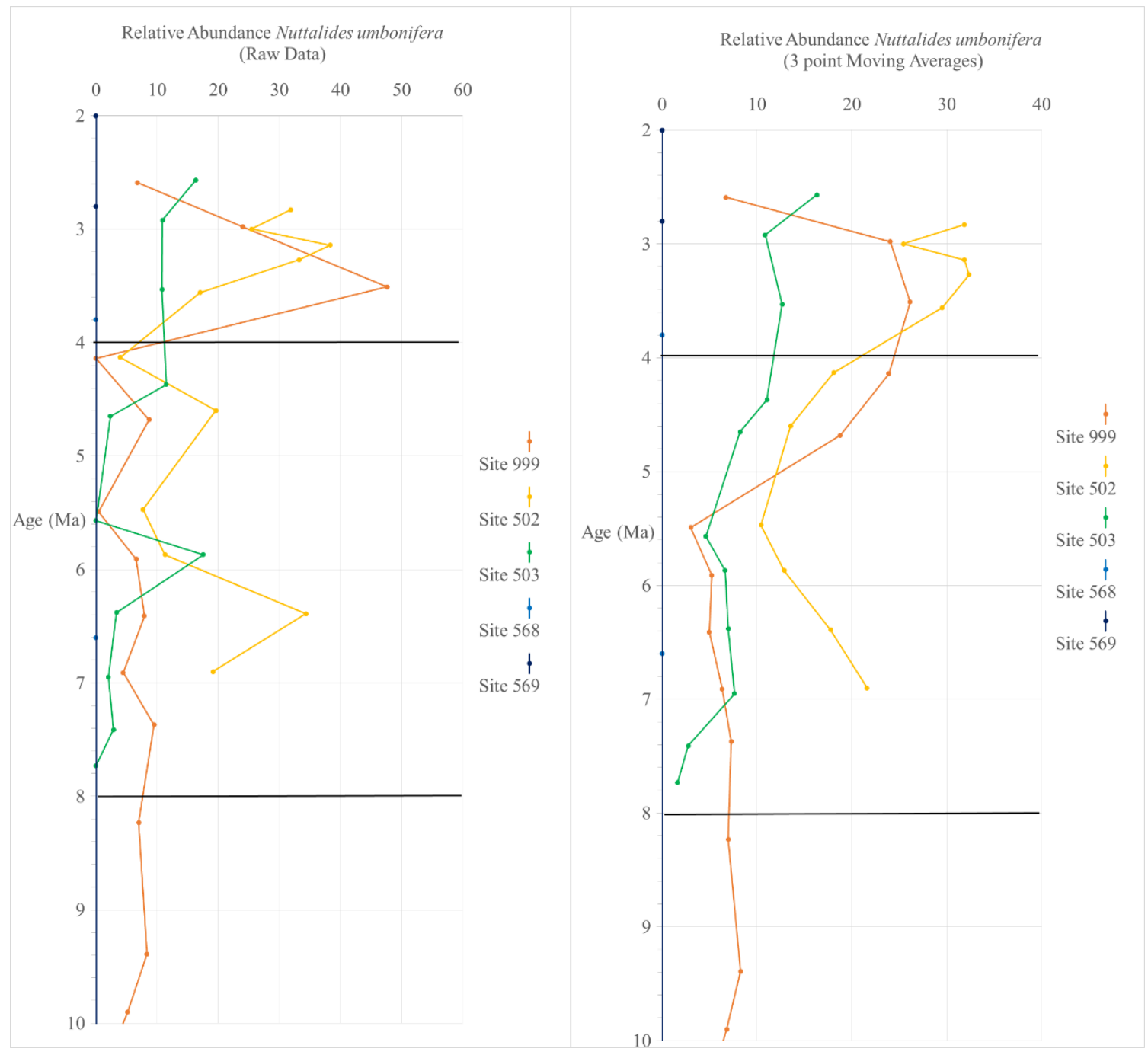

Figure 5a. Relative abundance curves of Nuttalides umbonifera (oligotrophy indicator) for all five sites: Caribbean ODP Site 999 and DSDP Site 502, and Pacific DSDP sites 503, 568 and 569 (younger interval). Previously determined paleoceanographic events noted. Left graph: calculated values. Right graph: 3-point moving averages using original values for 2 youngest points. 


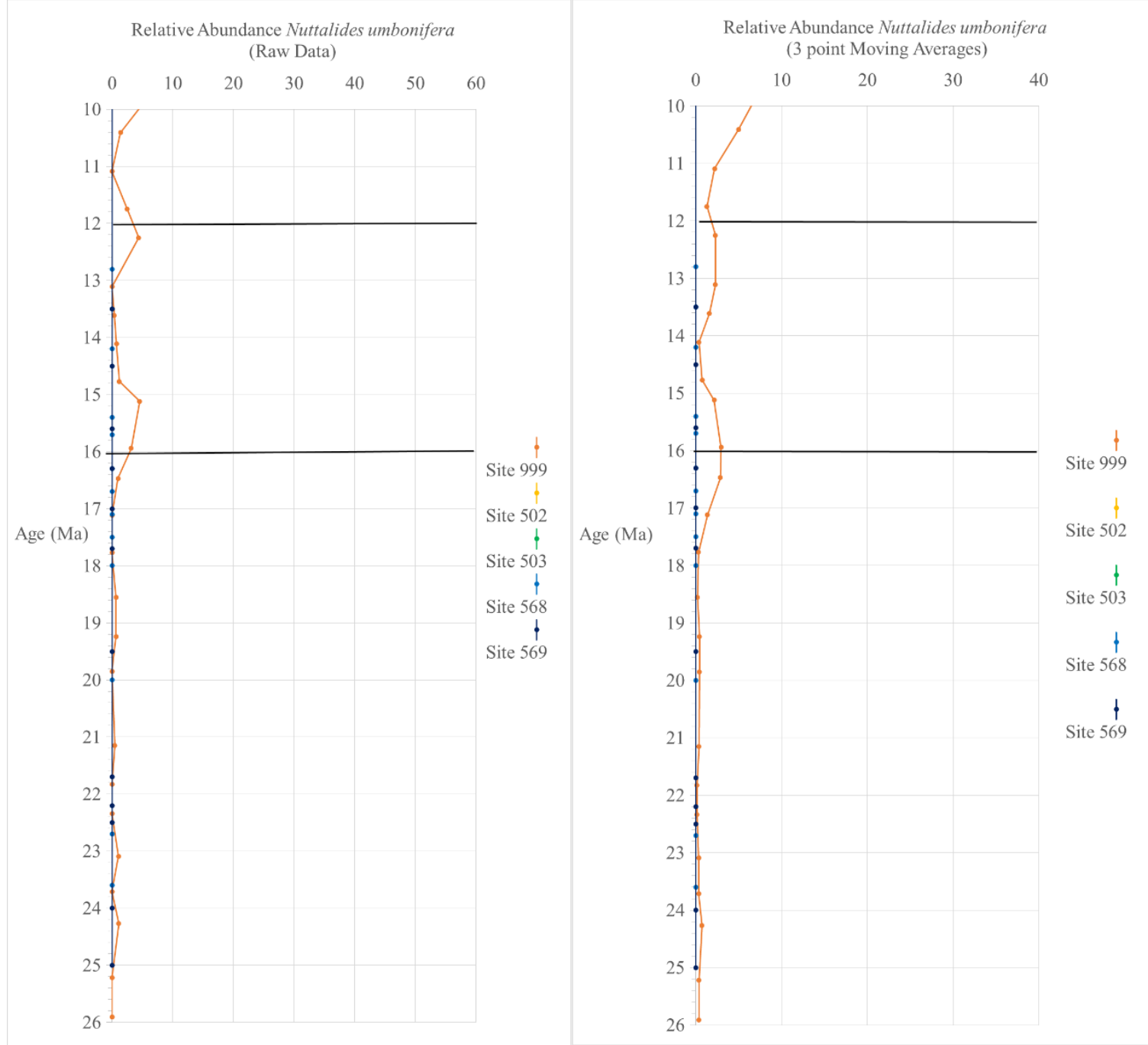

Figure 5b. Relative abundance curves of Nuttalides umbonifera (oligotrophy indicator) for all five sites: Caribbean ODP Site 999 and DSDP Site 502, and Pacific DSDP sites 503, 568 and 569 (older interval). Previously determined paleoceanographic events noted. Left graph: calculated values. Right graph: 3-point moving averages. 


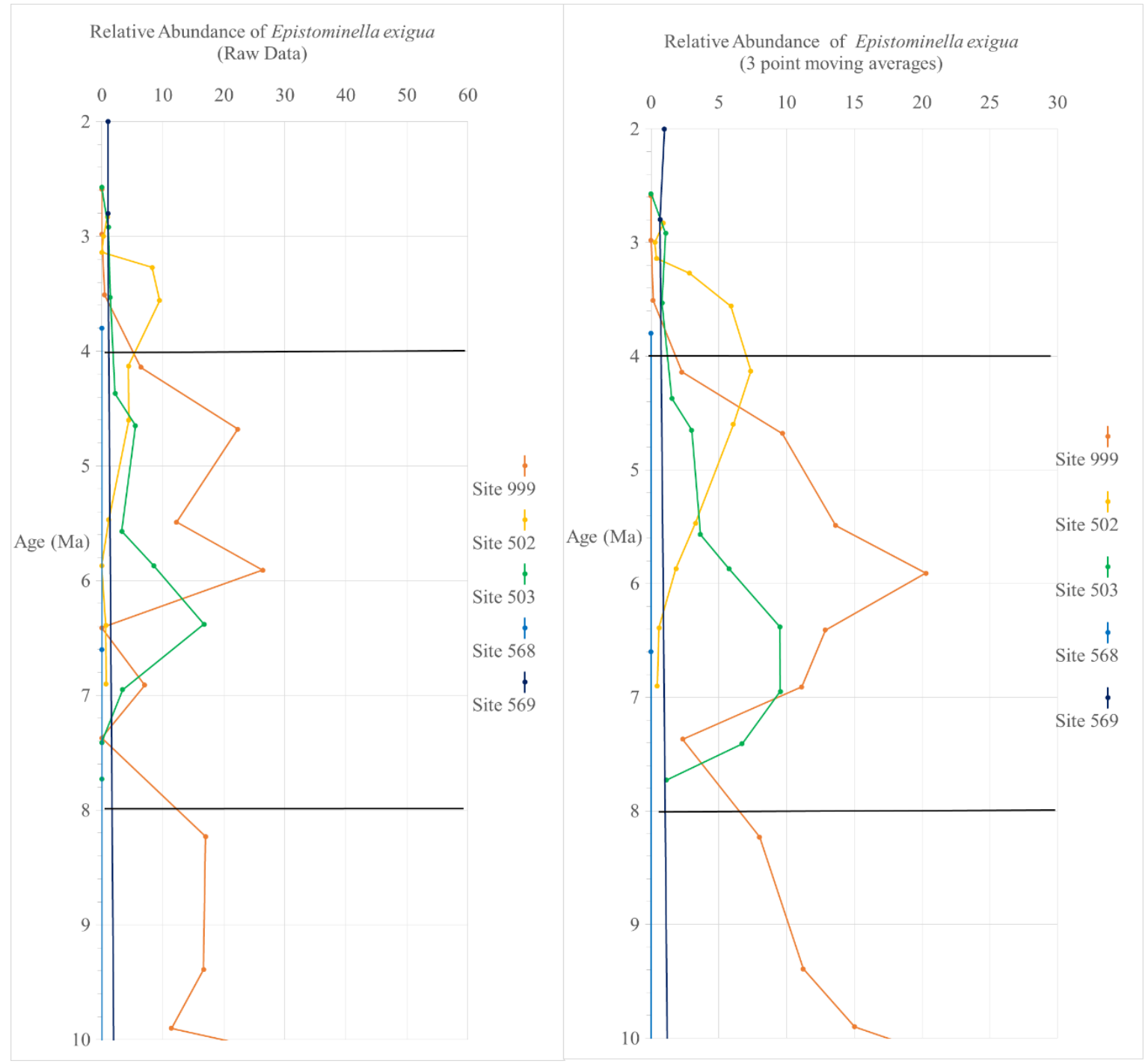

Figure 6a. Relative abundance curves of Epistominella exigua (mesotrophy indicator) for all five sites: Caribbean ODP Site 999 and DSDP Site 502, and Pacific DSDP sites 503, 568 and 569 (younger interval). Previously determined paleoceanographic events noted. Left graph: calculated values. Right graph: 3-point moving averages using original values for 2 youngest points. 


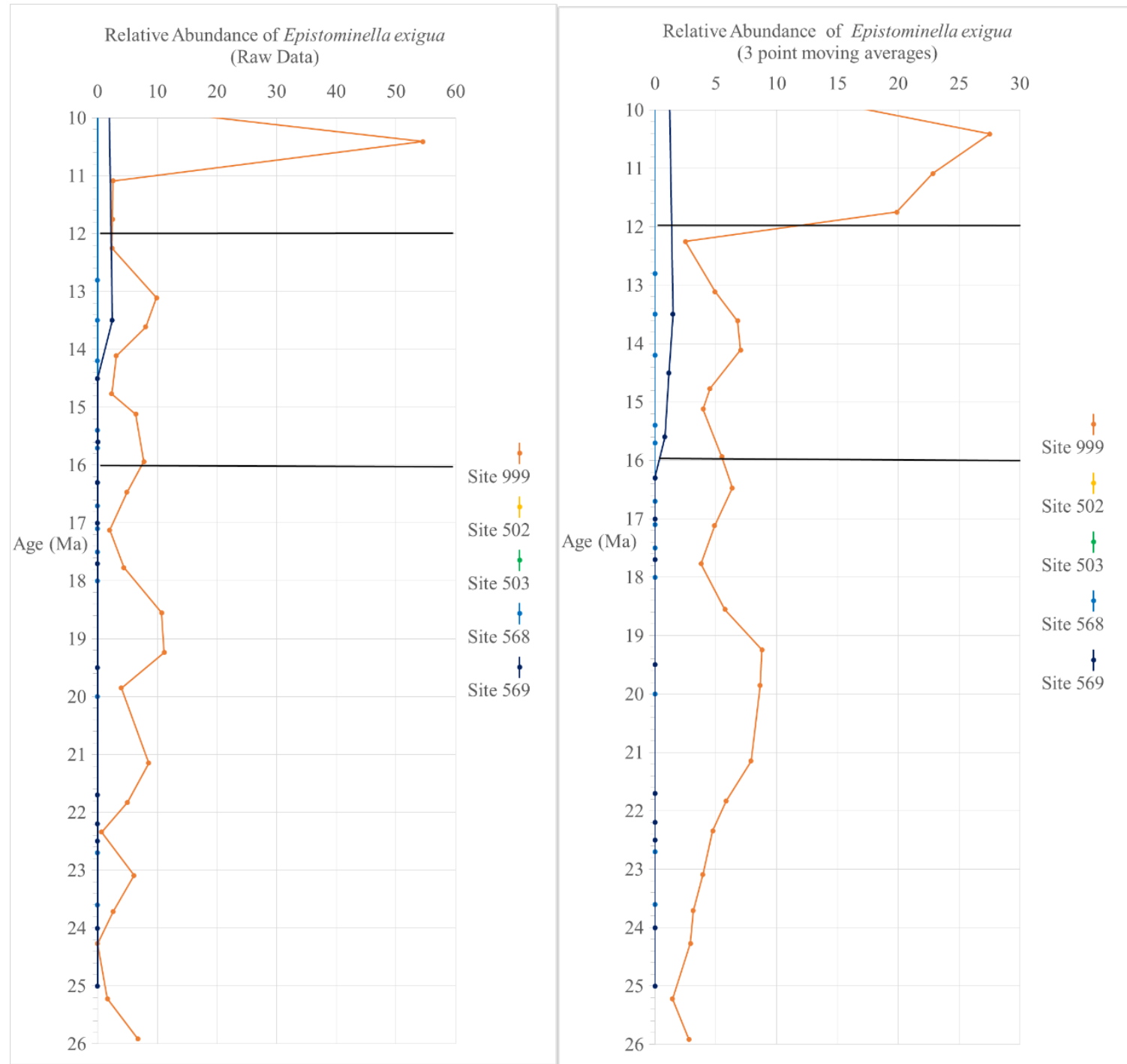

Figure 6b. Relative abundance curves of Epistominella exigua (mesotrophy indicator) for all five sites: Caribbean ODP Site 999 and DSDP Site 502, and Pacific DSDP sites 503, 568 and 569 (older interval). Previously determined paleoceanographic events noted. Left graph: calculated values. Right graph: 3-point moving averages. 


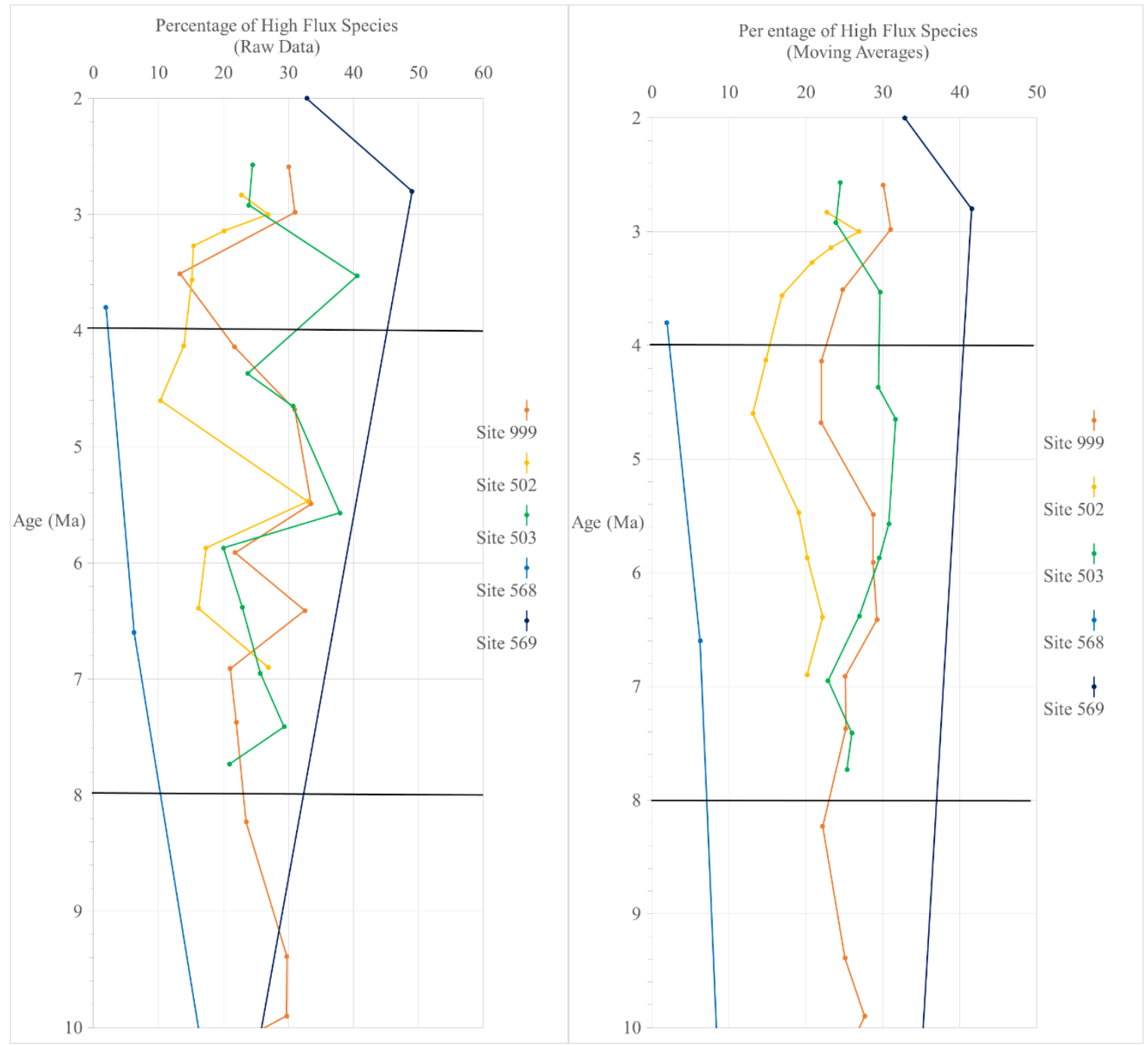

Figure 7a. Relative abundance curves of eutrophic species (high-organic-carbon flux) for all five sites: Caribbean ODP Site 999 and DSDP Site 502, and Pacific DSDP sites 503, 568 and 569 (younger interval). Previously determined paleoceanographic events noted. Left graph: calculated values. Right graph: 3-point moving averages using original values for 2 youngest points. 


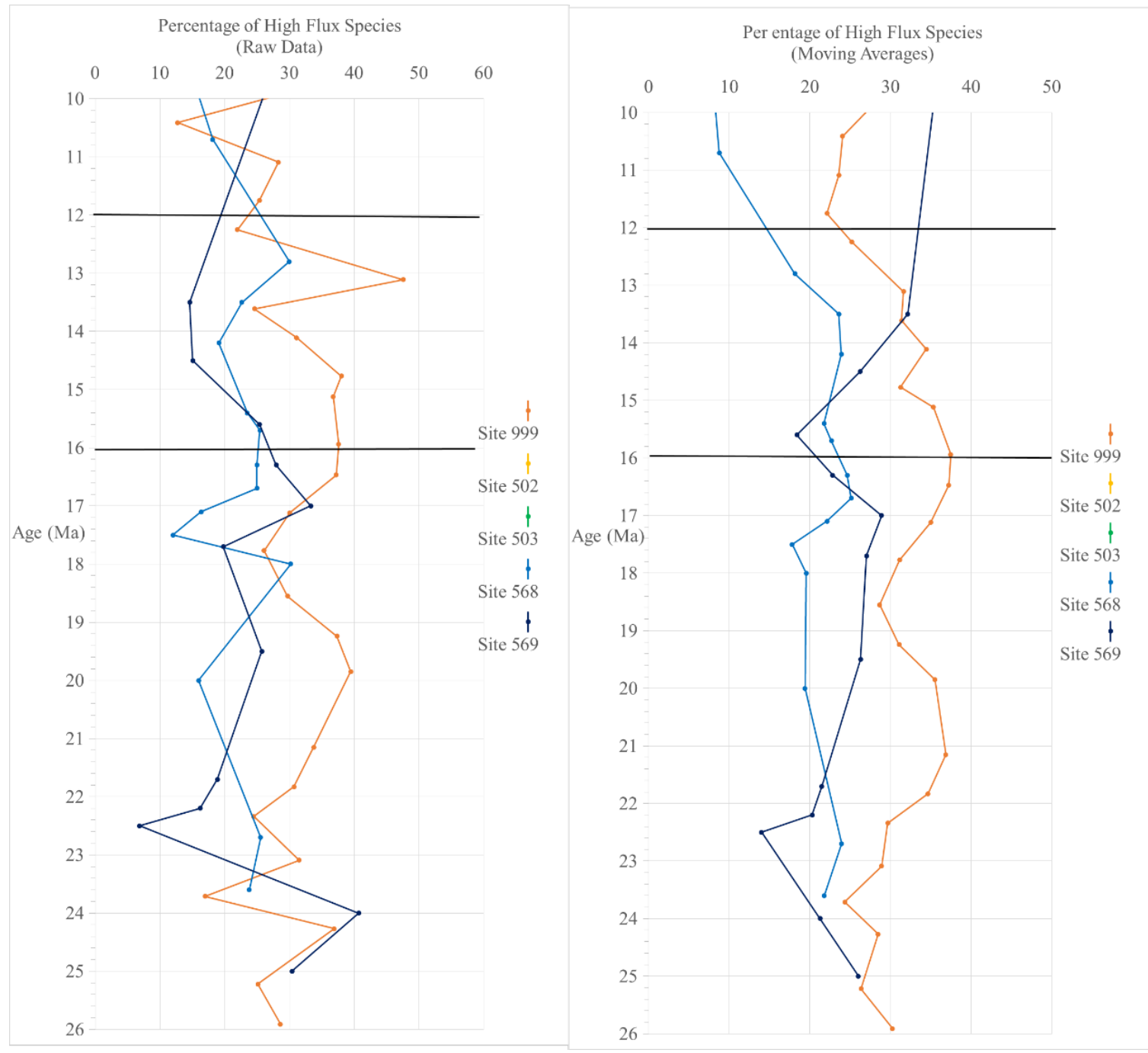

Figure 7b. Relative abundance curves of eutrophic species (high-organic-carbon flux) for all five sites: Caribbean ODP Site 999 and DSDP Site 502, and Pacific DSDP sites 503, 568 and 569 (older interval). Previously determined paleoceanographic events noted. Left graph: calculated values. Right graph: 3-point moving averages. 

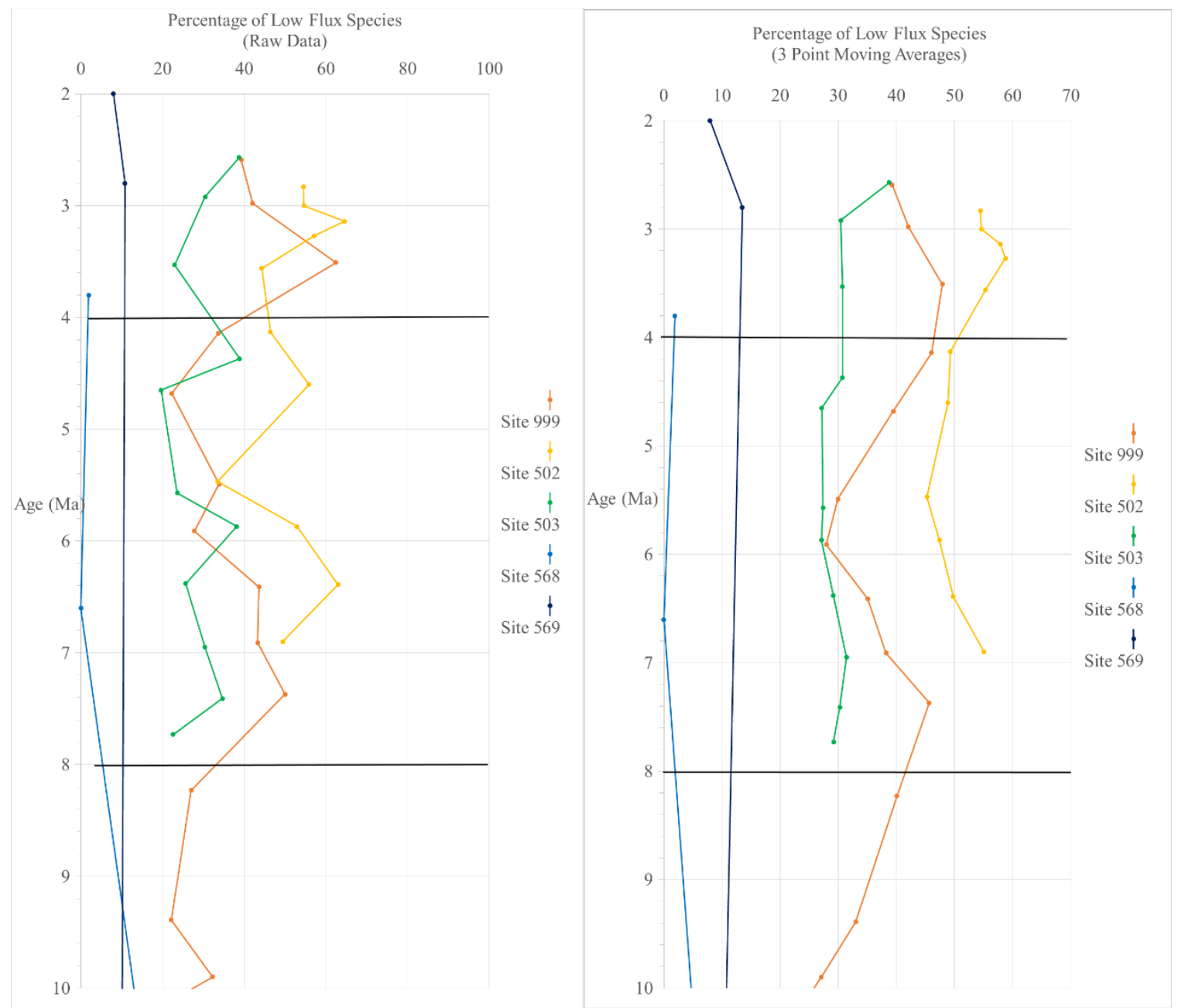

Figure 8a. Relative abundance curves of oligotrophic species (low-organic-carbon flux) for all five sites: Caribbean ODP Site 999 and DSDP Site 502, and Pacific DSDP sites 503, 568 and 569 (younger interval). Previously determined paleoceanographic events noted. Left graph: calculated values. Right graph: 3-point moving averages using original values for 2 youngest points. 


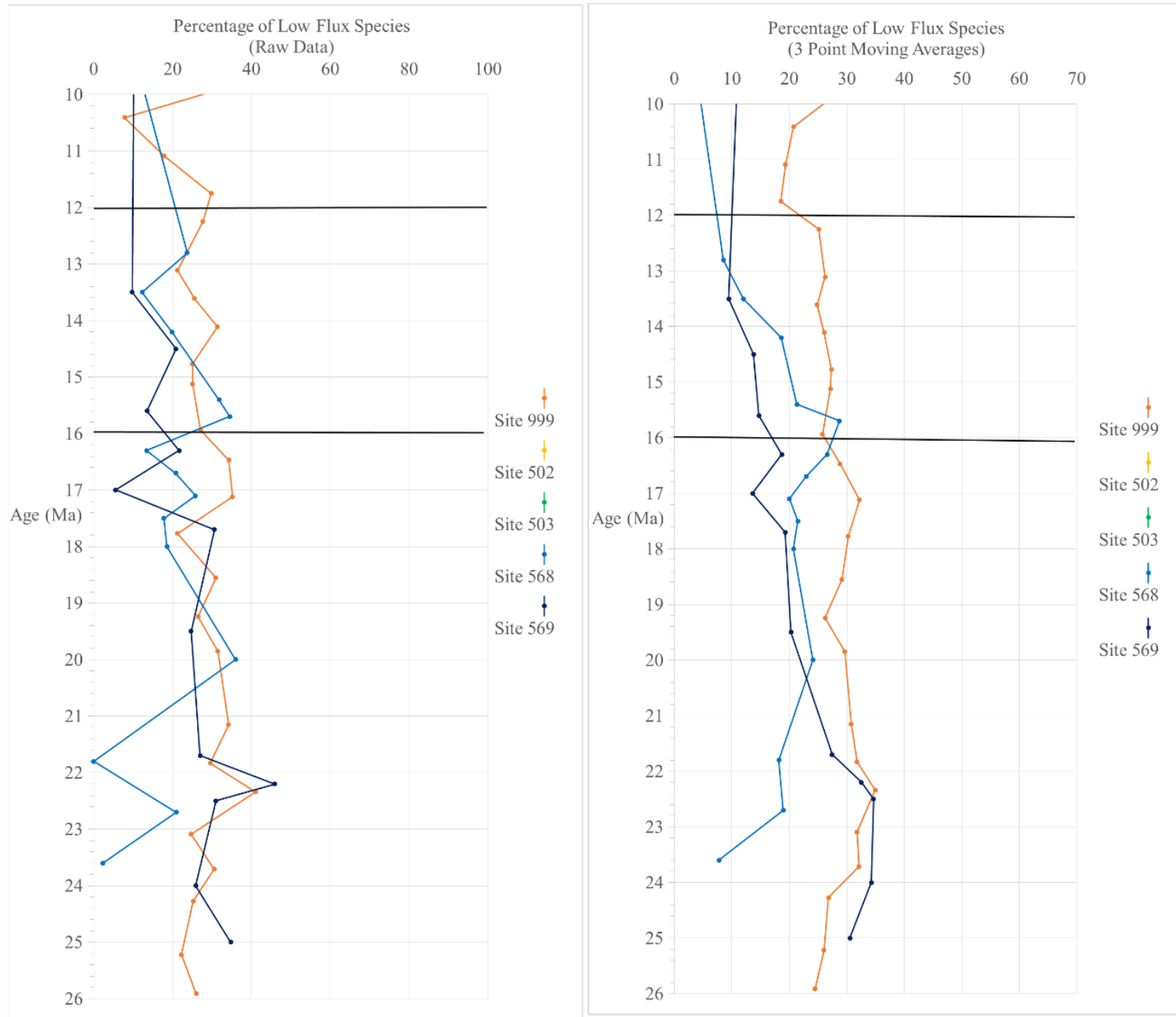

Figure 8b. Relative abundance curves of oligotrophic species (low-organic-carbon flux) for all five sites: Caribbean ODP Site 999 and DSDP Site 502, and Pacific DSDP sites 503, 568 and 569 (older interval). Previously determined paleoceanographic events noted. Left graph: calculated values. Right graph: 3-point moving averages using original values for 2 youngest points. 


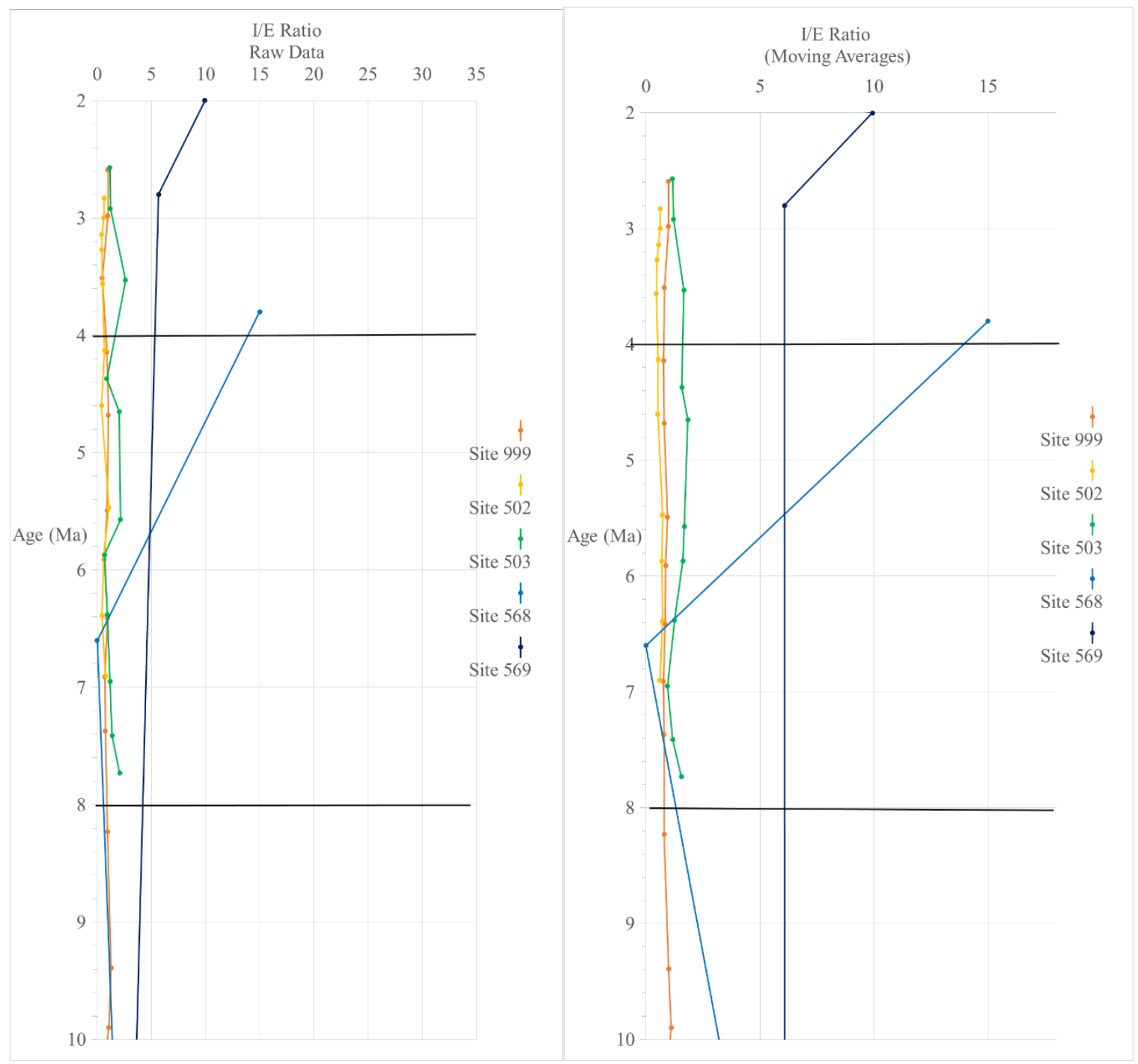

Figure 9a. Infaunal/Epifaunal Ratios (High-organic-carbon/low-organic-carbon) for all five sites: Caribbean ODP Site 999 and DSDP Site 502, and Pacific DSDP sites 503, 568 and 569 (younger interval). Previously determined paleoceanographic events noted. Left graph: calculated values. Right graph: 3-point moving averages using original values for 2 youngest points. 


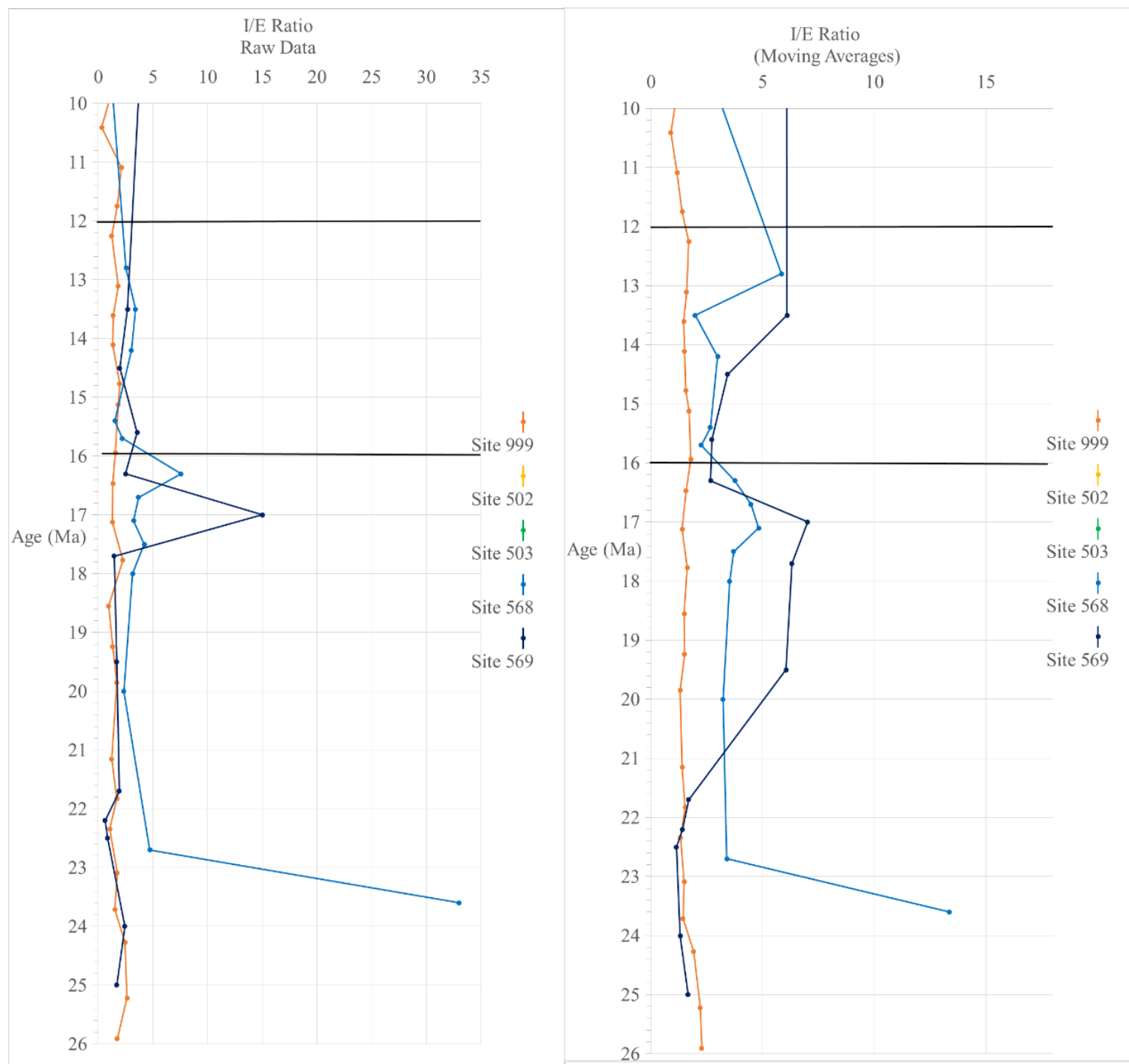

Figure 9b. Infaunal/Epifaunal Ratios (High-organic-carbon/low-organic-carbon) for all five sites: Caribbean ODP Site 999 and DSDP Site 502, and Pacific DSDP sites 503, 568 and 569 (older interval). Previously determined paleoceanographic events noted. Left graph: calculated values. Right graph: 3-point moving averages. 


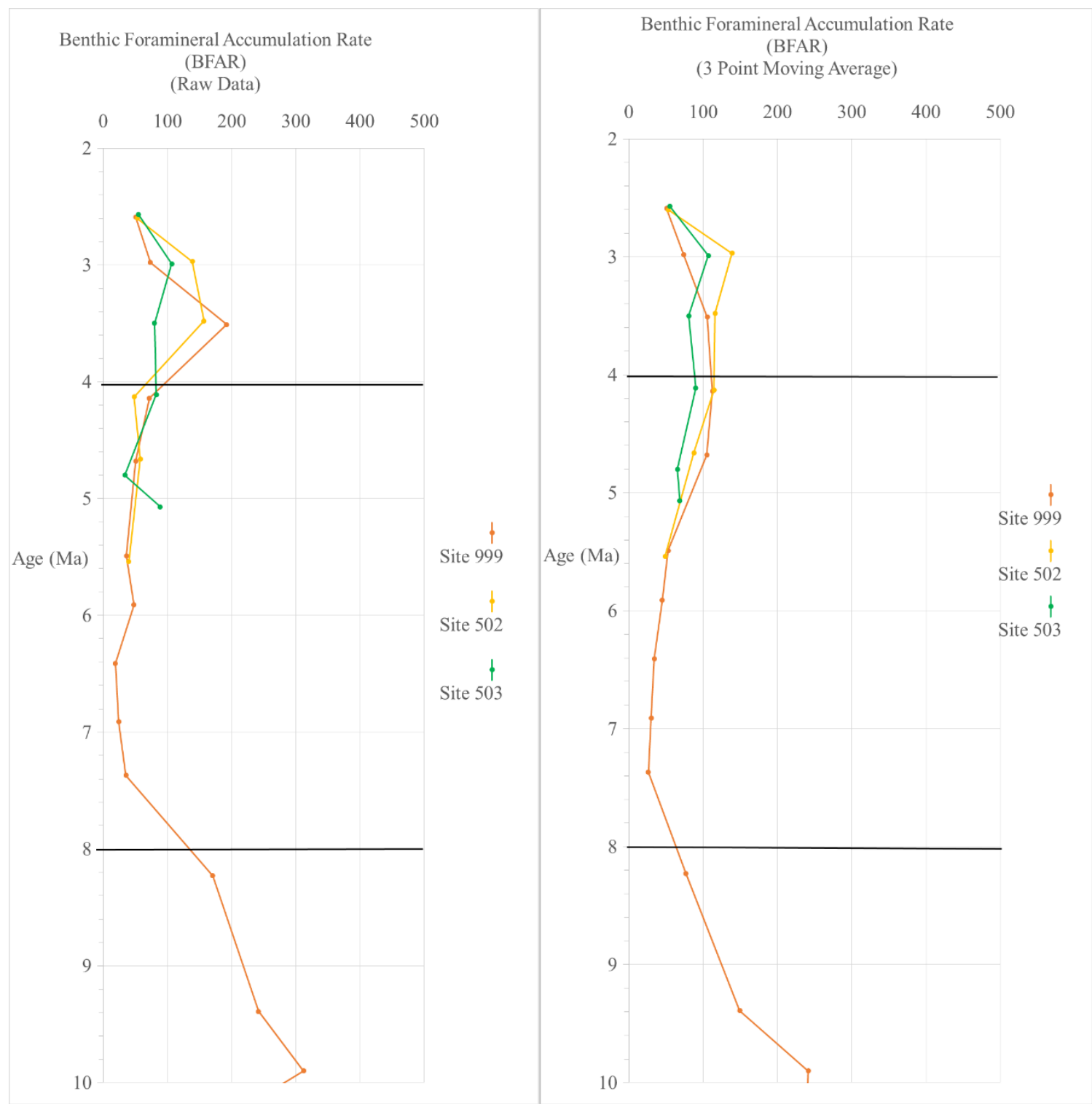

Figure 10a. BFAR for three sites where data were available. BFAR values for Caribbean ODP Site 999 were calculated in this study and those for Caribbean DSDP Site 502, and Pacific DSDP Site 503 were acquired from Bornmalm (1997) (younger interval). Left graph: calculated values. Right graph: 3-point moving averages using original values for 2 youngest points. 


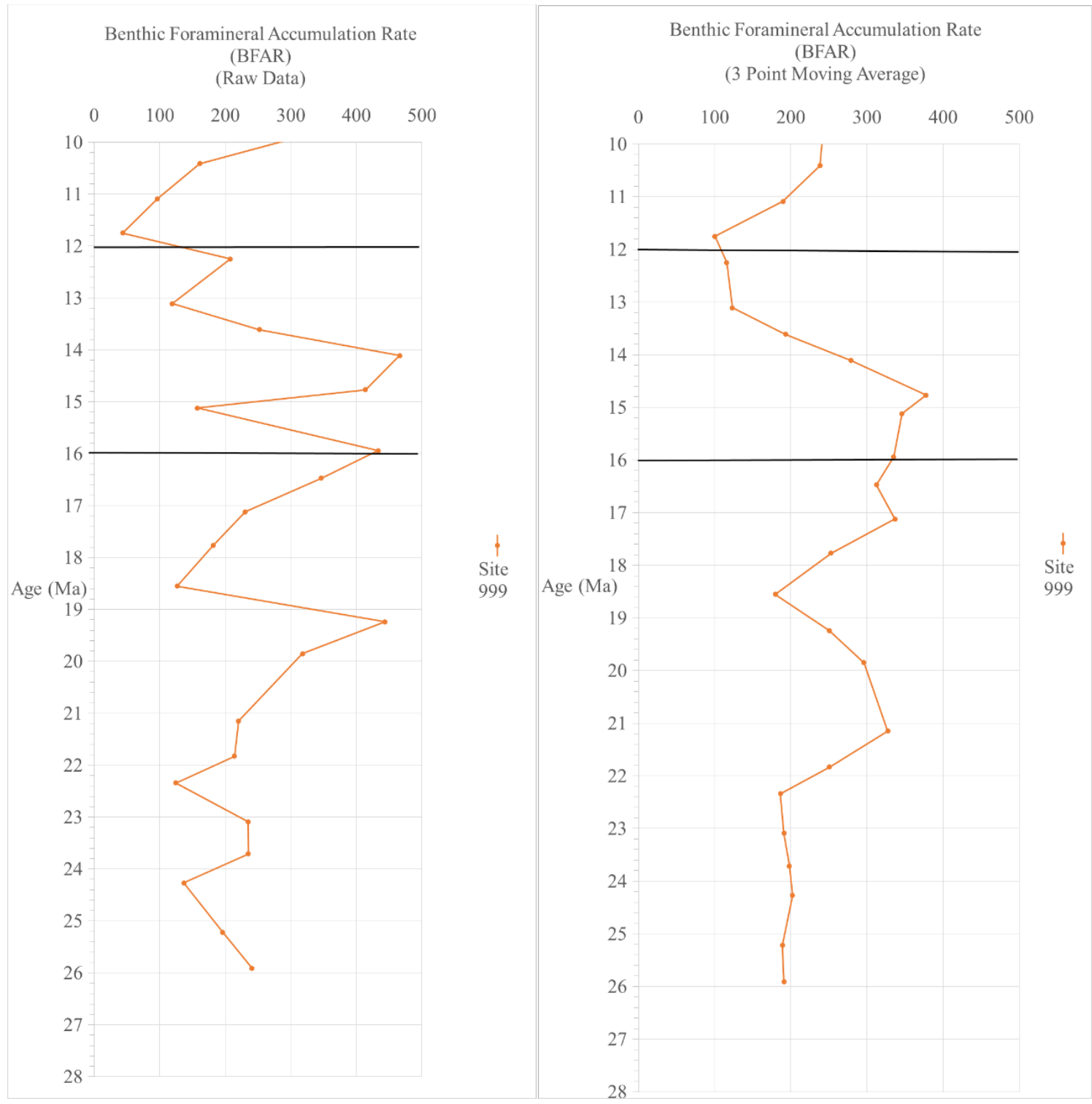

Figure 10b. BFAR for three sites where data was available. BFAR for Caribbean ODP Site 999 was calculated in this study and BFAR for Caribbean DSDP Site 502, and Pacific DSDP Site 503 were acquired from Bornmalm (1997) (older interval). Left graph: calculated values. Right graph: 3-point moving averages. 


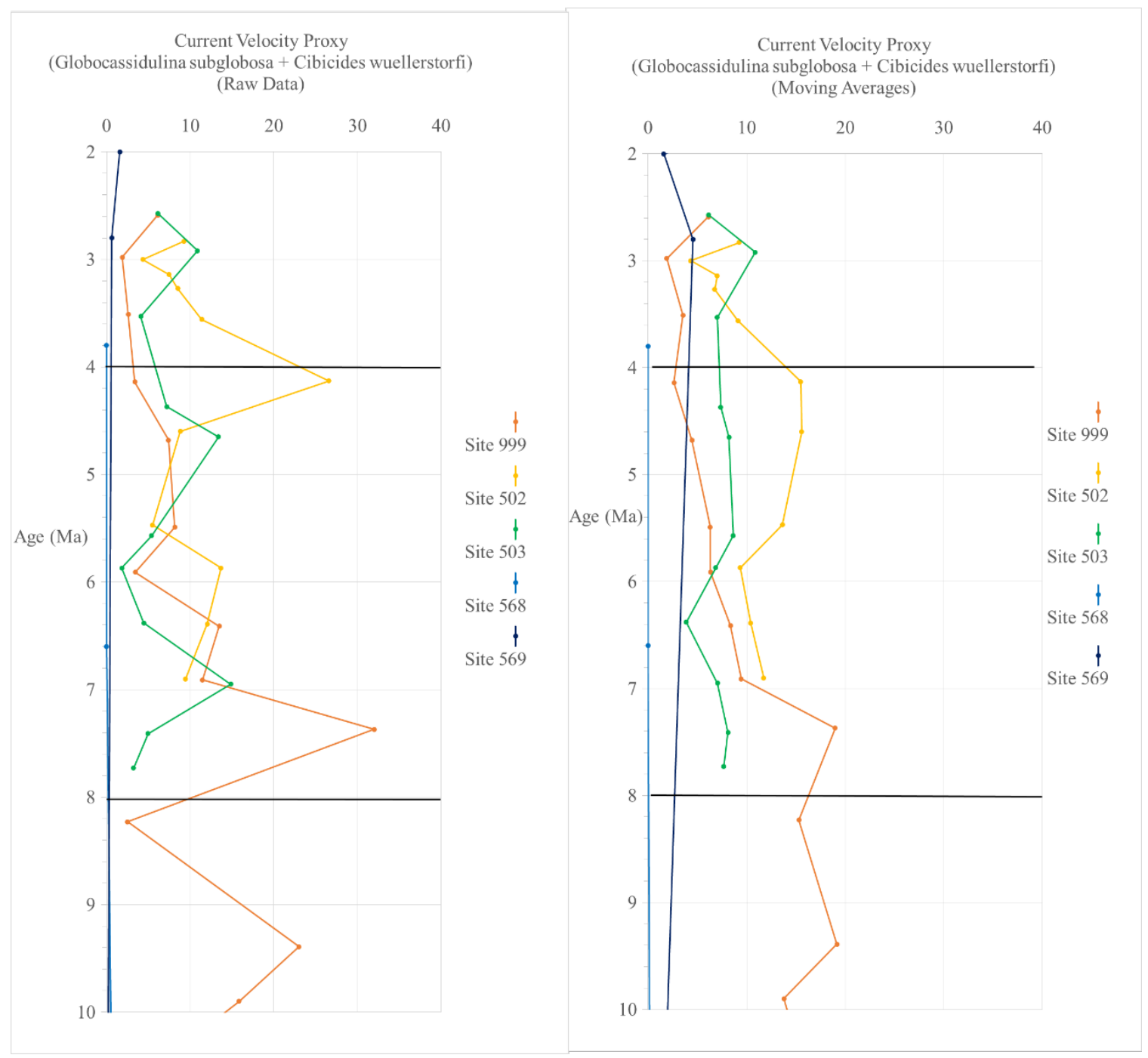

Figure 11a. Relative abundance curves of Globocassidulina subglobosa plus Cibicides wuellerstorfi (proxy for current velocity) for all sites: Caribbean ODP Site 999 and DSDP Site 502, and Pacific DSDP sites 503, 568 and 569. Left graph: calculated values. Right graph: 3-point moving averages using original values for 2 youngest points. 


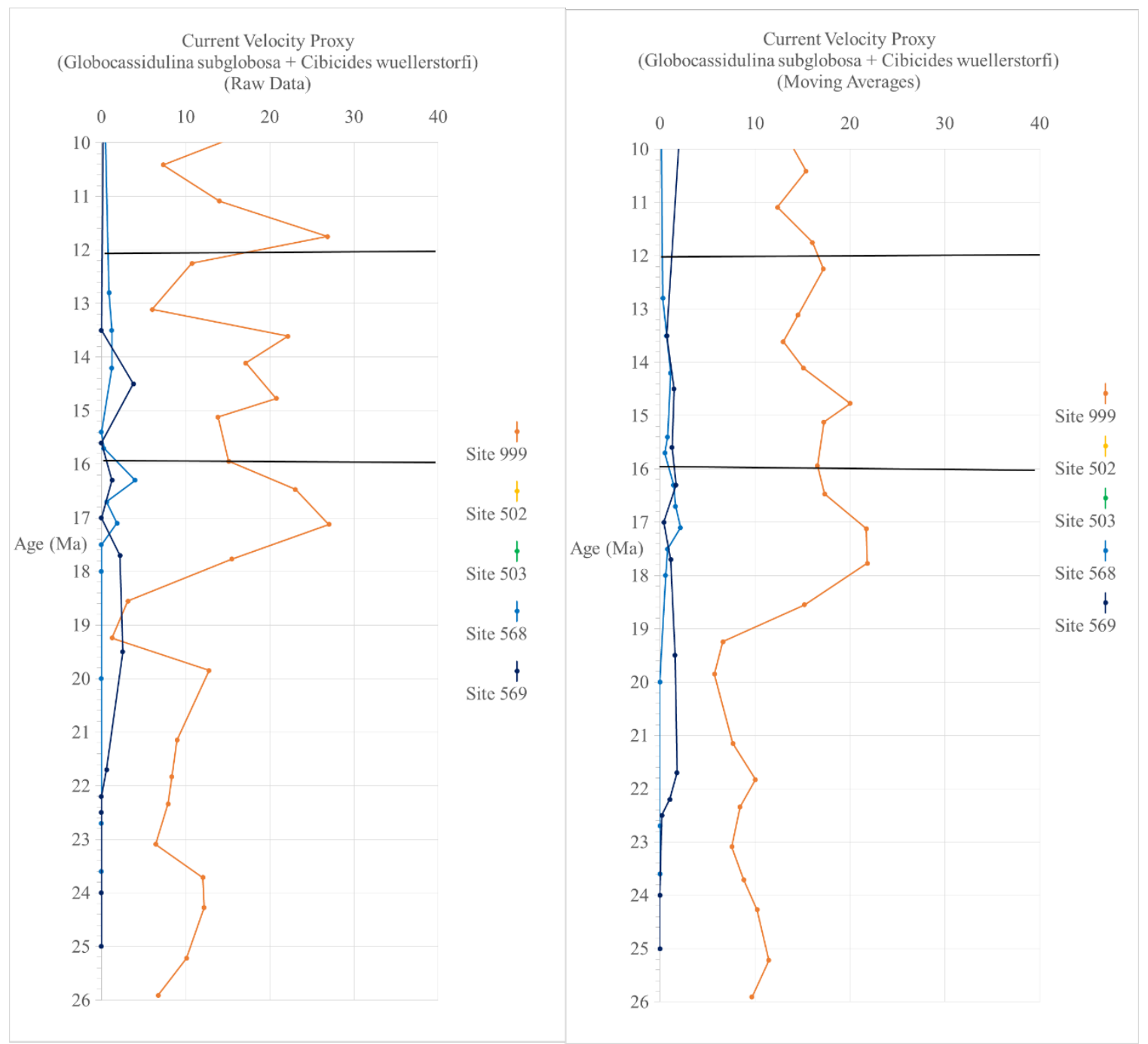

Figure 11b. Relative abundance curves of Globocassidulina subglobosa plus Cibicides wuellerstorfi (proxy for current velocity) for all five sites: Caribbean ODP Site 999 and DSDP Site 502, and Pacific DSDP sites 503, 568 and 569. Left graph: calculated values. Right graph: 3-point moving averages. 
Table 1. Infaunal species used for the Infaunal/Epifaunal ratio.

\begin{tabular}{|c|c|c|c|}
\hline Infaunal Species & References & Infaunal Species & References \\
\hline Astacolus spp. & Corliss and Chen, 1988 & Gyroidina orbicularis & Fontanier et al., 2002 \\
\hline Astrononion spp. & Jorissen et al., 1998 & Gyroidina spp. & Fontanier et al., 2002 \\
\hline Bolivina seminuda & Barmawidjaja et al., 1992 & Lagena spp. & Corliss and Chen, 1988 \\
\hline Bolivina spp. & \begin{tabular}{|c|} 
Corliss, 1985; Corliss, 1991; \\
Miao and Thunell, 1993; Jorissen, \\
1999; Ernst et al., 2002
\end{tabular} & Lenticulina spp. & $\begin{array}{l}\text { Corliss, } 1991 \text {; Rathburn and } \\
\text { Corliss, } 1994\end{array}$ \\
\hline $\begin{array}{c}\text { Bolivina } \\
\text { subaenariensis }\end{array}$ & Jannink et al., 1998 & Marginulina spp. & Corliss and Chen, 1988 \\
\hline Bulimina alazanensis & $\begin{array}{c}\text { Corliss, 1991; Miao and Thunell, } \\
\text { 1993; Jorissen, } 1999\end{array}$ & Melonis barleeanum & $\begin{array}{c}\text { Corliss, 1991; Buzas et al., 1993; } \\
\text { Gooday, 1994; Fontanier et al., } \\
2002\end{array}$ \\
\hline $\begin{array}{l}\text { Bulimina rostrata } \\
\text { Brady }\end{array}$ & Jannink et al., 1998 & Melonis spp. & $\begin{array}{l}\text { Corliss, 1991; Buzas et al., 1993; } \\
\text { Gooday, 1994; Fontanier et al., } \\
2002\end{array}$ \\
\hline Bulimina spp. & Jannink et al., 1998 & Nodosaria spp. & Corliss and Chen, 1988 \\
\hline Chilostomella oolina & $\begin{array}{c}\text { Corliss, 1991; Bernhard, 1992; } \\
\text { De Stigter et al., 1998; Jorissen et } \\
\text { al., 1998; Fontanier et al., } 2002\end{array}$ & Nonion spp. & Gooday and Rathburn, 1999 \\
\hline Dentalina spp. & Corliss and Chen, 1988 & Nonionella spp. & Jorissen et al., 1992 \\
\hline $\begin{array}{l}\text { Ehrenbergina trigona } \\
=\text { Textularia triquetra }\end{array}$ & Corliss and Chen, 1988 & Oolina spp. & Corliss and Chen, 1988 \\
\hline Fissurina spp. & Corliss and Chen, 1988 & Parafissurina spp. & Corliss and Chen, 1988 \\
\hline $\begin{array}{l}\text { Globobulimina affinis } \\
=\text { Bulimina affinis }\end{array}$ & $\begin{array}{c}\text { Corliss, 1991; Bernhard, 1992; } \\
\text { Buzas et al., 1993; Faridduddin } \\
\text { and Loubere, 1997; Jannink et al., } \\
\text { 1998; Gooday and Rathburn, } \\
\text { 1999; Fontanier et al., } 2002\end{array}$ & Pleurostomella spp. & McCorkle et al., 1997 \\
\hline $\begin{array}{l}\text { Globobulimina } \\
\text { pacifica Cushman }\end{array}$ & $\begin{array}{c}\text { Corliss, 1991; Bernhard, 1992; } \\
\text { Buzas et al., 1993; Faridduddin } \\
\text { and Loubere, 1997; Jannink et al., } \\
\text { 1998; Jorissen et al., 1998; } \\
\text { Gooday and Rathburn, 1999; } \\
\text { Fontanier et al., } 2002\end{array}$ & $\begin{array}{l}\text { Pullenia bulloides }= \\
\text { Nonionina bulloides }\end{array}$ & Corliss, 1991 \\
\hline Globobulimina spp. & $\begin{array}{c}\text { Corliss, 1991; Bernhard, 1992; } \\
\text { Buzas et al., 1993; Faridduddin } \\
\text { and Loubere, 1997; Jannink et al., } \\
\text { 1998; Jorissen et al., 1998; } \\
\text { Gooday and Rathburn, 1999; } \\
\text { Fontanier et al., } 2002\end{array}$ & Pullenia spp. & Corliss, 1991 \\
\hline $\begin{array}{c}\text { Globocassidulina } \\
\text { subglobosa = } \\
\text { Cassidulina } \\
\text { subglobosa }\end{array}$ & $\begin{array}{c}\text { Rathburn and Corliss, 1994; } \\
\text { McCorkle et al., 1997; Fontanier } \\
\text { et al., } 2002\end{array}$ & Sphaeroidina bulloides & $\begin{array}{c}\text { Corliss, 1991; Bernhard, 1992; } \\
\text { Buzas et al., 1993; Faridduddin } \\
\text { and Loubere, 1997; Jannink et al., } \\
\text { 1998; Jorissen et al., 1998; } \\
\text { Gooday and Rathburn, 1999; } \\
\text { Fontanier et al., } 2002\end{array}$ \\
\hline Gyroidina altiformis & Fontanier et al., 2002 & Uvigerina peregrina & $\begin{array}{c}\text { Jorissen et al., 1994; Fontanier et } \\
\text { al., } 2002\end{array}$ \\
\hline Gyroidina soldanii & Fontanier et al., 2002 & Uvigerina spp. & $\begin{array}{c}\text { Jorissen et al., 1994; Fontanier et } \\
\text { al., } 2002\end{array}$ \\
\hline
\end{tabular}


Table 2. Epifaunal species used for the Infaunal/Epifaunal ratio.

\begin{tabular}{|c|c|}
\hline Epifaunal Species & References \\
\hline Anomalinoides spp. & Jorissen, 1999 \\
\hline Cibicides spp. & $\begin{array}{c}\text { Corliss, } 1985 \text {; Corliss and Chen, } \\
\text { 1988; Corliss, 1991; De Stigter et al., } \\
1998\end{array}$ \\
\hline $\begin{array}{c}\text { Cibicides wuellerstorfi }=\text { Anomalina } \\
\text { wuellerstorf } \mathrm{i}\end{array}$ & $\begin{array}{c}\text { Corliss, } 1985 \text {; Corliss and Chen, } \\
\text { 1988; Corliss, 1991; De Stigter et al., } \\
1998\end{array}$ \\
\hline $\begin{array}{c}\text { Epistominella exigua }=\text { Pulvinulina } \\
\text { exigua }\end{array}$ & McCorkle et al., 1997 \\
\hline Epistominella spp. & Miao and Thunell, 1993 \\
\hline Miliolids & Corliss, 1991 ; De Stigter et al., 1998 \\
\hline $\begin{array}{l}\text { Nuttallides umbonifera }= \\
\text { Pulvinulinella umbonifera }\end{array}$ & Bernhard, 1992 \\
\hline Oridorsalis umbonatus & Barmawidjaja et al., 1992 \\
\hline Osangularia culter & $\begin{array}{l}\text { Corliss, } 1985 \text {; Gooday and } \\
\text { Rathburn, } 1999\end{array}$ \\
\hline
\end{tabular}


Table 3. Species used to identify high- or low-organic-carbon flux.

\begin{tabular}{|c|c|c|c|}
\hline $\begin{array}{c}\text { High-Organic Carbon } \\
\text { Flux Species }\end{array}$ & References & $\begin{array}{c}\text { Low-Organic } \\
\text { Carbon Flux Species }\end{array}$ & References \\
\hline Bolivina spp. & $\begin{array}{c}\text { Sen Gupta et al, 1981; Miller and Lohman, 1982; Corliss et } \\
\text { al., 1986; Altenbach, 1992; Rathburn and Corliss, 1994; } \\
\text { Loubere, 1996; Bernhardt et al., 1997; Schmiedl et al., } \\
\text { 1997; Gooday, } 2003 \\
\end{array}$ & Cibicides spp. & $\begin{array}{l}\text { Altenbach, 1992; Sarnthein and Altenbach, 1995; } \\
\text { Altenbach, et al., 1999; Loubere and Faridduddin, } \\
\text { 1999; Fontanier et al., 2001; Gooday, } 2003\end{array}$ \\
\hline Bulimina spp. & $\begin{array}{l}\text { Miller and Lohman, 1982; Altenbach, 1992; Rathburn and } \\
\text { Corliss, 1994; Schmiedl et al., 1997; Gooday et al., 2001; } \\
\text { Gooday, } 2003\end{array}$ & Miliolids & $\begin{array}{c}\text { Altenbach, 1992; Altenbach, et al., 1999; Loubere } \\
\text { and Faridduddin, 1999; Fontanier et al., 2001; } \\
\text { Gooday, } 2003\end{array}$ \\
\hline Chilostomella oolina & Lutz and Coulbourne, 1984; Loubere, 1996; Gooday, 2003 & $\begin{array}{l}\text { Nuttallides } \\
\text { umbonifera }\end{array}$ & $\begin{array}{l}\text { Altenbach, 1992; Altenbach, et al., 1999; Loubere } \\
\text { and Faridduddin, 1999; Fontanier et al., 2001; } \\
\text { Gooday, } 2003\end{array}$ \\
\hline Globobulimina spp. & $\begin{array}{l}\text { Miller and Lohman, 1982; Lutz and Coulbourne, 1984; } \\
\text { Corliss et al., 1986; Loubere, 1991; Altenbach, 1992; } \\
\text { Rathburn and Corliss, 1994; Schmiedl and Mackensen, } \\
\text { 1997; Schmiedl et al., 1997 Altenbach, et al., 1999; } \\
\text { Gooday et al., 2001; Gooday, } 2003\end{array}$ & $\begin{array}{l}\text { Oridorsalis } \\
\text { umbonatus }\end{array}$ & $\begin{array}{c}\text { Altenbach, 1992; Altenbach, et al., 1999; Loubere } \\
\text { and Faridduddin, 1999; Fontanier et al., 2001; } \\
\text { Gooday, } 2003\end{array}$ \\
\hline Gyroidina spp. & Fontanier et al., 2001 & Osangularia culter & $\begin{array}{c}\text { Altenbach, 1992; Altenbach, et al., 1999; Loubere } \\
\text { and Faridduddin, 1999; Fontanier et al., 2001; } \\
\text { Gooday, } 2003\end{array}$ \\
\hline Melonis barleeanum & $\begin{array}{l}\text { Loubere, 1991; Altenbach, 1992; Jorissen et al., 1998; } \\
\text { Altenbach, et al., 1999; Gooday et al., 2001; Gooday, } 2003\end{array}$ & Hoeglundina elegans & $\begin{array}{c}\text { Altenbach, 1992; Altenbach, et al., 1999; Loubere } \\
\text { and Faridduddin, 1999; Fontanier et al., 2001; } \\
\text { Gooday, } 2003 \\
\end{array}$ \\
\hline Melonis spp. & $\begin{array}{l}\text { Loubere, 1991; Altenbach, 1992; Jorissen et al., 1998; } \\
\text { Altenbach, et al., 1999; Gooday et al., 2001; Gooday, } 2003\end{array}$ & & \\
\hline Pullenia spp. & Corliss and Chen, 1988; Sarnthein and Altenbach, 1995 & & \\
\hline $\begin{array}{c}\text { Sphaeroidina } \\
\text { bulloides }\end{array}$ & Corliss et al., 1986; Altenbach, 1992; Fontanier et al., 2001 & & \\
\hline Uvigerina peregrina & $\begin{array}{l}\text { Lutz and Coulbourne, 1984; Loubere, 1991; Loubere, 1996; } \\
\text { Jorissen et al., 1998; Gooday, } 2003\end{array}$ & & \\
\hline Uvigerina spp. & $\begin{array}{l}\text { Lutz and Coulbourne, 1984; Loubere, 1991; Schmiedl and } \\
\text { Mackensen, 1997; Jorissen et al., 1998; Gooday, } 2003\end{array}$ & & \\
\hline
\end{tabular}

Table 4. Differences in magnetic chron ages (Kent and Sapriosu, 1982a, b; Berggren et al., 1995).

\begin{tabular}{|c|c|c|c|c|c|c|}
\hline Chron & $\begin{array}{c}\text { Upper Age Limit } \\
\text { (Ma) from Berggren } \\
\text { et al. (1995) }\end{array}$ & $\begin{array}{c}\text { Upper Age Limit } \\
\text { (Ma) from Kent and } \\
\text { Sapriosu (1982a,b) }\end{array}$ & $\begin{array}{c}\text { Difference in } \\
\text { Upper Age } \\
\text { Limit (Ma) }\end{array}$ & $\begin{array}{c}\text { Lower Age Limit } \\
\text { (Ma) from } \\
\text { Berggren et al. } \\
\text { (1995) }\end{array}$ & $\begin{array}{c}\text { Lower Age Limit } \\
\text { (Ma) from Kent } \\
\text { and Sapriosu (1982 } \\
\text { a,b) }\end{array}$ & $\begin{array}{c}\text { Difference in } \\
\text { Lower Age } \\
\text { Limit (Ma) }\end{array}$ \\
\hline Matuyama & 0.78 & 0.73 & 0.05 & 2.58 & 2.48 & 0.1 \\
\hline Olduvai & 1.77 & 1.66 & 0.11 & 1.95 & 1.88 & 0.07 \\
\hline Gauss & 2.58 & 2.48 & 0.1 & 3.58 & 3.4 & 0.18 \\
\hline Mammoth & 3.22 & 3.18 & 0.04 & 3.33 & 3.4 & -0.07 \\
\hline Cochiti & 4.18 & 3.86 & 0.32 & 4.29 & 3.95 & 0.34 \\
\hline
\end{tabular}


Table 5. Site and foraminiferal data set. Data for Site 999 are from Jain (2006), Jain and Collins (2007), Jain et al. (2007), and this study. Data for sites 502, 503, 568, 569 are from McDougall (1985, 1996, written comm., 2015).

\begin{tabular}{|c|c|c|c|c|c|c|c|c|}
\hline Region & $\begin{array}{c}\text { ODP/DSDP } \\
\text { Site }\end{array}$ & $\begin{array}{c}\text { Number of } \\
\text { Samples } \\
\text { (utilized in } \\
\text { this study) }\end{array}$ & $\begin{array}{c}\text { Minimum } \\
\text { Specimen } \\
\text { Number per } \\
\text { Sample }\end{array}$ & $\begin{array}{c}\text { Maximum } \\
\text { Specimen } \\
\text { Number per } \\
\text { Sample }\end{array}$ & $\begin{array}{c}\text { Average } \\
\text { Specimen } \\
\text { Number per } \\
\text { Sample }\end{array}$ & $\begin{array}{c}\text { Minimum } \\
\text { Number of } \\
\text { Species per } \\
\text { Sample }\end{array}$ & $\begin{array}{c}\text { Maximum } \\
\text { Number of } \\
\text { Species per } \\
\text { Sample }\end{array}$ & $\begin{array}{c}\text { Average } \\
\text { Number of } \\
\text { Species per } \\
\text { Sample }\end{array}$ \\
\hline \multirow{2}{*}{ Caribbean } & 999 & 37 & 126 & 995 & 350 & 28 & 70 & 44 \\
\cline { 2 - 10 } & 502 & 12 & 15 & 659 & 326 & 8 & 62 & 43 \\
\hline \multirow{2}{*}{$\begin{array}{c}\text { Eastern } \\
\text { Equatorial }\end{array}$} & 503 & 11 & 49 & 335 & 154 & 24 & 63 & 39 \\
\cline { 2 - 10 } & 568 & 24 & 1 & 382 & 103 & 1 & 61 & 21 \\
\hline
\end{tabular}




\title{
CHAPTER 3
}

\section{NEOGENE DIVERSITY OF CARIBBEAN BENTHIC FORAMINIFERA RELATED TO THE CLOSURE OF THE CENTRAL AMERICAN SEAWAY}

\begin{abstract}
\end{abstract}
The diversity indices Shannon's H, Fisher's $\alpha$, Dominance and Evenness, determined from benthic foraminiferal assemblages from the Late Oligocene ( 26 Ma) to Late Pliocene/Early Pleistocene ( 2.5 Ma), were used to test the hypothesis that diversity prior to closure of the Central American Seaway was similar in the Caribbean and equatorial Eastern Pacific, and showed changes by the time of early shoaling events. The present study utilizes published data from the Equatorial Eastern Pacific (DSDP sites 503, 568, and 569) examined in conjunction with new data (ODP Site 999) and previously published Caribbean data (DSDP Site 502, and ODP Site 999). These previous studies of the region used different data sets produced by other scientists: this study standardized the taxonomy among sites and extended the Caribbean data farther back in geologic time than the prior works.

The effects of a major geologic change on a benthic community are seen in the diversity indices. In this study, Shannon's H proved to be the most effective as it took into account the relative abundances of species and gave greater weight to common species, thereby addressing the issue of comparing sites with low abundances. The greatest changes in diversity occurred during the interval between $16 \mathrm{Ma}$ and 8 Ma with the most variation in diversity occurring older than $\sim 8 \mathrm{Ma}$. This interval also contained the largest increases in Dominance, with values ranging from 0.06 to 0.33. Caribbean diversity showed a decrease at $8 \mathrm{Ma}$, when there was an effective barrier to deep-water 
exchange between the tropical Atlantic and equatorial Eastern Pacific. Finally, after complete closure of the Central American Seaway, there was a decrease in diversity at both Caribbean sites at $3.5 \mathrm{Ma}$, which was followed by an increase back to previous levels at 3 Ma. At this time the equatorial Eastern Pacific site (DSDP Site 503) began to decrease in diversity. Thus, the differentiation in bottom-water source for the Caribbean and equatorial Eastern Pacific at $\sim 16$ Ma and the barrier to deep-circulation flow at $\sim 12$ Ma had a greater effect on Caribbean and Pacific deep-sea diversity than closure of the seaway.

\section{Introduction}

The objective of this study is to show the effects of a major geologic and oceanic change, the closure of the Central American Seaway in comparison to previous oceanographic events, on the diversity of benthic foraminiferal assemblages of the regions. The closure of the Central American Seaway caused by the emplacement of the Isthmus of Panama provides a unique setting in which to study the effects of the isolation of benthic foraminiferal communities in two major bodies of water. The Isthmus of Panama began shoaling and affecting deep circulation in the early Neogene as seen from decreases in radiolarian productivity and shell thickness (Maurrasse, 1979). The initial uplift resulted in changes in open-ocean sedimentation, producing a hiatus in both the Caribbean and the Pacific (Keller and Barron, 1983; Duque-Caro, 1990). Miocene hiatus NH2 (Keller and Barron, 1983) is identified at 16 Ma based on the first and last occurrence biostratigraphic datums of planktic foraminifera and radiolarians from multiple DSDP sites. This is the only Miocene hiatus identified in the study that did not 
coincide with rapid cooling, as indicated by $\delta^{18} \mathrm{O}$ values. This change in sedimentation is attributed to bottom-water source differentiation around 16-15 Ma with the closure of the deep connection between the equatorial Eastern Pacific (EEP) and the Caribbean. During the middle Miocene (12.9-11.8 Ma) there was interruption of flow between the tropical Pacific and Atlantic due to partial emergence of the isthmus (Duque-Caro, 1990). DuqueCaro (1990) found that sea level dropped with the onset of the cooler California current at this time, and there was uplift to middle bathyal depths.

Further circulation changes began in the late Miocene ( $\sim \mathrm{Ma})$ as seen in studies using deep-water $\mathrm{Nd}$ and $\mathrm{Pb}$ isotopes to determine timings of change that support the restriction of water-mass exchange”(Frank et al., 1999; Reynolds et al., 1999). Changes in $\delta{ }^{13} \mathrm{C}$ and $\delta^{18} \mathrm{O}$ values saw gradients emerge that agree with this restriction of deepwater flow (Billups, 2002; Spezzferri et al., 2002). Divergence of Caribbean and equatorial Eastern Pacific (EEP) staple isotopes of planktic foraminifera show that the shallow-water connection was closed with complete emergence of the Central American isthmus during the early Pliocene (Keigwin, 1982 a, b; Duque-Caro, 1990; Haug et al., 2001), as is discussed below.

When the surface currents flowed freely between the tropical Atlantic and Pacific, significant mixing occurred, causing both surface waters to have similar salinity values. Haug and Tiedemann (1998), using $\delta^{13} \mathrm{C}$ values of the benthic foraminifer Cibicidoides wuellerstorfi as a proxy to track deep-water circulation, showed that before 4.6 Ma, Antarctic Intermediate Water was the dominant occupier of the Caribbean. After this time, less corrosive bottom water from the north was indicated by increases in carbonate preservation and deep-water ventilation. A maximum Caribbean ventilation was noted at 
3.6 Ma when $\delta^{13} \mathrm{C}$ values were similar to those of North Atlantic waters. A study of the $\delta^{18} \mathrm{O}$ of planktonic foraminifera (Haug et al., 2001) further constrained the timing of surface-water changes. They suggested that prior to $4.7 \mathrm{Ma}$, salinity values of the Caribbean were lower than, or similar to those of, the EEP. Haug et al. (2001) determined that around 4.7 Ma, a sill of $<100 \mathrm{~m}$ depth had shoaled to restrict water exchange between the EEP and Caribbean, based on the subsequent increase in $\delta^{18} \mathrm{O}$ values in the Caribbean (Haug et al., 2001). Another increase at 4.2 Ma showed a stepwise constriction of flow, in agreement with earlier, similar research by Keigwin (1982 a, b).

Timing of the rise of the isthmus is also documented in the Bocas del Toro basin of Caribbean Panama by changes in water depths interpreted for the formations (Coates et al., 2003, 2004). When flow restriction between the EEP and Atlantic surface waters occurred, the tropical western Atlantic and Caribbean became approximately 1 per mil more saline than the EEP because of an increased atmospheric transport of vapor to the Pacific across the isthmus (Haug et al., 2001). Studies by Prange and Schulz (2004) and Steph et al. (2006), examining the salinity of the western Atlantic and tropical Pacific, found the same increase in Caribbean salinity which was attributed to the increased transport of heat and salt away from the Caribbean region as a result of the closure of the Central American Seaway. In the Caribbean, ODP Site 999 (Fig. 1) was affected by the influx of lower-salinity surface waters from tropical Pacific flow through the Central American Seaway around 4.4 Ma, but the more northern ODP Site 1000 did not show the same variability (Steph et al., 2006). Studies of Keigwin (1982a, b) and Haug et al. (2001) both showed the increase in salinity in Caribbean water compared to the EEP at 
4 Ma. General Circulation Model simulations (Nisancioglu, et al., 2003; Lunt et al., 2008) examining the effects of the closure of the Central American Isthmus on oceanic circulation showed that with a shoaling of the isthmus and the prevention of the flow of North Atlantic Deep Water to the Pacific, modern global circulation was achieved.

The current study tests the hypothesis that diversity values of benthic foraminifera prior to the closure of the Central American Seaway were similar in the Caribbean and EEP, and had changed by the time of early shoaling. Expanding downcore on studies conducted by Jain (2006) and Jain et al. (2007), the hypothesis is tested by examining the diversity indices Shannon Wiener Index H(S), Dominance, Evenness and Fisher's $\alpha$ for Caribbean and EEP sites, as they relate to previously established times of geologic change.

There have been three previous diversity studies of deep-sea Caribbean and EEP benthic foraminifera of the younger interval of this study (8.3-2.5 Ma). At Caribbean ODP Site 502 and Pacific ODP Site 503, McDougall (1996) found that the Shannon Diversity Index was nearly constant from Late Miocene to Pleistocene, with the Pacific site having slightly higher diversity than the Caribbean. In a separate study (Bornmalm, 1997) of Caribbean Site 502 and Pacific Site 503 ( 6 - 2 Ma), no major difference in diversity between holes was found. However, Bornmalm’s (1997) study only utilized benthic foraminifera from the size $125 \mu$ sieve, which precludes smaller specimens such as Epistominella exigua from being counted. Jain et al. (2007), utilizing the same cores of this study, found that the trends of diversity at Caribbean ODP Site 999, as measured with Fisher's $\alpha$ and the Shannon Wiener Index H(S), paralleled rates of paleoproductivity determined by the proxies Benthic Foraminiferal Accumulation Rate (BFAR), 
Infaunal/Epifaunal species ratio and organic carbon flux. The study also found a decrease in both diversity and paleoproductivity at 7.9 Ma, followed by an increase until closure of the Central American Seaway at $\sim 4$ Ma that was attributed to the restriction of flow between the Caribbean and equatorial Eastern Pacific.

\section{Methodology}

\subsection{Sites Used}

This study utilizes data from sites (Fig. 1) obtained through the Ocean Drilling Project (ODP) and Deep Sea Drilling Project (DSDP). The current study incorporates new benthic foraminiferal data from ODP Caribbean Site 999 with previously studied data from DSDP Caribbean Site 502 and DSDP Equatorial Eastern Pacific (EEP) Site 503. Additional EEP data were incorporated from DSDP Leg 85, sites 568 and 569, chosen for their extensive age range and fewer hiatuses, as EEP Leg 85 sites 566, 567, and 570 all included large hiatuses. All comparison sites (Caribbean Site 502 and EEP sites 503, 568, and 569) were also chosen for their availability of complete benthic foraminiferal datasets and the publication of foraminiferal images (McDougall, 1984, 1985, 1996; Thomas, 1985), improving taxonomic standardization and thus, comparison of the same species. Sampling interval (Fig. 2) and sample size (both original sediment sample size and number of foraminifers) did vary in the EEP sites, so where possible, general trends of increases, decreases and peaks in the diversity indices are used, as opposed to direct comparison with absolute abundances. 


\subsection{Sample Preparation and Foraminiferal Taxonomy}

Samples were chosen from ODP Caribbean Site 999 (Figs. 2, 3) at an approximately 0.5-million-year interval. Due to differences in preservation and benthic foraminiferal abundance, this interval was adjusted at times to provide a more robust data set. Benthic foraminiferal analysis of whole assemblages was conducted on 37 samples. Eleven of these were examined for benthic foraminifera in previous studies (Jain 2006; Jain and Collins, 2007; Jain et al., 2007). For purposes of taxonomic standardization with older samples and previously studied datasets, the author re-identified all species on faunal slides provided by Jain. Jain’s samples (10H-03 thru 25X-03), which were $10 \mathrm{~cm}^{3}$ samples, were treated with $1 \%$ hydrogen peroxide, soaked, and washed through a $63 \mu \mathrm{m}$ sieve, then dried in an oven. All benthic foraminifera were then picked and mounted on faunal slides.

The 26 sediment samples from ODP Site 999, newly investigated for this study, were soaked in deionized water for several days to disaggregate clays, and then washed over a $63 \mu \mathrm{m}$ sieve. However, differing from Jain’s original study, samples were split using a standard sample splitter to ideally achieve 300 specimens, a statistically robust number. Each sample was split to ideally achieve 300 or more specimens. In sampling, it is statistically important to achieve a representative sample set. At a sample size of 200400 , a confidence level of $+/-93-95 \%$ is achieved, which means that there is $93-95 \%$ confidence that there will be less than +/-0.07 error per sample (Hayek and Buzas, 1997) when compared to the original sediments. In cases where the assemblage did not recover at least 200 specimens, the entire sample was counted. 
Individual specimens were then sorted by species and identified using literature and comparative collections at the U.S. National Museum and in the collections of L. Collins. Correctly identifying benthic foraminifera is a difficult process because of morphologic variation within species, synonyms, and rare species, so species were identified using only comparative collections, and literature with excellent plates and figures. All specimens were identified to the species level where possible. When the species level could not be achieved, due to poor preservation or quality of identifying features, specimens were assigned to the generic level and listed as “spp.” in the appendices. To standardize taxonomy throughout the current study of ODP Site 999, once a specimen was identified, that specimen's sample, slide location and reference citation were listed in the author's collection to allow for later comparison. Subsequent specimens were then compared to those initially identified to confirm similarity. After data of McDougall (2015) for DSDP sites 502, 503, 568, and 569 were incorporated into the study set, all species names were checked for synonymies and updated generic assignation. Several species in the additional data sets were found to be in synonymy, and in those instances, all species were researched to determine correct names. All species counts were input into Excel spreadsheets, where percentages of entire assemblages were calculated.

\subsection{Age Determinations}

A potential problem with age determination arose when comparing datasets from different sites. Ages for Caribbean Site 999 (this study) were taken from published tables from Proceedings of the Ocean Drilling Program, Volume 165 (Sigurdsson, et al., 1997), 
which used calcareous nannofossil and planktic foraminiferal biostratigraphy (Berggren et al., 1995; Curry et al., 1995) to achieve preliminary age designations which were then calibrated to Cande and Kent’s (1995) magnetic polarity time scale.

The EEP sites 568 and 569 had no published absolute ages, but utilized planktic foraminifera (Berggren et al., 1995) and calcareous nannofossil zonations (Bukry, 1973, 1975; Okada and Bukry, 1980) to identify biozones. Since the ages provided for Site 999 were determined from a calibrated time scale that utilized these biozonations, absolute age datums were established for the two EEP sites by identifying the limits of each identified zonation and interpolating ages between those points, so that data could be directly compared to those of this study. This technique assumed a steady rate of sedimentation within a biozone.

Both DSDP Caribbean Site 502 and EEP Site 503 had published absolute age data (McDougall, 1996) that were calculated from planktic foraminiferal zonations and magnetostratigraphy using the time scales of Kent and Spariosu (1982 a, b), Zenker (1986), Zenker et al. (1987), and Keller et al. (1989). Since these datums were not established using the same time scales described above, limits on identified magnetochrons were compared to those used in the current study (Berggren et al., 1995) to identify relevant differences (Table 1). The ages calculated for Site 999 used several magnetic polarity time scales, including that of Berggren et al. (1995) but there is no difference in age determination that affects definition of the four time intervals used in this study, approximately 25-16 Ma, 16-8 Ma, and 8-4 Ma. For example, this comparison found that there is up to only a 32-34 kyr discrepancy, the largest (Table 1) surrounding the complete closure of the Central American Seaway at $~ 4$ Ma. The data points from 
Caribbean Site 502 and EEP Site 503 are younger than the other noted geologic events at $\sim 16, \sim 12$, and $\sim 8 \mathrm{Ma}$, and therefore, the possible discrepancy only applies to the data younger than 8 Ma. Since Caribbean Site 999 uses a different time scale (Berggren et al., 1995) than that of Caribbean Site 502 and EEP 503 (Zenker, 1986; Zenker et al., 1987; Keller et al., 1989, and Kent and Spariosu, 1982 a, b), data points at exactly the same age datums were not directly compared.

\subsection{Diversity Indices}

Individual species counts from all sites were used in calculations of the diversity indices Fisher's $\alpha$, Dominance, and Shannon's H and E, using PAST Paleontological Statistics software v. 3.07 (Hammer et al., 2001). The diversity index Shannon's H takes into account both the number of taxa as well as the number of individuals because in general, the number of taxa increases with the number of individuals counted (Hayek and Buzas, 1997). Shannon's $H$ is written: $H=-\sum\left(n_{i} / n\right) \ln \left(n_{i} / n\right)$, where $n_{i}=$ the number of individuals of a species and $\mathrm{n}=$ the total number of individuals. The value of $\mathrm{H}$ ranges from zero for a sample with only a single taxon, to higher values where there are many species present (Hammer et al., 2001). The diversity index Fisher's $\alpha$ is determined by $\mathrm{S}$ $=\alpha * \ln (1-\mathrm{n} / \alpha)$ where $\mathrm{S}=$ species richness or the number of taxa, $\mathrm{n}=$ the number of individuals, and $\alpha=$ Fisher's $\alpha$. Evenness reflects the distribution of individuals across species and can also be referred to as a dominance or equitability measure (Hayek and Buzas, 1997). The Evenness measure used here is that of Buzas and Gibson, calculated as $\mathrm{E}=\mathrm{e}^{\mathrm{H}} / \mathrm{S}$. Dominance (D) is measured using the equation $\mathrm{D}=\sum\left(\mathrm{n}_{\mathrm{i}} / \mathrm{n}\right)^{2}$ (Hammer, 2015). This measure can range between zero and one, where zero means that all taxa are equally 
present and one means that there is complete dominance by one taxon in the sample (Hammer et al., 2001).

Hayek and Buzas (2013) evaluated various indices that measure diversity and found that most studies used S (species richness), Fisher's $\alpha$, Shannon's H, dominance and Evenness. The use of S alone only accounts for the number of species present and causes single specimens of a species to have the same weight a species that has multiple specimens. Fisher's $\alpha$ requires both n (number of individuals) and S (number of species). The constraint of Fisher's $\alpha$ is that it is not sensitive to the proportional differences among the observed species (Hayek and Buzas, 2013) and therefore is not informative about the true complexity of the sample. Shannon's H is a more robust measure of diversity because it takes into account the number of individuals of a species and the total number of individuals, as well as relative abundance, which gives more weight to common species found in assemblages (Hayek and Buzas, 2013).

All species counts and calculated diversity indices were placed into a spreadsheet of Excel software where indices versus time were plotted graphically. All graphs (Figs. 4-7) are displayed with both raw data and 3-point moving averages calculated with the averages of the current and two preceding samples. The youngest two points could not be calculated using 3-point moving averages so the actual data points for those two samples are used for ease of graphical display. The 3-point moving average "smooths" the data so that the "noise" within each proxy or graph is subdued enough to see general trends. It is most useful where a large variability obscures observation of trends, but where variability is small, it can distort the trends in values. 
It is important to note the limits of the usability of some of the EEP datasets that were acquired. Whereas EEP sites 568 and 569 provide a good amount of comparative data, especially for the older studied interval ( 26 - $8 \mathrm{Ma}$ ), that are not present at DSDP sites 502 and 503, Pacific diversity measurements are not directly comparable to either Caribbean Site 502 or the other EEP sites 568 and 569, because multiple samples contain very low abundances and thus, diversities. Site 568 has 9 samples with less than 25 individuals; Site 569 has 5 samples with less than 25 individuals; while Site 502 has 1 sample with less than 25 individuals. In the current study, samples were selected to provide a robust species count where possible (Table 2), and as such, ODP Site 999 possesses higher average numbers of specimens per sample, as well as a much higher minimum specimen number (153), compared to a minimum of 1 or 15 at all other studied sites. Appendices $1-5$ list all counts of each site.

\section{Results}

This study identified 12,522 foraminiferal specimens, including 237 species in 71 genera, for ODP Site 999 (Appendix 1). These counts, coupled with counts for EEP DSDP sites 503, 568 and 569, and Caribbean DSDP Site 502, were used in all diversity index calculations (Figs. 4-7 and Tables 3-7). The data are divided into sections according to the previously established times of known geologic change described in greater detail above, to compare changes in diversity from section to section, 26-2 Ma. These divisions are as follows, in chronologic order:

16 Ma - differentiation of bottom-water source between Caribbean and EEP (Keller and Barron, 1983; Duque-Caro, 1990) 
12 Ma - deep circulation barrier between Caribbean and EEP (Woodruff, 1985;

Duque-Caro, 1990)

$\sim 8 M a$ - Constriction of Central American Seaway (CAS) (Collins et al., 1996a;

Frank et al., 1999; Reynolds et al., 1999; Billups, 2002)

4 Ma - complete closure of the CAS (Keigwin 1978, 1982a, b; Haug and

Tiedemann, 1998; Haug et al., 2001)

\subsection{Diversity}

Prior to $20 \mathrm{Ma}$, the Pacific sites show a large amount of variation in Fisher's $\alpha$ (Fig. 4b). EEP Site 569 has three data points in this interval with $>25$ species while Site 568 only has two. Within the interval where both EEP sites had > 25 specimens ( $22.5 \mathrm{Ma})$, EEP Site 569 and Caribbean Site 999 had similar values of Fisher's $\alpha$. Following this, the EEP data points have higher values than that of the Caribbean for the remainder of the interval. The Caribbean site remains fairly consistent in this interval with Fisher's $\alpha$ values between 10 and 16, with a noticeable drop at 24.5 Ma that is repeated at 22.5 Ma. This trend of higher diversity in the EEP continues until 10 Ma.

In the younger interval (10-2 Ma, Fig. 4a) there are very few data points from sites 568 and 569 (EEP), and of those present, only two at each site contain > 25 specimens. Prior to the event at $\sim 8$ Ma, Caribbean Site 999 had the highest Fisher's $\alpha$ of the study with a value of 23.55. After $\sim 8 \mathrm{Ma}$ at Caribbean Site 999, Fisher's $\alpha$ lowered to previous levels. From 8-4 Ma, for the most part, the Caribbean sites remain lower than that of EEP Site 503, but not EEP Site 568. After the closure of the Central American Seaway at 4 Ma, Site 999 (Caribbean) showed a gradual but consistent decrease in Fisher's $\alpha$. 
Overall, from 4-2 Ma, Pacific sites had higher values of Fisher's $\alpha$ except for EEP Site 568, which maintained extremely low values compared to all other sites.

Shannon's H (Fig. 5) values had similar trends to those of Fisher's $\alpha$. From $\sim 26-17$ Ma, at Caribbean Site 999, values were fairly consistent (2.85-3.43), while steadily decreasing a bit more than Fisher's $\alpha$. The EEP sites before $\sim 20$ Ma had much lower values than the Caribbean but between 19.5 Ma to 17.5 Ma, they increased to levels slightly higher than those of Caribbean Site 999. Between 17-13 Ma, all three sites converged to have similar diversity values as they did for Fisher's $\alpha$ (Fig. 4). At $\sim 15$ Ma, all sites began a steady decrease until 10.5 Ma; after that, Site 999 showed a sharp increase, and remained fairly consistent until 4.5 Ma. With few exceptions, Caribbean Site 502 followed the same trend. From 6 Ma to 4.5 Ma, EEP Site 503 had consistently higher values than the two Caribbean sites, although only slightly higher. Prior to the closure of the Central American Seaway at $\sim 4 \mathrm{Ma}$, both Caribbean sites showed slight increases in Shannon's H values. However, immediately following the closure, Site 999 sharply decreased, more sharply than seen for Fisher's $\alpha$. Site 502 followed the same trends seen in the Fisher's alpha with a later decrease in Shannon’s H at 3.5 Ma, when Site 999 began to increase again. At 3.5 Ma, the diversity at EEP Site 503 began to decrease and remained lower than Caribbean Site 999 for the remainder of the samples.

\subsection{Dominance}

The Dominance values (Fig. 6) for ODP Site 999 were consistently low, between 0.04 and 0.10, with little variation throughout the studied interval, with the exception of two peaks (up to 0.33 ), at $\sim 10.5 \mathrm{Ma}$ and $\sim 3.5 \mathrm{Ma}$. The peak at $\sim 10.5$ was a dominance by 
Epistominella exigua and the peak at $~ 3.5$ was caused by a dominance by Nuttalides umbonifera. Sites 568 and 569 were mostly as low as the Caribbean (in samples with > 25 specimens) until after $~ 8$ Ma, when EEP Site 568 had two samples with much higher Dominance than those of the other sites. EEP Site 503 showed little variation but had a slight increase at 3 Ma. Caribbean Site 502 had very similar trends to Caribbean Site 999, with overall little variation, but consistently higher values than EEP Site 503 and a similar increase from 4.2 Ma to 3.2 Ma.

\subsection{Evenness}

All sites show a general decreasing trend in Evenness from 26 to 17 Ma. Both Site 999 (Caribbean) and EEP Site 568 have a marked decrease in Evenness at 17-17.5 Ma, while EEP Site 569 has a marked increase. Around the event at $16 \mathrm{Ma}$, all three sites had decreases which are followed by increases. In the case of Caribbean Site 999, variability in Evenness increased until 10 Ma. In the older interval (Fig. 7b), both EEP sites had higher values of Evenness in general (0.5-0.89, excluding samples with low specimen counts) than the Caribbean (0.44-0.68). At 15.5 Ma, the difference between the Evenness values of the EEP and Caribbean sites lessened slightly, because of a decrease in Evenness of the EEP sites.

After 14 Ma EEP values generally increased to higher levels than the Caribbean, with few exceptions. The EEP Site 569 maintained higher levels than the Caribbean site. The two lowest Evenness values at Site 999 occurred 10.5 Ma and 3.5 Ma. Caribbean Site 502 again showed similar trends to Caribbean Site 999, with a great deal of variation throughout, but with corresponding increases and decreases. The EEP Site 503 had little 
overall trend in Evenness values, but maintained higher values than both Caribbean sites from $~ 5.5$ Ma to 2.5 Ma.

\section{Discussion}

Hayek and Buzas (2013) have found that Shannon's H is one of the most valuable measures of diversity, along with species richness and dominance. As an informationbased measure, Shannon's H takes into account the distribution of species within a sample (Hayek and Buzas, 1997, 2003). Whereas trends in Fisher's $\alpha$ showed greater variation than Shannon's H, they also provide less information about the assemblages. The sample with the highest Shannon's H did not correspond to the highest diversity sample as measured by Fisher's $\alpha$, nor did the lowest diversity sample for each measure agree. In the case of Caribbean ODP Site 999, the sample with the highest diversity (the oldest sample examined in this study), had the lowest Dominance of the study and one of the higher measures of Evenness. This indicates that the samples were not dominated by a particular species, and had a more even distribution. The measure of Evenness takes into account the actual distribution of individuals within the assemblage. When the Evenness values are lower, more rare species are dominant (Hayek and Buzas, 2010). The Dominance values indicate to what extent an assemblage is dominated by a few species overall.

Below, the results of this study are compared among five time intervals defined by geologic events that occurred in the region: $~ 16 \mathrm{Ma}$ - differentiation of bottom water source (Keller and Barron, 1983; and Duque-Caro, 1990); 12 Ma-deep circulation barrier (Woodruff, 1985; Duque-Caro, 1990); 8 Ma - effective barrier to water exchange 
(Collins, 1996a; Frank et al., 1999; Reynolds et al., 1999; Billups, 2002); 4 Macomplete closure of the CAS at (Keigwin, 1982 a, b; Haug and Tiedemann, 1998).

\subsection{Bottom-Water Source Differentiation ( 16 Ma)}

Prior to the differentiation of the bottom water between the Caribbean and Equatorial Eastern Pacific (EEP), the diversity indices Shannon's H and Fisher's $\alpha$ for the Caribbean were fairly consistent with a slight decreasing trend. The EEP sites showed a greater degree of variation with several samples of $<25$ specimens, therefore providing less reliable data. While the EEP and the Caribbean did not consistently have similar values in diversity, there were a few samples that did show the relationship between the two bodies of water by having similar values at those points. Coates et al. (2003) supported this early separation at 18-16 Ma with the identification of a rapid rise of the pre-isthmian sill, noted in the Valiente Formation of the Bocas Del Toro Basin. The presence of a sill, especially one with a rapid rise, would have contributed to both a change in current flow, as well as a divergence in the benthic communities of the EEP and the Caribbean sites.

Following $\sim 16 \mathrm{Ma}$, trends in the measured indices for all of the sites began to change. The change to North Atlantic Deep Water in the Caribbean is seen in these changes (Morrison and Nowlin, 1982; Keller and Barron, 1983; Duque-Caro, 1990; Haddad and Droxler, 1996). The Evenness measure showed divergence between the Caribbean and EEP at this point, with average Caribbean values slightly decreasing and both EEP site values increasing. The two diversity measurements of Shannon's H and Fisher's $\alpha$ had similar patterns. At $\sim 14 \mathrm{Ma}-15 \mathrm{Ma}$, there was a decrease in diversity at all 
sites. This change is likely because of the increase in intensity of Caribbean flow, which co-occurred with a warming in bottom water temperatures at 16-15 Ma (Keller and Barron, 1983). Hiatus NH2, lasting from 16-15 Ma, was only identified in the Caribbean and North Atlantic (Barron and Keller, 1982). Modern deep circulation is thought to have been established during this interval, and faunal changes and the resultant impact on diversity can partially be attributed to increased corrosivity due to the influx of Antarctic Deep Water at 13 Ma, which suggested a general rise in the CCD (Keller and Barron, 1983). This rise would have increased the dissolution of calcareous foraminiferal tests, leading to lower abundances and diversities. In an examination Caribbean Site 999 samples prior to study, preservation of benthic foraminifera was average, with no samples with high preservation, supporting possible greater dissolution at the time. The global oceanographic and climatic changes at $16-15 \mathrm{Ma}$, due to Pacific Ocean cooling and Antarctic glacial growth, as well as an increase in thermal stratification is also noted at 15 Ma (Woodruff, 1985; Woodruff and Savin, 1985), which could lead to the noted decrease in diversity at this time, due to the immediate impact on several of the species, and the inability to quickly recover after a change in water temperature. The faunal turnover at $\sim 14$ Ma that is also attributed to these global changes is also seen in this study with a decrease in diversity indices at all sites (Woodruff, 1985).

\subsection{Barrier to Deep Circulation ( 12 Ma)}

The interval following this event in general showed similar trends in Dominance and Evenness to the previous interval. Evenness maintained a similar transisthmian separation established at 14.5-13.5 Ma, with Caribbean ODP Site 999 lower than 
Pacific DSDP sites 568 and 569. This interval had the lowest Evenness value for the Caribbean at 10.5 Ma. Dominance values showed very little change at the Caribbean site in this interval, with a peak at $11.7-10.5 \mathrm{Ma}$, before returning to previous low values. Diversity values of both Shannon H and Fisher's $\alpha$ continued the CaribbeanPacific divergence that began at 20 Ma. In this interval, and most of the next, Shannon's $\mathrm{H}$ at the Pacific sites had much lower values than those of the Caribbean. This interval contains the lowest Fisher's $\alpha$ and the second-lowest Shannon $H$ values for the Caribbean. The EEP sites are not easily comparable as there is only one data point that has $>25$ specimens, and there are very few samples in the EEP at all.

The barrier to flow, combined with the change in bottom water at 16 Ma, resulted in varied responses in the Pacific and Caribbean. The general decrease in all diversity is likely a result of the impedance of flow and the barrier that then effectively stopped transport between the two areas. The emergence of a volcanic arc in the Bocas del Toro area was noted by $12 \mathrm{Ma}$ in volcanoclastic rock deposits in a study by Coates et al (2003). The continued barrier to deep flow that began with the differentiation in the source of bottom water in the previous interval, influenced Caribbean diversity by decreasing it, likely the result of changes in nutrient supply and oxygenation. Multiple studies have shown that benthic foraminiferal assemblages reflect these changes in oceanographic conditions, both in terms of diversity and paleoproductivity (Altenbach, 1992; Gooday, 1994; Altenbach et al., 1999; Gooday, 2003; Collins and Jain, 2007). The decrease in diversity at the EEP sites could have been the result of the effect of an influx of cold water from the California Current that Duque-Caro (1990) hypothesized, which could have been severe for the benthic foraminiferal communities. A change in faunal 
assemblage sometime between 16 and 12 Ma was also noted by Woodruff (1985) in several Pacific study sites. This change in assemblage composition could have resulted in lower diversities for the Pacific sites.

\subsection{Seaway Constriction ( 8 Ma)}

Shannon’s H diversity values did not alter greatly in this interval and continued the trends seen in the previous interval, with Caribbean sites having consistently higher diversity than Pacific sites 568 and 569. Pacific Site 503 had very similar values to the Caribbean sites, and, in fact, were higher. Jain, et al (2007) also found an abrupt decrease in diversity values at 7.9 Ma that was observed in this study, noticeably as a peak in diversity indices at $\sim 8.2$, followed by a sharp decrease after the event at 8 Ma. The abrupt decrease in diversity $~ 8$ Ma can be attributed to the presence of a barrier preventing the exchange of surface waters of the EEP and the Caribbean (Collins et al., 1996a; Frank et al., 1999; Reynolds et al., 1999; Billups, 2002). This barrier furthered the effects seen in earlier intervals with continued decreases in diversity as Caribbean and EEP water masses diverged. Spezzaferri et al. (2002) noted a general cooling of the Bahamas in this time interval, while Billups (2002) showed that the modern gradient of $\delta^{13} \mathrm{C}$ between the Pacific and the North Atlantic was established at 8-7 Ma. These changes in paleoceanographic conditions, in terms of temperature and productivity, likely caused the sharp decrease 8 Ma in Caribbean diversity. However, the diversity indices soon leveled out in terms of increases and decreases, and therefore implied a less significant impact at this time by surface-water exchange than deep exchange, as seen in older intervals. The global "carbon isotope shift” that occurred 7.5 - 6.5 Ma (Shackleton and Kennett, 1975; 
Bickert et al., 2004), is noted in this study by a decrease in diversity in both Caribbean and EEP sites, as well as a slight increase in dominance in the Caribbean. The noted decrease in biomass at this time is directly seen in the diversity indices and the increase in Caribbean dominance could be due to more "hardy" species flourishing.

From 8 Ma to 6.5 Ma, Evenness increased for Caribbean Site 999 and decreased at Pacific Site 568. There is only one sample at Site 568 that had $>25$ specimens, while Site 569 had no samples in this interval with enough individuals to be confident of results. Around 6.5 Ma, Caribbean Site 999 showed a sharp decrease in Evenness, which was mirrored in the other Caribbean Site (502) slightly earlier ( 7 Ma). For the remainder of the interval, the two Caribbean sites had very similar increases and decreases, although Caribbean Site 502 was slightly higher. From 7.5 -6.5 Ma, Pacific Site 503 had values similar to Caribbean Site 999. At 6 Ma, Pacific Site 503 was higher than the Caribbean and although the Caribbean rebounded to similar values at 5.5 Ma, they soon diverged again with the Pacific Site maintaining higher values of Evenness. This interval also contained the oldest studied samples of DSDP Sites 502 (Caribbean) and 503 (Pacific). From 8-4 Ma, all sites, except Pacific Site 569, showed similar values of Evenness, with the Pacific having, on average, higher values than the Caribbean. This similarity suggests that, during this interval, all samples had fairly even distributions of the species among the assemblages. However, Dominance at Pacific Site 503 was lower than the two Caribbean sites and only one sample from Pacific sites 568 and 569 had a specimen count high enough to allow for confident comparison. 


\subsection{Complete Closure of the Central American Seaway ( $4 \mathrm{Ma})$}

Following seaway closure, diversity showed marked decreases at the two Caribbean sites, followed by an increase. This drop was also seen in previous diversity studies (Jain et al., 2007) and was attributed to the Atlantic-Pacific salinity contrast that was established with the complete closure of the CAS (Haug et al., 2001; Steph et al.;

2006a, b), as well as the increase in oxygen-rich and nutrient depleted waters (Haug and Tiedemann, 1998; Haug et al., 2001; Jain and Collins, 2007). At the same time of the sharp decrease in Caribbean Site 999, there was a lesser increase in diversity at Pacific Site 503, which was then followed by a marked decrease. The lesser increase noted in the Pacific corresponds well to the assumption that paleoceanographic conditions in the Pacific likely did not change much immediately after CAS closure and therefore, would not have a major reaction in diversity indices. The decrease in diversity seen in the Caribbean can be attributed to the change in the differences of the oceanographic characteristics of the Atlantic and Pacific noted in salinity changes (Haug et al., 2001).

The closure of the Central American Seaway resulted initially in lower Evenness for the Caribbean, before a rebound after $3 \mathrm{Ma}$, and a slightly higher value for Pacific Site 503 before returning to similar values. Dominance increased at the point, and Evenness decreased for Caribbean Site 999. Dominance at Pacific Site 503 and Caribbean Site 502 showed slight increases in the interval younger than 4 Ma.

Previous studies, and Chapter 2 of this study, showed that a reduction of paleoproductivity occurred at the time of closure of the CAS (Jain, 2006; and Jain et al., 2007). This decrease in paleoproductivity, due to an increase in oxygenation and nutrientdepleted waters in the Caribbean, led to a decrease in diversity as a result of lessening 
food availability at the seafloor. While my study of this interval showed a great deal of similarity to the previous study of Jain et al. (2007), it lacks the high-resolution data of Jain (2006) and Jain et al., (2007). The slight differences seen in the diversity indices could be attributed to the rate of sampling interval. The previous studies of this core (Jain, 2006; Jain and Collins, 2007; and Jain et al., 2007) had a much greater sampling interval condensed over a shorter time frame so the rapid changes of those studies could likely be masked over the $\sim 0.5$ million year interval currently used.

\section{Conclusions}

The hypothesis was that diversity values of benthic foraminifera prior to the closure of the Central American Seaway were similar in the Caribbean and EEP, until the time of early shoaling. The hypothesis was partially true in that while the diversity measures had periods of similarity, or at least similarity in trends, Caribbean - Pacific divergence, for the most part, paralleled times of paleoceanographic circulation change. The greatest changes in diversity, by both Shannon's H and Fisher's $\alpha$ measures, occurred prior to $\sim 8 \mathrm{Ma}$ when the barrier to deep water exchange occurred. The most significant changes occurred in the intervals between bottom water source differentiation at $\sim 16 \mathrm{Ma}$, and the barrier to deep circulation at $\sim 12 \mathrm{Ma}$. The former interval also contained the largest increases in Dominance, indicating more robust, or tolerant, taxa flourished during the period of stressful conditions that existed during these circulation changes. The noted changes in bottom water, and the deep-circulation barrier at $12 \mathrm{Ma}$ caused the most decreases in diversity leading to the conclusion that, at bathyal depths, oceanographic conditions and transport at the sea floor may have a greater impact on 
benthic communities than oceanographic or tectonic events that occur at shallower depths. The younger noted paleoceanographic events, the constriction of flow at $\sim 8 \mathrm{Ma}$ and the complete closure of the CAS at $\sim 4 \mathrm{Ma}$, also had significant changes that paralleled previous studies, but diversity indices during these intervals tended to rebound to previous values at faster rates. 


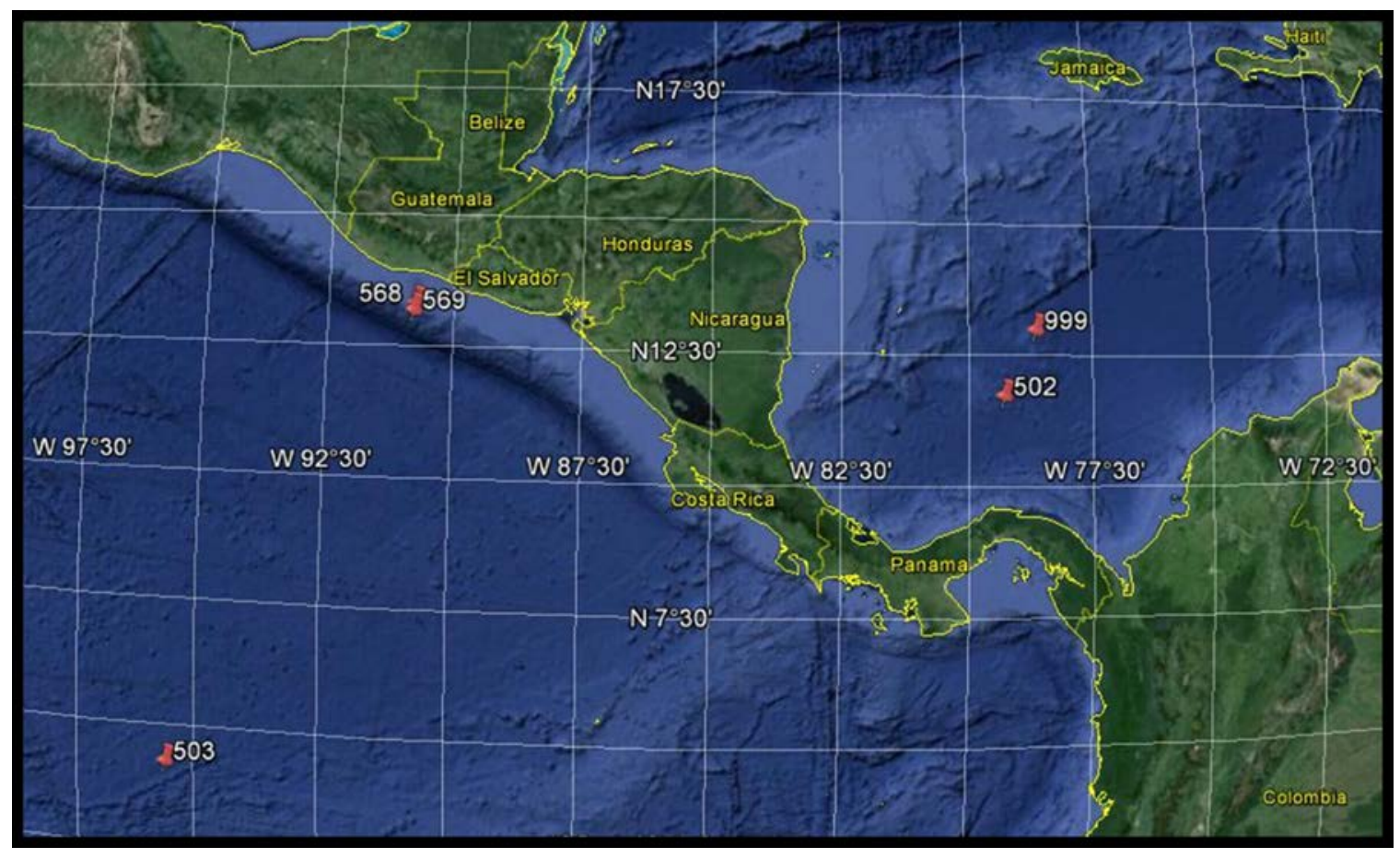

Figure 1. Site locations used for this study: Caribbean ODP Site 999, DSDP Site 502, and Equatorial Eastern Pacific DSDP sites 503, 568 and 569. 


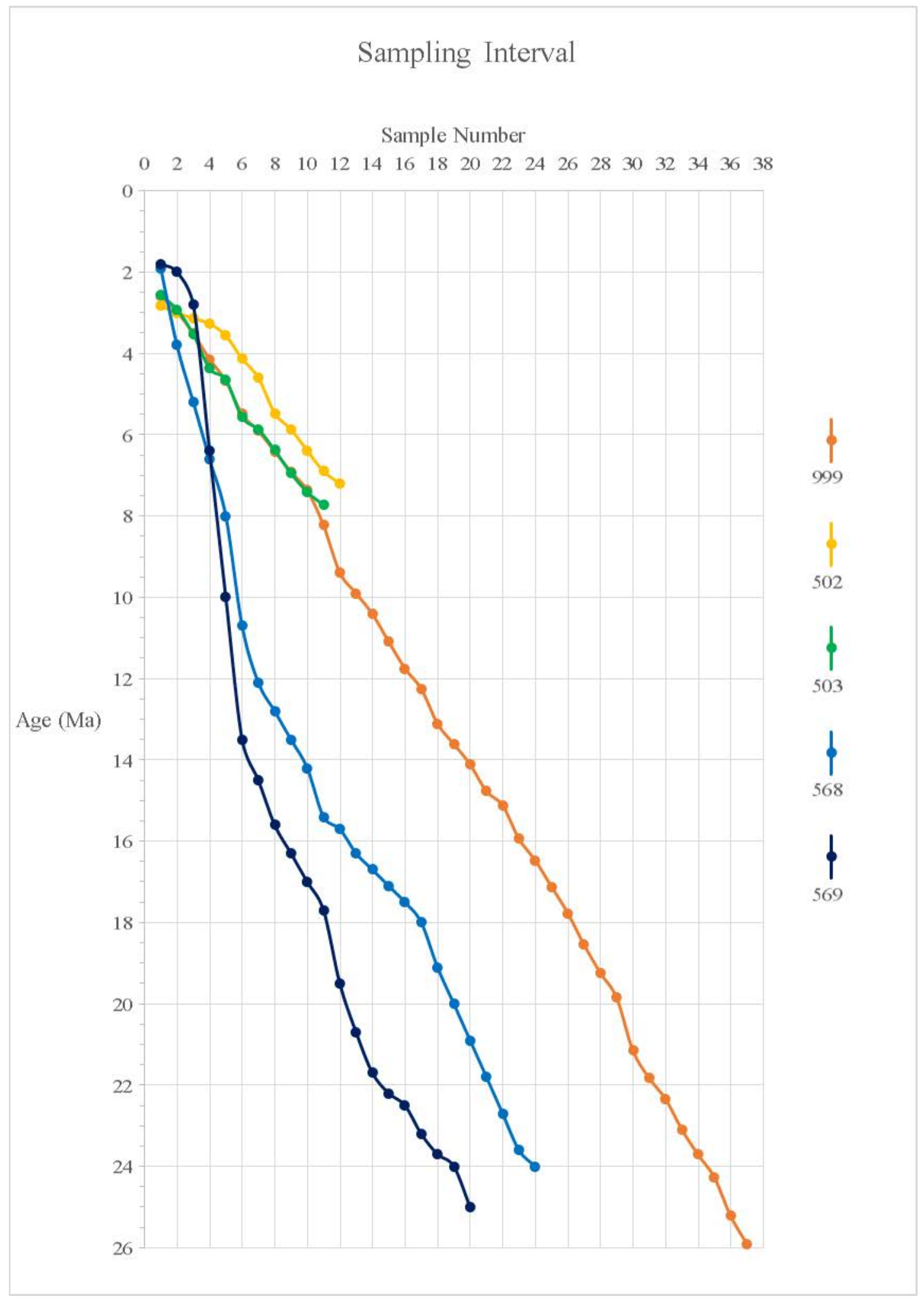

Figure 2. Sampling interval for all sites. 


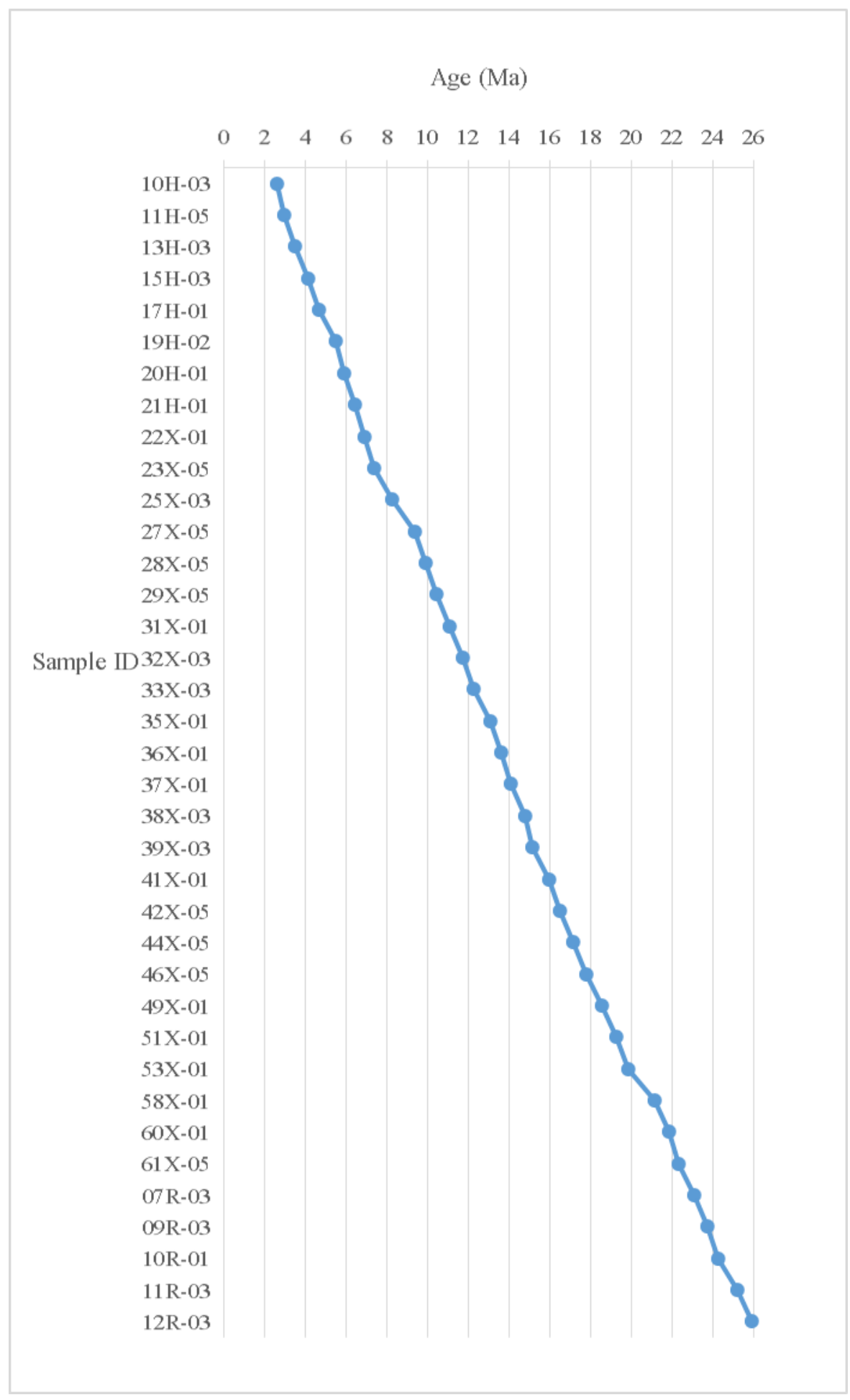

Figure 3. Samples prepared for benthic foraminiferal assemblages, ODP Site 999. Where sample conditions allowed, samples were selected at a 0.5-million-year interval. All ages acquired from ODP Leg 165 (including site 999) publications (Sigurdsson, et al., 1997). 


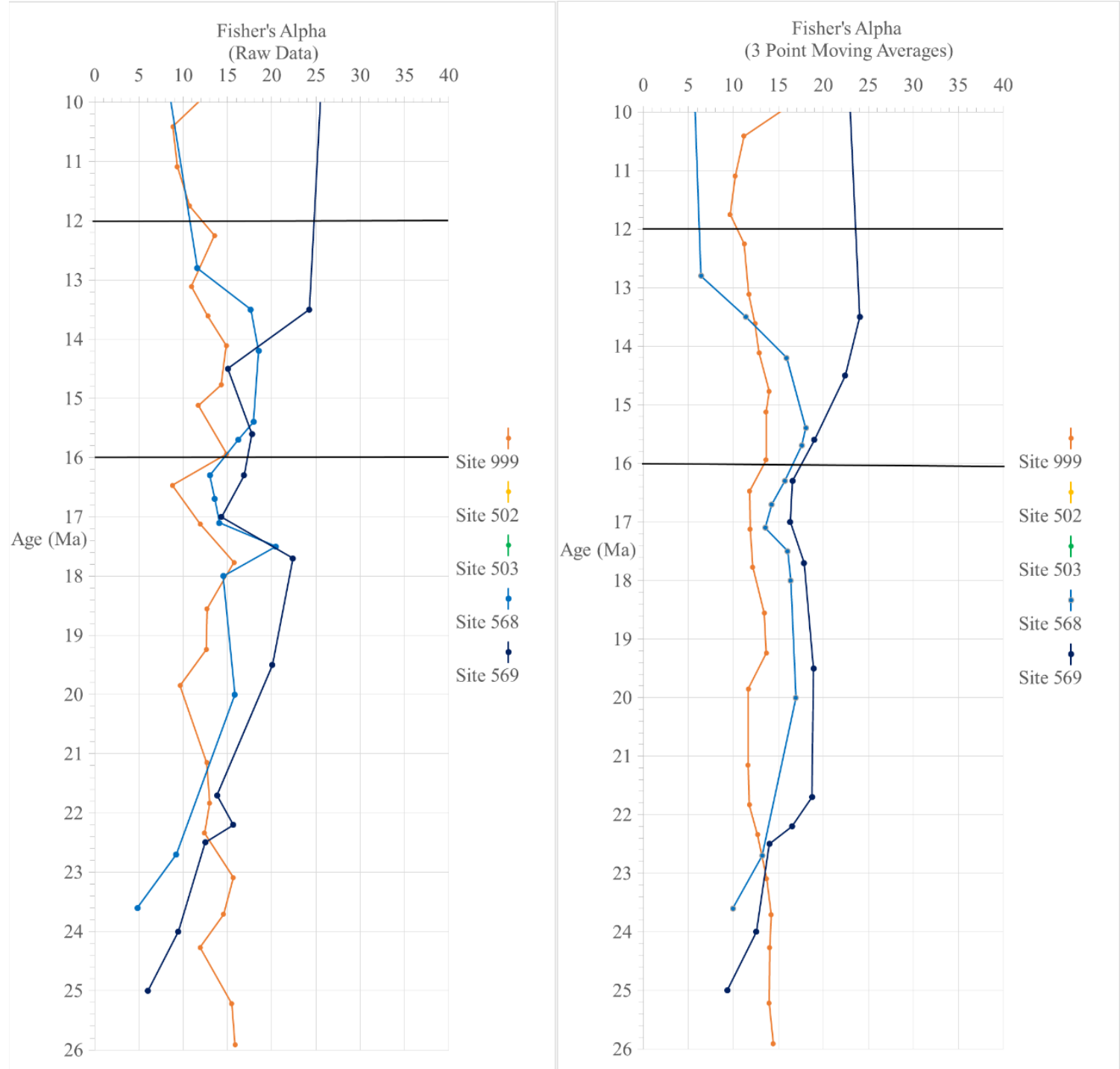

Figure 4a. Fisher's $\alpha$ for all five sites: Caribbean ODP Site 999 and DSDP Site 502, and Pacific DSDP sites 503, 568 and 569 (older interval). Previously determined paleoceanographic events noted. Left graph: calculated values. Right graph: 3-point moving averages. 


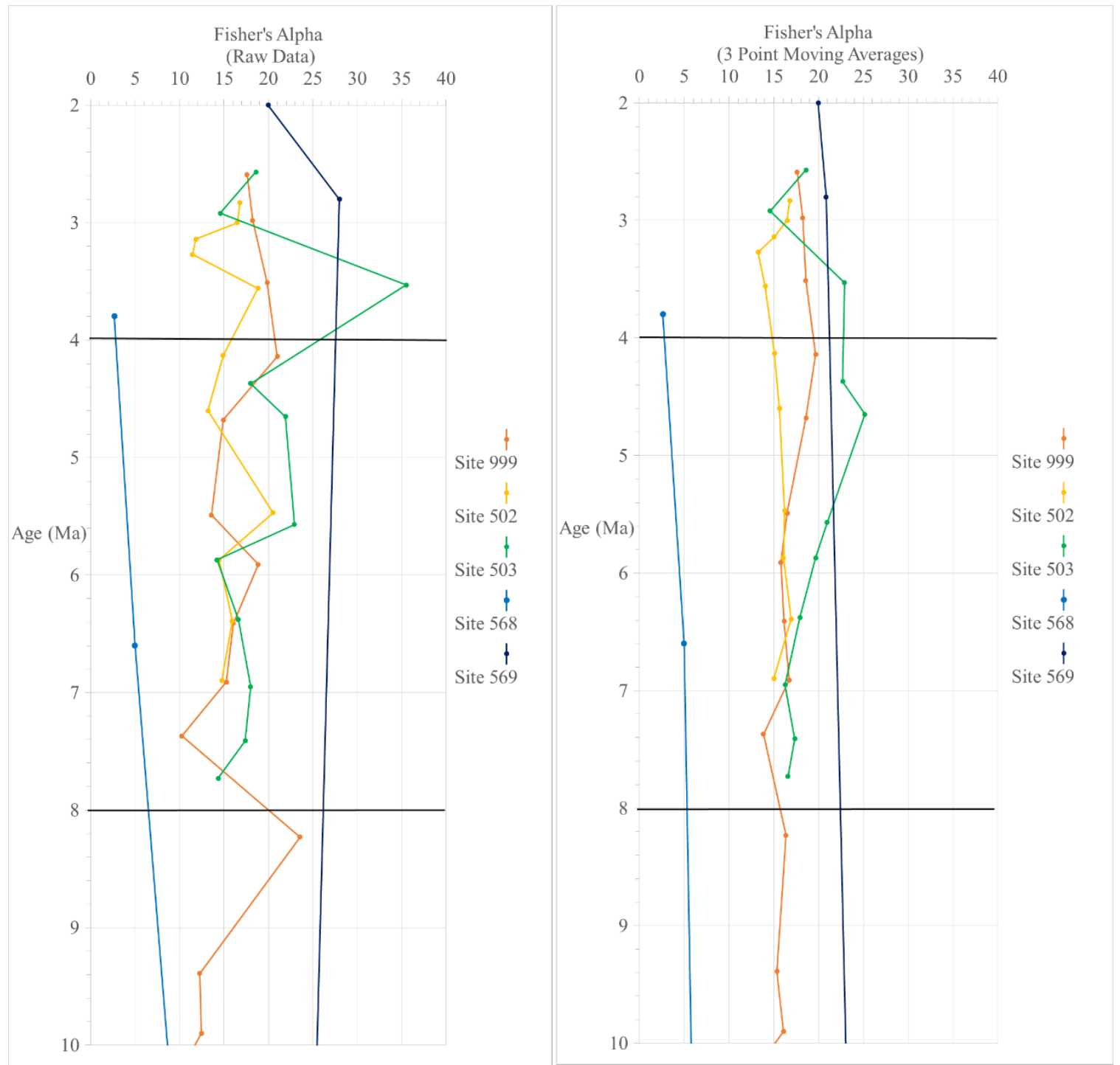

Figure 4b. Fisher's $\alpha$ for all five sites: Caribbean ODP Site 999 and DSDP Site 502, and Pacific DSDP sites 503, 568 and 569 (younger interval). Previously determined paleoceanographic events noted. Left graph: calculated values. Right graph: 3-point moving averages using original values for 2 youngest points. 


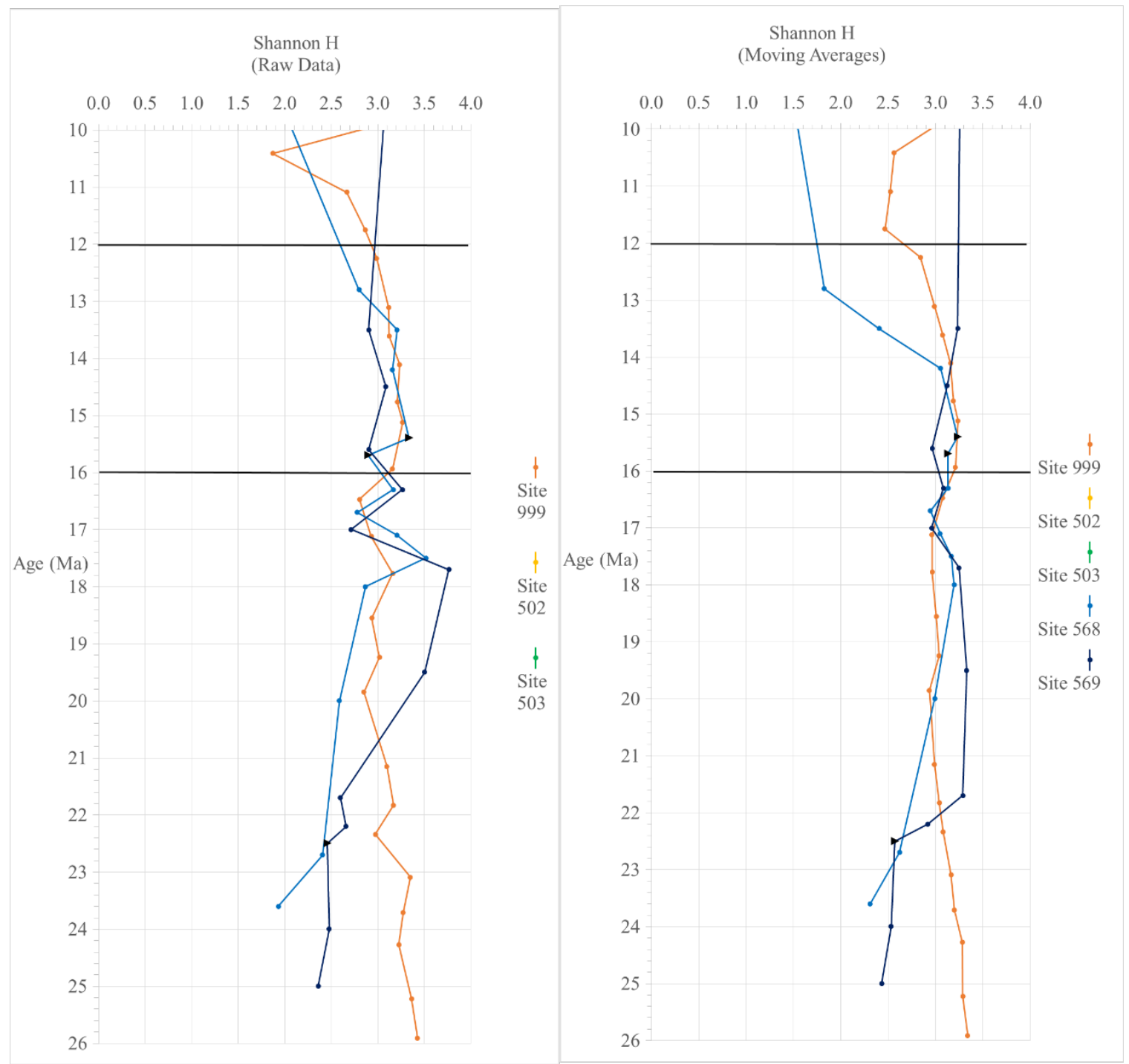

Figure 5a. Shannon H (diversity measure) for all five sites: Caribbean ODP Site 999 and DSDP Site 502, and Pacific DSDP sites 503, 568 and 569 (older interval). Previously determined paleoceanographic events noted. Left graph: calculated values. Right graph: 3-point moving averages. The lines at the tops of the figures are continued in the younger interval. 


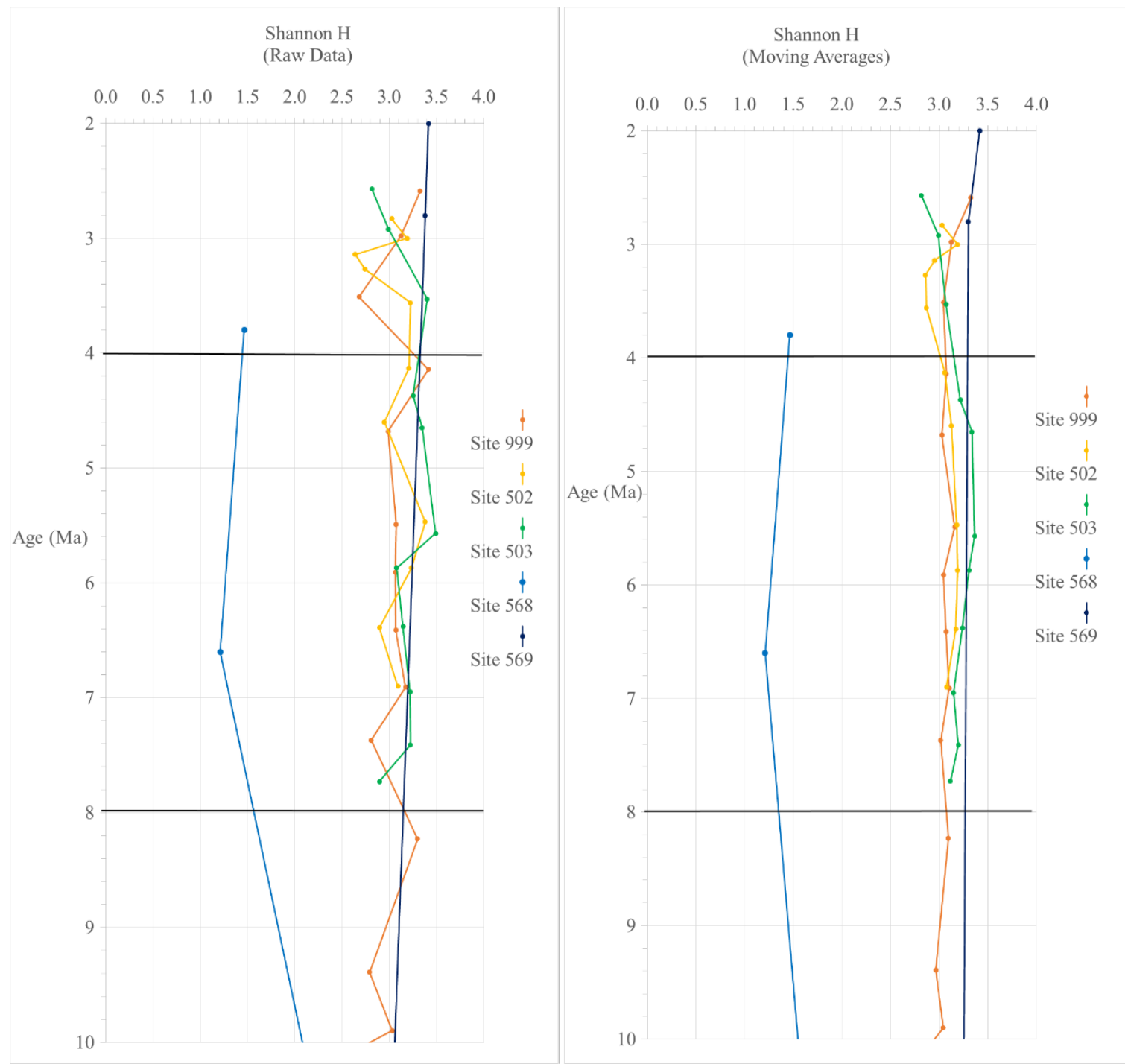

Figure 5b. Shannon H (diversity measure) for all five sites: Caribbean ODP Site 999 and DSDP Site 502, and Pacific DSDP sites 503, 568 and 569 (younger interval). Previously determined paleoceanographic events noted. Left graph: calculated values. Right graph: 3 -point moving averages using original values for 2 youngest points. 


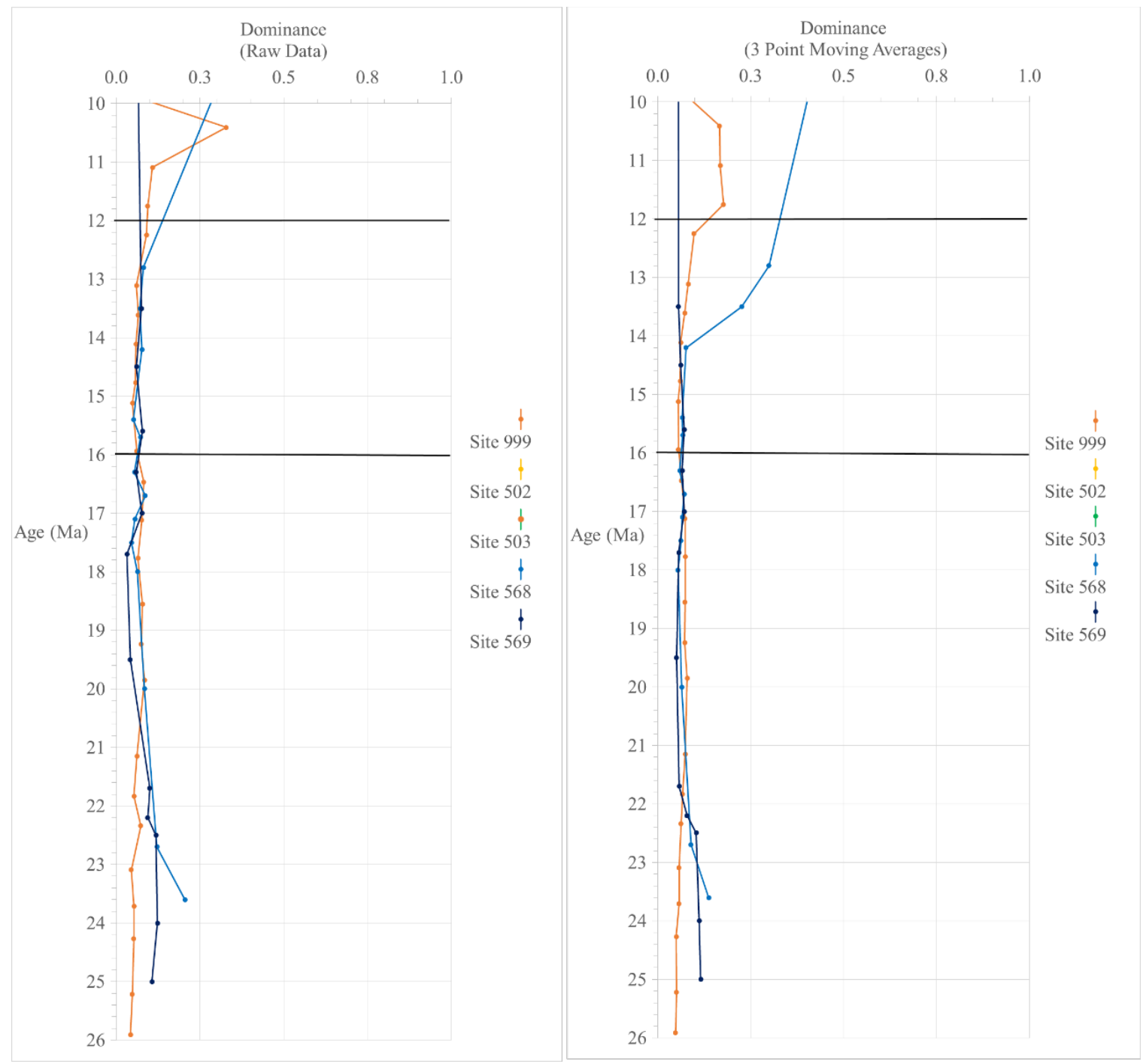

Figure 6a. Dominance for all five sites: Caribbean ODP Site 999 and DSDP Site 502, and Pacific DSDP sites 503, 568 and 569 (older interval). Previously determined paleoceanographic events noted. Left graph: calculated values. Right graph: 3-point moving averages. The lines at the tops of the figures are continued in the younger interval. 


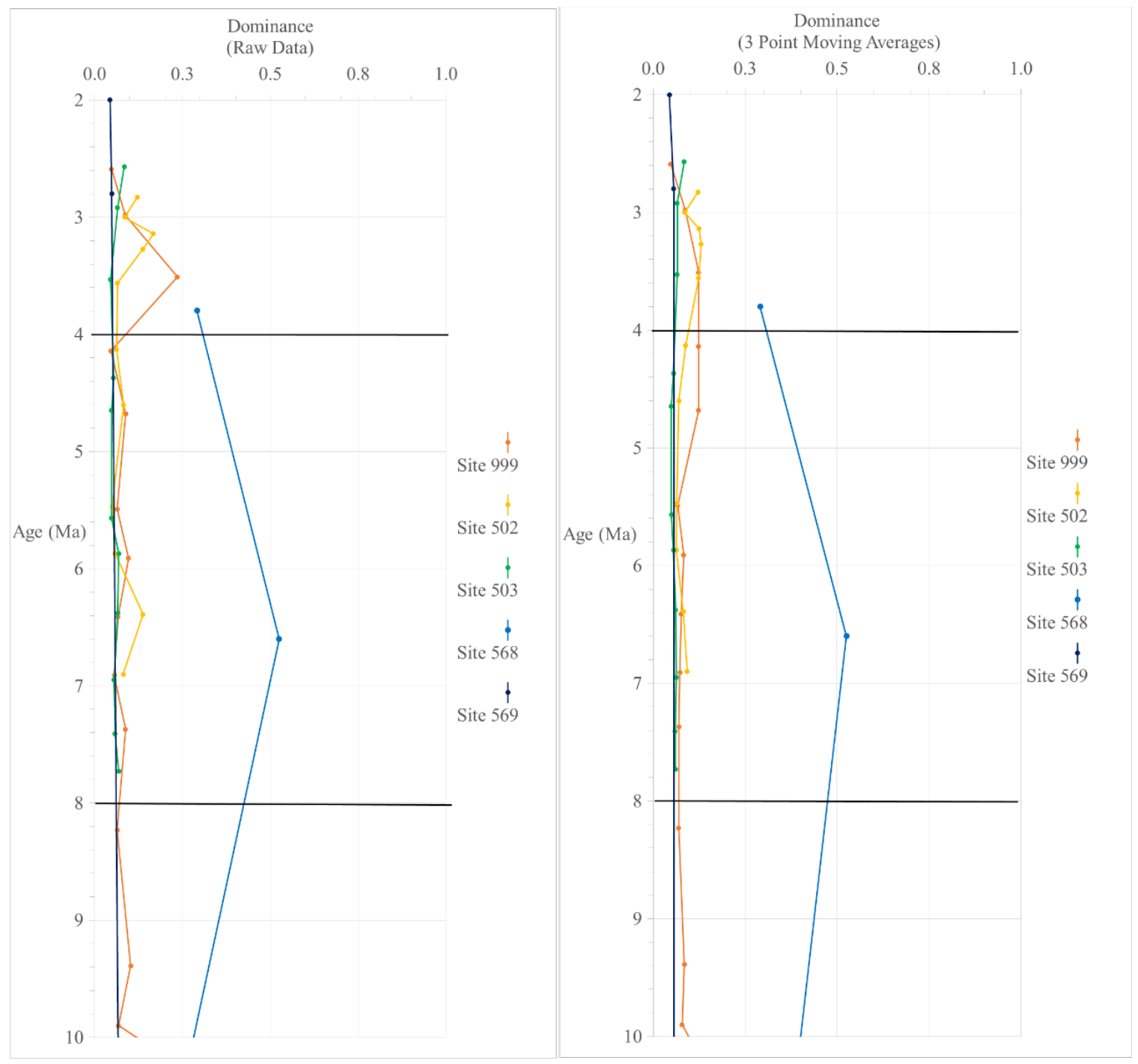

Figure 6b. Dominance for all five sites: Caribbean ODP Site 999 and DSDP Site 502, and Pacific DSDP sites 503, 568 and 569 (younger interval). Previously determined paleoceanographic events noted. Left graph: calculated values. Right graph: 3-point moving averages using original values for 2 youngest points. 


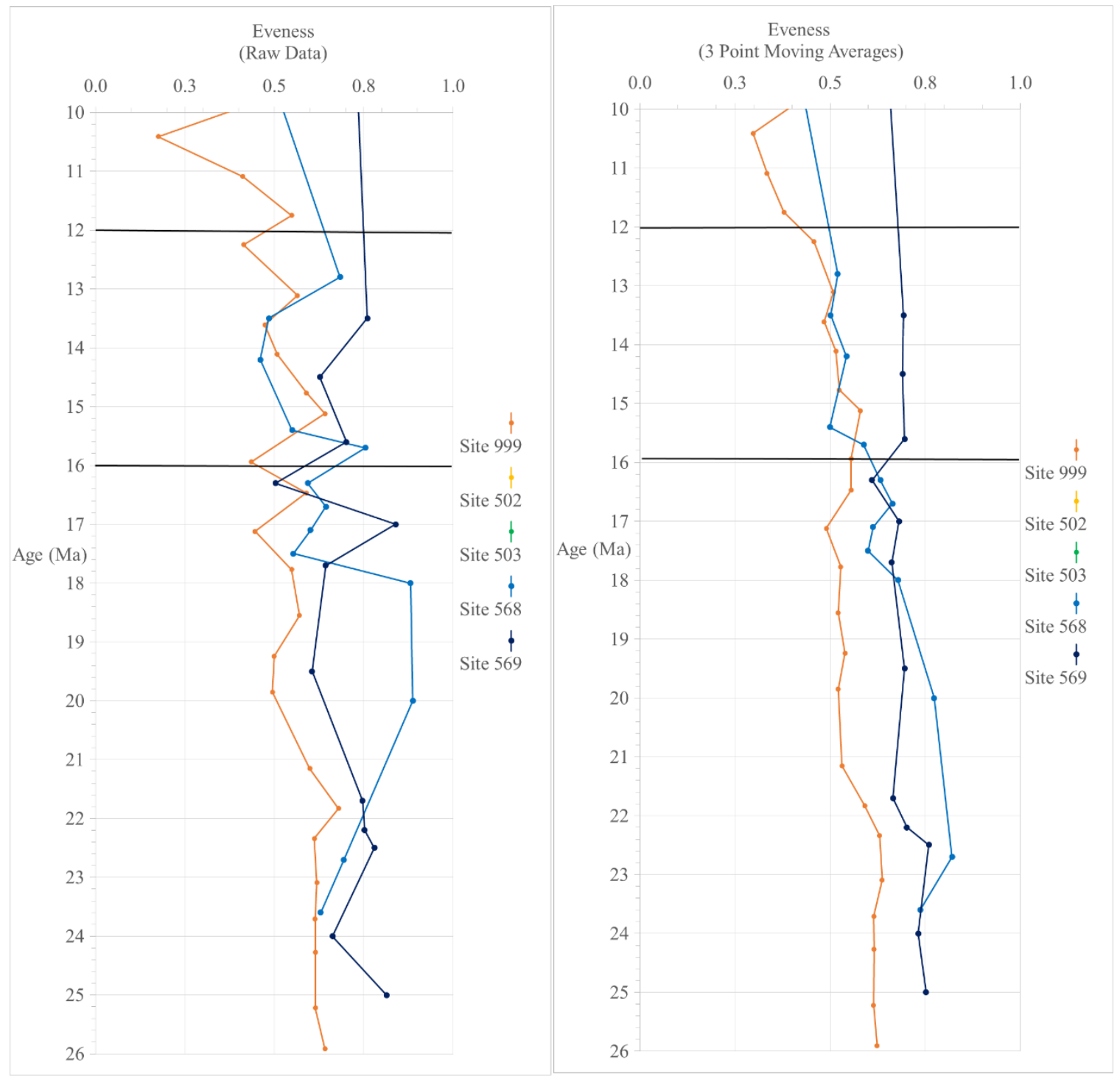

Figure 7a. Evenness (diversity measure) for all five sites: Caribbean ODP Site 999 and DSDP Site 502, and Pacific DSDP sites 503, 568 and 569 (older interval). Previously determined paleoceanographic events noted. Left graph: calculated values. Right graph: 3 -point moving averages. The lines at the tops of the figures are continued in the younger interval. 


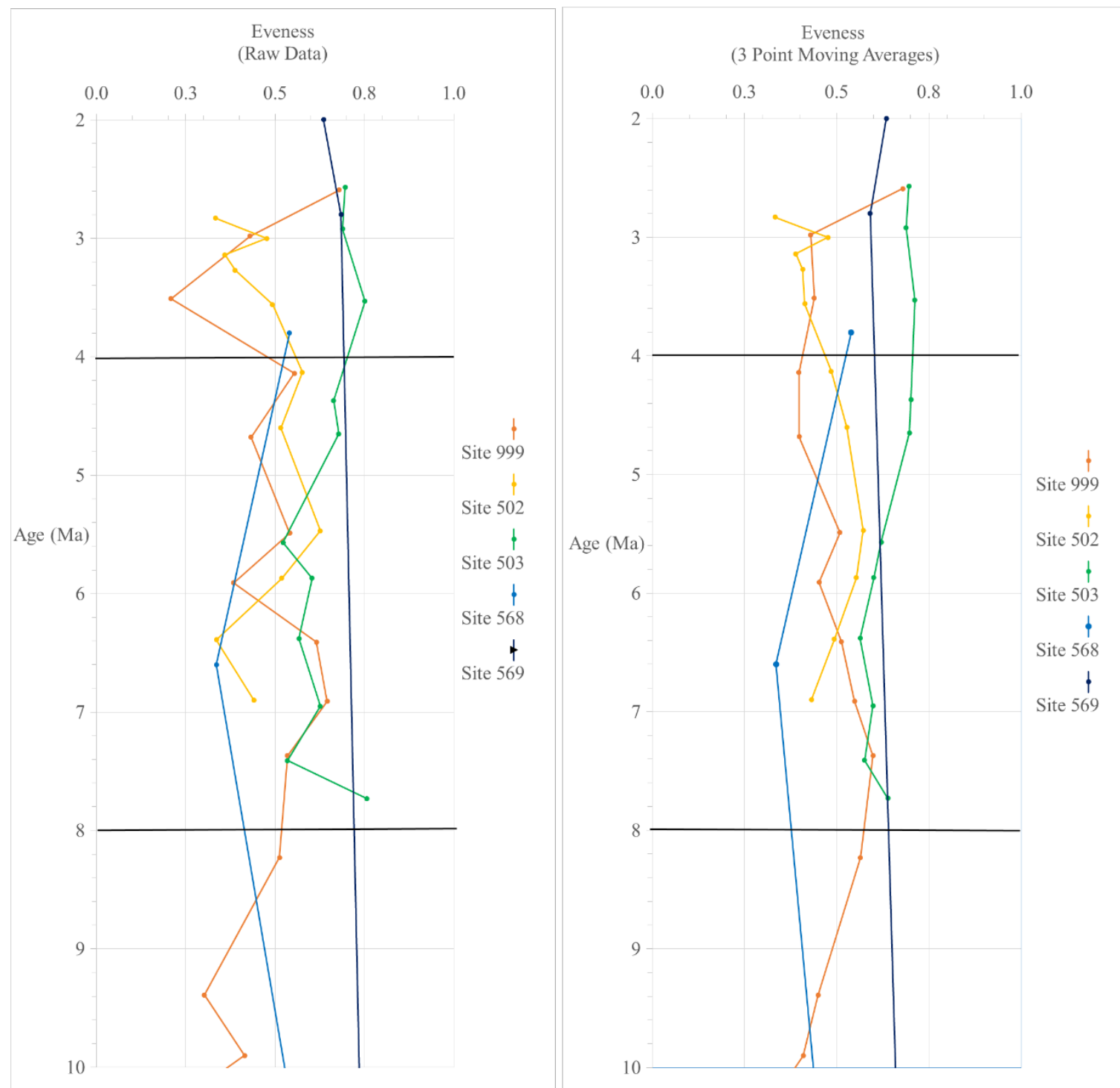

Figure 7b. Evenness (diversity measure) for all five sites: Caribbean ODP Site 999 and DSDP Site 502, and Pacific DSDP sites 503, 568 and 569 (younger interval). Previously determined paleoceanographic events noted. Left graph: calculated values. Right graph: 3 -point moving averages using original values for 2 youngest points. 
Table 1. Differences in magnetic chron ages (Kent and Sapriosu, 1982 a, b; Berggren et al., 1995).

\begin{tabular}{|c|c|c|c|c|c|c}
\hline Chron & $\begin{array}{c}\text { Upper Age Limit } \\
\text { (Ma) from Berggren } \\
\text { et al. (1995) }\end{array}$ & $\begin{array}{c}\text { Upper Age Limit } \\
\text { (Ma) from Kent and } \\
\text { Sapriosu (1982a,b) }\end{array}$ & $\begin{array}{c}\text { Difference in } \\
\text { Upper Age } \\
\text { Limit (Ma) }\end{array}$ & $\begin{array}{c}\text { Lower Age Limit } \\
\text { (Ma) from } \\
\text { Berggren et al. } \\
\text { (1995) }\end{array}$ & $\begin{array}{c}\text { Lower Age Limit } \\
\text { (Ma) from Kent } \\
\text { and Sapriosu (1982 } \\
\text { a,b) }\end{array}$ & $\begin{array}{c}\text { Difference in } \\
\text { Lower Age } \\
\text { Limit (Ma) }\end{array}$ \\
\hline Matuyama & 0.78 & 0.73 & 0.05 & 2.58 & 2.48 & 0.1 \\
\hline Olduvai & 1.77 & 1.66 & 0.11 & 1.95 & 0.07 \\
\hline Gauss & 2.58 & 2.48 & 0.1 & 3.58 & 3.4 & 0.18 \\
\hline Mammoth & 3.22 & 3.18 & 0.04 & 3.33 & 3.4 & -0.07 \\
\hline Cochiti & 4.18 & 3.86 & 0.32 & 4.29 & 3.95 \\
\hline
\end{tabular}

Table 2. Site and foraminiferal data set. Data for Site 999 are from Jain (2006), Jain and Collins (2007), Jain et al. (2007), and this study. Data for sites 502, 503, 568, 569 are from McDougall (1985, 1996, written comm., 2015).

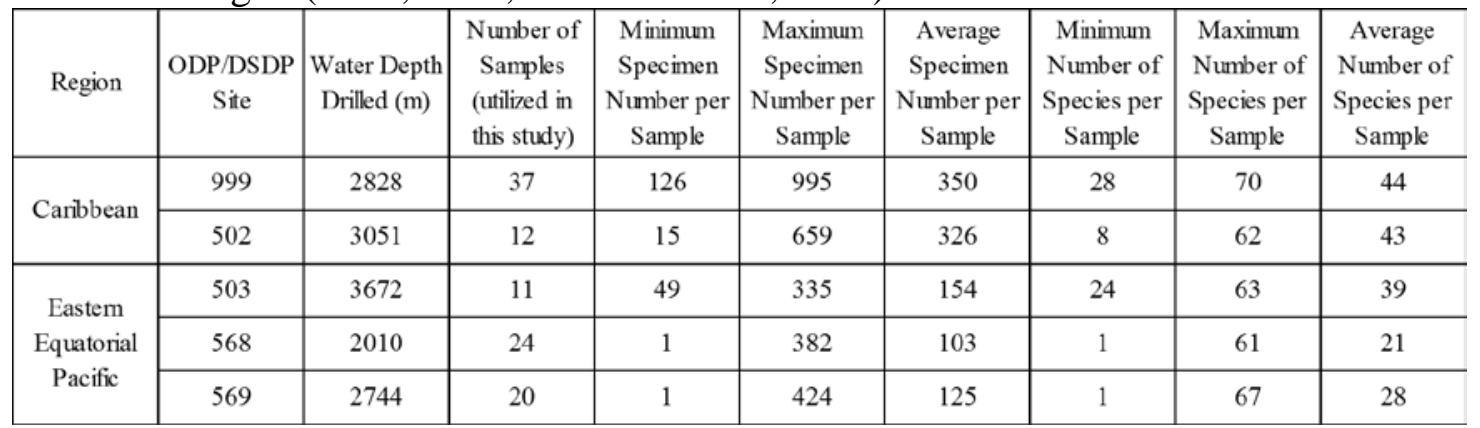


Table 3. Diversity index values for Caribbean ODP Site 999.

\begin{tabular}{|l|r|r|r|r|r|}
\hline 999 Sample ID & 999 Age & Shannon's H & Fisher's Alpha & Dominance & Evenness \\
\hline $999-10$ & 2.59 & 3.33 & 17.61 & 0.05 & 0.68 \\
\hline $999-11$ & 2.98 & 3.13 & 18.22 & 0.09 & 0.43 \\
\hline $999-13$ & 3.51 & 2.68 & 19.85 & 0.24 & 0.21 \\
\hline $999-15$ & 4.14 & 3.42 & 21.01 & 0.05 & 0.55 \\
\hline $999-17$ & 4.68 & 2.99 & 14.94 & 0.09 & 0.43 \\
\hline $999-19$ & 5.49 & 3.08 & 13.57 & 0.06 & 0.54 \\
\hline $999-20$ & 5.91 & 3.07 & 18.85 & 0.10 & 0.38 \\
\hline $999-21$ & 6.41 & 3.07 & 16.05 & 0.07 & 0.62 \\
\hline $999-22$ & 6.91 & 3.17 & 15.27 & 0.06 & 0.65 \\
\hline $999-23$ & 7.37 & 2.81 & 10.27 & 0.09 & 0.53 \\
\hline $999-25$ & 8.23 & 3.30 & 23.55 & 0.06 & 0.51 \\
\hline $999-27$ & 9.39 & 2.79 & 12.25 & 0.10 & 0.30 \\
\hline $999-28$ & 9.9 & 3.03 & 12.46 & 0.07 & 0.41 \\
\hline $999-29$ & 10.41 & 1.87 & 8.84 & 0.33 & 0.18 \\
\hline $999-31$ & 11.09 & 2.67 & 9.36 & 0.11 & 0.41 \\
\hline $999-32$ & 11.75 & 2.86 & 10.73 & 0.09 & 0.55 \\
\hline $999-33$ & 12.25 & 2.99 & 13.55 & 0.09 & 0.41 \\
\hline $999-35$ & 13.11 & 3.12 & 10.93 & 0.06 & 0.56 \\
\hline $999-36$ & 13.61 & 3.12 & 12.80 & 0.07 & 0.47 \\
\hline $999-37$ & 14.11 & 3.24 & 14.87 & 0.06 & 0.51 \\
\hline $999-38$ & 14.77 & 3.21 & 14.31 & 0.06 & 0.59 \\
\hline $999-39$ & 15.12 & 3.27 & 11.73 & 0.05 & 0.64 \\
\hline $999-41$ & 15.94 & 3.16 & 14.92 & 0.06 & 0.44 \\
\hline $999-42$ & 16.47 & 2.80 & 8.79 & 0.08 & 0.59 \\
\hline $999-44$ & 17.12 & 2.93 & 11.92 & 0.08 & 0.45 \\
\hline $999-46$ & 17.77 & 3.16 & 15.74 & 0.06 & 0.55 \\
\hline $999-49$ & 18.55 & 2.94 & 12.70 & 0.08 & 0.57 \\
\hline $999-51$ & 19.24 & 3.02 & 12.61 & 0.07 & 0.50 \\
\hline $999-53$ & 19.85 & 2.85 & 9.66 & 0.08 & 0.49 \\
\hline $999-58$ & 21.15 & 3.10 & 12.68 & 0.06 & 0.60 \\
\hline $999-60$ & 21.83 & 3.17 & 13.00 & 0.05 & 0.68 \\
\hline $999-61$ & 22.34 & 2.97 & 12.42 & 0.07 & 0.61 \\
\hline $999-07 \mathrm{R}$ & 23.09 & 3.35 & 15.68 & 0.05 & 0.62 \\
\hline $999-09 \mathrm{R}$ & 23.71 & 3.27 & 14.55 & 0.05 & 0.61 \\
\hline $999-10 \mathrm{R}$ & 24.27 & 3.23 & 11.92 & 0.05 & 0.61 \\
\hline $999-11 \mathrm{R}$ & 25.22 & 3.36 & 15.50 & 0.05 & 0.61 \\
\hline $999-12 \mathrm{R}$ & 25.91 & 3.43 & 15.87 & 0.04 & 0.64 \\
\hline & & & & & \\
\hline
\end{tabular}


Table 4. Diversity index values for Caribbean DSDP Site 502.

\begin{tabular}{|l|r|r|r|r|r|}
\hline 502 Sample ID & 502 Age & Shannon's H & Fisher's Alpha & Dominance & Evenness \\
\hline $502-18$ & 2.83 & 3.03 & 16.78 & 0.12 & 0.33 \\
\hline $502-20$ & 3.00 & 3.19 & 16.51 & 0.09 & 0.48 \\
\hline $502-21$ & 3.14 & 2.64 & 11.83 & 0.17 & 0.36 \\
\hline $502-22$ & 3.27 & 2.74 & 11.47 & 0.14 & 0.39 \\
\hline $502-24$ & 3.56 & 3.22 & 18.82 & 0.07 & 0.49 \\
\hline $502-28$ & 4.13 & 3.21 & 14.90 & 0.06 & 0.58 \\
\hline $502-33$ & 4.60 & 2.95 & 13.22 & 0.08 & 0.52 \\
\hline $502-43$ & 5.47 & 3.38 & 20.53 & 0.05 & 0.63 \\
\hline $502-48$ & 5.87 & 3.24 & 14.43 & 0.06 & 0.52 \\
\hline $502-55$ & 6.39 & 2.90 & 15.92 & 0.14 & 0.34 \\
\hline $502-63$ & 6.90 & 3.09 & 14.75 & 0.08 & 0.44 \\
\hline $502-68$ & 7.20 & 1.81 & 6.97 & 0.22 & 0.76 \\
\hline
\end{tabular}

Table 5. Diversity index values for Pacific DSDP Site 503.

\begin{tabular}{|l|r|r|r|r|r|}
\hline 503 Sample ID & 503 Age & Shannon's H & Fisher's Alpha & Dominance & Evenness \\
\hline $503-13$ & 2.57 & 2.82 & 18.60 & 0.08 & 0.70 \\
\hline $503-15$ & 2.92 & 2.99 & 14.58 & 0.07 & 0.69 \\
\hline $503-19$ & 3.53 & 3.40 & 35.53 & 0.05 & 0.75 \\
\hline $503-27$ & 4.37 & 3.25 & 18.01 & 0.05 & 0.66 \\
\hline $503-29$ & 4.65 & 3.35 & 21.92 & 0.05 & 0.68 \\
\hline $503-36$ & 5.57 & 3.49 & 22.92 & 0.05 & 0.52 \\
\hline $503-41$ & 5.87 & 3.08 & 14.20 & 0.07 & 0.60 \\
\hline $503-44$ & 6.38 & 3.15 & 16.63 & 0.07 & 0.57 \\
\hline $503-49$ & 6.95 & 3.22 & 18.01 & 0.05 & 0.63 \\
\hline $503-52$ & 7.41 & 3.22 & 17.39 & 0.06 & 0.53 \\
\hline $503-54$ & 7.73 & 2.90 & 14.36 & 0.07 & 0.76 \\
\hline
\end{tabular}


Table 6. Diversity index values for Pacific DSDP Site 568.

\begin{tabular}{|l|r|r|r|r|r|}
\hline 568 Sample ID & 568 Est. Age & Shannon's H & Fisher's Alpha & Dominance & Evenness \\
\hline $568-22 / C C$ & 1.9 & 0.17 & 0.52 & 0.92 & 0.59 \\
\hline $568-23 / C C$ & 3.8 & 1.46 & 2.64 & 0.29 & 0.54 \\
\hline $568-24 / 4$ & 5.2 & 0.00 & 0.80 & 1.00 & 1.00 \\
\hline $568-24 / C C$ & 6.6 & 1.21 & 4.99 & 0.53 & 0.34 \\
\hline $568-25 / 2$ & 8 & 0.00 & 0.80 & 1.00 & 1.00 \\
\hline $568-25 / C C$ & 10.7 & 1.54 & 5.40 & 0.27 & 0.78 \\
\hline $568-27 / 3$ & 12.1 & 2.31 & 18.17 & 0.12 & 0.84 \\
\hline $568-27 / C C$ & 12.8 & 2.80 & 11.62 & 0.08 & 0.68 \\
\hline $568-28 / 5$ & 13.5 & 3.21 & 17.64 & 0.07 & 0.48 \\
\hline $568-33 / C C$ & 14.2 & 3.16 & 18.53 & 0.08 & 0.46 \\
\hline $568-36 / C C$ & 15.4 & 3.33 & 17.97 & 0.05 & 0.55 \\
\hline $568-38 / 3$ & 15.7 & 2.90 & 16.22 & 0.07 & 0.75 \\
\hline $568-39 / 3$ & 16.3 & 3.17 & 13.02 & 0.05 & 0.59 \\
\hline $568-40 / 1$ & 16.7 & 2.78 & 13.58 & 0.09 & 0.64 \\
\hline $568-40 / C C$ & 17.1 & 3.21 & 14.10 & 0.06 & 0.60 \\
\hline $568-41 / 3$ & 17.5 & 3.52 & 20.48 & 0.05 & 0.55 \\
\hline $568-42 / 3$ & 18 & 2.87 & 14.54 & 0.06 & 0.88 \\
\hline $568-42 / C C$ & 19.1 & 1.83 & 5.97 & 0.22 & 0.69 \\
\hline $568-43 / 1$ & 20 & 2.59 & 15.83 & 0.08 & 0.89 \\
\hline $568-43 / 3$ & 20.9 & 1.39 & 0.00 & 0.25 & 1.00 \\
\hline $568-43 / C C$ & 21.8 & 0.00 & 0.00 & 1.00 & 1.00 \\
\hline $568-44 / 1$ & 22.7 & 2.41 & 9.23 & 0.12 & 0.69 \\
\hline $568-44 / 3$ & 23.6 & 1.93 & 4.85 & 0.21 & 0.63 \\
\hline $568-44 / C C$ & 24 & 0.00 & 0.00 & 1.00 & 1.00 \\
\hline
\end{tabular}


Table 7. Diversity index values for Pacific DSDP Site 569.

\begin{tabular}{|l|r|r|r|r|r|}
\hline 569 Sample ID & 569 Est. Age & Shannon's H & Fisher's Alpha & Dominance & Evenness \\
\hline $569-7 / 5$ & 1.8 & 3.10 & 14.56 & 0.07 & 0.45 \\
\hline $569-7 / C C$ & 2 & 3.42 & 19.97 & 0.04 & 0.64 \\
\hline $569-8 / 1$ & 2.8 & 3.38 & 28.01 & 0.05 & 0.68 \\
\hline $569-8 / 3$ & 6.4 & 0.00 & 0.00 & 1.00 & 1.00 \\
\hline $569-9 / 1$ & 10 & 2.24 & 9.33 & 0.12 & 0.85 \\
\hline $569-10 / 1$ & 13.5 & 2.90 & 24.24 & 0.08 & 0.76 \\
\hline $569-10 / C C$ & 14.5 & 3.09 & 15.05 & 0.06 & 0.63 \\
\hline $569-11 / 1$ & 15.6 & 2.90 & 17.77 & 0.08 & 0.70 \\
\hline $569-11 / C C$ & 16.3 & 3.26 & 16.89 & 0.06 & 0.50 \\
\hline $569-12 / 1$ & 17 & 2.72 & 14.33 & 0.08 & 0.84 \\
\hline $569-12 / C C$ & 17.7 & 3.76 & 22.39 & 0.03 & 0.64 \\
\hline $569-14 / 2$ & 19.5 & 3.51 & 20.07 & 0.04 & 0.61 \\
\hline $569-15 / C C$ & 20.7 & 2.16 & 10.81 & 0.16 & 0.72 \\
\hline $569-17 / C C$ & 21.7 & 2.60 & 13.83 & 0.10 & 0.75 \\
\hline $569-20 / 1$ & 22.2 & 2.66 & 15.68 & 0.09 & 0.75 \\
\hline $569-21 / 1$ & 22.5 & 2.46 & 12.50 & 0.12 & 0.78 \\
\hline $569-24 / 3$ & 23.2 & 2.04 & 34.61 & 0.14 & 0.96 \\
\hline $569-26 / 3$ & 23.7 & 1.58 & 3.54 & 0.27 & 0.69 \\
\hline $569-27 / 1$ & 24 & 2.48 & 9.46 & 0.12 & 0.66 \\
\hline $569-27 / 3$ & 25 & 2.36 & 6.03 & 0.11 & 0.81 \\
\hline
\end{tabular}




\section{CHAPTER 4}

\section{NEOGENE PALEOBIOGEOGRAPHY OF CARIBBEAN DEEP-SEA BENTHIC FORAMINIFERA}

Abstract

This study examines benthic foraminiferal assemblage data from the Late Oligocene ( 26 Ma) until the Early Pleistocene ( 2.5 Ma), and tests the hypothesis that with decreasing similarity of water chemistry, food availability and temperature, preisthmus assemblages at equatorial Eastern Pacific (EEP) sites and Caribbean sites had decreasing similarity as closure of the Central American Seaway (CAS) progressed, with the greatest dissimilarity after complete closure at 4 Ma. Published data from the EEP (DSDP sites 503, 568 and 569) are examined in conjunction with new data from ODP Site 999 and previously published Caribbean data (DSDP Site 502).

The gradual closure of the CAS, noted through multiple geologic events, can be seen in a comparison of benthic foraminiferal assemblages from the Caribbean and the Pacific. Similarity was examined with biogeographic similarity coefficients (Jaccard, Dice, and Simpson), which were then plotted using similarity coefficients and non-metric multi-dimensional scaling. Dominant species, abundances and assemblage composition were also examined. The oldest event, the differentiation in bottom water source between the Caribbean and EEP, co-occurred with a change in Caribbean assemblage composition from Antarctic Bottom Water to North Atlantic Deep Water. Contrary to the hypothesis, similarity, for the most part, actually increased between the Caribbean and EEP as the CAS closed, with the exception of a decrease in similarity between $\sim 12 \mathrm{Ma}$ and $\sim 8 \mathrm{Ma}$, when a barrier to deep circulation was established. The increase in similarity could have been caused by coeval evolution in continuous populations. Complete closure at $\sim 4 \mathrm{Ma}$ 
changed Caribbean assemblages to dominance by one species, Nuttalides umbonifera, which corresponds to previously noted decreases in Caribbean paleoproductivity.

\section{Introduction}

When Central America was emplaced between North and South America in the Neogene, it was a major barrier to dispersal amongst marine tropical populations. With similar water chemistry, food availability and temperature, the pre-isthmus tropical Eastern Pacific and Caribbean sites are predicted to have had a greater degree of similarity prior to closure of the Central American Seaway (CAS), with dissimilarity growing as closure progressed. This study tests the hypothesis that during the Miocene to early Pleistocene ( 26-2 Ma), the progressive constriction of the CAS affected deep-sea benthic foraminiferal assemblages by increasing their dissimilarity between the Caribbean and equatorial Eastern Pacific (EEP).

The closure of the Central American Seaway was a long-term process from 16-4 Ma (Duque-Caro, 1990; Coates and Obando, 1996; Collins et al., 1996a; Coates, et al., 2003; Coates, et al., 2004; Kirby, et al., 2008) and had a great impact on paleoceanography. Recent studies (Montes, et al., 2012, 2015), addressed in Chapter 1 suggested that the timing of the closure of the Central American Seaway was far earlier that all other research suggests. The initial uplift of the isthmus $\sim 16$ Ma resulted in changes in open-ocean sedimentation, producing a hiatus in both the Caribbean and the Pacific that is attributed to bottom-water source differentiation around 16-15 Ma, when the North Atlantic Deep Water is shown to be occupying the Caribbean (Morrison and Nowlin, 1982; Keller and Barron, 1983; Duque-Caro, 1990; Haddad and Droxler, 1996). 
A deep circulation barrier between 12.9 and 11.8 Ma was interpreted by Duque-Caro (1990) as partial emergence of the isthmus and closing of the intermediate water connection. This is based on the presence of distinctly deep-sea benthic foraminiferal assemblages that changed from lower bathyal depths to middle bathyal depths.

Studies of Caribbean-EEP divergence in foraminifera by Collins and others (1996a, b) utilized paleontological and geological data from the Miocene Gatun and Chagres formations on the Caribbean side of the Panama Canal Basin. At 8 Ma, there was an effective barrier between surface waters of the equatorial Pacific and the Caribbean, based on the Caribbean affinity of shallow-water benthic foraminiferal assemblages of the Gatun Formation (Collins et al., 1996a); changes in deep-water Nd/Pb ratios supported the restriction of water-mass exchange between the Pacific and Atlantic (Frank et al., 1999). Subsequent deepening of the Panama isthmian strait to $\geq 200 \mathrm{~m}$ at 6 Ma allowed interchange between surface waters of the tropical Eastern Pacific and the Caribbean, which resulted locally in a Pacific affinity of benthic foraminifera within the overlying Chagres Formation (Collins et al., 1996a). Also at $\sim 6 \mathrm{Ma}$, a gradient in $\delta^{13} \mathrm{C}$ in tropical and subtropical Atlantic waters indicated the formation of bottom waters from different source regions (Billups, 2002). Collins et al. (1996b) found increasing originations of Caribbean benthic foraminifera from $\sim 6$ to 3.5 Ma that they related to an increase in carbonate-rich sediments due to lessening Pacific water interchange caused by the constriction and closure of the seaway, which reduced productivity and nutrients through decreased coastal upwelling.

Timing of the rise of the isthmus is documented in the Bocas del Toro Basin of Panama by changes in water depths interpreted for the formations (Coates et al., 2003, 
2005). Complete closure of the CAS, in terms of Atlantic and Pacific differentiation and full restriction of water exchange, occurred at 4 Ma (Keigwin 1978, 1982a, 1982b; Haug and Tiedemann, 1998; Haug et al., 2001).

This reconstruction of deep-sea Miocene paleobiogeography of the isthmian region focuses on the changing similarity of deep-water assemblages between the equatorial Pacific and Caribbean. Statistical analyses of similarity indices and environmental or microhabitat preferences of representative taxa from the benthic foraminiferal assemblages are used to evaluate the effects of known paleoceanographic events. Previous studies provide data on the environmental preferences of species, such as bottom water ventilation, productivity, carbon flux, bottom water corrosiveness (Corliss, 1985; Gooday, 1994; Mackensen et al., 1995; Bornmalm, 1997; Smart and Gooday, 1997) and bathymetry (van Morkhoven, et al., 1986; McDougall, 1996; Hayward et al., 2002; Hobourn et al., 2013).

The ultimate goal of this work is to show the effects of major geologic and oceanic changes on deep-sea benthic foraminiferal assemblages, as related to the closure of the CAS. In particular, a paleobiogeographical reconstruction of deep-sea Caribbean benthic foraminifera for any time interval has not been previously investigated.

\section{Methods}

\subsection{Site Locations}

This study utilizes data from sites (Fig. 1) obtained through the Ocean Drilling Project (ODP) and Deep Sea Drilling Project (DSDP). The current study incorporates new benthic foraminiferal data from Caribbean Site 999 with previously studied data from equatorial Eastern Pacific (EEP) sites 503, 568 and 569, and Caribbean sites 502 
and 999 (younger portion). Sites 568 and 569 were chosen from DSDP Leg 85 for their extensive age range and their fewer number and extent of hiatuses than at sites 566, 567 and 570. All comparison sites (Caribbean Site 502 and EEP sites 503, 568 and 569) were also chosen for their availability of complete benthic foraminiferal datasets, and the publication of high-quality foraminiferal images to achieve taxonomic standardization (Thomas, 1985; Woodruff, 1985; McDougall, 1984, 1985, 1996, written comm., 2015). Sampling interval (Fig. 2) and sample size (Table 1) did vary at the EEP sites, so where possible, percentages of individual species counts and general trends of increases and decreases are used, as opposed to direct comparison of absolute or proportional abundances.

\subsection{Sample Preparation and Taxonomy}

Samples were chosen from ODP Caribbean Site 999 (Figs. 2 and 3) at an approximate 0.5-million-year interval. Due to differences in preservation and benthic foraminiferal abundance, this interval was adjusted at times to provide a more robust data set. Benthic foraminiferal analysis of whole assemblages was conducted on 37 samples, 11 of which from the youngest interval were previously examined for benthic foraminifera by Jain and Collins (2007) and Jain et al. (2007). For purposes of taxonomic standardization with older samples and previously studied datasets, the author confirmed identifications of all species on faunal slides provided by Jain. All of Jain’s samples (ODP Site 999, sections 10H-03 through 25X-03), were previously treated with 1\% hydrogen peroxide, soaked, and washed through a $63 \mu \mathrm{m}$ sieve, then dried in an oven; benthic foraminifera were then picked from a $10 \mathrm{~cm}^{3}$ sample and mounted on faunal 
slides. The 26 sediment samples newly investigated for this study were soaked in deionized water for several days to disaggregate clays, and then washed over a $63 \mu \mathrm{m}$ sieve. However, differing from Jain’s original study, samples were split using a standard sample splitter to achieve a statistically robust number of specimens. Each sample was split to ideally achieve 200 or more specimens, a representative sample set. At a sample size range of 200-400, a confidence level of $+/-93-95 \%$ is achieved, which means that there is a 93-95\% confidence that there will be less than $+/-0.07$ error per sample when compared to the original sediments (Hayek and Buzas 1997). In cases where the assemblage did not recover greater than 200 specimens, the entire sample was counted. Individual specimens were sorted by species and identified using literature and comparative collections at the U.S. National Museum and in the collections of L. Collins. Correctly identifying benthic foraminifera is a difficult process due to morphologic variation within species, synonyms, and rare species, so species were identified using only comparative collections and literature with excellent plates and figures. All specimens were identified to the species level where possible. When the species level could not be achieved due to poor preservation or quality of identifying features, specimens were assigned to the generic level and listed as "spp.” (Appendix 1). To standardize taxonomy throughout the current study of ODP Site 999, once a specimen was identified, that specimen's sample, slide location and reference citation were listed in the author's collection to allow for later comparison. Subsequent specimens were then compared to those initially identified to confirm similarity. After data of McDougall (written comm., 2015) for DSDP sites 502, 503, 568, and 569 were incorporated into the study set, all species names were checked for synonymies and correct, updated generic 
assignation. Several species in the additional data sets were found to be in synonymy, and in those instances, all species were researched to determine correct names. All species counts were entered into Excel spreadsheets where percentages of entire assemblages were calculated to standardize counts relative to abundances.

Overall, the assemblages showed a large amount of variation, some of which was due to the lack of uniform sampling, with several EEP samples having less than 200 specimens (N) per sample. Whereas EEP sites 568 and 569 provide substantial data for comparison, especially for the older studied interval ( 26 - $8 \mathrm{Ma})$, that are not present at sites 502 and 503, some data-points cannot be directly compared to either Caribbean site or EEP Site 503 because some samples contain very low abundances which directly affect assemblage data: Site 568 has 9 studied samples with $<25$ individuals, Site 569 has 5 studied samples with $<25$ individuals, and Site 502 has 1 sample with $<25$ individuals. Although an $\mathrm{N}=25$ still does not approximate the robust specimen counts in Caribbean Site 999, it allows for some comparison among the older EEP sites. In this study, samples were selected to provide robust specimen counts ( $\mathrm{N} \geq 200)$ where possible, so Site 999 possesses the higher average number of specimens, as well as a much higher minimum specimen number (153), compared to a minimum of 1 or 15 at all other sites (Table 1). Thus, when examining the dominant species in assemblages, only those samples with $\mathrm{N}>200$ are listed.

\subsection{Age Determinations}

A potential problem with age determination arose when comparing datasets from different sites. Ages for Caribbean Site 999 (this study) were taken from published tables 
from Proceedings of the Ocean Drilling Program, Volume 165 (Sigurdsson et al., 1997). This study used calcareous nannofossil and planktic foraminiferal biostratigraphy (Berggren et al, 1995; Curry, Shackleton, Richter, et al., 1995) to achieve preliminary age designations which were then calibrated to Cande and Kent's (1995) were not associated with any published absolute age data, but utilized planktic foraminiferal zonations (Berggren et al, 1995) and calcareous nannofossil zonations (Bukry, 1973, 1975; Okada and Bukry, 1980). Since the ages provided for Site 999 were determined from a calibrated time scale that utilized these biozonations, absolute age datums were established herein by identifying the limits of each identified zonation and interpolating ages between points, so that data could be directly compared to those of this study. This technique assumed a steady rate of sedimentation within a biozone.

Caribbean Site 502 and EEP Site 503 had associated absolute age data (McDougall, 1996). These ages were calculated from planktic foraminiferal zonations and magnetostratigraphy using the time scales of Kent and Spariosu (1982 a, b), Zenker (1986), Zenker et al. (1987), Keller et al. (1989). Since these datums were not established using the same schemes, limits on identified magnetochrons were compared to those used in the current study (Berggren et al., 1995) to observe possible differences (Table 2). The ages calculated for Site 999 used several magnetic polarity time scales, including that of Berggren et al. (1995) and found that all five were compatible with only a 32-34 kyr discrepancy surrounding the complete closure of the CAS at $~ 4$ Ma. Since Caribbean Site 999 uses a different time scale than that of Caribbean Site 502 and EEP Site 503, data points at exact age datums could not be directly compared. The scope of this study 
did not allow for the transfer of multiple datasets into one coherent, up -to-date time scale, but differences are too small to have affected general patterns of change.

\subsection{Data Analysis and Interpretation}

Raw species counts for all sites were placed into an Excel spreadsheet for examination. Percentages of each species were calculated within Excel in order to standardize the data. The percentages allowed for trends to be seen when raw counts showed variability due to wide ranges of the number of specimens in a sample $(\mathrm{N})$. For the remaining statistical analyses, all data were square-root transformed, which has been shown to more closely approximate a normal distribution (Ahren et al., 1990). For examinations of whole benthic foraminiferal assemblages, relative abundances were calculated for each sample with those comprising $\sim 20 \%$ or greater of the assemblage being noted.

The Jaccard, Dice, and Simpson similarity coefficients are biogeographic similarity indices that are in common use. Jaccard and Dice similarity coefficients are very similar and are calculated using presence/absence in both assemblages. The Dice coefficient weighs more heavily on joint occurrences than on mismatches (Hammer, 2015). The Simpson coefficient is also calculated using the number of matches, but instead of using the total number of species with presence in just one assemblage, it only uses the smaller of the number of presences in the two assemblages (Hammer, 2015). The Simpson coefficient is often most commonly used in paleontological studies because it minimizes the effect of diversity discrepancies (and thus, differences due to inequal preservation) by only using the number of species in the assemblage with the lower 
number of taxa (Smith et al., 2013). Dice's similarity coefficient is calculated as $2 \mathrm{C} /\left(\mathrm{N}_{1}+\right.$ $\mathrm{N}_{2}$ ) with $\mathrm{C}$ = the number of taxa common to both samples, $\mathrm{N}_{1}$ = the number of taxa in the sample with the smaller number of species, and $\mathrm{N}_{2}=$ the number of species in the sample with the larger number of species (Dice, 1945). Simpson's index is calculated as $\mathrm{C} / \mathrm{N}_{1}$ (Simpson, 1943). Jaccard's (1912) coefficient $=\mathrm{C} /\left(\mathrm{N}_{1}+\mathrm{N}_{2}-\mathrm{C}\right)$. Calculations of similarity, as well as non-metric multidimensional scaling (MDS), used all samples with $\mathrm{N} \geq 25$ so that there was some incorporation of EEP data.

All indices and MDS were calculated with the Paleontological Statistics software v. 3.07 PAST (Hammer, 2015). Plots with MDS display the data for all sites in a two-dimensional coordinate system to show the ranked differences between sites. Nonmetric MDS utilizes a chosen biogeographic similarity coefficient to calculate the distance matrix (Hammer, 2015). In this study, since all similarity coefficents used had similar results and trends, only one index, Simpson's coefficient, was plotted. The coordinates provided by PAST were then placed into Excel for graphic display.

Analysis of variance (ANOVA) was also conducted using the software statistical package SPSS to determine if there was statistical significance in changes in similarity (Simpson's coefficient) between intervals. If ANOVA proved to be significant ( $\mathrm{p} \leq 0.05$ ), then the Bonferroni post hoc test, which tests the significance among the intervals, was performed.

\section{Results}

This study of ODP Site 999 produced 12,522 identified foraminiferal specimens, including 237 species in 71 genera. The counts, coupled with previously published counts 
for EEP DSDP sites 503, 568 and 569 (McDougall 1985, 1986, written comm., 2015), and Caribbean DSDP Site 502 (McDougall 1985, 1986, written comm., 2015) were all used to characterize the assemblages. Appendices $1-5$ list all counts of each site.

The data are divided into sections (as in Chapters 2-3) according to the previously established times of known geologic or paleoceanographic change to allow for a paleobiogeographic reconstruction from 26-2 Ma (For explanations of these events, see Chapter 1). These divisions are as follows, in chronological order:

16 Ma - differentiation of bottom-water source between Caribbean and EEP (Keller and Barron, 1983; Duque-Caro, 1990) 12 Ma - deep circulation barrier between Caribbean and EEP (Duque-Caro, 1990)

$\sim 8 M a-$ constriction of the CAS (Collins et al., 1996a; Frank et al., 1999) 4 Ma - complete closure of the CAS (Keigwin 1978, 1982a, 1982b; Haug and Tiedemann, 1998; Haug et al., 2001)

A total of 457 pairwise (Caribbean to EEP) comparisons were calculated for Dice, Jaccard, and Simpson similarity coefficients by placing all sample counts for both regions into PAST, subdivided into the previously determined intervals. The calculated values for each interval were then averaged for each similarity coefficient and graphically displayed (Fig. 4, Table 3). Since the interval averages consisted of a single data point for each interval, average Dice, Jaccard, and Simpson similarity coefficients were then calculated for each Caribbean sample using all EEP sites in that particular interval (Fig. 5, Table 4) to show the fluctuations in similarity throughout each time interval. With the exception of the 12-8 Ma interval, only sites with $\mathrm{N}>25$ specimens were used in calculations of 
averages. In the 12-8 Ma interval, there were only three EEP sites, two of which had $\mathrm{N}$ $<25$ specimens. Since so few samples were available, one EEP (569-9/1) sample with N $=21$ was used in calculating an average.

The ANOVA results of similarity measured between time intervals provided a significant $\mathrm{p}$ value $(\mathrm{p}<0.0001)$, which allowed the Bonferroni post hoc test to determine the significance of differences between time intervals (Table 5). These results showed that the mean differences in similarity were significant at the .05 level between most of the intervals. Overall, the intervals showed significant differences between the neighboring intervals with the exceptions of the oldest and youngest intervals. The interval prior to bottom water change ( $>\sim 16 \mathrm{Ma}$ ) showed a statistically significant difference with the interval from bottom water change to the deep circulation barrier ( 16- $12 \mathrm{Ma}$ ), as well as the younger intervals of constriction to closure of the seaway ( 8-4 Ma) and post closure ( 4- $2 \mathrm{Ma}$ ). The youngest interval (post closure $\sim 4-2 \mathrm{Ma}$ ), showed differences with both the oldest interval (prior to bottom-water change) and the interval from the barrier to deep circulation and the constriction of the seaway ( 12- 8 Ma).

$3.1 \sim 26$ - 16 Ma and Older (Differentiation of Bottom-Water Source Between Caribbean and EEP)

Of the 36 samples that comprise the interval older than $16 \mathrm{Ma}$, only 15 samples have $\mathrm{N}>200$ specimens, with only 4 of those in the EEP. Therefore, in calculations of similarity coefficients, EEP samples with $\mathrm{N}>25$ were used to provide some comparison. The majority of the Caribbean samples (Site 999) were dominated ( 20\% of assemblage or more) by Globocassidulina subglobosa, Cibicidoides mundulus, Melonis barleeanum 
and Oridorsalis umbonatus. The Pacific sites (568 and 569) were dominated by Siphonodosaria spp., Uvigerina spp., Dentalina spp. and Cassidulina spp. (Table 6). The average similarity index (Table 4, Fig. 5) in the interval prior to 16 Ma included several increases and decreases, but had no overall trend. The non-metric MDS (Fig. 6) showed the EEP assemblages to be more variable than those of the Caribbean, and were distinctly differentiated to the left of the Caribbean assemblages. The Caribbean samples (999) are more tightly clustered than those of the Pacific (sites 568 and 569).

\subsection{6 - 12 Ma (Deep Circulation Barrier Between Caribbean and EEP)}

The Caribbean sites were dominated in this interval by Eponides turgidus, Cassidulina subglobosa, Cibicidoides spp., Melonis barleeanum and Oridorsalis umbonatus. The Pacific sites were dominated by Nodosaria longiscata and Planulina renzi (Table 7). This interval showed an increase in mean similarity (Fig. 4) that is seen in the detailed Caribbean data with a large increase $15 \mathrm{Ma}$ (Fig. 5). After the initial increase, the similarity dropped slightly but maintained higher levels than in the previous interval. The MDS for this interval shows a similar spread in values across the axes, as for the previous interval (Fig. 7). The Caribbean sites still plot to the left of the Pacific sites except for one point.

\section{$3.3 \sim 12-8$ Ma - (Constriction of Seaway Between Caribbean and EEP)}

The Caribbean samples are dominated by Epistominella exigua, Cassidulina subglobosa, Eponides turgidus and Cibicidoides mundulus (Table 8). This interval does not contain any Pacific samples with an N > 200, so due to small N, no dominant species are identified. This interval showed a marked decrease in the similarity indices. The MDS 
plot (Fig. 8) shows an enormous range in the two EEP sites, with one near the fairly wide ranging Caribbean sites.

$3.4 \sim 8$ - 4 Ma (Constriction to Complete Closure of the CAS)

Caribbean samples are dominated by Globocassidulina subglobosa, Oridorsalis umbonatus, Nuttalides umbonifera, Epistominella exigua and Cibicidoides spp. Pacific samples are dominated by Globocassidulina subglobosa, Pullenia bulloides, Laticarinina pauperata, Epistominella exigua, and Gyroidina lamarckiana (Table 9). Similarity coefficients recovered from the low values of the previous interval to the highest average levels of the study (Fig. 4). Sampling frequency was higher in this interval (Fig. 5) and included two Caribbean and three EEP sites. The MDS in this interval (Fig. 9) shows a tightly clustered group of mixed Caribbean and EEP sites, with a few outliers.

\section{$3.5 \sim 4$ - 2 Ma (Post-CAS Closure)}

In this youngest study interval, Caribbean samples are dominated overwhelmingly by Nuttalides umbonifera. One site is also partially dominated by Epistominella exigua. The two Pacific sites with $\mathrm{N} \geq 200$ are dominated by Gyroidina lamarckiana, Nodosaria parexilis, Bulimina alazanensis, Nodosaria longiscata, and Uvigerina hispida (Table 10). The similarity coefficients (Fig. 5) show a slight decrease immediately after the CAS closure at $\sim 4 \mathrm{Ma}$, then rebound to high levels, most noticeably Simpsons, followed by a very sharp decrease $\sim 3$ Ma. The similarity coefficients then rebound to higher levels, again with the Simpson coefficient showing the most extreme change. The NMDS plot (Fig. 10) shows the majority of the Caribbean samples clustered 
together on the negative end of Axis 2 and the majority of the EEP sites clustering on the positive end of Axis 2.

\section{Discussion}

It is important to note that preferences of various genera, including predominance facies and biofacies (Poag, 2015), to define paleoenvironments has proven to be useful, partially due to the number of extant genera in the Cenozoic. The habitat and depth preferences, along with general oceanographic limits are used in the following section to define factors during the study interval. Deep-water foraminiferal species often have much wider geographic ranges than coastal and sublittoral species because of the more homogeneous conditions in the deep sea, but still have an extensive amount of morphological variation (Gooday and Jorissen, 2012).

\subsection{6 - 16 Ma (Differentiation of Bottom-water Source Between Caribbean and EEP)}

The Caribbean and EEP sites showed fairly low levels of similarity with some variation throughout the interval and were dominated by similar bathyal species. With Pacific sites being dominated by Uvigerina spp. and Cassidulina spp. (Table 6), the paleoceanographic conditions were normal marine (salinity), cold water and likely bathyal (Murray, 1973), as they are today. According to McDougall (1996), Uvigerina spp. is indicative of upper North Atlantic Deep Water (NADW). These conditions can also apply to the Caribbean samples with their dominance by Globocassidulina subglobosa, Cibicidoides mundulus, Melonis barleeanum and Oridorsalis umbonatus. These genera indicate similar conditions to those of the Pacific sites previously mentioned (Murray, 1973). This interval predates the differentiation of bottom water 
source at 16 Ma (Keller and Barron, 1983; Duque-Caro, 1990). Based on water mass characteristics (McDougall, 1996), the Caribbean was likely occupied by NADW due to the dominance of G. subglobosa and O. umbonatus. Studies of Caribbean water masses have supported the presence of NADW via entrance into the Colombian Basin between Jamaica and Hispaniola (Morrison and Nowlin, 1982; Haddad and Droxler, 1996). The noted decrease in similarity between the Caribbean and EEP (Fig. 5) at 17 Ma could have resulted from the change in bottom water source at 16 Ma (Keller and Barron, 1983; Duque-Caro, 1990). The Caribbean samples in this interval are more tightly clustered on the MDS plot while the EEP samples show less similarity. The cluster of Caribbean samples could be due to a localized food source or substratum that encouraged similar species growth (Gooday and Jorissen, 2012), or simply closer proximity of the site locations while the EEP sites had more variable environmental conditions among the more widespread drilling sites.

\subsection{6 - 12 Ma (Deep Circulation Barrier Between Caribbean and EEP)}

The intensity of bottom water flow corresponds to the presence of hiatuses (Keller and Barron, 1983; Duque-Caro, 1990). The isthmian barrier at 16 Ma was marked by a large hiatus, attributed to a change in bottom water flow (Keller and Barron, 1983). The benthic foraminiferal faunal turnover noted at 14 Ma (Woodruff, 1985), attributed to changes in deep and bottom water masses, corresponds to an increase in similarity between the Caribbean and EEP. This is seen in the current study by a surprising increase in similarity between the Caribbean and EEP with a much steadier level of similarity throughout the interval than the previous interval. After $16 \mathrm{Ma}$, there is a peak in 
similarity that is seen in the MDS plot (Fig. 7) with both Caribbean and EEP samples having greater variability, but still segregated. In a study testing the decrease of similarity due to distance in spruces, Nekola and White (1999) found that while similarity did decrease with distance, certain species or variants had greater similarity decay than others and there was no decrease in distance with rare species. They also found that common species underwent less decay in similarity than those with intermediate frequency (Nekola and White, 1999). The increase in similarity in this interval could be due to an increase in common or rare species that began flourishing after the change in bottomwater source. This interval does contain an increase in the number of sites that have species abundances of $<1 \%$ (rare species). Since foraminiferal propagules have been shown to survive difficult conditions, they have the ability to recolonize quickly (Kuhnt et al., 2005; Alve and Goldstein, 2010), and have wide bathymetric ranges (e.g. Murray, 1973; Gooday and Jorissen, 2012; Poag, 2015), so this change of bottom-water source likely did not have a large impact on the similarity of benthic foraminiferal communities in the Caribbean and EEP.

The EEP sites showed dominance by Planulina renzi and Nodosaria longiscata (Table 6). The Caribbean maintained dominance by Cassidulina subglobosa and Oridorsalis umbonatus, but also showed an increase in the abundances of Eponides turgidus, Cibicidoides spp. and Melonis barleeanum. With this variety of species, it is likely that the bottom water source changed at this point from Antarctic Bottom Water (AABW) in the previous interval to NADW in this interval (McDougall, 1996). 


\subsection{2 - 8 Ma (Constriction of Seaway Between Caribbean and EEP)}

The deep circulation barrier at 12 Ma noted by Duque-Caro (1990) is based on a change in the paleobathymetry determined by Pacific deep-sea benthic foraminiferal assemblages. In this study, the Caribbean species with higher relative abundances indicate a paleodepth range of bathyal to abyssal based on the ecologies (McDougall, 1996; Hobourn et al., 2013; Poag, 2015) of Epistominella exigua, Cassidulina subglobosa, Eponides turgidus, and Cibicidoides mundulus (Table 7). These dominant species do not necessarily indicate a change in the paleobathymetry of the Caribbean samples as these species vary from bathyal to abyssal (Murray, 1973; van Morkhoven, 1986; Holbourn et al., 2013). However, their presence does indicate that the water mass occupying the basin is still NADW (McDougall, 1996). This interval only contained three Pacific samples, which had abundances of 32 specimens or fewer, and these low numbers make it difficult to identify paleoceanographic conditions and it makes Caribbean-EEP comparisons less reliable. Thus, the marked decrease in similarity coefficients in this interval (Figs. 4, 5; Tables 3, 4) may only partially be attributable to the constriction of the seaway. In terms of averaging, this interval only had one sample with $\mathrm{N}>25$ specimens, so comparison with other intervals with multiple samples is unreliable. To aid in "standardizing" the numbers, a sample with $\mathrm{N}=21$ was incorporated. However, the decrease in similarity is so great, that it is possible that the constriction of the seaway did separate the populations and increase the dissimilarity between them. On the MDS plot (Fig. 8), the samples are fairly widespread with no major grouping. The barrier to deep circulation may therefore have been more effective in decreasing similarity between the Caribbean and EEP than the previous change in source of bottom water. This barrier 
could have caused a cessation or decrease in food supply to one of the areas which would change the assemblage to one with more tolerant taxa. Oxygenation, food inputs, organic carbon content and carbonate saturation have been shown to be the most influential parameters that affect deep-sea assemblage composition (Mackensen et al., 1995;

Schmiedl et al., 1997; Jorissen et al., 2007; Gooday and Jorissen, 2012). One sample is dominated by greater than 50\% of Epistominella exigua (Chapters 2 and 3) which indicates a large flux of organic matter to the seafloor (Gooday, 1988, 1996; Smart et al., 1994), so this could have caused an increase in differences with the other Caribbean sites.

\subsection{8 - 4 Ma (Complete Closure of the CAS)}

The event at $~ 8$ Ma created an effective barrier between the EEP and Caribbean surface waters based on shallow-water benthic foraminiferal assemblages (Collins et al., 1996a) and changes in $\mathrm{Nd} / \mathrm{Pb}$ ratios that support a restriction in the exchange of watermasses (Frank et al., 1999). The change in the Caribbean assemblages is seen with an increase in the abundance of Nuttalides umbonifera. This species has been known to be associated with carbonate-corrosive bottom water (Mackensen et al., 1990). The other dominant species are similar to previous intervals that also have high abundances of $G$. subglobosa, O. umbonatus and E. exigua. The Pacific samples are dominated by different species, including Pullenia bulloides, Cibicidoides wuellerstorfi and Laticarinina pauperata, in addition to other common species such as G. subglobosa and E. exigua.

The similarity coefficients showed a rapid recovery from the low values seen in the previous interval, and in fact, contain the highest value for similarity within the study area. This interval allows for greater comparisons due to the availability of abundant 
specimens at EEP Site 503 and Caribbean Site 502. There are rapid fluctuations within the similarity coefficient in this interval that could be the result of occasional exchange of surface water from reopening of isthmian straits that has been noted at $\sim 6 \mathrm{Ma}$ (Collins et al., 1996a). The MDS plot for this interval actually shows a fairly tight cluster of samples on Axis 1 with only a few outliers. This increase in similarity and decrease in distance on the MDS could imply populations concurrently evolving or a continuous population surrounding South America. This increase in similarity could also show a similar response by the benthic foraminiferal assemblages to the noted global event (carbon isotope shift) at 7.5 - 6.5 Ma (Shackleton and Kennett, 1975; Bickert et al., 2004). Although there was a constriction of the seaway and a barrier to flow between the Caribbean and EEP, the foramiferal assemblages obviously shared similar characteristics, again possibly due to an increase in rare species or tolerant taxa that thrived in the changing environment in both regions (Nekola and White, 1999; Kuhnt et al., 2005; Gooday and Jorissen, 2012).

\section{$4.5 \sim 4$ - 2 Ma (Post-CAS Closure)}

This interval contains those assemblages that occurred after the complete closure of the CAS at $\sim 4 \mathrm{Ma}$, which resulted from a complete barrier to direct flow between Caribbean and EEP waters(Keigwin 1978, 1982a, 1982b; Haug and Tiedemann, 1998; Haug et al., 2001). There is a marked change in species dominance in the Caribbean samples to Nuttalides umbonifera (Table 9). The Pacific samples have varying composition with no clear dominance by any one species. The Caribbean sites have a

noted increase in oligotrophy as seen in the previous study of paleoproductivity (Chapter 
2) by the indicator taxon $N$. umbonifera. All samples in this interval are fairly widespread (Fig. 10). The similarity coefficients show a slight decrease in similarity at $\sim 4$ Ma (Figs. 4, 5; Tables 3, 4), followed by a marked increase, then sharp decrease at 3 Ma that rebounds to higher similarity levels. This further increase in similarity, with separation of the regions in terms of distance plotting using MDS, could again be due to an increase in tolerant taxa that thrived in changing conditions.

\section{Conclusions}

The progressive closure of the CAS, noted through multiple geologic events, can be seen in a comparison of benthic foraminiferal assemblages from both the Caribbean and the Pacific, although not as predicted in the original hypothesis that stated that dissimilarity between the Caribbean and EEP would increase with progressive constriction of the CAS. A sharp increase in similarity at the first paleoceanographic event at $~ 16$ Ma could be attributed to the increase of rare species noted. The decrease in similarity at $12 \mathrm{Ma}$ indicates that the barrier to deep circulation had the greatest impact on the benthic foraminiferal communities in the EEP and Caribbean, likely by alteration of organic flux, carbonate content and food availability (Thomas and Vincent, 1987; Herguera, 1992; Gooday and Rathburn, 1999; Licari, et al., 2003; Jain and Collins, 2007). However, the studied EEP samples are less reliable in the $12-8$ Ma interval due to low numbers of specimens. Subsequent events at $\sim 8 \mathrm{Ma}$ (constriction of seaway) and $\sim 4 \mathrm{Ma}$ (final closure) showed increased similarity, leading to the conclusion that the closure, although effecting change in species composition amongst the two regions, did not decrease similarity between the EEP and Caribbean. Final closure at $\sim 4$ Ma had a noted 
impact on the Caribbean assemblages by a change in dominance to one species, Nuttalides umbonifera, which corresponds to decreased paleoproductivity. 


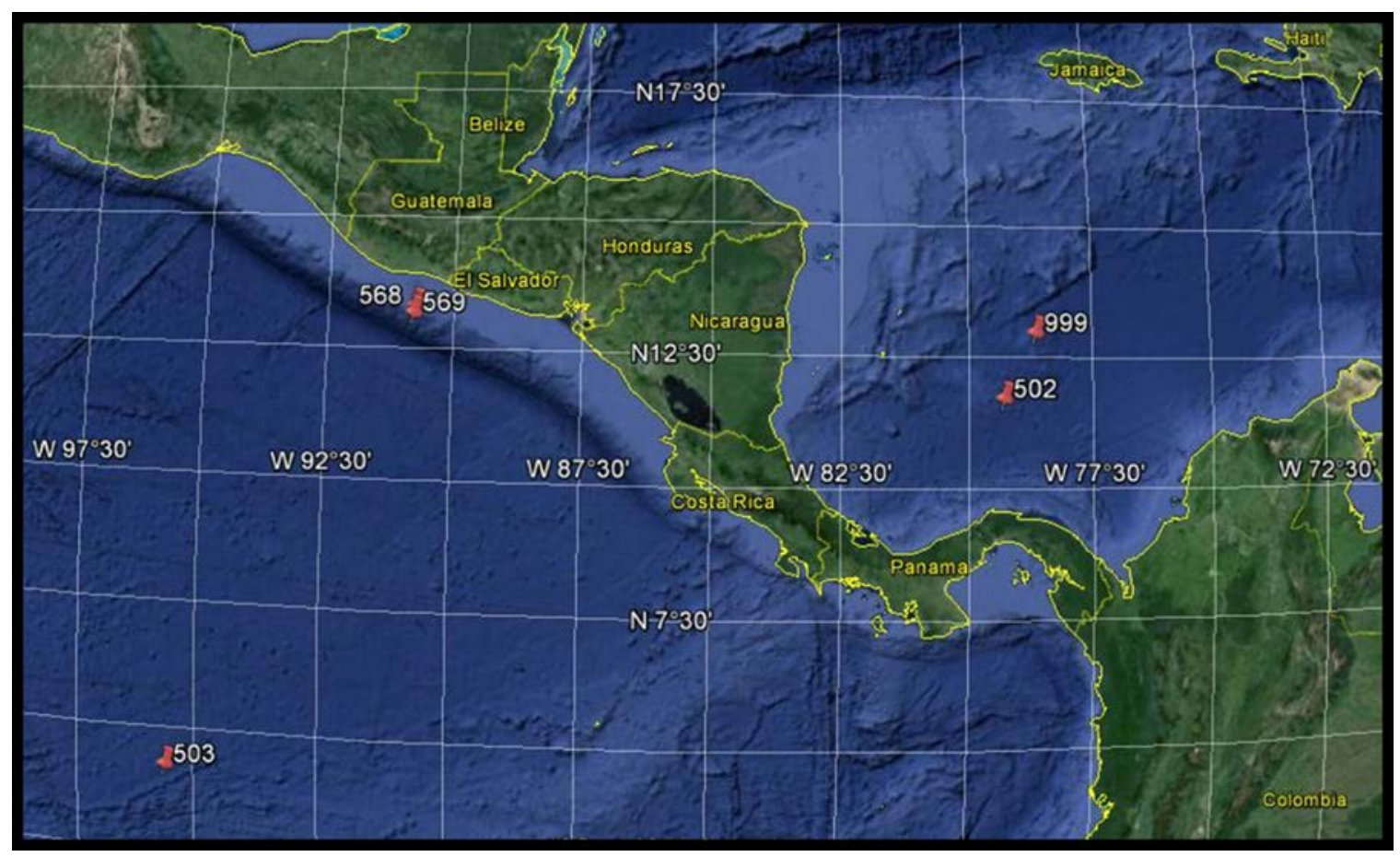

Figure 1. Site locations used for this study: Caribbean ODP Site 999, DSDP Site 502, and Equatorial Eastern Pacific DSDP sites 503, 568 and 569. 


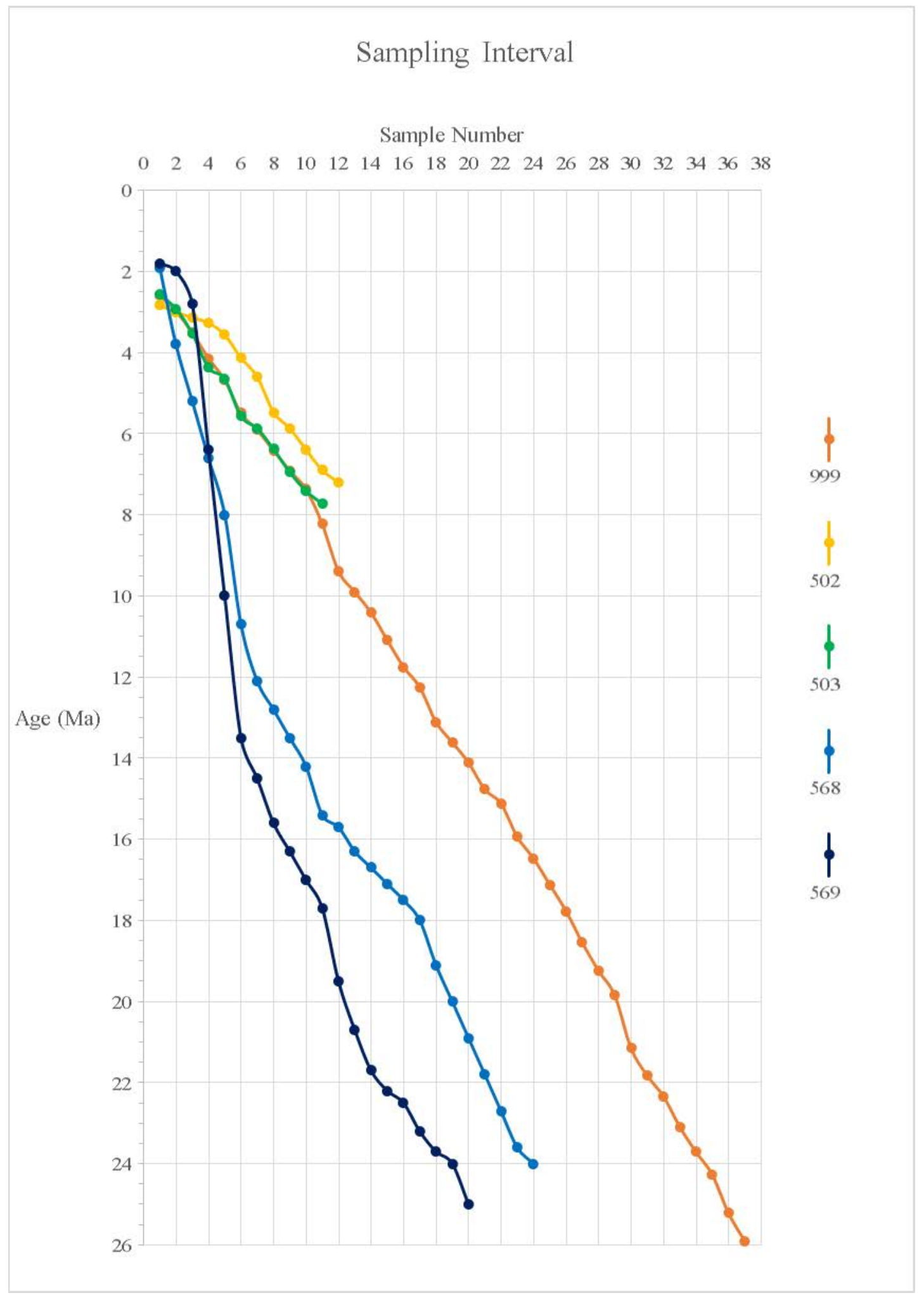

Figure 2. Sampling interval for all sites. 


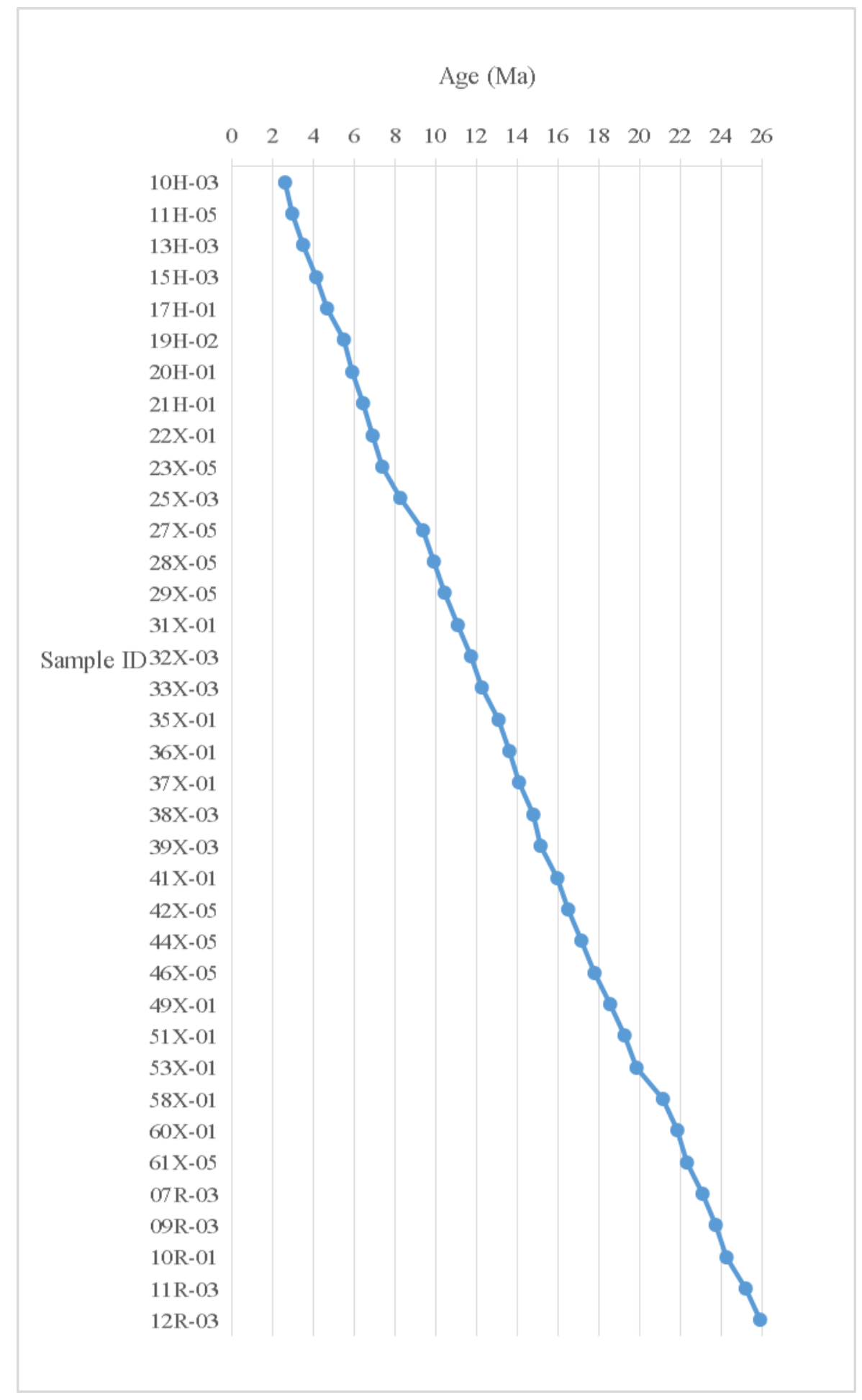

Figure 3. Samples prepared for benthic foraminiferal assemblages, ODP Site 999. Where sample conditions allowed, samples were selected at a 0.5 million year interval. All ages acquired from ODP Leg 165 (including Site 999) publications (Sigurdsson, et al., 1997). 


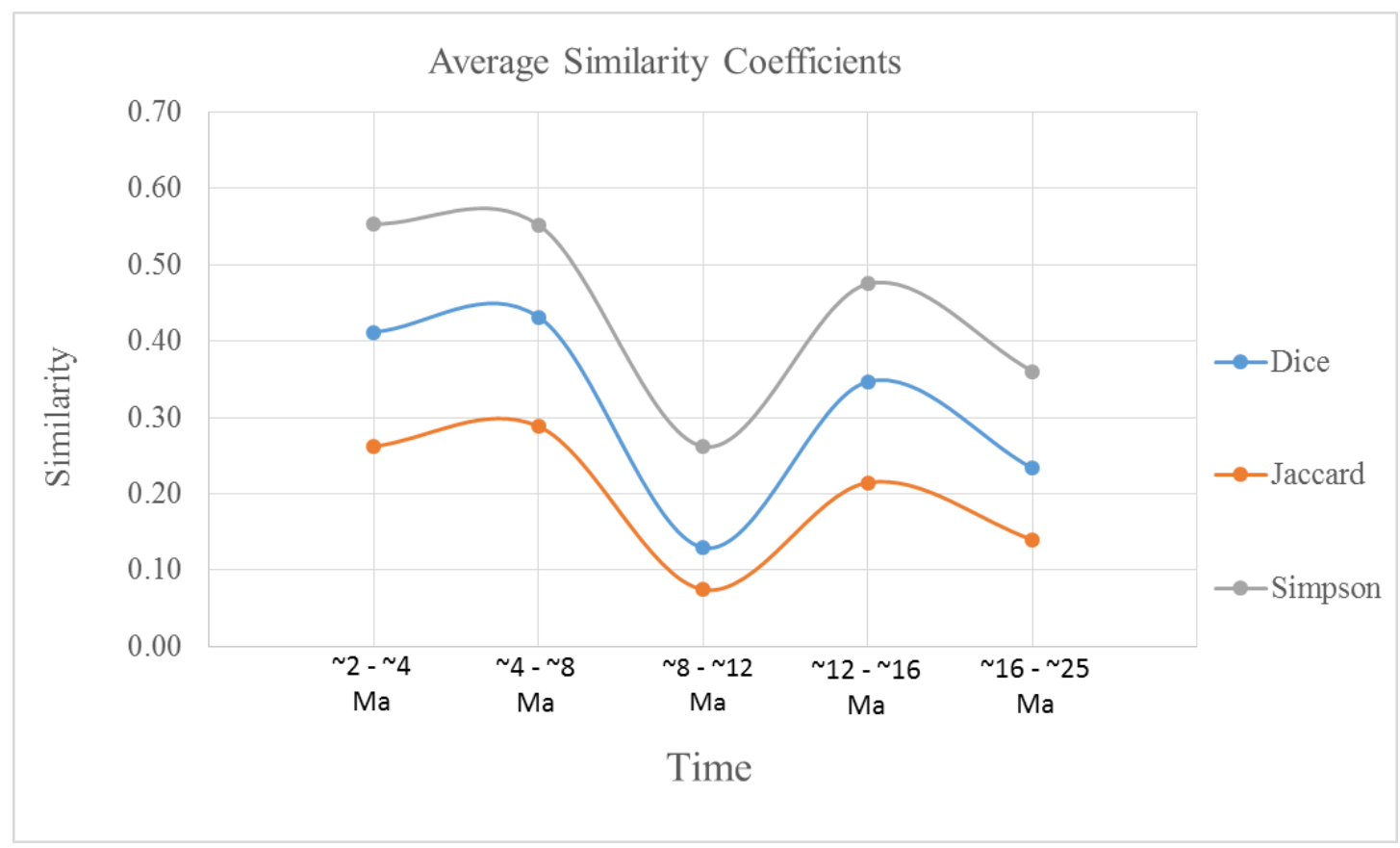

Figure 4. Average of Dice, Jaccard, and Simpson similarity coefficients for Caribbean and EEP pairs for each time interval. 


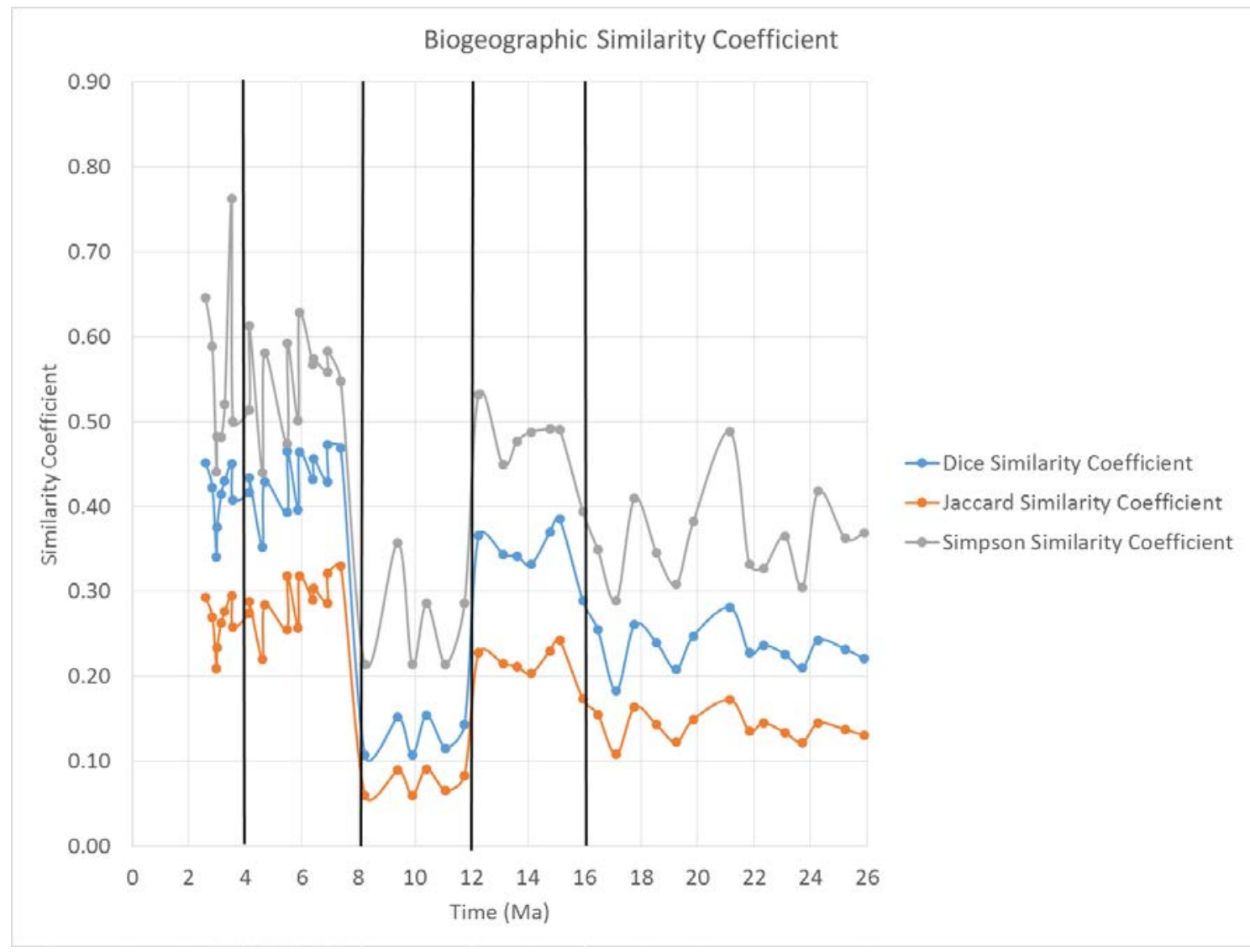

Figure 5. Similarity coefficients; average similarity of all EEP sites within each interval is shown for each Caribbean site. 


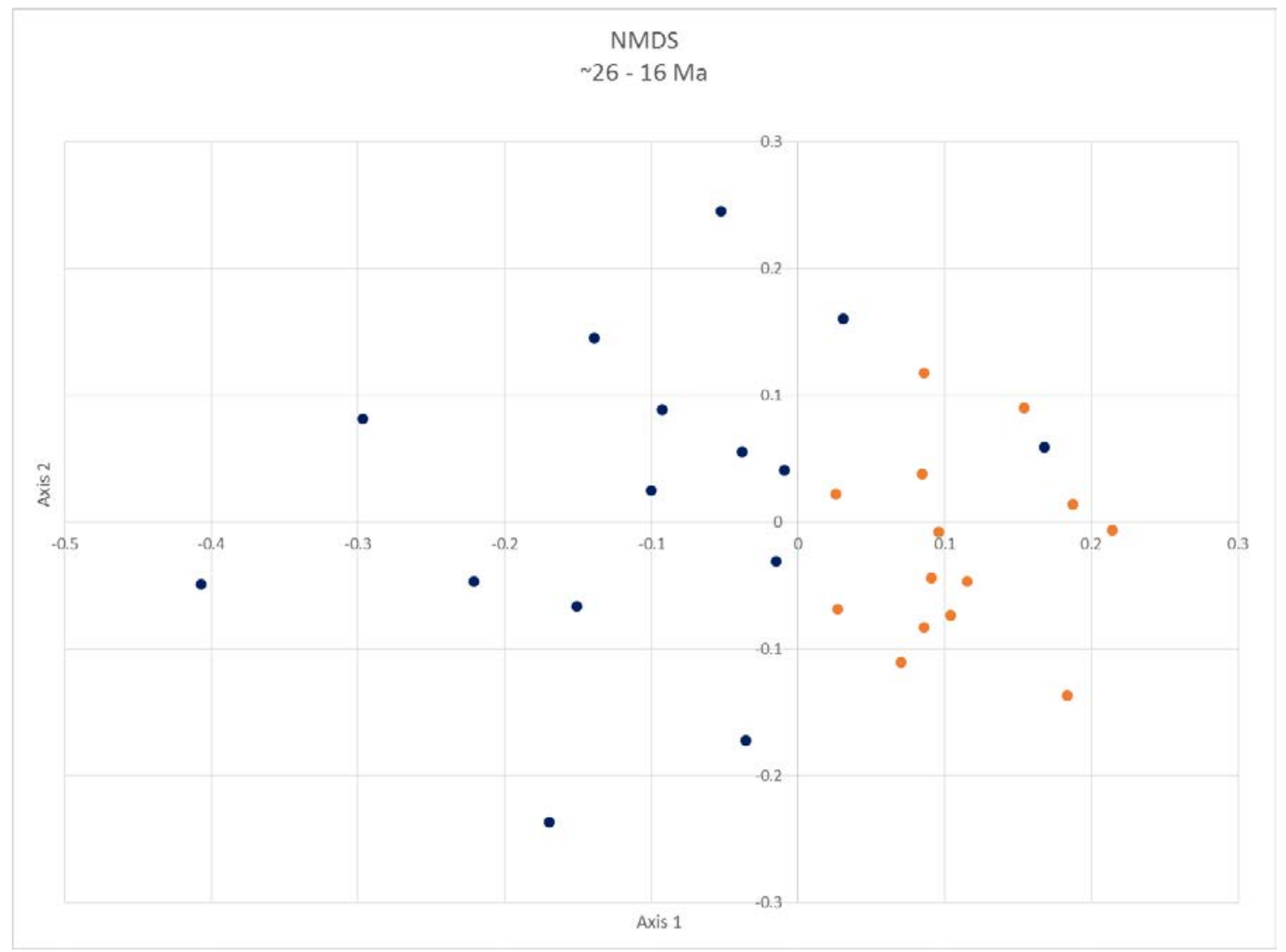

Figure 6. Non-metric MDS (Simpson coefficient of similarity), 16 Ma and older; blue= equatorial Eastern Pacific, orange $=$ Caribbean . 


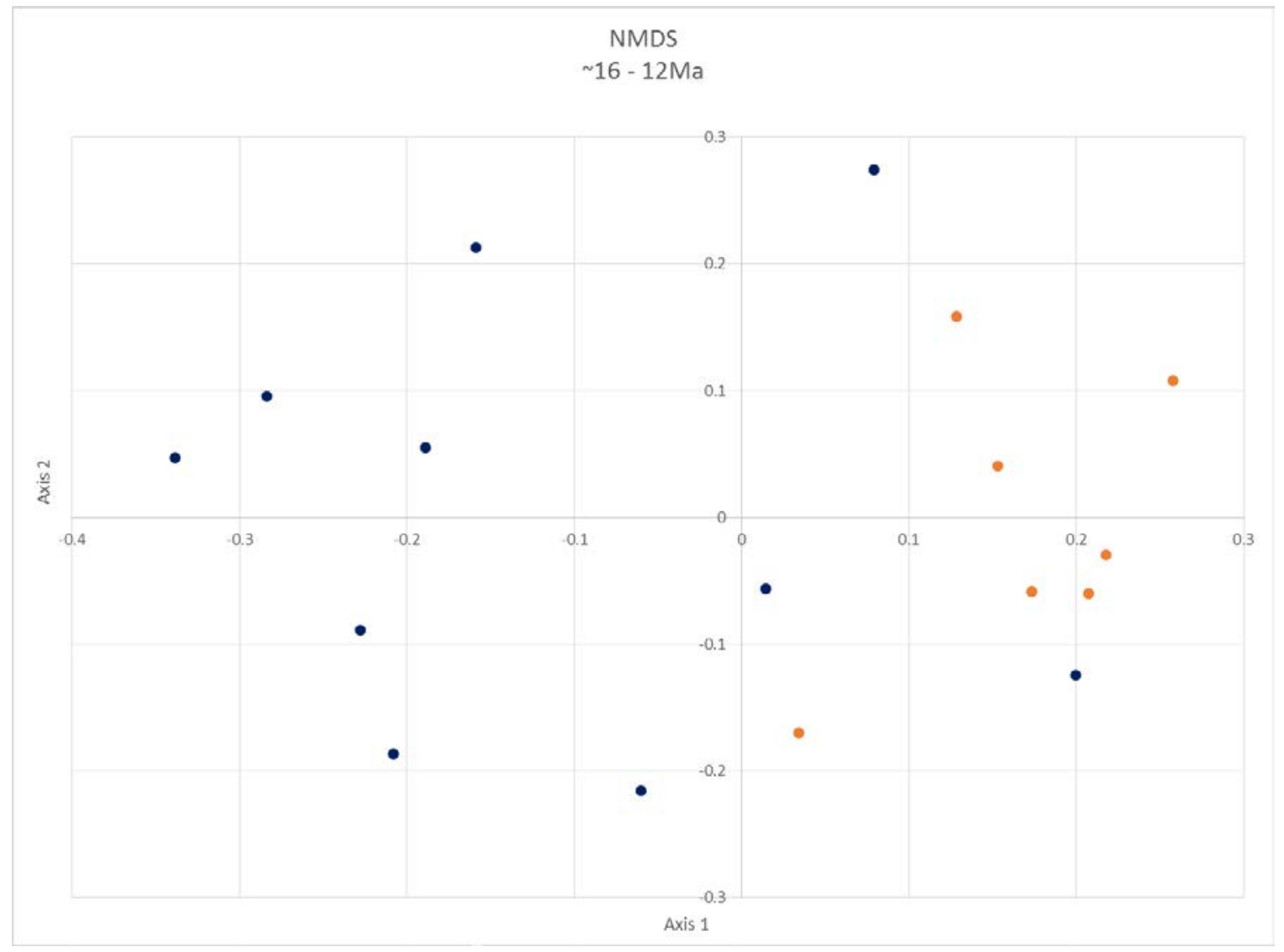

Figure 7. Non-metric MDS (Simpson coefficient of similarity), 16 - 12 Ma; blue= equatorial Eastern Pacific, orange $=$ Caribbean . 


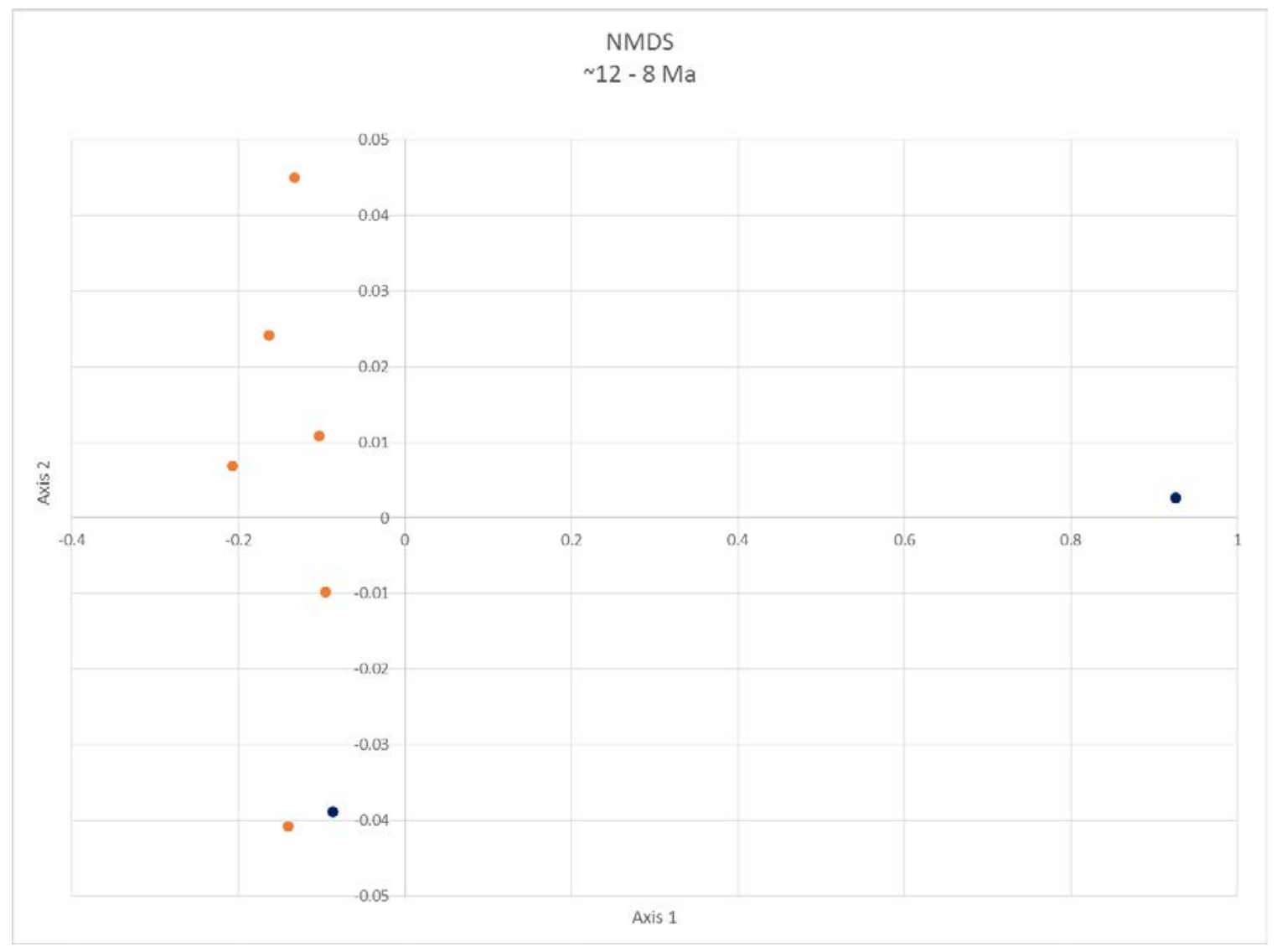

Figure 8. Non-metric MDS (Simpson coefficient of similarity), 12 - 8 Ma; blue= equatorial Eastern Pacific, orange = Caribbean . 


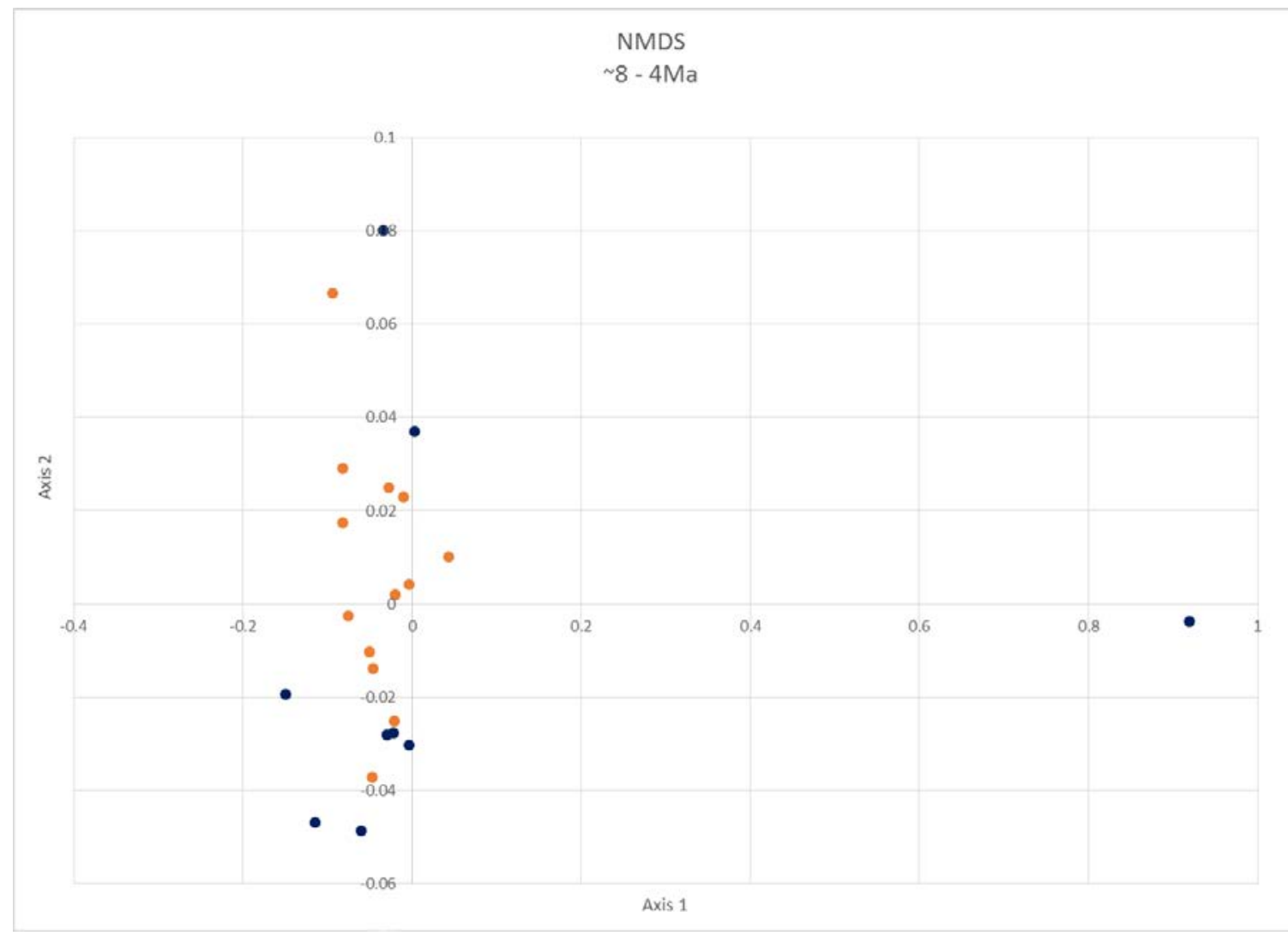

Figure 9. Non-metric MDS (Simpson coefficient of similarity), 8 - $4 \mathrm{Ma}$; blue= equatorial Eastern Pacific, orange $=$ Caribbean . 


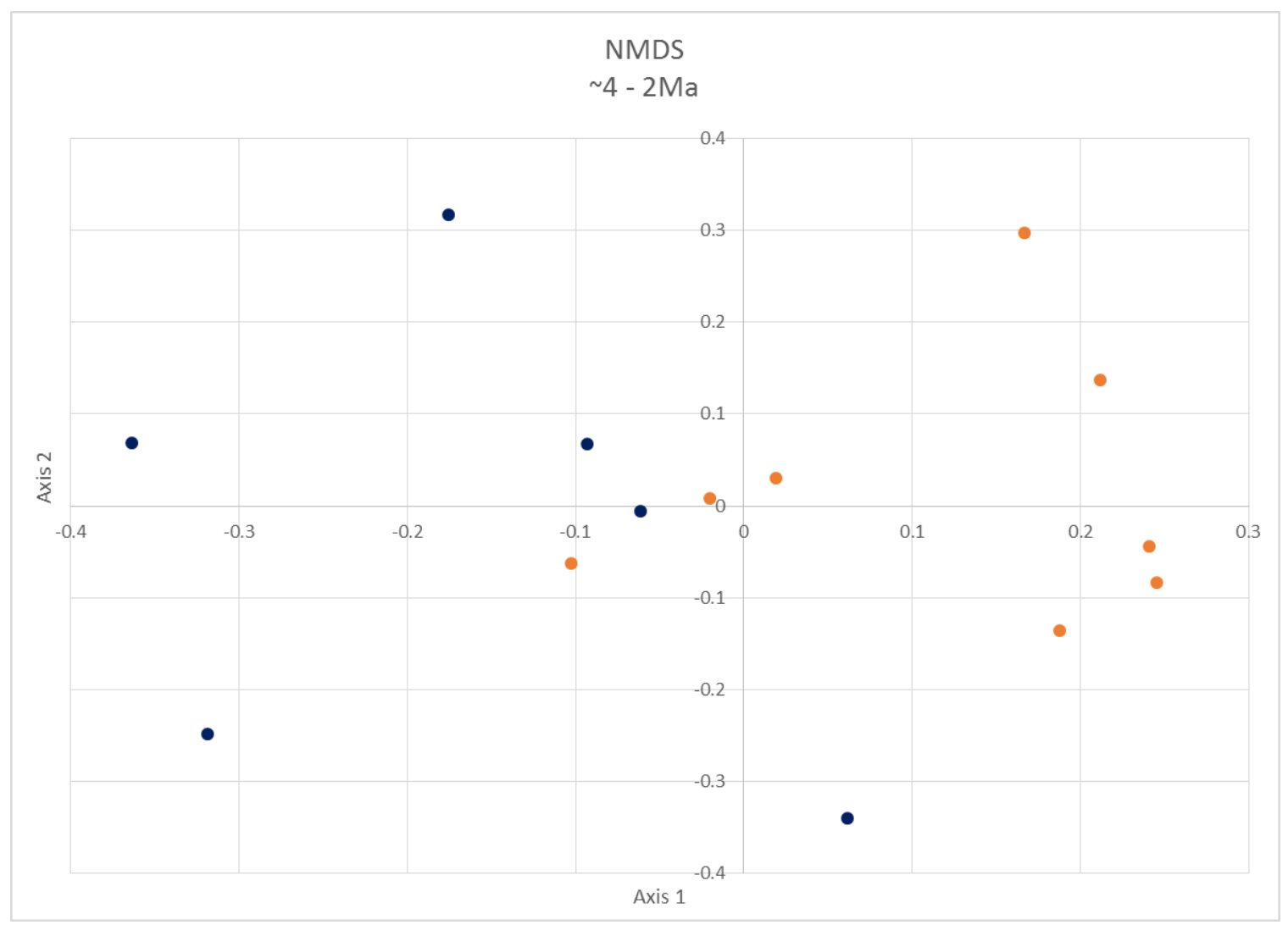

Figure 10. Non-metric MDS (Simpson coefficient of similarity), 2 - 4 Ma; blue= equatorial Eastern Pacific, orange $=$ Caribbean . 
Table 1. . Site and foraminiferal data set. Data for Site 999 are from Jain (2006), Jain and Collins (2007), Jain et al. (2007), and this study; Data for sites 502, 503, 568, 569 are from McDougall (1985, 1996, written comm., 2015).

\begin{tabular}{|c|c|c|c|c|c|c|c|c|c|}
\hline Region & $\begin{array}{c}\text { ODP/DSDP } \\
\text { Site }\end{array}$ & $\begin{array}{l}\text { Water Depth } \\
\text { Drilled (m) }\end{array}$ & $\begin{array}{l}\text { Number of } \\
\text { Samples } \\
\text { (utilized in } \\
\text { this study) }\end{array}$ & \begin{tabular}{c|} 
Minimum \\
Specimen \\
Number per \\
Sample
\end{tabular} & $\begin{array}{c}\text { Maximum } \\
\text { Specimen } \\
\text { Number per } \\
\text { Sample }\end{array}$ & \begin{tabular}{|c|} 
Average \\
Specimen \\
Number per \\
Sample \\
\end{tabular} & $\begin{array}{c}\text { Minimum } \\
\text { Number of } \\
\text { Species per } \\
\text { Sample }\end{array}$ & $\begin{array}{c}\text { Maximum } \\
\text { Number of } \\
\text { Species per } \\
\text { Sample }\end{array}$ & $\begin{array}{c}\text { Average } \\
\text { Number of } \\
\text { Species per } \\
\text { Sample }\end{array}$ \\
\hline \multirow{2}{*}{ Caribbean } & 999 & 2828 & 37 & 126 & 995 & 350 & 28 & 70 & 44 \\
\hline & 502 & 3051 & 12 & 15 & 659 & 326 & 8 & 62 & 43 \\
\hline \multirow{2}{*}{$\begin{array}{l}\text { Eastem } \\
\text { Equatorial } \\
\text { Pacific }\end{array}$} & 568 & 2010 & 24 & 1 & 382 & 103 & 1 & 61 & 21 \\
\hline & 569 & 2744 & 20 & 1 & 424 & 125 & 1 & 67 & 28 \\
\hline
\end{tabular}

Table 2. Differences in magnetic chron ages (Kent and Sapriosu, 1982a, b; Berggren et al., 1995).

\begin{tabular}{|c|c|c|c|c|c|c|}
\hline Chron & $\begin{array}{c}\text { Upper Age Limit } \\
\text { (Ma) from Berggren } \\
\text { et al., (1995) }\end{array}$ & $\begin{array}{c}\text { Upper Age Limit } \\
\text { (Ma) from Kent and } \\
\text { Sapriosu (1982a,b) }\end{array}$ & $\begin{array}{c}\text { Difference in } \\
\text { Upper Age } \\
\text { Limit (Ma) }\end{array}$ & $\begin{array}{c}\text { Lower Age Limit } \\
\text { (Ma) from } \\
\text { Berggren et al., } \\
\text { (1995) }\end{array}$ & $\begin{array}{c}\text { Lower Age Limit } \\
\text { (Ma) from Kent } \\
\text { and Sapriosu (1982 } \\
\text { a,b) }\end{array}$ & $\begin{array}{c}\text { Difference in } \\
\text { Lower Age } \\
\text { Limit (Ma) }\end{array}$ \\
\hline Matuyama & 0.78 & 0.73 & 0.05 & 2.58 & 2.48 & 0.1 \\
\hline Olduvai & 1.77 & 1.66 & 0.11 & 1.95 & 1.88 & 0.07 \\
\hline Gauss & 2.58 & 2.48 & 0.1 & 3.58 & 3.4 & 0.18 \\
\hline Mammoth & 3.22 & 3.18 & 0.04 & 3.33 & 3.4 & -0.07 \\
\hline Cochiti & 4.18 & 3.86 & 0.32 & 4.29 & 3.95 & 0.34 \\
\hline
\end{tabular}


Table 3. Average similarity coefficients for each time interval.

\begin{tabular}{|c|c|c|c|}
\hline \multicolumn{4}{|c|}{ Similarity Indices, $\sim 2$ - $4 \mathrm{Ma}$} \\
\hline Caribbean & Dice & Jaccard & Simpson \\
\hline Range of Similarity Coefficients & $0.18-0.58$ & $0.10-0.41$ & $0.30-0.92$ \\
\hline Average Similarity Coefficient & 0.41 & 0.26 & 0.55 \\
\hline \multicolumn{4}{|c|}{ Similarity Indices, $\sim 4-8 \mathrm{Ma}$} \\
\hline Caribbean & Dice & Jaccard & Simpson \\
\hline Range of Similarity Coefficients & $0.07-0.71$ & $0.04-0.55$ & $0.13-0.80$ \\
\hline Average Similarity Coefficient & 0.43 & 0.29 & 0.55 \\
\hline \multicolumn{4}{|c|}{ Similarity Indices, $\sim 8-12 \mathrm{Ma}$} \\
\hline Caribbean & Dice & Jaccard & Simpson \\
\hline Range of Similarity Coefficients & $0.00-0.31$ & $0.00-0.18$ & $0.00-0.71$ \\
\hline Average Similarity Coefficient & 0.13 & 0.07 & 0.26 \\
\hline \multicolumn{4}{|c|}{ Similarity Indices, 12 - $16 \mathrm{Ma}$} \\
\hline Caribbean & Dice & Jaccard & Simpson \\
\hline Range of Similarity Coefficients & $0.12-0.62$ & $0.06-0.45$ & $0.18-0.67$ \\
\hline Average Similarity Coefficient & 0.35 & 0.21 & 0.47 \\
\hline \multicolumn{4}{|c|}{ Similarity Indices, $>\sim 16 \mathrm{Ma}$} \\
\hline Caribbean & Dice & Jaccard & Simpson \\
\hline Range of Similarity Coefficients & $0.00-0.59$ & $0.00-0.42$ & $0.00-0.89$ \\
\hline Average Similarity Coefficient & 0.23 & 0.14 & 0.36 \\
\hline
\end{tabular}


Table 4. Similarity coefficients for each Caribbean site, calculated by averaging all EEP pairs (per interval) for each Caribbean site.

\begin{tabular}{|c|c|c|c|c|}
\hline Age & Caribbean & $\begin{array}{c}\text { Dice Similarity } \\
\text { Coefficient }\end{array}$ & $\begin{array}{l}\text { Jaccard Similarity } \\
\text { Coefficient }\end{array}$ & $\begin{array}{l}\text { Simpson Similarity } \\
\text { Coefficient }\end{array}$ \\
\hline 2.59 & CAR-999-10H-03 & 0.45 & 0.29 & 0.65 \\
\hline 2.83 & CAR-502-18-CC & 0.42 & 0.27 & 0.59 \\
\hline 2.98 & CAR-999-11H-05 & 0.34 & 0.21 & 0.44 \\
\hline 3 & CAR-502-20-1 & 0.38 & 0.23 & 0.48 \\
\hline 3.14 & CAR-502-21-1 & 0.41 & 0.26 & 0.48 \\
\hline 3.27 & CAR-502-22-1 & 0.43 & 0.28 & 0.52 \\
\hline 3.51 & CAR-999-13H-03 & 0.45 & 0.29 & 0.76 \\
\hline 3.56 & CAR-502-24-1 & 0.41 & 0.26 & 0.50 \\
\hline 4.13 & CAR-502-28-1 & 0.42 & 0.27 & 0.51 \\
\hline 4.14 & CAR-999-15H-03 & 0.43 & 0.29 & 0.61 \\
\hline 4.6 & CAR-502-33-1 & 0.35 & 0.22 & 0.44 \\
\hline 4.68 & CAR-999-17H-01 & 0.43 & 0.28 & 0.58 \\
\hline 5.47 & CAR-502-43-1 & 0.39 & 0.26 & 0.47 \\
\hline 5.49 & CAR-999-19H-02 & 0.47 & 0.32 & 0.59 \\
\hline 5.87 & CAR-502-48-1 & 0.40 & 0.26 & 0.50 \\
\hline 5.91 & CAR-999-20H-01 & 0.46 & 0.32 & 0.63 \\
\hline 6.39 & CAR-502-55-1 & 0.43 & 0.29 & 0.57 \\
\hline 6.41 & CAR-999-21H-01 & 0.46 & 0.30 & 0.57 \\
\hline 6.9 & CAR-502-63-1 & 0.43 & 0.29 & 0.56 \\
\hline 6.91 & CAR-999-22X-01 & 0.47 & 0.32 & 0.58 \\
\hline 7.37 & CAR-999-23X-05 & 0.47 & 0.33 & 0.55 \\
\hline 8.23 & CAR-999-25X-03 & 0.11 & 0.06 & 0.21 \\
\hline 9.39 & CAR-999-27X-05 & 0.15 & 0.09 & 0.36 \\
\hline 9.9 & CAR-999-28X-05 & 0.11 & 0.06 & 0.21 \\
\hline 10.41 & CAR-999-29X-05 & 0.15 & 0.09 & 0.29 \\
\hline 11.09 & CAR-999-31X-01 & 0.12 & 0.07 & 0.21 \\
\hline 11.75 & CAR-999-32X-03 & 0.14 & 0.08 & 0.29 \\
\hline 12.25 & CAR-999-33X-03 & 0.37 & 0.23 & 0.53 \\
\hline 13.11 & CAR-999-35X-01 & 0.34 & 0.22 & 0.45 \\
\hline 13.61 & CAR-999-36X-01 & 0.34 & 0.21 & 0.48 \\
\hline 14.11 & CAR-999-37X-01 & 0.33 & 0.20 & 0.49 \\
\hline \begin{tabular}{|l|}
14.77 \\
\end{tabular} & CAR-999-38X-03 & 0.37 & 0.23 & 0.49 \\
\hline 15.12 & CAR-999-39X-03 & 0.38 & 0.24 & 0.49 \\
\hline 15.94 & CAR-999-41X-01 & 0.29 & 0.17 & 0.39 \\
\hline 16.47 & CAR-999-42X-05 & 0.25 & 0.16 & 0.35 \\
\hline 17.12 & CAR-999-44X-05 & 0.18 & 0.11 & 0.29 \\
\hline 17.77 & CAR-999-46X-05 & 0.26 & 0.16 & 0.41 \\
\hline 18.55 & CAR-999-49X-01 & 0.24 & 0.14 & 0.35 \\
\hline 19.24 & CAR-999-51X-01 & 0.21 & 0.12 & 0.31 \\
\hline 19.85 & CAR-999-53X-01 & 0.25 & 0.15 & 0.38 \\
\hline 21.15 & CAR-999-58X-01 & 0.28 & 0.17 & 0.49 \\
\hline 21.83 & CAR-999-60X-01 & 0.23 & 0.14 & 0.33 \\
\hline 22.34 & CAR-999-61X-05 & 0.24 & 0.15 & 0.33 \\
\hline \begin{tabular}{|l|}
23.09 \\
\end{tabular} & CAR-999-07R-03 & 0.23 & 0.13 & 0.36 \\
\hline 23.71 & CAR-999-09R-03 & 0.21 & 0.12 & 0.30 \\
\hline 24.27 & CAR-999-10R-01 & 0.24 & 0.14 & 0.42 \\
\hline 25.22 & CAR-999-11R-03 & 0.23 & 0.14 & 0.36 \\
\hline 25.91 & CAR-999-12R-03 & 0.22 & 0.13 & 0.37 \\
\hline
\end{tabular}


Table 5. Bonferroni post hoc test results. Age interval designations: 1 - Prior to bottom water change ( $\sim 16 \mathrm{Ma}), 2$ - Change in bottom-water to barrier to deep circulation ( 16 $12 \mathrm{Ma}), 3$ - Barrier to deep circulation to constriction of seaway ( 12 - $8 \mathrm{Ma}), 4-$ Constriction of seaway to closure of seaway $(\sim 8-4 \mathrm{Ma}), 5$ - Post seaway closure $(\sim 4-2$ Ma). * Mean difference is significant at the 0.05 level.

\begin{tabular}{|c|c|c|c|c|c|c|}
\hline \multirow{2}{*}{$\begin{array}{l}\text { (I) Age } \\
\text { Interval }\end{array}$} & \multirow{2}{*}{$\begin{array}{l}\text { (J) Age } \\
\text { Interval }\end{array}$} & \multirow{2}{*}{$\begin{array}{c}\text { Mean Difference } \\
\text { (I-J) }\end{array}$} & \multirow{2}{*}{$\begin{array}{l}\text { Std. } \\
\text { Error }\end{array}$} & \multirow[t]{2}{*}{$\mathrm{P}<0.05$} & \multicolumn{2}{|c|}{$\begin{array}{l}\text { 95\% Confidence Interval for } \\
\text { Difference }\end{array}$} \\
\hline & & & & & Lower Bound & Upper Bound \\
\hline \multirow{4}{*}{1} & 2 & $*_{-0.114}$ & 0.023 & 0.000 & -0.179 & -0.050 \\
\hline & 3 & 0.098 & 0.049 & 0.456 & -0.040 & 0.237 \\
\hline & 4 & *-0.191 & 0.019 & 0.000 & -0.245 & -0.138 \\
\hline & 5 & *-0.193 & 0.026 & 0.000 & -0.267 & -0.118 \\
\hline \multirow{4}{*}{2} & 1 & $* 0.114$ & 0.023 & 0.000 & 0.050 & 0.179 \\
\hline & 3 & $* 0.213$ & 0.052 & 0.000 & 0.067 & 0.359 \\
\hline & 4 & $*_{-0.077}$ & 0.025 & 0.022 & -0.148 & -0.007 \\
\hline & 5 & -0.078 & 0.031 & 0.120 & -0.166 & 0.009 \\
\hline \multirow{4}{*}{3} & 1 & 0.098 & 0.049 & 0.456 & -0.237 & 0.040 \\
\hline & 2 & *-0.213 & 0.052 & 0.000 & -0.359 & -0.067 \\
\hline & 4 & *-0.290 & 0.05 & 0.000 & -0.431 & -0.148 \\
\hline & 5 & *-0.291 & 0.053 & 0.000 & -0.442 & -0.140 \\
\hline \multirow{4}{*}{4} & 1 & *0.191 & 0.019 & 0.000 & 0.138 & 0.245 \\
\hline & 2 & *0.077 & 0.025 & 0.022 & 0.007 & 0.148 \\
\hline & 3 & $* 0.290$ & 0.05 & 0.000 & 0.148 & 0.431 \\
\hline & 5 & -0.001 & 0.028 & 1.000 & -0.081 & 0.079 \\
\hline \multirow{4}{*}{5} & 1 & $* 0.193$ & 0.026 & 0.000 & 0.118 & 0.267 \\
\hline & 2 & 0.078 & 0.031 & 0.120 & -0.009 & 0.166 \\
\hline & 3 & *0.291 & 0.053 & 0.000 & 0.140 & 0.442 \\
\hline & 4 & 0.001 & 0.028 & 1.000 & -0.079 & 0.081 \\
\hline
\end{tabular}


Table 6. Abundances of species (>1\%) in percentages for older than 16 Ma.

\begin{tabular}{|c|c|c|c|c|c|c|c|c|c|c|c|c|c|c|c|}
\hline Sample & $999-42 X-05$ & 568-40/CC & \begin{tabular}{|l|}
$568-41 / 3$ \\
\end{tabular} & \begin{tabular}{|l|}
$999-44 X-05$ \\
\end{tabular} & \begin{tabular}{|l|}
$999-46 X-05$ \\
\end{tabular} & $569-12 / \mathrm{CC}$ & $569-14 / 2$ & \begin{tabular}{|l|}
$999-51 X-01$ \\
\end{tabular} & \begin{tabular}{|l|}
$999-53 \mathrm{X}-01$ \\
\end{tabular} & \begin{tabular}{|l|}
$999-58 \mathrm{X}-01$ \\
\end{tabular} & \begin{tabular}{|l|}
$999-07 \mathrm{R}-03$ \\
\end{tabular} & \begin{tabular}{|l|}
$999-09 R-03$ \\
\end{tabular} & \begin{tabular}{|l|}
$999-10 R-01$ \\
\end{tabular} & \begin{tabular}{|l|l|}
$999-11 R-03$ \\
\end{tabular} & \begin{tabular}{|l|l|}
$999-12 R-03$ \\
\end{tabular} \\
\hline \begin{tabular}{|l|} 
Age (Ma) \\
\end{tabular} & 16.47 & \begin{tabular}{|l|}
16.67 \\
\end{tabular} & \begin{tabular}{|l|}
17.11 \\
\end{tabular} & \begin{tabular}{|r|}
17.12 \\
\end{tabular} & $\begin{array}{l}17.77 \\
\end{array}$ & $\begin{array}{ll}17.95 \\
\end{array}$ & $\begin{array}{l}18.67 \\
\end{array}$ & \begin{tabular}{|r|}
19.24 \\
\end{tabular} & \begin{tabular}{|r|}
19.85 \\
\end{tabular} & \begin{tabular}{|r|}
21.15 \\
\end{tabular} & \begin{tabular}{|r|}
23.09 \\
\end{tabular} & \begin{tabular}{|r|}
23.71 \\
\end{tabular} & \begin{tabular}{|r|r|}
24.27 \\
\end{tabular} & 25.22 & 25.91 \\
\hline Individuals & 204 & 244 & 382 & 392 & 226 & 424 & 291 & 313 & 352 & 222 & 279 & 265 & 360 & 306 & 311 \\
\hline Alabamina polita & & 2.05 & 2.09 & & & & 1.37 & & & & & & & & \\
\hline Ammoglobigerina cf. globigeriniformis & & & & & & & & & & & & & & & 1.93 \\
\hline \begin{tabular}{|l} 
Ammoglobigerina globigeriniformis \\
\end{tabular} & & & & 1.02 & & & & & & & & & 1.11 & & \\
\hline Anamlinoides globosa & & & & 1.28 & & & & & & & & & & & \\
\hline \multirow{2}{*}{\multicolumn{16}{|c|}{\begin{tabular}{|l|} 
Astrononion guadalupae \\
Astrononion novozealandicum \\
\end{tabular}}} \\
\hline & & & & & & & & & & & & & & & \\
\hline Bolivina cf. harangensis & 9.31 & & & 2.55 & & & & 13.10 & & 2.25 & 3.94 & 1.89 & 4.72 & 4.25 & 3.54 \\
\hline \begin{tabular}{|l|} 
Bolivina cf. hughesi \\
\end{tabular} & & & & & & & & & 1.70 & & 1.08 & & & & \\
\hline \begin{tabular}{|l} 
Bolivina cf. seminuda \\
\end{tabular} & & & & & & & & & & & & & & & \\
\hline Bolivina cf. sp. A & & & & & & & & & & & & & & & \\
\hline \begin{tabular}{|l|l} 
Bolivina cf. striatula \\
\end{tabular} & & & & & & & & & & & & & & & \\
\hline \begin{tabular}{|l|} 
Bolivina imporcata \\
\end{tabular} & & & & & & & & & & & & & & & \\
\hline Bolivina marginata & & 2.05 & & & & & 4.81 & & & & & & & & \\
\hline \begin{tabular}{|l} 
Bolivina spp. \\
\end{tabular} & & & & & & & & & & & & & & & 2.89 \\
\hline Bolivina striatula & & & & & 4.87 & & & & 2.84 & 1.80 & & & 1.11 & & \\
\hline \begin{tabular}{|l} 
Brizalina aff. subspinescens \\
\end{tabular} & & & & & & & & & & & & 3.40 & 3.06 & & \\
\hline Brizalina antegressa & & & & & & & & & & & & & & & \\
\hline \begin{tabular}{|l} 
Bulimina alazaensis \\
\end{tabular} & & & & & & 1.18 & & & & & & & & & \\
\hline Bulimina cf. elongata & & & & & & & & & & & & 3.40 & & & \\
\hline \begin{tabular}{|l} 
Bulimina mexicana \\
\end{tabular} & & & & & & & 1.37 & & & & & & & & \\
\hline Bulimina rostrata & & & & & & & & & & & & & & & \\
\hline \begin{tabular}{|l} 
Buliminella cf. pusilla \\
\end{tabular} & & & & & 3.54 & & & 4.47 & & & & 1.89 & & 1.63 & \\
\hline \begin{tabular}{|l|l|} 
Buliminella curta \\
\end{tabular} & & & 1.05 & & & & & & & & & & & & \\
\hline Cassidulina californica & & & 1.83 & & & & & & & & & & & & \\
\hline \begin{tabular}{|l|l|} 
Cassidulina carapitana \\
\end{tabular} & 1.47 & & & 2.81 & & & & 1.28 & & & & & & & \\
\hline \begin{tabular}{|l|} 
Cassidulina cf. corbyi \\
\end{tabular} & & & & & & & & & & & 4.30 & & & & \\
\hline \begin{tabular}{|l|} 
Cassidulina laevigata \\
\end{tabular} & & & & & & & 9.97 & & & & & & & & \\
\hline \begin{tabular}{|l|} 
Cassidulina minuta \\
\end{tabular} & & & & & & & & & & & & & & & \\
\hline \begin{tabular}{|l} 
Cassidulina spinifera \\
\end{tabular} & & 2.87 & & & & & & & & & & & & & \\
\hline Cassidulina tricamerata & & & & & & & & & & & & & & & \\
\hline \begin{tabular}{|l} 
Ceratobulimina alazaensis \\
\end{tabular} & & & 1.05 & & & & & & & & & & & & \\
\hline \begin{tabular}{|l} 
Chrysalogonium lanceolum \\
\end{tabular} & & & & & & & & & & & & & & & \\
\hline Chrysalogonium longiscatatum & & & & & & & & & & & & & & & \\
\hline \begin{tabular}{|l|} 
Cibicides barnetti \\
\end{tabular} & & & & & & 1.42 & 1.37 & & & & & & & & \\
\hline Cibicides cf. C. spiralis & & & & & & 2.36 & & & & & & & & & \\
\hline Cibicides cf. mundulus & & & & & & & & & & & & 1.89 & & & \\
\hline \begin{tabular}{|l} 
Cibicides cf. robertsanius \\
\end{tabular} & & & & & & & & & & & & & & & \\
\hline \begin{tabular}{|l} 
Cibicides floridanus \\
\end{tabular} & & & & & & & 2.41 & & & & & & & & \\
\hline \begin{tabular}{|l} 
Cibicides granulosa \\
\end{tabular} & & & & & & 3.07 & & & & & & & & & \\
\hline Cibicides guraboensus & & & & & & & & & & & & & & & \\
\hline Cibicides heminwayae & & & & & & & & & & & & & & & \\
\hline \begin{tabular}{|l} 
Cibicides io Cushman \\
\end{tabular} & & & & & & & & & & & & & & & \\
\hline \begin{tabular}{|l} 
Cibicides lobatulus \\
\end{tabular} & & & & & & & & & & & & & & & \\
\hline \begin{tabular}{|l} 
Cibicides matanzaensis \\
\end{tabular} & & & & & & & & & & & & & & & \\
\hline 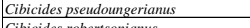 & & & & & & & & & & & & & & & \\
\hline Cibicides robertsonianus & & & & & & & & & & & & & & & \\
\hline \begin{tabular}{|l|l|} 
Cibicides spiralis \\
\end{tabular} & & & & & & 7.08 & & & & & & & & & \\
\hline \begin{tabular}{|l|} 
Cibicides spirolimbatus \\
\end{tabular} & & 8.20 & 3.14 & & & & 7.22 & & & & & & & & \\
\hline \begin{tabular}{|l|} 
Cibicides spp. \\
\end{tabular} & & & & 3.32 & & 1.18 & & 1.60 & 1.70 & 9.01 & 4.66 & 9.43 & 4.17 & 1.63 & 1.61 \\
\hline \begin{tabular}{|l|l} 
Cibicides trincherasensis \\
\end{tabular} & & & & & & 2.12 & & & & & & & & & \\
\hline \begin{tabular}{|l} 
Cibicides umbonatus \\
\end{tabular} & & & & & & & & & & & & & & & \\
\hline \begin{tabular}{|l} 
Cibicides yagatensis \\
\end{tabular} & & 3.28 & 3.93 & & & 7.78 & 4.12 & & & & & & & & \\
\hline \begin{tabular}{|l|} 
Cibicidoides cf. Ilaurisae \\
Cibrideids.
\end{tabular} & & & & & & & & & & & & 3.02 & 1.11 & 1.31 & \\
\hline \begin{tabular}{|l} 
Cibicidoides grimsdalei \\
\end{tabular} & & & & & & & & & & & & & & & \\
\hline \begin{tabular}{|l} 
Cibicidoides bradyi \\
\end{tabular} & & & & & & & 1.03 & & 5.68 & & 1.08 & & 3.89 & 1.96 & 2.57 \\
\hline Cibicidoides cicatricosus & & & & & & & & & & 1.35 & & & & & \\
\hline \begin{tabular}{|l|} 
Cibicidoides mundulus \\
\end{tabular} & 10.29 & & & 9.44 & 10.62 & & & 15.02 & 10.80 & 13.06 & 5.38 & 5.28 & 4.17 & 7.84 & 4.18 \\
\hline Cibicidoides pachyderma & & & & & & & & & & & & & & & \\
\hline Cibicidoides wuellerstorffi & & & & & & & 2.41 & & & & & & & & \\
\hline \begin{tabular}{|l} 
Dentalina cocoaensis \\
\end{tabular} & & 10.66 & 7.59 & & & & & & & & & & & & \\
\hline \begin{tabular}{|l} 
Dentalina cooperensis \\
\end{tabular} & & 1.64 & & & & & & & & & & & & & \\
\hline Dentalina pseudoobliqua & & & & & & & & & & & & & & 2.29 & 1.29 \\
\hline Dentalina soluta Reuss & & & & & & & & & & & & & & & \\
\hline \begin{tabular}{|l} 
Eggerella bradyi \\
\end{tabular} & & & & & & & & & & 1.35 & & & & & 1.61 \\
\hline \begin{tabular}{|l} 
Ehrenbergina bradyi \\
\end{tabular} & & & 2.36 & & & & & & & & & & & & \\
\hline Ehrenbergina caribbea & & & & & & & & & & & & & & & \\
\hline Ehrenbergrina sp. A & & & & & & & & & & & & & & & \\
\hline Epistominella exigua & 4.90 & & & 2.04 & 4.42 & & & \begin{tabular}{|c|c|c|}
11.18 \\
\end{tabular} & 3.98 & 8.56 & 6.09 & 2.64 & & 1.63 & 6.75 \\
\hline Eponides turgidus & & & & & & & & & & & & & & & \\
\hline Eponides regularis & & & & & & & & & & & & & & & \\
\hline Fissuirina pseudoglobosa & & & & & & & & & & 1.80 & & & & & \\
\hline Fissurina cucullata & & & & & & & & & & & & & & & \\
\hline Fissurina marginata & & & & & & & & & & & & & & & \\
\hline Fissurina orbignyana & & & & & & & & & & & & & & & \\
\hline Fissurina seminifroma & & & & & & & & & & & & & & & \\
\hline Fissurina spinosa & & & & & & & & & & & & & & & \\
\hline Fissurina turbiniformis & & & & & & & & & & & & & & & \\
\hline
\end{tabular}


Table 6, Continued.

\begin{tabular}{|c|c|c|c|c|c|c|c|c|c|c|c|c|c|c|c|}
\hline Sample & $\begin{array}{ll}999-42 X-05 \\
\end{array}$ & \begin{tabular}{|l|}
$568-40 / \mathrm{CC}$ \\
\end{tabular} & $568-41 / 3$ & $\begin{array}{l}999-44 \mathrm{X}-05 \\
\end{array}$ & $\begin{array}{ll}999-46 X-05 \\
\end{array}$ & \begin{tabular}{|l|}
$569-12 / \mathrm{CC}$ \\
\end{tabular} & $569-14 / 2$ & \begin{tabular}{|l|} 
999-51X-01 \\
\end{tabular} & 999-53X-01 & $\begin{array}{l}999-58 X-01 \\
\end{array}$ & \begin{tabular}{|l|}
$999-07 R-03$ \\
\end{tabular} & \begin{tabular}{|l|} 
999-09R-03 \\
\end{tabular} & \begin{tabular}{|l|} 
999-10R-01 \\
\end{tabular} & \begin{tabular}{|l|} 
999-11R-03 \\
\end{tabular} & \begin{tabular}{|l|} 
999-12R-03 \\
\end{tabular} \\
\hline Age (Ma) & 16.47 & 16.67 & 17.11 & 17.12 & 17.77 & 17.95 & 18.67 & 19.24 & 19.85 & 21.15 & 23.09 & 23.71 & 24.27 & 25.22 & 25.91 \\
\hline Individuals & 204 & 244 & 382 & 392 & 226 & 424 & 291 & 313 & 352 & 222 & 279 & 265 & 360 & 306 & 311 \\
\hline Fissurina wiesneri & & & & & & & & & & & & & & & \\
\hline Francesita advena & & & & & & & & & & & & & & & \\
\hline Gen 1. ind. sp. ind & & & & & 1.77 & & & & & & & & & & \\
\hline Globobulimina affinis & & & & & & & & & & & & & & & \\
\hline Globobulimina cf. ovula & & & & & & & & & & & & & & & \\
\hline Globobulimina ovula & & & & & & & & & & & & & & & \\
\hline \begin{tabular}{|l|l|l|l} 
Globocassidulina subglobosa \\
\end{tabular} & 9.80 & 2.46 & & 13.78 & 15.49 & 1.65 & & 1.28 & 12.78 & 7.21 & 5.73 & 12.08 & 12.22 & 10.13 & 6.75 \\
\hline Gyroidina altiformis & 1.96 & & & 2.81 & 1.33 & & & 1.60 & 1.42 & & & \begin{tabular}{l|l}
1.13 \\
\end{tabular} & & & \\
\hline Gyroidina altispira & & & & & & & & & & & & & & & \\
\hline Gyroidina cf. planulata & & & & & & & & & & & & 1.51 & & & \\
\hline Gyroidina condoni & & & & & & & & & & & & & & & \\
\hline Gyroidina lamarckiana & & & & & & & & & & & & & & & \\
\hline Gyroidina perampla & & & & & & & & & & & & & & & \\
\hline \begin{tabular}{|l|} 
Gyroidina planulata \\
\end{tabular} & 14.71 & & & 2.04 & & & 1.37 & 1.60 & 6.25 & 1.80 & 7.53 & & 3.89 & 1.63 & 1.61 \\
\hline Gyroidina planulata & & & & & & & & & & & & & & & \\
\hline Gyroidinoides soldanii & 1.47 & & 7.59 & 9.18 & 9.29 & & & 3.19 & 4.83 & 2.25 & 3.94 & 1.13 & 3.06 & 2.29 & 5.47 \\
\hline Gyroidina umbonata & & & & & & & & & & & & & & & \\
\hline Gyroidina zelandica Finlay & & 2.46 & & & & & 1.03 & & & & & & & & \\
\hline $\begin{array}{l}\text { Hanzawaia isidroensis } \\
\end{array}$ & & & & & & & 2.75 & & & & & & & & \\
\hline Hanzawaia mantaensis & & 1.23 & & & & & & & & & & & & & \\
\hline $\begin{array}{l}\text { Hoeglundina elegans } \\
\end{array}$ & & 9.84 & 6.28 & & & 2.59 & 2.75 & & & & & & & & \\
\hline Karreriella bradyi & & & & & & & & & & & 1.43 & & 1.11 & 1.63 & \\
\hline Laevidentalina advena & & & & & & & & & & & & & & & \\
\hline Laevidentalina communis & & & & & & & & & & & & & & & \\
\hline \begin{tabular}{|l} 
Laevidentalina inornata \\
\end{tabular} & & & & & & & & & & & & 1.51 & & 1.31 & \\
\hline Lagena cf. auriculata var. inc & & & & & & & & & & & & & & & \\
\hline Lagena cf. elongata & & & & & 1.77 & & & & & & & & & & \\
\hline Lagena cf. laevis & & & & & & & & & & & & & & 3.27 & \\
\hline Lagena elongata & & & & & & & & & & & & & & & \\
\hline Lagena elongata & & & & & & & & & & & & & & & \\
\hline $\begin{array}{l}\text { Lagena laevis } \\
\end{array}$ & & & & & & & & & & & & & & & 1.29 \\
\hline Lagena meridonaus & 1.47 & & & & 1.33 & & & & & & & & & & \\
\hline Lagena spp. & & & & & & & & & 1.42 & 3.15 & 8.60 & 3.02 & 4.72 & 6.54 & 7.72 \\
\hline Lagena stelligerea & & & & & & & & & & & & & & & \\
\hline Laticarinina pauperata & 2.94 & & & 3.06 & & & & & & & & & & & \\
\hline Lenticulina altolimbatus & & & & & & 1.42 & 1.72 & & & & & & & & \\
\hline Lenticulina arcuatostriata & & 7.38 & 2.88 & & & & & & & & & & & & \\
\hline Lenticulina calcar & & 4.10 & 4.97 & & & & & & & & & & & & \\
\hline Lenticulina dicampyla & & & & & & & & & & & & & & & \\
\hline Lenticulina iota & & & & & & & & & & & & & & & \\
\hline Lenticulina limbosa & & 1.23 & 1.05 & & & & & & & & & & & & \\
\hline Lenticulina melvilli & & 3.69 & $\begin{array}{l}1.57 \\
1.57\end{array}$ & & & & & & & & & & & & \\
\hline Lenticulina pliocaena & & & & & & & & & & & & & & & \\
\hline Lenticulina rotulata & & & & & & 1.89 & & & & & & & & & \\
\hline Lenticulina spp. & & & 1.31 & & & & & & & & & & & & \\
\hline Lenticulina terryi & & & 2.62 & & & & 1.03 & & & & & & & & \\
\hline Lenticulina texana & & & & & & 1.18 & & & & & & & & & \\
\hline Lenticulina yaguensis & & & \begin{tabular}{l|l|}
1.57 \\
\end{tabular} & & & & & & & & & & & & \\
\hline Martinottiella pallida & & & & & & & & & & & & & & & \\
\hline Martinottiella spp. & & & & & & & & & & & \begin{tabular}{l|l|l|l|}
1.08 \\
\end{tabular} & & & & \\
\hline Melonis aff. pompiloides & & & & & & & & 3.51 & & & & & & & \\
\hline Melonis affinis & & & & & & & & & & & & & & & \\
\hline Melonis barleeanum & 2.94 & & & 8.67 & 2.21 & & & 9.58 & 16.76 & 4.50 & 6.09 & 2.26 & 8.06 & 1.96 & 1.93 \\
\hline Melonis cf. barleeanum & & & & & & & & & & & & & & 7.52 & \\
\hline Melonis cf. pompiloides & & & & & & & & & & & & & & & 3.54 \\
\hline Melonis pompilioides & & & & & & & & & & & & & & & \\
\hline Miliammina fusca & & & & & & & & & & & & & & & \\
\hline Nodosaria fistuca & & & & & & & & & & & & & & & \\
\hline Nodosaria lamellata & & & & & & 1.18 & & & & & & & & & \\
\hline Nodosaria latejugata & & & & & & 1.89 & & & & & & & & & \\
\hline Nodosaria longiscata & & & 3.14 & & & 2.36 & & & & & & & & & \\
\hline Nodosaria parexilis & & & & & & & & & & & & & & & \\
\hline Nodosaria pyrula & & & & & & & & & & & & & & & \\
\hline Nodosaria spp. & & & & & & 2.36 & 3.44 & & & & & & & & \\
\hline Nodosaria stainforthia & & & & & & & & & & & & & & & \\
\hline Nonion mesonense & & & & & & & & & & & & 2.26 & & & \\
\hline Nonion commune & & & & & 2.65 & & & & & & 1.08 & & & & \\
\hline Nonion havanense & & & & & & & & & & & & & & & \\
\hline Nonion spp. & & & & & & & & & & & & & & & \\
\hline Nonionella miocenica & & 1.64 & & & & & & & & & & & & & \\
\hline Nonionella spp. & & & & & & & & & & & & & & & \\
\hline Nuttalides umbonifera & & & & & & & & & & & 1.08 & & 1.11 & & \\
\hline Oolina cf. globosa ovalis & & & & & & & & & & & & & & & 1.29 \\
\hline \begin{tabular}{|l|} 
Oolina globosa \\
\end{tabular} & & & & & & & & & & & & & & & \\
\hline Oolina spp. & & & & & & & & & & & & & & & \\
\hline Oridorsalis umbonatus & 7.35 & & & 8.42 & 5.75 & 2.59 & 2.06 & 5.75 & 11.36 & 3.60 & 6.45 & 4.91 & 7.78 & 5.23 & 8.04 \\
\hline Orthomorphina jetladschai & & & & & & & & & & & & & & & \\
\hline Orthomorphina perversa & & & & & & & & & & & & & & & \\
\hline Orthomorphina spp. & & & & & & & & & & & & & & & \\
\hline
\end{tabular}


Table 6, Continued.

\begin{tabular}{|c|c|c|c|c|c|c|c|c|c|c|c|c|c|c|c|}
\hline Sample & $999-42 X-05$ & \begin{tabular}{|l|l|}
$568-40 / C C$ \\
\end{tabular} & \begin{tabular}{|l|}
$568-41 / 3$ \\
\end{tabular} & \begin{tabular}{|l|}
$999-44 X-05$ \\
\end{tabular} & \begin{tabular}{|l|}
$999-46 X-05$ \\
\end{tabular} & $\mid 569-12 / \mathrm{CC}$ & $569-14 / 2$ & \begin{tabular}{|l|}
$999-51 X-01$ \\
\end{tabular} & \begin{tabular}{|l|}
$999-53 \mathrm{X}-01$ \\
\end{tabular} & \begin{tabular}{|l|}
$999-58 X-01$ \\
\end{tabular} & $\mid 999-07 \mathrm{R}-03$ & \begin{tabular}{|l|}
$999-09 R-03$ \\
\end{tabular} & \begin{tabular}{|l|}
$999-10 \mathrm{R}-01$ \\
\end{tabular} & \begin{tabular}{|l|l|} 
& $999-11 R-03$ \\
\end{tabular} & \begin{tabular}{|l|}
$999-12 R-03$ \\
\end{tabular} \\
\hline Age (Ma) & 16.47 & 16.67 & 17.11 & 17.12 & 17.77 & \begin{tabular}{l|l}
17.95 \\
\end{tabular} & 18.67 & 19.24 & 19.85 & 21.15 & 23.09 & 23.71 & 24.27 & 25.22 & 25.91 \\
\hline Individuals & 204 & 244 & \begin{tabular}{l|l}
382 \\
\end{tabular} & 392 & 226 & 424 & 291 & 313 & 352 & 222 & 279 & 265 & 360 & 306 & 311 \\
\hline \begin{tabular}{|l|} 
Osangularia culteri \\
\end{tabular} & & & 1.31 & & & & & & & & & & & & \\
\hline Parafissurina cavigera & & & & & & & & & & 1.80 & & & & & \\
\hline \multicolumn{16}{|l|}{ Parafissurina lateralis f. crassa } \\
\hline \multicolumn{16}{|l|}{\begin{tabular}{|l|} 
Parafissurina spp. \\
\end{tabular}} \\
\hline Planularia venezuelana & & 1.23 & & & & & & & & & & & & & \\
\hline \begin{tabular}{|l} 
Planulina ornata \\
\end{tabular} & & & & & & 1.18 & & & & & & & & & \\
\hline Planulina renz & & & 1.31 & & & \begin{tabular}{l|l|}
3.07 \\
\end{tabular} & 1.03 & & & & & & & & \\
\hline Planulina rugosa & & & & & & & & & & & & & & & \\
\hline Planulina wuellerstorfi & 13.24 & & & 13.27 & & & & & & 1.80 & & & & & \\
\hline Plectofrondicularia californica & & 1.23 & & & & & & & & & & & & & \\
\hline Plectofrondicularia vaughani & & & 1.05 & & & & & & & & & & & & \\
\hline $\begin{array}{l}\text { Pleurostomella acuminata } \\
\end{array}$ & & & & 3.32 & 7.52 & & & 4.79 & & & 2.87 & 9.06 & 4.44 & 8.50 & 2.25 \\
\hline Pleurostomella alternans & & & & & 1.33 & & & 1.60 & 3.13 & 2.70 & 1.08 & & 2.22 & 1.96 & 3.22 \\
\hline Pleurostomella brevis & & & & & & & & & & & & 3.40 & & 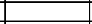 & \\
\hline Pleurostomella cf. brevis & & & & & & & & & & & & & & & \\
\hline \begin{tabular}{|l} 
Pleurostomella spp. \\
\end{tabular} & 1.96 & & & & & & & & 1.42 & & & & & & \\
\hline Pleurostomella subnodosa & & & & & & & & 1.28 & & & & 1.51 & & & 1.29 \\
\hline $\begin{array}{l}\text { Praeglobobulimina auriculata } \\
\end{array}$ & & & & & & & & & & & & & & & \\
\hline Pullenia alazaensis & & & & & & & & & & & & & & & \\
\hline Pullenia angusta & & & & & & & & & & & & & & & \\
\hline Pullenia bulloides & 3.43 & & 1.83 & & 2.21 & & & & 2.56 & 4.95 & 2.15 & 2.26 & 3.33 & 1.63 & 2.25 \\
\hline Pullenia malkinae & & & & & & & & & & & & & & & 2.2 \\
\hline \begin{tabular}{|l|} 
Pullenia quadriloba \\
\end{tabular} & 1.47 & & & 3.32 & 2.21 & & & 2.24 & 1.14 & & & & & & 1.61 \\
\hline \begin{tabular}{|l|} 
Pullenia quinqueloba \\
\end{tabular} & & & & & & & & & & 4.50 & 1.79 & 1.89 & 5.83 & 2.61 & 3.22 \\
\hline \begin{tabular}{|l} 
Pyrgo depressa \\
\end{tabular} & & & & & & & & & & & & & & & \\
\hline Pyrgo murrhina & & & & & & & & & & & & & & & \\
\hline \begin{tabular}{|l|} 
Pyrgo oblonga \\
\end{tabular} & & & & & & & & & & & & & & & \\
\hline Pyrgo rotalaria & & & & & & & & & & & & & & & \\
\hline Pyrgo serrata & & & & & & & & & & & & & & & \\
\hline Pyrulina albatrossi & & & & & & & & & & & & & & & \\
\hline Quinqeuloculina cf. Iamarckiana & & & & & & & & & & & & 3.77 & & 2.29 & \\
\hline \begin{tabular}{|l|} 
Quinqeuloculina spp. \\
\end{tabular} & & & & & & & & & & & 1.08 & & 2.22 & & 7.40 \\
\hline Quinqeuloculina lamarckiana & & & & & 2.65 & & & 1.92 & 1.42 & 2.70 & 3.58 & & & & \\
\hline Quinqueloculina venusta & & & & & & & & & & & & & & & \\
\hline Rectuvigerina basispinata & & & & & & 1.42 & 3.44 & & & & & & & & \\
\hline \begin{tabular}{|l|} 
Schenkiella spp. \\
\end{tabular} & & & & & & & & & & & & & 1.39 & & \\
\hline Sigmoilopsis schlumbergeri & & & & & & & & & & & & & & & \\
\hline Sigmoilina spp. & & & & & 1.33 & & & & & & & & & & \\
\hline Sigmoilina tenuis & & 3.28 & 1.31 & & & & & & & & & & & & \\
\hline Siphogenerina multicostata & & & & & & & & & & & & & & & \\
\hline \begin{tabular}{|l} 
Siphogenerina senni \\
\end{tabular} & & & 1.31 & & & & 1.37 & & & & & & & & \\
\hline Siphogenerina transversa & & 6.97 & 12.30 & & & & & & & & & & & & \\
\hline Siphonia pulchra & & & & & & 5.66 & 4.12 & & & & & & & & \\
\hline Siphonina tenuicarnata & & & & & & & & & & & 4.30 & & & & \\
\hline Siphonodosaria bradyi & & & & & & & & & & & & & & & \\
\hline Siphonodosaria consobrina & & & & & & & & & & & & & & & \\
\hline Siphonodosaria gracillima & & & & & & 1.18 & 2.75 & & & & & & & & \\
\hline Siphonodosaria paucistriata & & & & & & & & & & & & & & & \\
\hline Siphonodosaria verneuilla & & & & & & & & & & & & & & & \\
\hline Siphotextularia catenata & & & & & & & & & & & & & & & \\
\hline Siphotextularia cf. catenata & & & & & & & & & & & & & & & \\
\hline Sphaeroidina bulloides & & 1.64 & & & & 1.65 & 1.37 & & & & & & & & \\
\hline Stilostomella a dolphina & & & & & & & & & & & & & & & \\
\hline Stilostomella consobrina & & & & & 3.10 & & & 1.60 & & & & & & & \\
\hline Stilostomella gracilis & & & & & & & & & & & & & & & \\
\hline Stilostomella lepidula & 2.94 & & & 1.02 & & 5.66 & 2.06 & & & & & & & & \\
\hline \begin{tabular}{|l|} 
Stilostomella spp. \\
\end{tabular} & & & & & 1.77 & & & & & & & & & 4.90 & \\
\hline Stilostomella subspinosa & & 1.64 & & & & & & 1.28 & & & 1.08 & 6.42 & 5.00 & & 2.25 \\
\hline Textularia agglutinanas & & & & & & & & & & & & & & & 1.61 \\
\hline Uvigerina auberiana & & & & & & & & & & & 2.15 & & & & \\
\hline \begin{tabular}{|l|} 
Uvigerina carapitana \\
\end{tabular} & & & & & & & 4.81 & & & & & & & & \\
\hline Uvigerina cf. ciperana & & & & & & & & & & & & & & & \\
\hline Uvigerina cf. hollicki & & & & & & & & & & & & & & & \\
\hline Uvigerina cf. senticosa & & & & & & & & & & & & & & & \\
\hline Uvigerina cf. striata attenuata & & & & & & & & & & 10.36 & 2.15 & & 2.50 & & 1.61 \\
\hline \begin{tabular}{|l|} 
Uvigerina gallowayi \\
\end{tabular} & & & & & & 2.36 & & & & & & & & & \\
\hline Uvigerina hispida & & & & & & 2.59 & 1.37 & & & & & & & & \\
\hline Uvigerina hispida-costata & & & & & & & & & & & & & & & \\
\hline \begin{tabular}{|l|} 
Uvigerina peregrina \\
\end{tabular} & & & & & & & & & & & & & & & \\
\hline Uvigerina rustica & & & & & & 4.01 & & & & & & & & & \\
\hline Uvigerina senticosa & & & & & & & & & & & & & & & \\
\hline \begin{tabular}{|l} 
Uvigerina sp. (costate) \\
\end{tabular} & & 8.61 & & & & & 7.56 & & & & & & & & \\
\hline Uvigerina striata & & & & & & & & & & & & & & & \\
\hline Uvigerina vaderescens & & & & & & & & & & & & & & & \\
\hline Vaginulinopsis nudicostata & & 1.23 & 3.66 & & & & & & & & & & & & \\
\hline \begin{tabular}{|l|} 
Vulvulina pennatula \\
\end{tabular} & & & & & & & & \begin{tabular}{l|l}
1.60 \\
\end{tabular} & & & & & & & \\
\hline
\end{tabular}


Table 7. Abundances of species (>1\%) in percentages for 16-12 Ma.

\begin{tabular}{|c|c|c|c|c|c|c|c|c|c|c|c|c|}
\hline Sample & 999-33X-03 & 999-35X-01 & 999-36X-01 & $568-28 / 5$ & \begin{tabular}{|l|}
$999-37 X-01$ \\
\end{tabular} & $568-33 / \mathrm{CC}$ & $568-36 / \mathrm{CC}$ & 999-38X-03 & 999-39X-03 & 568-39/3 & $569-11 / \mathrm{CC}$ & 999-41X-01 \\
\hline Age (Ma) & 12.25 & 13.11 & 13.61 & 13.62 & 14.11 & 14.16 & 14.7 & 14.77 & 15.12 & 15.79 & 15.92 & 15.94 \\
\hline Individuals & 455 & 414 & 532 & 300 & 414 & 272 & 289 & 255 & 375 & 268 & 350 & 542 \\
\hline Alabamina polita & & & & & & & & & & 1.12 & & \\
\hline \multicolumn{13}{|c|}{ Ammoglobigerina cf. globigeriniformis } \\
\hline \multicolumn{13}{|c|}{\begin{tabular}{|l|} 
Ammoglobigerina globigeriniformis \\
\end{tabular}} \\
\hline Anamlinoides globosa & 1.76 & 1.21 & 3.38 & 1.33 & 1.21 & & 1.04 & 1.18 & & & & \\
\hline \multicolumn{13}{|l|}{ Astrononion guadalupae } \\
\hline Astrononion novozealandicum & & & & & & & & & & & & \\
\hline Bolivina cf. harangensis & & & & & 1.21 & & & & & & & 6.27 \\
\hline Bolivina cf. hughesi & 2.42 & 1.21 & & & 1.69 & & & & & & & \\
\hline Bolivina cf. seminuda & & & & & & & & & & & & \\
\hline Bolivina cf. sp. A & & & & & & & & & & & & \\
\hline Bolivina cf. striatula & & & & & & & & & & & & \\
\hline Bolivina imporcata & & & & & & & & & & & & \\
\hline Bolivina marginata & & & & & & & & & & 1.12 & & \\
\hline Bolivina spp. & & & & & & & & 7.06 & 9.33 & & & \\
\hline Bolivina striatula & & & & & & & & 4.31 & 4.80 & & & 4.80 \\
\hline Brizalina aff. subspinescens & & & & & 4.11 & & & & & & & \\
\hline Brizalina antegressa & & 6.04 & & & 3.62 & & & 2.75 & & & & \\
\hline Bulimina alazaensis & & & & 4.00 & 1.69 & 1.47 & 6.23 & 1.18 & & & 2.57 & \\
\hline Bulimina cf. elongata & & & & & & & & & & & & \\
\hline Bulimina mexicana & & & & & & 1.84 & 1.38 & & & & & \\
\hline Bulimina rostrata & & & & & & & & & & & & \\
\hline Buliminella cf. pusilla & & & & & 2.90 & & & & & & & \\
\hline Buliminella curta & & & & & & & & & & & & \\
\hline Cassidulina californica & & & & & & & & & & & & \\
\hline Cassidulina carapitana & & & & & & & & & & & & \\
\hline Cassidulina cf. corbyi & & & & & & & & & & & & \\
\hline Cassidulina laevigata & & & & & & & & & & & & \\
\hline Cassidulina minuta & & & & & & & & & & & & \\
\hline Cassidulina spinifera & & & & & & & & & & 2.61 & & \\
\hline Cassidulina tricamerata & & & & & & & & & & & 4.57 & \\
\hline Ceratobulimina alazaensis & & & & & & & & & & & & \\
\hline Chrysalogonium lanceolum & & & & & & & & & & & & \\
\hline Chrysalogonium longiscatatum & & & & 3.00 & & & & & & & & \\
\hline Cibicides barnetti & & & & & & & & & & & & \\
\hline Cibicides cf. C. spiralis & & & & & & & & & & & & \\
\hline Cibicides cf. mundulus & & & & & & & & & & & & \\
\hline Cibicides cf. robertsanius & & & & & & & & 1.57 & & & & \\
\hline Cibicides floridanus & & & & & & & & & & & & \\
\hline Cibicides granulosa & & & & & & & & & & & 1.14 & \\
\hline Cibicides guraboensus & & & & & & & 1.38 & & & & & \\
\hline Cibicides heminwayae & & & & & & & & & & & & \\
\hline Cibicides io Cushman & & & & & & & & & & & & \\
\hline Cibicides lobatulus & & & & & & & & & & & & \\
\hline Cibicides matanzaensis & & & & & & & 2.08 & & & & & \\
\hline Cibicides pseudoungerianus & & & & & & & & & & & & \\
\hline Cibicides robertsonianus & & & & & & & & & & & & \\
\hline Cibicides spiralis & & & & & & & & & & & & \\
\hline Cibicides spirolimbatus & & & & 1.33 & & 6.62 & 7.27 & & & 2.99 & 4.57 & \\
\hline Cibicides spp. & 5.27 & 4.83 & 1.50 & & & & & 2.75 & & & & 1.85 \\
\hline Cibicides trincherasensis & & & & & & & 3.46 & & & & 2.86 & \\
\hline Cibicides umbonatus & & & & & & & & & & & & \\
\hline Cibicides yagatensis & & & & & & & 6.57 & & & 3.73 & 5.71 & \\
\hline Cibicidoides cf. laurisae & & & & & & & & & & & & \\
\hline Cibicidoides grimsdalei & & & & & & & & & 2.13 & & & \\
\hline Cibicidoides bradyi & 5.05 & 4.35 & 2.63 & & \begin{tabular}{l|l}
14.73 \\
\end{tabular} & & 2.77 & 2.35 & & & & \\
\hline Cibicidoides cicatricosus & & & & & & & & & & & & \\
\hline Cibicidoides mundulus & 5.71 & 2.66 & 10.15 & 1.33 & 1.45 & & & 1.96 & 6.40 & & & 6.64 \\
\hline Cibicidoides pachyderma & & & & & & & & & & & & \\
\hline Cibicidoides wuellerstorffi & & & & & & & & & & & & \\
\hline Dentalina cocoaensis & & & & & & & & & & 3.36 & & \\
\hline Dentalina cooperensis & & & & 2.67 & & 1.10 & & & & & & \\
\hline Dentalina pseudoobliqua & & & & & & & & & & & & \\
\hline Dentalina soluta Reuss & & & & & & & 3.81 & & & & & \\
\hline Eggerella bradyi & & & & & & & & & 1.33 & & & \\
\hline Ehrenbergina bradyi & & & & & & & & & & & & \\
\hline Ehrenbergina caribbea & & & & & & & & & & & & \\
\hline Ehrenbergrina sp. A & & & & & & & & & 2.40 & & & \\
\hline Epistominella exigua & 2.42 & 9.90 & 8.08 & & 3.14 & & & 2.35 & 6.40 & & & 7.75 \\
\hline Eponides turgidus & 24.40 & 2.90 & 4.89 & & 6.04 & & & 8.24 & 2.67 & & & 5.54 \\
\hline Eponides regularis & & & & & & & & & & & & \\
\hline Fissuirina pseudoglobosa & & & & & & & & & & & & \\
\hline Fissurina cucullata & & & & & & & & & & & & \\
\hline Fissurina marginata & & & & & & & 1.04 & & & & & \\
\hline Fissurina orbignyana & & & & & & & & & & & & \\
\hline Fissurina seminifroma & & & & & & & & & & & & \\
\hline Fissurina spinosa & & & & & & & & & & & & \\
\hline Fissurina turbiniformis & & & & & & & & & & & & \\
\hline
\end{tabular}


Table 7, Continued.

\begin{tabular}{|c|c|c|c|c|c|c|c|c|c|c|c|c|}
\hline Sample & \begin{tabular}{|l|}
$999-33 X-03$ \\
\end{tabular} & 999-35X-01 & 999-36X-01 & $568-28 / 5$ & \begin{tabular}{|l|} 
999-37X-01 \\
\end{tabular} & $568-33 / \mathrm{CC}$ & 568-36/CC & 999-38X-03 & 999-39X-03 & $568-39 / 3$ & $569-11 / \mathrm{CC}$ & 999-41X-01 \\
\hline Age (Ma) & 12.25 & 13.11 & 13.61 & 13.62 & 14.11 & 14.16 & 14.7 & \begin{tabular}{|c|}
14.77 \\
\end{tabular} & 15.12 & 15.79 & 15.92 & 15.94 \\
\hline Individuals & 455 & 414 & 532 & 300 & 414 & 272 & 289 & 255 & 375 & 268 & 350 & 542 \\
\hline \multicolumn{13}{|l|}{\begin{tabular}{|l} 
Fissurina wiesneri \\
\end{tabular}} \\
\hline \multicolumn{13}{|l|}{ Francesita advena } \\
\hline Gen 1. ind. sp. ind & & & & & & & & & & & & 1.11 \\
\hline Globobulimina affinis & & & & & & & & & & & & \\
\hline Globobulimina cf. ovula & & & & & & & & & & & & \\
\hline Globobulimina ovula & & & & & & & & & & & & \\
\hline Globocassidulina subglobosa & 7.69 & 4.59 & 15.79 & 1.33 & 9.90 & 1.47 & & \begin{tabular}{l|l|l|}
13.73 \\
\end{tabular} & \begin{tabular}{l|l}
9.33 \\
\end{tabular} & 4.85 & 1.14 & 9.41 \\
\hline Gyroidina altiformis & & & & & & & & & & & & 1.48 \\
\hline Gyroidina altispira & & & & 2.00 & & & & & & & & \\
\hline Gyroidina cf. planulata & & & & & & & & & & & & \\
\hline Gyroidina condoni & & & & & & & & & & & & \\
\hline Gyroidina lamarckiana & & & & & & & & & & & & \\
\hline Gyroidina perampla & & & & & & 2.57 & & & & & & \\
\hline Gyroidina planulata & & 3.14 & 3.38 & & 2.42 & 1.84 & & \begin{tabular}{l|l}
7.06 \\
\end{tabular} & 4.00 & & & 2.95 \\
\hline Gyroidina planulata & & & & & & & & & & & & \\
\hline Gyroidinoides soldanii & 7.47 & 5.31 & 2.82 & & 1.45 & & & 5.88 & 3.47 & 2.99 & 1.43 & 2.40 \\
\hline Gyroidina umbonata & & & & & & & & & & & & \\
\hline Gyroidina zelandica Finlay & & & & & & & & & & & & \\
\hline Hanzawaia isidroensis & & & & & & & & & & & & \\
\hline Hanzawaia mantaensis & & & & & & & & & & & & \\
\hline Hoeglundina elegans & & & & 3.67 & & 5.51 & 1.38 & & & 5.60 & 4.00 & \\
\hline Karreriella bradyi & & & & & & & & & & & & \\
\hline Laevidentalina advena & & & & & & & & & & & & \\
\hline Laevidentalina communis & & & & & & & & & \begin{tabular}{l|l}
1.33 \\
\end{tabular} & & & \\
\hline Laevidentalina inornata & & & & & & & & & & & & \\
\hline Lagena cf. auriculata var. inc & & & & & & & & & & & & \\
\hline Lagena cf. elongata & & & & & & & & & & & & \\
\hline Lagena cf. laevis & & & & & & & & & & & & \\
\hline Lagena elongata & 1.98 & & 1.88 & & 1.93 & & & & & & & \\
\hline Lagena elongata & & & & & & & & & & & & \\
\hline Lagena laevis & & & & & & & & & & & & \\
\hline Lagena meridonaus & & & & & & & & & & & & \\
\hline Lagena spp. & & & & & & & & & & & & \\
\hline Lagena stelligerea & & & & & & & & & & & & \\
\hline Laticarinina pauperata & & 2.42 & 3.95 & & 2.66 & & & 2.75 & 1.60 & & & \\
\hline Lenticulina altolimbatus & & & & & & & & & & & & \\
\hline Lenticulina arcuatostriata & & & & & & & 5.88 & & & \begin{tabular}{l|l}
3.73 \\
\end{tabular} & 1.14 & \\
\hline Lenticulina calcar & & & & & & & & & & & & \\
\hline Lenticulina dicampyla & & & & & & & 1.73 & & & & & \\
\hline Lenticulina iota & & & & & & & & & & \begin{tabular}{l|l}
1.87 \\
\end{tabular} & & \\
\hline Lenticulina limbosa & & & & & & & & & & 4.48 & & \\
\hline Lenticulina melvilli & & & & & & & & & & & & \\
\hline Lenticulina pliocaena & & & 1.32 & & & & & & & & & \\
\hline Lenticulina rotulata & & & & & & & & & & & 2.86 & \\
\hline Lenticulina spp. & & & & & & & & & & & & \\
\hline Lenticulina terryi & & & & & & & & & & & & \\
\hline Lenticulina texana & & & & & & & & & & & & \\
\hline Lenticulina yaguensis & & & & & & & & & & & & \\
\hline Martinottiella pallida & & & & & & & & & & & & \\
\hline Martinottiella spp. & & & & & & & & & & & & \\
\hline Melonis aff. pompiloides & & 2.17 & & & & & & & & & & \\
\hline Melonis affinis & & & & & & & & & & & & \\
\hline Melonis barleeanum & 5.93 & 11.11 & 8.46 & & 6.52 & & & 2.35 & 5.07 & & & 12.55 \\
\hline Melonis cf. barleeanum & & & & & & & & & 1.60 & & & \\
\hline Melonis cf. pompiloides & & & & & & & & & & & & \\
\hline Melonis pompilioides & & & & 1.33 & & 1.10 & & & & & & \\
\hline Miliammina fusca & & & & & & & 1.04 & & & & & \\
\hline Nodosaria fistuca & & & & & & & & & & & & \\
\hline Nodosaria lamellata & & & & & & & & & & 4.85 & & \\
\hline Nodosaria latejugata & & & & & & & & & & & & \\
\hline Nodosaria longiscata & & & & & & 18.01 & 6.57 & & & 8.58 & 2.29 & \\
\hline Nodosaria parexilis & & & & & & & & & & & & \\
\hline Nodosaria pyrula & & & & & & & 1.38 & & & & & \\
\hline Nodosaria spp. & & & & & & & \begin{tabular}{l|l}
1.73 \\
\end{tabular} & & & & \begin{tabular}{l|l}
5.43 \\
\end{tabular} & \\
\hline Nodosaria stainforthia & & & & 5.33 & & 1.10 & & & & & & \\
\hline Nonion mesonense & & & & & & & & & & & & \\
\hline Nonion commune & & & & & & & & & 1.07 & & & 1.11 \\
\hline Nonion havanense & & & & & & & & & & & & \\
\hline Nonion spp. & & & & & & & & & & & & \\
\hline Nonionella miocenica & & & & & & & & & & & & \\
\hline Nonionella spp. & & & & & & & & & & & & \\
\hline Nuttalides umbonifera & 4.40 & & & & & & & 1.18 & 4.53 & & & 3.14 \\
\hline Oolina cf. globosa ovalis & & & & & & & & & & & & \\
\hline Oolina globosa & & & & & & & & & & & & \\
\hline Oolina spp. & & & & & & & & & & & & \\
\hline Oridorsalis umbonatus & 1.76 & 7.73 & 4.32 & 2.00 & 5.56 & 2.21 & 3.81 & 7.06 & \begin{tabular}{l|l}
6.93 \\
\end{tabular} & & 1.14 & 9.23 \\
\hline Orthomorphina jetladschai & & & & & & & & & & & & \\
\hline Orthomorphina perversa & & & & & & & & & & & & \\
\hline Orthomorphina spp. & & & & & & & & & 1.33 & & & \\
\hline
\end{tabular}


Table 7, Continued.

\begin{tabular}{|c|c|c|c|c|c|c|c|c|c|c|c|c|}
\hline Sample & \begin{tabular}{|l|}
$999-33 X-03$ \\
\end{tabular} & 999-35X-01 & 999-36X-01 & $568-28 / 5$ & \begin{tabular}{|l|} 
999-37X-01 \\
\end{tabular} & $568-33 / \mathrm{CC}$ & $568-36 / \mathrm{CC}$ & \begin{tabular}{|l|}
$999-38 X-03$ \\
\end{tabular} & 999-39X-03 & $568-39 / 3$ & $569-11 / \mathrm{CC}$ & 999-41X-01 \\
\hline Age (Ma) & 12.25 & 13.11 & 13.61 & 13.62 & 14.11 & 14.16 & 14.7 & 14.77 & 15.12 & 15.79 & 15.92 & 15.94 \\
\hline Individuals & 455 & 414 & 532 & 300 & 414 & 272 & 289 & 255 & 375 & 268 & 350 & 542 \\
\hline \multicolumn{13}{|l|}{ Osangularia culteri } \\
\hline \multicolumn{13}{|l|}{\begin{tabular}{|l|} 
Parafissurina cavigera \\
\end{tabular}} \\
\hline Parafissurina lateralis f. crassa & & & & & & & & 1.18 & & & & \\
\hline \multicolumn{13}{|l|}{\begin{tabular}{|l|} 
Parafissurina spp. \\
\end{tabular}} \\
\hline Planularia venezuelana & & & & & & & & & & & & \\
\hline Planulina ornata & & & & & & 1.84 & & & & & & \\
\hline Planulina renz & & & & 19.33 & & 1.10 & & & & & & \\
\hline Planulina rugosa & & & & & & & & & & & & \\
\hline Planulina wuellerstor $f i$ & 3.08 & 1.45 & 6.39 & & 7.25 & & & 7.06 & \begin{tabular}{l|l}
4.53 \\
\end{tabular} & & & 5.72 \\
\hline Plectofrondicularia californica & & & & & & & & & & & & \\
\hline Plectofrondicularia vaughani & & & & & & & & & & & & \\
\hline Pleurostomella acuminata & 1.54 & & & & & & & & & & & 1.11 \\
\hline Pleurostomella alternans & 1.98 & 1.69 & 1.32 & & & & & & 3.20 & & & \\
\hline Pleurostomella brevis & & & & & & & & & & & & 1.11 \\
\hline Pleurostomella cf. brevis & & & 1.50 & & & & & & & & & \\
\hline Pleurostomella spp. & & & & & & & & & & & & \\
\hline Pleurostomella subnodosa & & 1.93 & & & & & & & & & & \\
\hline Praeglobobulimina auriculata & & & & & & & & & & & & \\
\hline Pullenia alazaensis & & & & & & & & & & & & \\
\hline Pullenia angusta & & & & & & & & & & & & \\
\hline Pullenia bulloides & 1.76 & 2.66 & 2.26 & & 5.31 & & & 1.96 & & & & 2.58 \\
\hline Pullenia malkinae & & & & & & & & & & & & \\
\hline Pullenia quadriloba & & 1.69 & 2.82 & & & & & & 1.60 & & & 1.66 \\
\hline Pullenia quinqueloba & 2.64 & & & & 1.21 & & & 1.57 & & & & \\
\hline Pyrgo depressa & & & & & & & & & & & & \\
\hline Pyrgo murrhina & & & & 2.00 & & & & & & & & \\
\hline Pyrgo oblonga & & & & & & & & & & & & \\
\hline Pyrgo rotalaria & & & & & & & & & & & & \\
\hline Pyrgo serrata & & & & & & & & & & & & \\
\hline Pyrulina albatrossi & & & & & & & & & & & & \\
\hline Quinqeuloculina cf. lamarckiana & & & & & & & & & & & & \\
\hline Quinqeuloculina spp. & & & & & & & & & & & & \\
\hline Quinqeuloculina lamarckiana & & & & & & & & & & & & \\
\hline Quinqueloculina venusta & & & & & & & & & & & & \\
\hline Rectuvigerina basispinata & & & & 4.00 & & 4.78 & 1.73 & & & & & \\
\hline Schenkiella spp. & & & & & & & & & & & & \\
\hline Sigmoilopsis schlumbergeri & & & & & & 1.47 & & & & & & \\
\hline Sigmoilina spp. & & & & & & & & & & & & \\
\hline Sigmoilina tenuis & 1.54 & & & & & & & & & & & \\
\hline Siphogenerina multicostata & & & & & & & & & & & 3.43 & \\
\hline Siphogenerina senni & & & & & & & & & & & & \\
\hline Siphogenerina transversa & & & & & & & & & & 8.21 & & \\
\hline Siphonia pulchra & & & & & & & 8.30 & & & & 3.71 & \\
\hline Siphonina tenuicarnata & & & & & & & & & 1.60 & & & 1.29 \\
\hline Siphonodosaria bradyi & & & & & & & & & & & & \\
\hline Siphonodosaria consobrina & & & & & & & & & & & & \\
\hline Siphonodosaria gracillima & & & & 12.00 & & 15.44 & 2.77 & & & & 16.57 & \\
\hline Siphonodosaria paucistriata & & & & 4.33 & & & & & & & & \\
\hline Siphonodosaria verneuilla & & & & & & & & & & 9.70 & & \\
\hline Siphotextularia catenata & & & & & & & & & & & & \\
\hline Siphotextularia cf. catenata & & & & & & & & & & & & \\
\hline Sphaeroidina bulloides & & & & 3.00 & & & & & 1.07 & 5.22 & 2.86 & \\
\hline Stilostomella adolphina & & & & 1.00 & & 1.47 & 2.08 & & & & & \\
\hline Stilostomella consobrina & 1.76 & 1.21 & 2.26 & & & & & 1.18 & 1.33 & & & \\
\hline Stilostomella gracilis & & & & & & 1.47 & & & & & & \\
\hline Stilostomella lepidula & & & & 3.00 & 1.21 & 2.21 & & & 1.33 & & & \\
\hline Stilostomella spp. & & & & & & & & & & & & \\
\hline Stilostomella subspinosa & & & & 1.33 & & 3.68 & & & & & 1.43 & \\
\hline Textularia agglutinanas & & & & & & & & & & & & \\
\hline Uvigerina auberiana & & & & & & & & & & & & \\
\hline Uvigerina carapitana & & & & & & & & & & 3.73 & 2.29 & \\
\hline Uvigerina cf. ciperana & & & & & & & & 1.18 & & & & \\
\hline Uvigerina cf. hollicki & & 11.59 & & & & & & & 3.73 & & & \\
\hline Uvigerina cf. senticosa & & & & & & & & & & & & 1.29 \\
\hline Uvigerina cf. striata attenuata & & & & & & & & & & & & \\
\hline Uvigerina gallowayi & & & & & & & & & & & & \\
\hline Uvigerina hispida & & & & 3.67 & & 1.10 & 11.76 & & & & 7.43 & \\
\hline Uvigerina hispida-costata & & & & & & & & & & & & \\
\hline Uvigerina peregrina & & & & & & & & & & & & \\
\hline Uvigerina rustica & & & & 4.67 & & 6.62 & 1.38 & & & 1.12 & 7.71 & \\
\hline Uvigerina senticosa & & & & & & & & & & & & \\
\hline Uvigerina sp. (costate) & & & & & & & & & & 9.70 & 2.29 & \\
\hline Uvigerina striata & & & & & & & & & & & & \\
\hline Uvigerina vaderescens & & & & & & & & & & & & \\
\hline Vaginulinopsis nudicostata & & & & & & & & & & 1.49 & & \\
\hline Vulvulina pennatula & & & & & & & & & & & & \\
\hline
\end{tabular}


Table 8 . Abundances of species ( $>1 \%)$ in percentages for $~ 12-8$ Ma.

\begin{tabular}{|c|c|c|c|c|c|c|}
\hline Sample & 999-25X-03 & 999-27X-05 & 999-28X-05 & \begin{tabular}{l|l|}
$999-29 X-05$ \\
\end{tabular} & 999-31X-01 & 999-32X-03 \\
\hline Age (Ma) & 8.23 & 9.39 & 9.90 & 10.41 & 11.09 & 11.75 \\
\hline Individuals & 200 & 995 & 676 & 572 & 385 & 201 \\
\hline \multicolumn{7}{|l|}{ Alabamina polita } \\
\hline \multicolumn{7}{|c|}{\begin{tabular}{|l} 
Ammoglobigerina cf. globigeriniformis \\
\end{tabular}} \\
\hline \multicolumn{7}{|c|}{ Ammoglobigerina globigeriniformis } \\
\hline Anamlinoides globosa & 1.50 & 3.12 & & & & 1.00 \\
\hline \multicolumn{7}{|l|}{\begin{tabular}{|l} 
Astrononion guadalupae \\
\end{tabular}} \\
\hline \multicolumn{7}{|l|}{ Astrononion novozealandicum } \\
\hline \multirow{2}{*}{\multicolumn{7}{|c|}{\begin{tabular}{|l|} 
Bolivina cf. harangensis \\
Bolivina cf. hughesi
\end{tabular}}} \\
\hline & & & & & & \\
\hline Bolivina cf. seminuda & & & & & & \\
\hline Bolivina cf. sp. A & & & & & & \\
\hline Bolivina cf. striatula & & & & & & \\
\hline Bolivina imporcata & & & & & & \\
\hline Bolivina marginata & & & & & & \\
\hline Bolivina spp. & & & & & & \\
\hline Bolivina striatula & & & & & & \\
\hline Brizalina aff. subspinescens & & 2.11 & & & & \\
\hline Brizalina antegressa & 1.50 & & & & & \\
\hline Bulimina alazaensis & & & & & & \\
\hline Bulimina cf. elongata & & & & & & \\
\hline Bulimina mexicana & & & & & & \\
\hline Bulimina rostrata & & & & & & \\
\hline Buliminella cf. pusilla & & & & 2.10 & 11.43 & \\
\hline Buliminella curta & & & & & & \\
\hline Cassidulina californica & & & & & & \\
\hline Cassidulina carapitana & & & & & & \\
\hline Cassidulina cf. corbyi & & & & & & \\
\hline Cassidulina laevigata & & & & & & \\
\hline Cassidulina minuta & & & & & & \\
\hline Cassidulina spinifera & & & & & & \\
\hline Cassidulina tricamerata & & & & & & \\
\hline Ceratobulimina alazaensis & & & & & & \\
\hline Chrysalogonium lanceolum & & & & & & \\
\hline Chrysalogonium longiscata & & & & & & \\
\hline Cibicides barnetti & & & & & & \\
\hline Cibicides cf. C. spiralis & & & & & & \\
\hline Cibicides cf. mundulus & & 1.61 & & & & \\
\hline Cibicides cf. robertsanius & & & & & & \\
\hline Cibicides floridanus & & & & & & \\
\hline Cibicides granulosa & & & & & & \\
\hline Cibicides guraboensus & & & & & & \\
\hline Cibicides heminwayae & & & & & & \\
\hline Cibicides io Cushman & & & & & & \\
\hline Cibicides lobatulus & & & & & & 1.00 \\
\hline Cibicides matanzaensis & & & & & & \\
\hline Cibicides pseudoungerianus & & & & & & \\
\hline Cibicides robertsonianus & & & & & & \\
\hline Cibicides spiralis & & & & & & \\
\hline Cibicides spirolimbatus & & & & & & \\
\hline Cibicides spp. & & & & & & 4.98 \\
\hline Cibicides trincherasensis & & & & & & \\
\hline Cibicides umbonatus & & & & & & \\
\hline Cibicides yagatensis & & & & & & \\
\hline Cibicidoides cf. laurisae & & & & & & \\
\hline Cibicidoides grimsdalei & & & & & 1.04 & \\
\hline Cibicidoides bradyi & 1.00 & 1.51 & & & 5.71 & 2.99 \\
\hline Cibicidoides cicatricosus & & & & & & \\
\hline Cibicidoides mundulus & 10.50 & 3.42 & 9.17 & & 3.12 & 10.45 \\
\hline Cibicidoides pachyderma & 1.00 & & & & & \\
\hline Cibicidoides wuellerstorffi & & & & & & \\
\hline Dentalina cocoaensis & & & & & & \\
\hline Dentalina cooperensis & & & & & & \\
\hline Dentalina pseudoobliqua & & & & & & \\
\hline Dentalina soluta Reuss & & & & & & \\
\hline Eggerella bradyi & 1.00 & & & & & \\
\hline Ehrenbergina bradyi & & & & & & \\
\hline Ehrenbergina caribbea & & & & & & \\
\hline Ehrenbergrina sp. A & & & & & & \\
\hline Epistominella exigua & 17.00 & 16.68 & 11.39 & 54.55 & 2.60 & 2.49 \\
\hline Eponides turgidus & 1.50 & & 3.55 & 15.03 & 21.82 & 2.49 \\
\hline Eponides regularis & & & & & & \\
\hline Fissuirina pseudoglobosa & 2.50 & & & & & \\
\hline Fissurina cucullata & & & & & & \\
\hline Fissurina marginata & & & & & & \\
\hline Fissurina orbignyana & & & & & & \\
\hline Fissurina seminifroma & & & & & & \\
\hline Fissurina spinosa & & & & & & \\
\hline Fissurina turbiniformis & & & & & & \\
\hline
\end{tabular}


Table 8, Continued.

\begin{tabular}{|c|c|c|c|c|c|c|}
\hline Sample & \begin{tabular}{|l|}
$999-25 X-03$ \\
\end{tabular} & 999-27X-05 & \begin{tabular}{|l|}
$999-28 X-05$ \\
\end{tabular} & \begin{tabular}{|l|}
$999-29 X-05$ \\
\end{tabular} & \begin{tabular}{|l|}
$999-31 X-01$ \\
\end{tabular} & \begin{tabular}{|l|}
$999-32 X-03$ \\
\end{tabular} \\
\hline Age (Ma) & 8.23 & 9.39 & 9.90 & 10.41 & 11.09 & 11.75 \\
\hline Individuals & 200 & 995 & 676 & 572 & 385 & 201 \\
\hline \multicolumn{7}{|l|}{ Fissurina wiesneri } \\
\hline \multicolumn{7}{|l|}{ Francesita advena } \\
\hline \multicolumn{7}{|l|}{ Gen 1. ind. sp. ind } \\
\hline Globobulimina affinis & 1.00 & & & & & \\
\hline Globobulimina cf. ovula & 1.50 & & & & & \\
\hline Globobulimina ovula & 1.00 & & & & & \\
\hline Globocassidulina subglobosa & & 18.19 & 10.36 & 5.42 & 11.17 & 24.38 \\
\hline Gyroidina altiformis & & & & & & 2.49 \\
\hline \multicolumn{7}{|l|}{\begin{tabular}{|l|} 
Gyroidina altispira \\
\end{tabular}} \\
\hline \multicolumn{7}{|l|}{ Gyroidina cf. planulata } \\
\hline Gyroidina condoni & & & & & & \\
\hline Gyroidina lamarckiana & & & & & & \\
\hline Gyroidina perampla & & & & & & \\
\hline Gyroidina planulata & & 2.11 & 4.44 & & 4.68 & 5.47 \\
\hline Gyroidina planulata & & & & & & \\
\hline Gyroidinoides soldanii & 8.50 & 1.31 & 1.63 & & 2.86 & 6.47 \\
\hline Gyroidina umbonata & & & & & & \\
\hline Gyroidina zelandica Finlay & & & & & & \\
\hline Hanzawaia isidroensis & & & & & & \\
\hline Hanzawaia mantaensis & & & & & & \\
\hline Hoeglundina elegans & & & & & & \\
\hline Karreriella bradyi & & & & & & \\
\hline Laevidentalina advena & 2.50 & & & & & \\
\hline Laevidentalina communis & & & & & & \\
\hline Laevidentalina inornata & & & & & & \\
\hline Lagena cf. auriculata var. incarituba & 1.50 & & & & & \\
\hline Lagena cf. elongata & 1.00 & & & & & \\
\hline Lagena cf. laevis & & & & & & \\
\hline Lagena elongata & 1.50 & & & & 1.82 & \\
\hline Lagena elongata & & & & & & \\
\hline Lagena laevis & & & & & & \\
\hline Lagena meridonaus & & & & & & \\
\hline Lagena spp. & & & & & & 1.00 \\
\hline Lagena stelligerea & & & & & & \\
\hline Laticarinina pauperata & & 1.41 & 1.92 & & & 4.98 \\
\hline Lenticulina altolimbatus & & & & & & \\
\hline Lenticulina arcuatostriata & & & & & & \\
\hline Lenticulina calcar & & & & & & \\
\hline Lenticulina dicampyla & & & & & & \\
\hline Lenticulina iota & & & & & & \\
\hline Lenticulina limbosa & & & & & & \\
\hline Lenticulina melvilli & & & & & & \\
\hline Lenticulina pliocaena & & & & & & \\
\hline Lenticulina rotulata & & & & & & \\
\hline Lenticulina spp. & & & & & & \\
\hline Lenticulina terryi & & & & & & \\
\hline Lenticulina texana & & & & & & \\
\hline Lenticulina yaguensis & & & & & & \\
\hline Martinottiella pallida & & & & & & \\
\hline Martinottiella spp. & & & & & & \\
\hline Melonis aff. pompiloides & & & & & & 1.00 \\
\hline Melonis affinis & & & & & & \\
\hline Melonis barleeanum & 6.50 & 16.18 & 8.43 & 5.77 & 15.58 & 1.00 \\
\hline Melonis cf. barleeanum & 1.00 & & & & & \\
\hline Melonis cf. pompiloides & & & & & 1.30 & \\
\hline Melonis pompilioides & & & & & & \\
\hline Miliammina fusca & & & & & & \\
\hline Nodosaria fistuca & & & & & & \\
\hline Nodosaria lamellata & & & & & & \\
\hline Nodosaria latejugata & & & & & & \\
\hline Nodosaria longiscata & & & & & & \\
\hline Nodosaria parexilis & & & & & & \\
\hline Nodosaria pyrula & & & & & & \\
\hline Nodosaria spp. & & & & & & \\
\hline Nodosaria stainforthia & & & & & & \\
\hline Nonion mesonense & & & & & & \\
\hline Nonion commune & 1.00 & & 1.78 & & & \\
\hline Nonion havanense & & & & & & \\
\hline Nonion spp. & 1.00 & & & & & \\
\hline Nonionella miocenica & & & & & & \\
\hline Nonionella spp. & & & & & & \\
\hline Nuttalides umbonifera & 7.00 & 8.34 & 5.18 & 1.40 & & 2.49 \\
\hline Oolina cf. globosa ovalis & 1.00 & & & & & \\
\hline Oolina globosa & & & 1.18 & & & \\
\hline Oolina spp. & 1.00 & & & & & \\
\hline Oridorsalis umbonatus & 2.00 & 2.01 & 10.21 & & 3.12 & 4.48 \\
\hline Orthomorphina jetladschai & & & & & & \\
\hline Orthomorphina perversa & & & & & & \\
\hline Orthomorphina spp. & & & & & & \\
\hline
\end{tabular}


Table 8, Continued.

\begin{tabular}{|c|c|c|c|c|c|c|}
\hline Sample & \begin{tabular}{|l|}
$999-25 X-03$ \\
\end{tabular} & 999-27X-05 & \begin{tabular}{|l|}
$999-28 X-05$ \\
\end{tabular} & 999-29X-05 & 999-31X-01 & $999-32 X-03$ \\
\hline Age (Ma) & 8.23 & 9.39 & 9.90 & 10.41 & 11.09 & 11.75 \\
\hline Individuals & 200 & 995 & 676 & 572 & 385 & 201 \\
\hline \multicolumn{7}{|l|}{ Osangularia culteri } \\
\hline \multicolumn{7}{|l|}{ Parafissurina cavigera } \\
\hline \multicolumn{7}{|l|}{ Parafissurina lateralis f. crassa } \\
\hline \multicolumn{7}{|l|}{ Parafissurina spp. } \\
\hline \multicolumn{7}{|l|}{ Planularia venezuelana } \\
\hline \multicolumn{7}{|l|}{ Planulina ornata } \\
\hline Planulina renz & & & & & & \\
\hline Planulina rugosa & & & & & & \\
\hline Planulina wuellerstorfi & 2.50 & 4.82 & 5.47 & 1.92 & 2.86 & 2.49 \\
\hline Plectofrondicularia californica & & & & & & \\
\hline Plectofrondicularia vaughani & & & & & & \\
\hline Pleurostomella acuminata & 2.00 & & & & & \\
\hline Pleurostomella alternans & & 1.71 & & & & \\
\hline Pleurostomella brevis & & & & & & \\
\hline Pleurostomella cf. brevis & & & & & & \\
\hline Pleurostomella spp. & & & & & & \\
\hline Pleurostomella subnodosa & & & & & & 4.98 \\
\hline Praeglobobulimina auriculata & & & & & & \\
\hline Pullenia alazaensis & & & & & & \\
\hline Pullenia angusta & & & & & & \\
\hline Pullenia bulloides & & & & & & 4.48 \\
\hline Pullenia malkinae & & & & & & \\
\hline Pullenia quadriloba & & 3.82 & 2.22 & & 1.30 & 1.49 \\
\hline Pullenia quinqueloba & & 1.61 & 1.63 & 1.05 & 1.30 & \\
\hline Pyrgo depressa & & & & & & \\
\hline Pyrgo murrhina & & & & & & \\
\hline Pyrgo oblonga & & & & & & \\
\hline Pyrgo rotalaria & & & & & & \\
\hline Pyrgo serrata & & & & & & \\
\hline Pyrulina albatrossi & 1.00 & & & & & \\
\hline Quinqeuloculina cf. lamarckian & & & & & & \\
\hline Quinqeuloculina spp. & & & & & & \\
\hline Quinqeuloculina lamarckiana & 2.00 & & & & & 1.00 \\
\hline Quinqueloculina venusta & & & & & & \\
\hline Rectuvigerina basispinata & & & & & & \\
\hline Schenkiella spp. & & & & & & \\
\hline Sigmoilopsis schlumbergeri & 4.50 & & 1.48 & & & \\
\hline Sigmoilina spp. & & & & & & \\
\hline Sigmoilina tenuis & & & & & & \\
\hline Siphogenerina multicostata & & & & & & \\
\hline Siphogenerina senni & & & & & & \\
\hline Siphogenerina transversa & & & & & & \\
\hline Siphonia pulchra & & & & & & \\
\hline Siphonina tenuicarnata & & & & & & \\
\hline Siphonodosaria bradyi & & & & & & \\
\hline Siphonodosaria consobrina & & & & & & \\
\hline Siphonodosaria gracillima & & & & & & \\
\hline Siphonodosaria paucistriata & & & & & & \\
\hline Siphonodosaria verneuilla & & & & & & \\
\hline Siphotextularia catenata & & & & & & \\
\hline Siphotextularia cf. catenata & & & & & & \\
\hline Sphaeroidina bulloides & & & & 1.57 & & \\
\hline Stilostomella adolphina & & & & & & \\
\hline Stilostomella consobrina & & & & & & \\
\hline Stilostomella gracilis & & & & & & \\
\hline Stilostomella lepidula & & & & & & \\
\hline Stilostomella spp. & & & & & & 1.00 \\
\hline Stilostomella subspinosa & & & & & & \\
\hline Textularia agglutinanas & & & & & & \\
\hline Uvigerina auberiana & & & & & & \\
\hline Uvigerina carapitana & & & & & & \\
\hline Uvigerina cf. ciperana & & & & & & \\
\hline Uvigerina cf. hollicki & & & 8.28 & & & \\
\hline Uvigerina cf. senticosa & & & & & & \\
\hline Uvigerina cf. striata attenuata & & & & & & \\
\hline Uvigerina gallowayi & & & & & & \\
\hline Uvigerina hispida & & & & & & \\
\hline Uvigerina hispida-costata & & & & & & \\
\hline Uvigerina peregrina & & & & & & 1.49 \\
\hline Uvigerina rustica & & & & & & \\
\hline Uvigerina senticosa & & & & & & \\
\hline Uvigerina sp. (costate) & & & & & & \\
\hline Uvigerina striata & & & & & & \\
\hline Uvigerina vaderescens & & & & & & \\
\hline Vaginulinopsis nudicostata & & & & & & \\
\hline Vulvulina pennatula & & & & & & \\
\hline
\end{tabular}


Table 9. Abundances of species ( $>1 \%)$ in percentages for $\sim 8-4 \mathrm{Ma}$

\begin{tabular}{|c|c|c|c|c|c|c|c|c|c|c|c|c|}
\hline Sample & 502-28-1 & 999-15H-03 & 502-33-1 & 503-29-1 & 999-17H-01 & 999-19H-02 & 502-48-1 & 999-20H-01 & 502-55-1 & 502-63-1 & 503-49-1 & 999-23X-05 \\
\hline Age (Ma) & 4.13 & 4.14 & 4.6 & 4.65 & 4.68 & 5.49 & 5.87 & 5.91 & 6.39 & 6.9 & 6.95 & 7.37 \\
\hline Individuals & 252 & 267 & 204 & 335 & 310 & 245 & 416 & 349 & 457 & 423 & 242 & 200 \\
\hline \multicolumn{13}{|l|}{ Alabamina polita } \\
\hline \multicolumn{13}{|c|}{\begin{tabular}{|l|} 
Ammoglobigerina cf. globigeriniformis \\
\end{tabular}} \\
\hline \multicolumn{13}{|c|}{ Ammoglobigerina globigeriniformis } \\
\hline Anamlinoides globosa & & & & & & & & & & & 2.48 & 1.50 \\
\hline Astrononion guadalupae & & & & & & & & & & & & \\
\hline Astrononion novozealandicu & & & & & & & & & & & & \\
\hline Bolivina cf. harangensis & & & & & & & & & & & & \\
\hline Bolivina cf. hughesi & & 5.99 & & & & & & & & & & \\
\hline Bolivina cf. seminuda & & & & & & & & & & & & \\
\hline Bolivina cf. sp. A & & & & & & & & & & & & \\
\hline Bolivina cf. striatula & & & & & & & & & & & & \\
\hline Bolivina imporcata & & & & & & & & & & & & \\
\hline Bolivina marginata & & & & & & & & & & & & \\
\hline Bolivina spp. & & & & & & & & & & & & \\
\hline Bolivina striatula & & & & & & 7.76 & & & & & & \\
\hline Brizalina aff. subspinescens & & & & & & & & & & & & \\
\hline Brizalina antegressa & & & & & & & & & & & & \\
\hline Bulimina alazaensis & & & & & & & & & & & & \\
\hline Bulimina cf. elongata & & & & & & & & & & & & \\
\hline Bulimina mexicana & & & & & & & & & & & & \\
\hline Bulimina rostrata & & & 2.45 & & & & 1.20 & & & 16.08 & & \\
\hline Buliminella cf. pusilla & & & & & & & & & & & & \\
\hline Buliminella curta & & & & & & & & & & & & \\
\hline Cassidulina californica & & & & & & & & & & & & \\
\hline Cassidulina carapitana & & & & & & & & & & & & \\
\hline Cassidulina cf. corbyi & & & & & & & & & & & & \\
\hline Cassidulina laevigata & & & & & & & & & & & & \\
\hline Cassidulina minuta & & & & & & & & & & & & \\
\hline Cassidulina spinifera & & & & & & & & & & & & \\
\hline Cassidulina tricamerata & & & & & & & & & & & & \\
\hline Ceratobulimina alazaensis & & & & & & & & & & & & \\
\hline Chrysalogonium lanceolum & & & & & & & & & 2.19 & & & \\
\hline Chrysalogonium longiscatat & & & & & & & & & & & & \\
\hline Cibicides barnetti & & & & & & & & & & & & \\
\hline Cibicides cf. C. spiralis & & & & & & & & & & & & \\
\hline Cibicides cf. mundulus & & & & & & & & & & & & \\
\hline Cibicides cf. robertsanius & & & & & & & & & & & & \\
\hline Cibicides floridanus & & & & & & & & & & & & \\
\hline Cibicides granulosa & & & & & & & & & & & & \\
\hline Cibicides guraboensus & & & & & & & & & & & & \\
\hline Cibicides heminwayae & 6.35 & & & & & & & & & 2.60 & & \\
\hline Cibicides io Cushman & & & & & & & & & & & & \\
\hline Cibicides lobatulus & & & & & & & & & & & & \\
\hline Cibicides matanzaensis & & & & & & & & & & & & \\
\hline Cibicides pseudoungerianus & & & & & & & & & & & & \\
\hline Cibicides robertsonianus & & & & & & & & & & & & \\
\hline Cibicides spiralis & & & & & & & 1.20 & & & & & \\
\hline Cibicides spirolimbatus & & & & & & & & & & & & \\
\hline Cibicides spp. & & & & & & & & & & & & \\
\hline Cibicides trincherasensis & & & & & & & & & & & & \\
\hline Cibicides umbonatus & & & 5.39 & & & & 2.16 & & & & & \\
\hline Cibicides yagatensis & & & & & & & & & & & & \\
\hline Cibicidoides cf. laurisae & & & & & & & & & & & & \\
\hline Cibicidoides grimsdalei & & & & & & & & & & & & \\
\hline Cibicidoides bradyi & 2.78 & 3.37 & 10.78 & & 1.29 & 7.76 & 11.54 & 5.44 & 4.38 & 3.31 & & 1.00 \\
\hline Cibicidoides cicatricosus & & & & & & & & & & & & \\
\hline Cibicidoides mundulus & & 7.87 & & & 4.19 & 1.22 & 1.92 & 7.45 & 3.06 & 1.42 & 3.72 & 1.00 \\
\hline Cibicidoides pachyderma & & & & & & 1.22 & & & & & & 5.50 \\
\hline Cibicidoides wuellerstorffi & 17.06 & & 5.39 & & & & 10.58 & & 8.10 & \begin{tabular}{l|l}
6.38 \\
\end{tabular} & 2.89 & \\
\hline Dentalina cocoaensis & & & & & & & & & & & & \\
\hline Dentalina cooperensis & & & & & & & & & & & & \\
\hline Dentalina pseudoobliqua & & & & & & & & & & & & \\
\hline Dentalina soluta Reuss & & & & & & & & & & & & \\
\hline Eggerella bradyi & 2.78 & & 10.78 & & & & 5.77 & 1.43 & 2.19 & 3.78 & 1.65 & \\
\hline Ehrenbergina bradyi & & & & & & & & & & & & \\
\hline Ehrenbergina caribbea & & & & & & & & & & & & \\
\hline Ehrenbergrina sp. A & & & & & & & & & & & & \\
\hline Epistominella exigua & 4.37 & 6.37 & 4.41 & 2.09 & 22.26 & 12.24 & & 26.36 & & & 2.07 & \\
\hline Eponides turgidus & & & & & & & & & & & & \\
\hline Eponides regularis & 1.19 & & & & & & & & & & & \\
\hline Fissuirina pseudoglobosa & & & & & & & & & & & & \\
\hline Fissurina cucullata & & & & & & & & & & & & \\
\hline Fissurina marginata & & & 1.96 & & & & & & & & & \\
\hline Fissurina orbignyana & & & & & & & & & & & & \\
\hline Fissurina seminifroma & & & & & & & & & & & & 1.00 \\
\hline Fissurina spinosa & & & 1.96 & & & & & & & & & \\
\hline Fissurina turbiniformis & & & & & & & & 1.72 & & & & \\
\hline
\end{tabular}


Table 9, Continued.

\begin{tabular}{|c|c|c|c|c|c|c|c|c|c|c|c|c|}
\hline Sample & 502-28-1 & 999-15H-03 & 502-33-1 & 503-29-1 & 999-17H-01 & 999-19H-02 & $502-48-1$ & 999-20H-01 & 502-55-1 & 502-63-1 & 503-49-1 & 999-23X-05 \\
\hline Age (Ma) & 4.13 & 4.14 & 4.6 & 4.65 & 4.68 & 5.49 & $\begin{array}{l}5.87 \\
\end{array}$ & 5.91 & 6.39 & 6.9 & 6.95 & 7.37 \\
\hline Individuals & 252 & 267 & 204 & 335 & 310 & 245 & 416 & 349 & 457 & 423 & 242 & 200 \\
\hline Fissurina wiesneri & 1.59 & & & & & & & & & & & \\
\hline \multicolumn{13}{|l|}{ Francesita advena } \\
\hline \multicolumn{13}{|l|}{ Gen 1. ind. sp. ind } \\
\hline Globobulimina affinis & & & & & & & & & & & & \\
\hline Globobulimina cf. ovula & & & & & & & & & & & & \\
\hline Globobulimina ovula & & & & & & & & & & & & \\
\hline Globocassidulina subglobosa & 9.52 & 1.87 & 3.43 & $\begin{array}{l}4.18 \\
\end{array}$ & 5.16 & & 3.13 & 2.58 & 3.94 & 3.07 & 6.20 & 12.50 \\
\hline Gyroidina altiformis & 3.17 & 2.25 & & 1.49 & & 4.08 & & & \begin{tabular}{l|l}
4.16 \\
\end{tabular} & & 2.89 & 1.00 \\
\hline Gyroidina altispira & & & & & & & & & & & & \\
\hline Gyroidina cf. planulata & & & & & & & & & & & & \\
\hline Gyroidina condoni & 2.78 & & & & & & & & & & & \\
\hline Gyroidina lamarckiana & & & & 2.09 & & & & & & 1.42 & & \\
\hline Gyroidina perampla & & & & & & & & & & & & \\
\hline Gyroidina planulata & & 1.87 & & & 7.10 & 4.08 & & 5.16 & & & & 3.50 \\
\hline Gyroidina planulata & & & & & & & & & & & & \\
\hline Gyroidinoides soldanii & 1.98 & 1.50 & & 1.19 & 1.29 & 6.53 & 3.13 & 3.72 & 2.19 & & 2.89 & 6.00 \\
\hline Gyroidina umbonata & & & & 1.49 & & & 2.40 & & 2.19 & 1.65 & & \\
\hline Gyroidina zelandica Finlay & & & & & & & & & & & & \\
\hline Hanzawaia isidroensis & & & & & & & & & & & & \\
\hline Hanzawaia mantaensis & & & & & & & & & & & & \\
\hline Hoeglundina elegans & & & & & & & & & & & & \\
\hline Karreriella bradyi & & & & & & & & & & & & \\
\hline Laevidentalina advena & & & & & & & & & & & & \\
\hline Laevidentalina communis & & & & & & & & & & & & \\
\hline Laevidentalina inornata & & & & & & 1.22 & & & & & & \\
\hline Lagena cf. auriculata var. inca & & & & & & & & & & & & \\
\hline Lagena cf. elongata & & & & & & & & & & & & \\
\hline Lagena cf. laevis & & & & & & & & & & & & \\
\hline Lagena elongata & & & & & & & & & & & & \\
\hline Lagena elongata & & & & & & & & & & & & \\
\hline Lagena laevis & & & & & & & & & & & & \\
\hline Lagena meridonaus & & & & & & & & & & & & \\
\hline Lagena spp. & & & & & & & & & & & & \\
\hline Lagena stelligerea & & 1.50 & & & & & & & & & & \\
\hline Laticarinina pauperata & 5.95 & 4.87 & 1.47 & 3.58 & 3.87 & 1.22 & 4.09 & 1.15 & 2.41 & 4.26 & 4.55 & 5.00 \\
\hline Lenticulina altolimbatus & & & & & & & & & & & & \\
\hline Lenticulina arcuatostriata & & & & & & & & & & & & \\
\hline Lenticulina calcar & & & & & & & & & & & & \\
\hline Lenticulina dicampyla & & & & & & & & & & & & \\
\hline Lenticulina iota & & & & & & & & & & & & \\
\hline Lenticulina limbosa & & & & & & & & & & & & \\
\hline Lenticulina melvilli & & & & & & & & & & & & \\
\hline Lenticulina pliocaena & & & & & & & & & & & & \\
\hline Lenticulina rotulata & & & & & & & & & & & & \\
\hline Lenticulina spp. & & & & & & & & & & & & \\
\hline Lenticulina terryi & & & & & & & & & & & & \\
\hline Lenticulina texana & & & & & & & & & & & & \\
\hline Lenticulina yaguensis & & & & & & & & & & & & \\
\hline Martinottiella pallida & & & & 1.49 & & & 1.44 & & & & & \\
\hline Martinottiella spp. & & & & & & & & & & & & \\
\hline Melonis aff. pompiloides & & & & & & & & & & & & \\
\hline Melonis affinis & & & & & & & 2.64 & & 1.31 & 3.07 & 1.24 & \\
\hline Melonis barleeanum & & 7.49 & & & 11.61 & 6.12 & & 6.02 & & & & 7.00 \\
\hline Melonis cf. barleeanum & & & & & & & & & & & & \\
\hline Melonis cf. pompiloides & & & & & & & & & & & & \\
\hline Melonis pompilioides & & & & & & & & & & & & \\
\hline Miliammina fusca & & & & & & & & & & & & \\
\hline Nodosaria fistuca & & & & & & & & & & & & \\
\hline Nodosaria lamellata & & & & & & & & & & & & \\
\hline Nodosaria latejugata & & & & & & & & & & & & \\
\hline Nodosaria longiscata & 3.97 & & & & & & \begin{tabular}{ll|}
6.73 \\
\end{tabular} & & 1.09 & 2.36 & & \\
\hline Nodosaria parexilis & & & & & & & & & & & & \\
\hline Nodosaria pyrula & & & & & & & & & & & & \\
\hline Nodosaria spp. & & & & & & & & & & & & \\
\hline Nodosaria stainforthia & & & & & & & & & & & & \\
\hline Nonion mesonense & & & & & & & & & & & & \\
\hline Nonion commune & & & & & & & & 3.44 & & & & \\
\hline Nonion havanense & & & & & & & & & & & & \\
\hline Nonion spp. & & & & & & & & & & & & \\
\hline Nonionella miocenica & & & & & & & & & & & & \\
\hline Nonionella spp. & & & & & & & 1.20 & & & & & \\
\hline Nuttalides umbonifera & 3.97 & & 19.61 & & 8.71 & & 11.30 & 6.59 & 34.35 & 19.15 & 1.24 & 9.50 \\
\hline Oolina cf. globosa ovalis & & & & & & & & & & & & \\
\hline Oolina globosa & & & & & & & & & & & & \\
\hline Oolina spp. & & & & & & & & & & & & \\
\hline Oridorsalis umbonatus & 4.37 & 10.11 & 4.90 & 1.49 & 2.26 & 12.24 & & 3.44 & 1.97 & 4.73 & 6.20 & 8.00 \\
\hline Orthomorphina jetladschai & & & & & & & & & & & & \\
\hline Orthomorphina perversa & & & & & & & & & & & & \\
\hline Orthomorphina spp. & & & & & & & & & & & & \\
\hline
\end{tabular}


Table 9, Continued.

\begin{tabular}{|c|c|c|c|c|c|c|c|c|c|c|c|c|}
\hline Sample & \begin{tabular}{|l|}
$502-28-1$ \\
\end{tabular} & 999-15H-03 & \begin{tabular}{|l|}
$502-33-1$ \\
\end{tabular} & \begin{tabular}{|l|}
$503-29-1$ \\
\end{tabular} & \begin{tabular}{|l|}
$999-17 \mathrm{H}-01$ \\
\end{tabular} & 999-19H-02 & \begin{tabular}{|l|}
$502-48-1$ \\
\end{tabular} & \begin{tabular}{|l|}
$999-20 \mathrm{H}-01$ \\
\end{tabular} & \begin{tabular}{|l|}
$502-55-1$ \\
\end{tabular} & \begin{tabular}{|l|}
$502-63-1$ \\
\end{tabular} & \begin{tabular}{|l|}
$503-49-1$ \\
\end{tabular} & $999-23 X-05$ \\
\hline \begin{tabular}{|l|} 
Age (Ma) \\
\end{tabular} & 4.13 & 4.14 & 4.6 & 4.65 & 4.68 & 5.49 & 5.87 & 5.91 & 6.39 & 6.9 & 6.95 & 7.37 \\
\hline Individuals & 252 & 267 & 204 & 335 & 310 & 245 & 416 & 349 & 457 & 423 & 242 & 200 \\
\hline \multicolumn{13}{|l|}{ Osangularia culteri } \\
\hline \multicolumn{13}{|l|}{ Parafissurina cavigera } \\
\hline \multicolumn{13}{|l|}{ Parafissurina lateralis f. crassa } \\
\hline Parafissurina spp. & & & & & & & & & & & 1.24 & \\
\hline Planularia venezuelana & & & & & & & & & & & & \\
\hline Planulina ornata & & & & & & & & & & & & \\
\hline Planulina renz & & & & & & & & & & & & \\
\hline Planulina rugosa & & 4.12 & & & 1.61 & & & 2.58 & & & & 2.50 \\
\hline Planulina wuellerstorfi & & 1.50 & & & 2.26 & 7.35 & & & & & & 19.50 \\
\hline Plectofrondicularia californica & & & & & & & & & & & & \\
\hline Plectofrondicularia vaughani & & & & & & & & & & & & \\
\hline Pleurostomella acuminata & & 1.12 & & & & 1.63 & & & & & & \\
\hline Pleurostomella alternans & & & & & & & & & & & & \\
\hline Pleurostomella brevis & & & & & & & & & & & & \\
\hline Pleurostomella cf. brevis & & & & & & & & & & & & \\
\hline Pleurostomella spp. & & & & & & & & & & & & \\
\hline Pleurostomella subnodosa & & 1.87 & & & 1.29 & & & 1.15 & & & & \\
\hline Praeglobobulimina auriculata & & & & & & & & & & & & \\
\hline Pullenia alazaensis & 1.19 & & & & & & & & 1.75 & & & \\
\hline Pullenia angusta & 1.19 & & 1.47 & & & & 1.44 & & & & & \\
\hline Pullenia bulloides & 2.38 & 1.12 & 2.94 & 2.99 & 3.87 & & & & 1.31 & 1.18 & 6.20 & 2.00 \\
\hline Pullenia malkinae & & & & & & & & & & & & \\
\hline Pullenia quadriloba & & & & & 2.26 & & & 1.15 & & & & \\
\hline Pullenia quinqueloba & & & & 1.19 & 4.19 & 2.45 & & 1.43 & 1.31 & & & 1.50 \\
\hline Pyrgo depressa & & & & & & & & & & & & \\
\hline Pyrgo murrhina & 1.59 & 2.62 & & & & 1.63 & 3.13 & 1.15 & 4.16 & 4.73 & & 2.50 \\
\hline Pyrgo oblonga & & 3.00 & & & & & & & & & & 2.50 \\
\hline Pyrgo rotalaria & 1.59 & & & & & & 1.68 & & 1.97 & & & \\
\hline Pyrgo serrata & & & & & & 1.22 & & & & & & \\
\hline Pyrulina albatrossi & & 1.50 & & & & 2.04 & & & & & & \\
\hline Quinqeuloculina cf. lamarckia & & & & & & & & & & & & \\
\hline Quinqeuloculina spp. & & & & & & & & & & & & \\
\hline Quinqeuloculina lamarckiana & & 1.87 & & & & & & & & 1.18 & & \\
\hline Quinqueloculina venusta & 1.19 & & 1.47 & 1.49 & & & & & 1.09 & 1.65 & 2.07 & \\
\hline Rectuvigerina basispinata & & & & & & & & & & & & \\
\hline Schenkiella spp. & & & & & & & & & & & & \\
\hline Sigmoilopsis schlumbergeri & & 7.49 & 6.86 & & 1.94 & 4.90 & 5.53 & 2.29 & 2.19 & & & 1.00 \\
\hline Sigmoilina spp. & & & & & & & & & & & & \\
\hline Sigmoilina tenuis & 5.16 & 3.37 & & & & & & & & & & \\
\hline Siphogenerina multicostata & & & & & & & & & & & & \\
\hline Siphogenerina senni & & & & & & & & & & & & \\
\hline Siphogenerina transversa & & & & & & & & & & & & \\
\hline Siphonia pulchra & & & & & & & & & & & & \\
\hline Siphonina tenuicarnata & & & & & & & & & & & & \\
\hline Siphonodosaria bradyi & & & & & & & & & & & & \\
\hline Siphonodosaria consobrina & & & & & & & & & & & & \\
\hline Siphonodosaria gracillima & & & & & & & & & & & 1.24 & \\
\hline Siphonodosaria paucistriata & & & & & & & & & & & & \\
\hline Siphonodosaria verneuilla & & & & & & & & & & & & \\
\hline Siphotextularia catenata & & & 1.96 & & & & & & & & & \\
\hline Siphotextularia cf. catenata & & 1.12 & & & & & & & & & & \\
\hline Sphaeroidina bulloides & & & & & & & 3.61 & 1.43 & & & & 1.00 \\
\hline Stilostomella adolphina & & & & & & & & & & & & \\
\hline Stilostomella consobrina & & & & & 1.29 & 2.04 & & & & & & \\
\hline Stilostomella gracilis & & & & & & & & & & & & \\
\hline Stilostomella lepidula & & & & & & & & & & & & \\
\hline Stilostomella spp. & & & & & & & & & & & & \\
\hline Stilostomella subspinosa & & & & & & & & & & & & \\
\hline Textularia agglutinanas & 2.38 & & & & & & 1.20 & & & 2.36 & & \\
\hline Uvigerina auberiana & & & & & & & & & & & & \\
\hline \begin{tabular}{|l|} 
Uvigerina carapitana \\
\end{tabular} & & & & & & & & & & & & \\
\hline Uvigerina cf. ciperana & & & & & & & & & & & & \\
\hline Uvigerina cf. hollicki & & & & & & & & & & & & \\
\hline Uvigerina cf. senticosa & & & & & & & & & & & & \\
\hline Uvigerina $\mathrm{cf}$. striata attenuata & & & & & & & & & & & & \\
\hline Uvigerina gallowayi & & & & & & & & & & & & \\
\hline Uvigerina hispida & & & & & & & & & & 1.42 & & \\
\hline Uvigerina hispida-costata & & & & & & 1.63 & & & & & & \\
\hline Uvigerina peregrina & & & & & & & & & & & & \\
\hline Uvigerina rustica & & & & & & & & & & & & \\
\hline Uvigerina senticosa & & & & & & & & & & & & \\
\hline Uvigerina sp. (costate) & & & & & & & & & & & & \\
\hline Uvigerina striata & & & & & & & & & & & & \\
\hline Uvigerina vaderescens & & & & & & & & & & & & \\
\hline Vaginulinopsis nudicostata & & & & & & & & & & & & \\
\hline Vulvulina pennatula & & & & & & & & & & & & \\
\hline
\end{tabular}


Table 10. Abundances of species ( $>1 \%)$ in percentages for $\sim 4-2 \mathrm{Ma}$.

\begin{tabular}{|c|c|c|c|c|c|c|c|c|c|c|}
\hline Sample & $569-7 / 5$ & $569-7 / \mathrm{CC}$ & \begin{tabular}{|l|}
$502-18-C C$ \\
\end{tabular} & $999-11 \mathrm{H}-05$ & 999-11H-05 & \begin{tabular}{|l|}
$502-20-1$ \\
\end{tabular} & \begin{tabular}{|l|}
$502-21-1$ \\
\end{tabular} & \begin{tabular}{|l|}
$502-22-1$ \\
\end{tabular} & \begin{tabular}{|l|}
$999-13 \mathrm{H}-03$ \\
\end{tabular} & \begin{tabular}{|l|}
$502-24-1$ \\
\end{tabular} \\
\hline Age (Ma) & 2.39 & 2.49 & 2.83 & 2.98 & 2.98 & 3 & 3.14 & 3.27 & 3.51 & 3.56 \\
\hline Individuals & 407 & 201 & 659 & 316 & 316 & 346 & 308 & 364 & 655 & 264 \\
\hline \multicolumn{11}{|l|}{ Alabamina polita } \\
\hline \multicolumn{11}{|c|}{ Ammoglobigerina cf. globigeriniformis } \\
\hline \multicolumn{11}{|c|}{ Ammoglobigerina globigeriniformis } \\
\hline \multicolumn{11}{|l|}{ Anamlinoides globosa } \\
\hline Astrononion guadalupae & & & 1.97 & & & & 2.27 & 7.97 & & \\
\hline Astrononion novozealandicum & & & & & & & & & 2.29 & \\
\hline Bolivina cf. harangensis & & & & & & & & & & \\
\hline Bolivina cf. hughesi & & & & & & & & & & \\
\hline Bolivina cf. seminuda & & & & & & & & & & \\
\hline Bolivina cf. sp. A & & & & & & & & & & \\
\hline Bolivina cf. striatula & & & & & & & & & & \\
\hline Bolivina imporcata & & & & & & & & & & \\
\hline Bolivina marginata & & & & & & & & & & \\
\hline Bolivina spp. & & & & & & & & & & \\
\hline Bolivina striatula & & & & 1.90 & 1.90 & & & & & \\
\hline Brizalina aff. subspinescens & & & & & & & & & & \\
\hline Brizalina antegressa & & & & & & & & & & \\
\hline Bulimina alazaensis & & 7.46 & & 1.27 & 1.27 & & & & 1.68 & \\
\hline Bulimina cf. elongata & & & & & & & & & & \\
\hline Bulimina mexicana & 1.97 & & & & & & & & & \\
\hline Bulimina rostrata & & & 1.21 & & & 4.62 & & 2.20 & & \\
\hline Buliminella cf. pusilla & & & & 1.27 & 1.27 & & & & & \\
\hline Buliminella curta & & & & & & & & & & \\
\hline Cassidulina californica & & & & & & & & & & \\
\hline Cassidulina carapitana & & & & & & & & & & \\
\hline Cassidulina cf. corbyi & & & & & & & & & & \\
\hline Cassidulina laevigata & & & & & & & & & & \\
\hline Cassidulina minuta & & & & & & & & & & 2.27 \\
\hline Cassidulina spinifera & & & & & & & & & & \\
\hline Cassidulina tricamerata & & & & & & & & & & \\
\hline Ceratobulimina alazaensis & & & & & & & & & & \\
\hline Chrysalogonium lanceolum & & & & & & & & & & \\
\hline Chrysalogonium longiscatatu & & & & & & & & & & \\
\hline Cibicides barnetti & & & & & & & & & & \\
\hline Cibicides cf. C. spiralis & & & & & & & & & & \\
\hline Cibicides cf. mundulus & & & & & & & & & & \\
\hline Cibicides cf. robertsanius & & & & & & & & & & \\
\hline Cibicides floridanus & & & & & & & & & & \\
\hline Cibicides granulosa & & & & & & & & & & \\
\hline Cibicides guraboensus & & & & & & & & & & \\
\hline Cibicides heminwayae & & & 1.37 & & & & & 2.20 & & 1.52 \\
\hline Cibicides io Cushman & & & 1.06 & & & & & & & \\
\hline Cibicides lobatulus & & & & 5.70 & 5.70 & & & & 1.68 & \\
\hline Cibicides matanzaensis & & & & & & & & & & \\
\hline Cibicides pseudoungerianus & & 1.00 & & & & & & & & \\
\hline Cibicides robertsonianus & & & & & & 2.89 & & & & \\
\hline Cibicides spiralis & & & & & & & & & & \\
\hline Cibicides spirolimbatus & & & & & & & & & & \\
\hline Cibicides spp. & & & & & & & & & & \\
\hline Cibicides trincherasensis & & & & & & & & & & \\
\hline Cibicides umbonatus & & & & & & & 2.60 & & & \\
\hline Cibicides yagatensis & & & & & & & & & & \\
\hline Cibicidoides cf. laurisae & & & & & & & & & & \\
\hline Cibicidoides grimsdalei & & & & & & & & & & \\
\hline Cibicidoides bradyi & & 3.98 & 1.52 & 1.58 & 1.58 & 2.31 & 1.62 & & & 4.17 \\
\hline Cibicidoides cicatricosus & & & & & & & & & & \\
\hline Cibicidoides mundulus & & & & 2.22 & 2.22 & & & & & \\
\hline Cibicidoides pachyderma & & & & & & & & & & \\
\hline Cibicidoides wuellerstorffi & 7.37 & & 6.53 & & 1.90 & 4.34 & 7.14 & 6.04 & & 7.20 \\
\hline Dentalina cocoaensis & & & & & & & & & & \\
\hline Dentalina cooperensis & & 1.99 & & & & & & & & \\
\hline Dentalina pseudoobliqua & & & & & & & & & & \\
\hline Dentalina soluta Reuss & & & & & & & & & & \\
\hline Eggerella bradyi & 1.97 & & 2.43 & & & 1.16 & 1.30 & 1.65 & & 7.58 \\
\hline Ehrenbergina bradyi & & & & & & & & & & \\
\hline Ehrenbergina caribbea & & 4.98 & & & & & & & & \\
\hline Ehrenbergrina sp. A & & & & & & & & & & \\
\hline Epistominella exigua & & 1.00 & & & & & & 8.24 & & 9.47 \\
\hline Eponides turgidus & & & & & & & & & & \\
\hline Eponides regularis & & & 1.52 & & & & & & & \\
\hline Fissuirina pseudoglobosa & & & & & & & & & & \\
\hline Fissurina cucullata & 1.23 & & & & & & & & & \\
\hline Fissurina marginata & & & & & & & & & & \\
\hline Fissurina orbignyana & & & & & & & & & & 1.14 \\
\hline Fissurina seminifroma & & & & & & & & & & \\
\hline Fissurina spinosa & & & & & & & & & & \\
\hline Fissurina turbiniformis & & & & & & & & & & \\
\hline
\end{tabular}




\section{Table 10, Continued.}

\begin{tabular}{|c|c|c|c|c|c|c|c|c|c|c|}
\hline Sample & $569-7 / 5$ & $569-7 / \mathrm{CC}$ & \begin{tabular}{|l|}
$502-18-C C$ \\
\end{tabular} & 999-11H-05 & 999-11H-05 & \begin{tabular}{|l|}
$502-20-1$ \\
\end{tabular} & \begin{tabular}{|l|}
$502-21-1$ \\
\end{tabular} & \begin{tabular}{|l|}
$502-22-1$ \\
\end{tabular} & \begin{tabular}{|l|}
$999-13 \mathrm{H}-03$ \\
\end{tabular} & \begin{tabular}{|l|}
$502-24-1$ \\
\end{tabular} \\
\hline Age (Ma) & 2.39 & 2.49 & 2.83 & 2.98 & 2.98 & 3 & 3.14 & 3.27 & 3.51 & 3.56 \\
\hline Individuals & \begin{tabular}{l|l}
407 \\
\end{tabular} & 201 & 659 & 316 & 316 & 346 & 308 & 364 & 655 & 264 \\
\hline \multicolumn{11}{|l|}{ Fissurina wiesneri } \\
\hline Francesita advena & & & 1.06 & & & & & & & \\
\hline \multicolumn{11}{|l|}{ Gen 1. ind. sp. ind } \\
\hline Globobulimina affinis & & 1.00 & & & & & & & & \\
\hline \multicolumn{11}{|l|}{ Globobulimina cf. ovula } \\
\hline Globobulimina ovula & & & & & & & & & & \\
\hline Globocassidulina subglobosa & 1.47 & 1.99 & 2.73 & & & & & 2.47 & 1.68 & 4.17 \\
\hline Gyroidina altiformis & 1.72 & & 1.97 & & & & & 2.47 & 1.37 & 1.52 \\
\hline Gyroidina altispira & & & & & & & & & & \\
\hline Gyroidina cf. planulata & & & & & & & & & & \\
\hline Gyroidina condoni & & & & & & & 2.60 & & & \\
\hline Gyroidina lamarckiana & 17.69 & & & & & 1.73 & & & & 7.58 \\
\hline Gyroidina perampla & & & & & & & & & & \\
\hline Gyroidina planulata & & & & & & & & & 1.07 & \\
\hline Gyroidina planulata & & & & & & & & & & \\
\hline Gyroidinoides soldanii & & & 5.92 & 2.22 & 2.22 & 4.91 & 4.22 & 2.20 & 1.53 & 1.89 \\
\hline Gyroidina umbonata & & & & & & & & & & \\
\hline Gyroidina zelandica Finlay & & 1.99 & & & & & & & & \\
\hline Hanzawaia isidroensis & & & & & & & & & & \\
\hline Hanzawaia mantaensis & & & & & & & & & & \\
\hline Hoeglundina elegans & & 1.49 & & & & & & & & \\
\hline Karreriella bradyi & & & & & & & & & & \\
\hline Laevidentalina advena & & & & & & & & & & \\
\hline Laevidentalina communis & & & & & & & & & & \\
\hline Laevidentalina inornata & & & & & & & & & & \\
\hline Lagena cf. auriculata var. ince & & & & & & & & & & \\
\hline Lagena cf. elongata & & & & & & & & & & \\
\hline Lagena cf. laevis & & & & & & & & & & \\
\hline Lagena elongata & & & & & & & & & & \\
\hline Lagena elongata & & 1.00 & & & & & & & & \\
\hline Lagena laevis & & & & & & & & & & \\
\hline Lagena meridonaus & & & & & & & & & & \\
\hline Lagena spp. & & & & & & & & & & \\
\hline Lagena stelligerea & & & & & & & & & & \\
\hline Laticarinina pauperata & & 1.99 & 2.73 & 3.16 & 3.16 & 3.18 & 2.27 & 2.20 & & 4.17 \\
\hline Lenticulina altolimbatus & & & & & & & & & & \\
\hline Lenticulina arcuatostriata & & & & & & & & & & \\
\hline Lenticulina calcar & & & & & & & & & & \\
\hline Lenticulina dicampyla & & & & & & & & & & \\
\hline \begin{tabular}{|l} 
Lenticulina iota \\
\end{tabular} & & & & & & & & & & \\
\hline Lenticulina limbosa & & & & & & & & & & \\
\hline Lenticulina melvilli & & & & & & & & & & \\
\hline Lenticulina pliocaena & & & & & & & & & & \\
\hline Lenticulina rotulata & & & & & & & & & & \\
\hline Lenticulina spp. & & & & & & & & & & \\
\hline Lenticulina terryi & & & & & & & & & & \\
\hline Lenticulina texana & & & & & & & & & & \\
\hline Lenticulina yaguensis & & & & & & & & & & \\
\hline Martinottiella pallida & & 1.99 & & & & 1.45 & 2.27 & & & 1.14 \\
\hline Martinottiella spp. & & & & & & & & & & \\
\hline Melonis aff. pompiloides & & & & & & & & & & \\
\hline Melonis affinis & 4.91 & 2.49 & & & & 4.05 & 3.90 & 1.65 & & 1.14 \\
\hline Melonis barleeanum & & & & 9.49 & 9.49 & & & & 2.60 & \\
\hline Melonis cf. barleeanum & & & & & & & & & & \\
\hline Melonis cf. pompiloides & & & & & & & & & & \\
\hline Melonis pompilioides & & & & & & & & & & \\
\hline Miliammina fusca & & & & & & & & & & \\
\hline Nodosaria fistuca & 1.47 & 3.98 & & & & & & & & \\
\hline Nodosaria lamellata & & & & & & & & & & \\
\hline Nodosaria latejugata & & & & & & & & & & \\
\hline Nodosaria longiscata & & 7.46 & & & & & 1.62 & & & \\
\hline Nodosaria parexilis & \begin{tabular}{l|l|l}
3.93 \\
\end{tabular} & 9.45 & & & & & & & & \\
\hline Nodosaria pyrula & & & & & & & & & & \\
\hline Nodosaria spp. & & & & & & & & & & \\
\hline Nodosaria stainforthia & & & & & & & & & & \\
\hline Nonion mesonense & & & & & & & & & & \\
\hline Nonion commune & & & & & & & & & & \\
\hline Nonion havanense & & & & & & 1.45 & & & & \\
\hline Nonion spp. & & & & & & & & & & \\
\hline Nonionella miocenica & & & & & & & & & & \\
\hline $\begin{array}{l}\text { Nonionella spp. } \\
\end{array}$ & & & & & & & & & & \\
\hline Nuttalides umbonifera & & & 31.87 & 24.05 & 24.05 & 25.43 & 38.31 & 33.24 & \begin{tabular}{l|l}
47.63 \\
\end{tabular} & 17.05 \\
\hline Oolina cf. globosa ovalis & & & & & & & & & & \\
\hline Oolina globosa & & & & & & & & & & \\
\hline Oolina spp. & & & & & & & & & & \\
\hline Oridorsalis umbonatus & 13.27 & 1.00 & \begin{tabular}{l|l}
4.86 \\
\end{tabular} & 3.80 & 3.80 & 3.76 & 4.87 & 6.04 & 5.50 & 3.79 \\
\hline Orthomorphina jetladschai & & & & 1.27 & 1.27 & & & & & \\
\hline Orthomorphina perversa & 3.69 & & & & & & & & & \\
\hline Orthomorphina spp. & & & & & & & & & & \\
\hline
\end{tabular}


Table 10, Continued.

\begin{tabular}{|c|c|c|c|c|c|c|c|c|c|c|}
\hline Sample & 569-7/5 & 569-7/CC & 502-18-CC & 999-11H-05 & 999-11H-05 & 502-20-1 & 502-21-1 & 502-22-1 & 999-13H-03 & 502-24-1 \\
\hline Age (Ma) & 2.39 & 2.49 & 2.83 & 2.98 & 2.98 & 3 & 3.14 & 3.27 & 3.51 & 3.56 \\
\hline Individuals & 407 & 201 & 659 & 316 & 316 & 346 & 308 & 364 & 655 & 264 \\
\hline Osangularia culteri & & & & & & 1.45 & & & & \\
\hline \multicolumn{11}{|l|}{ Parafissurina cavigera } \\
\hline \multicolumn{11}{|l|}{ Parafissurina lateralis f. crassa } \\
\hline \multicolumn{11}{|l|}{ Parafissurina spp. } \\
\hline \multicolumn{11}{|l|}{ Planularia venezuelana } \\
\hline Planulina ornata & & & & & & & & & & \\
\hline Planulina renz & & & & & & & & & & \\
\hline Planulina rugosa & & & & 1.58 & 1.58 & & & & 1.68 & \\
\hline Planulina wuellerstorfi & & & & 1.90 & & & & & & \\
\hline Plectofrondicularia californica & & & & & & & & & & \\
\hline Plectofrondicularia vaughani & & & & & & & & & & \\
\hline Pleurostomella acuminata & & & & 1.90 & 1.90 & & & & 1.53 & \\
\hline Pleurostomella alternans & & 2.99 & & & & & & & & \\
\hline Pleurostomella brevis & & & & & & & & & & \\
\hline Pleurostomella cf. brevis & & & & & & & & & & \\
\hline Pleurostomella spp. & & & & & & & & & & \\
\hline Pleurostomella subnodosa & & & & & & & & & 1.83 & \\
\hline Praeglobobulimina auriculata & 5.65 & 2.49 & & & & & & & & \\
\hline Pullenia alazaensis & & & & & & 2.02 & & & & \\
\hline Pullenia angusta & & & 3.34 & & & 1.73 & & 1.10 & & \\
\hline Pullenia bulloides & 3.19 & & 5.16 & 5.70 & 5.70 & & & 1.10 & & 1.14 \\
\hline Pullenia malkinae & & 1.00 & & & & & & & & \\
\hline Pullenia quadriloba & & & & & & & & & 1.07 & \\
\hline Pullenia quinqueloba & & & 1.52 & & & & & 1.37 & & 1.14 \\
\hline Pyrgo depressa & & & & & & 1.73 & & & & \\
\hline Pyrgo murrhina & & & & & & & 1.95 & 2.75 & & 1.89 \\
\hline Pyrgo oblonga & & & & & & & & & 1.98 & \\
\hline Pyrgo rotalaria & & & 1.06 & & & 2.31 & & & & \\
\hline Pyrgo serrata & & & & & & & & & & \\
\hline Pyrulina albatrossi & & & & & & & & & & \\
\hline Quinqeuloculina cf. lamarckiand & & & & & & & & & & \\
\hline Quinqeuloculina spp. & & & & & & & & & & \\
\hline Quinqeuloculina lamarckiana & & & & 1.58 & 1.58 & & & & 1.53 & \\
\hline Quinqueloculina venusta & & 1.99 & & & & 1.45 & & 1.65 & & \\
\hline Rectuvigerina basispinata & & & & & & & & & & \\
\hline Schenkiella spp. & & & & & & & & & & \\
\hline Sigmoilopsis schlumbergeri & & & 2.43 & 5.38 & 5.38 & 5.49 & 1.30 & 2.20 & 2.60 & 2.27 \\
\hline Sigmoilina spp. & & & & & & & & & & \\
\hline Sigmoilina tenuis & & & & & & & 3.90 & 1.10 & & \\
\hline Siphogenerina multicostata & & & & & & & & & & \\
\hline Siphogenerina senni & & & & & & & & & & \\
\hline Siphogenerina transversa & & & & & & & & & & \\
\hline Siphonia pulchra & & & & & & & & & & \\
\hline Siphonina tenuicarnata & & & & & & & & & & \\
\hline Siphonodosaria bradyi & & & & & & & & & & \\
\hline Siphonodosaria consobrina & & 3.98 & & & & & & & & \\
\hline Siphonodosaria gracillima & & & & & & & & & & \\
\hline Siphonodosaria paucistriata & & & & & & & & & & \\
\hline Siphonodosaria verneuilla & & & & & & & & & & \\
\hline Siphotextularia catenata & & & 1.06 & & & & 1.62 & & & 1.89 \\
\hline Siphotextularia cf. catenata & & & & 1.27 & 1.27 & & & & & \\
\hline Sphaeroidina bulloides & 1.23 & 1.49 & & & & & & & & \\
\hline Stilostomella adolphina & & & & & & & & & & \\
\hline Stilostomella consobrina & & & & & & & & & & \\
\hline Stilostomella gracilis & & & & & & & & & & \\
\hline Stilostomella lepidula & 6.39 & 3.98 & & & & & & & & \\
\hline Stilostomella spp. & & & & & & & & & & \\
\hline Stilostomella subspinosa & & & & & & & & & & \\
\hline Textularia agglutinanas & & & & & & 3.18 & & 1.10 & & 1.52 \\
\hline Uvigerina auberiana & & & & & & & & & & \\
\hline Uvigerina carapitana & & & & & & & & & & \\
\hline Uvigerina cf. ciperana & & & & & & & & & & \\
\hline Uvigerina cf. hollicki & & & & 6.33 & 6.33 & & & & & \\
\hline Uvigerina cf. senticosa & & & & & & & & & & \\
\hline Uvigerina cf. striata attenuata & & & & & & & & & & \\
\hline Uvigerina gallowayi & & & & & & & & & & \\
\hline Uvigerina hispida & 2.70 & 7.46 & & & & & & & & \\
\hline Uvigerina hispida-costata & & & & & & 3.76 & 5.52 & 1.65 & & \\
\hline Uvigerina peregrina & & & & & & & & & & \\
\hline Uvigerina rustica & & & & & & & & & & \\
\hline Uvigerina senticosa & 1.97 & 4.98 & & & & & & & & \\
\hline Uvigerina sp. (costate) & & & & & & & & & & \\
\hline Uvigerina striata & & & 1.52 & & & 1.16 & & & & \\
\hline Uvigerina vaderescens & 4.67 & 3.48 & & & & & & & & \\
\hline Vaginulinopsis nudicostata & & & & & & & & & & \\
\hline Vulvulina pennatula & & & & & & & & & & \\
\hline
\end{tabular}




\section{CHAPTER 5}

\section{CONCLUSIONS}

This study examined the long-term effects of the closure of the Central American Seaway on paleoproductivity, and the diversity and paleobiogeography of benthic foraminiferal assemblages. Seaway closure was a major, protracted paleoceanographic event caused by the uplift of the Isthmus of Panama. The interval examined, 26 Ma to 2 Ma, extended from the pre-closure to post-closure of the seaway and included several other major paleoceanographic events that are also examined herein. Four major intervals were used to examine the effects of the closure: (1) differentiation in bottom-water source, with a change to North Atlantic Deep Water for the Caribbean, to deep circulation barrier ( 16 - $12 \mathrm{Ma})$, deep circulation barrier to seaway constriction ( 12 - $8 \mathrm{Ma})$, seaway constriction to complete seaway closure ( 8 - 4 Ma), and complete seaway closure to post closure ( 4 - $2 \mathrm{Ma})$.

A total of 104 samples of benthic foraminifera from two Caribbean sites and three equatorial eastern Pacific sites were analyzed. The following three hypotheses were tested and are discussed below in that order:

(1) Paleoproductivity values prior to closure of the Central American Seaway were similar in both the Caribbean and equatorial Pacific and then diverged by the time of early shoaling events.

(2) Diversity values of benthic foraminifera prior to the closure of the Central American Seaway were similar in the Caribbean and EEP, and had changed by the time of early shoaling. 
(3) During the Miocene and into the Pleistocene, the progressive constriction of the CAS affected deep-sea benthic foraminiferal assemblages by increasing their dissimilarity between the Caribbean and eastern equatorial Pacific.

(1) The hypothesis that paleoproductivity values were similar prior to closure and then diverged was supported in this study. Prior to change in bottom-water source to North Atlantic Deep Water for the Caribbean at 16 Ma, there were similarities in the eutrophic, oligotrophic, and infaunal/epifaunal ratio proxies for paleoproductivity in the Caribbean and equatorial Eastern Pacific. Between 20-14 Ma, benthic foraminiferal accumulation rates (BFAR), which indicate surface-water productivity, had some noticeable peaks, suggesting that the change in bottom-water source for the Caribbean at 16 Ma caused generally high levels of paleoproductivity in the surface waters, possibly through upwelling. Some small changes, a decrease in Caribbean BFAR and decreases in Caribbean and Pacific oligotrophy, were noted at 12 Ma when a barrier to deep circulation was emplaced. The bulk of major changes seen occurred when there was an event that directly affected the area at the seafloor. When there was constriction of the Central American Seaway at $\sim 8 \mathrm{Ma}$, values of organic-flux-indicator species and BFAR at Caribbean and EEP sites diverged, with the Caribbean generally undergoing major decreases in high-organic flux and decreases in paleoproductivity. However, complete closure of the CAS is seen in the Caribbean with decreases in high-flux species, and an anomalous increase in BFAR that is attributed to an increase in Nuttalides umbonifera, leading to the conclusion that without the nutrient-rich EEP waters, the Caribbean became oligotrophic. 
(2) The hypothesis that the diversity indices Shannon's H, Fisher’s alpha, dominance and evenness diverged with progressive closure of the Central American Seaway was supported in the current study. Shannon's H, a diversity measure that takes into account the distribution of species within samples, giving more weight to common species, experienced the greatest changes in diversity prior to $\sim 8$ Ma when the barrier to deep water exchange occurred. Another diversity measure, Fisher's alpha, which is correlated with Shannon's H, also showed this. The most significant change occurred in the interval between bottom-water source differentiation at 16 Ma and constriction of the seaway at 8 Ma. These same intervals also contained the largest increases in dominance, suggesting more variable or periodically extreme conditions. The noted changes in bottom water and the deep-circulation barrier at 12 Ma caused the largest decreases in diversity, leading to the conclusion that, in the deep-sea, changes in oceanographic conditions and transport at the sea floor had a greater impact on benthic communities than complete closure of the CAS.

(3) The hypothesis that equatorial Eastern Pacific and Caribbean benthic foraminiferal assemblages showed a greater degree of similarity before CAS closure was not supported in the current study, based on Jaccard, Dice, and Simpson biogeographic similarity coefficients and non-metric multidimensional scaling. The noted differentiation in bottom-water source at $~ 16$ Ma was seen in the study as a change in composition of dominant species. While assemblage data, in terms of species abundances, did not show much change at the time of deep-water restriction ( 12 Ma) or the constriction of the seaway ( $\sim 8 \mathrm{Ma}$ ), a decrease in similarity was noted between $\sim 12 \mathrm{Ma}$ and $\sim 8 \mathrm{Ma}$ in all three biogeographic similarity coefficients, showing the greater effect of deep-water flow 
than that of bottom-water or shallower flow on deep-sea benthic foraminiferal communities. An increase in similarity was seen after the seaway constriction $\sim 8 \mathrm{Ma}$ and complete closure of the seaway ( $4 \mathrm{Ma}$ ), leading to the conclusion that, while Caribbean and EEP communities were geographically separated, they maintained similar species composition, with similarity actually increasing instead of decreasing. For the Caribbean assemblages, final closure of the Central American Seaway resulted in a change of dominance to Nuttalides umbonifera, a proxy for oligotrophic conditions.

In summary (Fig. 1), between 26-2 Ma, the greatest changes in paleoproductivity occurred at $\sim 8$ Ma with constriction of the Central American Seaway. The largest changes in species-level diversity occurred with the barrier to deep-water flow at 12 Ma. While deep-sea foraminiferal paleobiogeography did not have the expected response to the progressive closure of the Central American Seaway, the only decrease in similarity co-occurred at 12 Ma with emplacement of the deep-water barrier. The increase in similarity as closure of the seaway progressed is also seen with the application of a regression line in the younger interval (Fig. 2). Apparently, the deep-water barrier at $~ 12$ Ma had more effect than the largest change in paleoproductivity ( $\sim \mathrm{Ma})$ or the closure of the Central American Seaway at $\sim 4$ Ma.

This study of the 22 Ma leading up to the closure of the Central American Seaway provides a long-term perspective on the scale of changes seen in the studies of complete closure. It also tests the effect of older events such as the change in bottom-water source and barrier to deep-circulation on the deep-sea benthic foraminiferal assemblages. The global paleoceanographic and geologic events noted at 16 - 15 Ma (Woodruff, 1985; and Woodruff and Savin, 1985) and 7.5 - 6.5 Ma (Shackleton and Kennett, 1975; 
Bickert et al., 2004) are both identified by changes in $\delta^{13} \mathrm{C}$ seen in several proxies and indices of the study. The $\delta^{13} \mathrm{C}$ maxima $~ 16-15 \mathrm{Ma}$, attributed to Pacific deep water cooling and Antarctic glaciation, resulted in decreases in diversity indices and an increase in biogeographic similarity coefficients between the Caribbean and the EEP, as well as the benthic foraminiferal faunal turnover at 14 Ma (Woodruff, 1985, and Woodruff and Savin, 1985). The carbon isotope shift at 7.5 - 6.5 Ma (Shackleton and Kennett, 1975; Bickert et al., 2004), also possibly due to Antarctic glaciation or a global biomass decrease, is also marked by decreases in diversity indices and an increase in biogeographic similarity. The effect of these global events on the benthic foraminiferal assemblages was similar and showed the similar responses of the two faunas to these changes.

Further studies could help constrain some of these paleobiogeographic events, as well as provide more information regarding the effects of the closure on the proxies. Primarily, additional data points from the equatorial Eastern Pacific, with more robust specimen counts, should be acquired for multiple intervals so that more useful data can be integrated with the current study's new Caribbean data. Additionally, I would like to examine the planktic foraminifera and see if any increased originations or extinctions correspond to noted geologic events. In order to analyze the interesting conclusions on increasing paleobiogeographic similarity, I would like to examine studies of deep-sea benthic foramifera populations surrounding South America to determine if populations were continuous or restricted to the tropics. 

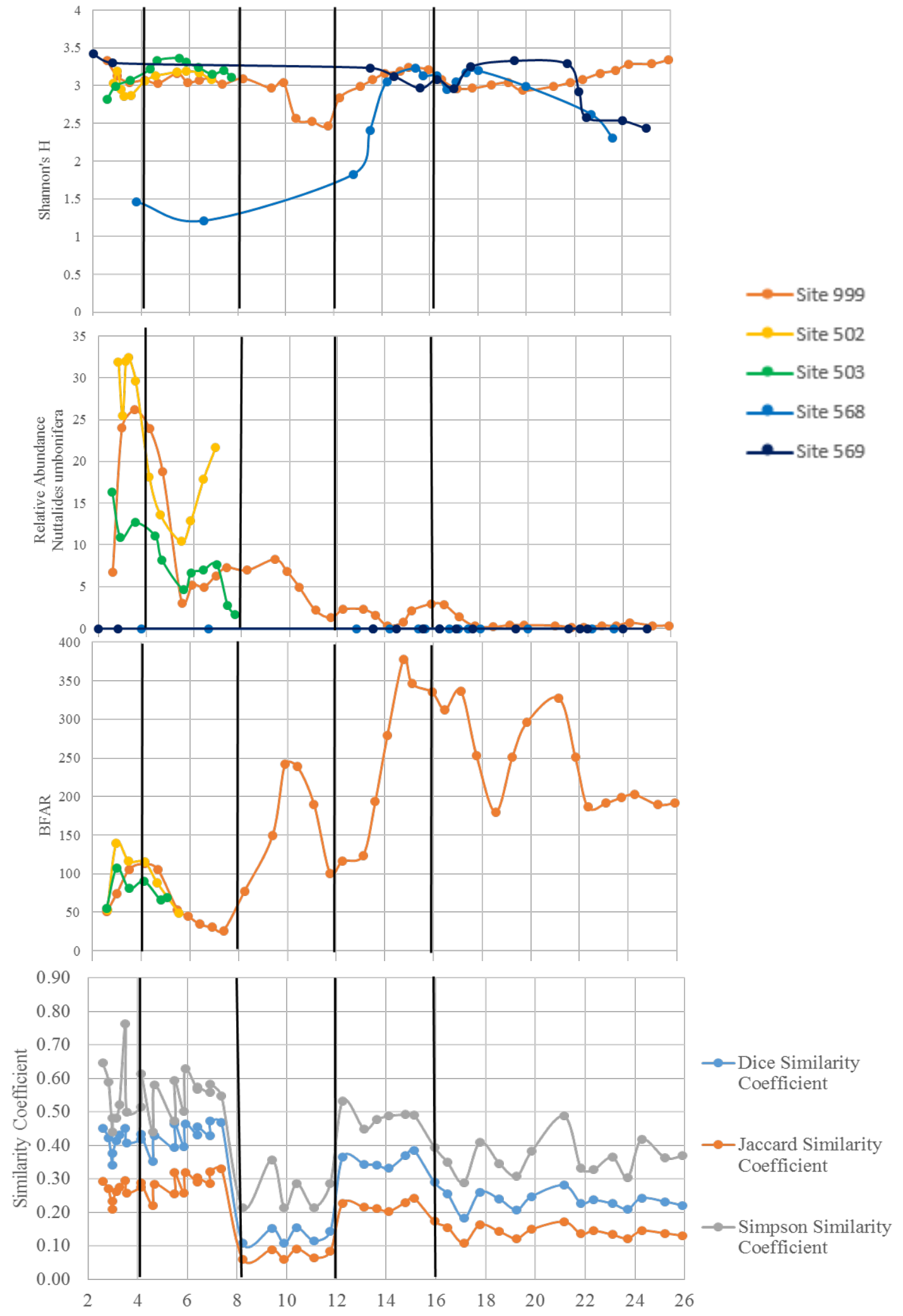

Figure 1. Summary chart of majồ (Ma) results, entire study interval. 


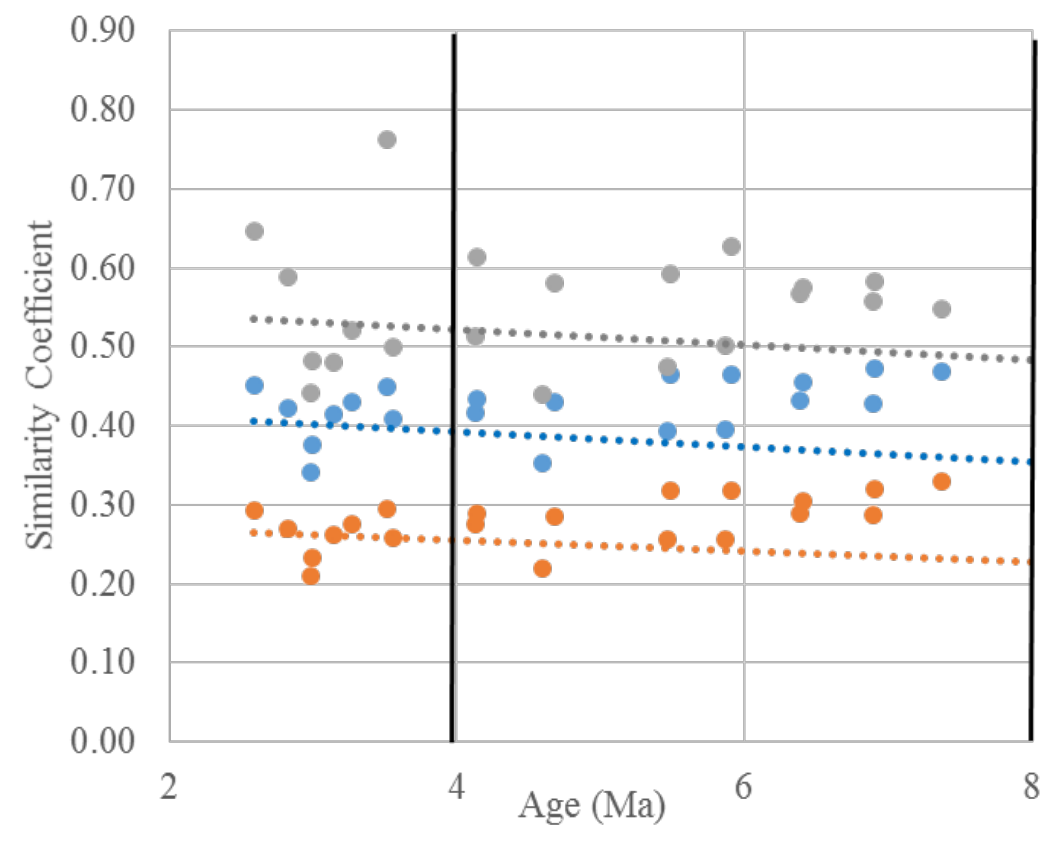

- Dice Similarity Coefficient

- Jaccard Similarity Coefficient

- Simpson Similarity Coefficient

...... Linear (Dice Similarity Coefficient) Linear (Jaccard Similarity Coefficient) ...... Linear (Simpson Similarity Coefficient)

Figure 2. Summary chart of similarity coefficients, younger interval with regression lines. 


\section{REFERENCES}

Ahrens, W.H., Cox, D.J., and Budhwar. G., 1990. Use of the arcsine and square root transformations for subjectively determined percentage data. Weed Science. 38. p. 452-458.

Allmon, W.D., 2001. Nutrients, temperature, disturbance, and evolution: a model for the late Cenozoic marine record of the western Atlantic. Palaegeography, Palaeoclimatology, Palaeoecology. 166. p. 9-26.

Altenbach, A.V., 1992. Short-term processes and patterns in the foraminiferal response to organic flux rates. Marine Micropaleontology. 19. p. 119-129

Altenbach A., Pflaumann U., Schiebel R., Thies A., Timm S., and Trauth M., 1999. Scaling relatives and distributional patterns of benthic foraminifera with flux rates of organic carbon. Journal of Foraminiferal Research. 29. p. 173-185.

Alve, E., and Goldstein, S.T., 2014. The propagule method as an experimental tool in foraminiferal ecology In Kitazato, H. and Bernhard, J.M.. (Eds.), Approaches to Study Living Foraminifera: Collection, Maintenance, and Experimentation, Springer. p. 1-12.

Barron, J.A., and Keller, G., 1982. Widespread Miocene deep-sea hiatuses: Coincidence with periods of global cooling. Geology. 10. p. 577-581.

Barmawidjaja, D.M., Jorissen, F.J., Puskaric, S., and Van der Zwaan, G. J., 1992. Microhabitat selection by benthic foraminifera in the northern Adriatic Sea. Journal of Foraminiferal Research. 22. p. 297-317.

Bartoli, G., Sarnthein, M., Weinelt, M., Erlenkeuser, H., Garbe-Schonberg, D., and Lea, D.W., 2005. Final closure of Panama and the onset of northern hemisphere glaciation. Earth and Planetary Science Letters. 237. p. 33-44.

Berggren, W.A., and Miller, K.G., 1989. Cenozoic bathyal and abyssal calcareous benthic foraminiferal zonation. Micropaleontology. 35. p. 308-320.

Berggren, J.A., Kent, D., Swisher, C.C., Aubry, M.-P., 1995. A revised Cenozoic geochronology and chronostratigraphy, geochronology time scales and global stratigraphic correlation. SEPM Special Publication. 54. p. 129-212.

Bernhard, J. M., 1992. Benthic foraminiferal distribution and biomass related to porewater oxygen content: Central California continental slope and rise. Deep-Sea Research. 39. p. 585-605. 
Bernhard, J.M., Sen Gupta, B.K., and Borne, P.F., 1997. Benthic foraminiferal proxy to estimate dysoxic bottom-water oxygen concentrations: Santa Barbara Basin U.S. Pacific continental margin. Journal of Foraminiferal Research. 27. p. 301-310.

Bickert, T., Haug, G.H., and Tiedemann, R., 2004. Late Neogene benthic stable isotope record of Ocean Drilling Program Site 999: Implications for Caribbean paleoceanography, organic carbon burial, and the Messinian Salinity Crisis. Paleoceanography. 19. p. 1-11.

Billups, K., 2002. Late Miocene through early Pliocene deep water circulation and climate change viewed from the sub-Antarctic South Atlantic. Palaeogeography, Palaeoclimatology, Palaeoecology. 185. p. 287-307.

Bornmalm, L., 1997. Taxonomy and paleoecology of late Neogene benthic foraminifera from the Caribbean Sea and equatorial Eastern Pacific Ocean. Fossils \& Strata. $41.96 \mathrm{p}$.

Bornmalm, L., Widmark, J.G.V. and Malmgren, B.A., 1999. Changes in circulation and trophic levels in the Pliocene Caribbean Sea: evidence from benthic foraminifer accumulation rates. Journal of Foraminiferal Research. 29. p. 209-221.

Bukry, D., 1973. Low-latitude coccolith biostratigraphic zonation. In Edgar, N.T., Saunders, J.B., et al (Eds.), Initial Reports of the Deep Sea Drilling Project. 15. Washington. p. 685-703.

Bukry, D., 1975. Coccolith and silicoflagellate stratigraphy, northwestern Pacific Ocean, Deep Sea Drilling Project Leg 32. In Larson, R.L., Moberly, R., et al., (Eds.) Initial Reports of the Deep Sea Drilling Project. 32. Washington. p. 677-701.

Burton, K.W., Ling, H-F., and O’Nions, R.K., 1997. Closure of the Central American Isthmus and its effect on deep-water formation in the North Atlantic. Nature. 386. p. 382-385.

Buzas, M.,A., and Culver, S.J., 1991. Species diversity and dispersal of benthic foraminifera: analysis of extant organisms and fossils of waters around North America. BioScience. 41. p. 483-489.

Buzas, M.A., Culver, S.J., and Jorissen, F.J., 1993. A statistical evaluation of the microhabitats of living (stained) infaunal benthic foraminifera. Marine Micropaleontology. 20. p. 311-320.

Buzas, M.A., and Gibson, T.G., 1969. Species diversity: benthonic foraminifera in western North Atlantic. Science. 163. p. 72-75. 
Cande, S.C., and Kent, D.V., 1995. Revised calibration of the geomagnetic polarity timescale for the Late Cretaceous and Cenozoic. Journal of Geophysical Research, 100. p. 6093-6095.

Chaisson, W.P., and D'Hondt, S.L., 2000. Neogene planktonic foraminifer biostratigraphy at Site 999, western Caribbean Sea. In Leckie, R.M., Sigurdsson, H., Acton, G.D., and Draper, G. (Eds.), Proceedings Ocean Drilling Project, Scientific. Results, 165. College Station, TX (Ocean Drilling Program). p. 19-56.

Coates, A.G., and Obando, J.A., 1996. The geologic evolution of the Central American isthmus. In: Jackson, J.B.C, Budd, A.F., and Coates, A.G. (Eds.), Evolution \& Environment in Tropical America. Chicago: The University of Chicago Press, p. 21-56.

Coates, A.G., Jackson, J.B.C., Collins, L.S., Cronin, T.M., Dowsett, H.J., Bybell, L.M., Jung, P.,and Obando, J.A., 1992. Closure of the Isthmus of Panama: The nearshore record of Costa Rica and western Panama. Geological Society of America Bulletin. 104. p. 814-828.

Coates, A.G., Aubry, M.-P., Berggren, W.A., Collins, L.S., and Kunk, M., 2003. Early Neogene history of the Central American arc from Bocas del Toro, western Panama. Geological Society of America Bulletin. 115. p. 271-287.

Coates, A.G., Collins, L.S., Aubry, M-P., and Berggren, W.A., 2004. The geology of the Darien, Panama, and the late Miocene-Pliocene collision of the Panama arc with northwestern South America. Geological Society of America Bulletin. 116. p. $1327-1344$.

Coates, A.G., McNeill, D.F., Aubry, M-P., Berggren, W.A., and Collins, L.S., 2005. An introduction to the geology of the Bocas del Toro archipelago, Panama.

Caribbean Journal of Science. 41. p. 374-391.

Coates, A.G., and Stallard, R.F., 2013. How old is the isthmus of Panama? Bulletin of Marine Science. 89. p. 801-812.

Collins, L.S., Coates, A.G., Jackson, J.B.C., and Obando, J.A., 1995. Timing and rates of emergence of the Limón and Bocas del Toro basins: Caribbean effects of Cocos Ridge subduction?. In Mann, P. (ed.), Geologic and Tectonic Development of the Caribbean Plate Boundary in southern Central America. Geological Society of America, Special Paper. p. 263-289.

Collins, L.S., Coates, A.G., Berggren, W.A., Aubry, M-P., and Zhang, J., 1996a. The late Miocene Panama isthmian strait. Geology. 24. p. 687-690. 
Collins, L.S., Budd, A.F., and Coates, A.G., 1996b. Earliest evolution associated with closure of the Tropical American Seaway. Proceedings of the National Academy of Sciences. 93. p. 6069-6072.

Corliss, B.H., 1985. Microhabitats of benthic foraminifera within deep-sea sediments. Nature. 314. p. 435-438.

Corliss, B. H., 1991. Morphology and microhabitat preferences of benthic foraminifera from the northwest Atlantic Ocean. Marine Micropaleontology. 17. p. 195-236.

Corliss, B. H., and Chen, C., 1988. Morphotype patterns of Norwegian Sea deep-sea benthic foraminifera and ecological implications. Geology. 16. p. 716-719.

Corliss, B. H., Martinson, Douglas, and G. M. Keffer, T., 1986. Late Quaternary deepocean circulation. Geological Society of America Bulletin. 97. p. 1106-1121.

Curry, W.B., Shackleton, N.J., Richter, C, et al., 1995. Proceedings Ocean Drilling Project, Initial Reports. 154. College Station, TX (Ocean Drilling Program). p. 138.

de Stigter, H.C., Jorissen, F.J., and van der Zwaan, G.J., 1998. Bathymetric distribution and microhabitat partitioning of live (Rose Bengal stained) benthic foraminifera along a shelf to bathyal transect in the southern Adriatic Sea. Journal of Foraminiferal Research. 28. p. 40-65.

Dice, L.R., 1945. Measures of the amount of ecologic association between species. Ecology. 26. p. 297-302.

Donnelly, T.W., Beets, D., Carr, M.J., Jackson, T., Klaver, G., Lewis, J., Maury, R., Schellenkens, H., Smith, A.L., Wadge, G., and Westercamp, D., 1990. History and tectonic setting of Caribbean magmatism. In G. Dengo, (Ed.), The Geology of North America: The Caribbean Region, The Geological Society of America, Inc., Boulder, CO. p. 339-374.

Douglas, R.G., 1979. Benthic foraminiferal ecology and paleoecolgy. In Foraminiferal Ecology and Paleoecology: SEPM Short Course No. 6. Society of Economic Paleontologists and Mineralogists. p. 21-53.

Douglas, R., and Woodruff, F., 1981. Deep sea benthic foraminifera. In Emiliani, C., (Ed.) The Oceanic Lithosphere, Wiley-Interscience, NY. p. 1240-1327.

Droxler, A.,W., Burke, K., Cunninham, A.D., Hine, A.C., Rosencrantz, E., Duncan, D.S., Hallock, P., Robinson, E., 1998. Caribbean constraints on circulation between Atlantic and Pacific oceans overs the past 40 million years. In Crowley, T., Burke, 
K. (Eds.) Tectonic Boundary Conditions for Climate Reconstruction. Oxford Monographs on Geology and Geophysics.

Duque-Caro, H., 1990. Neogene stratigraphy, paleoceanography and paleobiogeography in northwest South America and the evolution of the Panama seaway.

Paleogeography, Paleoclimatoloy, Paleoecology. 77. p. 203-234.

Ernst, S., Duijnstee, I., and van der Zwaan, B., 2002. The dynamics of the benthic foraminiferal microhabitat, recovery after experimental disturbance. Marine Micropaleontology. 46. p. 343- 361.

Escalante, G., 1990. The geology of southern Central America and western Columbia. In G. Dengo, (Ed.), The Geology of North America: The Caribbean Region, The Geological Society of America, Inc., Boulder, CO. p. 201-231.

Fontanier, C., Jorissen, F.J., Licari, L., Alexandre, A., and Anschutz, Carbonel, 2002. Live benthic foraminiferal faunas from the Bay of Biscay: faunal density, composition, and microhabitats. Deep-Sea Research I. 49. p. 751-785.

Frank, M., Reynolds, B.C., O'Nions, R. K., 1999. Nd and Pb isotopes in Atlantic and Pacific water masses before and after closure of the Panama Gateway. Geology 27. p. $1147-1150$.

Goldstein, S.T. and Alve, E., 2011. Experimental assembly of foraminiferal communities from coastal propagule banks. Marine Ecology Progress Series. 437. p. 1-11.

Gooday, A.,J., 1994. The biology of deep-sea foraminifera: a review of some advances and their applications in paleoceanography. Palaios. 9. p 14-31.

Gooday, A.J., 2003. Benthic foraminifera (Protista) as tools in deep-water paleoceanography: environmental influences on faunal characteristics. Advances in Marine Biology. 46. p. 1-90.

Gooday, A.J., and Rathburn, A.E., 1999. Temporal variability in living deep-sea benthic foraminifera: a review. Earth-Science Reviews. 46. p. 188-212.

Gooday, A.J., Huges, J.A., and Levin, L., 2001. The foraminiferan macrofauna from three North Carolina (U. S. A) slope sites with contrasting carbon fluxes: a comparison with the metazoan macrofauna. Deep-Sea Research I. 47. p. 25-54.

Gooday, A.J., and Jorissen, F.J., 2012. Benthic foraminiferal biogeography: Controls on global distribution patterns in deep-water settings. Annual Review of Marine Science. 4. p. 237-262. 
Grassle, J.F., 1991. Deep-sea benthic biodiversity: the ocean bottom supports communities that may be as diverse as those on any habitat on earth. Bioscience. 41. p. 464-470.

Gussone, N., Eisenhauer, A., Tiedemann, R., Haug, G.H., Heuser, A., Bock, B., Nagler, Th.F., Muller, A., 2004. Reconstruction of Caribbean Sea surface temperature and salinity fluctuations in response to the Pliocene closure of the Central American Gateway and radiative forcing, using $\delta^{44 / 40} \mathrm{Ca}, \delta^{18} \mathrm{O}$ and $\mathrm{Mg} / \mathrm{Ca}$ ratios. Earth and Planetary Science Letters. 227. p. 201-214.

Haddad, G.A., and Droxler, A.W., 1996. Metastable CaCO3 dissolution at intermediate water depths of the Caribbean and western North Atlantic: Implications for intermediate water circulation during the past 200,000 years. Paleoceangraphy. 11. p. 701-716.

Hammer, Ø., Harper, D.A.T., Ryan, P.D., 2001. PAST: Paleontological statistics software package for education and data analysis. Palaeontologia Electronica 4(1): 9 p. http://palaeo-electronica.org/2001_1/past/issue1_01.htm

Hasson, P.F., and Fischer, A.G., 1986. Observations on the Neogene of northwestern Ecuador. Micropaleontology. 32. p. 32-42.

Haug, G.H., and Tiedemann, R., 1998. Effect of the formation of the Isthmus of Panama on Atlantic Ocean thermohaline circulation. Nature. 393. p. 673-676.

Haug, G.H., Tiedemann, R., Zahn, R., and Ravelo, A.C., 2001. Role of Panama uplift on oceanic freshwater balance. Geological Society of America Bulletin. 29. p. 207210.

Haug, G.H., Tiedemann, R., and Keigwin, L.D., 2004. How the Isthmus of Panama put ice in the Arctic. Oceanus. 42. p. 1-4.

Hayek, L.C., and Buzas, M.A., 1997. Surveying Natural Populations. Columbia University Press. New York. 563 pp.

Hayek, L.C., and Buzas, M.A., 2010. Surveying Natural Populations: Quantitative Tools for Assessing Biodiversity, $2^{\text {nd }}$ (ed.) Columbia University Press. New York. 616 pp.

Hayek, L.C., and Buzas, M.A., 2013. On the proper and efficient use of diversity measures with individual field samples. Journal of Foraminiferal Research. 43. p. 305-313. 
Hayward, B.W., 2002. Late Pliocene to middle Pleistocene extinctions of deep-sea benthic foraminifera ("Stilostomella extinction") in the southwest Pacific. Journal of Foraminiferal Research. 32. p. 274-307.

Hayward, B.W., Neil, H., Carter, R., Grenfell, H.R., and Hayward, J.J., 2002. Factors influencing the distribution patterns of Recent deep-sea benthic foraminifera, east of New Zealand, Southwest Pacific Ocean. Marine Micropaleontolgy. 46. p. 139176.

Hayward, B.W., Grenfell, H.R., Carter, R., and Hayward, J.J., 2004. Benthic foraminiferal proxy evidence for the Neogene palaeoceanographic history of the Southwest Pacific, east of New Zealand. Marine Geology. 205. p. 147-184.

Hayward, B.W., Kawagata, S., Grenfell, H.R., Droxler, A.W., and Shearer, M., 2006. Mid-Pleistocene extinction of bathyal benthic foraminifera in the Caribbean Sea. Micropaleontology. 52. p. 245-266.

Heinz, P., Ruschmeier, and Hemleben, C., 2008. Live benthic foraminiferal assemblages at the Pacific continental margin of Costa Rica and Nicaragua. Journal of Foraminiferal Research. 38. p. 215-227.

Herguera, J.C., 1992. Deep-sea benthic foraminifera and biogenic opal: Glacial to postglacial productivity changes in the western equatorial Pacific. Marine Micropaleontology. 19. p. 79-98.

Ibaraki, M., 1997. Closing of the Central American Seaway and Neogene coastal upwelling along the Pacific coast of South America. Tectonophysics. 281. p. 99104.

Iturralde-Vincent, M.A., 2006. Meso-Cenozoic Caribbean paleogeography: Implications for the historical biogeography of the region. International Geology Review. 28. p. 791-827.

Jaccard, P., 1912. The distribution of the flora in the alpine zone. New Phytologist. 11. p. 37-50.

Jain, S., 2006. Changes in Caribbean Paleoproductivity, Diversity and Benthic Foraminiferal Test Size caused by the Neogene Closing of the Tropical AtlanticPacific Ocean Gateway. PhD Dissertation. Florida International University, Miami. 132 p.

Jain, S., and Collins, L., 2007. Trends in Caribbean paleoproductivity related to the Neogene closure of the Central American Seaway. Marine Micropaleontology. 63. p. 57-74. 
Jain, S., Collins, L.S., and Hayek, L.C., 2007. Relationship of benthic foraminiferal diversity to paleoproductivity in the Neogene Caribbean. Palaeogeography, Palaeoclimatology, Palaeocology. 255. p. 233-245.

Jannink, N.T., Zachariasse, W.J., and van der Zwaan, G.J., 1998. Living (Rose Bengal stained) benthic foraminifers from the Pakistan continental margin (northern Arabian Sea). Deep-Sea Research. 45. p. 1438-1513.

Jorissen, F.J., 1999. Benthic foraminiferal microhabitats below the sediment-water interface. In: Sen Gupta, B.K. (Ed.), Modern Foraminifera. Kluwer Academic Press: Dordrecht. 161-179 pp.

Jorissen, F.J., De Stigter, H.C., and Widmark, J.G., 1995. A conceptual model explaining benthic foraminiferal microhabitats. Marine Micropaleontology. 22. p. 3-15.

Jorissen, F.J., Wittling, I., Peypouquet, J., Rabouille, C., and Relexans, J.C., 1998. Live benthic foraminiferal faunas off Cap Blanc, NW Africa: community structure and microhabitats. Deep-Sea Research I. 45. p. 2157-2188.

Kameo, K., 2002. Late Pliocene Caribbean surface water dynamics and climatic changes based on calcareous nannofossil records. Palaeogeography, Palaeoclimatology, Palaeocology. 179. p. 211-226.

Kameo, K., and Bralower, T.J., 2000. Neogene calcareous nannofossil biostratigraphy of sites 998, 999, and 1000, Caribbean Sea. Proceedings of the Ocean Drilling Program, Scientific Results. 165. p. 3-17.

Kameo, K., and Sato, T., 2000. Biogeography of Neogene calcareous nannofossils in the Caribbean and the equatorial Eastern Pacific - floral response to the emergence of the Isthmus of Panama. Marine Micropaleontology. 39. p. 201-218.

Katz, M.E., and Miller, K.G., 1993. Latest Oligocene to earliest Pliocene benthic foraminiferal biofacies of the northeastern Gulf of Mexico. Micropaleontology. 32. p. 32-42.

Katz, M.E., and Thunell, R.C., 1984. Benthic foraminiferal biofacies associated with middle Miocene to early Pliocene oxygen-deficient conditions in the eastern Mediterranean. Journal of Foraminiferal Research. 14. p. 187-202.

Katz, M.E., Katz, D.R., Wright, J.D., Miller, K.G., Pak, D., K., Shackleton, N.J., and Thomas, E., 2003. Early Cenozoic benthic foraminiferal isotopes: Species reliability and interspecies correction factors. Paleoceanography. 18. p. 1-12. 
Keigwin, L., 1978. Pliocene closing of the Isthmus of Panama, based on biostratigraphic evidence from nearby Pacific Ocean and Caribbean Sea cores. Geology. 6. p. 630634.

Keigwin, L., 1982a. Isotopic paleoceanography of the Caribbean and East Pacific: Role of Panama uplift in Late Neogene time. Science. 217. p. 350-353.

Keigwin, L., 1982b. Stable isotope stratigraphy and paleoceanography of sites 502 and 503. Initial Reports of the Deep Sea Drilling Project. 68. p. 445-453.

Keller, G., and Barron, J., 1983. Paleoceanographic implications of Miocene deep-sea hiatuses. Geological Society America Bulletin. 94. p. 590-613.

Keller, G., Zenker, C.E., Stone, S.M., 1989. Late Neogene history of the Caribbean gateway. Journal of South American Earth Sciences. 2. p. 73108.

Kent, D.V. and Spariosu, D.J., 1982a. Magnetostratigraphy of Caribbean Site 502 hydraulic piston cores. Initial Reports of the Deep Sea Drilling Project. 68. p. 419-434.

Kent, D.V. and Spariosu, D.J., 1982b. Magnetostratigraphy of Equatorial Pacific Site 503 hydraulic piston cores. Initial Reports of the Deep Sea Drilling Project, 68. p. 435-440.

Kirby, M.C., Jones, D.S., and MacFadden, B.J., 2008. Lower Miocene Stratigraphy along the Panama and its bearing on the Central American Peninsula. PLoS ONE. 3. p. $1-14$.

Knappertsbush, M., 2007. Morphological variability of Globorotalia menardii (planktonic foraminifera) in two Deep Sea Drilling Project cores from the Caribbean Sea and the Equatorial Eastern Pacific. Notebooks on Geology. 4. p. 134.

Kuhnt, W., Hess, S., Holbourn, A., Paulsen, H., and Salomon, B., 2005. The impact of the 1991 Mt. Pinatubo eruption on deep-sea foraminiferal communities: A model for the Cretaceous-Tertiary (K/T) boundary? Palaeogeography, Palaeoclimatology, Palaeoecology. 224. p. 83-107.

Lear, C.H., Rosenthal, Y. and Wright, J.D., 2003. The closing of a seaway: ocean water masses and global climate change. Earth and Planetary Science Letters. 210. p. 425-436. 
Leduc, G., Vidal, L., Tachikawa, K., Rostek, F., Sonzogni, C., Beaufort, L., and Bard, E., 2007. Moisture transport across Central America as a positive feedback on abrupt climatic changes. Paleoceanography. 445. p. 908-911.

Leon-Rodriguez, L., 2007. Benthic Foraminiferal Record of the Pleistocene Uplift of the Sedimentary Deposits of the Burica Peninsula (Costa Rica-Panama) as a Result of Cocos Ridge Subduction beneath the Central American Arc. Master's Thesis. Florida International University, Miami. 151 pp.

Lessios, H.A., 2008. The great american schism: Divergence of marine organisms after the rise of the Central American Isthmus. Annual Review of Ecology, Evolution, and Systematics. 39. p. 63-91.

Licari, L.N., Schumacher, S., Wenzhofer, F., Zabel, M., and Mackensen, A., 2003. Communities and microhabitats of living benthic foraminifera from the tropical east Atlantic: Impact of different productivity regimes. Journal of Foraminiferal Research. 33. p. 10-31.

Linke, P., 1992. Metabolic adaptations of deep-sea benthic foraminifera to seasonally varying food input. Marine Ecology Progress Series. 81. p. 51-63.

Loubere, P., 1991. Deep sea benthic foraminiferal assemblage response to a surface ocean productivity gradient: A test. Paleoceanography. 6. p. 193-204.

Loubere, P., 1996. The surface ocean productivity and bottom water oxygen signals in deep water benthic foraminiferal assemblages. Marine Micropaleontology. 28. p. 247-261.

Loubere, P. and Faridudden, M., 1999. Benthic foraminifera and the flux of organic carbon to the seabed. In Sen Gupta, B.K., (Ed.), Modern Foraminifera. Dordrecht, Kluwer Academic Publishers. p. 181-199.

Lunt, D.J., Valdes, P.J., Haywood, A., and Rutt, I.C., 2008. Closure of the Panama seaway during the Pliocene: implications for climate and Northern Hemisphere glaciation. Climate Dynamics. 30. p. 1-18.

Lutze, G.F., and Thiel, H., 1989. Epibenthic foraminifera from elevated microhabitats: Cibicidoides wuellerstorfi and Planulina ariminensis. Journal of Foraminiferal Research. 19. p. 153-158.

Lyle, M., Dadey, K.A., and Farrell, J.W., 1995. The late Miocene (11-8 Ma) eastern pacific carbonate crash: evidence for reorganization of deep-water circulation by the closure of the Panama gateway. Proceedings of the Ocean Drilling Project, Scientific Results. 138. p. 821-838. 
Mackensen, A., Sejrup, H., and Jansen, E., 1985. The distribution of living and dead benthic foraminifera on the continental slope and rise off southwest Norway. Marine Micropaleontology. 9. p. 275-306.

Mackensen, A., Schmiedl, G., Harloff, J., and Giese, M., 1995. Deep-sea foraminifera in the South Atlantic Ocean: Ecology and assemblage generation. Micropaleontology. 41. p. 342-358.

Maier-Reimer, E., Mikolajewicz, U., and Crowley, T., 1990. Ocean General Circulation Model sensitivity experiment with an open Central American Isthmus. Paleoceanography. 5. p. 349-366.

Maurrasse, F.J.M., 1979. Cenozoic radiolarian paleobiogeography: Implications concerning plate tectonics and climatic cycles. Palaeogeography, Palaeoclimatology, Palaeoecology. 26. p. 253-289.

Maurrasse, F.J.M., 1993. Taxonomy, biostratigraphy, and paleoecologic significance of calcareous-siliceous facies of the Neogene Montpelier Formation, northeastern Jamaica. In Wright, R.M., and Robinson, E., (Eds.), Biostratigraphy of Jamaica.. Geological Society of America Memoir 182 Boulder, Colorado. p. 255-283.

McCorkle, D.C., Corliss, B.H., and Farnham, C., 1997. Vertical distributions and isotopic compositions of live (stained) benthic foraminifera from the North Carolina and California continental margins. Deep-Sea Research. 44. p. 983-1024.

McDougall, K., 1985. Miocene to Pleistocene benthic foraminfers and paleoceanography of the middle America slope, deep sea drilling project leg 84. Initial Reports of the Deep Sea Drilling Project. 84. p. 363-411.

McDougall, K., 1996. Benthic foraminiferal response to the emergence of the Isthmus of Panama and coincident paleoceanographic changes. Marine Micropaleontology. 28. p. 133-169.

McKinney, M.L., and Frederick, D., 1992. Extinction and population dynamics: New methods and evidence from Paleogene foraminifera. Geology. 20. p. 343-346.

Meschede, M., Weiss, R., Schmiedl, G., and Hemleben, C., 2002. Benthic foraminiferal distribution and sedimentary structures suggest tectonic erosion at the Costa Rica convergent plate margin. Terra Nova. 14. p. 388-396.

Miao, Q.M., and Thunell, R.C., 1993. Recent deep-sea benthic foraminiferal distributions in the South China and Sulu Seas. Marine Micropaleontology. 22. p. 1-32. 
Miller, K.G. and Katz, M.E., 1987. Oligocene to Miocene benthic foraminiferal and abyssal circulation changes in the North Atlantic. Micropaleontology. 33. p. 367403.

Miller, K.G., and Lohmann, G.P., 1982. Environmental distribution of Recent benthic foraminifera on the northeast United States continental slope. Geological Society of America Bulletin. 93. p. 200-206.

Miller, K.G., Janecek, T.R., Katz, M.E., and Keil, D.J., 1987. Abyssal circulation and benthic foraminiferal changes near the Paleocene/Eocene boundary.

Paleoceanography. 2. p. 741-761.

Montes, C., Cardona, A., McFadden, R., Moron, S.E., Silva, C.A., Restrepo-Moreno, S., Ramirez, D.A., Hoyos, N., Wilson, J., Farris, D., Bayona, G.A., Jaramillo, V., Valnencia, J.B., and Flores, J.A., 2012. Evidence for middle Eocene and younger land emergence in central Panama: Implications for Isthmus closure. Geological Society of America Bulletin. 124. p. 780-799.

Montes, C., Cardona, A., Jaramillo, C., Pardo, A., Silva, J.C., Valencia, V., Ayala, C., Perez-Angel, L.C., Rodriguez-Parra, L.A., Ramirez, V., and Nino, H., 2015. Middle Miocene closure of the Central American Seaway. Science. 348. p. 226229.

Moodley, L., and Hess, C., 1992. Tolerance of infaunal benthic foraminifera for low and high oxygen concentrations. Biological Bulletin. 183. p. 94-98.

Moore, T.C., van Andel, T.H., Sancetta, C., and Pisias, N., 1978. Cenozoic hiatuses in pelagic sediments. Micropaleontology. 24. p. 113-135.

Morrison, J.M., and Nowlin, W.D., 1982. General distribution of water masses within the eastern Caribbean Sea during the winter of 1972 and fall of 1973. Journal of Geophysical Research: Oceans. 87. p. 4207-4229.

Murray, J.W., 1973. Distribution and Ecology of Living Benthic Foraminiferids. Heinemann Educational Books: London. 274 pp.

Murray, J. W., 1991. Ecology and Paleoecology of Benthic Foraminifera. John Wiley and Sons Incorporation: New York. 397 pp.

Murray, J.W., 2000. The niche of benthic foramifera, critical thresholds and proxies. Micro Notes, Marine Micropaleontology. p. 1-10.

Mutti, M., Droxler, A.W., and Cunningham, A.D., 2005. Evolution of the northern Nicaragua Rise during the Oligocene-Miocene: Drowning by environmental factors. Sedimentary Geology. 175. p. 237-258. 
Nekola, J.C., and White, P.S., 1999. The distance decay of similarity in biogeography and ecology. Journal of Biogeography. 26. p. 867-878.

Newkirk, D.R., and Martin, E.E., 2009. Circulation through the Central American Seaway during the Miocene carbonate crash. Geology. 37. p. 87-90.

Nisancioglu, K.H., Raymo, M.E., and Stone, P.H., 2003. Reorganization of Miocene deep water circulation in response to the shoaling of the Central American Seaway. Paleoceanography. 18. p. 1-12.

Nof, D., and Van Gorder, S., 2003. Did an open Panama isthmus correspond to an invasion of Pacific Water into the Atlantic? Journal of Physical Oceanography. 33. p. 1324-1336.

Okada, H., and Bukry, D., 1980. Supplementary modification and introduction of code numbers to the low-latitude coccolith biostratigraphic zonation (Bukry, 1973; 1975). Marine Micropaleontology. 5. p. 321-325.

Poag, C.W., 2015. Benthic Foraminifera of the Gulf of Mexico, Distribution, Ecology, Paleoecology. Texas A\&M University Press, College Station, TX. 239 pp.

Pindell, J.L., and Barrett, S.F., 1990. Geologic evolution of the Caribbean region: a platetectonic perspective. In Dengo, G., (Ed.), The Geology of North America: The Caribbean Region. The Geological Society of America, Inc., Boulder, CO. p. 405-432.

Potter, P.E., and Szatmari, P., 2009. Global Miocene tectonics and the modern world. Earth-Science Reviews. 96. p. 279-295.

Poulson, C.J., Seidov, D., Barron, E.J., and Peterson, W.H., 1998. The impact of paleogeographic evolution on the surface oceanic circulation and the marine environment within the mid-Cretaceous Tethys. Paleoceanography. 13. p. 546559.

Prange, M., and Schulz, M., 2004. A coastal upwelling seesaw in the Atlantic Ocean as a result of the closure of the Central American Seaway. Geophysical Research Letters. 31. p. 1-4.

Rathburn, A.E., and Corliss, B.H., 1994. The ecology of living stained deep-sea benthic foraminifera from the Sulu Sea. Paleoceanography. 9. p. 87-150.

Raup, D.M., and Crick, R.E., 1979. Measurement of faunal similarity in paleontology. Journal of Paleontology. 53. p. 1213-1227. 
Reuning, L., Reigmer, J.J.G., Betzler, C., Swart, P., and Bauch, T., 2005. The use of paleoceanographic proxies in carbonate periplatform settings-opportunities and pitfalls. Sedimentary Geology. 175. p. 131-152.

Reynolds, B.C., Frank, M., O'Nions, R.K., 1999. Nd- and Pb-isotope time series from Atlantic ferromanganese crusts: implications for changes in provenance and paleocirculation over the last 8 Myr. Earth and Planetary Science Letters. 173. p. 381-396.

Roth, J.M., Droxler, A.W., and Kameo, K., 2000. The Caribbean carbonate crash at the middle to Late Miocene transition: Linkage to the establishment of the modern global ocean conveyor. Proceedings of the Ocean Drilling Program, Scientific Results. 165. p. 249-273.

Saito, T., 1976. Geologic significance of coiling direction in the planktonic foraminifera Pulleniatina. Geology. 4. p. 305-309.

Sarnthein, M., and Altenbach, A., 1995. Late Quaternary changes in surf ace water and deep water masses of the Nordic Seas and northern North Atlantic: a review. Geologische Rundschau. 84. p. 89-107.

Schmidt, M.W., Spero, H.J., and Lea, D.W., 2004. Links between salinity variation in the Caribbean and North Atlantic thermohaline circulation. Nature. 428. p. 160-163.

Schmiedl, G., and Mackensen, A., 1997. Late Quaternary paleoproductivity and deep water circulation in the eastern South Atlantic Ocean: Evidence from benthic foraminifera. Palaeogeography, Palaeoclimatology, Palaeoecology. 130. p. 4380 .

Schmiedl, G., Mackensen, A., and Muller, P.J., 1997. Recent benthic foraminifera from the eastern South Atlantic Ocean: Dependence on food supply and water masses. Marine Micropaleontology. 32. p. 249-287.

Schmuker, B., and Schiebel, R., 2002. Planktic foraminifers and hydrography of the eastern and northern Caribbean Sea. Marine Micropaleontology. 46. p. 387-403.

Schneider, B., and Schmittner, A., 2006. Simulating the impact of the Panamanian seaway closure on ocean circulation, marine productivity and nutrient cycling. Earth and Planetary Science Letters. 246. p. 367-380.

Schonfeld, J., 2001. Benthic foraminifera and pore-water oxygen profiles: a reassessment of species boundary conditions at the western Iberian margin. Journal of Foraminiferal Research. 31. p. 86-107. 
Schröder, C.J., Scott, D.B., and Medioli, F.S., 1987. Can smaller benthic foraminifera be ignored in paleoenvironmental analyses? Journal of Foraminiferal Research. 17. p. 101-105.

Shackleton, N.J., Kennett, J.P., 1975. Paleotemperature history of the Cenozoic and the initiation of Antarctic glaciation: oxygen and carbon isotope analyses in DSDP Sites 277, 279, and 281. In Kennett, J.P., Houtz, R.E., et al., Initial Reports, Deep Sea Drilling Project. 29, p. 743-755.

Seidenkrantz, M.-S., Kouwenhoven, T.J., Jorissen, F.J., Shackleton, N.J., and van der Zwaan, G.J., 2000. Benthic foraminifera as indicators of changing MediterraneanAtlantic water exchange in the late Miocene. Marine Geology. 163. p. 387-407.

Sen Gupta, B.K., Lee., R.F., and May, M.S., 1981. Upwelling and an unusual assemblage of benthic foraminifera on the northern Florida continental slope. Journal of Paleontology. 55. p. 853-857.

Shin, I.C., and Yi, H-I., 2001. Holocene paleoceanography in the southeast Venezuela Basin, Caribbean Sea. Geosciences Journal. 5. p. 101-122.

Sigurdsson, H., Leckie, R.M., Acton, G.D., et al., 1997. Proceedings of the Ocean Drilling Program, Initial Reports. 165. 401 pp.

Simpson, G.G., 1943. Mammals and the nature of continents. American Journal of Science. 241. p. 1-31.

Smart, C.W., and Gooday, A.J., 1997. Recent benthic foraminifera in the abyssal northeast Atlantic Ocean: relation to phytodetrital inputs. Journal of Foraminiferal Research. 27. p. 85-92.

Smith, C.J., Collins, L.S., and Hayek, L-A.C., 2013. Biogeographic effects of the closing Central American Seaway on benthic foraminifera of Venezuela. Bulletin of Marine Science. 89. p. 921-936.

Spezzaferri, S., McKenzie, J.A., Isern, A., 2002. Linking the oxygen isotope record of Late Neogene eustasy to sequence stratigraphic patterns along the Bahamas Margin: Results from a paleoceanographic study of ODP Leg 166, Site 1006 sediments. Marine Geology. 185. p. 95-120.

Steph, S. R., Tiedemann, R., Groeneveld, J., Sturm, A., and Nürnberg D., 2006a. Pliocene changes in tropical east Pacific upper ocean stratification: response to tropical gateways? In Tiedemann, R., Mix, A.C., Richter, C., and Ruddiman, W.F. (Eds.), Proceedings of the Ocean Drilling Project, Scientific Results. 202. p. 151. 
Steph, S., R. Tiedemann, M. Prange, J. Groeneveld, D. Nürnberg, L. Reuning, M. Schulz, and G. H. Haug, 2006b. Changes in Caribbean surface hydrography during the Pliocene shoaling of the Central American Seaway. Paleoceanography. 21. PA4221.

Steph, S., Regenberg, M., Tiedemann, R., Mulitza, S., and Nurnberg, D., 2009. Stable isotopes of planktonic foraminifera from tropical Atlantic/Caribbean core-tops: Implications for reconstructing upper ocean stratification. Marine Micropaleontolgy. 71. p. 1-19.

Sun, X., Corliss, B.H., Brown, C.W., and Showers, W. J., 2006. The effect of primary productivity and seasonality on the distribution of deep-sea benthic foraminifera in the North Atlantic. Deep Sea Research Part I: Oceanographic Research Papers. 53. p. 28-47.

Tappan, H., and Loeblich, A.R., Jr., 1988, Foraminiferal evolution, diversification, and extinction. Journal of Paleontology. 63. p. 695-714.

Thomas, E., 1985. Late Eocene to Recent deep-sea benthic foraminifers from the central equatorial Pacific ocean. Initial Reports of the Deep Sea Drilling Project. 85. p. 655-679.

Thomas, E., and Vincent, E., 1987. Equatorial Pacific deep-sea benthic foraminifera: Faunal changes before the middle Miocene polar cooling. Geology. 15. p. 10351039.

van Morkhoven, F.P.C.M., Berggren, W.A., and Edwards, A.S., 1986. Cenozoic Cosmopolitan Deep-water Benthic Foraminifera. Bulletin de Centres de Recherches Exploration-Production Elf-Aquitaine, Memoir 11. 421 pp.

Vannucchi, P., Ranero, C.R., Galeotti, S., Straub, S.M., Scholl, D.W., and McDougallRied, K., 2003. Fast rates of subduction erosion along the Costa Rica Pacific margin: Implications for nonsteady rates of crustal recycling at subduction zones. Journal of Geophysical Research. 108. p. 1-13.

Woodruff, F., 1985. Changes in Miocene deep-sea benthic foramiferal distribution in the Pacific Ocean: Relationship to paleoceanography. Geological Society of America. 163. p. 131-175.

Woodruff, F., and Savin, S., 1985. $\delta^{13} \mathrm{C}$ values of Miocene Pacific benthic foraminifera: Correlations with sea level and biological productivity. Geology. 13. p. 119-122.

Wright, J.D., Miller, K.G., Fairbanks, R.G., 1991. Evolution of modern deep water circulation: evidence from the late Miocene Southern Ocean. Paleoceanography. 6. p. $275-290$. 
Zachos, J., Pagani, M., Sloan, L., Thomas, E., and Billups, K. 2001. Trends, rhythms, and aberrations in global climate 65 Ma to present. Science. 292. p. 686-693.

Zenker, C.E., 1986. The Emergence of the Isthmus of Panama in the Late Neogene and Associated Paleoclimatic and Paleoceanographic Changes. Master's Thesis. University of California Santa Cruz. 80 pp.

Zenker, C.E., Stone, S.M. and Keller, G., 1987. Planktonic foraminifers and the emergence of the Isthmus of Panama. $4^{\text {th }}$ International Congress on Regional Pacific Neogene Stratigraphy, July 29-3 1, 1987. Abstracts Volume. Berkeley, CA. 131 pp. 
APPENDIX 1

Caribbean Site 999: Complete Benthic Foraminiferal Counts 


\begin{tabular}{|c|c|c|c|c|c|c|c|c|c|}
\hline Hole & 999A & 999A & 999A & 999A & 999A & 999A & 999A & 999A & 999A \\
\hline Sample & $10 \mathrm{H}-03$ & $11 \mathrm{H}-05$ & $13 \mathrm{H}-03$ & $15 \mathrm{H}-03$ & $17 \mathrm{H}-01$ & $19 \mathrm{H}-02$ & $20 \mathrm{H}-01$ & $21 \mathrm{H}-01$ & $22 \mathrm{X}-01$ \\
\hline Age & 2.59 & 2.98 & 3.51 & 4.14 & 4.68 & 5.49 & 5.91 & 6.41 & 6.91 \\
\hline \multicolumn{10}{|l|}{ Ammodiscus spp. } \\
\hline \multicolumn{10}{|l|}{ Ammoglobigerina cf. globigeriniformis } \\
\hline Ammoglobigerina globigeriniformis & & & & & & & & & \\
\hline Anamlinoides cf. globosa & & & & & & & & & \\
\hline Anamlinoides globosa & & & & & & 1 & 3 & 1 & \\
\hline Astacolus crepidulus & & & 2 & & & & & & \\
\hline Astrononion novozealandicum & & & 15 & & & & & & \\
\hline Bolivina aff. salinasensis & & & & & & & & & \\
\hline Bolivina cf. harangensis & & & & & & & & & \\
\hline Bolivina cf. hughesi & & & & 16 & & & & & \\
\hline Bolivina cf. seminuda & & & & & & & & & \\
\hline Bolivina cf. sp. A & & & & & & & & & \\
\hline Bolivina cf. striatula & & & & 1 & & & & & \\
\hline Bolivina cf. subaeranensis & & & & & & & & & \\
\hline Bolivina imporcata & & & & & & & & & \\
\hline Bolivina isidroensis & & & & & & & & & \\
\hline Bolivina spp. & 1 & & & & & & & & \\
\hline Bolivina striatula & 1 & 6 & & & & 19 & 1 & & 1 \\
\hline Brizalina aff. subspinescens & & 3 & 3 & & & & & & \\
\hline Brizalina antegressa & & & & & & & & & \\
\hline Bulimina alazaensis & & 4 & 11 & 1 & & & & 3 & \\
\hline Bulimina cf. aculeata & & & & & & & & & \\
\hline Bulimina cf. elongata & & & & & & & & & \\
\hline Bulimina rostrata & & & & & 1 & & 1 & & \\
\hline Bulimina spp. & & & & & & & 1 & & \\
\hline Buliminella cf. pusilla & & 4 & & & & & & & \\
\hline Cancris nuttalli & & & & 1 & & & & 1 & \\
\hline Cassidulina carapitana & & & & & & & & & \\
\hline Cassidulina cf. corbyi & & & & & & & & & \\
\hline Cassidulina cf. woodsi & & & & & & & & & \\
\hline Cassidulina monicana & & & & & & & & & \\
\hline Cassidulina subglobosa & 4 & & 11 & 5 & 16 & 2 & 9 & 6 & 2 \\
\hline Cassidulinoides bradyi & & & & 1 & & & & & \\
\hline Chilostomella oolina & & & & & & & 1 & & \\
\hline Chrysaloganium spp. & & & 2 & & & & & & \\
\hline Chrysalogonium cf. eximium & & & & & & & & & \\
\hline Chrysalogonium tenuicostatum & & & & & & & & 1 & \\
\hline Cibicides cf. mundulus & & & & & & & & & \\
\hline Cibicides cf. pachyderma & & & & & & & & & \\
\hline Cibicides cf. robertsanius & & & & & & & & & \\
\hline Cibicides choctawensis & & & & & & & & & \\
\hline Cibicides lobatulus & 2 & 18 & 11 & & & & & & \\
\hline Cibicides 'marsi' & & & & & & & & & \\
\hline Cibicides spp. & 2 & 1 & 4 & & 2 & 1 & 1 & & 1 \\
\hline Cibicides umbonatus & & & 1 & & & & & & \\
\hline Cibicidoides cf. guazamalensis & & & & & & & & & 2 \\
\hline Cibicidoides cf. laurisae & & & & & & & & & \\
\hline Cibicidoides grimsdalei & & & & & & & & & \\
\hline Cibicidoides bradyi & & 5 & 2 & 9 & 4 & 19 & 19 & 11 & 1 \\
\hline Cibicidoides cicatricosus & & & & & & & & & \\
\hline Cibicidoides grossperforatus & & & & & & & 1 & & \\
\hline Cibicidoides mexicanus & & & & & & & & & \\
\hline Cibicidoides mundulus & 1 & 7 & 1 & 21 & 13 & 3 & 26 & 3 & 2 \\
\hline Cibicidoides pachyderma & & & 3 & & 2 & 3 & 1 & 3 & 6 \\
\hline Cibicidoides perlucidus & & & & & 1 & & & & \\
\hline Cibicidoides robertsanius & & & & & & & & & \\
\hline Cyclammina spp. & & & & & & & & & \\
\hline Dentalina pseudoobliqua & & & & & & & & & \\
\hline Dentalina roemeri & & & & & & 1 & & & \\
\hline Eggerella bradyi & 2 & & 2 & & & 2 & 5 & & \\
\hline Eggerella spp. & & & & & & & & & \\
\hline Ehrenbergrina sp. A & & & & & & & & & \\
\hline Enantiodentalina murai & & & & & & & & 1 & \\
\hline Epistominella exigua & & & 3 & 17 & 69 & 30 & 92 & & 11 \\
\hline Eponides turgidus & & & & & & & & & \\
\hline Eponides sp. A & & & & & & & & & \\
\hline Eponides spp. & & 1 & & & & & 1 & & \\
\hline Fingerina weaveri & & 1 & & & & & & & \\
\hline Fissuirina cf. seguenzlana & & & & & & & 1 & & \\
\hline Fissuirina pseudoglobosa & & & & & & & & & 1 \\
\hline Fissurina aff. fimbriata & & & & & & & & & \\
\hline Fissurina bradii & & & & & & & & & \\
\hline Fissurina cf. fimbriata & & & 2 & 1 & & & & & \\
\hline Fissurina cf. formosa & & & & & & & & & \\
\hline Fissurina cf. trubiniformis & & & & & & & & & \\
\hline Fissurina collifera & & 1 & & 2 & & & & & \\
\hline Fissurina formosa & & & & & & & & & \\
\hline Fissurina lagenoides & & & & & & & & & 1 \\
\hline Fissurina radiata & & & 3 & & & & & & \\
\hline Fissurina seminifroma & & & & & & & & & \\
\hline Fissurina spp. & & 2 & & & & & & & \\
\hline
\end{tabular}




\begin{tabular}{|c|c|c|c|c|c|c|c|c|c|}
\hline Hole & 999A & 999A & 999A & 999A & 999A & 999A & 999A & 999A & 999A \\
\hline Sample & $10 \mathrm{H}-03$ & $11 \mathrm{H}-05$ & $13 \mathrm{H}-03$ & $15 \mathrm{H}-03$ & $17 \mathrm{H}-01$ & $19 \mathrm{H}-02$ & $20 \mathrm{H}-01$ & $21 \mathrm{H}-01$ & $22 \mathrm{X}-01$ \\
\hline Age & 2.59 & 2.98 & 3.51 & 4.14 & 4.68 & 5.49 & 5.91 & 6.41 & 6.91 \\
\hline Fissurina turbiniformis & & 1 & 3 & & & & 6 & & \\
\hline Francesita advena & & & 1 & & & & & & \\
\hline \multicolumn{10}{|l|}{ Indet. Gen 1. ind. spec. 1} \\
\hline Globobulimina affinis & & 1 & 3 & & & & 1 & & \\
\hline \multicolumn{10}{|l|}{ Globobulimina cf. ovula } \\
\hline \multicolumn{10}{|l|}{ Globobulimina ovula } \\
\hline \multicolumn{10}{|l|}{ Globobulimina spp. } \\
\hline Gyroidina altiformis & 1 & 1 & 9 & 6 & & 10 & 1 & & 2 \\
\hline Gyroidina cf. planulata & & & & & & & & & \\
\hline Gyroidina planulata & 5 & 3 & 7 & 5 & 22 & 10 & 18 & 2 & 6 \\
\hline Gyroidinoides soldanii & & 7 & 10 & 4 & 4 & 16 & 13 & 10 & 5 \\
\hline Hoeglodina elegans & 1 & & & & & & & & \\
\hline Indet. Gen. 2 indet. spec. 1 & & & & & & & & & \\
\hline Karreriella bradyi & 1 & 1 & & 1 & & & & & \\
\hline Karreriella subglaba & & & & 1 & & & & & \\
\hline Laevidentalina advena & & & 1 & 1 & & & & & \\
\hline Laevidentalina cf. advena & & & & & & & & & \\
\hline Laevidentalina cf. communis & & & & & & 2 & & & \\
\hline Laevidentalina communis & 3 & 1 & 4 & 1 & 2 & & 2 & 1 & \\
\hline Laevidentalina inornata & & & & & & 3 & & & 1 \\
\hline Lagena auriculata var. incarituba & & 1 & & & & 1 & & & \\
\hline Lagena castirensis & & 1 & 1 & & & & & & \\
\hline Lagena cf. auriculata var. incarituba & & & & & & & & & \\
\hline Lagena cf. elongata & & & & & & & & & \\
\hline Lagena cf. exsculpta "winged" & & & & 1 & 1 & & 1 & & \\
\hline Lagena cf. gracilis & & & 3 & 2 & & & & & \\
\hline Lagena cf. hispida & & & & & & & 1 & & \\
\hline Lagena cf. laevis & & & & & 1 & & & & \\
\hline Lagena cf. nebulosa & & & & 1 & & & 1 & & \\
\hline Lagena elongata & & & & & & & 1 & & \\
\hline Lagena feildeniana & & & & & & & & & \\
\hline Lagena gortanii & & & & & & 1 & 1 & & \\
\hline Lagena gracilis & & & & & & & & & \\
\hline Lagena hispida & & & & & 1 & & & & \\
\hline Lagena laevis & & & & 1 & 2 & & & & \\
\hline Lagena meridonaus & & 3 & 2 & 1 & 2 & & & & \\
\hline Lagena montagui & & & & & & & & & \\
\hline Lagena paradoxa & & 3 & 2 & & & & & & \\
\hline Lagena sp. Hispid & & & 2 & & & & & & \\
\hline Lagena spp. & & 1 & & & & & & & \\
\hline Lagena stelligerea & & 2 & & 4 & 3 & & & & \\
\hline Lagena sulcata & & 1 & & & & & & & \\
\hline Laticarinina pauperata & 7 & 10 & 2 & 13 & 12 & 3 & 4 & 3 & 12 \\
\hline Lenticulina cf. alta & & & & & & & & & \\
\hline Lenticulina cf. americana & & & 1 & & & & 1 & & \\
\hline Lenticulina gibba & & & & 1 & & & & & \\
\hline Lenticulina pliocaena (Silvestri) & & & & & & 1 & 1 & & 1 \\
\hline Lenticulina spp. & & & & & & & & & \\
\hline Martinottiella spp. & 3 & 2 & 3 & & & & 1 & & \\
\hline Melonis aff. barleeanum & & & & & & & & & \\
\hline Melonis aff. pompiloides & & & & 1 & & & & 1 & \\
\hline Melonis barleeanum & 9 & 30 & 17 & 20 & 36 & 15 & 21 & 20 & 16 \\
\hline Melonis cf. barleeanum & & & & & & & 3 & 1 & \\
\hline Melonis cf. pompiloides & & & & & & & & & \\
\hline Melonis pompiloides & & & & & & & & & \\
\hline Melonis spp. & & & & & & & & & \\
\hline Nodosaria spp. & & & & & & & & 1 & 1 \\
\hline Nonion mesonense & & & & & & & & & \\
\hline Nonion commune & & & & & & & 12 & & \\
\hline Nonion sp. A & & & & & & & & & \\
\hline Nonion spp. & & 1 & & & & & & & \\
\hline Nuttalides umbonifera & 11 & 76 & 312 & & 27 & 1 & 23 & 10 & 7 \\
\hline Oolina cf. globosa ovalis & 1 & & & & & & 1 & & 1 \\
\hline Oolina globosa & & & 2 & & 2 & & & & \\
\hline Oolina spp. & & & & & & & & & \\
\hline Oridorsalis stellatus & & & & & & & & & \\
\hline Oridorsalis umbonatus & 17 & 12 & 36 & 27 & 7 & 30 & 12 & 8 & 15 \\
\hline Orthomorhpina perversa & & & & 1 & & & & & \\
\hline Orthomorphina cf. nodulosatriata & & & & & & & & & \\
\hline Orthomorphina cf. rohri & & & & & & & & & \\
\hline Orthomorphina challengeriana & & & & & & & & 1 & \\
\hline Orthomorphina jetladschai & & 4 & 2 & & & & & & \\
\hline Orthomorphina nodulosatriata & & & & 2 & & & & 1 & \\
\hline Orthomorphina rohri & & & & 2 & & & & & \\
\hline Orthomorphina sp. 1 (as in Bornmalm) & & & & & & & & & \\
\hline Orthomorphina spp. & & & & & & & & & \\
\hline Osangularia culter & & & 2 & & & & & 2 & \\
\hline Ovulina striata & & & & 1 & & & & & \\
\hline
\end{tabular}




\begin{tabular}{|c|c|c|c|c|c|c|c|c|c|}
\hline Hole & 999A & 999A & 999A & 999A & 999A & 999A & $999 \mathrm{~A}$ & 999A & 999A \\
\hline Sample & $10 \mathrm{H}-03$ & $11 \mathrm{H}-05$ & $13 \mathrm{H}-03$ & $15 \mathrm{H}-03$ & $17 \mathrm{H}-01$ & $19 \mathrm{H}-02$ & $20 \mathrm{H}-01$ & $21 \mathrm{H}-01$ & $22 \mathrm{X}-01$ \\
\hline Age & 2.59 & 2.98 & 3.51 & 4.14 & 4.68 & 5.49 & 5.91 & 6.41 & 6.91 \\
\hline Parafissurina aff. ventricosa & 1 & & 2 & 2 & & & & & \\
\hline Parafissurina cavigera & & 2 & & & & & 1 & & \\
\hline \multicolumn{10}{|l|}{ Parafissurina cf. dorbignyana } \\
\hline Parafissurina cf. Iateralis f. crassa & & 1 & & & 1 & & & & \\
\hline \multicolumn{10}{|l|}{ Parafissurina cf. ventricosa } \\
\hline Parafissurina dorbignyana & & 1 & 4 & & 2 & & & 2 & \\
\hline Parafissurina fusuliformis & & & 6 & & & & & & \\
\hline Parafissurina lateralis f. crassa & & & & & 2 & 1 & & & 1 \\
\hline Parafissurina pseudomarginata & & & 1 & 1 & & & 1 & & \\
\hline Parafissurina spp. & & & & & 1 & & & & \\
\hline \multicolumn{10}{|l|}{ Parafissurina tectulostoma } \\
\hline Parafissurina ventricosa & 1 & 2 & 2 & 2 & 1 & 1 & 1 & & \\
\hline Parafissurina vidriosa & 1 & & 3 & & 2 & & & & \\
\hline Planulina rugosa & 3 & 5 & 11 & 11 & 5 & 1 & 9 & 2 & 3 \\
\hline Planulina wuellerstorfi & 6 & 6 & 6 & 4 & 7 & 18 & 3 & 11 & 16 \\
\hline Pleurostomella acuminata & 2 & 6 & 10 & 3 & & 4 & 1 & & 1 \\
\hline Pleurostomella alternans & & & 6 & 2 & 2 & 1 & 3 & & 6 \\
\hline Pleurostomella bierigi & & & & & & & & & \\
\hline Pleurostomella brevis & & & & & 1 & & & & 1 \\
\hline Pleurostomella cf. brevis & & & & & & & & & \\
\hline Pleurostomella spp. & & & & & & & & & \\
\hline Pleurostomella subnodosa & & 2 & 12 & 5 & 4 & 2 & 4 & 1 & 1 \\
\hline Polymorphinidae formae fistulosis & & & & & & & & & \\
\hline Proxifrons advena & & & & & & & & & \\
\hline Pullenia bulloides & 2 & 18 & 5 & 3 & 12 & & & 1 & 3 \\
\hline Pullenia quadriloba & & 2 & 7 & & 7 & & 4 & & \\
\hline Pullenia quinqueloba & 5 & 3 & 3 & & 13 & 6 & 5 & & \\
\hline Pullenia subcarinata & & & & & & & & 1 & \\
\hline Pyrgo lucernula & & & & & 1 & & & & \\
\hline Pyrgo murrhina & 8 & 2 & 3 & 7 & 1 & 4 & 4 & 4 & 3 \\
\hline Pyrgo oblonga & 8 & & 13 & 8 & & & 2 & & 2 \\
\hline Pyrgo serrata & & & & & & 3 & & & \\
\hline Pyrulina albatrossi & 2 & 1 & 1 & 4 & 1 & 5 & 1 & 3 & \\
\hline Pyrulina sp. A & & & & & & & & & 2 \\
\hline Pyrulina spp. & 1 & & & & & & & & \\
\hline Quinqeuloculina cf. Iamarckiana & & & & & & & & & \\
\hline Quinqeuloculina lamarckiana & 5 & 5 & 10 & 5 & 3 & 1 & 2 & 3 & 4 \\
\hline Quinqeuloculina sp. A & & & & & & & & & \\
\hline Quinqeuloculina sp. B & & & & & & & & & \\
\hline Quinqeuloculina spp. & & & 2 & & & & & & \\
\hline Rectoglandulina sp. A & & & & & & & & & \\
\hline Rectuvigerina bassispirata & & & & & & & & & \\
\hline Reophax sp. A & & & & & & & & & \\
\hline Scallopostoma ovicula & & & & 1 & & 1 & 1 & & \\
\hline Schenkiella spp. & & & & & & & & & \\
\hline Sigmoilina spp. & & & & & & & & & \\
\hline Sigmoilina tenuis & 3 & 1 & 3 & 9 & 1 & & 3 & & 9 \\
\hline Sigmoilopsis schlumbergeri & 10 & 17 & 17 & 20 & 6 & 12 & 8 & 1 & 2 \\
\hline Siphonina tenuicarnata & & & & & & & & & \\
\hline Siphonodosaria bradyi & & & 1 & & & & & & 4 \\
\hline Siphonodosaria nuttalli gracillima & & 1 & & & & & & & \\
\hline Siphotextularia cf. catenata & 5 & 4 & 2 & 3 & & & & & \\
\hline Sphaeroidina bulloides & 3 & & & 1 & & 1 & 5 & 1 & \\
\hline Spriroplectammina cubensis & & & & & & & & & \\
\hline Stilostomella abyssorum & & & & 1 & 1 & & & & \\
\hline Stilostomella cf. subspinosa & & & 1 & & & & & & \\
\hline Stilostomella consobrina & 2 & 2 & 6 & 1 & 4 & 5 & 2 & 4 & 4 \\
\hline Stilostomella lepidula & 1 & & 3 & 1 & & & & & \\
\hline Stilostomella spp. & & & 1 & & 1 & & & & \\
\hline Stilostomella subspinosa & & & & & & & & & \\
\hline Stilostomella verneuli paucistriata & & & & & & & & & \\
\hline Textularia agglutinans & & & 1 & 1 & & & & & \\
\hline Textularia spp. & & & & & & & & & \\
\hline Trochammina spp. & & & & & & & & & \\
\hline Uvigerina auberiana & & & & & & & & & \\
\hline Uvigerina cf. auberiana & & & & & & & & & \\
\hline Uvigerina cf. ciperana & & & & & & & & & \\
\hline Uvigerina cf. hollicki & & 20 & & & & & & & \\
\hline Uvigerina cf. mantaensis & 2 & & 1 & & & & & & \\
\hline Uvigerina cf. senticosa & 3 & & & & & & & & \\
\hline Uvigerina cf. striata attenuata & & & & & & & & & \\
\hline Uvigerina ciperana & & & & & & & 1 & & \\
\hline Uvigerina hispida & & & 1 & & 1 & & & 1 & \\
\hline Uvigerina hispida-costata & 16 & & 5 & & & 4 & & & \\
\hline Uvigerina peregrina & 1 & & 5 & & & 1 & & & \\
\hline Uvigerina spp. & & & & & & & & & \\
\hline Vulvulina pennatula & & & & & & & & & \\
\hline Vulvulina spinosa & & & & & & & & & \\
\hline Number of Forams & 163 & 316 & 655 & 267 & 310 & 245 & 349 & 126 & 157 \\
\hline Number of Species & 41 & 53 & 70 & 55 & 46 & 40 & 56 & 35 & 37 \\
\hline
\end{tabular}




\begin{tabular}{|c|c|c|c|c|c|c|c|c|c|}
\hline Hole & 999A & 999A & 999A & 999A & 999A & 999A & 999A & 999A & 999A \\
\hline Sample & 23X-05 & 25X-03 & $27 \mathrm{X}-05$ & 28X-05 & 29X-05 & $31 \mathrm{X}-01$ & $32 \mathrm{X}-03$ & $33 \mathrm{X}-03$ & $35 \mathrm{X}-01$ \\
\hline Age & 7.37 & 8.23 & 9.39 & 9.9 & 10.41 & 11.09 & 11.75 & 12.25 & 13.11 \\
\hline Ammodiscus spp. & & 1 & & & & & & & \\
\hline \multicolumn{10}{|l|}{ Ammoglobigerina cf. globigeriniformis } \\
\hline Ammoglobigerina globigeriniformis & & & & & & & & 3 & \\
\hline \multicolumn{10}{|l|}{ Anamlinoides cf. globosa } \\
\hline Anamlinoides globosa & 3 & 3 & 31 & 2 & & 3 & 2 & 8 & 5 \\
\hline Astacolus crepidulus & & & & & & & & & \\
\hline Astrononion novozealandicum & & & & & & & & & \\
\hline Bolivina aff. salinasensis & & & & & & & & & \\
\hline Bolivina cf. harangensis & & & 4 & & & 1 & & & \\
\hline Bolivina cf. hughesi & & & & & & & & & \\
\hline Bolivina cf. seminuda & & & & & & & & 11 & \\
\hline Bolivina cf. sp. A & & & & & & & & & \\
\hline Bolivina cf. striatula & & & & & & & & & \\
\hline Bolivina cf. subaeranensis & & & & & & & & & \\
\hline Bolivina imporcata & & & & & 2 & 1 & & 2 & 5 \\
\hline Bolivina isidroensis & & & & & & & & & \\
\hline Bolivina spp. & & & & & & & 1 & & \\
\hline Bolivina striatula & & & & & 4 & & & & 2 \\
\hline Brizalina aff. subspinescens & & & 21 & 5 & & 2 & & & 4 \\
\hline Brizalina antegressa & & 3 & & 3 & & & & & 25 \\
\hline Bulimina alazaensis & & 1 & & & & & & 2 & \\
\hline Bulimina cf. aculeata & & & & & & & & 1 & \\
\hline Bulimina cf. elongata & & & & & & & & & \\
\hline Bulimina rostrata & & & & & 3 & & & & 1 \\
\hline Bulimina spp. & & & & & & & & & \\
\hline Buliminella cf. pusilla & & 1 & & & 12 & 44 & & & \\
\hline Cancris nuttalli & & & & 1 & & & & & \\
\hline Cassidulina carapitana & & & & & & & & & \\
\hline Cassidulina cf. corbyi & & & & & & & & & \\
\hline Cassidulina cf. woodsi & & & & & 1 & & & & \\
\hline Cassidulina monicana & & & & & & & & & \\
\hline Cassidulina subglobosa & 25 & & 181 & 70 & 31 & 43 & 49 & 35 & 19 \\
\hline Cassidulinoides bradyi & & 1 & & & & & & & \\
\hline Chilostomella oolina & & & & & & & & & \\
\hline Chrysaloganium spp. & & & & & & & & & \\
\hline Chrysalogonium cf. eximium & & & & & & & & & \\
\hline Chrysalogonium tenuicostatum & & & & & & & & & \\
\hline Cibicides cf. mundulus & & & 16 & & & & & 2 & \\
\hline Cibicides cf. pachyderma & & & & & & & & & \\
\hline Cibicides cf. robertsanius & & & & & & & & & \\
\hline Cibicides choctawensis & & & & & & & & & \\
\hline Cibicides lobatulus & & & & & & & 2 & & \\
\hline Cibicides 'marsi' & & & & & & & & & \\
\hline Cibicides spp. & & & & 6 & & 1 & 10 & 24 & 20 \\
\hline Cibicides umbonatus & & & & & & & & & \\
\hline Cibicidoides cf. guazamalensis & & & & 1 & & & & & \\
\hline Cibicidoides cf. laurisae & & & & & & & & & \\
\hline Cibicidoides grimsdalei & & 1 & & 5 & & 4 & & & \\
\hline Cibicidoides bradyi & 2 & 2 & 15 & & 2 & 22 & 6 & 23 & 18 \\
\hline Cibicidoides cicatricosus & & & & & & & & & \\
\hline Cibicidoides grossperforatus & & & & & & & & & \\
\hline Cibicidoides mexicanus & & & & & & & & & \\
\hline Cibicidoides mundulus & 2 & 21 & 34 & 62 & 5 & 12 & 21 & 26 & 11 \\
\hline Cibicidoides pachyderma & 11 & 2 & & & & & & & \\
\hline Cibicidoides perlucidus & & & & & & & & & \\
\hline Cibicidoides robertsanius & & & & & & & & & \\
\hline Cyclammina spp. & & & & & & & & & \\
\hline Dentalina pseudoobliqua & & & & & & & & & \\
\hline Dentalina roemeri & & & & & & 1 & & & \\
\hline Eggerella bradyi & 1 & 2 & 4 & & & & & 3 & 3 \\
\hline Eggerella spp. & & & & & & & & & \\
\hline Ehrenbergrina sp. A & & & & & & & & & \\
\hline Enantiodentalina murai & & & & & & & & 1 & \\
\hline Epistominella exigua & & 34 & 166 & 77 & 312 & 10 & 5 & 11 & 41 \\
\hline Eponides turgidus & & 3 & & 24 & 86 & 84 & 5 & 111 & 12 \\
\hline Eponides sp. A & & & & & & & & & \\
\hline Eponides spp. & & & & & & & & & \\
\hline Fingerina weaveri & & & & & & & & & \\
\hline Fissuirina cf. seguenzlana & & & & & & & & & \\
\hline Fissuirina pseudoglobosa & & 5 & & & & & & & \\
\hline Fissurina aff. fimbriata & & & & & & & & 1 & \\
\hline Fissurina bradii & & & 2 & & & & & & \\
\hline Fissurina cf. fimbriata & & & 2 & & & & & & \\
\hline Fissurina cf. formosa & & & & & & & & & \\
\hline Fissurina cf. trubiniformis & & & & & & & & & \\
\hline Fissurina collifera & & & & & & & & 2 & \\
\hline Fissurina formosa & & & & & & & & & \\
\hline Fissurina lagenoides & & & & & & & & & \\
\hline Fissurina radiata & & & & & & & & & \\
\hline Fissurina seminifroma & 2 & & & & & & & & \\
\hline Fissurina spp. & & & 2 & & & & 1 & & \\
\hline
\end{tabular}




\begin{tabular}{|c|c|c|c|c|c|c|c|c|c|}
\hline Hole & 999A & 999A & 999A & 999A & 999A & 999A & 999A & 999A & 999A \\
\hline Sample & $23 X-05$ & $25 \mathrm{X}-03$ & $27 \mathrm{X}-05$ & $28 \mathrm{X}-05$ & $29 \mathrm{X}-05$ & $31 X-01$ & $32 \mathrm{X}-03$ & $33 X-03$ & $35 \mathrm{X}-01$ \\
\hline Age & 7.37 & 8.23 & 9.39 & 9.9 & 10.41 & 11.09 & 11.75 & 12.25 & 13.11 \\
\hline Fissurina turbiniformis & & & & & & 1 & & & 3 \\
\hline Francesita advena & & 1 & & 1 & & & & & \\
\hline Indet. Gen 1. ind. spec. 1 & & & 3 & & & & & & \\
\hline Globobulimina affinis & & 2 & & & & & & & \\
\hline Globobulimina cf. ovula & & 3 & & & & & & & \\
\hline Globobulimina ovula & & 2 & & & & & & & \\
\hline \multicolumn{10}{|l|}{ Globobulimina spp. } \\
\hline Gyroidina altiformis & 2 & & 9 & 6 & 2 & & 5 & 1 & 2 \\
\hline \multicolumn{10}{|l|}{ Gyroidina cf. planulata } \\
\hline Gyroidina planulata & 7 & & 21 & 30 & 2 & 18 & 11 & & 13 \\
\hline Gyroidinoides soldanii & 12 & 17 & 13 & 11 & 5 & 11 & 13 & 34 & 22 \\
\hline Hoeglodina elegans & & & & & 4 & 2 & & & \\
\hline \multicolumn{10}{|l|}{ Indet. Gen. 2 indet. spec. 1} \\
\hline Karreriella bradyi & & & 1 & & & & & & 2 \\
\hline Karreriella subglaba & & & & 1 & & & & & \\
\hline Laevidentalina advena & & 5 & & & & & & & \\
\hline Laevidentalina cf. advena & & & 1 & & & & & & \\
\hline \multicolumn{10}{|l|}{ Laevidentalina cf. communis } \\
\hline Laevidentalina communis & 1 & & 1 & & & & 1 & & 1 \\
\hline Laevidentalina inornata & & & 1 & 1 & & & & & \\
\hline Lagena auriculata var. incarituba & & & & & & & & & \\
\hline Lagena castirensis & & & & & & & & & \\
\hline Lagena cf. auriculata var. incarituba & & 3 & & & & & & & \\
\hline Lagena cf. elongata & & 2 & & & & & & & \\
\hline Lagena cf. exsculpta "winged" & & & & & & & & & \\
\hline Lagena cf. gracilis & & & & & & & & & \\
\hline Lagena cf. hispida & & & & & & & & & \\
\hline Lagena cf. laevis & & 1 & & & & & & & \\
\hline Lagena cf. nebulosa & & 1 & 4 & & & & & & \\
\hline Lagena elongata & & 3 & & 1 & & 7 & & 9 & \\
\hline Lagena feildeniana & & & & & & & & & \\
\hline Lagena gortanii & & 1 & & & & & & & \\
\hline Lagena gracilis & & & 1 & & 1 & & & 3 & 2 \\
\hline Lagena hispida & 1 & & & & & & & & \\
\hline Lagena laevis & & 1 & & 4 & & & & & \\
\hline Lagena meridonaus & & & & & & & & & \\
\hline Lagena montagui & & & & & & 1 & & & \\
\hline Lagena paradoxa & & & & & & & & & \\
\hline Lagena sp. Hispid & & & & & & & & & \\
\hline Lagena spp. & & & & & & & 2 & 1 & 2 \\
\hline Lagena stelligerea & & & & & & & & & \\
\hline Lagena sulcata & & & & 1 & & & & 1 & \\
\hline Laticarinina pauperata & 10 & & 14 & 13 & 1 & 3 & 10 & 3 & 10 \\
\hline Lenticulina cf. alta & & & & & & & & & \\
\hline Lenticulina cf. americana & & 1 & & 3 & & & & 1 & \\
\hline Lenticulina gibba & & & 1 & & & & & & \\
\hline Lenticulina pliocaena (Silvestri) & & & 9 & & & 3 & & & 3 \\
\hline Lenticulina spp. & & & & & & & & & \\
\hline Martinottiella spp. & 1 & & & & & & & 1 & \\
\hline Melonis aff. barleeanum & & & 1 & & & & & & \\
\hline Melonis aff. pompiloides & & & 5 & & & & 2 & & 9 \\
\hline Melonis barleeanum & 14 & 13 & 161 & 57 & 33 & 60 & 2 & 27 & 46 \\
\hline Melonis cf. barleeanum & & 2 & & 1 & 2 & & & & \\
\hline Melonis cf. pompiloides & & & & & & 5 & & & \\
\hline Melonis pompiloides & & & & & & & & & \\
\hline Melonis spp. & & & & & & & & & \\
\hline Nodosaria spp. & & 1 & & & & & & & \\
\hline Nonion mesonense & & & & & & & & & \\
\hline Nonion commune & & 2 & & 12 & & & & & \\
\hline Nonion sp. A & & & & & & & & & \\
\hline Nonion spp. & & 2 & & & & & & & \\
\hline Nuttalides umbonifera & 19 & 14 & 83 & 35 & 8 & & 5 & 20 & \\
\hline Oolina cf. globosa ovalis & & 2 & & & & 2 & & 1 & \\
\hline Oolina globosa & & & 2 & 8 & & & & & \\
\hline Oolina spp. & & 2 & & & & & & & \\
\hline Oridorsalis stellatus & & & 5 & & & & & & \\
\hline Oridorsalis umbonatus & 16 & 4 & 20 & 69 & & 12 & 9 & 8 & 32 \\
\hline Orthomorhpina perversa & & & & & & & & & \\
\hline Orthomorphina cf. nodulosatriata & & & & & & & & & \\
\hline Orthomorphina cf. rohri & & & & & & & & & \\
\hline Orthomorphina challengeriana & & & & & & & & & \\
\hline Orthomorphina jetladschai & & & & & & & & & \\
\hline Orthomorphina nodulosatriata & & & & & & & & & \\
\hline Orthomorphina rohri & & & & & & & & & 2 \\
\hline Orthomorphina sp. 1 (as in Bornmalm) & & & & & & & & & \\
\hline Orthomorphina spp. & & & & 2 & & & 1 & 1 & 1 \\
\hline Osangularia culter & & & 1 & & & & & & \\
\hline Ovulina striata & & & & 2 & & & & 1 & \\
\hline
\end{tabular}




\begin{tabular}{|c|c|c|c|c|c|c|c|c|c|}
\hline Hole & $999 \mathrm{~A}$ & 999A & $999 \mathrm{~A}$ & 999A & $999 \mathrm{~A}$ & $999 \mathrm{~A}$ & 999A & 999A & $999 \mathrm{~A}$ \\
\hline Sample & 23X-05 & $25 \mathrm{X}-03$ & $27 \mathrm{X}-05$ & $28 \mathrm{X}-05$ & $29 \mathrm{X}-05$ & $31 \mathrm{X}-01$ & $32 \mathrm{X}-03$ & $33 \mathrm{X}-03$ & $35 \mathrm{X}-01$ \\
\hline Age & 7.37 & 8.23 & 9.39 & 9.9 & 10.41 & 11.09 & 11.75 & 12.25 & 13.11 \\
\hline Parafissurina aff. ventricosa & & 1 & & & & & & 1 & \\
\hline Parafissurina cavigera & & & & & & & & 2 & \\
\hline Parafissurina cf. dorbignyana & & & 3 & & 1 & & & & \\
\hline Parafissurina cf. Iateralis f. crassa & & 1 & & 1 & & & & & \\
\hline Parafissurina cf. ventricosa & 1 & & & & & & & & \\
\hline Parafissurina dorbignyana & & & & 3 & & & & 1 & 1 \\
\hline \multicolumn{10}{|l|}{ Parafissurina fusuliformis } \\
\hline Parafissurina lateralis f. crassa & & & 1 & & 3 & & & & \\
\hline Parafissurina pseudomarginata & & & & 1 & 1 & & & 1 & \\
\hline \multicolumn{10}{|l|}{ Parafissurina spp. } \\
\hline Parafissurina tectulostoma & & & 1 & & & & & & \\
\hline Parafissurina ventricosa & 1 & & & 1 & 1 & & 1 & & \\
\hline \multicolumn{10}{|l|}{ Parafissurina vidriosa } \\
\hline Planulina rugosa & 5 & & & 1 & & & & & \\
\hline Planulina wuellerstorfi & 39 & 5 & 48 & 37 & 11 & 11 & 5 & 14 & 6 \\
\hline Pleurostomella acuminata & & 4 & 8 & & & & & 7 & \\
\hline Pleurostomella alternans & & 1 & 17 & 4 & & 2 & & 9 & 7 \\
\hline Pleurostomella bierigi & 1 & & & & & & & & \\
\hline Pleurostomella brevis & & & & & & & & & \\
\hline Pleurostomella cf. brevis & & & & & & & & & \\
\hline Pleurostomella spp. & & & 2 & & & & 1 & & \\
\hline Pleurostomella subnodosa & & & 1 & 2 & & & 10 & & 8 \\
\hline Polymorphinidae formae fistulosis & & & & & & & & & \\
\hline Proxifrons advena & & 1 & & & & & & & \\
\hline Pullenia bulloides & 4 & 1 & 5 & 5 & 1 & & 9 & 8 & 11 \\
\hline Pullenia quadriloba & & & 38 & 15 & & 5 & 3 & & 7 \\
\hline Pullenia quinqueloba & 3 & 1 & 16 & 11 & 6 & 5 & 1 & 12 & 2 \\
\hline Pullenia subcarinata & & & & & & & & & \\
\hline Pyrgo lucernula & & 1 & & & & & & & \\
\hline Pyrgo murrhina & 5 & & 1 & 1 & 1 & & & & 1 \\
\hline Pyrgo oblonga & 5 & & 2 & & 3 & & & & \\
\hline Pyrgo serrata & & & & & & & & & \\
\hline Pyrulina albatrossi & & 2 & 1 & & 2 & 1 & & & \\
\hline Pyrulina sp. A & & & 4 & 1 & & & & & \\
\hline Pyrulina spp. & & & & & & & & & \\
\hline Quinqeuloculina cf. Iamarckiana & & & & & & & & & \\
\hline Quinqeuloculina lamarckiana & 1 & 4 & & & 2 & 2 & 2 & 2 & \\
\hline Quinqeuloculina sp.A & & & & & 2 & & & & \\
\hline Quinqeuloculina sp. B & & & & & 1 & & & & \\
\hline Quinqeuloculina spp. & & & & & 3 & & & & \\
\hline Rectoglandulina sp. A & & & 1 & & & & & & \\
\hline Rectuvigerina bassispirata & & & & & & & & 1 & \\
\hline Reophax sp. A & & & & & & & & & \\
\hline Scallopostoma ovicula & & 1 & & & & 1 & & & \\
\hline Schenkiella spp. & & & & & & & & 1 & \\
\hline Sigmoilina spp. & & & & & & & & & \\
\hline Sigmoilina tenuis & & & & 2 & 3 & 3 & & 7 & \\
\hline Sigmoilopsis schlumbergeri & 2 & 9 & & 10 & & & & & \\
\hline Siphonina tenuicarnata & & & & & & & & & \\
\hline Siphonodosaria bradyi & & & & 4 & & & & & \\
\hline Siphonodosaria nuttalli gracillima & & & & 1 & & & & & 1 \\
\hline Siphotextularia cf. catenata & & & & & & & & & \\
\hline Sphaeroidina bulloides & 2 & 1 & & & 9 & 1 & 1 & 2 & \\
\hline Spriroplectammina cubensis & & & & & & & & & \\
\hline Stilostomella abyssorum & & 1 & 1 & & & & & & \\
\hline Stilostomella cf. subspinosa & & & & & & & & & \\
\hline Stilostomella consobrina & & & 5 & 5 & & 1 & & 8 & 5 \\
\hline Stilostomella lepidula & 1 & & 3 & & & & & & 1 \\
\hline Stilostomella spp. & & & & & & & 2 & & \\
\hline Stilostomella subspinosa & & & & & & & & & \\
\hline Stilostomella verneuli paucistriata & & & & & & & & & \\
\hline Textularia agglutinans & & & & & & & & & \\
\hline Textularia spp. & & & & & & & & & \\
\hline Trochammina spp. & & & & & & & & & \\
\hline Uvigerina auberiana & & & & & & & & & \\
\hline Uvigerina cf. auberiana & & & & & & & & & \\
\hline Uvigerina cf. ciperana & & & & & & & & & \\
\hline Uvigerina cf. hollicki & & 1 & 1 & 56 & 4 & & & & 48 \\
\hline Uvigerina cf. mantaensis & & & & & & & & & \\
\hline Uvigerina cf. senticosa & & & & & & & & & \\
\hline Uvigerina cf. striata attenuata & & & & & & & & & \\
\hline Uvigerina ciperana & & & & 1 & & & & & \\
\hline Uvigerina hispida & & & & & & & & & \\
\hline Uvigerina hispida-costata & & & & & & & & & \\
\hline Uvigerina peregrina & & & & & & & 3 & 1 & \\
\hline Uvigerina spp. & & & 1 & & & & & & \\
\hline Vulvulina pennatula & & & & & 2 & & & & \\
\hline Vulvulina spinosa & 1 & & & & & & & & \\
\hline Number of Forams & 200 & 200 & 995 & 676 & 572 & 385 & 201 & 455 & 414 \\
\hline Number of Species & 31 & 53 & 54 & 50 & 37 & 35 & 32 & 48 & 40 \\
\hline
\end{tabular}




\begin{tabular}{|c|c|c|c|c|c|c|c|c|c|}
\hline Hole & 999A & 999A & 999A & 999A & 999A & 999A & 999A & $999 \mathrm{~A}$ & 999A \\
\hline Sample & $36 \mathrm{X}-01$ & $37 \mathrm{X}-01$ & $38 \mathrm{X}-03$ & $39 \mathrm{X}-03$ & $41 \mathrm{X}-01$ & $42 \mathrm{X}-05$ & $44 \mathrm{X}-05$ & $46 \mathrm{X}-05$ & $49 \mathrm{X}-01$ \\
\hline Age & 13.61 & 14.11 & 14.77 & 15.12 & 15.94 & 16.47 & 17.12 & 17.77 & 18.55 \\
\hline \multicolumn{10}{|l|}{ Ammodiscus spp. } \\
\hline Ammoglobigerina cf. globigeriniformis & & & & & & & & & 1 \\
\hline Ammoglobigerina globigeriniformis & & & & 2 & 1 & & 4 & & \\
\hline Anamlinoides cf. globosa & & & & & & & & & 1 \\
\hline Anamlinoides globosa & 18 & 5 & 3 & & 1 & & 5 & 2 & \\
\hline Astacolus crepidulus & & & 2 & & 1 & & & & \\
\hline \multicolumn{10}{|l|}{ Astrononion novozealandicum } \\
\hline Bolivina aff. salinasensis & & & 1 & & 1 & & & & \\
\hline Bolivina cf. harangensis & 5 & 5 & 2 & & 34 & 19 & 10 & & \\
\hline Bolivina cf. hughesi & & & & & & & & & \\
\hline Bolivina cf. seminuda & & & & & & & & & \\
\hline Bolivina cf. sp. A & & & & & & & & & \\
\hline Bolivina cf. striatula & & 7 & & & & & & & \\
\hline Bolivina cf. subaeranensis & & & & & & 1 & & & \\
\hline Bolivina imporcata & & & & & & & & & \\
\hline Bolivina isidroensis & & & & & & & & & \\
\hline Bolivina spp. & & & 18 & 35 & & & & & 1 \\
\hline Bolivina striatula & 3 & & 11 & 18 & 26 & & & 11 & \\
\hline Brizalina aff. subspinescens & 1 & 17 & & 2 & 2 & 1 & & 1 & 1 \\
\hline Brizalina antegressa & 4 & 15 & 7 & 2 & 3 & & & & \\
\hline Bulimina alazaensis & & 7 & 3 & 1 & & & & 1 & \\
\hline Bulimina cf. aculeata & & & & & & & & & \\
\hline Bulimina cf. elongata & & & & & & & & & \\
\hline Bulimina rostrata & & & & & & & & & \\
\hline Bulimina spp. & 2 & & & & & & & & \\
\hline Buliminella cf. pusilla & 2 & 12 & & & 3 & & 1 & 8 & 2 \\
\hline Cancris nuttalli & & & & & & & & & \\
\hline Cassidulina carapitana & & & & & & 3 & 11 & & 2 \\
\hline Cassidulina cf. corbyi & & & & & & & & & \\
\hline Cassidulina cf. woodsi & & & & & & & & & \\
\hline Cassidulina monicana & & & & & & & & & \\
\hline Cassidulina subglobosa & 84 & 41 & 35 & 35 & 51 & 20 & 54 & 35 & 5 \\
\hline Cassidulinoides bradyi & 1 & & & & & & & & \\
\hline Chilostomella oolina & & 1 & & & 1 & & & & \\
\hline Chrysaloganium spp. & & & & & & & & 1 & \\
\hline Chrysalogonium cf. eximium & & & & & & & & & 1 \\
\hline Chrysalogonium tenuicostatum & & & & & & & 2 & & \\
\hline Cibicides cf. mundulus & & & & & & & & & \\
\hline Cibicides cf. pachyderma & & & & & & & & & \\
\hline Cibicides cf. robertsanius & & & 4 & & & & & & \\
\hline Cibicides choctawensis & & & & & & & & & \\
\hline Cibicides lobatulus & & & & & & & & & \\
\hline Cibicides 'marsi' & & & & & & & 1 & & \\
\hline Cibicides spp. & 8 & 4 & 7 & & 10 & 1 & 13 & 1 & \\
\hline Cibicides umbonatus & & & & & & & & & \\
\hline Cibicidoides cf. guazamalensis & & & & & & & & & \\
\hline Cibicidoides cf. laurisae & & & & & & & & & \\
\hline Cibicidoides grimsdalei & & & & 8 & & & & & \\
\hline Cibicidoides bradyi & 14 & 61 & 6 & 2 & & 2 & & & 3 \\
\hline Cibicidoides cicatricosus & & & & & & 1 & 1 & 1 & \\
\hline Cibicidoides grossperforatus & & & & & & & & & \\
\hline Cibicidoides mexicanus & & & & & & & & & \\
\hline Cibicidoides mundulus & 54 & 6 & 5 & 24 & 36 & 21 & 37 & 24 & 28 \\
\hline Cibicidoides pachyderma & & & 2 & & & & & & \\
\hline Cibicidoides perlucidus & & & & & & & & & \\
\hline Cibicidoides robertsanius & & 1 & & & & 1 & 1 & & \\
\hline Cyclammina spp. & & & & & & & & & \\
\hline Dentalina pseudoobliqua & & & & & & & & & \\
\hline Dentalina roemeri & & & & & & & & & \\
\hline Eggerella bradyi & 1 & 2 & & 5 & & & 2 & 1 & \\
\hline Eggerella spp. & & & & & & & & & 2 \\
\hline Ehrenbergrina sp. A & & & & 9 & 1 & 2 & 1 & & \\
\hline Enantiodentalina murai & & & & & & & 1 & & \\
\hline Epistominella exigua & 43 & 13 & 6 & 24 & 42 & 10 & 8 & 10 & 17 \\
\hline Eponides turgidus & 26 & 25 & 21 & 10 & 30 & & & & 1 \\
\hline Eponides sp. A & & & & & & & & 1 & \\
\hline Eponides spp. & & & & & & & & & \\
\hline Fingerina weaveri & & & & & & & & & \\
\hline Fissuirina cf. seguenzlana & 3 & 1 & & & & & & & \\
\hline Fissuirina pseudoglobosa & & & & & & & & & \\
\hline Fissurina aff. fimbriata & & & & & & & & & \\
\hline Fissurina bradii & & & & & & & & & \\
\hline Fissurina cf. fimbriata & & & & & & & 1 & & \\
\hline Fissurina cf. formosa & & & & & 1 & & & & \\
\hline Fissurina cf. trubiniformis & & & & & & & & & \\
\hline Fissurina collifera & & & & & & & & & \\
\hline Fissurina formosa & & & & & 1 & & & & \\
\hline Fissurina lagenoides & & & & & & & & & \\
\hline Fissurina radiata & & & & & & & & & \\
\hline Fissurina seminifroma & & & & & & & & & \\
\hline Fissurina spp. & 1 & & & & & & & & \\
\hline
\end{tabular}




\begin{tabular}{|c|c|c|c|c|c|c|c|c|c|}
\hline Hole & 999A & 999A & 999A & 999A & 999A & 999A & 999A & 999A & 999A \\
\hline Sample & $36 \mathrm{X}-01$ & $37 \mathrm{X}-01$ & $38 \mathrm{X}-03$ & $39 \mathrm{X}-03$ & $41 \mathrm{X}-01$ & $42 \mathrm{X}-05$ & $44 \mathrm{X}-05$ & $46 \mathrm{X}-05$ & $49 \mathrm{X}-01$ \\
\hline Age & 13.61 & 14.11 & 14.77 & 15.12 & 15.94 & 16.47 & 17.12 & 17.77 & 18.55 \\
\hline \multicolumn{10}{|l|}{ Fissurina turbiniformis } \\
\hline Francesita advena & & 1 & & & & & & 1 & \\
\hline Indet. Gen 1. ind. spec. 1 & & 1 & 2 & 2 & 6 & & 3 & 4 & \\
\hline Globobulimina affinis & & & 1 & & 1 & & & & \\
\hline \multicolumn{10}{|l|}{ Globobulimina cf. ovula } \\
\hline Globobulimina ovula & & & 2 & & & & & & \\
\hline Globobulimina spp. & & 1 & & & 1 & & & & \\
\hline Gyroidina altiformis & & 4 & 1 & & 8 & 4 & 11 & 3 & 2 \\
\hline \multicolumn{10}{|l|}{ Gyroidina cf. planulata } \\
\hline Gyroidina planulata & 18 & 10 & 18 & 15 & 16 & 30 & 8 & 1 & 8 \\
\hline Gyroidinoides soldanii & 15 & 6 & 15 & 13 & 13 & 3 & 36 & 21 & 4 \\
\hline \multicolumn{10}{|l|}{ Hoeglodina elegans } \\
\hline Indet. Gen. 2 indet. spec. 1 & & & 1 & & 2 & & 2 & & \\
\hline Karreriella bradyi & & 3 & & 2 & & & 1 & & 2 \\
\hline Karreriella subglaba & & & & & & & & & \\
\hline Laevidentalina advena & & & & & & & & & \\
\hline Laevidentalina cf. advena & & & & & & & & & \\
\hline Laevidentalina cf. communis & & & & & & & & & \\
\hline Laevidentalina communis & & & & 5 & & & & 1 & \\
\hline Laevidentalina inornata & & & 1 & & & & & 1 & \\
\hline Lagena auriculata var. incarituba & 1 & & & 1 & & & & & \\
\hline Lagena castirensis & 2 & & & & & & & & \\
\hline Lagena cf. auriculata var. incarituba & & & & & & & & 1 & \\
\hline Lagena cf. elongata & & & & & & & & 4 & \\
\hline Lagena cf. exsculpta "winged" & & & & & & & & & \\
\hline Lagena cf. gracilis & & & & & & & & & \\
\hline Lagena cf. hispida & & & & & & & & & \\
\hline Lagena cf. laevis & & & & & & & & & \\
\hline Lagena cf. nebulosa & & & & & & & & & \\
\hline Lagena elongata & 10 & 8 & & & 2 & & & & \\
\hline Lagena feildeniana & & & & & & & & & \\
\hline Lagena gortanii & & & & & & & & & \\
\hline Lagena gracilis & & & & 1 & & & & & \\
\hline Lagena hispida & & 1 & & & & & & & \\
\hline Lagena laevis & & & & & & & & & \\
\hline Lagena meridonaus & & & 2 & & 1 & 3 & & 3 & \\
\hline Lagena montagui & & & & & & & & & \\
\hline Lagena paradoxa & & & & & & & & & \\
\hline Lagena sp. Hispid & & & & & & & & & \\
\hline Lagena spp. & & 3 & 1 & 1 & 1 & & 1 & 2 & 1 \\
\hline Lagena stelligerea & & & & & & & & & \\
\hline Lagena sulcata & & & & & & & & & \\
\hline Laticarinina pauperata & 21 & 11 & 7 & 6 & 4 & 6 & 12 & & 1 \\
\hline Lenticulina cf. alta & & & & 1 & & & & & \\
\hline Lenticulina cf. americana & & & & & 1 & & & & \\
\hline Lenticulina gibba & & & & & 1 & & & & \\
\hline Lenticulina pliocaena (Silvestri) & 7 & & & & 2 & 2 & & & \\
\hline Lenticulina spp. & & & & & & & & & \\
\hline Martinottiella spp. & & & & & & & & & \\
\hline Melonis aff. barleeanum & & & & & & & & 2 & \\
\hline Melonis aff. pompiloides & & & & & & & & & 3 \\
\hline Melonis barleeanum & 45 & 27 & 6 & 19 & 68 & 6 & 34 & 5 & 18 \\
\hline Melonis cf. barleeanum & & & & 6 & & 2 & 3 & & \\
\hline Melonis cf. pompiloides & 2 & & & & & & & & 1 \\
\hline Melonis pompiloides & & & & & & & & & \\
\hline Melonis spp. & & & & & & & & & \\
\hline Nodosaria spp. & & & & & & & & & \\
\hline Nonion mesonense & & & & & & & & & \\
\hline Nonion commune & & 2 & 1 & 4 & 6 & & 2 & 6 & \\
\hline Nonion sp. A & & & & & & & 1 & & \\
\hline Nonion spp. & & & & & & & & & \\
\hline Nuttalides umbonifera & 2 & 3 & 3 & 17 & 17 & 2 & & & 1 \\
\hline Oolina cf. globosa ovalis & 4 & & & & & & & & \\
\hline Oolina globosa & & & & & & & & & \\
\hline Oolina spp. & & & & & 1 & & & & \\
\hline Oridorsalis stellatus & & & & & & & & & \\
\hline Oridorsalis umbonatus & 23 & 23 & 18 & 26 & 50 & 15 & 33 & 13 & 12 \\
\hline Orthomorhpina perversa & & & & & & & & & \\
\hline Orthomorphina cf. nodulosatriata & & & & & & & 1 & & \\
\hline Orthomorphina cf. rohri & & & & & & & & & \\
\hline Orthomorphina challengeriana & & & & & & & & & \\
\hline Orthomorphina jetladschai & & & & & & & & & \\
\hline Orthomorphina nodulosatriata & & & & & & & & & \\
\hline Orthomorphina rohri & & 2 & 2 & & & & & & \\
\hline Orthomorphina sp. 1 (as in Bornmalm) & & & & 1 & & & & & \\
\hline Orthomorphina spp. & 1 & 1 & & 5 & 2 & & & & \\
\hline Osangularia culter & & & & & & & & & \\
\hline Ovulina striata & & & & & & & & & \\
\hline
\end{tabular}




\begin{tabular}{|c|c|c|c|c|c|c|c|c|c|}
\hline Hole & 999A & 999A & 999A & $999 \mathrm{~A}$ & 999A & 999A & $999 \mathrm{~A}$ & 999A & $999 \mathrm{~A}$ \\
\hline Sample & $36 \mathrm{X}-01$ & $37 \mathrm{X}-01$ & $38 \mathrm{X}-03$ & $39 \mathrm{X}-03$ & 41X-01 & $42 \mathrm{X}-05$ & 44X-05 & $46 \mathrm{X}-05$ & $49 \mathrm{X}-01$ \\
\hline Age & 13.61 & 14.11 & 14.77 & 15.12 & 15.94 & 16.47 & 17.12 & 17.77 & 18.55 \\
\hline Parafissurina aff. ventricosa & & & 1 & & & & & & \\
\hline Parafissurina cavigera & 1 & & & & & & & & \\
\hline Parafissurina cf. dorbignyana & & & & & & & & 2 & \\
\hline Parafissurina cf. Iateralis f. crassa & & & & & & & & & \\
\hline \multicolumn{10}{|l|}{ Parafissurina cf. ventricosa } \\
\hline \multicolumn{10}{|l|}{ Parafissurina dorbignyana } \\
\hline \multicolumn{10}{|l|}{ Parafissurina fusuliformis } \\
\hline Parafissurina lateralis f. crassa & & & 3 & & 1 & & 1 & & \\
\hline Parafissurina pseudomarginata & 1 & 2 & & & & & & & \\
\hline Parafissurina spp. & & & & & & & 1 & & \\
\hline Parafissurina tectulostoma & & & & & & & & & \\
\hline Parafissurina ventricosa & 1 & 1 & & 1 & & & & & \\
\hline Parafissurina vidriosa & & & & & & & & & \\
\hline Planulina rugosa & & & & & & & & & \\
\hline Planulina wuellerstorfi & 34 & 30 & 18 & 17 & 31 & 27 & 52 & & \\
\hline Pleurostomella acuminata & & 2 & & & 6 & & 13 & 17 & 7 \\
\hline Pleurostomella alternans & 7 & 1 & & 12 & 2 & & & 3 & 3 \\
\hline Pleurostomella bierigi & 3 & & & & & & & & \\
\hline Pleurostomella brevis & & 2 & & & 6 & & 1 & & \\
\hline Pleurostomella cf. brevis & 8 & & & & & & & & \\
\hline Pleurostomella spp. & & & & & & 4 & & & \\
\hline Pleurostomella subnodosa & 3 & 4 & & & & & & & \\
\hline Polymorphinidae formae fistulosis & & & & & 1 & & & 2 & \\
\hline Proxifrons advena & & & & & & & & & \\
\hline Pullenia bulloides & 12 & 22 & 5 & 3 & 14 & 7 & & 5 & 5 \\
\hline Pullenia quadriloba & 15 & 2 & & 6 & 9 & 3 & 13 & 5 & 4 \\
\hline Pullenia quinqueloba & 1 & 5 & 4 & & & & 3 & 2 & \\
\hline Pullenia subcarinata & & & & & & & & & \\
\hline Pyrgo lucernula & & & & & & & & & \\
\hline Pyrgo murrhina & & & & & & & & & \\
\hline Pyrgo oblonga & & 1 & & & & & & & \\
\hline Pyrgo serrata & & & & & & & & & \\
\hline Pyrulina albatrossi & 2 & & & & 1 & & & & \\
\hline Pyrulina sp. A & & 1 & & & & & 1 & & 1 \\
\hline Pyrulina spp. & & & & & & & & & \\
\hline Quinqeuloculina cf. Iamarckiana & & & & & & & & & \\
\hline Quinqeuloculina lamarckiana & 1 & & & & 2 & & & 6 & 4 \\
\hline Quinqeuloculina sp. A & & & & & & & & & \\
\hline Quinqeuloculina sp. B & & & & & & & & & \\
\hline Quinqeuloculina spp. & & & 1 & & & & & & 1 \\
\hline Rectoglandulina sp. A & & & & & & & & & \\
\hline Rectuvigerina bassispirata & & & & & & & & & \\
\hline Reophax sp. A & & & & & & & 1 & & \\
\hline Scallopostoma ovicula & & & & & & & & & \\
\hline Schenkiella spp. & & & 2 & & 2 & & & & \\
\hline Sigmoilina spp. & & 1 & & & & & & 3 & \\
\hline Sigmoilina tenuis & & & & & 1 & & & & \\
\hline Sigmoilopsis schlumbergeri & & & & & & & & & \\
\hline Siphonina tenuicarnata & & & & & & & & & \\
\hline Siphonodosaria bradyi & & & & 6 & 7 & & & & \\
\hline Siphonodosaria nuttalli gracillima & & 1 & & & & 2 & & & \\
\hline Siphotextularia cf. catenata & & & & & & & & 1 & \\
\hline Sphaeroidina bulloides & 4 & & & 4 & & & & 1 & \\
\hline Spriroplectammina cubensis & & & & & & & & & \\
\hline Stilostomella abyssorum & & & & & & & & & \\
\hline Stilostomella cf. subspinosa & & & & & 3 & & 1 & & \\
\hline Stilostomella consobrina & 12 & 4 & 3 & 5 & 1 & & & 7 & 12 \\
\hline Stilostomella lepidula & 2 & 5 & & 5 & & 6 & 4 & & 3 \\
\hline Stilostomella spp. & & & & & & & & 4 & \\
\hline Stilostomella subspinosa & & & & & & & & & \\
\hline Stilostomella verneuli paucistriata & & & & & & & & & \\
\hline Textularia agglutinans & & & & & & & & & \\
\hline Textularia spp. & & & & & & & & & \\
\hline Trochammina spp. & & & & & & & & & \\
\hline Uvigerina auberiana & & & & & & & & 1 & \\
\hline Uvigerina cf. auberiana & & & & & & & & & \\
\hline Uvigerina cf. ciperana & & & 3 & & & & & & \\
\hline Uvigerina cf. hollicki & & & & 14 & & & & & \\
\hline Uvigerina cf. mantaensis & 3 & & & & & & & & \\
\hline Uvigerina cf. senticosa & 1 & & & & 7 & & & & \\
\hline Uvigerina cf. striata attenuata & & & & & & & & & \\
\hline Uvigerina ciperana & & & & & & & & & \\
\hline Uvigerina hispida & & & & & & & & & \\
\hline Uvigerina hispida-costata & & & & & & & & & \\
\hline Uvigerina peregrina & & & & & & & & & \\
\hline Uvigerina spp. & & & & & & & & & \\
\hline Vulvulina pennatula & & & & & & & & & \\
\hline Vulvulina spinosa & & & 1 & & & & & 2 & \\
\hline Number of Forams & 532 & 414 & 255 & 375 & 542 & 204 & 392 & 226 & 158 \\
\hline Number of Species & 48 & 50 & 42 & 41 & 54 & 28 & 42 & 43 & 33 \\
\hline
\end{tabular}




\begin{tabular}{|c|c|c|c|c|c|c|c|c|c|c|}
\hline Hole & 999A & 999A & 999A & 999A & 999A & 999B B & 999B & 999B & 999B & 999B \\
\hline Sample & $51 X-01$ & $53 \mathrm{X}-01$ & $58 \mathrm{X}-01$ & $60 \mathrm{X}-01$ & $61 \mathrm{X}-05$ & $07 \mathrm{R}-03$ & $09 \mathrm{R}-03$ & 10R-01 & 11R-03 & 12R-03 \\
\hline Age & 19.24 & 19.85 & 21.15 & 21.83 & 22.34 & 23.09 & 23.71 & 24.27 & 25.22 & 25.91 \\
\hline \multicolumn{11}{|l|}{ Ammodiscus spp. } \\
\hline Ammoglobigerina cf. globigeriniformis & & & & & 3 & & 1 & & & 6 \\
\hline Ammoglobigerina globigeriniformis & & 3 & & & & & & 4 & & \\
\hline \multicolumn{11}{|l|}{ Anamlinoides cf. globosa } \\
\hline Anamlinoides globosa & 1 & & & & & & & & & \\
\hline Astacolus crepidulus & & & & & & & & & & \\
\hline Astrononion novozealandicum & & & & & & & & & & \\
\hline Bolivina aff. salinasensis & & & & 4 & 1 & 1 & & & & \\
\hline Bolivina cf. harangensis & 41 & & 5 & 4 & 1 & 11 & 5 & 17 & 13 & 11 \\
\hline Bolivina cf. hughesi & & 6 & & & & & & & & \\
\hline Bolivina cf. seminuda & & & & & & & & & & \\
\hline Bolivina cf. sp. A & & & & & & 3 & & & & \\
\hline Bolivina cf. striatula & & & & & & & & & & \\
\hline Bolivina cf. subaeranensis & & & & & & & & & & \\
\hline Bolivina imporcata & & & & & & & & & & \\
\hline Bolivina isidroensis & 1 & & & & & & & & & \\
\hline Bolivina spp. & & & & 3 & & & & & & 9 \\
\hline Bolivina striatula & & 10 & 4 & & & & & 4 & 3 & \\
\hline Brizalina aff. subspinescens & & & & 6 & 1 & & 9 & 11 & 2 & \\
\hline Brizalina antegressa & & & & & & & & & & \\
\hline Bulimina alazaensis & & & & & 1 & & & & & \\
\hline Bulimina cf. aculeata & & & & & & & & & & \\
\hline Bulimina cf. elongata & & & & & & & 9 & & 1 & \\
\hline Bulimina rostrata & & & & & & & & & & \\
\hline Bulimina spp. & & & & 1 & & & 1 & & & \\
\hline Buliminella cf. pusilla & 14 & 1 & 1 & 1 & & 2 & 5 & 3 & 5 & 2 \\
\hline Cancris nuttalli & & & & & & & & & & \\
\hline Cassidulina carapitana & 4 & & & & & 1 & & & 3 & 2 \\
\hline Cassidulina cf. corbyi & & & & & & 12 & & & 2 & \\
\hline Cassidulina cf. woodsi & & & & & & & & & & \\
\hline Cassidulina monicana & & & & & & & & 1 & & \\
\hline Cassidulina subglobosa & 4 & 45 & 16 & 14 & 9 & 16 & 32 & 44 & 31 & 21 \\
\hline Cassidulinoides bradyi & & & & & & & & & & \\
\hline Chilostomella oolina & & & & & & & & & & \\
\hline Chrysaloganium spp. & 1 & & & & & & & & & \\
\hline Chrysalogonium cf. eximium & & & & 1 & 1 & & 1 & & 1 & \\
\hline Chrysalogonium tenuicostatum & & & & & & & & & 1 & \\
\hline Cibicides cf. mundulus & & & & & & & 5 & & & \\
\hline Cibicides cf. pachyderma & & & & & 3 & & & & & \\
\hline Cibicides cf. robertsanius & & & & & & & & & & \\
\hline Cibicides choctawensis & & & & 7 & 1 & & & 2 & & \\
\hline Cibicides lobatulus & & & & & & & 2 & & & \\
\hline Cibicides 'marsi' & 2 & 2 & 1 & & & & & & & \\
\hline Cibicides spp. & 5 & 6 & 20 & 15 & 26 & 13 & 25 & 15 & 5 & 5 \\
\hline Cibicides umbonatus & & & & & & & & & & \\
\hline Cibicidoides cf. guazamalensis & & & & & & & & & & \\
\hline Cibicidoides cf. laurisae & & & & & & & 8 & 4 & 4 & 2 \\
\hline Cibicidoides grimsdalei & & & & & & & & & & \\
\hline Cibicidoides bradyi & & 20 & 2 & 5 & & 3 & & 14 & 6 & 8 \\
\hline Cibicidoides cicatricosus & & & 3 & & & & & & & \\
\hline Cibicidoides grossperforatus & & & & & & & & & & \\
\hline Cibicidoides mexicanus & & & & & & & 2 & 1 & & 1 \\
\hline Cibicidoides mundulus & 47 & 38 & 29 & 12 & 18 & 15 & 14 & 15 & 24 & 13 \\
\hline Cibicidoides pachyderma & & & & & & 1 & 1 & & & 2 \\
\hline Cibicidoides perlucidus & & & & & & & & & & \\
\hline Cibicidoides robertsanius & & & & & 2 & 1 & & & 3 & \\
\hline Cyclammina spp. & & & & & & & & & & 1 \\
\hline Dentalina pseudoobliqua & & & & & & & & & 7 & 4 \\
\hline Dentalina roemeri & & & & & & & 1 & & & \\
\hline Eggerella bradyi & & 1 & 3 & 3 & & 1 & 2 & 1 & 1 & 5 \\
\hline Eggerella spp. & & & & & & & & & & \\
\hline Ehrenbergrina sp. A & & & & & & & & & & \\
\hline Enantiodentalina murai & & & & & & & & & & \\
\hline Epistominella exigua & 35 & 14 & 19 & 9 & 1 & 17 & 7 & & 5 & 21 \\
\hline Eponides turgidus & & & 2 & & & & & & & \\
\hline Eponides sp. A & & & & & & & & & & \\
\hline Eponides spp. & & & & & & & & & & \\
\hline Fingerina weaveri & & & & & & & & & & \\
\hline Fissuirina cf. seguenzlana & & & & & & & & & & \\
\hline Fissuirina pseudoglobosa & & & 4 & & & & & & & \\
\hline Fissurina aff. fimbriata & & & & & & & & & & \\
\hline Fissurina bradii & & & & & & & & & & \\
\hline Fissurina cf. fimbriata & & & & & & & & 1 & & \\
\hline Fissurina cf. formosa & & & & & & & & & & \\
\hline Fissurina cf. trubiniformis & 1 & & & 1 & & & & & & \\
\hline Fissurina collifera & & & & & & & & & & \\
\hline Fissurina formosa & & & & & & & & & & \\
\hline Fissurina lagenoides & & & & & & & & & & \\
\hline Fissurina radiata & & & & & & & & & & \\
\hline Fissurina seminifroma & & & & & & & & & & \\
\hline Fissurina spp. & & & & & & 1 & & & & \\
\hline
\end{tabular}




\begin{tabular}{|c|c|c|c|c|c|c|c|c|c|c|}
\hline Hole & 999A & 999A & 999A & 999A & 999A & 999B B & 999B & 999B & 999B & $999 \mathrm{~B}$ \\
\hline Sample & $51 X-01$ & $53 \mathrm{X}-01$ & $58 \mathrm{X}-01$ & $60 \mathrm{X}-01$ & $61 \mathrm{X}-05$ & $07 R-03$ & $09 \mathrm{R}-03$ & 10R-01 & 11R-03 & $12 \mathrm{R}-03$ \\
\hline Age & 19.24 & 19.85 & 21.15 & 21.83 & 22.34 & 23.09 & 23.71 & 24.27 & 25.22 & 25.91 \\
\hline \multicolumn{11}{|l|}{ Fissurina turbiniformis } \\
\hline Francesita advena & & & & & & 1 & & & & \\
\hline Indet. Gen 1. ind. spec. 1 & 1 & 2 & & & 1 & & & 2 & 2 & \\
\hline \multicolumn{11}{|l|}{ Globobulimina affinis } \\
\hline \multicolumn{11}{|l|}{ Globobulimina cf. ovula } \\
\hline Globobulimina ovula & & & & & & & & 2 & & \\
\hline Globobulimina spp. & & & & & & 1 & & & & 1 \\
\hline Gyroidina altiformis & 5 & 5 & & & 2 & & 3 & & & 1 \\
\hline Gyroidina cf. planulata & & & & & & & 4 & & & \\
\hline Gyroidina planulata & 5 & 22 & 4 & 7 & 6 & 21 & & 14 & 5 & 5 \\
\hline Gyroidinoides soldanii & 10 & 17 & 5 & 7 & 12 & 11 & 3 & 11 & 7 & 17 \\
\hline Hoeglodina elegans & & & & & & & & & & \\
\hline Indet. Gen. 2 indet. spec. 1 & & & & & & & & & & \\
\hline Karreriella bradyi & & & & & & 4 & 1 & 4 & 5 & 1 \\
\hline Karreriella subglaba & & & & & & & & & & \\
\hline Laevidentalina advena & & & & & & & & & & \\
\hline Laevidentalina cf. advena & & & & & & & & & & \\
\hline Laevidentalina cf. communis & & & & & & & & & & \\
\hline Laevidentalina communis & 3 & 2 & & & & & & & & \\
\hline Laevidentalina inornata & & & & & & 1 & 4 & & 4 & 1 \\
\hline Lagena auriculata var. incarituba & & & & & & & & & & \\
\hline Lagena castirensis & & & & & & & & & & \\
\hline Lagena cf. auriculata var. incarituba & & & & & 1 & & & & & \\
\hline Lagena cf. elongata & & & & & & & & & & \\
\hline Lagena cf. exsculpta "winged" & & & & & & & & & & \\
\hline Lagena cf. gracilis & & & & & & & & & & \\
\hline Lagena cf. hispida & & & & & & & & & & \\
\hline Lagena cf. laevis & & & & 2 & & & & & 10 & \\
\hline Lagena cf. nebulosa & & & & & & & & & & \\
\hline Lagena elongata & & & & & & & & & & 1 \\
\hline Lagena feildeniana & & & & & & & & & 1 & 1 \\
\hline Lagena gortanii & & & & & & & & & & \\
\hline Lagena gracilis & & & & & & & & & & \\
\hline Lagena hispida & & & & & & & & & & \\
\hline Lagena laevis & & & & & & & & 2 & & 4 \\
\hline Lagena meridonaus & & & & & 3 & & & & 3 & \\
\hline Lagena montagui & & & & & & & & & & \\
\hline Lagena paradoxa & & & & & & & & & & \\
\hline Lagena sp. Hispid & & & & & & & & & & \\
\hline Lagena spp. & & 5 & 7 & 20 & & 24 & 8 & 17 & 20 & 24 \\
\hline Lagena stelligerea & & & & & & & & & & \\
\hline Lagena sulcata & & & & & & & & & & \\
\hline Laticarinina pauperata & 2 & 1 & 2 & 1 & & 1 & & & 2 & 1 \\
\hline Lenticulina cf. alta & 3 & & & & & 2 & & & 1 & \\
\hline Lenticulina cf. americana & & & & & & & & & & \\
\hline Lenticulina gibba & & & & & & & & & & \\
\hline Lenticulina pliocaena (Silvestri) & & & & & 1 & & & & & \\
\hline Lenticulina spp. & & & & & 1 & & & & & 1 \\
\hline Martinottiella spp. & & & & & & 3 & 2 & & & \\
\hline Melonis aff. barleeanum & & & 1 & & & & & & & \\
\hline Melonis aff. pompiloides & 11 & & & & & & & & & \\
\hline Melonis barleeanum & 30 & 59 & 10 & 11 & 6 & 17 & 6 & 29 & 6 & 6 \\
\hline Melonis cf. barleeanum & & & 1 & 1 & & & & & 23 & 1 \\
\hline Melonis cf. pompiloides & & 3 & & & & & & & & 11 \\
\hline Melonis pompiloides & & & & 1 & & & & 2 & & \\
\hline Melonis spp. & & & & & & & & & & \\
\hline Nodosaria spp. & & & & & & & & & & \\
\hline Nonion mesonense & 1 & 1 & & & & & 6 & & 4 & \\
\hline Nonion commune & & & & 1 & & 3 & & & & \\
\hline Nonion sp. A & & & & 1 & & & & & & 1 \\
\hline Nonion spp. & & 1 & & & & & & & & \\
\hline Nuttalides umbonifera & 2 & & 1 & & & 3 & & 4 & & \\
\hline Oolina cf. globosa ovalis & & & & 1 & & & & & & 4 \\
\hline Oolina globosa & & & & & & & & & & \\
\hline Oolina spp. & & & & & & & & & & \\
\hline Oridorsalis stellatus & & & & & & & & & & \\
\hline Oridorsalis umbonatus & 18 & 40 & 8 & 6 & 4 & 18 & 13 & 28 & 16 & 25 \\
\hline Orthomorhpina perversa & & & & & & & & & & \\
\hline Orthomorphina cf. nodulosatriata & & & & & & & & & & \\
\hline Orthomorphina cf. rohri & & & & & & & & & & \\
\hline Orthomorphina challengeriana & & & & & & & & & & \\
\hline Orthomorphina jetladschai & & & & & & & & & & \\
\hline Orthomorphina nodulosatriata & & & & & & & & & & \\
\hline Orthomorphina rohri & & & & & & & & & & \\
\hline Orthomorphina sp. 1 (as in Bornmalm) & & & & & & & & & & \\
\hline Orthomorphina spp. & & & & & & 1 & 1 & & & \\
\hline Osangularia culter & & & & & & & & & & \\
\hline Ovulina striata & & & & & & & & & & \\
\hline
\end{tabular}




\begin{tabular}{|c|c|c|c|c|c|c|c|c|c|c|}
\hline Hole & 999A & 999A & 999A & 999A & 999A & 999B & 999B & 999B & 999B & 999B B \\
\hline Sample & $51 X-01$ & $53 \mathrm{X}-01$ & $58 \mathrm{X}-01$ & $60 \mathrm{X}-01$ & $61 \mathrm{X}-05$ & 07R-03 & $09 \mathrm{R}-03$ & 10R-01 & 11R-03 & 12R-03 \\
\hline Age & 19.24 & 19.85 & 21.15 & 21.83 & 22.34 & 23.09 & 23.71 & 24.27 & 25.22 & 25.91 \\
\hline \multicolumn{11}{|l|}{ Parafissurina aff. ventricosa } \\
\hline Parafissurina cavigera & & & 4 & & & & & & & 2 \\
\hline Parafissurina cf. dorbignyana & & 1 & & & & & & & & \\
\hline \multicolumn{11}{|l|}{ Parafissurina cf. Iateralis f. crassa } \\
\hline Parafissurina cf. ventricosa & & & & & & & & & & \\
\hline Parafissurina dorbignyana & & & & & & 1 & & 1 & & \\
\hline Parafissurina fusuliformis & & & & & & & & & 1 & \\
\hline Parafissurina lateralis f. crassa & & & & & & & & & & \\
\hline Parafissurina pseudomarginata & & & & & & & & & & \\
\hline Parafissurina spp. & & & & & & & & & & \\
\hline Parafissurina tectulostoma & & & & & & & & & & \\
\hline Parafissurina ventricosa & & & 1 & & & & 1 & & & \\
\hline Parafissurina vidriosa & & & & & & & & & & \\
\hline Planulina rugosa & & & & & & & & & & \\
\hline Planulina wuellerstorfi & & & 4 & 1 & 3 & 2 & & & & \\
\hline Pleurostomella acuminata & 15 & & 2 & 8 & & 8 & 24 & 16 & 26 & 7 \\
\hline Pleurostomella alternans & 5 & 11 & 6 & 2 & 2 & 3 & & 8 & 6 & 10 \\
\hline Pleurostomella bierigi & & & & & & 2 & & & & \\
\hline Pleurostomella brevis & 2 & & & & & & 9 & 1 & 1 & 2 \\
\hline Pleurostomella cf. brevis & & & & & & & & & & \\
\hline Pleurostomella spp. & & 5 & & & 12 & & & & & \\
\hline Pleurostomella subnodosa & 4 & & & & & & 4 & & & 4 \\
\hline Polymorphinidae formae fistulosis & 1 & & & & & & & 1 & & \\
\hline Proxifrons advena & & & & & & & & & & \\
\hline Pullenia bulloides & 2 & 9 & 11 & 9 & 7 & 6 & 6 & 12 & 5 & 7 \\
\hline Pullenia quadriloba & 7 & 4 & & & & & & 1 & 2 & 5 \\
\hline Pullenia quinqueloba & 3 & 2 & 10 & & & 5 & 5 & 21 & 8 & 10 \\
\hline Pullenia subcarinata & & & & & & & & & & \\
\hline Pyrgo lucernula & & & & & & & & & & \\
\hline Pyrgo murrhina & & & & & & & & & & \\
\hline Pyrgo oblonga & & & & & & & & & & \\
\hline Pyrgo serrata & & & & & & & & & & \\
\hline Pyrulina albatrossi & & & & & & & & & & \\
\hline Pyrulina sp. A & & & & & & & & & & \\
\hline Pyrulina spp. & & & & & & & & & & \\
\hline Quinqeuloculina cf. lamarckiana & & & & & & & 10 & & 7 & \\
\hline Quinqeuloculina lamarckiana & 6 & 5 & 6 & & 5 & 10 & & & & \\
\hline Quinqeuloculina sp. A & & & & & & & & & & \\
\hline Quinqeuloculina sp. B & & & & & & & & & & \\
\hline Quinqeuloculina spp. & & & & 7 & & 3 & & 8 & & 23 \\
\hline Rectoglandulina sp. A & & & & & & & & & & \\
\hline Rectuvigerina bassispirata & & & & & & & & & & \\
\hline Reophax sp. A & & & 1 & & & & & & & \\
\hline Scallopostoma ovicula & & & & & & & & & & \\
\hline Schenkiella spp. & 1 & 1 & & & & & 1 & 5 & & 3 \\
\hline Sigmoilina spp. & 3 & & & & & & 1 & & 3 & 2 \\
\hline Sigmoilina tenuis & & & 2 & & & & & & & \\
\hline Sigmoilopsis schlumbergeri & & & & & & & & & & \\
\hline Siphonina tenuicarnata & & & & & 2 & 12 & & & & \\
\hline Siphonodosaria bradyi & & & & & & & & & & \\
\hline Siphonodosaria nuttalli gracillima & & & & & 3 & & & & & \\
\hline Siphotextularia cf. catenata & & & & & & & & & & \\
\hline Sphaeroidina bulloides & & & 1 & & & & & & & \\
\hline Spriroplectammina cubensis & & & & & & 1 & & & & \\
\hline Stilostomella abyssorum & & & & & & & & & & \\
\hline Stilostomella cf. subspinosa & 1 & & & & & & & & & \\
\hline Stilostomella consobrina & 5 & 3 & 1 & 2 & & & & & & \\
\hline Stilostomella lepidula & & 3 & 1 & & 7 & & & 3 & & \\
\hline Stilostomella spp. & & & & 4 & & & & 3 & 15 & \\
\hline Stilostomella subspinosa & 4 & & & & 5 & 3 & 17 & 18 & 1 & 7 \\
\hline Stilostomella verneuli paucistriata & & 2 & 1 & & & & & & 1 & \\
\hline Textularia agglutinans & & & & & & 1 & 2 & & 1 & 5 \\
\hline Textularia spp. & & & & & & & & 1 & & \\
\hline Trochammina spp. & & & & & & & 1 & & & \\
\hline Uvigerina auberiana & 1 & & & & & 6 & & & & \\
\hline Uvigerina cf. auberiana & & & & & & & 1 & & & \\
\hline Uvigerina cf. ciperana & 1 & & & & & & 2 & & & \\
\hline Uvigerina cf. hollicki & & & & & & & & & & \\
\hline Uvigerina cf. mantaensis & & & & 1 & & & & & & \\
\hline Uvigerina cf. senticosa & & & & & & & & & & \\
\hline Uvigerina cf. striata attenuata & & & 23 & & & 6 & & 9 & 3 & 5 \\
\hline Uvigerina ciperana & & & & & & & & & & \\
\hline Uvigerina hispida & & & & & & & & & & \\
\hline Uvigerina hispida-costata & & & & & & & & & & \\
\hline Uvigerina peregrina & & & & & & & & & & \\
\hline Uvigerina spp. & & 2 & & & & & & & & \\
\hline Vulvulina pennatula & 5 & & & & & 1 & & & & \\
\hline Vulvulina spinosa & & & & & & & & & & \\
\hline Number of Forams & 313 & 352 & 222 & 179 & 151 & 279 & 265 & 360 & 306 & 311 \\
\hline Number of Species & 41 & 35 & 37 & 35 & 32 & 46 & 43 & 41 & 47 & 48 \\
\hline
\end{tabular}


APPENDIX 2

Caribbean Site 502: Complete Benthic Foraminiferal Counts 


\begin{tabular}{|c|c|c|c|c|c|c|}
\hline SITE 502A & $18-\mathrm{CC}$ & $20-1$ & $21-1$ & $22-1$ & $24-1$ & $28-1$ \\
\hline Alabamina polita Becker and Dusenbury & & & & 1 & & \\
\hline Allomorphina pacifica Cushman and Todd & & & & & & 1 \\
\hline \multicolumn{7}{|l|}{ Amphicoryna bradii (Silvestri) } \\
\hline \multicolumn{7}{|l|}{ Anomalinoides cf. A. alazaensis Nuttall } \\
\hline \multicolumn{7}{|l|}{ Anomalinoides globulosus (Chapman and Parr) } \\
\hline Astrononion guadalupae (Parker) & 13 & 1 & 7 & 29 & & \\
\hline Bathysiphon spp. & & & & & & \\
\hline Bolivina decussata Brady & & & & & & \\
\hline Bolivina scabrata Cushman and Bermudez & & & & & & \\
\hline Bolivina semiperforata Martin & & & & & & \\
\hline Bolivina striatula Cushman & & & & & & \\
\hline Bolivina tongi filacostata Cushman and McCulloch & 1 & & & & & \\
\hline Bulimina cf. B. acanthia Costa & & 3 & & & & \\
\hline Bulimina aculeata d'Orbigny & & & & & & \\
\hline Bulimina mexicana Cushman & & & & & & \\
\hline Bulimina rostrata Brady & 8 & 16 & 1 & 8 & & \\
\hline Cassidulina depressa Asano and Nakamura & & & & & & \\
\hline Cassidulina Iaevigata carinata Silvestri & & & & & & \\
\hline Cassidulina laevigata d'Orbigny & & & & & & \\
\hline Cassidulina minuta Cushman & & & & & 6 & \\
\hline Cassidulina oblonga Reuss & & & & & & \\
\hline Cassidulinoides tenuis Phleger and Parker & & & & & & 1 \\
\hline Ceratobulimnasp. & & & & & & \\
\hline Chilostomella oolina Schwager & 4 & & 2 & 1 & & \\
\hline Chrysalogonium elongatum Cushman and Jarvis & & & & & & \\
\hline Chrysalogonium lanceolum Cushman and Jarvis & & & & & & \\
\hline Chrysalogonium teniucostatum Cushman and Bermude & & & & & & \\
\hline Cibicides deprimus Phleger and Parker & & & & & & \\
\hline Cibicides heminwayae Bermudez & 9 & 2 & & 8 & 4 & 16 \\
\hline Cibicides io Cushman & 7 & & & & & \\
\hline Cibicides lobatulus (Walker and Jacob) & & & & & & \\
\hline Cibicides mckannai Galloway and Wissler & & & & & & \\
\hline Cibicidoides bradyi (Trauth) & 10 & 8 & 5 & 2 & 11 & 7 \\
\hline Cibicidoides cf. C. grimsdalei (Nuttall) & & & & & & \\
\hline Cibicidoides kullenbergi (Parker)? & & & 1 & & 1 & \\
\hline Cibicidoides kullenbergi (Parker) & 3 & 1 & & & & \\
\hline Cibicidoides wuellerstorffi (Schwager) & 43 & 15 & 22 & 22 & 19 & 43 \\
\hline Cibicides cf. C. robertsonianus (Brady) & & & & & & \\
\hline Cibicides robertsonianus (Brady) & & 10 & 3 & & 1 & \\
\hline Cibicides spiralis Natland & & & & & 2 & \\
\hline Cibicides spp. & & & & 2 & 1 & 2 \\
\hline Cibicides umbonatus Phleger and Parker & & & 8 & & 1 & 2 \\
\hline Cyclammina cancellata Brady & & & & & & \\
\hline Cyclogyrasp. & & & & & & \\
\hline Dentalina advena (Cushman) & 3 & 1 & & & & \\
\hline Dentalina communis (d'Orbigny) & & & & & & 1 \\
\hline Dentalina consobrina (d'Orbigny) & & & & & & \\
\hline Dentalina intorta (Dervieux) & & & & & & \\
\hline Dentalina pauperata d'Orbigny & & & & & & \\
\hline Dentalina soluta Reuss & & & & & & \\
\hline Dentalina spp. & & & & & & \\
\hline Eggerella bradyi (Cushman) & 16 & 4 & 4 & 6 & 20 & 7 \\
\hline Ehrenbergina bradyi Cushman & 5 & & & & & \\
\hline Ellipsoglandulina principiensis Cushman and Bermude & & & & & & \\
\hline Ellipsoidina abbreviata Sequenza & & 1 & & & & \\
\hline Elphidium spp. & & & & & & \\
\hline Epistominella bradyana (Cushman) & & 1 & & & 1 & \\
\hline Epistominella exiqua (Brady) & 6 & 1 & & 30 & 25 & 11 \\
\hline Epistominellasp. & & & & & & \\
\hline Epistominella umbonifera (Cushman) & 210 & 88 & 118 & 121 & 45 & 10 \\
\hline Eponides regularis Phleger and Parker & 10 & & & 1 & & 3 \\
\hline Fissurina alveolata (Brady) & & & & & & \\
\hline Fissurina auriculata (Brady) & & & & & & \\
\hline Fissurina subformosa Parr & & & & & 1 & 1 \\
\hline Fissurina bodjonegoroensis (Boomaart) & & & & & & \\
\hline Fissurina carteri (McLean) & 1 & 1 & & & & \\
\hline Fissurina clathrata (Brady) & & & & & & \\
\hline Fissurina cucullata Silvestri & 5 & 3 & & & 2 & \\
\hline Fissurina cf. F. cucullata Silvestri & & & & & & \\
\hline Fissurina dominicana (Bermudez) & 1 & & 1 & & 2 & \\
\hline Fissurina exsculpta (Brady) & & & & & & \\
\hline Fissurina fimbrata (Brady) & 4 & & 3 & & 2 & 2 \\
\hline Fissurina marginata (Montagu) & 3 & 2 & 1 & 1 & & 1 \\
\hline Fissurina semimarginata (Reuss) & & & & & & \\
\hline Fissurina semisculpta Parr & & & & & & \\
\hline Fissurina solida Sequenza & & & & & & \\
\hline Fissurina orbignyana Sequenza & 3 & 3 & 1 & & 3 & \\
\hline Fissurina aff. F. orbignyana Sequenza & & & & & & \\
\hline Fissurina spinosa (Sidebottom) & & & & & & \\
\hline Fissurina spp. & & & & & & \\
\hline Fissurina staphylleraria Schwager & 2 & & & & 1 & \\
\hline Fissurina cf. F. trigonomarginata (Parker and Jones) & & & & & & \\
\hline Fissurina wiesneri Barker & & & & & 1 & 4 \\
\hline Fissurina cf. F. wiesneri Barker & & 3 & & 2 & & \\
\hline
\end{tabular}




\begin{tabular}{|c|c|c|c|c|c|c|}
\hline $\begin{array}{ll}\text { SITE 502A } \\
\text { S }\end{array}$ & $18-\mathrm{CC}$ & $20-1$ & $21-1$ & $22-1$ & $24-1$ & $28-1$ \\
\hline Francesita advena (Cushman) & 7 & & 1 & 2 & 1 & \\
\hline \multicolumn{7}{|l|}{ Fursenkoina bramletti (Galloway and Morrey) } \\
\hline \multicolumn{7}{|l|}{ Fursenkoina rotundata (Parr) } \\
\hline \multicolumn{7}{|l|}{ Fursenkoina seminuda (Natland) } \\
\hline \multicolumn{7}{|l|}{ Globocassidulina ornata (Cushman) } \\
\hline Globocassidulina subglobosa (Brady) & 18 & & 1 & 9 & 11 & 24 \\
\hline \multicolumn{7}{|l|}{ Glomospira charoides (Jones and Parker) } \\
\hline Guttulina caudata d'Orbigny & & 3 & & & & \\
\hline Guttulina sp. (fistulose) & 1 & & 1 & 1 & & \\
\hline Guttulinaspp. & 2 & & & & & \\
\hline Gyroidina altiformis Stewart and Stewart & 13 & 2 & 3 & 9 & 4 & 8 \\
\hline Gyroidina broekhiana Karrer & 1 & & & & & \\
\hline Gyroidina condoni (Cushman and Schenck) & & & 8 & & & 7 \\
\hline \multicolumn{7}{|l|}{ Gyroidina io Resig } \\
\hline Gyroidina lamarckiana d'Orbigny & & 6 & & 3 & 20 & \\
\hline Gyroidina nitidula (Schwager) & & & & & & \\
\hline Gyroidina planulata Cushman and Renz & & & & & & \\
\hline Gyroidina soldanii d'Orbigny & 39 & 17 & 13 & 8 & 5 & 5 \\
\hline Gyroidina cf. G. soldanii d'Orbigny & & & & & & \\
\hline Gyroidina spp. & & & & & & \\
\hline Gyroidina umbonata (Silvestri) & & & & 1 & & \\
\hline Hanzawaia sp. & & & & & & \\
\hline Hoeglundina elegans (d'Orbigny) & & & & & & \\
\hline Karreriella baccata (Schwager) & & & & & & \\
\hline Karreriella bradyi (Cushman) & & & & & & 1 \\
\hline Karreriella brevis (Cushman and Stainforth) & & & & & & \\
\hline Lagena advena Cushman & & & & & 1 & \\
\hline Lagena advena Cushman cf. L. striata & & & & & & \\
\hline Lagena aspera Reuss & & & & & & \\
\hline Lagena costata (Williamson) & & & 2 & & & \\
\hline Lagena crenulata capistriata Cushman and Stainfo & & & & & & \\
\hline Lagena feildeniana Brady & & & & & & \\
\hline Lagena flatulenta Loeblich and Tappan & & 1 & & & 2 & \\
\hline Lagena gracilis Williamson & & & & & & \\
\hline Lagena gracillima (Sequenza) & & & & & & \\
\hline Lagena hexagona (Williamson) & 1 & & & & & 1 \\
\hline Lagena hispida Reuss & & & & & & \\
\hline Lagena cf. L. Iaevis (Montagu) & & & & & & \\
\hline Lagena aff. L. laevis (Montagu) & & & & & & \\
\hline Lagena plumigera Brady & & & & & & \\
\hline Lagena setigera Millett & 2 & & & & & 2 \\
\hline Lagena spp. & & & & & & \\
\hline Laticarinina pauperata (Parker and Jones) & 18 & 11 & 7 & 8 & 11 & 15 \\
\hline Lenticulina crassa d'Orbigny & & & & & & \\
\hline Lenticulina cushmani (Galloway and Wissler) & 3 & & & & 1 & 2 \\
\hline Lenticulina spp. & & & & & & \\
\hline Marginulina asperuliformis (Nuttall) & & & & & & \\
\hline Marginulina exima Neugeboren & & & & & & \\
\hline Marginulina planata Phleger and Parker & & & & & & \\
\hline Marginulina subbullata Hantken & & & & & & \\
\hline Marginulina sublituus (Nuttall) & & & & & & \\
\hline Marginulina subrecta Franke & & & & & & \\
\hline Martinottiella pallida (Cushman) & 3 & 5 & 7 & 2 & 3 & \\
\hline Martinotiella patens (Cushman and Laiming) & & & & & & \\
\hline Melonis affinis (Reuss) & 6 & 14 & 12 & 6 & 3 & 2 \\
\hline Melonis pompilioides (Fitchel and Moll) & & & & & & \\
\hline Melonis soldanii (d'Orbigny) & & & & & & \\
\hline Melonis sp. & 1 & & 1 & & & \\
\hline Milolinella irregularis (d'Orbigny) & & & & & & \\
\hline Nonionella spp. & & & & & & \\
\hline Nonionella stella Cushman and Moyer & & & & & & \\
\hline Nodogenerina challengeriana Thalmann & 1 & & 1 & & & \\
\hline Nodogenerina laevigata Bermudez & 1 & & & & & \\
\hline Nodosaria fistuca Schwager & & & & & & \\
\hline Nodosaria flintii Cushman & & & & & & \\
\hline Nodosaria hispida d'Orbigny & & & & & & \\
\hline Nodosaria lamellata Cushman and Stainforth & & & & & & \\
\hline Nodosaria longiscata d'Orbigny & & & 5 & 2 & & 10 \\
\hline Nodosaria pyrula d'Orbigny & & & & & & \\
\hline Nodosaria vertebralis (Batsch) & & & & & & \\
\hline Nodosaria cf. N. vertebralis (Batsch) & & & & & & \\
\hline Nodosarella robusta Cushman & & & & & & \\
\hline Nodosarella salmojraghii Martinotti & & & & & & \\
\hline Nonion havanense Cushman and Bermudez & 1 & 5 & & & & \\
\hline Oolina caudigera (Wiesner) & & & & & & \\
\hline Oolina desmophora (Rymer Jones) & 2 & & & & & \\
\hline Oolinaglobulosa (Montagu) & 3 & & & & 1 & \\
\hline Oolina ovum (Ehrenberg) & 1 & 1 & & & & \\
\hline
\end{tabular}




\begin{tabular}{|c|c|c|c|c|c|c|}
\hline SITE 502A & $18-\mathrm{CC}$ & $20-1$ & $21-1$ & $22-1$ & $24-1$ & $28-1$ \\
\hline Oolinasp. & & & & & 1 & \\
\hline Opthalmidium inconstans Brady & & & & & & \\
\hline Oridorsalis multiseptus (Koch) & & & & & & \\
\hline Oridorsalis umbonatus (Reuss) & 32 & 13 & 15 & 22 & 10 & 11 \\
\hline Oridorsalis cf. O. umbonatus (Reuss) & & & & & & \\
\hline Oridorsalis aff. O. umbonatus (Reuss) & & & & & & \\
\hline Orthomorphina rohri (Cushman and Stainfort & & & & & & \\
\hline Osangularia culteri (Parker and Jones) & & 5 & 1 & 2 & 1 & \\
\hline Parafissurina cf. "Lagena" fistulifera Buchne & & & & & & \\
\hline Parafissurina lateralis carinata (Buchner) & & & & & & \\
\hline Parafissurina sp. & & & & & & \\
\hline Parafissurina spp. & & & & 1 & & \\
\hline Parafissurina pseudomarginata (Buchner) & & & & & & \\
\hline Parafissurina tectulostoma Loeblich and Tapp & & & & & & \\
\hline Planulina spp. & & & & & & \\
\hline Plectofrondicularia advena (Cushman) & & & & & & \\
\hline Plectofrondicularia apicularis (Cushman) & & & & & & \\
\hline Plectofrondicularia vaughani Cushman & & & & & & \\
\hline Pleurostomella acuminata Cushman & & 2 & & & & 2 \\
\hline Pleurostomella acuta Hantken & & & & & & \\
\hline Pleurostomellaalternans Schwager & 5 & & & & & 1 \\
\hline Pleurostomella cf. P. alternans Schwager & & & & & & \\
\hline Pleurostomella bierigi Palmer and Bermude & & & & & & \\
\hline Pleurostomella brevis Schwager & 1 & 1 & & 1 & & \\
\hline Pleurostomella praegerontica Cushman and Stair & & & & & & \\
\hline Pleurostomella subglobosa Rey & & & & & & \\
\hline Pleurostomella spp. & & & & & 2 & \\
\hline Praeglobobulimina affinis (d'Orbigny) & & & & & & \\
\hline Praeglobobulimina auriculata (Bailey) & & & & & & \\
\hline Praeglobobulimina pupoides (d'Orbigny) & & & & & & \\
\hline Pseudoglandulina $s p$. & & & & & & \\
\hline Pullenia alazaensis Cushman & & 7 & & 1 & & 3 \\
\hline Pullenia cf. P. alazaensis Cushman & & & & & & \\
\hline Pullenia angusta Cushman and Todd & 22 & 6 & & 4 & 1 & 3 \\
\hline Pullenia bulloides (d'Orbigny) & 34 & 2 & 3 & 4 & 3 & 6 \\
\hline Pullenia quatriloba (Sequenza) & & & & & & \\
\hline Pullenia quinqueloba (Reuss) & 10 & 3 & 2 & 5 & 3 & \\
\hline Pullenia salisburyi Stewart and Stewart & & & & & & \\
\hline Pullenia spp. & & & & & & \\
\hline Pyrulina albatrossi Cushman and Ozawa & & 1 & & & & 1 \\
\hline Pyrulina cylindroides curvatura Cushman and Stai & & & & & & \\
\hline Pyrulina cylindroides (Roemer) & & & & & & \\
\hline Pyrgo anomala (Schlumberger) & & & & & 1 & \\
\hline Pyrgo depressa (d'Orbigny) & 5 & 6 & & & 2 & \\
\hline Pyrgo lucernula (Schwager) & & 2 & & & & \\
\hline Pyrgo cf. P. lucernula (Schwager) & 4 & & & & & \\
\hline Pyrgo murrhina (Schwager) & & & 6 & 10 & 5 & 4 \\
\hline Pyrgo cf. P. murrhina (Schwager) & & & & & & \\
\hline Pyrgo rotalaria Loeblich and Tappan & 7 & 8 & 1 & & 1 & 4 \\
\hline Pyrgo cf. P. rotularia Loeblich and Tappan & & & & & & \\
\hline Pyrgo aff. P. rotularia Loeblich and Tappan & & 1 & 2 & & & \\
\hline Pyrgo serrata (Bailey) & & & & & & \\
\hline Pyrgo spp. & & & & & & \\
\hline Pyrgo williamsoni (Silvestri) & 1 & & & & & \\
\hline Quinqueloculina auberiana d'Orbigny & 1 & & & & 1 & 2 \\
\hline Quinqueloculina lamarckiana d'Orbigny & 1 & 2 & & & & \\
\hline Quinqueloculina seminulum (Linne) & & & & & & \\
\hline Quinqueloculina cf. Q. seminulum (Linne) & & & & & & \\
\hline Quinqueloculina spp. & & & & & 2 & \\
\hline Quinqueloculina venusta Karrer & 5 & 5 & 1 & 6 & 1 & 3 \\
\hline Robertinoidessp. & & & & & & \\
\hline Rosalina columbiensis (Cushman) & & & & & & \\
\hline Saracenaria acutauricularis (Fitchell and Mol & & & & & & \\
\hline Sigmoilina schlumbergeri Silvestri & 16 & 19 & 4 & 8 & 6 & \\
\hline Sigmoilina sp. & & 1 & & & & \\
\hline Sigmoilina tenuis (Czjeck) & 4 & 3 & 12 & 4 & 2 & 13 \\
\hline Siphonodosaria abyssorum (Brady) & & & & & & \\
\hline Siphonodosaria paucistriata (Galloway and Mor & & & & & & \\
\hline Siphonodosaria verneuilla (d'Orbigny) & & & & & & \\
\hline Siphotextularia catenata (Cushman) & 7 & & 5 & & 5 & 1 \\
\hline Sphaeroidina bulloides d'Orbigny & 1 & & & & & \\
\hline Spiroloculina robusta Brady & & & & & & \\
\hline Stilostomella advena (Cushman and Laiming & & & & & & \\
\hline Stilostomella lepidula (Schwager) & 1 & & & & & 2 \\
\hline Stilostomella subspinosa (Cushman) & & 2 & & & & \\
\hline Stilostomella sp. & & & & & & \\
\hline Textularia agglutinanas d'Orbigny & & 11 & & 4 & 4 & 6 \\
\hline Triloculina trihedra Loeblich and Tappan & 1 & & & 1 & & \\
\hline Uvigerina hispidocostata Cushman and Tod & & 13 & 17 & 6 & 1 & \\
\hline Uvigerina cf. U. hispidocostata Cushman and T & & & & & & \\
\hline Uvigerina hispida Schwager & & & & & & 1 \\
\hline Uvigerina peregrina Cushman & & & & & & \\
\hline Uvigerina rustica Cushman and Edwards & & & & & & \\
\hline Uvigerina senticosa Cushman & & & & & & \\
\hline Uvigerina striata d'Orbigny & 10 & 4 & & & & \\
\hline Valvulineria araucana (d'Orbigny) & & & & & & \\
\hline Valvulineria glabra Cushman & & & & & & \\
\hline Valvulineria mexicana Parker & & & & & & \\
\hline Valvulineria minuta (Schubert) & & & & & & \\
\hline Valvulineriasp. & & & & & & \\
\hline Vulvulina spinosa Cushman & & & & & & \\
\hline
\end{tabular}

196 


\begin{tabular}{|c|c|c|c|c|c|}
\hline SITE 502A & $33-1$ & 43-1 & $48-1$ & $55-1$ & $63-1$ \\
\hline \multicolumn{6}{|l|}{ Alabamina polita Becker and Dusenbury } \\
\hline Allomorphina pacifica Cushman and Todd & & & & & \\
\hline \multicolumn{6}{|l|}{ Amphicoryna bradii (Silvestri) } \\
\hline \multicolumn{6}{|l|}{ Anomalinoides cf. A. alazaensis Nuttall } \\
\hline Anomalinoides globulosus (Chapman and Parr) & & 11 & & & \\
\hline Astrononion guadalupae (Parker) & 1 & 1 & & & \\
\hline \multicolumn{6}{|l|}{ Bathysiphon spp. } \\
\hline Bolivina decussata Brady & & & & & \\
\hline Bolivina scabrata Cushman and Bermudez & & & & & \\
\hline Bolivina semiperforata Martin & 1 & & & & \\
\hline Bolivina striatula Cushman & & & & & \\
\hline Bolivina tongi filacostata Cushman and McCulloch & & & & & \\
\hline Bulimina cf. B. acanthia Costa & & 1 & & & \\
\hline Bulimina aculeata d'Orbigny & & & & & \\
\hline Bulimina mexicana Cushman & & & & & \\
\hline Bulimina rostrata Brady & 5 & 2 & 5 & & 68 \\
\hline Cassidulina depressa Asano and Nakamura & & & & & \\
\hline Cassidulina laevigata carinata Silvestri & & & & & \\
\hline Cassidulina laevigata d'Orbigny & & & & & \\
\hline Cassidulina minuta Cushman & & & & & \\
\hline Cassidulina oblonga Reuss & & & & & \\
\hline Cassidulinoides tenuis Phleger and Parker & & & & & \\
\hline Ceratobulimnasp. & & & & & \\
\hline Chilostomella oolina Schwager & & & & & \\
\hline Chrysalogonium elongatum Cushman and Jarvis & & & & & \\
\hline Chrysalogonium lanceolum Cushman and Jarvis & & & & 10 & \\
\hline Chrysalogonium teniucostatum Cushman and Bermud & & & & & \\
\hline Cibicides deprimus Phleger and Parker & & & & & \\
\hline Cibicides heminwayae Bermudez & & & & & 11 \\
\hline Cibicides io Cushman & & & & & \\
\hline Cibicides lobatulus (Walker and Jacob) & & & & & \\
\hline Cibicides mckannai Galloway and Wissler & & & & & \\
\hline Cibicidoides bradyi (Trauth) & 22 & 11 & 48 & 20 & 14 \\
\hline Cibicidoides cf. C. grimsdalei (Nuttall) & & & & & \\
\hline Cibicidoides kullenbergi (Parker)? & & & & & \\
\hline Cibicidoides kullenbergi (Parker) & & 1 & 8 & 14 & 6 \\
\hline Cibicidoides wuellerstorffi (Schwager) & 11 & 9 & 44 & 37 & 27 \\
\hline Cibicides cf. C. robertsonianus (Brady) & & & & & \\
\hline Cibicides robertsonianus (Brady) & & & 4 & 2 & 4 \\
\hline Cibicides spiralis Natland & & & 5 & & \\
\hline Cibicides spp. & & & & 3 & \\
\hline Cibicides umbonatus Phleger and Parker & 11 & 4 & 9 & & \\
\hline Cyclammina cancellata Brady & & & & & \\
\hline Cyclogyrasp. & & & & & \\
\hline Dentalina advena (Cushman) & & & & & \\
\hline Dentalina communis (d'Orbigny) & & & & & \\
\hline Dentalina consobrina (d'Orbigny) & & & & & \\
\hline Dentalina intorta (Dervieux) & & & & & \\
\hline Dentalina pauperata d'Orbigny & & & & & \\
\hline Dentalina soluta Reuss & & 1 & & & \\
\hline Dentalina spp. & & & & & \\
\hline Eggerella bradyi (Cushman) & 22 & 9 & 24 & 10 & 16 \\
\hline Ehrenbergina bradyi Cushman & & & & & \\
\hline Ellipsoglandulina principiensis Cushman and Bermud & & & & & \\
\hline Ellipsoidina abbreviata Sequenza & 1 & & & & \\
\hline Elphidiumspp. & & & & & \\
\hline Epistominella bradyana (Cushman) & & & 1 & & \\
\hline Epistominella exiqua (Brady) & 9 & 2 & & 3 & 3 \\
\hline Epistominellasp. & & & & & \\
\hline Epistominella umbonifera (Cushman) & 40 & 14 & 47 & 157 & 81 \\
\hline Eponides regularis Phleger and Parker & & 2 & & & \\
\hline Fissurina alveolata (Brady) & & & & 1 & \\
\hline Fissurina auriculata (Brady) & & & & & \\
\hline Fissurina subformosa Parr & & & & & \\
\hline Fissurina bodjonegoroensis (Boomaart) & & & & & \\
\hline Fissurina carteri (McLean) & & & & 1 & \\
\hline Fissurina clathrata (Brady) & & & & & \\
\hline Fissurina cucullata Silvestri & & & 2 & & 2 \\
\hline Fissurina cf. F. cucullata Silvestri & & & & & \\
\hline Fissurina dominicana (Bermudez) & & & & 1 & \\
\hline Fissurina exsculpta (Brady) & & & & & \\
\hline Fissurina fimbrata (Brady) & & 2 & 4 & & 3 \\
\hline Fissurina marginata (Montagu) & 4 & & & 3 & 1 \\
\hline Fissurina semimarginata (Reuss) & & & & & 1 \\
\hline Fissurina semisculpta Parr & & & & & \\
\hline Fissurina solida Sequenza & & & & & \\
\hline Fissurina orbignyana Sequenza & 2 & & 4 & 4 & \\
\hline Fissurina aff. F. orbignyana Sequenza & & & & & \\
\hline Fissurina spinosa (Sidebottom) & 4 & & & 1 & \\
\hline Fissurina spp. & & & 1 & & \\
\hline Fissurina staphylleraria Schwager & & & & & \\
\hline Fissurina cf. F. trigonomarginata (Parker and Jones) & & & & & \\
\hline Fissurina wiesneri Barker & 1 & & & & \\
\hline Fissurina cf. F. wiesneri Barker & & & & & \\
\hline
\end{tabular}




\begin{tabular}{|c|c|c|c|c|c|}
\hline SITE 502A & $33-1$ & $43-1$ & $48-1$ & $55-1$ & $63-1$ \\
\hline \multicolumn{6}{|l|}{ Francesita advena (Cushman) } \\
\hline Fursenkoina bramletti (Galloway and Morrey) & & 1 & & & \\
\hline \multicolumn{6}{|l|}{ Fursenkoina rotundata (Parr) } \\
\hline \multicolumn{6}{|l|}{ Fursenkoina seminuda (Natland) } \\
\hline \multicolumn{6}{|l|}{ Globocassidulina ornata (Cushman) } \\
\hline Globocassidulina subglobosa (Brady) & 7 & 1 & 13 & 18 & 13 \\
\hline \multicolumn{6}{|l|}{ Glomospira charoides (Jones and Parker) } \\
\hline \multicolumn{6}{|l|}{ Guttulina caudata d'Orbigny } \\
\hline Guttulina sp. (fistulose) & & 1 & 1 & 2 & 1 \\
\hline Guttulinaspp. & & 1 & & & \\
\hline Gyroidina altiformis Stewart and Stewart & & 6 & 3 & 19 & 2 \\
\hline Gyroidina broekhiana Karrer & & 1 & & & \\
\hline \multicolumn{6}{|l|}{ Gyroidina condoni (Cushman and Schenck) } \\
\hline Gyroidina io Resig & & & & & \\
\hline Gyroidina lamarckiana d'Orbigny & & & & 2 & 6 \\
\hline Gyroidina nitidula (Schwager) & & & & & \\
\hline Gyroidina planulata Cushman and Renz & & & & & \\
\hline Gyroidina soldanii d'Orbigny & 2 & 3 & 13 & 10 & 4 \\
\hline Gyroidina cf. G. soldanii d'Orbigny & & & & & \\
\hline Gyroidina spp. & & & & & \\
\hline Gyroidina umbonata (Silvestri) & & 8 & 10 & 10 & 7 \\
\hline Hanzawaia sp. & & & & & \\
\hline Hoeglundina elegans (d'Orbigny) & & & & & 1 \\
\hline Karreriella baccata (Schwager) & & & & & \\
\hline Karreriella bradyi (Cushman) & & & & & \\
\hline Karreriella brevis (Cushman and Stainforth) & & & & & \\
\hline Lagena advena Cushman & 1 & & & 2 & \\
\hline Lagena advena Cushman cf. L. striata & & & & & \\
\hline Lagena aspera Reuss & & 2 & 2 & 2 & 1 \\
\hline Lagena costata (Williamson) & 1 & & & & \\
\hline Lagena crenulata capistriata Cushman and Stainforth & & & & 1 & 1 \\
\hline Lagenafeildeniana Brady & & & & & \\
\hline Lagena flatulenta Loeblich and Tappan & & & 1 & 1 & \\
\hline Lagena gracilis Williamson & & & & & \\
\hline Lagena gracillima (Sequenza) & & & & & 3 \\
\hline Lagena hexagona (Williamson) & 1 & & & 1 & \\
\hline Lagena hispida Reuss & & & & 1 & \\
\hline Lagena cf. L. laevis (Montagu) & & & & & \\
\hline Lagena aff. L. laevis (Montagu) & & & & & \\
\hline Lagena plumigera Brady & & & & & \\
\hline Lagena setigera Millett & 2 & 2 & 2 & 1 & \\
\hline Lagena spp. & & & & & \\
\hline Laticarinina pauperata (Parker and Jones) & 3 & 1 & 17 & 11 & 18 \\
\hline Lenticulina crassa d'Orbigny & & & & & \\
\hline Lenticulina cushmani (Galloway and Wissler) & & 2 & 1 & 1 & 2 \\
\hline Lenticulina spp. & & & & & \\
\hline Marginulina asperuliformis (Nuttall) & & & & & \\
\hline Marginulina exima Neugeboren & & & & & \\
\hline Marginulina planata Phleger and Parker & 2 & & & & \\
\hline Marginulina subbullata Hantken & & & & & \\
\hline Marginulina sublituus (Nuttall) & & & & & \\
\hline Marginulina subrecta Franke & & & & & \\
\hline Martinottiella pallida (Cushman) & 1 & 3 & 6 & 2 & 1 \\
\hline Martinotiella patens (Cushman and Laiming) & & & & & \\
\hline Melonis affinis (Reuss) & & 26 & 11 & 6 & 13 \\
\hline Melonis pompilioides (Fitchel and Moll) & & & & & \\
\hline Melonis soldanii (d'Orbigny) & & & & & \\
\hline Melonissp. & & & & & \\
\hline Milolinella irregularis (d'Orbigny) & 1 & & 2 & & \\
\hline Nonionella spp. & & 1 & 5 & 4 & 3 \\
\hline Nonionella stella Cushman and Moyer & & & & & \\
\hline Nodogenerina challengeriana Thalmann & & & 1 & & \\
\hline Nodogenerina laevigata Bermudez & & & & & \\
\hline Nodosaria fistuca Schwager & & & & & \\
\hline Nodosaria flintii Cushman & & & & & \\
\hline Nodosaria hispida d'Orbigny & & & & & \\
\hline Nodosaria lamellata Cushman and Stainforth & & & & & 1 \\
\hline Nodosaria longiscata d'Orbigny & & 3 & 28 & 5 & 10 \\
\hline Nodosaria pyrula d'Orbigny & & & & & \\
\hline Nodosaria vertebralis (Batsch) & & & & & \\
\hline Nodosaria cf. N. vertebralis (Batsch) & & & & & \\
\hline Nodosarella robusta Cushman & & & & & \\
\hline Nodosarella salmojraghii Martinotti & & & & & \\
\hline Nonion havanense Cushman and Bermudez & & & & & 3 \\
\hline Oolina caudigera (Wiesner) & & & 1 & & \\
\hline Oolina desmophora (Rymer Jones) & & & & & \\
\hline Oolina globulosa (Montagu) & & 1 & & 1 & \\
\hline Oolina ovum (Ehrenberg) & & 2 & & & \\
\hline
\end{tabular}




\begin{tabular}{|c|c|c|c|c|c|}
\hline SITE 502A & 33-1 & 43-1 & $48-1$ & $55-1$ & $63-1$ \\
\hline Oolinasp. & & & 1 & & \\
\hline & & & & & \\
\hline Oridorsalis multiseptus (Koch) & & & & & \\
\hline Oridorsalis umbonatus (Reuss) & 10 & & 1 & 9 & 20 \\
\hline Oridorsalis cf. O. umbonatus (Reuss) & & & & & \\
\hline Oridorsalis aff. O. umbonatus (Reuss) & & & & & \\
\hline Orthomorphina rohri (Cushman and Stainforth) & & & & & \\
\hline Osangularia culteri (Parker and Jones) & & 2 & & & \\
\hline Parafissurina cf. "Lagena" fistulifera Buchner & & & & & \\
\hline Parafissurina lateraliscarinata (Buchner) & & & & & \\
\hline $\begin{array}{l}\text { Parafissurinasp. } \\
\end{array}$ & & & & & \\
\hline Parafissurinaspp. & & & & & 3 \\
\hline Parafissurina pseudomarginata (Buchner) & & & & & \\
\hline Parafissurina tectulostoma Loeblich and Tappan & & & & & \\
\hline Planulina spp. & & & & & \\
\hline Plectofrondicularia advena (Cushman) & & & & & \\
\hline Plectofrondicularia apicularis (Cushman) & & & & & \\
\hline Plectofrondiculariavaughani Cushman & & & & & \\
\hline Pleurostomella acuminata Cushman & & 1 & & 2 & \\
\hline Pleurostomella acuta Hantken & & & & & \\
\hline Pleurostomellaalternans Schwager & & & & 1 & 2 \\
\hline Pleurostomella cf. P. alternans Schwager & & & & & \\
\hline Pleurostomella bierigi Palmerand Bermudez & 1 & 1 & & & 1 \\
\hline Pleurostomella brevis Schwager & & & & 1 & \\
\hline Pleurostomella praegerontica Cushman and Stainforth & & & & & \\
\hline Pleurostomella subglobosa Rey & & & & & \\
\hline Pleurostomella spp. & & & & & \\
\hline Praeglobobulimina affinis (d'Orbigny) & & & & & \\
\hline Praeglobobulimina auriculata (Bailey) & & & 1 & & \\
\hline Praeglobobulimina pupoides (d'Orbigny) & & & & & \\
\hline Pseudoglandulina $s p$. & & & & & \\
\hline Pullenia alazaensis Cushman & & & 2 & 8 & \\
\hline Pullenia cf. P. alazaensis Cushman & & & & & \\
\hline Pullenia angusta Cushman and Todd & 3 & & 6 & 1 & \\
\hline Pullenia bulloides (d'Orbigny) & 6 & 2 & 4 & 6 & 5 \\
\hline Pullenia quatriloba (Sequenza) & & & & & \\
\hline Pullenia quinqueloba (Reuss) & 1 & 5 & 1 & 6 & 3 \\
\hline Pullenia salisburyi Stewart and Stewart & & & 2 & & \\
\hline Pullenia spp. & & & & & \\
\hline Pyrulina albatrossi Cushman and Ozawa & & 2 & & & \\
\hline Pyrulina cylindroides curvatura Cushman and Stainforth & & & & 2 & \\
\hline Pyrulina cylindroides (Roemer) & & & & & \\
\hline Pyrgo anomala (Schlumberger) & & & & & 1 \\
\hline Pyrgo depressa (d'Orbigny) & & & 1 & 1 & 1 \\
\hline Pyrgo lucernula (Schwager) & & & & & \\
\hline Pyrgo cf. P. lucernula (Schwager) & & & & & \\
\hline Pyrgo murrhina (Schwager) & 2 & 6 & 13 & 19 & 20 \\
\hline Pyrgo cf. P. murrhina (Schwager) & & & & & \\
\hline Pyrgo rotalaria Loeblich and Tappan & & 2 & 7 & 9 & 2 \\
\hline Pyrgo cf. P. rotularia Loeblich and Tappan & & & & & \\
\hline Pyrgo aff. P. rotularia Loeblich and Tappan & & 2 & 3 & & 3 \\
\hline Pyrgo serrata (Bailey) & & 1 & & & \\
\hline Pyrgo spp. & & & & & 1 \\
\hline Pyrgo williamsoni (Silvestri) & & & & & \\
\hline Quinqueloculina auberiana d'Orbigny & & & & & \\
\hline Quinqueloculina lamarckiana d'Orbigny & & & & & 5 \\
\hline Quinqueloculina seminulum (Linne) & & & & & \\
\hline Quinqueloculina cf. Q. seminulum (Linne) & & & & & \\
\hline Quinqueloculina spp. & & & & & \\
\hline Quinqueloculina venusta Karrer & 3 & 5 & 4 & 5 & 7 \\
\hline Robertinoidessp. & & & & & \\
\hline Rosalina columbiensis (Cushman) & & & & & \\
\hline Saracenaria acutauricularis (Fitchell and Moll) & & & & & \\
\hline Sigmoilina schlumbergeri Silvestri & 14 & 4 & 23 & 10 & 4 \\
\hline Sigmoilina sp. & & & & & \\
\hline Sigmoilina tenuis (Czjeck) & 1 & & 3 & 2 & 1 \\
\hline Siphonodosaria abyssorum (Brady) & & & & & \\
\hline Siphonodosaria paucistriata (Galloway and Morrey) & & & & & \\
\hline Siphonodosaria verneuilla (d'Orbigny) & & 1 & & & \\
\hline Siphotextularia catenata (Cushman) & 4 & & & & \\
\hline Sphaeroidina bulloides d'Orbigny & & 6 & 15 & 3 & \\
\hline Spiroloculina robusta Brady & & & & & \\
\hline Stilostomella advena (Cushman and Laiming) & & & & & \\
\hline Stilostomella lepidula (Schwager) & & & & & \\
\hline Stilostomella subspinosa (Cushman) & & & & & \\
\hline Stilostomellasp. & 1 & & & & \\
\hline Textularia agglutinanas d'Orbigny & & 7 & 5 & 1 & 10 \\
\hline Triloculina trihedra Loeblich and Tappan & & & & & \\
\hline Uvigerina hispidocostata Cushman and Todd & 1 & & & & \\
\hline Uvigerina cf. U. hispidocostata Cushman and Todd & & & & & \\
\hline Uvigerina hispida Schwager & 2 & & & & 6 \\
\hline Uvigerina peregrina Cushman & & & & & \\
\hline Uvigerina rustica Cushman and Edwards & & & & & \\
\hline Uvigerina senticosa Cushman & & & & & \\
\hline Uvigerina striata d'Orbigny & & & & 3 & \\
\hline Valvulineria araucana (d'Orbigny) & & & & & \\
\hline Valvulineria glabra Cushman & & & & & \\
\hline Valvulineria mexicana Parker & & & & & \\
\hline Valvulineria minuta (Schubert) & & & & & \\
\hline Valvulineriasp. & & & 1 & & \\
\hline Vulvulina spinosa Cushman & & & & 1 & 1 \\
\hline
\end{tabular}

199 


\section{APPENDIX 3}

Equatorial Eastern Pacific Site 503: Complete Benthic Foraminiferal Counts 


\begin{tabular}{|c|c|c|c|c|c|c|}
\hline DSDP SITE 503A & $13-1$ & $15-1$ & $19-1$ & $27-1$ & $29-1$ & $36-1$ \\
\hline Alabamina polita Becker and Dusenbury & & & & & & \\
\hline \multicolumn{3}{|l|}{ Allomorphina pacifica Cushman and Todd } & & & & \\
\hline \multicolumn{7}{|l|}{ Alveolophragmium crassimargo (Norman) } \\
\hline \multicolumn{7}{|l|}{ Alveolophragmium subglobosum (Sars) } \\
\hline \multicolumn{7}{|l|}{ Ammodiscus incertus (d'Orbigny) } \\
\hline Anomalinoides cf. A. alazaensis Nuttall & & & & & & \\
\hline Anomalinoides globulosus (Chapman and Parr) & & & & 5 & 1 & \\
\hline Anomalinoides pompilioides (Galloway and Wissler) & & & & & & \\
\hline Anomalina cicatricosus Schwager & & & & & & \\
\hline Astacolus sp. & & & & & & \\
\hline Astrononion gallowayi Loeblich and Tappan & & & & & & \\
\hline Astrononion guadalupae (Parker) & & & 1 & 3 & & 15 \\
\hline Bathysiphonsp. & & & & & & \\
\hline Bolivina cf. B. bradyi Asano & & & & & & \\
\hline Bolivinoides cubensis (Cushman and Bermudez) & & & & 1 & & \\
\hline Bolivina pacifica Cushman and McCulloch & & & & & & \\
\hline Bolivina translucens Phleger and Parker & & & & & & \\
\hline Bulimina cf. B. acanthia Costa & & & 3 & & & \\
\hline Bulimina rostrata Brady & & & & & & \\
\hline Cassidulina depressa Asano and Nakamura & & & & & & \\
\hline Cassidulina oblonga Reuss & & & & & & \\
\hline Cassidulinoides bradyi (Norman) & & & & & & \\
\hline Cassidulinoides tenuis Phleger and Parker & & & & & & 2 \\
\hline Chilostomella oolina Schwager & 3 & & & 2 & & 9 \\
\hline Chrysalogonium elongatum Cushman and Jarvis & & & 1 & & & 1 \\
\hline Chrysalogonium longiscatatum Cushman and Jarvis & & & & & & \\
\hline Chrysalogonium sp. & & & & & & 1 \\
\hline Chrysalogonium teniucostatum Cushman and Bermude & & & & & & \\
\hline Cibicides deprimus Phleger and Parker & & 5 & & 7 & & 2 \\
\hline Cibicides fletcheri Galloway and Wissler & & & & & & \\
\hline Cibicides granulosa Bermudez & & & & & 2 & \\
\hline Cibicides cf. C. granulosa Bermudez & & & & & & \\
\hline Cibicides heminwayae Bermudez & & 2 & & & & \\
\hline Cibicides io Cushman & & & & & & \\
\hline Cibicides aff. C. io Cushman & & & & 2 & 2 & 2 \\
\hline Cibicides lobatulus (Walker and Jacob) & & & & & & \\
\hline Cibicides mckannai Galloway and Wissler & & & 1 & & & \\
\hline Cibicides mollis Phleger and Parker & & & & & & \\
\hline Cibicides nucleatus (Sequenza) & & & & & & \\
\hline Cibicidoides bradyi (Trauth) & 1 & & & & 3 & 7 \\
\hline Cibicidoides kullenbergi (Parker) & & & 1 & 5 & & 13 \\
\hline Cibicidoides miocenica (Colom) & & & & & & \\
\hline Cibicidoides mundulus (Brady & & & & & & 1 \\
\hline Cibicidoidessp. & & & & & & \\
\hline Cibicidoides wuellerstorffi (Schwager) & 2 & 2 & & 1 & 3 & \\
\hline Cibicides robertsonianus (Brady) & & & & & & \\
\hline Cibicides aff. C. robertsonianus (Brady) & & & & & & \\
\hline Cibicides spiralis Natland & & & & & & \\
\hline Cibicides spp. & & & & 1 & & 1 \\
\hline Cyclammina cancellata Brady & & 1 & & & & \\
\hline Cyclogyra foliacea (Philippi) & & & 1 & & & \\
\hline Dentalina communis (d'Orbigny) & & & & & & 1 \\
\hline Dentalina consobrina (d'Orbigny) & & & 2 & & & \\
\hline Dentalina cooperensis Cushman & & & & & & 1 \\
\hline Dentalina ittai Loeblich and Tappan & & & & & & \\
\hline Dentalina mucronata Neugeboren & & & & 1 & 1 & \\
\hline Dentalina pauperata d'Orbigny & & & & 1 & & \\
\hline Dentalina sp. & & & & & & \\
\hline Eggerella bradyi (Cushman) & 1 & 1 & 1 & 11 & 3 & 8 \\
\hline Ehrenbergina bradyi Cushman & & & 1 & & & \\
\hline Ehrenbergina glabra Heron-Allen and Earland & & & & & & \\
\hline Ellipsonodosaria decurta Bermudez & & & & & & \\
\hline Ellipsoidina abbreviata Sequenza & & & & & & \\
\hline Epistominella bradyana (Cushman) & & & & & & \\
\hline Epistominella exiqua (Brady) & & 1 & 1 & 3 & 7 & 11 \\
\hline Epistominella umbonifera (Cushman) & 8 & 10 & 8 & 16 & 3 & \\
\hline Epistominella vitrea Parker & & & & & & \\
\hline Eponides regularis Phleger and Parker & & & 1 & & & \\
\hline Favocassidulina australis Eade & 1 & 12 & 2 & & & \\
\hline Fissurina alveolata (Brady) & & & 1 & & 1 & \\
\hline Fissurina auriculata (Brady) & & & & & & \\
\hline Fissurina subformosa Parr & & & & & & 1 \\
\hline Fissurina bodjonegoroensis (Boomaart) & & & & & & \\
\hline Fissurina carteri (McLean) & & & & 1 & 2 & 6 \\
\hline Fissurina cucullata Silvestri & & 1 & 1 & & 1 & \\
\hline Fissurina exsculpta (Brady) & & & & & & \\
\hline Fissurina cf. F. exsculpta (Brady) & & & & & & \\
\hline Fissurina fimbrata (Brady) & & & & & & 1 \\
\hline Fissurina cf. F. fimbrata (Brady) & & & & & & \\
\hline Fissurina kugleri (Cushman and Stainforth) & & & & & & \\
\hline Fissurina marginata (Montagu) & & & & & & 4 \\
\hline Fissurina semimarginata (Reuss) & & & & & & \\
\hline Fissurina semisculpta Parr & & & & & & \\
\hline
\end{tabular}




\begin{tabular}{|c|c|c|c|c|c|c|}
\hline DSDP SITE 503A & $13-1$ & $15-1$ & $19-1$ & $27-1$ & $29-1$ & $36-1$ \\
\hline \multicolumn{7}{|l|}{ Fissurina solida Sequenza } \\
\hline Fissurina orbignyana Sequenza & & 1 & 1 & 2 & & \\
\hline Fissurina spinosa (Sidebottom) & 1 & & & 1 & 2 & \\
\hline \multicolumn{7}{|l|}{ Fissurina spp. } \\
\hline Fissurina staphylleraria Schwager & & & & & 1 & \\
\hline Fissurina trigonomarginata (Parker and Jones) & & & & & & \\
\hline Fissurina wiesneri Barker & & & & & & \\
\hline Francesita advena (Cushman) & & & & & 1 & 4 \\
\hline Fursenkoina bramletti (Galloway and Morrey) & & & 1 & & & 1 \\
\hline Fursenkoina compressa (Bailey) & & & & & & 1 \\
\hline Fursenkoina rotundata (Parr) & 2 & & & & & \\
\hline Fursenkoina seminuda (Natland) & & & & & & \\
\hline Fursenkoina squammosa (d'Orbigny) & 1 & & & & & \\
\hline Globobulimina pacifica Cushman & & & & & & 1 \\
\hline Globocassidulina subglobosa (Brady) & 1 & 8 & 3 & 9 & 14 & 18 \\
\hline Glandulina laevigata (d'Orbigny) & & & & & & \\
\hline Guttulina caudata d'Orbigny & & & & & & \\
\hline Guttulina sp. (fistulose) & & & & & & \\
\hline Guttulinaspp. & & & & & & 1 \\
\hline Gyroidina altiformis Stewart and Stewart & & 2 & 5 & 5 & 5 & 19 \\
\hline Gyroidina broekhiana Karrer & & & 1 & & & 1 \\
\hline Gyroidina lamarckiana d'Orbigny & & 3 & 3 & 2 & 7 & 5 \\
\hline Gyroidina orbicularis d'Orbigny & & & & & & \\
\hline Gyroidina planulata Cushman and Renz & & & & 1 & & \\
\hline Gyroidina soldanii d'Orbigny & & & 2 & 1 & 4 & \\
\hline Gyroidina umbonata (Silvestri) & 1 & 2 & 1 & & 5 & 15 \\
\hline Hoeglundina elegans (d'Orbigny) & & & & & & \\
\hline Karreriella alticamerata Cushman and Stainforth & & & & & & \\
\hline Karreriella bradyi (Cushman) & & & & & & \\
\hline Lagena advena Cushman & & & & & & \\
\hline Lagena cf. L. advena Cushman & & & & & & \\
\hline Lagena aspera Reuss & & & & & & \\
\hline Lagena cf. L. costata & & & & & & \\
\hline Lagena costata (Williamson) & & & & & & 1 \\
\hline Lagena crenulata capistriata Cushman and Stainforth & & & & & & \\
\hline Lagena flatulenta Loeblich and Tappan & & & & 1 & & 1 \\
\hline Lagena gracilis Williamson & 1 & & 1 & & & \\
\hline Lagena gracillima (Sequenza) & & & & & & \\
\hline Lagena hexagona (Williamson) & & & & & & \\
\hline Lagena hispida Reuss & & & & & & 1 \\
\hline Lagena laevis (Montagu) & & & & & & \\
\hline Lagena setigera Millett & & 1 & & & 1 & 1 \\
\hline Lagena cf. L. setigera Millett & & & & & & \\
\hline Lagena semilineata Wright & & & & & & \\
\hline Lagenasp. & & & & 1 & 1 & \\
\hline Lagena striata (d'Orbigny) & & & & & & \\
\hline Lagena cf. L. striata (d'Orbigny) & & & & & & \\
\hline Laticarinina pauperata (Parker and Jones) & & 1 & 1 & 5 & 12 & 4 \\
\hline Lenticulina crassa d'Orbigny & & & & & 1 & \\
\hline Lenticulina limbosa (Reuss) & & & & & & \\
\hline Lenticulinaspp. & & & 1 & & & \\
\hline Marginulina subbullata Hantken & & & & & & \\
\hline Marginulina sublituus (Nuttall) & & & & & & \\
\hline Marginulina simplex (d'Orbigny) & & & & & & \\
\hline Marginulinasp. & & & & & & \\
\hline Martinottiella pallida (Cushman) & 1 & 2 & & 2 & 5 & \\
\hline Melonis affinis (Reuss) & 2 & 1 & & 4 & 1 & 5 \\
\hline Melonis pompilioides (Fitchel and Moll) & 1 & & & & 2 & 7 \\
\hline Melonis soldanii (d'Orbigny) & & 1 & & & & \\
\hline Milolinella irregularis (d'Orbigny) & 1 & & & & & \\
\hline Nonionella basispinata (Cushman and Moyer) & & & & & & \\
\hline Nonionellaspp. & & & & & & \\
\hline Nodogenerinachallengeriana Thalmann & & & & & 1 & \\
\hline Nodogenerinalaevigata Bermudez & & & & & & \\
\hline Nodogenerinatrincherasensis Bermudez & & & & & & 2 \\
\hline Nodosaria fistuca Schwager & & & & & & \\
\hline Nodosaria longiscata d'Orbigny & 7 & & 1 & & & 8 \\
\hline Nodosaria sublineata Brady & & & 1 & & & \\
\hline Nodosarella subnodosa (Guppy) & & & & & & \\
\hline Nonion havanense Cushman and Bermudez & & & & & & \\
\hline Oolina desmophora (Rymer Jones) & & & 1 & & 1 & \\
\hline Oolina melo d'Orbigny & & & & & & \\
\hline Oolina ovum (Ehrenberg) & & & & & & \\
\hline Oolina sp. & & & & & & \\
\hline Ophthalmidium pusillum (Earland) & & & & & & \\
\hline Oridorsalissp. & & & & & & 1 \\
\hline Oridorsalisumbonatus (Reuss) & 7 & 7 & 3 & 16 & 5 & 34 \\
\hline Osangularia culteri (Parker and Jones) & & & & & & \\
\hline Parafissurina cf. P. fusiformis Loeblich and Tappan & & & & & 1 & \\
\hline Parafissurina lateralis (Cushman) & & & & & & \\
\hline Parafissurinaspp. & & & & & & 1 \\
\hline Parafissurina pseudomarginata (Buchner) & & & & & & \\
\hline Planulina sp. 1 & & & & & & \\
\hline Planularia trinae Bermudez & & & & & & \\
\hline Pleurostomella acuminata Cushman & & 2 & & & & 3 \\
\hline Pleurostomella alternans Schwager & & & 1 & & 1 & \\
\hline
\end{tabular}




\begin{tabular}{|c|c|c|c|c|c|c|}
\hline DSDP SITE 503A & $13-1$ & $15-1$ & $19-1$ & $27-1$ & $29-1$ & $36-1$ \\
\hline Pleurostomella bierigi Palmer and Bermudez & & & 1 & 2 & & 2 \\
\hline \multicolumn{7}{|l|}{ Pleurostomella brevis Schwager } \\
\hline \multicolumn{7}{|l|}{ Pleurostomella gerontica Galloway and Heminway } \\
\hline Pleurostomella praegerontica Cushman and Stainforth & & & & & & 1 \\
\hline \multicolumn{7}{|l|}{ Pleurostomella subglobosa Rey } \\
\hline \multicolumn{7}{|l|}{ Polymorphinasp. } \\
\hline \multicolumn{7}{|l|}{ Praeglobobulimina affinis (d'Orbigny) } \\
\hline \multicolumn{7}{|l|}{ Praeglobobulimina auriculata (Bailey) } \\
\hline Pullenia alazaensis Cushman & & 1 & 1 & 3 & & 4 \\
\hline \multicolumn{7}{|l|}{ Pullenia angusta Cushman and Todd } \\
\hline Pullenia bulloides (d'Orbigny) & 2 & 7 & 8 & 7 & 10 & 16 \\
\hline Pullenia quinqueloba (Reuss) & & & & & 4 & \\
\hline \multicolumn{7}{|l|}{ Pullenia riveroi Bermudez } \\
\hline \multicolumn{7}{|l|}{ Pullenia salisburyi Stewart and Stewart } \\
\hline \multicolumn{7}{|l|}{ Pullenia subcarinata d'Orbigny } \\
\hline Pulleniasp. & & & 1 & & & 2 \\
\hline Pyrulina albatrossi Cushman and Ozawa & & & & 2 & 2 & 2 \\
\hline \multicolumn{7}{|l|}{ Pyrulina cylindroides curvatura Cushman and Stainforth } \\
\hline Pyrgo depressa (d'Orbigny) & & & & & 1 & 1 \\
\hline Pyrgo murrhina (Schwager) & 1 & & & 2 & & \\
\hline \multicolumn{7}{|l|}{ Pyrgocf. P. murrhina (Schwager) } \\
\hline Pyrgo rotalaria Loeblich and Tappan & & 1 & & & 1 & 2 \\
\hline Pyrgo aff. P. rotularia Loeblich and Tappan & & & & & & 2 \\
\hline Pyrgo serrata (Bailey) & & & & & & 2 \\
\hline \multicolumn{7}{|l|}{ Pyrulina gutta (d'Orbigny) } \\
\hline \multicolumn{7}{|l|}{ Pyrgo williamsoni (Silvestri) } \\
\hline Pyrulinasp. & & & & & & \\
\hline Quinqueloculina akneriana d'Orbigny & & & & & & \\
\hline Quinqueloculina auberiana d'Orbigny & & & & & & 2 \\
\hline Quinqueloculina lamarckiana d'Orbigny & & & & 1 & & \\
\hline Quinqueloculina seminulum (Linne) & & & & & & \\
\hline Quinqueloculina venusta Karrer & & 1 & 3 & 3 & 5 & 5 \\
\hline Rectobolivinasp. & & & & & & \\
\hline Reophaxsp. & & & & & & \\
\hline Rosalina columbiensis (Cushman) & & & & & & \\
\hline Saracenaria acutauricularis (Fitchell and Moll) & & & & & & \\
\hline Sigmoilina tenuis (Czjeck) & & & & & & 5 \\
\hline Siphonodosaria abyssorum (Brady) & & 5 & & & & \\
\hline Siphonodosaria gracillima (Cushman and Jarvis) & & 1 & & & & 1 \\
\hline Siphonodosaria modesta (Bermudez) & & & & & & \\
\hline Siphonia pulchra Cushman & 1 & & & & & \\
\hline Siphotextularia catenata (Cushman) & & & & & & 9 \\
\hline Sphaeroidina bulloides d'Orbigny & 1 & & & 2 & & \\
\hline Stilostomella adolphina (d'Orbigny) & & 5 & & & & \\
\hline Stilostomella advena (Cushman and Laiming) & & & & & & 1 \\
\hline Stilostomella gracilis (Palmer and Bermudez) & & & & 1 & & \\
\hline Stilostomella lepidula (Schwager) & & & 1 & & 1 & 6 \\
\hline Stilostomella subspinosa (Cushman) & & & & & & \\
\hline Textularia agglutinanas d'Orbigny & & & & 1 & 1 & 5 \\
\hline Textularia earlandi Parker & & & & & & \\
\hline Triloculina circularis Bornemann & & & & & & \\
\hline Triloculina globosa (Hanna and Hanna) & & & & & & \\
\hline Triloculina trihedra Loeblich and Tappan & & & 1 & & & \\
\hline Trochamminaspp. & & & & & & \\
\hline Uvigerina hispidocostata Cushman and Todd & 1 & & & & & \\
\hline Uvigerina hispida Schwager & 1 & 5 & 2 & 5 & 1 & 43 \\
\hline Uvigerina peregrina Cushman & & & & & & \\
\hline Uvigerina rustica Cushman and Edwards & & & & & & \\
\hline Uvigerina senticosa Cushman & & & & & & \\
\hline Uvigerina striata d'Orbigny & & & & & & \\
\hline Uvigerina vaderescens Cushman & & & 3 & & & \\
\hline Valvulineria glabra Cushman & & & & & & 1 \\
\hline Valvulineria minuta (Schubert) & & & & & 1 & 1 \\
\hline
\end{tabular}




\begin{tabular}{|c|c|c|c|c|c|}
\hline DSDP SITE 503A & $41-1$ & $44-1$ & $49-1$ & $52-1$ & $54-1$ \\
\hline \multicolumn{6}{|l|}{ Alabamina polita Becker and Dusenbury } \\
\hline Allomorphina pacifica Cushman and Todd & & & & 1 & \\
\hline \multicolumn{6}{|l|}{ Alveolophragmium crassimargo (Norman) } \\
\hline \multicolumn{6}{|l|}{ Alveolophragmium subglobosum (Sars) } \\
\hline \multicolumn{6}{|l|}{ Ammodiscus incertus (d'Orbigny) } \\
\hline Anomalinoides cf. A. alazaensis Nuttall & & & & 1 & 1 \\
\hline Anomalinoides globulosus (Chapman and Parr) & & & 6 & & \\
\hline Anomalinoides pompilioides (Galloway and Wissler) & & & & & \\
\hline Anomalina cicatricosus Schwager & & 1 & & & \\
\hline Astacolus sp. & & & & & \\
\hline Astrononion gallowayi Loeblich and Tappan & & & & & \\
\hline Astrononionguadalupae (Parker) & 1 & 6 & & & \\
\hline Bathysiphonsp. & & & & & 1 \\
\hline Bolivina cf. B. bradyi Asano & & & & & \\
\hline Bolivinoides cubensis (Cushman and Bermudez) & & & & & \\
\hline Bolivina pacifica Cushman and McCulloch & & & & & \\
\hline Bolivina translucens Phleger and Parker & & & & & \\
\hline Bulimina cf. B. acanthia Costa & & & & & \\
\hline Bulimina rostrata Brady & & & & & \\
\hline Cassidulina depressa Asano and Nakamura & & & & & \\
\hline Cassidulina oblonga Reuss & & & & 1 & \\
\hline Cassidulinoides bradyi (Norman) & & & & & \\
\hline Cassidulinoides tenuis Phleger and Parker & & & & & \\
\hline Chilostomella oolina Schwager & & 1 & 1 & & \\
\hline Chrysalogonium elongatum Cushman and Jarvis & & & 1 & 1 & \\
\hline Chrysalogonium longiscatatum Cushman and Jarvis & & & & & \\
\hline Chrysalogoniumsp. & & & & & \\
\hline Chrysalogonium teniucostatum Cushman and Bermudez & & & & & 1 \\
\hline Cibicides deprimus Phleger and Parker & 8 & 9 & 1 & 6 & 1 \\
\hline Cibicides fletcheri Galloway and Wissler & & & & & \\
\hline Cibicides granulosa Bermudez & & & & & \\
\hline Cibicides cf. C. granulosa Bermudez & & 2 & & & \\
\hline Cibicides heminwayae Bermudez & & & & & \\
\hline Cibicides io Cushman & & & & & \\
\hline Cibicides aff. C. io Cushman & 1 & & 1 & 1 & \\
\hline Cibicides lobatulus (Walker and Jacob) & & & & & \\
\hline Cibicides mckannai Galloway and Wissler & & & & & \\
\hline Cibicides mollis Phleger and Parker & & & & & \\
\hline Cibicides nucleatus (Sequenza) & & & & & \\
\hline Cibicidoides bradyi (Trauth) & & 1 & & & \\
\hline Cibicidoideskullenbergi (Parker) & 10 & 6 & 9 & 30 & 5 \\
\hline Cibicidoides miocenica (Colom) & & 1 & & & \\
\hline Cibicidoides mundulus (Brady & & & & & \\
\hline Cibicidoidessp. & & & & & \\
\hline Cibicidoides wuellerstorffi (Schwager) & & & 7 & & \\
\hline Cibicides robertsonianus (Brady) & & & 2 & & \\
\hline Cibicides aff. C. robertsonianus (Brady) & & & & & \\
\hline Cibicides spiralis Natland & & & & & \\
\hline Cibicides spp. & & & & 2 & \\
\hline Cyclammina cancellata Brady & & & & & \\
\hline Cyclogyrafoliacea (Philippi) & & & & & \\
\hline Dentalina communis (d'Orbigny) & & & 1 & 1 & 2 \\
\hline Dentalina consobrina (d'Orbigny) & & & & & \\
\hline Dentalina cooperensis Cushman & & & & & \\
\hline Dentalina ittai Loeblich and Tappan & & & & & \\
\hline Dentalina mucronata Neugeboren & & & & & \\
\hline Dentalina pauperata d'Orbigny & 2 & & & & \\
\hline Dentalinasp. & & & & & 2 \\
\hline Eggerella bradyi (Cushman) & 12 & 9 & 4 & 8 & 3 \\
\hline Ehrenbergina bradyi Cushman & & 2 & & & \\
\hline Ehrenbergina glabra Heron-Allen and Earland & & & & & \\
\hline Ellipsonodosaria decurta Bermudez & & & & & \\
\hline Ellipsoidina abbreviata Sequenza & & & & & 1 \\
\hline Epistominella bradyana (Cushman) & & & & & \\
\hline Epistominella exiqua (Brady) & 14 & 30 & 5 & & \\
\hline Epistominella umbonifera (Cushman) & 29 & 6 & 3 & 7 & \\
\hline Epistominella vitrea Parker & & & & & \\
\hline Eponides regularis Phleger and Parker & & & & & 3 \\
\hline Favocassidulina australis Eade & 6 & 9 & & & \\
\hline Fissurina alveolata (Brady) & & 1 & & & \\
\hline Fissurina auriculata (Brady) & & & & & \\
\hline Fissurina subformosa Parr & & & & 1 & \\
\hline Fissurina bodjonegoroensis (Boomaart) & & & & & \\
\hline Fissurina carteri (McLean) & 1 & 2 & & 6 & \\
\hline Fissurina cucullata Silvestri & 2 & 2 & 2 & 1 & \\
\hline Fissurina exsculpta (Brady) & & & & & \\
\hline Fissurina cf. F. exsculpta (Brady) & & & & & \\
\hline Fissurina fimbrata (Brady) & & & 2 & & 1 \\
\hline Fissurina cf. F. fimbrata (Brady) & & & & & \\
\hline Fissurina kugleri (Cushman and Stainforth) & & & & & \\
\hline Fissurina marginata (Montagu) & & 4 & & 2 & \\
\hline Fissurina semimarginata (Reuss) & 2 & & 1 & & \\
\hline Fissurina semisculpta Parr & & & & & \\
\hline
\end{tabular}




\begin{tabular}{|c|c|c|c|c|c|}
\hline DSDP SITE 503A & $41-1$ & $44-1$ & $49-1$ & $52-1$ & $54-1$ \\
\hline Fissurina solida Sequenza & 2 & & 1 & & \\
\hline Fissurina orbignyana Sequenza & & & & 4 & \\
\hline Fissurina spinosa (Sidebottom) & 1 & & 1 & & \\
\hline \multicolumn{6}{|l|}{ Fissurina spp. } \\
\hline Fissurina staphylleraria Schwager & 1 & 1 & & 1 & \\
\hline \multicolumn{6}{|l|}{ Fissurina trigonomarginata (Parker and Jones) } \\
\hline \multicolumn{6}{|l|}{ Fissurina wiesneri Barker } \\
\hline Francesita advena (Cushman) & & & & & \\
\hline Fursenkoina bramletti (Galloway and Morre & & & & & \\
\hline Fursenkoina compressa (Bailey) & & & & & \\
\hline Fursenkoina rotundata (Parr) & & & & 1 & \\
\hline Fursenkoina seminuda (Natland) & & & & & \\
\hline Fursenkoina squammosa (d'Orbigny) & & & & & \\
\hline Globobulimina pacifica Cushman & & & & & \\
\hline Globocassidulina subglobosa (Brady) & 3 & 8 & 15 & 12 & 2 \\
\hline Glandulina laevigata (d'Orbigny) & & & & & \\
\hline Guttulina caudata d'Orbigny & & & & & \\
\hline Guttulina sp. (fistulose) & & & & 1 & \\
\hline Guttulinaspp. & & & 1 & & \\
\hline Gyroidina altiformis Stewart and Stewart & 2 & 7 & 7 & 12 & 1 \\
\hline Gyroidina broekhiana Karrer & & & & & \\
\hline Gyroidina lamarckiana d'Orbigny & 2 & 1 & 2 & & \\
\hline Gyroidina orbicularis d'Orbigny & & & & & \\
\hline Gyroidina planulata Cushman and Renz & & & & & \\
\hline Gyroidina soldanii d'Orbigny & 5 & 4 & 7 & 8 & 7 \\
\hline Gyroidina umbonata (Silvestri) & 1 & & 1 & 6 & \\
\hline Hoeglundina elegans (d'Orbigny) & & & & & \\
\hline Karreriella alticamerata Cushman and Stainf & & & & & \\
\hline Karreriella bradyi (Cushman) & & & 2 & & \\
\hline Lagena advena Cushman & & & & & \\
\hline Lagena cf. L. advena Cushman & & & & & \\
\hline Lagena aspera Reuss & & & & & \\
\hline Lagena cf. L. costata & & & & & \\
\hline Lagena costata (Williamson) & & & & & \\
\hline Lagena crenulata capistriata Cushman and Stai & & & & & \\
\hline Lagena flatulenta Loeblich and Tappan & 2 & & & 1 & \\
\hline Lagena gracilis Williamson & & & & & \\
\hline Lagena gracillima (Sequenza) & & & & & \\
\hline Lagena hexagona (Williamson) & & & & & \\
\hline Lagena hispida Reuss & & & & & \\
\hline Lagena laevis (Montagu) & & & & & \\
\hline Lagena setigera Millett & & & & & \\
\hline Lagena cf. L. setigera Millett & & & & & \\
\hline Lagena semilineata Wright & 1 & & & & \\
\hline Lagenasp. & & & & & \\
\hline Lagena striata (d'Orbigny) & & & & & \\
\hline Lagena cf. L. striata (d'Orbigny) & & & & & \\
\hline Laticarinina pauperata (Parker and Jones & 8 & 5 & 11 & 21 & 1 \\
\hline Lenticulina crassa d'Orbigny & & & & & \\
\hline Lenticulina limbosa (Reuss) & & & & & \\
\hline Lenticulinaspp. & & & & & \\
\hline Marginulina subbullata Hantken & & & & & \\
\hline Marginulina sublituus (Nuttall) & & & & & \\
\hline Marginulina simplex (d'Orbigny) & & & & & \\
\hline Marginulinasp. & & & & & \\
\hline Martinottiella pallida (Cushman) & 4 & & & 1 & \\
\hline Melonis affinis (Reuss) & & 2 & 3 & 7 & \\
\hline Melonis pompilioides (Fitchel and Moll) & 3 & & & & \\
\hline Melonis soldanii (d'Orbigny) & & 2 & & & \\
\hline Milolinella irregularis (d'Orbigny) & & 1 & & & \\
\hline Nonionella basispinata (Cushman and Moy & & & & & \\
\hline Nonionella spp. & & & & & \\
\hline Nodogenerina challengeriana Thalmann & & & & & \\
\hline Nodogenerina laevigata Bermudez & 1 & & & 1 & \\
\hline Nodogenerinatrincherasensis Bermudez & & & & & \\
\hline Nodosaria fistuca Schwager & & & & & \\
\hline Nodosaria longiscata d'Orbigny & 2 & & 1 & 13 & 8 \\
\hline Nodosaria sublineata Brady & & & & & \\
\hline Nodosarella subnodosa (Guppy) & & & & & \\
\hline Nonion havanense Cushman and Bermude & & & & & \\
\hline Oolina desmophora (Rymer Jones) & & 2 & 1 & 1 & \\
\hline Oolina melo d'Orbigny & & & & & \\
\hline Oolina ovum (Ehrenberg) & & & & & \\
\hline Oolinasp. & & & & & \\
\hline Ophthalmidium pusillum (Earland) & & & & & \\
\hline Oridorsalissp. & & & & & \\
\hline Oridorsalis umbonatus (Reuss) & 6 & 17 & 15 & 15 & 6 \\
\hline Osangularia culteri (Parker and Jones) & & & & & \\
\hline Parafissurina cf. P. fusiformis Loeblich and Ta & & & & & \\
\hline Parafissurina lateralis (Cushman) & & & & & \\
\hline Parafissurinaspp. & & & 3 & & \\
\hline Parafissurina pseudomarginata (Buchner & & & & & \\
\hline Planulina sp. 1 & & & & & \\
\hline Planularia trinae Bermudez & & & & & \\
\hline Pleurostomella acuminata Cushman & & & 1 & 1 & \\
\hline Pleurostomella alternans Schwager & & 1 & & 3 & 2 \\
\hline
\end{tabular}




\begin{tabular}{|c|c|c|c|c|c|}
\hline DSDP SITE 503A & $41-1$ & $44-1$ & $49-1$ & $52-1$ & $54-1$ \\
\hline Pleurostomella bierigi Palmer and Bermudez & & 1 & & & 1 \\
\hline \multicolumn{6}{|l|}{ Pleurostomella brevis Schwager } \\
\hline \multicolumn{6}{|l|}{ Pleurostomella gerontica Galloway and Heminway } \\
\hline \multicolumn{6}{|l|}{ Pleurostomella praegerontica Cushman and Stainforth } \\
\hline \multicolumn{6}{|l|}{ Pleurostomella subglobosa Rey } \\
\hline \multicolumn{6}{|l|}{ Polymorphinasp. } \\
\hline \multicolumn{6}{|l|}{ Praeglobobulimina affinis (d'Orbigny) } \\
\hline Praeglobobulimina auriculata (Bailey) & & & & & 4 \\
\hline Pullenia alazaensis Cushman & 2 & 4 & & & \\
\hline Pullenia angusta Cushman and Todd & & & 1 & 1 & \\
\hline Pullenia bulloides (d'Orbigny) & 15 & 18 & 15 & 29 & 5 \\
\hline \multicolumn{6}{|l|}{ Pullenia quinqueloba (Reuss) } \\
\hline Pullenia riveroi Bermudez & 1 & 1 & & & \\
\hline Pullenia salisburyi Stewart and Stewart & & & & 2 & \\
\hline \multicolumn{6}{|l|}{ Pullenia subcarinata d'Orbigny } \\
\hline Pulleniasp. & & & 1 & 3 & \\
\hline Pyrulina albatrossi Cushman and Ozawa & & 1 & & & \\
\hline Pyrulina cylindroides curvatura Cushman and Stainforth & & & 2 & 1 & \\
\hline Pyrgo depressa (d'Orbigny) & & & 1 & 2 & \\
\hline Pyrgo murrhina (Schwager) & & 1 & 1 & & \\
\hline \multicolumn{6}{|l|}{ Pyrgocf. P. murrhina (Schwager) } \\
\hline Pyrgo rotalaria Loeblich and Tappan & 2 & 1 & & & \\
\hline \multicolumn{6}{|l|}{ Pyrgo aff. P. rotularia Loeblich and Tappan } \\
\hline Pyrgo serrata (Bailey) & & & & 1 & \\
\hline \multicolumn{6}{|l|}{ Pyrulina gutta (d'Orbigny) } \\
\hline \multicolumn{6}{|l|}{ Pyrgo williamsoni (Silvestri) } \\
\hline \multicolumn{6}{|l|}{ Pyrulinasp. } \\
\hline \multicolumn{6}{|l|}{ Quinqueloculina akneriana d'Orbigny } \\
\hline Quinqueloculina auberiana d'Orbigny & 1 & & & 5 & 1 \\
\hline Quinqueloculina lamarckiana d'Orbigny & & & & 5 & \\
\hline Quinqueloculina seminulum (Linne) & & & & & \\
\hline Quinqueloculina venusta Karrer & 6 & 2 & 5 & 10 & 1 \\
\hline Rectobolivina $s p$. & & & & 1 & \\
\hline Reophaxsp. & & & & & \\
\hline Rosalina columbiensis (Cushman) & & & & & \\
\hline Saracenaria acutauricularis (Fitchell and Moll) & & & & 1 & \\
\hline Sigmoilina tenuis (Czjeck) & & & & & \\
\hline Siphonodosaria abyssorum (Brady) & & & & & \\
\hline Siphonodosaria gracillima (Cushman and Jarvis) & & & 3 & & \\
\hline Siphonodosaria modesta (Bermudez) & & & & & \\
\hline Siphonia pulchra Cushman & & & & & \\
\hline Siphotextularia catenata (Cushman) & & & & & \\
\hline Sphaeroidina bulloides d'Orbigny & & & & 2 & \\
\hline Stilostomella adolphina (d'Orbigny) & & & & & \\
\hline Stilostomella advena (Cushman and Laiming) & & & & & \\
\hline Stilostomella gracilis (Palmer and Bermudez) & & & & & 2 \\
\hline Stilostomella lepidula (Schwager) & & 1 & & & \\
\hline Stilostomella subspinosa (Cushman) & & & & & \\
\hline Textularia agglutinanas d'Orbigny & 4 & 1 & 1 & & \\
\hline Textularia earlandi Parker & & & & & \\
\hline Triloculina circularis Bornemann & & & & & \\
\hline Triloculina globosa (Hanna and Hanna) & & & & & \\
\hline Triloculina trihedra Loeblich and Tappan & & & & & \\
\hline Trochamminaspp. & & & & & \\
\hline Uvigerina hispidocostata Cushman and Todd & & & & & \\
\hline Uvigerina hispida Schwager & 2 & 1 & & 1 & \\
\hline Uvigerina peregrina Cushman & & & & & \\
\hline Uvigerina rustica Cushman and Edwards & & & & & \\
\hline Uvigerina senticosa Cushman & & & & & \\
\hline Uvigerina striata d'Orbigny & & & & & \\
\hline Uvigerina vaderescens Cushman & & & & & \\
\hline Valvulineria glabra Cushman & & & & & \\
\hline Valvulineria minuta (Schubert) & & 4 & & & \\
\hline
\end{tabular}




\section{APPENDIX 4}

Equatorial Eastern Pacific Site 568: Complete Benthic Foraminiferal Counts 


\begin{tabular}{|c|c|c|c|c|c|c|c|c|}
\hline SITE 568 & $23 / \mathrm{CC}$ & $24 / \mathrm{CC}$ & $27 / \mathrm{CC}$ & $28 / 5 / 128-1$ & $33 / \mathrm{CC}$ & $36 / \mathrm{CC}$ & $38 / 3 / 82-84$ & $39 / 3 / 84-88$ \\
\hline Alabamina polita Becker and Dusenbury & & & & & 1 & & 1 & 3 \\
\hline \multicolumn{9}{|l|}{ Alveolophragmium crassimargo (Norman) } \\
\hline \multicolumn{9}{|l|}{ Ammonia beccarii (Linne) } \\
\hline \multicolumn{9}{|l|}{ Amphistegina lessoni d'Orbigny } \\
\hline Anomalinoides globulosus (Chapman and Parr) & & & & 4 & & 3 & & \\
\hline \multicolumn{9}{|l|}{ Anomalinoides pompilioides (Galloway and Wissler) } \\
\hline \multicolumn{9}{|l|}{ Anomalinoides semicribratus (Beckman) } \\
\hline Anomalina flintii Cushman & & & & & 1 & 1 & & \\
\hline \multicolumn{9}{|l|}{ Astigerina guraboensis Bermudez } \\
\hline Astrononion guadalupae (Parker) & & & & & & & & \\
\hline Bathysiphonsp. & & & & & & & & \\
\hline Buliminella curta Cushman & & & & & & & & \\
\hline Buliminella subfusiformis Cushman & & & & & & & & \\
\hline Bolivina advena Cushman & & & & & & & & \\
\hline Bolivina alazaensis Cushman & & & & & & & & \\
\hline Bolivina argentea Cushman & & & & & & & & \\
\hline Bolivina beyrichi Reuss & & & & & & & & \\
\hline Bolivina bicostata Cushman & & & & & & & & \\
\hline Bolivina bradyi Asano & & & & & & & & \\
\hline Bolivina californica Cushman & & & & & & & & \\
\hline Bolivina decussata Brady & & & & & & & & \\
\hline Bolivina foraminata Stewart and Stewart & & & & & & & & \\
\hline Bolivina marginata Cushman & & & & & & & & 3 \\
\hline Bolivina pacifica Cushman and McCulloch & & & & & & & & \\
\hline Bolivina pseudobeyrichi Cushman & & & & & & & & \\
\hline Bolivina subadvena Cushman & & & & & & & & \\
\hline Bolivina subadvena sulpherensis Cushman and Adams & & & & & & & & \\
\hline Bolivina scabrata Cushman and Bermudez & & & & & & & & \\
\hline Bolivina cf. B. sinuata Galloway and Wissler & & & & & & & & \\
\hline Bolivina aff. B. sinuata Galloway and Wissler & & & & & & & 1 & \\
\hline Bolivina semiperforata Martin & & & & & & & & \\
\hline Bolivina seminuda Cushman & & & & & & & & \\
\hline Bolivina sp. & & & & & & & & \\
\hline Bolivina tongifilacostata Cushman and McCulloch & & & & & & & & \\
\hline Bolivina woodringi Kleinpelli & & & & & & & & \\
\hline Buccellasp. & & & & & & & & \\
\hline Bulimina alazaensis Cushman & & & & 12 & 4 & 18 & 2 & \\
\hline Bulimina denudata Cushman and Parker & & & & & & & & \\
\hline Bulimina mexicana Cushman & & & & 1 & 5 & 4 & & 2 \\
\hline Bulimina pagoda Cushman & & & & & & & & \\
\hline Cancris auricula (Fitchel and Moll) & & & & & & & & \\
\hline Cancrisinflatus (d'Orbigny) & & & & & & & & \\
\hline Cancris panamensis Natland & & & & & & & & \\
\hline Cassidulina californica Cushman and Hughes & & & & & & & & \\
\hline Cassidulina californica Cushman and Hughes variation & & & & & & & & \\
\hline Cassidulina caudriae Cushman and Stainforth & & & & & & 1 & & \\
\hline Cassidulina crassa d'Orbigny & & & & & & & & \\
\hline Cassidulina delicata Cushman & & & & & & & & \\
\hline Cassidulina laevigata carinata Silvestri & & & & & & & & \\
\hline Cassidulina laevigata d'Orbigny & & & & & & & & \\
\hline Cassidulina limbata Cushman and Hughes & & & & & & & & \\
\hline Cassidulina minuta Cushman & & & & & & & & \\
\hline Cassidulina oblonga Reuss & & & & & & & & \\
\hline Cassidulinoides bradyi (Norman) & & & & 1 & & & & \\
\hline Cassidulinoides tenuis Phleger and Parker & & & & & & & & \\
\hline Cassidulina spinifera Cushman and Jarvis & & & & & & & & 7 \\
\hline Cassidulina tricamerata Galloway and Heminway & & & & & & & & \\
\hline Cassidulina tumida Natland & & & & & & & & \\
\hline Ceratobulimina alazaensis Cushman and Harris & & & & 2 & 1 & & & 1 \\
\hline Chilostomella oolina Schwager & & & & & & & & \\
\hline Chilostomella ovoidea Reuss & & & & & & & & \\
\hline Chrysalogonium breviloculum Cushman and Jarvis & & & & 1 & & & & \\
\hline Chrysalogonium elongatum Cushman and Jarvis & & & & & & & & \\
\hline Chrysalogonium lanceolum Cushman and Jarvis & & & & & & & & \\
\hline Chrysalogonium longiscatatum Cushman and Jarvis & & & & 9 & & & & \\
\hline Cibicides barnetti Bermudez & & & & & & 1 & & \\
\hline Cibicides fletcheri Galloway and Wissler & & & & & & & & \\
\hline Cibicides floridanus (Cushman) & & & & & & 1 & & \\
\hline Cibicides granulosa Bermudez & & & & & 1 & & & \\
\hline Cibicidesguraboensus Bermudez & & & & & & 4 & & \\
\hline Cibicides cf. C. guraboensus Bermudez & & & & & & & & \\
\hline Cibicides heminwayae Bermudez & & & & & & & & \\
\hline Cibicides io Cushman & & & 1 & & & 2 & & \\
\hline Cibicides matanzaensis (Hadley) & & & & & & 6 & & \\
\hline Cibicides mckannai Galloway and Wissler & & & & & & & & \\
\hline Cibicides cf. C. mckannai Galloway and Wissler & & & & & & & & \\
\hline
\end{tabular}




\begin{tabular}{|c|c|c|c|c|c|c|c|c|}
\hline SITE 568 & $23 / \mathrm{CC}$ & $24 / \mathrm{CC}$ & $27 / \mathrm{CC}$ & 28/5/128-1 & $33 / \mathrm{CC}$ & $36 / \mathrm{CC}$ & $38 / 3 / 82-84$ & $39 / 3 / 84-88$ \\
\hline Cibicides nucleatus (Sequenza) & & & & & & 2 & & 1 \\
\hline Cibicidoides bradyi (Trauth) & & & & & 2 & 8 & & \\
\hline \multicolumn{9}{|l|}{ Cibicidoides coryelli (Bermudez) } \\
\hline Cibicidoides kullenbergi( (Parker) & & & 1 & 4 & 1 & & & \\
\hline \multicolumn{9}{|l|}{ Cibicidoides sinistralis (Coryell and Rivero) } \\
\hline \multicolumn{9}{|l|}{ Cibicidoides trinitatensis (Nuttall) } \\
\hline Cibicidoides wuellerstorffi (Schwager) & & & 1 & & & & & \\
\hline \multicolumn{9}{|l|}{ Cibicidesspp. } \\
\hline Cibicides spirolimbatus Galloway and Heminway & & & 7 & 4 & 18 & 21 & 2 & 8 \\
\hline Cibicides spiralis Natland & & & 1 & 2 & & & & \\
\hline Cibicides spp. & & & & & & 2 & & \\
\hline Cibicides trincherasensis Bermudez & & & & 1 & 1 & 10 & 1 & \\
\hline \multicolumn{9}{|l|}{ Cibicides umbonatus Phleger and Parker } \\
\hline Cibicides yagatensis Bermudez & & & 2 & 2 & 2 & 19 & 8 & 10 \\
\hline \multicolumn{9}{|l|}{ Cyclogyra foliacea (Philippi) } \\
\hline Dentalina cocoaensis (Cushman) & & & & & 1 & & & 9 \\
\hline Dentalina consobrina (d'Orbigny) & 1 & & & & & 1 & 2 & \\
\hline Dentalina cooperensis Cushman & 2 & 1 & & 8 & 3 & 1 & & \\
\hline Dentalina ittai Loeblich and Tappan & & & & & & & & \\
\hline Dentostomina guraboensis Bermudez & & & & & & & & \\
\hline Dentalina pauperata d'Orbigny & & & & & & & & \\
\hline Dentalina soluta Reuss & & & & & & 11 & & \\
\hline Dentalina spinosa d'Orbigny & & & & & & & & \\
\hline Eggerella bradyi (Cushman) & & & & 1 & & & & \\
\hline Ehrenbergina bradyi Cushman & & & & & & & & \\
\hline Ehrenbergina caribbea Galloway and Heminway & & & & & & & & \\
\hline Ellipsoglandulina multicostata (Galloway and Morrey) & & & & 1 & & & & \\
\hline Ellipsonodosaria decurta Bermudez & & & & & & & & \\
\hline Ellipsonodosaria mappa Cushman and Jarvis & & & & & & & & \\
\hline Elphidium tumidum Natland & & & & & & & & \\
\hline Epistominella bradyana (Cushman) & & & & & & & & \\
\hline Epistominella cf. E. bradyana (Cushman) & & & & & & & & \\
\hline Epistominella obesa Bandy and Arnal & & & & & & & & \\
\hline Epistominella smithi (Stewart and Stewart) & & & & & & & & \\
\hline Epistominella sp. of Resig (1980) & & & & & & & & \\
\hline Fissurina alveolata (Brady) & & & & & & & & \\
\hline Fissurina subformosa Parr & & & & 1 & & & & \\
\hline Fissurina carteri (McLean) & & & & & & & & \\
\hline Fissurina cucullata Silvestri & & & & 1 & & & & \\
\hline Fissurina dominicana (Bermudez) & & & & 1 & & & & \\
\hline Fissurina fimbrata (Brady) & & & & & & & & \\
\hline Fissurina cf. F. fimbrata (Brady) & & & & & & & & \\
\hline Fissurina aff. F. fimbrata (Brady) & & & & & & & & \\
\hline Fissurina marginata (Montagu) & & & & & & 3 & & \\
\hline Fissurina solida Sequenza & & & & & & & & \\
\hline Fissurina orbignyana Sequenza & & & & & & & & \\
\hline Fissurina sp. (double keel) & & & & & & & & \\
\hline Fissurina spinosa (Sidebottom) & & & & & & & & \\
\hline Fissurina spp. & & & & & & & & \\
\hline Fissurina staphylleraria Schwager & & & & & & & & \\
\hline Fissurina trigonomarginata (Parker and Jones) & & & & & & & & \\
\hline Fissurina ventricosa (Wiesner) & & & & & & & & \\
\hline Fissurina wiesneri Barker & & & & & & & & \\
\hline Fursenkoina bramletti (Galloway and Morrey) & & & & & & & & \\
\hline Fursenkoina cornuta (Cushman) & & & & & & & & \\
\hline Fursenkoina dibollensis (Cushman and Applin) & & & & & & & & \\
\hline Fursenkoina fusiformis (Cushman) & & & & & & & & \\
\hline Fursenkoina punctata (d'Orbigny) & & & & & & & & \\
\hline Fursenkoina rotundata (Parr) & & & & & & & & \\
\hline Fursenkoinaspp. & & & & & & & & \\
\hline Fursenkoina squammosa (d'Orbigny) & & & & & & & & 1 \\
\hline Gaudryina arenaria Galloway and Wissler & & & & & & & & \\
\hline Globobulimina barbata (Cushman) & & & & 2 & & & & \\
\hline Globobulimina pacifica Cushman & & & & 2 & & & & \\
\hline Globobulimina spinifera (Cushman) & & & & & & & & \\
\hline Globocassidulina subglobosa (Brady) & & & 2 & 4 & 4 & & 1 & 13 \\
\hline Glandulina laevigata (d'Orbigny) & & & & & & & & \\
\hline Glandulinasp. & & & & & & & & \\
\hline Globulinasp. & & & & & & & & \\
\hline Goesella flintii Cushman & & & & & & & & \\
\hline Goesellaguraboensis Bermudez & & & & & & & & \\
\hline Guttulina caudata d'Orbigny & & & & & & & & \\
\hline Guttulina irregularis (d'Orbigny) & & & & & 1 & 1 & & \\
\hline Guttulinasp. & & & & 1 & & & & \\
\hline Gyroidina altiformis Stewart and Stewart & & & 2 & 1 & 2 & & & \\
\hline Gyroidina altispira Cushman and Stainforth & & & & 6 & & & & \\
\hline
\end{tabular}




\begin{tabular}{|c|c|c|c|c|c|c|c|c|}
\hline SITE 568 & $23 / \mathrm{CC}$ & $24 / \mathrm{CC}$ & $27 / \mathrm{CC}$ & $28 / 5 / 128-1$ & $33 / \mathrm{CC}$ & $36 / \mathrm{CC}$ & $38 / 3 / 82-84$ & $39 / 3 / 84-88$ \\
\hline \multicolumn{9}{|l|}{ Gyroidina broekhiana Karrer } \\
\hline \multicolumn{9}{|l|}{ Gyroidina condoni (Cushman and Schenck) } \\
\hline \multicolumn{9}{|l|}{ Gyroidina cf. G. condoni (Cushman and Schenck) } \\
\hline \multicolumn{9}{|l|}{ Gyroidina lamarckiana d'Orbigny } \\
\hline \multicolumn{9}{|l|}{ Gyroidina multilocula Coryell and Mossman } \\
\hline \multicolumn{9}{|l|}{ Gyroidina nitidula (Schwager) } \\
\hline Gyroidina aff. G. nitidula (Schwager) & & & & & & & & \\
\hline Gyroidina neosoldanii Brotzen & & & & & & & & \\
\hline Gyroidina perampla Cushman and Stainforth & & & & & 7 & & & \\
\hline Gyroidina planulata Cushman and Renz & & & 1 & 1 & 5 & 1 & & 1 \\
\hline Gyroidina cf. G. planulata Cushman and Renz & & & & & & & & \\
\hline Gyroidina aff. G. planulata Cushman and Renz & & & & & & & & \\
\hline Gyroidina quinqueloba Uchio & & & & & & & & \\
\hline Gyroidina soldanii d'Orbigny & & & & 2 & & 2 & & 8 \\
\hline Gyroidinaspp. & & & & & & & & \\
\hline Gyroidina zelandica Finlay & & 1 & 2 & & & & & \\
\hline Hanzawaia basiloba (Cushman) & & & & & & & & 1 \\
\hline Hanzawaia illingi (Nuttall) & & & & & & & & \\
\hline Hanzawaia isidroensis (Cushman and Renz) & & & & & & & & \\
\hline Hanzawaia mantaensis (Galloway and Morrey) & & & & & & & & \\
\hline Hanzawaiasp. & & & & & & & & \\
\hline Hoeglundina elegans (d'Orbigny) & & & 2 & 11 & 15 & 4 & 8 & 15 \\
\hline Karreriella bradyi (Cushman) & & & & & & & & \\
\hline Karreriella chilostoma (Reuss) & & & & & & & & \\
\hline Karreriellasp. & & & & & & & & \\
\hline Lagena becki Sullivan & & & & & 2 & & & \\
\hline Lagena costata (Williamson) & & & & & & & & \\
\hline Lagenaelongata(Ehrenberg) & & & & & & & & \\
\hline Lagena gracillima (Sequenza) & & & & & & & & \\
\hline Lagena hexagona (Williamson) & & & & & & & & \\
\hline Lagena hispida Reuss & & & & & & & & \\
\hline Lagena laevis (Montagu) & & & & & & & & \\
\hline Lagena lineata (Williamson) & & & & & & & & \\
\hline Lagena meridionalis Wiesner & & & & & & & & \\
\hline Lagena setigera Millett & & & & & & & & \\
\hline Lagena semilineata Wright & & & & & & & & \\
\hline Lagena semistriata Williamson & & & & & & & & \\
\hline Lagenasp. & & & & & & & & \\
\hline Lagena striata (d'Orbigny) & & & & & & & & \\
\hline Laticarinina pauperata (Parker and Jones) & & & & 2 & & & & \\
\hline Lenticulina altolimbatus (Gumbel) & & & 1 & 1 & & 1 & 1 & \\
\hline Lenticulina arcuatostriata (Hantken) & & & & & & 17 & 4 & 10 \\
\hline Lenticulina arcuatostriata carolinianus (Cushman) & & & & & & & & 1 \\
\hline Lenticulina calcar (Linne) & & & & & & & & 1 \\
\hline Lenticulina caritae Bermudez & & & & & & & & \\
\hline Lenticulina colorata (Stache) & & & & & & & & \\
\hline Lenticulina crassa d'Orbigny & & & & & & & & 1 \\
\hline Lenticulina cushmani (Galloway and Wissler) & & & & & & & & \\
\hline Lenticulina dicampyla (Franzenau) & & & & & & 5 & 1 & 1 \\
\hline Lenticulina gibba d'Orbigny & & & & & & 1 & & \\
\hline Lenticulina iota (Cushman) & & & & & & & & 5 \\
\hline Lenticulina limbosa (Reuss) & & & & & & & & 12 \\
\hline Lenticulina melvilli (Cushman and Renz) & & & & & & & & \\
\hline Lenticulina nikobarensis (Schwager) & & & & & & & & \\
\hline Lenticulina occidentalis (Cushman) & & & & & 1 & & & \\
\hline Lenticulina occidentalis torrida (Cushman) & & & & & & & & \\
\hline Lenticulina plummerae (Cole) & & & & & & & & 1 \\
\hline Lenticulina rotulata Lamarck & & & & 1 & & & & \\
\hline Lenticulina submamilligera (Cushman) & & & & & & & & \\
\hline Lenticulinaspp. & & & & & & & & \\
\hline Lenticulina terryi (Coryell and Embich) & & & & & & & & 2 \\
\hline Lenticulina texana (Cushman and Applin) & & & & & & & & \\
\hline Lenticulina vaughani (Cushman) & & & & & & & & \\
\hline Lenticulina yaguensis (Bermudez) & & & & & & & & \\
\hline Marginulina alazaensis Nuttall & & & & & & & & \\
\hline Marginulina dubia Neugeboren & & & & & & & & \\
\hline Marginulina exima Neugeboren & & & & & & & & \\
\hline Marginulina subbullata Hantken & & & & & & & & \\
\hline Marginulina sublituus (Nuttall) & & & & & & & & \\
\hline Marginulina subrecta Franke & & & & & & & & \\
\hline Marginulinasp. & & & & & & & & \\
\hline Martinottiella communis (d'Orbigny) & & & & & & & & \\
\hline Martinottiella pallida (Cushman) & 22 & 1 & & & 2 & 1 & & \\
\hline Melonis affinis (Reuss) & & & & & 2 & & & \\
\hline Melonis pompilioides (Fitchel and Moll) & & & & 4 & 3 & 1 & & \\
\hline Miliammina fusca (Brady) & & & & & & 3 & & \\
\hline
\end{tabular}




\begin{tabular}{|c|c|c|c|c|c|c|c|c|}
\hline SITE 568 & $23 / \mathrm{CC}$ & $24 / \mathrm{CC}$ & $27 / \mathrm{CC}$ & $28 / 5 / 128-1$ & $33 / \mathrm{CC}$ & $36 / \mathrm{CC}$ & $38 / 3 / 82-84$ & $39 / 3 / 84-88$ \\
\hline & & & & & & \\
\hline & \multicolumn{8}{|c|}{ Nonionella incisa (Cushman) } \\
\hline \multicolumn{9}{|l|}{ Nonionella miocenica Cushman } \\
\hline \multicolumn{9}{|l|}{ Nonionella stella Cushman and Moyer } \\
\hline Nodogenerina challengeriana Thalmann & & & 1 & & & & & \\
\hline \multicolumn{9}{|l|}{ Nodogenerina laevigata Bermudez } \\
\hline Nodosaria calomorpha Reuss & & & & & 1 & 2 & & \\
\hline Nodosaria fistuca Schwager & & & 2 & & & & & \\
\hline \multicolumn{9}{|l|}{ Nodosaria hispida d'Orbigny } \\
\hline Nodosaria lamellata Cushman and Stainforth & & 1 & & & & & & 13 \\
\hline Nodosaria longiscata d'Orbigny & 10 & 23 & 12 & & 49 & 19 & & 23 \\
\hline Nodosaria obliqua (Linne) & & & & & & & & \\
\hline Nodosaria parexilis Cushman and Stewart & & & & & & & & \\
\hline Nodosaria pyrula d'Orbigny & & & & & & 4 & & \\
\hline Nodosariaspp. & 1 & & 2 & & 2 & 5 & 1 & \\
\hline Nodosaria stainforthia Cushman and Renz & & & & 16 & 3 & 1 & & \\
\hline Oolina melo d'Orbigny & & & & & & & & \\
\hline Oolina squamosa (Montagu) & & & & & & & & \\
\hline Oridorsalina subtenera (Galloway and Wissler) & & & & & & & & \\
\hline Oridorsalis sp. & & & & & & & & \\
\hline Oridorsalis umbonatus (Reuss) & 1 & & & 6 & 6 & 11 & & 2 \\
\hline Osangularia culteri (Parker and Jones) & & & & & 1 & & & \\
\hline Osangularia mexicana (Cole) & & & & & & & & \\
\hline Parafissurinasp. & & & & & & & & \\
\hline Planulina exorna Phleger and Parker & & & & & & & & \\
\hline Planulina marialana Hadley & & & & & & & & 2 \\
\hline Planulina ornata (d'Orbigny) & & & & & 5 & & 2 & 1 \\
\hline Planulina cf. P. ornata d'Orbigny & & & & & & & & \\
\hline Planulina renz Cushman and Stainforth & & & 2 & 58 & 3 & 1 & & 1 \\
\hline Planulinaspp. & & & & & & & & \\
\hline Planularia venezuelana Hedberg & & & & & & & & \\
\hline Plectofrondiculariaadvena(Cushman) & & & & & & & & \\
\hline Plectofrondicularia californica Cushman and Stewa & & & & & & & & \\
\hline Plectofrondicularia keijzeri Bermudez & & & & & 1 & & & \\
\hline Plectofrondicularia miocenica Cushman & & & & & 1 & & & \\
\hline Plectofrondicularia morreyae Cushman & & & & & & & & \\
\hline Plectofrondicularia ruthvanmurrayi Cushman & & & & & & & & \\
\hline Plectofrondicularia vaughani Cushman & & & & & & & & \\
\hline Plectofrondicularia yumuriana Palmer & & & & & 1 & & & \\
\hline Pleurostomella acuta Hantken & & & & & & & & \\
\hline Pleurostomella alternans Schwager & & & & 1 & & & & \\
\hline Pleurostomella brevis Schwager & & & & & & & & \\
\hline Pleurostomella narajoensis Cushman and Bermud & & & & & & & & \\
\hline Pseudonodosaria conica (Neugeboren) & & & & & & & & \\
\hline Pseudonodosaria sp. & & & & & & & & \\
\hline Praeglobobulimina affinis (d'Orbigny) & & & & 1 & & & & \\
\hline Praeglobobulimina auriculata (Bailey) & & & & & & & & \\
\hline Praeglobobulimina ovata (d'Orbigny) & & & & & & & & \\
\hline Praeglobobulimina pupoides (d'Orbigny) & & & & & & & & \\
\hline Praeglobobulimina spp. & & & & & & & & \\
\hline Pullenia bulloides (d'Orbigny) & & & & 1 & 2 & 1 & & \\
\hline Pullenia cf. P. duplicata Stainforth & & & & & & & & \\
\hline Pullenia malkinae Coryell and Mossman & & & & 2 & & & & \\
\hline Pullenia quinqueloba (Reuss) & & & & & & & & \\
\hline Pullenia salisburyi Stewart and Stewart & & & & & & 1 & & \\
\hline Pullenia sp. & & & & & & & & \\
\hline Pyrgo depressa (d'Orbigny) & & & & & & & & \\
\hline Pyrgo murrhina (Schwager) & & & & 6 & & 1 & & \\
\hline Pyrgo rotalaria Loeblich and Tappan & & & & & & & & \\
\hline Pyrgo cf. P. rotularia Loeblich and Tappan & & & & & & & & \\
\hline Pyrgo aff. P. rotularia Loeblich and Tappan & & & & 1 & & & & \\
\hline Pyrgo serrata (Bailey) & & & 4 & & & & & \\
\hline Pyrgo williamsoni (Silvestri) & & & & & & & & \\
\hline Quinqueloculina lamarckiana d'Orbigny & & & & & & & & \\
\hline Quinqueloculina sp. & & & & & & & & \\
\hline Quinqueloculina venusta Karrer & & & & & 1 & & & \\
\hline Rectobolivina mexicana (Cushman) & & & & & & & & \\
\hline Rosalina columbiensis (Cushman) & & & & & & & & \\
\hline Rotorbinella tholus (Galloway and Heminway) & & & & & 1 & & 2 & \\
\hline Saccamina spp. & & & & & & & & \\
\hline Saracenaria acutauricularis (Fitchell and Moll) & & & & & & & & \\
\hline Saracenaria schencki Cushman and Hobson & & & 1 & & & & & \\
\hline Saracenaria senni Hedberg & & & & & & & & \\
\hline Sigmoilina schlumbergeri Silvestri & & & & & 4 & & & \\
\hline Sigmoilina sigmoidea (Brady) & & & & & & & & \\
\hline Sigmoilina tenuis (Czjeck) & & & & & 2 & & & \\
\hline
\end{tabular}




\begin{tabular}{|c|c|c|c|c|c|c|c|c|}
\hline SITE 568 & $23 / \mathrm{CC}$ & $24 / \mathrm{CC}$ & $27 / \mathrm{CC}$ & 28/5/128-1 & $33 / \mathrm{CC}$ & $36 / \mathrm{CC}$ & $38 / 3 / 82-84$ & $39 / 3 / 84-88$ \\
\hline Siphogenerina basispinata Cushman and Jarvis & 14 & 1 & & 12 & 13 & 5 & 3 & \\
\hline Siphogenerina multicostata Cushman and Jarvis & & & & & & & & 2 \\
\hline \multicolumn{9}{|l|}{ Siphogenerina senni Cushman and Renz } \\
\hline \multicolumn{9}{|l|}{ Siphogenerinasp. } \\
\hline \multicolumn{9}{|l|}{ Siphogenerina tenua Cushman and Kleinpell } \\
\hline Siphogenerina transversa Cushman & & & & & & 1 & 1 & 22 \\
\hline \multicolumn{9}{|l|}{ Siphonodosaria abyssorum (Brady) } \\
\hline Siphonodosaria gracillima (Cushman and Jarvis) & & 1 & 6 & 36 & 42 & 8 & & \\
\hline Siphonodosaria paucistriata (Galloway and Morrey) & & 1 & & 13 & & & & \\
\hline \multicolumn{9}{|l|}{ Siphonodosaria spp. } \\
\hline Siphonodosaria verneuilla (d'Orbigny) & & & & & & & & 26 \\
\hline Siphonia pulchra Cushman & & & & & 2 & 24 & 1 & \\
\hline \multicolumn{9}{|l|}{ Siphotextularia catenata (Cushman) } \\
\hline Sphaeroidina bulloides d'Orbigny & & & 2 & 9 & 1 & 2 & 3 & 14 \\
\hline \multicolumn{9}{|l|}{ Spiroplectammina $s p}$. \\
\hline Spiroloculina texana Cushman and Ellisor & & & & & & 1 & & \\
\hline Stilostomella adolphina (d'Orbigny) & & & 8 & 3 & 4 & 6 & & \\
\hline Stilostomella advena (Cushman and Laiming) & & & & 2 & & & & \\
\hline Stilostomella gracilis (Palmer and Bermudez) & & & & & 4 & & & \\
\hline Stilostomella lepidula (Schwager) & & & & 9 & 6 & & & \\
\hline Stilostomella subspinosa (Cushman) & & 1 & & 4 & 10 & & 1 & \\
\hline \multicolumn{9}{|l|}{ Stilostomellasp. } \\
\hline \multicolumn{9}{|l|}{ Suggrunda californica Kleinpell } \\
\hline \multicolumn{9}{|l|}{ Suggrunda eckisi Natland } \\
\hline Textularia leuzingeri Cushman and Renz & & & & & & & & 1 \\
\hline \multicolumn{9}{|l|}{ Trifarina angulosa (Williamson) } \\
\hline \multicolumn{9}{|l|}{ Trifarina bradyi Cushman } \\
\hline \multicolumn{9}{|l|}{ Trifarina carinata (Cushman) } \\
\hline \multicolumn{9}{|l|}{ Triloculina globosa (Hanna and Hanna) } \\
\hline \multicolumn{9}{|l|}{ Triloculina trihedra Loeblich and Tappan } \\
\hline \multicolumn{9}{|l|}{ Tritaxilina colei Cushman and Siegfus } \\
\hline Uvigerina carapitana Hedberg & & & & & & & & 10 \\
\hline \multicolumn{9}{|l|}{ Uvigerina excellens Todd } \\
\hline \multicolumn{9}{|l|}{ Uvigerina gallowayi Cushman } \\
\hline Uvigerina cf. U. gallowayi Cushman & & & & & & & & \\
\hline Uvigerina hispidocostata Cushman and Todd & & & & & & & & \\
\hline Uvigerina hispida Schwager & 1 & & 5 & 11 & 3 & 34 & 3 & \\
\hline Uvigerina incilis Todd & & & & & & & & \\
\hline Uvigerina juncea Cushman and Todd & & & & & & & & \\
\hline Uvigerina peregrina Cushman & & & & & & & & \\
\hline Uvigerina peregrina dirupta Todd & & & & & & & & \\
\hline Uvigerina rustica Cushman and Edwards & & 1 & 12 & 14 & 18 & 4 & 4 & 3 \\
\hline Uvigerina senticosa Cushman & & & & & & & & \\
\hline Uvigerina sp. (costate) & & & & & & & 1 & 26 \\
\hline Uvigerina striata d'Orbigny & & & & & & & & \\
\hline Uvigerina vaderescens Cushman & & & & & & & & \\
\hline Vaginulina americana Cushman & & & & 1 & & & & \\
\hline Vaginulinopsis nudicostata (Cushman and Hanna) & & & & & & & & 4 \\
\hline Valvulineria araucana (d'Orbigny) & & & & & & & & \\
\hline Valvulineria glabra Cushman & & & & & & & & \\
\hline Valvulineria malagaensis Kleinpell & & & & & & & & \\
\hline Vulvulina spinosa Cushman & & & & & 1 & 2 & 1 & 1 \\
\hline
\end{tabular}




\begin{tabular}{|c|c|c|c|c|c|c|c|}
\hline SITE 568 & 40/1/125-1 & $40 / \mathrm{CC}$ & $41 / 3 / 123-1$ & $42 / 3 / 72-76$ & \begin{tabular}{|l|l|}
$43 / 1 / 14-18$ \\
\end{tabular} & $44 / 1 / 138-1$ & $44 / 3 / 138-1$ \\
\hline Alabamina polita Becker and Dusenbury & & 5 & 8 & & & & \\
\hline \multicolumn{8}{|l|}{ Alveolophragmium crassimargo (Norman) } \\
\hline \multicolumn{8}{|l|}{ Ammonia beccarii (Linne) } \\
\hline \multicolumn{8}{|l|}{ Amphistegina lessoni d'Orbigny } \\
\hline \multicolumn{8}{|l|}{ Anomalinoides globulosus (Chapman and Parr) } \\
\hline Anomalinoides pompilioides (Galloway and Wissler) & 1 & 1 & 2 & & & & \\
\hline \multicolumn{8}{|l|}{ Anomalinoides semicribratus (Beckman) } \\
\hline \multicolumn{8}{|l|}{ Anomalina flintii Cushman } \\
\hline \multicolumn{8}{|l|}{ Astigerina guraboensis Bermudez } \\
\hline Astrononion guadalupae (Parker) & & & & & & & \\
\hline Bathysiphonsp. & & & & & & & \\
\hline Buliminella curta Cushman & & 1 & 4 & & & & \\
\hline Buliminella subfusiformis Cushman & & & & & & & \\
\hline Bolivina advena Cushman & & & & & & & \\
\hline Bolivina alazaensis Cushman & & & & & & & \\
\hline Bolivina argentea Cushman & & & & & & & \\
\hline Bolivina beyrichi Reuss & & & & & & & \\
\hline Bolivina bicostata Cushman & & & & & & & \\
\hline Bolivina bradyi Asano & & & & & & & \\
\hline Bolivina californica Cushman & & & & & & & \\
\hline Bolivina decussata Brady & & & & & & & \\
\hline Bolivina foraminata Stewart and Stewart & & & & & & & \\
\hline Bolivina marginata Cushman & 1 & 5 & 1 & & & & \\
\hline Bolivina pacifica Cushman and McCulloch & & & & & & & \\
\hline Bolivina pseudobeyrichi Cushman & & & & & & & \\
\hline Bolivina subadvena Cushman & & & & & & & \\
\hline Bolivina subadvena sulpherensis Cushman and Adams & & & & & & & \\
\hline Bolivina scabrata Cushman and Bermudez & & & & & & & \\
\hline Bolivina cf. B. sinuata Galloway and Wissler & & & & & & & \\
\hline Bolivina aff. B. sinuata Galloway and Wissler & & & & & & & \\
\hline Bolivina semiperforata Martin & & & & & & & \\
\hline Bolivina seminuda Cushman & & & & & & & \\
\hline Bolivina sp. & & & & & & & \\
\hline Bolivina tongi filacostata Cushman and McCulloch & & & & & & & \\
\hline Bolivina woodringi Kleinpelli & & & & & & & \\
\hline Buccella sp. & & & & & & & \\
\hline Bulimina alazaensis Cushman & & & & & & & \\
\hline Bulimina denudata Cushman and Parker & & & & & & & \\
\hline Bulimina mexicana Cushman & 2 & 2 & 3 & 3 & & 3 & \\
\hline Bulimina pagoda Cushman & & & & & & & \\
\hline Cancris auricula (Fitchel and Moll) & & & & & & & \\
\hline Cancris inflatus (d'Orbigny) & & & & & & & \\
\hline Cancris panamensis Natland & & & & & & & \\
\hline Cassidulina californica Cushman and Hughes & & & 7 & 1 & & & \\
\hline Cassidulina californica Cushman and Hughes variation & & & & & & & \\
\hline Cassidulina caudriae Cushman and Stainforth & & & & & & & \\
\hline Cassidulina crassa d'Orbigny & & & & & & & \\
\hline Cassidulina delicata Cushman & & & & & & & \\
\hline Cassidulina laevigata carinata Silvestri & & & & & & & \\
\hline Cassidulina laevigata d'Orbigny & & & & & & & \\
\hline Cassidulina limbata Cushman and Hughes & & & & & & & \\
\hline Cassidulina minuta Cushman & & & & & & & \\
\hline Cassidulina oblonga Reuss & & & & & & & \\
\hline Cassidulinoides bradyi (Norman) & & & 1 & & & & \\
\hline Cassidulinoides tenuis Phleger and Parker & & & & & & & \\
\hline Cassidulina spinifera Cushman and Jarvis & & 7 & 3 & & & & \\
\hline Cassidulina tricamerata Galloway and Heminway & & & & & & & \\
\hline Cassidulina tumida Natland & & & & & & & \\
\hline Ceratobulimina alazaensis Cushman and Harris & & 1 & 4 & & & & \\
\hline Chilostomella oolina Schwager & & & & & & & \\
\hline Chilostomella ovoidea Reuss & & & & & & & \\
\hline Chrysalogonium breviloculum Cushman and Jarvis & & & & & & & 1 \\
\hline Chrysalogonium elongatum Cushman and Jarvis & & & & & & & \\
\hline Chrysalogonium lanceolum Cushman and Jarvis & & & & & & & \\
\hline Chrysalogonium longiscatatum Cushman and Jarvis & & & & & & & \\
\hline Cibicides barnetti Bermudez & & & & & & & \\
\hline Cibicides fletcheri Galloway and Wissler & & & & & & & \\
\hline Cibicidesfloridanus (Cushman) & & 2 & & 4 & & 1 & \\
\hline Cibicides granulosa Bermudez & & & & & & & \\
\hline Cibicides guraboensus Bermudez & & & & & & & \\
\hline Cibicides cf. C. guraboensus Bermudez & & & & & & & \\
\hline Cibicides heminwayae Bermudez & & & & & & & \\
\hline Cibicides io Cushman & & & & & & & \\
\hline Cibicides matanzaensis (Hadley) & & & & & & & \\
\hline Cibicides mckannai Galloway and Wissler & & & & & & & \\
\hline Cibicides cf. C. mckannai Galloway and Wissler & & & & & & & \\
\hline
\end{tabular}




\begin{tabular}{|c|c|c|c|c|c|c|c|}
\hline SITE 568 & $40 / 1 / 125-1$ & $40 / \mathrm{CC}$ & $41 / 3 / 123-1$ & $42 / 3 / 72-76$ & $43 / 1 / 14-18$ & 44/1/138-1 & $44 / 3 / 138-1$ \\
\hline \multicolumn{8}{|l|}{ Cibicides nucleatus (Sequenza) } \\
\hline Cibicidoides bradyi (Trauth) & & & 2 & & 1 & 4 & \\
\hline \multicolumn{8}{|l|}{ Cibicidoides coryelli (Bermudez) } \\
\hline Cibicidoides kullenbergi (Parker) & & & & & 2 & & \\
\hline \multicolumn{8}{|l|}{ Cibicidoides sinistralis (Coryell and Rivero) } \\
\hline \multicolumn{8}{|l|}{ Cibicidoides trinitatensis (Nuttall) } \\
\hline \multicolumn{8}{|l|}{ Cibicidoides wuellerstorffi (Schwager) } \\
\hline \multicolumn{8}{|l|}{ Cibicides spp. } \\
\hline Cibicides spirolimbatus Galloway and Heminway & 7 & 20 & 12 & 3 & & & \\
\hline \multicolumn{8}{|l|}{ Cibicides spiralis Natland } \\
\hline Cibicides spp. & & & & & & & \\
\hline Cibicides trincherasensis Bermudez & & & & & & & \\
\hline Cibicides umbonatus Phleger and Parker & & & & & & & \\
\hline Cibicides yagatensis Bermudez & & 8 & 15 & & & & \\
\hline Cyclogyra foliacea (Philippi) & & & & & & & \\
\hline Dentalina cocoaensis (Cushman) & 2 & 26 & 29 & & & & \\
\hline Dentalina consobrina (d'Orbigny) & & & 16 & & & & \\
\hline Dentalina cooperensis Cushman & & 4 & & & & & \\
\hline Dentalina ittai Loeblich and Tappan & & & & & & & \\
\hline Dentostomina guraboensis Bermudez & & & & & & & \\
\hline Dentalina pauperata d'Orbigny & & & & & 2 & & \\
\hline Dentalina soluta Reuss & & & & & & & \\
\hline Dentalina spinosa d'Orbigny & & & & & & 1 & 4 \\
\hline Eggerella bradyi (Cushman) & & & & & & & \\
\hline Ehrenbergina bradyi Cushman & & & 9 & & & & \\
\hline Ehrenbergina caribbea Galloway and Heminway & & & & 1 & & & \\
\hline Ellipsoglandulina multicostata (Galloway and Morrey & & & & & & & \\
\hline Ellipsonodosaria decurta Bermudez & & & & & & & \\
\hline Ellipsonodosaria mappa Cushman and Jarvis & & & & & & & \\
\hline Elphidium tumidum Natland & & & & & & & \\
\hline Epistominella bradyana (Cushman) & & & & & & & \\
\hline Epistominella cf. E. bradyana (Cushman) & & & & & & & \\
\hline Epistominella obesa Bandy and Arnal & & & & & & & \\
\hline Epistominella smithi (Stewart and Stewart) & & & & & & & \\
\hline Epistominella sp. of Resig (1980) & & & & & & & \\
\hline Fissurina alveolata (Brady) & & & & & & & 1 \\
\hline Fissurina subformosa Parr & & & & & & & \\
\hline Fissurina carteri (McLean) & & & & & & & \\
\hline Fissurina cucullata Silvestri & & & & & & & \\
\hline Fissurina dominicana (Bermudez) & & & & & & & \\
\hline Fissurina fimbrata (Brady) & & & & & & & \\
\hline Fissurina cf. F. fimbrata (Brady) & & & & & & & \\
\hline Fissurina aff. F. fimbrata (Brady) & & & & & & & \\
\hline Fissurina marginata (Montagu) & & & & & & & \\
\hline Fissurina solida Sequenza & & & & & & & \\
\hline Fissurina orbignyana Sequenza & & & & & & & \\
\hline Fissurina sp. (double keel) & & & & & & & \\
\hline Fissurina spinosa (Sidebottom) & & & & & & & \\
\hline Fissurina spp. & & & & & & & \\
\hline Fissurina staphylleraria Schwager & & & & 1 & & & \\
\hline Fissurina trigonomarginata (Parker and Jones) & & & & & & & \\
\hline Fissurina ventricosa (Wiesner) & & & & & & & \\
\hline Fissurina wiesneri Barker & & & & & & & \\
\hline Fursenkoina bramletti (Galloway and Morrey) & & & & & & & \\
\hline Fursenkoina cornuta (Cushman) & & & & & & & \\
\hline Fursenkoina dibollensis (Cushman and Applin) & & & & & & & \\
\hline Fursenkoina fusiformis (Cushman) & & & & & & & \\
\hline Fursenkoina punctata (d'Orbigny) & & & & & & & \\
\hline Fursenkoina rotundata (Parr) & & & 1 & & & & \\
\hline Fursenkoinaspp. & & & & & & & \\
\hline Fursenkoina squammosa (d'Orbigny) & & & & & & & \\
\hline Gaudryina arenaria Galloway and Wissler & & & & & & & \\
\hline Globobulimina barbata (Cushman) & & & & & & & \\
\hline Globobulimina pacifica Cushman & & & & & & & \\
\hline Globobulimina spinifera (Cushman) & & & & & & & \\
\hline Globocassidulina subglobosa (Brady) & 2 & 6 & & & & & \\
\hline Glandulina laevigata (d'Orbigny) & & & & & & & \\
\hline Glandulinasp. & & & & & & & \\
\hline Globulinasp. & & & & & & & \\
\hline Goesella flintii Cushman & & & & & & & \\
\hline Goesella guraboensis Bermudez & & & & & & & \\
\hline Guttulina caudata d'Orbigny & & & 1 & & & & \\
\hline Guttulina irregularis (d'Orbigny) & & & & & & & \\
\hline Guttulina sp. & & & & & & & \\
\hline Gyroidina altiformis Stewart and Stewart & & & & & & & \\
\hline Gyroidina altispira Cushman and Stainforth & & & & & & & \\
\hline
\end{tabular}




\begin{tabular}{|c|c|c|c|c|c|c|c|}
\hline SITE 568 & $40 / 1 / 125-1$ & $40 / \mathrm{CC}$ & $41 / 3 / 123-1$ & $42 / 3 / 72-76$ & $43 / 1 / 14-18$ & $44 / 1 / 138-1$ & $44 / 3 / 138-1$ \\
\hline \multicolumn{8}{|l|}{ Gyroidina broekhiana Karrer } \\
\hline \multicolumn{8}{|l|}{ Gyroidina condoni (Cushman and Schenck) } \\
\hline \multicolumn{8}{|l|}{ Gyroidina cf. G. condoni (Cushman and Schenck) } \\
\hline \multicolumn{8}{|l|}{ Gyroidina lamarckiana d'Orbigny } \\
\hline \multicolumn{8}{|l|}{ Gyroidina multilocula Coryell and Mossman } \\
\hline \multicolumn{8}{|l|}{ Gyroidina nitidula (Schwager) } \\
\hline \multicolumn{8}{|l|}{ Gyroidina aff. G. nitidula (Schwager) } \\
\hline Gyroidina neosoldanii Brotzen & & & & & & & \\
\hline Gyroidina perampla Cushman and Stainforth & & & & & 1 & & \\
\hline Gyroidina planulata Cushman and Renz & & & 1 & & & & \\
\hline Gyroidina cf. G. planulata Cushman and Renz & & & & 2 & & & \\
\hline Gyroidina aff. G. planulata Cushman and Renz & & & & & & & \\
\hline Gyroidina quinqueloba Uchio & & & & & & & \\
\hline Gyroidina soldanii d'Orbigny & 2 & & 29 & & & & \\
\hline Gyroidinaspp. & & & & & & & \\
\hline Gyroidina zelandica Finlay & & 6 & & & & & \\
\hline Hanzawaia basiloba (Cushman) & & & & & & & \\
\hline Hanzawaia illingi (Nuttall) & & & & & & & \\
\hline Hanzawaia isidroensis (Cushman and Renz) & & & & 2 & & & \\
\hline Hanzawaia mantaensis (Galloway and Morrey) & 1 & 3 & 1 & & & & \\
\hline Hanzawaiasp. & & & & & & & \\
\hline Hoeglundina elegans (d'Orbigny) & 7 & 24 & 24 & 1 & 3 & 2 & \\
\hline Karreriella bradyi (Cushman) & & & & & & & \\
\hline Karreriella chilostoma (Reuss) & & & & & & & \\
\hline Karreriellasp. & & & & & & & \\
\hline Lagena becki Sullivan & & & & & & & \\
\hline Lagena costata (Williamson) & & 2 & & & & & \\
\hline Lagenaelongata(Ehrenberg) & & & & & & & \\
\hline Lagena gracillima (Sequenza) & & & & & & & \\
\hline Lagena hexagona (Williamson) & & & & & & & \\
\hline Lagena hispida Reuss & & & & & & & \\
\hline Lagena laevis (Montagu) & & & & & & & \\
\hline Lagena lineata (Williamson) & & & & & & & \\
\hline Lagena meridionalis Wiesner & & & & & & & \\
\hline Lagena setigera Millett & & & & & & & \\
\hline Lagena semilineata Wright & & & & & & & \\
\hline Lagena semistriata Williamson & & & & & & & \\
\hline Lagenasp. & & & & & 1 & & \\
\hline Lagena striata (d'Orbigny) & & & & & & & \\
\hline Laticarinina pauperata (Parker and Jones) & & & & & & & \\
\hline Lenticulina altolimbatus (Gumbel) & & & 3 & 1 & & & \\
\hline Lenticulina arcuatostriata (Hantken) & 8 & 18 & 11 & & & & \\
\hline Lenticulina arcuatostriata carolinianus (Cushman) & & & 1 & & & & \\
\hline Lenticulina calcar (Linne) & & 10 & 19 & & 2 & & \\
\hline Lenticulina caritae Bermudez & & & & & & & \\
\hline Lenticulina colorata (Stache) & & & & & & & \\
\hline Lenticulina crassa d'Orbigny & & & 2 & & & & \\
\hline Lenticulina cushmani (Galloway and Wissler) & & & & & & & \\
\hline Lenticulina dicampyla (Franzenau) & & 2 & 1 & & & & \\
\hline Lenticulina gibba d'Orbigny & & & 3 & & & & \\
\hline Lenticulina iota (Cushman) & & & 2 & & & & \\
\hline Lenticulina limbosa (Reuss) & & 3 & 4 & & & & \\
\hline Lenticulina melvilli (Cushman and Renz) & & 9 & 6 & & & & \\
\hline Lenticulina nikobarensis (Schwager) & & & & & & & \\
\hline Lenticulina occidentalis (Cushman) & & & & & & & \\
\hline Lenticulina occidentalis torrida (Cushman) & & & & & & & \\
\hline Lenticulina plummerae (Cole) & & & & & & & \\
\hline Lenticulina rotulata Lamarck & & 1 & 1 & & & & \\
\hline Lenticulina submamilligera (Cushman) & & & & & & & \\
\hline Lenticulinaspp. & & & 5 & & & & \\
\hline Lenticulina terryi (Coryell and Embich) & & & 10 & & & & \\
\hline Lenticulina texana (Cushman and Applin) & & & & & & & \\
\hline Lenticulina vaughani (Cushman) & & 1 & & & & & \\
\hline Lenticulina yaguensis (Bermudez) & & & 6 & & & & \\
\hline Marginulina alazaensis Nuttall & & & & & & & \\
\hline Marginulina dubia Neugeboren & & & & & & & \\
\hline Marginulina exima Neugeboren & & & & & & & \\
\hline Marginulina subbullata Hantken & & & 2 & & & & \\
\hline Marginulina sublituus (Nuttall) & & & & & & & \\
\hline Marginulina subrecta Franke & & & & & & & \\
\hline Marginulinasp. & & & & & & & \\
\hline Martinottiella communis (d'Orbigny) & & & & & & & \\
\hline Martinottiella pallida (Cushman) & & & & & & & \\
\hline Melonis affinis (Reuss) & & & & & & & \\
\hline Melonis pompilioides (Fitchel and Moll) & 1 & & 1 & & & & \\
\hline Miliammina fusca (Brady) & & & & & & & \\
\hline
\end{tabular}




\begin{tabular}{|c|c|c|c|c|c|c|c|}
\hline SITE 568 & $40 / 1 / 125-1$ & $40 / \mathrm{CC}$ & $41 / 3 / 123-1$ & $42 / 3 / 72-76$ & 43/1/14-18 & $44 / 1 / 138-1$ & $44 / 3 / 138-1$ \\
\hline \multicolumn{8}{|l|}{ Nonionella auricula Heron-Allen and Earland } \\
\hline Nonionella incisa (Cushman) & & & & 2 & & & \\
\hline Nonionella miocenica Cushman & & 4 & 3 & & & & \\
\hline \multicolumn{8}{|l|}{ Nonionella stella Cushman and Moyer } \\
\hline \multicolumn{8}{|l|}{ Nodogenerina challengeriana Thalmann } \\
\hline \multicolumn{8}{|l|}{ Nodogenerina laevigata Bermudez } \\
\hline \multicolumn{8}{|l|}{ Nodosaria calomorpha Reuss } \\
\hline Nodosaria fistuca Schwager & & & & & & 1 & \\
\hline Nodosaria hispida d'Orbigny & & & & & & 8 & 2 \\
\hline Nodosaria lamellata Cushman and Stainforth & & 2 & 2 & & 1 & & \\
\hline Nodosaria longiscata d'Orbigny & 2 & 1 & 12 & 3 & 4 & 10 & 16 \\
\hline \multicolumn{8}{|l|}{ Nodosaria obliqua (Linne) } \\
\hline \multicolumn{8}{|l|}{ Nodosaria parexilis Cushman and Stewart } \\
\hline Nodosaria pyrula d'Orbigny & & & & & & & \\
\hline Nodosaria spp. & & & & & & 2 & \\
\hline Nodosaria stainforthia Cushman and Renz & 1 & & & 1 & & & \\
\hline Oolina melo d'Orbigny & & & & & & & \\
\hline Oolina squamosa (Montagu) & & & & & & & \\
\hline Oridorsalina subtenera (Galloway and Wissler) & & & & & & & \\
\hline Oridorsalissp. & & & & & & & \\
\hline Oridorsalis umbonatus (Reuss) & & & 2 & & 1 & 1 & \\
\hline Osangularia culteri (Parker and Jones) & & & 5 & & & & \\
\hline Osangularia mexicana (Cole) & 2 & & & & & & \\
\hline Parafissurinasp. & & & & & & & \\
\hline Planulina exorna Phleger and Parker & & & & & & & \\
\hline Planulina marialana Hadley & & & & & & & \\
\hline Planulina ornata (d'Orbigny) & & & & & & & \\
\hline Planulina cf. P. ornata d'Orbigny & & & & & & & \\
\hline Planulina renz Cushman and Stainforth & & & 5 & & & & \\
\hline Planulina spp. & & & & & & & \\
\hline Planularia venezuelana Hedberg & 2 & 3 & 3 & & & & \\
\hline Plectofrondiculariaadvena(Cushman) & & & & & & & \\
\hline Plectofrondicularia californica Cushman and Stewart & & 3 & 1 & 1 & & & \\
\hline Plectofrondicularia keijzeri Bermudez & & & & & & & \\
\hline Plectofrondicularia miocenica Cushman & & & & & & & \\
\hline Plectofrondicularia morreyae Cushman & & & & & & & \\
\hline Plectofrondicularia ruthvanmurrayi Cushman & & & & & & & \\
\hline Plectofrondicularia vaughani Cushman & & & 4 & & & & \\
\hline Plectofrondicularia yumuriana Palmer & & & & & & & \\
\hline Pleurostomella acuta Hantken & & & & & & & \\
\hline Pleurostomella alternans Schwager & & & & & & & \\
\hline Pleurostomella brevis Schwager & & & & & & & \\
\hline Pleurostomella narajoensis Cushman and Bermudez & & & & & & & \\
\hline Pseudonodosaria conica (Neugeboren) & & & 1 & & & & \\
\hline Pseudonodosaria sp. & & & & & & & \\
\hline Praeglobobulimina affinis (d'Orbigny) & & & & & & & \\
\hline Praeglobobulimina auriculata (Bailey) & 1 & & & & & & \\
\hline Praeglobobulimina ovata (d'Orbigny) & & & 3 & & & & \\
\hline Praeglobobulimina pupoides (d'Orbigny) & & & & & & & \\
\hline Praeglobobulimina spp. & & & & & & & \\
\hline Pullenia bulloides (d'Orbigny) & & & 7 & & & 4 & \\
\hline Pullenia cf. P. duplicata Stainforth & & & & & & & \\
\hline Pullenia malkinae Coryell and Mossman & & & & & & & \\
\hline Pullenia quinqueloba (Reuss) & & & & & & & 1 \\
\hline Pullenia salisburyi Stewart and Stewart & & & & & & & \\
\hline Pullenia sp. & & & & & & & \\
\hline Pyrgo depressa (d'Orbigny) & & & & & & & 1 \\
\hline Pyrgo murrhina (Schwager) & & & & & & & \\
\hline Pyrgo rotalaria Loeblich and Tappan & & & & & & & \\
\hline Pyrgo cf. P. rotularia Loeblich and Tappan & & & & & & & \\
\hline Pyrgo aff. P. rotularia Loeblich and Tappan & & & & & & & \\
\hline Pyrgo serrata (Bailey) & & & & & & & \\
\hline Pyrgo williamsoni (Silvestri) & & & & & & & \\
\hline Quinqueloculina lamarckiana d'Orbigny & & & & & & & \\
\hline Quinqueloculina $s p$ & & & & & & & \\
\hline Quinqueloculina venusta Karrer & & & 1 & & & 1 & \\
\hline Rectobolivina mexicana (Cushman) & & & & & & & \\
\hline Rosalina columbiensis (Cushman) & & & & & & & \\
\hline Rotorbinella tholus (Galloway and Heminway) & & & & & & & \\
\hline Saccaminaspp. & & & & & & & \\
\hline Saracenaria acutauricularis (Fitchell and Moll) & & & & & & & \\
\hline Saracenaria schencki Cushman and Hobson & 1 & & & & & & \\
\hline Saracenaria senni Hedberg & & & & & & & \\
\hline Sigmoilina schlumbergeri Silvestri & & & & & & & \\
\hline Sigmoilina sigmoidea (Brady) & & & & & 2 & & \\
\hline Sigmoilina tenuis (Czjeck) & 1 & 8 & 5 & & & & \\
\hline
\end{tabular}




\begin{tabular}{|c|c|c|c|c|c|c|c|}
\hline SITE 568 & $40 / 1 / 125-1$ & $40 / \mathrm{CC}$ & $41 / 3 / 123-1$ & $42 / 3 / 72-76$ & $43 / 1 / 14-18$ & $44 / 1 / 138-1$ & $44 / 3 / 138-1$ \\
\hline Siphogenerina basispinata Cushman and Jarvis & & & & 2 & & & \\
\hline Siphogenerina multicostata Cushman and Jarvis & 1 & & & 2 & & & \\
\hline Siphogenerina senni Cushman and Renz & & 1 & 5 & & & & \\
\hline \multicolumn{8}{|l|}{ Siphogenerinasp. } \\
\hline \multicolumn{8}{|l|}{ Siphogenerina tenua Cushman and Kleinpell } \\
\hline Siphogenerina transversa Cushman & 10 & 17 & 47 & 3 & & & \\
\hline \multicolumn{8}{|l|}{ Siphonodosaria abyssorum (Brady) } \\
\hline \multicolumn{8}{|l|}{ Siphonodosaria gracillima (Cushman and Jarvis) } \\
\hline \multicolumn{8}{|l|}{ Siphonodosaria paucistriata (Galloway and Morrey) } \\
\hline \multicolumn{8}{|l|}{ Siphonodosaria spp. } \\
\hline \multicolumn{8}{|l|}{ Siphonodosaria verneuilla (d'Orbigny) } \\
\hline Siphonia pulchra Cushman & 1 & 1 & 2 & & & & \\
\hline \multicolumn{8}{|l|}{ Siphotextularia catenata (Cushman) } \\
\hline Sphaeroidina bulloides d'Orbigny & & 4 & 2 & & 1 & 1 & 2 \\
\hline \multicolumn{8}{|l|}{ Spiroplectammina $s p}$. \\
\hline \multicolumn{8}{|l|}{ Spiroloculina texana Cushman and Ellisor } \\
\hline \multicolumn{8}{|l|}{ Stilostomella adolphina (d'Orbigny) } \\
\hline Stilostomella advena (Cushman and Laiming) & 1 & & & & & & \\
\hline Stilostomella gracilis (Palmer and Bermudez) & & & 1 & & & & 7 \\
\hline Stilostomella lepidula (Schwager) & & & & 2 & 1 & 1 & \\
\hline Stilostomella subspinosa (Cushman) & 1 & 4 & & & & & \\
\hline \multicolumn{8}{|l|}{ Stilostomellasp. } \\
\hline \multicolumn{8}{|l|}{ Suggrunda californica Kleinpell } \\
\hline \multicolumn{8}{|l|}{ Suggrunda eckisi Natland } \\
\hline Textularia leuzingeri Cushman and Renz & 2 & & & & 1 & & \\
\hline \multicolumn{8}{|l|}{ Trifarina angulosa (Williamson) } \\
\hline Trifarina bradyi Cushman & & & 3 & & & & \\
\hline \multicolumn{8}{|l|}{ Trifarina carinata (Cushman) } \\
\hline Triloculina globosa (Hanna and Hanna) & & 1 & 1 & & & & \\
\hline Triloculina trihedra Loeblich and Tappan & & & 1 & & & & \\
\hline Tritaxilina colei Cushman and Siegfus & & 2 & & & & & \\
\hline Uvigerina carapitana Hedberg & & 1 & & & & & \\
\hline \multicolumn{8}{|l|}{ Uvigerina excellens Todd } \\
\hline Uvigerina gallowayi Cushman & & & & & & 1 & 5 \\
\hline \multicolumn{8}{|l|}{ Uvigerina cf. U. gallowayi Cushman } \\
\hline \multicolumn{8}{|l|}{ Uvigerina hispidocostata Cushman and Todd } \\
\hline Uvigerina hispida Schwager & & 1 & & 3 & 2 & 2 & 2 \\
\hline Uvigerina incilis Todd & & & & & & & \\
\hline Uvigerina juncea Cushman and Todd & & & & & & & \\
\hline Uvigerina peregrina Cushman & & & & & & & \\
\hline Uvigerina peregrina dirupta Todd & & & & & & & \\
\hline Uvigerina rustica Cushman and Edwards & & & & & & & \\
\hline Uvigerina senticosa Cushman & & & & & & & \\
\hline Uvigerina sp. (costate) & 12 & 21 & 2 & 5 & & & \\
\hline Uvigerina striata d'Orbigny & & & & & & & \\
\hline Uvigerina vaderescens Cushman & & & & & & & \\
\hline Vaginulina americana Cushman & & & & & & & \\
\hline Vaginulinopsis nudicostata (Cushman and Hanna) & & 3 & 14 & & & & \\
\hline Valvulineria araucana (d'Orbigny) & & & & & & & \\
\hline Valvulineria glabra Cushman & & & & & & & \\
\hline Valvulineria malagaensis Kleinpell & & & & & & & \\
\hline Vulvulina spinosa Cushman & & & & & & & \\
\hline
\end{tabular}




\section{APPENDIX 5}

Equatorial Eastern Pacific Site 569: Complete Benthic Foraminiferal Counts 


\begin{tabular}{|c|c|c|c|c|c|c|c|c|}
\hline SITE 569 & $7 / 5 / 20-24$ & $7 / \mathrm{CC}$ & $8 / 1 / 18-22$ & $10 / 1 / 11-15$ & $10 / \mathrm{CC}$ & $11 / 1 / 30-34$ & $11 / \mathrm{CC}$ & $12 / 1 / 20-24$ \\
\hline Alabamina polita Becker and Dusenbury & & & & & 1 & & 1 & \\
\hline \multicolumn{9}{|l|}{ Amphistegina lessoni d'Orbigny } \\
\hline \multicolumn{9}{|l|}{ Amphistegina cf. A. lessoni d'Orbigny } \\
\hline Anomalinoides globulosus (Chapman and Parr) & & & & 1 & & 1 & & \\
\hline \multicolumn{9}{|l|}{ Anomalina flintii Cushman } \\
\hline Astrononion guadalupae (Parker) & & & & & & & 1 & \\
\hline Baggina dominicana Bermudez & & & & & & & & \\
\hline Buliminella curta Cushman & & & & & & & & \\
\hline Buliminella subfusiformis Cushman & & & 2 & & & & & \\
\hline Buliminella tenuata Cushman & & & & & & & & \\
\hline Bolivina acuminata Natland & & & & & & & & \\
\hline Bolivina advena Cushman & & & & & & & & \\
\hline Bolivina alazaensis Cushman & & & 2 & & & & & \\
\hline Bolivina argentea Cushman & & & & & & & & \\
\hline Bolivina cf. B. argentea Cushman & & & 1 & & & & & \\
\hline Bolivina bicostata Cushman & & & & & & & & \\
\hline Bolivina bradyi Asano & & & & & & & & \\
\hline Bolivina conica Cushman & & & & & & & & \\
\hline Boldia cushmani (Nuttall) & & & & & 1 & & & \\
\hline Bolivina foraminata Stewart and Stewart & & & & & & & & \\
\hline Bolivinita quadrilatera (Schwager) & & & & & & & & \\
\hline Bolivina marginata Cushman & & & & & & & 2 & \\
\hline Bolivina pacifica Cushman and McCulloch & & & & & & & & \\
\hline Bolivina plicata d'Orbigny & & & & & & & & \\
\hline Bolivina pseudobeyrichi Cushman & & & & & & & & \\
\hline Bolivina pseudospissa Kleinpell & & & & & & & & \\
\hline Bolivina subadvena Cushman & & & & & & & & \\
\hline Bolivina cf. B. subadvena Cushman & & & & & & & & \\
\hline Bolivina sinuata Galloway and Wissler & & & & & & & & \\
\hline Bolivina cf. B. sinuata Galloway and Wissler & & & & & & & & \\
\hline Bolivina semiperforata Martin & & & & & & & & \\
\hline Bolivina cf. B. semiperforata Martin & & & & & & & & \\
\hline Bolivina seminuda Cushman & & & 4 & & & & & \\
\hline Bolivina spissa Cushman & & & & & & & & \\
\hline Buccella sp. & & & & & & & & \\
\hline Bulimina alazaensis Cushman & & 15 & 12 & & 1 & 2 & 9 & \\
\hline Bulimina bleekeri Hedberg & & & & & & 2 & & \\
\hline Bulimina denudata Cushman and Parker & & & & & & & & \\
\hline Bulimina mexicana Cushman & 8 & 1 & & & & & & \\
\hline Bulimina uvigeriniformis Cushman and Kleinpell & & & 3 & & & & & \\
\hline Cancris auricula (Fitchel and Moll) & & & & & & & & \\
\hline Cancris inflatus (d'Orbigny) & 2 & 1 & & & & & & \\
\hline Cancris panamensis Natland & & & & & & & & \\
\hline Cassidulina californica Cushman and Hughes & & & & & & & & \\
\hline Cassidulina caudriae Cushman and Stainforth & & & & & & & & \\
\hline Cassidulina cushmani Stewart and Stewart & & & 1 & & & & & \\
\hline Cassidulina delicata Cushman & & & & & & & & \\
\hline Cassidulina laevigata d'Orbigny & & & & & & & & \\
\hline Cassidulina limbata Cushman and Hughes & & & & & & & & \\
\hline Cassidulina oblonga Reuss & & & & & & & & \\
\hline Cassidulinoides tenuis Phleger and Parker & & & & & & & & \\
\hline Cassidulina tricamerata Galloway and Heminway & & & & & & & 16 & \\
\hline Cassidulina tumida Natland & & & & & & & & \\
\hline Ceratobulimina alazaensis Cushman and Harris & & & & & 6 & & 2 & \\
\hline Chilostomella oolina Schwager & & & & & & 1 & & \\
\hline Chilostomella ovoidea Reuss & & & & & & & & \\
\hline Chrysalogonium breviloculum Cushman and Jarvis & 3 & & 1 & & & & & \\
\hline Chrysalogonium elongatum Cushman and Jarvis & & & & & & & & 2 \\
\hline Chrysalogonium Ianceolum Cushman and Jarvis & & & & 1 & & & & \\
\hline Chrysalogonium longiscatatum Cushman and Jarvis & & & & & & & 1 & \\
\hline Chrysalogonium teniucostatum Cushman and Bermudez & & & & & & 1 & & \\
\hline Cibicides barnetti Bermudez & & & & & & & & \\
\hline Cibicides floridanus (Cushman) & & & & & & & & \\
\hline Cibicides granulosa Bermudez & & & 3 & & 4 & 2 & 4 & \\
\hline Cibicides cf. C. granulosa Bermudez & & & & & & & & \\
\hline Cibicides heminwayae Bermudez & 3 & & & & & & & \\
\hline Cibicides io Cushman & & & & & & & & \\
\hline Cibicides mckannai Galloway and Wissler & 1 & & & & & & & \\
\hline Cibicidoides bradyi (Trauth) & & 8 & 1 & 2 & & 1 & 1 & \\
\hline Cibicidoides coryelli (Bermudez) & & & & & & & 2 & \\
\hline Cibicidoides cf. C. kullenbergi ( Parker) & & & & & 1 & 1 & & \\
\hline Cibicidoides kullenbergi (Parker) & & & & & 9 & 2 & & \\
\hline Cibicidoides trinitatensis (Nuttall) & & & & & & & & \\
\hline Cibicidoides cf. C. wuellerstorffi (Schwager) & & & & & & & & \\
\hline Cibicidoides wuellerstorffi (Schwager) & 30 & 1 & & & & & & \\
\hline Cibicides pseudoungerianus (Cushman) & & 2 & & & & & 2 & \\
\hline Cibicides richarsoni Bermudez & & & & & & & & \\
\hline Cibicides $s p$. & & & & & 1 & & & \\
\hline Cibicides spirolimbatus Galloway and Heminway & & & & & 3 & 2 & 16 & 1 \\
\hline Cibicides spiralis Natland & & & & 1 & 1 & & & 1 \\
\hline Cibicides cf. C. spiralis Natland & & & & & & & & \\
\hline Cibicides trincherasensis Bermudez & & & & & 4 & & 10 & \\
\hline
\end{tabular}




\begin{tabular}{|c|c|c|c|c|c|c|c|c|}
\hline SITE 569 & $7 / 5 / 20-24$ & $7 / \mathrm{CC}$ & $8 / 1 / 18-22$ & $10 / 1 / 11-15$ & $10 / \mathrm{CC}$ & $11 / 1 / 30-34$ & $11 / \mathrm{CC}$ & $12 / 1 / 20-24$ \\
\hline Cibicides umbonatus Phleger and Parker & & & & & & & 3 & \\
\hline \multicolumn{9}{|l|}{ Cibicides aff. C. umbonatus Phleger and Parker } \\
\hline Cibicides yagatensis Bermudez & & & & & & & 20 & \\
\hline \multicolumn{9}{|l|}{ Dentalina cocoaensis (Cushman) } \\
\hline Dentalina consobrina (d'Orbigny) & & 8 & & & & & & \\
\hline Dentalina cooperensis Cushman & & 4 & 2 & & & 1 & & \\
\hline Dentalina mucronata Neugeboren & & & & & & & & \\
\hline Dentostomina guraboensis Bermudez & & & & & 1 & & & \\
\hline Dentalina pauperata d'Orbigny & & & & & & & & \\
\hline Dentalina soluta Reuss & & 1 & & & & & & \\
\hline Dentalina spinosa d'Orbigny & & & & & & & & \\
\hline Eggerella bradyi (Cushman) & 8 & & & & & & & \\
\hline Ehrenbergina amina Bermudez & & & & & & & & \\
\hline Ehrenbergina bosoensis Takayanagi & & & & & & & & \\
\hline Ehrenbergina bradyi Cushman & 1 & & & & & & & \\
\hline Ehrenbergina caribbea Galloway and Heminway & & 10 & 2 & & & & & \\
\hline Ellipsoglandulina multicostata (Galloway and Morrey) & 1 & & & & & & 1 & \\
\hline Ellipsolagena barri Cushman and Stainforth & & & & & & & & \\
\hline Ellipsonodosaria mappa Cushman and Jarvis & & & & & & & & \\
\hline Elphidium tumidum Natland & & & & & & & & \\
\hline Epistominella bradyana (Cushman) & & & 4 & & & & & \\
\hline Epistominella exiqua (Brady) & & 2 & 1 & 1 & & & & \\
\hline Epistominella obesa Bandy and Arnal & & & & & & & & \\
\hline Epistominella cf. E. obesa Bandy and Arnal & & & & & & & & \\
\hline Epistominella pacifica (Cushman) & & 1 & & & & & & \\
\hline Epistominella cf. E. pacifica (Cushman) & & & & & & & & \\
\hline Epistominella smithi (Stewart and Stewart) & & & & & & & & \\
\hline Epistominella $s p$. & & & & & & & & \\
\hline Epistominella spp. & & & 1 & & & & & \\
\hline Epistominella umbonifera (Cushman) & & & & & & & & \\
\hline Fissurina alveolata (Brady) & 1 & & & & & & & \\
\hline Fissurina auriculata (Brady) & & & & & & & & \\
\hline Fissurina subformosa Parr & 2 & & & & & & & \\
\hline Fissurina cf. F. subformosa Parr & & & & & & & & \\
\hline Fissurina carteri (McLean) & 3 & & & & & & & \\
\hline Fissurina cucullata Silvestri & 5 & & 1 & & & & 1 & \\
\hline Fissurina fimbrata (Brady) & 3 & 1 & & & & & & \\
\hline Fissurina cf. F. fimbrata (Brady) & & & & & & & & \\
\hline Fissurina kugleri (Cushman and Stainforth) & & & & & & & & \\
\hline Fissurina marginata (Montagu) & & 1 & & & & & & \\
\hline Fissurina solida Sequenza & & & & & & & & \\
\hline Fissurina orbignyana Sequenza & 2 & 1 & & & & & & \\
\hline Fissurina sp. (double keel) & & & & & & & & \\
\hline Fissurina spinosa ( Sidebottom) & & & & & & & & \\
\hline Fissurina spp. & & & & & & & & \\
\hline Fissurina staphylleraria Schwager & & & & & 2 & & & \\
\hline Fissurina ventricosa (Wiesner) & & & & & & & & \\
\hline Fissurina wiesneri Barker & 2 & & & & & & & \\
\hline Fursenkoina bramletti (Galloway and Morrey) & 3 & & & & & & & \\
\hline Fursenkoina cornuta (Cushman) & & & & & & & & \\
\hline Fursenkoina dibollensis (Cushman and Applin) & & & & & & & & \\
\hline Fursenkoina rotundata (Parr) & & & & & & & & \\
\hline Fursenkoina spp. & & & & & & & & \\
\hline Globobulimina barbata (Cushman) & 2 & 1 & & & & & & \\
\hline Globobulimina pacifica Cushman & 4 & & & & & 1 & & \\
\hline Globobulimina spinifera (Cushman) & & & 1 & & & & & \\
\hline Globocassidulina subglobosa (Brady) & 6 & 4 & 2 & & 12 & & 4 & \\
\hline Glandulina laevigata (d'Orbigny) & & & & & & & & \\
\hline Guttulina irregularis (d'Orbigny) & & & & & 1 & & & \\
\hline Gyroidina altiformis Stewart and Stewart & 7 & & & & & & & \\
\hline Gyroidina altispira Cushman and Stainforth & & & & & & & & \\
\hline Gyroidina io Resig & & & & & & & & \\
\hline Gyroidina lamarckiana d'Orbigny & 72 & 1 & & & & & 1 & \\
\hline Gyroidina multilocula Coryell and Mossman & & & 1 & 1 & & & & \\
\hline Gyroidina nitidula (Schwager) & & & & & & & & \\
\hline Gyroidina neosoldanii Brotzen & 2 & & & & & & & \\
\hline Gyroidina perampla Cushman and Stainforth & & & & & 5 & 3 & & \\
\hline Gyroidina planulata Cushman and Renz & & & & & & & & \\
\hline Gyroidina cf. G. planulata Cushman and Renz & & & & & & & & \\
\hline Gyroidina quinqueloba Uchio & & & & & & & & \\
\hline Gyroidina soldanii d'Orbigny & & 1 & & & & & 5 & \\
\hline Gyroidina spp. & & & & & & & & \\
\hline Gyroidina zelandica Finlay & & 4 & 3 & 1 & & & 1 & \\
\hline Hanzawaia basiloba (Cushman) & & & & & & & & \\
\hline Hanzawaia concentrica (Cushman) & & & 2 & 1 & & & & \\
\hline Hanzawaia illingi ( Nuttall) & & & & & & & 1 & \\
\hline Hanzawaia isidroensis (Cushman and Renz) & & & & & & & & \\
\hline Hoeglundina elegans (d'Orbigny) & 1 & 3 & & & 5 & & 14 & \\
\hline Karreriella chilostoma (Reuss) & & & & & & & & \\
\hline Lagena cf. L. costata & & & & & & & & \\
\hline Lagena costata (Williamson) & & & & & & & 1 & 3 \\
\hline Lagena elongata (Ehrenberg) & & 2 & & & & & & \\
\hline Lagena gracilis Williamson & & & & & & & & \\
\hline Lagena gracillima (Sequenza) & & & & & & & & \\
\hline
\end{tabular}




\begin{tabular}{|c|c|c|c|c|c|c|c|c|}
\hline SITE 569 & $7 / 5 / 20-24$ & $7 / \mathrm{CC}$ & $8 / 1 / 18-22$ & $10 / 1 / 11-15$ & $10 / \mathrm{CC}$ & $11 / 1 / 30-34$ & $11 / \mathrm{CC}$ & $12 / 1 / 20-24$ \\
\hline Lagena hexagona (Williamson) & 1 & & & & & & & \\
\hline \multicolumn{9}{|l|}{ Lagena hispida Reuss } \\
\hline Lagena laevis (Montagu) & 1 & & & & & & & \\
\hline \multicolumn{9}{|l|}{ Lagena mollis Cushman } \\
\hline Lagena semistriata Williamson & 2 & & & & & & & \\
\hline Lagena vulgaris Williamson & & & & & & & & \\
\hline Laticarinina pauperat a (Parker and Jones) & & 4 & & & & & & \\
\hline Lenticulina altolimbatus (Gumbel) & 1 & & & & 1 & & & \\
\hline Lenticulina arcuatostriata (Hantken) & & & & & & & 4 & \\
\hline Lenticulina arcuatostriata carolinianus (Cushman) & & & & & & & & \\
\hline Lenticulina calcar (Linne) & & & & & & & & \\
\hline Lenticulina caritae Bermudez & & & & & & & & 1 \\
\hline Lenticulina dicampyla (Franzenau) & & & & & & & & 1 \\
\hline Lenticulina gibba d'Orbigny & & & & & & & & \\
\hline Lenticulina cf. L. gibba d'Orbigny & & & 1 & & & & & \\
\hline Lenticulina gutticostatus cocoaensis (Cushman) & & & & & & & & \\
\hline Lenticulina iota (Cushman) & & & & & & & & \\
\hline Lenticulina nikobarensis (Schwager) & & & & & 1 & & & \\
\hline Lenticulina occidentalis (Cushman) & & & & & & & & 1 \\
\hline Lenticulina occidentalis torrida (Cushman) & & & & & & 1 & & \\
\hline Lenticulina plummerae (Cole) & & & & & & & & \\
\hline Lenticulina rotulata Lamarck & & & & & & & 10 & 4 \\
\hline Lenticulina subpapillosa (Nuttall) & & & & & & & 1 & \\
\hline Lenticulina spp. & & & & & & & & \\
\hline Lenticulina striata & & & & & & & & \\
\hline Lenticulina terryi (Coryell and Embich) & & & & & & & & \\
\hline Lenticulina texana (Cushman and Applin) & & & & & & & & \\
\hline Marginulina abbreviata Neugeboren & & & & & & & & \\
\hline Marginulina alazaensis Nuttall & & 1 & & & & & & \\
\hline Marginulina cf. M. asperuliformis (Nuttall) & & & & & & & & \\
\hline Marginulina dominicana Bermudez & & & & & & & & \\
\hline Marginulina exima Neugeboren & & & & & & & & \\
\hline Marginulina subbullata Hantken & & & & & & & & \\
\hline Marginulina sublituus (Nuttall) & & & & & & & & \\
\hline Marginulina subrecta Franke & 2 & & & & & & & \\
\hline Martinottiella pallida (Cushman) & & 4 & & 2 & 1 & & 1 & \\
\hline Melonis affinis (Reuss) & 20 & 5 & 1 & 1 & 1 & & & \\
\hline Melonis pompilioides (Fitchel and Moll) & 1 & & & & & & 1 & \\
\hline Melonis soldanii (d'Orbigny) & 1 & & & & & & & \\
\hline Nonionella basispinata (Cushman and Moyer) & & & & & & & & \\
\hline Nonionella incisa (Cushman) & & & & 2 & & & 1 & \\
\hline Nonionella labradorica (Dawson) & & & & & & & & \\
\hline Nonionella stella Cushman and Moyer & & & & & & & & \\
\hline Nodogenerina challengeriana Thalmann & 15 & & 1 & & & & & \\
\hline Nodogenerina laevigata Bermudez & & 1 & & & & & & \\
\hline Nodosaria calomorpha Reuss & & & & & & 1 & 3 & \\
\hline Nodosaria elegantissima Hantken & & & & & & & & 3 \\
\hline Nodosaria fistuca Schwager & 6 & 8 & & & & & 1 & \\
\hline Nodosaria hispida d'Orbigny & & & 1 & 1 & & & & 2 \\
\hline Nodosaria lamellata Cushman and Stainforth & & 1 & & 1 & 1 & 1 & & 2 \\
\hline Nodosaria latejugata Gumbel & & & & & & & & \\
\hline Nodosaria longiscata d'Orbigny & & 15 & 7 & 6 & 8 & 11 & 8 & 1 \\
\hline Nodosaria obliqua (Linne) & & & & & & 2 & 1 & \\
\hline Nodosaria parexilis Cushman and Stewart & 16 & 19 & & & & & & \\
\hline Nodosaria spp. & & & 1 & & & & 19 & \\
\hline Nodosaria stainforthia Cushman and Renz & & & & & & & 1 & \\
\hline Nodosaria vertebralis (Batsch) & & & & & & & & \\
\hline Oolina desmophora (Rymer Jones) & & 1 & & & & & & \\
\hline Oridorsalis umbonatus (Reuss) & 54 & 2 & 5 & 1 & 1 & & 4 & \\
\hline Orthomorphina rohri (Cushman and Stainforth) & & & & & & & & \\
\hline Osangularia culteri (Parker and Jones) & & & & & & & & \\
\hline Osangularia mexicana (Cole) & & & & & & & 1 & \\
\hline Parafissurina $s p$. & & & & & & & & \\
\hline Planulina exorna Phleger and Parker & & & & & & & & \\
\hline Planulina cf. P. exorna Phleger and Parker & & & & 1 & & & & \\
\hline Planulina mexicana Cushsman & & & & & & & & \\
\hline Planulina ornata (d'Orbigny) & & & & 1 & & & & \\
\hline Planulina renz Cushman and Stainforth & & & & & 5 & & 2 & \\
\hline Planularia sp. & & & & & & & & \\
\hline Planularia venezuelana Hedberg & & & & & & & & \\
\hline Plectofrondicularia advena (Cushman) & 1 & 1 & & & & & & \\
\hline Plectofrondicularia californica Cushman and Stewart & & & 1 & & & & & \\
\hline Plectofrondicularia keijzeri Bermudez & & & & & & & & \\
\hline Plectofrondicularia mexicana & & & & & & & & \\
\hline Plectofrondicularia miocenica Cushman & 1 & & & & & & & \\
\hline Plectofrondicularia morreyae Cushman & & & & & & & & \\
\hline Plectofrondicularia ruthvanmurrayi Cushman & 1 & & & & & & & \\
\hline Plectofrondicularia vaughani Cushman & & 1 & & & & & & \\
\hline Plectofrondicularia cf. P. yumuriana Palmer & & & & & & & & \\
\hline Pleurostomella acuta Hantken & & & & & & & & \\
\hline Pleurostomella alternans Schwager & & 6 & & & & & & \\
\hline Pleurostomella bierigi Palmer and Bermudez & 2 & & & & & & & \\
\hline Pleurostomella brevis Schwager & & & & & & & & \\
\hline Pleurostomella jacksonensis Cushman and Applin & & & & & & & & \\
\hline
\end{tabular}




\begin{tabular}{|c|c|c|c|c|c|c|c|c|}
\hline SITE 569 & $7 / 5 / 20-24$ & $7 / \mathrm{CC}$ & $8 / 1 / 18-22$ & $10 / 1 / 11-15$ & $10 / \mathrm{CC}$ & $11 / 1 / 30-34$ & $11 / \mathrm{CC}$ & $12 / 1 / 20-24$ \\
\hline Pleurostomella narajoensis Cushman and Bermudez & & & & & 1 & & & \\
\hline Pleurostomella praegerontica Cushman and Stainforth & & & 1 & & & & & \\
\hline \multicolumn{9}{|l|}{ Pseudonodosaria conica (Neugeboren) } \\
\hline \multicolumn{9}{|l|}{ Pseudonodosaria inflata (Bornemann) } \\
\hline \multicolumn{9}{|l|}{ Pseudonodosaria sp. } \\
\hline Praeglobobulimina affinis (d'Orbigny) & & 2 & & 1 & & & 3 & 1 \\
\hline $\begin{array}{l}\text { Praeglobobulimina auriculata (Bailey) } \\
\end{array}$ & 23 & 5 & 1 & & & & 1 & \\
\hline Praeglobobulimina ovula (d'Orbigny) & & & & & & & & \\
\hline Praeglobobulimina pupoides (d'Orbigny) & & & & & & & & \\
\hline Pullenia bulloides (d'Orbigny) & 13 & 1 & & 1 & & 1 & & \\
\hline Pullenia duplicata Stainforth & & & & & & & & \\
\hline Pullenia malkinae Coryell and Mossman & & 2 & & & & & & \\
\hline Pullenia quinqueloba (Reuss) & 1 & & 1 & & & & & \\
\hline Pullenia salisburyi Stewart and Stewart & & & & & & & & \\
\hline Pyrulina fusiformis (Roemer) & & & & & & & & \\
\hline Pyrgo depressa (d'Orbigny) & & & 1 & & & & & \\
\hline Pyrgo murrhina (Schwager) & & & & & & & & \\
\hline Pyrgo cf. P. murrhina (Schwager) & & & & & & & & \\
\hline Pyrgo rotalaria Loeblich and Tappan & & & 1 & & & & & \\
\hline Pyrgo aff. P. rotularia Loeblich and Tappan & & & & & & & & \\
\hline Pyrgo serrata (Bailey) & & & & & & & & \\
\hline Pyrgo spp. & & & & & & & & \\
\hline Pyrgo williamsoni (Silvestri) & & & & & & & & \\
\hline Quinqueloculina lamarckiana d'Orbigny & & & & & & & & \\
\hline Quinqueloculina $s p$. & & & & & & & & \\
\hline Quinqueloculina venusta Karrer & & 4 & & & & & & \\
\hline Reusella pacifica Cushman and McCulloch & & & & & & & & \\
\hline Robulina $s p$. & & & & & & & & \\
\hline Rosalina columbiensis ( Cushman) & 4 & 1 & & & & & & \\
\hline Rosalina sp. & & & & & & & & \\
\hline Saracenaria schencki Cushman and Hobson & & & & & & & & \\
\hline Sigmoilina tenuis (Czjeck) & & & & & & & & \\
\hline Siphogenerina basispinata Cushman and Jarvis & & & & 3 & 15 & 6 & 1 & \\
\hline Siphogenerina multicostata Cushman and Jarvis & & & & & & & 12 & \\
\hline Siphogenerina senni Cushman and Renz & & & & & & & & \\
\hline Siphogenerian $s p$. & & & & & & & & \\
\hline Siphonodosaria abyssorum (Brady) & & & & & 1 & & & \\
\hline Siphonodosaria gracillima (Cushman and Jarvis) & & & & 7 & 2 & 1 & 58 & \\
\hline Siphonodosaria paucistriata (Galloway and Morrey) & & & & & 10 & & & \\
\hline Siphonia pulchra Cushman & & & & & 1 & 1 & 13 & \\
\hline Siphotextularia catenata (Cushman) & & & & & & & & \\
\hline Sphaeroidina bulloides d'Orbigny & 5 & 3 & 4 & & & 4 & 10 & \\
\hline Spiroloculina texana Cushman and Ellisor & & & & & & & & \\
\hline Stilostomella adolphina (d'Orbigny) & & & & & 5 & & & 1 \\
\hline Stilostomella advena (Cushman and Laiming) & & & 1 & & & & & \\
\hline Stilostomella caribbea Palmer and Bermudez & & 1 & 1 & & & & & \\
\hline Stilostomella gracilis ( Palmer and Bermudez) & & & & & 1 & & & \\
\hline Stilostomella lepidula (Schwager) & 26 & 8 & 6 & 1 & & 2 & 1 & \\
\hline Stilostomella subspinosa (Cushman) & & & & 1 & 12 & 7 & 5 & \\
\hline Stilostomella $s p$. & & & & & & & & \\
\hline Suggrunda eckisi Natland & & & & & & & & \\
\hline Suggrunda kleinpell Bramlette & & & & & & & & \\
\hline Trifarina angulosa (Williamson) & & & & & & & & \\
\hline Trifarina bradyi Cushman & & & & & & & & \\
\hline Triloculina globosa (Hanna and Hanna) & & & & & & & & \\
\hline Triloculina trigonula (Lamarck) & & & & & & & & \\
\hline Triloculina trihedra Loeblich and Tappan & & & & & & & & \\
\hline Tritaxilina mexicana Cushman & & & & & & & & \\
\hline Uvigerina baggi Galloway and Wissler & & & & & & & & \\
\hline Uvigerina carapitana Hedberg & & & & & & & 8 & 2 \\
\hline Uvigerina excellens Todd & & & 1 & & & & & \\
\hline Uvigerina gallowayi Cushman & & & & & & & & \\
\hline Uvigerina galloway basicordata Cushman and Renz & & & & & & & & \\
\hline Uvigerina hispidocostata Cushman and Todd & & & 1 & & & & & \\
\hline Uvigerina hispida Schwager & 11 & 15 & 11 & & & & 26 & 4 \\
\hline Uvigerina incilis Todd & & & & & & & & \\
\hline Uvigerina peregrina Cushman & & & & & & & & \\
\hline Uvigerina peregrina dirupta Todd & & & & & & & & \\
\hline Uvigerina rustica Cushman and Edwards & & & & 2 & 14 & 1 & 27 & \\
\hline Uvigerina senticosa Cushman & 8 & 10 & 1 & & & & & \\
\hline Uvigerina cf. U. senticosa Cushman & & & & & & & & \\
\hline Uvigerina semitrigonia Galloway and Wissler & & & & & & & & \\
\hline Uvigerina sp. (costate) & & & & & & & 8 & 1 \\
\hline Uvigerina spp. & & & & & & & & \\
\hline Uvigerina striata d'Orbigny & & & & & & & & 5 \\
\hline Uvigerina vaderescens Cushman & 19 & 7 & 3 & & & & & \\
\hline Vaginulinopsis nudicostata (Cushman and Hanna) & & & & & & & & \\
\hline Vaginulinopsis saundersi ( Hanna and Hanna) & & & & & & & & \\
\hline Valvulineria araucana (d'Orbigny) & & & & & & & & \\
\hline Valvulineria glabra Cushman & & & & & & & & \\
\hline Vulvulina spinosa Cushman & & & & & & & & \\
\hline Number of Forams & 407 & 201 & 102 & 41 & 139 & 59 & 350 & 36 \\
\hline
\end{tabular}




\begin{tabular}{|c|c|c|c|c|c|c|c|}
\hline SITE 569 & $12 / \mathrm{CC}$ & $14 / 2 / 52-57$ & $17 / \mathrm{CC}$ & \begin{tabular}{|l|}
$20 / 1 / 69-73$ \\
\end{tabular} & \begin{tabular}{|l|}
$21 / 1 / 43-47$ \\
\end{tabular} & $27 / 1 / 16-20$ & $27 / 3 / 16-20$ \\
\hline Alabamina polita Becker and Dusenbury & & 4 & & & & & \\
\hline Amphistegina lessoni d'Orbigny & & & & & 8 & & \\
\hline Amphistegina cf. A. lessoni d'Orbigny & & & & & 2 & & \\
\hline Anomalinoides globulosus (Chapman and Parr) & & & 1 & 1 & & & \\
\hline \multicolumn{8}{|l|}{ Anomalina flintii Cushman } \\
\hline Astrononion guadalupae (Parker) & 2 & & 2 & & & & \\
\hline Baggina dominicana Bermudez & & 1 & & & & & \\
\hline \multicolumn{8}{|l|}{ Buliminella curta Cushman } \\
\hline \multicolumn{8}{|l|}{ Buliminella subfusiformis Cushman } \\
\hline Buliminella tenuata Cushman & & & & & & & \\
\hline Bolivina acuminata Natland & & & & & & & \\
\hline Bolivina advena Cushman & & & & & & & \\
\hline Bolivina alazaensis Cushman & & & & & & & \\
\hline Bolivina argentea Cushman & & & & & & & \\
\hline Bolivina cf. B. argentea Cushman & & & & & & & \\
\hline Bolivina bicostata Cushman & & & & & & & \\
\hline Bolivina bradyi Asano & & & & & & & \\
\hline Bolivina conica Cushman & & & & & & & \\
\hline Boldia cushmani (Nuttall) & & & & & & & \\
\hline Bolivina foraminata Stewart and Stewart & & & & & & & \\
\hline Bolivinita quadrilatera (Schwager) & & & & & & & \\
\hline Bolivina marginata Cushman & & 14 & & & & & \\
\hline Bolivina pacifica Cushman and McCulloch & & & & & & & \\
\hline Bolivina plicata d'Orbigny & & & & & & & \\
\hline Bolivina pseudobeyrichi Cushman & & & & & & & \\
\hline Bolivina pseudospissa Kleinpell & & & & & & & \\
\hline Bolivina subadvena Cushman & & & & & & & \\
\hline Bolivina cf. B. subadvena Cushman & & & & & & & \\
\hline Bolivina sinuata Galloway and Wissler & & & & & & & \\
\hline Bolivina cf. B. sinuata Galloway and Wissler & & & & & & & \\
\hline Bolivina semiperforata Martin & & & & & & & \\
\hline Bolivina cf. B. semiperforata Martin & & & & & & & \\
\hline Bolivina seminuda Cushman & & & & & & & \\
\hline Bolivina spissa Cushman & & & & & & & \\
\hline Buccella sp. & & & & & & & \\
\hline Bulimina alazaensis Cushman & 5 & 1 & 1 & 1 & & & \\
\hline Bulimina bleekeri Hedberg & & & & & & & \\
\hline Bulimina denudata Cushman and Parker & & & & & & & \\
\hline Bulimina mexicana Cushman & 4 & 4 & & 1 & & 2 & 3 \\
\hline Bulimina uvigeriniformis Cushman and Kleinpell & & & & & & & \\
\hline Cancris auricula (Fitchel and Moll) & & & & & & & \\
\hline Cancris inflatus (d'Orbigny) & & & & & & & \\
\hline Cancris panamensis Natland & & 1 & & & 1 & & \\
\hline Cassidulina californica Cushman and Hughes & & & & & & & \\
\hline Cassidulina caudriae Cushman and Stainforth & & & & & & & \\
\hline Cassidulina cushmani Stewart and Stewart & & & & & & & \\
\hline Cassidulina delicata Cushman & & & & & & & \\
\hline Cassidulina laevigata d'Orbigny & & 29 & & & & & \\
\hline Cassidulina limbata Cushman and Hughes & & & & & & & \\
\hline Cassidulina oblonga Reuss & & & & & & & \\
\hline Cassidulinoides tenuis Phleger and Parker & & & & & & & \\
\hline Cassidulina tricamerata Galloway and Heminway & & & & & & & \\
\hline Cassidulina tumida Natland & & & & & & & \\
\hline Ceratobulimina alazaensis Cushman and Harris & 2 & & 1 & & & & 1 \\
\hline Chilostomella oolina Schwager & & & & & & & \\
\hline Chilostomella ovoidea Reuss & & & & & & & \\
\hline Chrysalogonium breviloculum Cushman and Jarvis & & & & & & & \\
\hline Chrysalogonium elongatum Cushman and Jarvis & & & & & & & \\
\hline Chrysalogonium Ianceolum Cushman and Jarvis & & & & & & & \\
\hline Chrysalogonium longiscatatum Cushman and Jarvis & & 1 & & & & & \\
\hline Chrysalogonium teniucostatum Cushman and Bermudez & & & & & & & \\
\hline Cibicides barnetti Bermudez & 6 & 4 & & & & & \\
\hline Cibicides floridanus (Cushman) & & 7 & & & & & \\
\hline Cibicides granulosa Bermudez & 13 & & & & & 5 & 7 \\
\hline Cibicides cf. C. granulosa Bermudez & & & & & & & \\
\hline Cibicides heminwayae Bermudez & & & & & & & \\
\hline Cibicides io Cushman & & & & & & & \\
\hline Cibicides mckannai Galloway and Wissler & & & & & & & \\
\hline Cibicidoides bradyi (Trauth) & 1 & 3 & & & 2 & 2 & 4 \\
\hline Cibicidoides coryelli (Bermudez) & & & & & & & \\
\hline Cibicidoides cf. C. kullenbergi ( Parker) & & & & & & & \\
\hline Cibicidoides kullenbergi (Parker) & & & 7 & 1 & & & \\
\hline Cibicidoides trinitatensis (Nuttall) & & & & & & & \\
\hline Cibicidoides cf. C. wuellerstorffi (Schwager) & & & & & & & \\
\hline Cibicidoides wuellerstorffi (Schwager) & & 7 & & & & & \\
\hline Cibicides pseudoungerianus (Cushman) & & & & & & & \\
\hline Cibicides richarsoni Bermudez & & & & & & & \\
\hline Cibicides $s p$. & & & & & & & \\
\hline Cibicides spirolimbatus Galloway and Heminway & & 21 & & 8 & 2 & 3 & \\
\hline Cibicides spiralis Natland & 30 & 1 & & & & & \\
\hline Cibicides cf. C. spiralis Natland & 10 & & & & & & \\
\hline Cibicides spp. & 5 & 2 & & & & & \\
\hline Cibicides trincherasensis Bermudez & 9 & & & 4 & 1 & & \\
\hline & & & & & & & \\
\hline
\end{tabular}




\begin{tabular}{|c|c|c|c|c|c|c|c|}
\hline SITE 569 & $12 / \mathrm{CC}$ & $14 / 2 / 52-57$ & $17 / \mathrm{CC}$ & $20 / 1 / 69-73$ & $21 / 1 / 43-47$ & $27 / 1 / 16-20$ & $27 / 3 / 16-20$ \\
\hline \multicolumn{8}{|l|}{ Cibicides umbonatus Phleger and Parker } \\
\hline \multicolumn{8}{|l|}{ Cibicides aff. C. umbonatus Phleger and Parker } \\
\hline Cibicides yagatensis Bermudez & 33 & 12 & & & & & \\
\hline \multicolumn{8}{|l|}{ Dentalina cocoaensis (Cushman) } \\
\hline Dentalina consobrina (d'Orbigny) & & & & & & 1 & \\
\hline Dentalina cooperensis Cushman & & & 1 & & & & 1 \\
\hline Dentalina mucronata Neugeboren & 3 & & & & & & \\
\hline Dentostomina guraboensis Bermudez & & & & & & & \\
\hline Dentalina pauperata d'Orbigny & 1 & & & & & & \\
\hline Dentalina soluta Reuss & 1 & & & & & & \\
\hline Dentalina spinosa d'Orbigny & 2 & & & & & & 1 \\
\hline Eggerella bradyi (Cushman) & & & & & & & \\
\hline Ehrenbergina amina Bermudez & & 1 & & & & & \\
\hline Ehrenbergina bosoensis Takayanagi & & & & & & & \\
\hline Ehrenbergina bradyi Cushman & & & & & & & \\
\hline Ehrenbergina caribbea Galloway and Heminway & & 1 & & & & & \\
\hline Ellipsoglandulina multicostata (Galloway and Morrey) & & & & & & & \\
\hline Ellipsolagena barri Cushman and Stainforth & & & & & & & \\
\hline Ellipsonodosaria mappa Cushman and Jarvis & & & & & & & \\
\hline Elphidium tumidum Natland & & & & & & & \\
\hline Epistominella bradyana (Cushman) & & & & & & & \\
\hline Epistominella exiqua (Brady) & & & & & & & \\
\hline Epistominella obesa Bandy and Arnal & & & & & & & \\
\hline Epistominella cf. E. obesa Bandy and Arnal & & & & & & & \\
\hline Epistominella pacifica (Cushman) & & & & & & & \\
\hline Epistominella cf. E. pacifica (Cushman) & & & & & & & \\
\hline Epistominella smithi (Stewart and Stewart) & & & & & & & \\
\hline Epistominella $s p$. & & & & & & & \\
\hline Epistominella spp. & & & & & & & \\
\hline Epistominella umbonifera (Cushman) & & & & & & & \\
\hline Fissurina alveolata (Brady) & & & & & & & \\
\hline Fissurina auriculata (Brady) & & & & & & & \\
\hline Fissurina subformosa Parr & & & & & & & \\
\hline Fissurina cf. F. subformosa Parr & & & & & & & \\
\hline Fissurina carteri (McLean) & & & & & & & \\
\hline Fissurina cucullata Silvestri & 2 & & 1 & 1 & & & \\
\hline Fissurina fimbrata (Brady) & & & & & & & \\
\hline Fissurina cf. F. fimbrata (Brady) & & & & & & & \\
\hline Fissurina kugleri (Cushman and Stainforth) & & & & & & & \\
\hline Fissurina marginata (Montagu) & & & & & & & \\
\hline Fissurina solida Sequenza & & & & & & & \\
\hline Fissurina orbignyana Sequenza & & & & & & & \\
\hline Fissurina sp. (double keel) & & & & & & & \\
\hline Fissurina spinosa ( Sidebottom) & & & & & & & \\
\hline Fissurina spp. & & & & & & & \\
\hline Fissurina staphylleraria Schwager & & & & 1 & & & \\
\hline Fissurina ventricosa (Wiesner) & & & & & & & \\
\hline Fissurina wiesneri Barker & & & & & & & \\
\hline Fursenkoina bramletti (Galloway and Morrey) & & & & & & & \\
\hline Fursenkoina cornuta (Cushman) & & & & & & & \\
\hline Fursenkoina dibollensis (Cushman and Applin) & & & & & & & \\
\hline Fursenkoina rotundata (Parr) & & & & & & & \\
\hline Fursenkoina spp. & & & & & & & \\
\hline Globobulimina barbata (Cushman) & & & & & & & \\
\hline Globobulimina pacifica Cushman & 1 & & & & & & \\
\hline Globobulimina spinifera (Cushman) & & & & & & & \\
\hline Globocassidulina subglobosa (Brady) & 7 & 1 & 2 & & & & \\
\hline Glandulina laevigata (d'Orbigny) & & & & & & & \\
\hline Guttulina irregularis (d'Orbigny) & & & & & & & \\
\hline Gyroidina altiformis Stewart and Stewart & & & & & & & \\
\hline Gyroidina altispira Cushman and Stainforth & 3 & & & & & & \\
\hline Gyroidina io Resig & & & & & & & \\
\hline Gyroidina lamarckiana d'Orbigny & 3 & 2 & & & & & \\
\hline Gyroidina multilocula Coryell and Mossman & & & & & & & \\
\hline Gyroidina nitidula (Schwager) & & & & & & & \\
\hline Gyroidina neosoldanii Brotzen & & & & & & & \\
\hline Gyroidina perampla Cushman and Stainforth & 4 & & & & & & \\
\hline Gyroidina planulata Cushman and Renz & 1 & 4 & & & & & \\
\hline Gyroidina cf. G. planulata Cushman and Renz & & & & & & & \\
\hline Gyroidina quinqueloba Uchio & & & & & & & \\
\hline Gyroidina soldanii d'Orbigny & 1 & & 2 & 1 & & & \\
\hline Gyroidina spp. & & & & & & & \\
\hline Gyroidina zelandica Finlay & 4 & 3 & & & & & \\
\hline Hanzawaia basiloba (Cushman) & & & & & & & \\
\hline Hanzawaia concentrica (Cushman) & & & & & 2 & & \\
\hline Hanzawaia illingi ( Nuttall) & & & & & & & \\
\hline Hanzawaia isidroensis (Cushman and Renz) & & 8 & & & & & \\
\hline Hoeglundina elegans (d'Orbigny) & 11 & 8 & & 2 & 2 & & \\
\hline Karreriella chilostoma (Reuss) & 2 & & & & & 3 & \\
\hline Lagena cf. L. costata & & & & & & & \\
\hline Lagena costata (Williamson) & 1 & 1 & & & & & \\
\hline Lagena elongata (Ehrenberg) & & & & & & & \\
\hline Lagena gracilis Williamson & & & & & & & \\
\hline Lagena gracillima (Sequenza) & & & & & & & \\
\hline
\end{tabular}




\begin{tabular}{|c|c|c|c|c|c|c|c|}
\hline SITE 569 & $12 / \mathrm{CC}$ & $14 / 2 / 52-57$ & $17 / \mathrm{CC}$ & $20 / 1 / 69-73$ & $21 / 1 / 43-47$ & $27 / 1 / 16-20$ & $27 / 3 / 16-20$ \\
\hline \multicolumn{8}{|l|}{ Lagena hexagona (Williamson) } \\
\hline \multicolumn{8}{|l|}{ Lagena hispida Reuss } \\
\hline \multicolumn{8}{|l|}{ Lagena laevis (Montagu) } \\
\hline Lagena mollis Cushman & & & & & & & \\
\hline Lagena semistriata Williamson & & & & & & & \\
\hline Lagena vulgaris Williamson & & & & & & & \\
\hline Laticarinina pauperat a (Parker and Jones) & & & & & & & \\
\hline Lenticulina altolimbatus (Gumbel) & 6 & 5 & & & 2 & & \\
\hline Lenticulina arcuatostriata (Hantken) & & & & & & & \\
\hline Lenticulina arcuatostriata carolinianus (Cushman) & 1 & & & & & & \\
\hline Lenticulina calcar (Linne) & & 1 & & & & & \\
\hline Lenticulina caritae Bermudez & & & & & & & \\
\hline Lenticulina dicampyla (Franzenau) & & 2 & & & & & \\
\hline Lenticulina gibba d'Orbigny & & & & & & & \\
\hline Lenticulina cf. L. gibba d'Orbigny & & & & & & & \\
\hline Lenticulina gutticostatus cocoaensis (Cushman) & 3 & & & & & & \\
\hline Lenticulina iota (Cushman) & & & & & & & \\
\hline Lenticulina nikobarensis (Schwager) & & & & & & & \\
\hline Lenticulina occidentalis (Cushman) & & & & & & 1 & 1 \\
\hline Lenticulina occidentalis torrida (Cushman) & & & & & & & \\
\hline Lenticulina plummerae (Cole) & & & & & & & \\
\hline Lenticulina rotulata Lamarck & 8 & 2 & & & 1 & & \\
\hline Lenticulina subpapillosa (Nuttall) & & & & & & & \\
\hline Lenticulina spp. & 4 & & & & & & \\
\hline Lenticulina striata & & & & & & & \\
\hline Lenticulina terryi (Coryell and Embich) & & 3 & & & & & \\
\hline Lenticulina texana (Cushman and Applin) & 5 & & & & & & \\
\hline Marginulina abbreviata Neugeboren & 1 & & & & & & \\
\hline Marginulina alazaensis Nuttall & & & & & & & \\
\hline Marginulina cf. M. asperuliformis (Nuttall) & & & & & & & \\
\hline Marginulina dominicana Bermudez & & 1 & & & & & \\
\hline Marginulina exima Neugeboren & & 1 & & & & & \\
\hline Marginulina subbullata Hantken & & & & & & & \\
\hline Marginulina sublituus (Nuttall) & & & & & & & \\
\hline Marginulina subrecta Franke & & & & & & & \\
\hline Martinottiella pallida (Cushman) & 3 & 2 & & & & & \\
\hline Melonis affinis (Reuss) & 4 & & & & & 1 & \\
\hline Melonis pompilioides (Fitchel and Moll) & & & & & & & \\
\hline Melonis soldanii (d'Orbigny) & & & & & & & \\
\hline Nonionella basispinata (Cushman and Moyer) & & & & & & & \\
\hline Nonionella incisa (Cushman) & & & & & & & \\
\hline Nonionella labradorica (Dawson) & & & & & & & \\
\hline Nonionella stella Cushman and Moyer & & & & & 1 & & \\
\hline Nodogenerina challengeriana Thalmann & & & & & & & \\
\hline Nodogenerina laevigata Bermudez & & & & & & & \\
\hline Nodosaria calomorpha Reuss & 4 & 1 & & & & & \\
\hline Nodosaria elegantissima Hantken & & 2 & & & & & \\
\hline Nodosaria fistuca Schwager & & 1 & & & & & \\
\hline Nodosaria hispida d'Orbigny & 3 & & 1 & & & & \\
\hline Nodosaria lamellata Cushman and Stainforth & 5 & & & & & & 7 \\
\hline Nodosaria latejugata Gumbel & 8 & & & & & & \\
\hline Nodosaria longiscata d'Orbigny & 10 & & 7 & 2 & & 7 & 3 \\
\hline Nodosaria obliqua (Linne) & & & & & & & \\
\hline Nodosaria parexilis Cushman and Stewart & & & & & & & \\
\hline Nodosaria spp. & 10 & 10 & & & & 3 & \\
\hline Nodosaria stainforthia Cushman and Renz & & & & & & & \\
\hline Nodosaria vertebralis (Batsch) & & & & & & & \\
\hline Oolina desmophora (Rymer Jones) & & & & & & & \\
\hline Oridorsalis umbonatus (Reuss) & 11 & 6 & 3 & 2 & 1 & 3 & 5 \\
\hline Orthomorphina rohri (Cushman and Stainforth) & & & & & & & \\
\hline Osangularia culteri (Parker and Jones) & & 1 & & & & 1 & \\
\hline Osangularia mexicana (Cole) & & & & & & & \\
\hline Parafissurina $s p$. & & & & & & & \\
\hline Planulina exorna Phleger and Parker & & & & & & & \\
\hline Planulina cf. P. exorna Phleger and Parker & & & & & & & \\
\hline Planulina mexicana Cushsman & & & & & & & \\
\hline Planulina ornata (d'Orbigny) & 5 & & & & & & \\
\hline Planulina renz Cushman and Stainforth & 13 & 3 & 1 & 3 & & & \\
\hline Planularia sp. & & & & & & & \\
\hline Planularia venezuelana Hedberg & 3 & & & & & & \\
\hline Plectofrondicularia advena (Cushman) & & & & & & & \\
\hline Plectofrondicularia californica Cushman and Stewart & & & & & & & \\
\hline Plectofrondicularia keijzeri Bermudez & & & & & & & \\
\hline Plectofrondicularia mexicana & & & & & & & \\
\hline Plectofrondicularia miocenica Cushman & & & & & & & \\
\hline Plectofrondicularia morreyae Cushman & & & & & & & \\
\hline Plectofrondicularia ruthvanmurrayi Cushman & & & & & & & \\
\hline Plectofrondicularia vaughani Cushman & & & & & & & \\
\hline Plectofrondicularia cf. P. yumuriana Palmer & & & & & & & \\
\hline Pleurostomella acuta Hantken & & & & & & & \\
\hline Pleurostomella alternans Schwager & & & & & & & \\
\hline Pleurostomella bierigi Palmer and Bermudez & & & & & & & \\
\hline Pleurostomella brevis Schwager & & & & & & & \\
\hline Pleurostomella jacksonensis Cushman and Applin & 1 & & & & & & \\
\hline
\end{tabular}




\begin{tabular}{|c|c|c|c|c|c|c|c|}
\hline SITE 569 & & 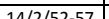 & $17 / 50$ & $20 / 1 / 6073 \mathrm{t}$ & $21 / 1 / 43-47$ & 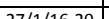 & \\
\hline \multicolumn{8}{|l|}{ Pleurostomella narajoensis Cushman and Bermudez } \\
\hline \multicolumn{8}{|l|}{ Pleurostomella praegerontica Cushman and Stainforth } \\
\hline \multicolumn{8}{|l|}{ Pseudonodosaria conica (Neugeboren) } \\
\hline \multicolumn{8}{|l|}{ Pseudonodosaria inflata (Bornemann) } \\
\hline Pseudonodosaria sp. & & & & & & & \\
\hline Praeglobobulimina affinis (d'Orbigny) & & & & & & & \\
\hline Praeglobobulimina auriculata (Bailey) & & 2 & & & & & \\
\hline Praeglobobulimina ovula (d'Orbigny) & & & & & & & \\
\hline Praeglobobulimina pupoides (d'Orbigny) & & & & & & & \\
\hline Pullenia bulloides (d'Orbigny) & 4 & 1 & & 1 & & & \\
\hline Pullenia duplicata Stainforth & & & & & & & \\
\hline Pullenia malkinae Coryell and Mossman & & & & & & & \\
\hline Pullenia quinqueloba (Reuss) & & 2 & 1 & & & & \\
\hline Pullenia salisburyi Stewart and Stewart & & & & & & & \\
\hline Pyrulina fusiformis (Roemer) & & & & & & & \\
\hline Pyrgo depressa (d'Orbigny) & & & & & 1 & & \\
\hline Pyrgo murrhina (Schwager) & & & & & & & \\
\hline Pyrgo cf. P. murrhina (Schwager) & & & & & & & \\
\hline Pyrgo rotalaria Loeblich and Tappan & & & & & & & \\
\hline Pyrgo aff. P. rotularia Loeblich and Tappan & & & & & & & \\
\hline Pyrgo serrata (Bailey) & & & & & & & \\
\hline Pyrgo spp. & & & & & & & \\
\hline Pyrgo williamsoni (Silvestri) & & & & & & & \\
\hline Quinqueloculina lamarckiana d'Orbigny & & & & & & & \\
\hline Quinqueloculina sp. & & & & & & & \\
\hline Quinqueloculina venusta Karrer & & & & & & & \\
\hline Reusella pacifica Cushman and McCulloch & & & & & & & \\
\hline Robulina sp. & & & & & & & \\
\hline Rosalina columbiensis (Cushman) & & & & & & & \\
\hline Rosalina sp. & & & & & & & \\
\hline Saracenaria schencki Cushman and Hobson & 1 & & & & & & \\
\hline Sigmoilina tenuis (Czjeck) & & & & & & & \\
\hline Siphogenerina basispinata Cushman and Jarvis & 6 & 10 & 2 & 1 & 1 & & \\
\hline Siphogenerina multicostata Cushman and Jarvis & 22 & 18 & & & & & \\
\hline Siphogenerina senni Cushman and Renz & & 4 & & & & & \\
\hline Siphogenerian $s p$. & & & & & & & \\
\hline Siphonodosaria abyssorum (Brady) & & & & & & & \\
\hline Siphonodosaria gracillima (Cushman and Jarvis) & 5 & 8 & 1 & & & & \\
\hline Siphonodosaria paucistriata (Galloway and Morrey) & 3 & & & & & & \\
\hline Siphonia pulchra Cushman & 24 & 12 & & & & & \\
\hline Siphotextularia catenata (Cushman) & & & & & & & \\
\hline Sphaeroidina bulloides d'Orbigny & 7 & 4 & 1 & 1 & & 3 & \\
\hline Spiroloculina texana Cushman and Ellisor & & & & & & & \\
\hline Stilostomella adolphina (d'Orbigny) & & & & & & & \\
\hline Stilostomella advena (Cushman and Laiming) & & & & & & & \\
\hline Stilostomella caribbea Palmer and Bermudez & & & & & & & \\
\hline Stilostomella gracilis ( Palmer and Bermudez) & & 1 & & & & 1 & 2 \\
\hline Stilostomella lepidula (Schwager) & 24 & 6 & & & & & \\
\hline Stilostomella subspinosa (Cushman) & 2 & & & & & 1 & \\
\hline Stilostomella sp. & & & & & & & \\
\hline Suggrunda eckisi Natland & & & & & & & \\
\hline Suggrunda kleinpell Bramlette & & & & & & & \\
\hline Trifarina angulosa (Williamson) & & & & & & & \\
\hline Trifarina bradyi Cushman & & & & & & & \\
\hline Triloculina globosa (Hanna and Hanna) & & & & & & & \\
\hline Triloculina trigonula (Lamarck) & 1 & & & & & & \\
\hline Triloculina trihedra Loeblich and Tappan & & & & & & & \\
\hline Tritaxilina mexicana Cushman & & & & 4 & & & \\
\hline Uvigerina baggi Galloway and Wissler & & & & & & & \\
\hline Uvigerina carapitana Hedberg & 3 & 14 & & & & & \\
\hline Uvigerina excellens Todd & & & & & & & \\
\hline Uvigerina gallowayi Cushman & 10 & & & & & 1 & 6 \\
\hline Uvigerina galloway basicordata Cushman and Renz & & & & & & & \\
\hline Uvigerina hispidocostata Cushman and Todd & & & & & & & \\
\hline Uvigerina hispida Schwager & 11 & 4 & & 1 & & 15 & 5 \\
\hline Uvigerina incilis Todd & & & & & & & \\
\hline Uvigerina peregrina Cushman & & & & & & & \\
\hline Uvigerina peregrina dirupta Todd & & & & & & & \\
\hline Uvigerina rustica Cushman and Edwards & 17 & & 2 & & 2 & & \\
\hline Uvigerina senticosa Cushman & & & & & & & \\
\hline Uvigerina cf. U. senticosa Cushman & & & & & & & \\
\hline Uvigerina semitrigonia Galloway and Wissler & & & & & & & \\
\hline Uvigerina sp. (costate) & & 22 & & & & & \\
\hline Uvigerina spp. & 2 & & & & & & \\
\hline Uvigerina striata d'Orbigny & & & & & & & \\
\hline Uvigerina vaderescens Cushman & & & & & & & \\
\hline Vaginulinopsis nudicostata (Cushman and Hanna) & 2 & & & & & & \\
\hline Vaginulinopsis saundersi ( Hanna and Hanna) & 3 & & & & & & \\
\hline Valvulineria araucana (d'Orbigny) & & 1 & & & & & \\
\hline Valvulineria glabra Cushman & & & & & & & \\
\hline Vulvulina spinosa Cushman & 2 & & & 1 & & 1 & \\
\hline Number of Forams & 424 & 291 & 37 & 37 & 29 & 54 & 6 \\
\hline
\end{tabular}


VITA

CRYSTAL RENAE PLETKA

Born in Huntington, West Virginia

1999-2003

B.S., Marine Science

Coastal Carolina University

Conway, South Carolina

2003-2006

Residential Life Coordinator, Eastern Washington

University

2006-2009

M.S., Geology

Florida Atlantic University

Boca Raton, Florida

2008-2011

Graduate Research Assistant

Florida International University

Miami, Florida

2010-2012

Graduate Teaching Assistant

Florida International University

Miami, Florida

2012-2013

Wellsite Geologist

Border to Border Exploration/Crystal Clear Mudlogging

Austin, Texas

2013-Present

Biostratigrapher

ALS Oil \& Gas

Houston, Texas

\section{PUBLICATIONS AND PRESENTATIONS}

Collins, L.S., Hallock, P., Pletka, C.R., and Beck, K.D., 2012. Deep-water Foraminiferal Response to the Catastrophic Deepwater Horizon Well Oil Spill, Northeastern Gulf of Mexico, GSA Abs with Prog. 44. p. 219

Collins, L.S., Ogg, J.G., Aubry, M.-P., Berggren, W.A., Coates, A.G., and Pletka, C.R., 2010. The Panama Paleontology Project Database: Using Timescale Creator for Automatic Age Updates to Paleontological Collections, GSA Abs. with Prog. 42. p. 461.

Pletka, C.R. and Petuch, E.J., 2009. Differentiation of fossil and Recent varieties of Melongena (Rexmela) corona, GSA Abs. with Prog. 41. p. 454. 